\title{
LA SITUACIÓN DEL ALUMNADO INMIGRANTE EN LOS CENTROS EDUCATIVOS VALLISOLETANOS Y SU PROCESO DE INTEGRACIÓN ESCOLAR.
}

\section{1.- Introducción}

\section{1.- Motivaciones personales de la investigadora}

Es difícil conocer las fuerzas que nos empujan a ir tomando decisiones en la vida, en mi caso, haciendo un ejercicio de reflexión, me remonto a mi etapa de maestra interina. Recuerdo con cierta nostalgia, una nostalgia placentera de la que habla Pablo Milanés, los viajes hacia ese pueblo, en el que se encontraba "ese" colegio y donde me esperaban "esos" niños. Alguno de ellos también había preparado las maletas, pero no para volver el fin de semana a reunirse con sus amigos, sino para quedarse allí, para hacerse un hueco dentro de un contexto desconocido para ellos, para volver a aprender las normas de la vida, porque para ellos, todo empezaba de nuevo.

Las tardes en la montaña palentina, también de las salmantinas, se hacían lo suficientemente extensas como para reflexionar sobre las situaciones de "Ayud", de "Russy", de "Solam", de "Carlos José", de "Ali", de "Mulai" de "Latifa", de..., de.... Quizá, la sensación de ser siempre "la chica nueva en la oficina" también pudo ser la causante de empatizar con estos alumnos y alumnas, ávidos de una mirada que les ayudara a entender el funcionamiento de la nueva cultura a la que se enfrentaban. Además, si la señal de ayuda provenía de un igual, el refuerzo afectivo todavía era mayor.

Y esto me lo demostró "Malú", un niño nuevo procedente del Magreb, al que le cambiaba no sólo la expresión del rostro sino su expediente académico cuando empezó a sentirse arropado entre su grupo de compañeros, cuando la ansiedad de querer pertenecer a un grupo, se transformó en sosiego para poder concentrarse en sus tareas escolares. Fruto del pálpito que esta situación tan evidente me produjo, me decidí a indagar en las situaciones personales de estos escolares y a contribuir, desde mi posición, a mejorar su integración.

Los libros sobre inmigración y escuela, muchas veces accidentados por la novedad del fenómeno, me proporcionaban pautas organizativas, incluso de metodologías educativas de aplicación. De ahí, la temática de mi trabajo de investigación tutelado, consistente en la aplicación de un programa de aprendizaje cooperativo dentro de una escuela vallisoletana con una marcada población inmigrante. Programa aprendido y llevado a la práctica en el proyecto final de un 
master de dos años, cursado en la Universidad Complutense, a cargo de la profesora Maria José Díaz Aguado.

A pesar de resultar una experiencia muy interesante, las lecturas acerca de la integración escolar, no me acercaban a los procesos sufridos por el niño inmigrante cuando accede por primera vez al contexto escolar, a sus situaciones personales, a sus necesidades reales. La mirada de "Malú", me hacía sospechar que existía un cierto distanciamiento entre los conceptos de los libros y la realidad. ¿Cómo acercarme a esta situación de la forma más cercana posible para entender la realidad vivida por los niños inmigrantes que se introducen en la cultura escolar, sin saber que se verán envueltos en una serie de procesos psicosociales que transformarán su vida? Pensé hacerlo de dos formas: una, investigando la integración escolar a partir de las relaciones que establecen los iguales; dos, conviviendo con ellos durante una larga temporada. La obtención de una beca de investigación (F.P.I.), financiada por la Junta de Castilla y León, en el curso 2001/2002, me ofreció la tranquilidad vital suficiente, como para poder implicarme en este doble enfoque de investigación.

La estrategia metodológica, utilizada en esta tesis, para acercarse a estas pretensiones, se concretó a través de la realización de dos estudios.

Con el primero, nos acercamos a todos los colegios públicos de la ciudad de Valladolid y evaluamos las relaciones del alumnado mediante unas técnicas sociométricas y unas escalas sobre prejuicio, elaboradas y validadas por la directora del master anteriormente citado: M.J. Díaz Aguado. La realización de este estudio tuvo un año de duración, curso 2002/2003, y además de permitirnos obtener muchos datos relacionados con el objeto de estudio, nos alertó de la situación marginal en la que se encuentran muchos colegios públicos de la ciudad y de la evolución tan drástica que estos mismos centros han sufrido en los últimos diez años.

El segundo estudio nos aportó una visión cualitativa y procesual sobre la situación del alumnado inmigrante en la escuela. Seguramente, las asignaturas cursadas en la carrera de antropología social y cultural en la UNED y los seminarios recibidos por un profesor de estos estudios, Ángel Díaz de Rada, durante estos años de investigación, nos sirvieron para entender el fenómeno social desde una perspectiva más naturalista. Además, aprendimos a utilizar la metodología etnográfica como forma de acercamiento a estos fenómenos.

Este estudio tuvo una duración de un curso escolar, 2005/2006, y la intención pretendida consistió en acercarme al proceso de integración sufrido por el alumnado inmigrante nuevo. ¿Qué forma mejor de hacerlo, que seguir durante toda la jornada escolar a algunos alumnos recién llegados de sus países? Seleccioné a tres alumnos con algunas peculiaridades: diferentes nacionalidades de procedencia, 
diferentes sexos, mismo colegio y mismo curso académico, $5^{\circ}$ de primaria, y, sobre todo, que acabaran de llegar a nuestro país. Así, se podría observar el proceso de adaptación desde el inicio. Con ayuda de un colega, inspector de educación, elegí el centro en el que se reunían estos requisitos (centro que conocía personalmente por haber trabajado en él como maestra varios años atrás). Presentando la propuesta de investigación al director del centro, me abrió las puertas del mismo con total generosidad, una actitud de apertura adoptada igualmente por el resto del profesorado del centro.

Durante el transcurso de esta experiencia, fui consciente de la diferencia entre el rol de maestra y el de investigadora. Esta segunda perspectiva permite tomar conciencia de la complejidad de la labor docente y la facilidad de verse en ella enmarañada por las continuas exigencias de la práctica, pudiendo velar el análisis sobre la propia acción. Al mismo tiempo, la "comodidad" de la práctica investigadora también está fácilmente expuesta al riesgo de alejarse progresivamente de la misma realidad. Por tanto, la realidad y la reflexión sobre la misma constituyen los pilares básicos de la presente investigación y, a su vez, suponen el compromiso que me asigno desde este momento.

\section{2.- Objetivos de la investigación}

El objetivo general que nos planteamos al realizar esta tesis doctoral fue, en una primera fase, evaluar el prejuicio y las relaciones sociométricas entre iguales $y$, en una segunda fase, analizar el proceso de socialización e integración escolar en el alumnado inmigrante nuevo.

Cada una de las fases fue investigada mediante dos estudios. El primer estudio, extensivo y cuantitativo, lo presentamos en el quinto capítulo de este documento y la etnografía, a partir del sexto.

Los objetivos específicos, formulados en forma de interrogante, que nos plateamos en la investigación fueron los siguientes:

- ¿Existe prejuicio a la hora de establecer relaciones sociales entre los escolares?

- ¿Podemos explicar de alguna manera por qué se produce el prejuicio en este contexto? (Relación de la variable prejuicio con factores sociodemográficos y de integración escolar)

- ¿Qué valoración sociométrica recibe el alumnado evaluado: "buenas", "malas" o "regulares"?

- ¿Qué valoración sociaométrica reciben los diferentes colectivos étnicos? 
- ¿Qué valoración sociométrica reciben las diferentes procedencias?

- ¿Qué grupo sociométrico tiene más prejuicio: los "populares", los "rechazados", los "ignorados" o los "medios"?

- ¿Cómo son las interacciones sociales entre los iguales y cómo éstas afectan al proceso de integración escolar?

- ¿Se pueden reconocer fases comunes por las que pasan los diferentes niños y niñas inmigrantes en su proceso de integración?

- ¿Existen factores que facilitan y dificultan este proceso?

- ¿Existen choques culturales en el alumnado al acceder a nuestra cultura escolar?

- ¿Cómo podemos explicar la exclusión social entre el alumnado?

La naturaleza de los interrogantes es diferente y, por tanto, requieren un método distinto de investigación para su respuesta. Para contestar a las seis primeras preguntas utilizamos un estudio extensivo y cuantitativo, realizado en la primera fase de la investigación, con el que evaluamos al alumnado de quinto de primaria de los colegios públicos de la ciudad de Valladolid.

Las cinco últimas preguntas las analizamos mediante una etnografía, de esta manera indagamos, de forma intensiva, aspectos de interés relacionados con el proceso de integración del alumnado inmigrante en una escuela. investigación.

En la siguiente tabla exponemos el planteamiento general de la 


\begin{tabular}{|c|c|}
\hline \multicolumn{2}{|c|}{$\begin{array}{l}\text { LA SITUACIÓN DEL ALUMNADO INMIGRANTE EN LOS CENTROS EDUCATIVOS } \\
\text { VALLISOLETANOS Y SU PROCESO DE INTEGRACIÓN ESCOLAR }\end{array}$} \\
\hline 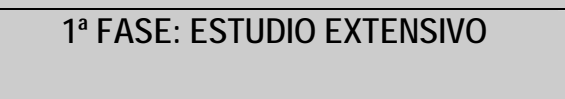 & $\begin{array}{l}2^{\text {a }} \text { FASE: ESTUDIO INTENSIVO. } \\
\text { ETNOGRAFÍA }\end{array}$ \\
\hline OBJETIVO GENERAL & OBJETIVO GENERAL \\
\hline $\begin{array}{l}\text { Evaluación del prejuicio y de las } \\
\text { relaciones sociométricas en el } \\
\text { alumnado de } 5^{\circ} \text { curso de los colegios } \\
\text { públicos de educación primaria de } \\
\text { Valladolid. }\end{array}$ & $\begin{array}{c}\text { Evaluación del proceso de integración } \\
\text { de tres alumnos inmigrantes nuevos en } \\
\text { un centro de educación primaria de } \\
\text { Valladolid. }\end{array}$ \\
\hline OBJETIVOS ESPECÍFICOS & OBJETIVOS ESPECÍFICOS \\
\hline $\begin{array}{c}\text { ¿Existe prejuicio a la hora de } \\
\text { establecer relaciones sociales entre } \\
\text { los escolares? }\end{array}$ & $\begin{array}{l}\text { ¿Cómo son las interacciones sociales } \\
\text { entre los iguales y cómo éstas afectan } \\
\text { al proceso de integración escolar? }\end{array}$ \\
\hline $\begin{array}{l}\text { ¿Podemos explicar de alguna manera } \\
\text { por qué se produce el prejuicio en } \\
\text { este contexto? (Relación de la } \\
\text { variable prejuicio con factores socio- } \\
\text { demográficos y de integración } \\
\text { escolar) }\end{array}$ & $\begin{array}{l}\text { ¿Se pueden reconocer fases } \\
\text { comunes por las que pasan los } \\
\text { diferentes niños y niñas inmigrantes } \\
\text { en su proceso de integración? }\end{array}$ \\
\hline $\begin{array}{l}\text { ¿Qué valoraciones sociométricas } \\
\text { recibe el alumnado evaluado: } \\
\text { "buenas", "malas" o "regulares"? }\end{array}$ & $\begin{array}{l}\text { ¿Existen factores que facilitan y que } \\
\text { dificultan este proceso? }\end{array}$ \\
\hline $\begin{array}{l}\text { ¿Qué valoración sociométrica reciben } \\
\text { los diferentes colectivos étnicos? }\end{array}$ & $\begin{array}{l}\text { ¿Existen choques culturales en este } \\
\text { alumnado al acceder a nuestra cultura } \\
\text { escolar? }\end{array}$ \\
\hline $\begin{array}{l}\text { ¿Qué valoración sociométrica recibe } \\
\text { el alumnado procedente de diferentes } \\
\text { procedencias? }\end{array}$ & $\begin{array}{c}\text { ¿Cómo podemos explicar la exclusión } \\
\text { social entre el alumnado? }\end{array}$ \\
\hline $\begin{array}{l}\text { ¿Qué grupo sociométrico tiene más } \\
\text { prejuicio; los "populares", los } \\
\text { "rechazados", los "ignorados" o los } \\
\text { "medios"? }\end{array}$ & \\
\hline
\end{tabular}

Tabla 1. Objetivos de la tesis doctoral. 


\section{3.- Justificación e interés del estudio}

La incorporación del alumnado inmigrante en los centros educativos es un hecho que está repercutiendo de forma importante en el sistema educativo.

El tema de la diversidad cultural en la escuela constituye un debate de actualidad entre profesionales de diferentes ámbitos, ya que es fenómeno multicausal que requiere un tratamiento interdisciplinar.

Desde la educación, se han revitalizado los estudios relacionados con la inclusión de las minorías étnicas en nuestro sistema educativo. Nos encontramos con estudios que analizan las líneas políticas de actuación para atender a las minorías étnicas (Delors, 1996; Plan Marco, 2002; Marchesi, 2003; Staimback y Staimback, 2001; Carbonell, 2005). Otros estudios hacen referencia a las medidas educativas del centro escolar para atender a la diversidad (Enguita, 2000, 2001; Martín y Marchesi, 1998; Martín y Coll, 2003; Del Cano, 2006; Martín, 2007). También se analizan, desde diferentes disciplinas, las metodologías más apropiadas para trabajar en las aulas, donde existe alumnado culturalmente diverso (Jordán, 1996; Díaz Aguado, 1999a, 1999b, 2006; Johnson, Johnson y Houlubec, 2001; Pujolás, 2004; López Melero, 2004). Las cuestiones relacionadas con el aprendizaje de la lengua en el alumnado inmigrante toman, igualmente, presencia en el panorama de la investigación (Navarro, 2005; Morales Orozco, 2006).

El análisis de las interacciones sociales entre los iguales, producidas en el contexto escolar, ha sido en esta tesis doctoral el medio idóneo con el que comprender el fenómeno de la integración del alumnado inmigrante. Otras investigaciones han utilizado este tema (el de la interacción social entre pares), de forma instrumental, para analizar aspectos escolares, como: el rendimiento académico y dificultades de los escolares, (Rodrigo, 1999; Noe, Cabello y Zúñiga, 2005), las habilidades sociales (Caballo 1987 y 2007; Monjas,1996; Verdugo, 1997), el desarrollo moral (Kolhberg 1992; Kolhberg, Power y Higgins, 1997; Díaz Aguado y Medrano,1996). También existen otros enfoques naturalistas que analizan el proceso de socialización del niño en contextos ajenos a la influencia directa de la escuela (Corsaro, 1985; Hartup, 1983, 1985 y 1996).

Nosotros nos proponemos estudiar el fenómeno de la integración escolar del alumnado inmigrante desde el análisis de las interacciones sociales entre iguales. Nos atraía la idea de investigar esta temática desde el punto de vista relacional. Pensábamos, además, que los resultados nos ofrecerían una visión de la problemática, original y próxima a las vivencias reales del alumnado.

En el cuadro que aparece a continuación situamos conceptualmente la temática de nuestro estudio: las interacciones sociales entre iguales en contextos 
étnicamente diversos. Somos conscientes de que dicho aspecto está relacionado con otras dimensiones donde se plasman estas relaciones. Son las que rodean la casilla central de color rojo; pero estas temáticas no son tratadas de forma directa en este trabajo.

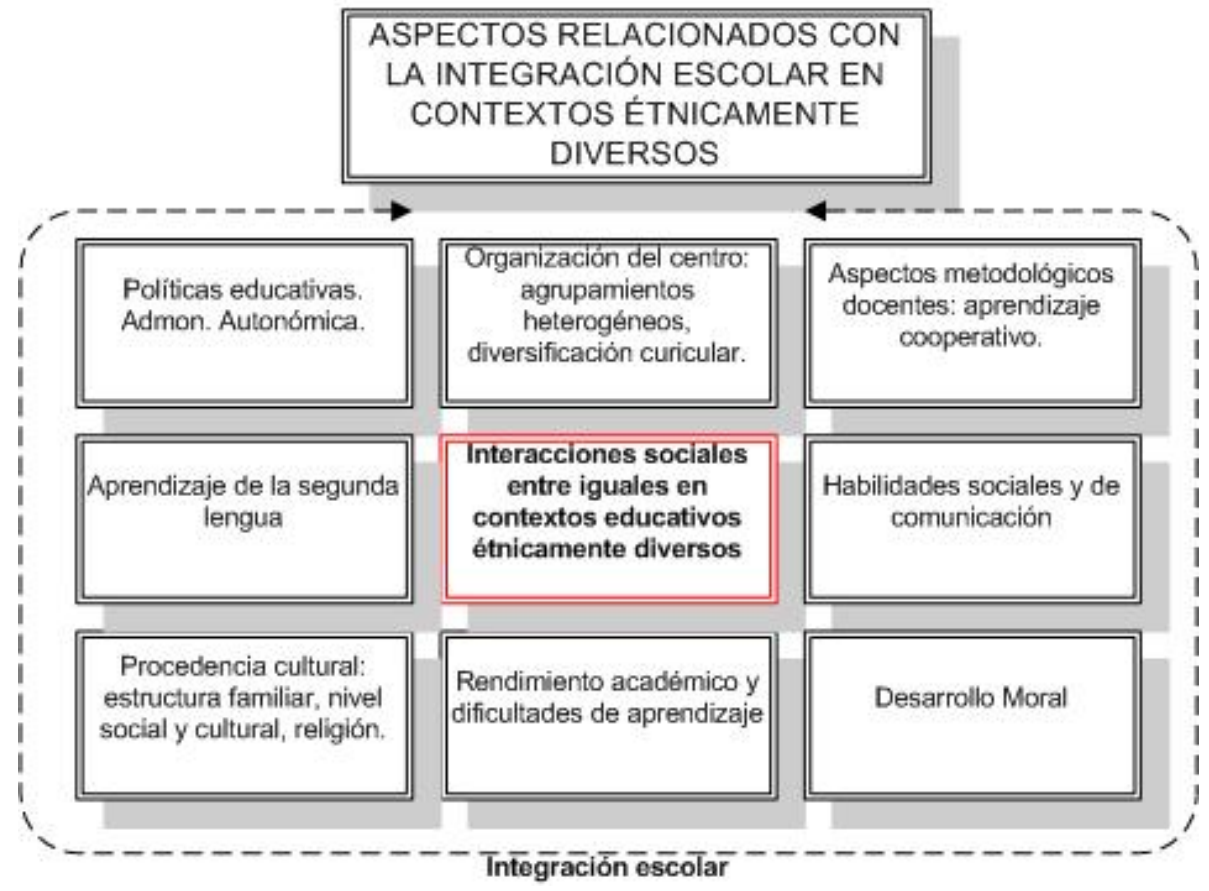

Figura 1. Ubicación conceptual de las interacciones sociales en contextos educativos étnicamente diversos.

\section{4.- Estructura conceptual de la tesis doctoral}

Para dar cumplida cuenta de las anteriores motivaciones e intenciones expuestas, daremos paso a los once capítulos de los que consta la presente tesis doctoral. El esqueleto del documento está vertebrado por tres bloques temáticos. El primero hace referencia al marco teórico y está constituido por tres capítulos, cuyos contenidos se van aproximando progresivamente a los pilares conceptuales del trabajo empírico. El segundo bloque se refiere a la parte empírica y el tercero, a las posibles aportaciones que se deducen de la investigación.

En primer lugar, empezamos explicando el estado de la cuestión de la inmigración y la escuela. Describimos las características principales de dicho fenómeno a nivel mundial, explicando posteriormente, el hecho migratorio en 
nuestro país y en Castilla y León, hasta llegar en último lugar a las escuelas de la ciudad de Valladolid, residencia habitual de la investigadora. Toda esta información aparece explicitada en el primer capítulo del primer bloque.

En el segundo capítulo, describimos la temática referida a las relaciones sociales y al prejuicio. En concreto, realizamos un breve recorrido por la psicología social, desde una perspectiva que enfatiza la desigualdad social con la que se han ido formando las relaciones sociales en la humanidad a lo largo de la historia. Este capítulo continúa explicando una posible característica que, por desgracia, suele darse en las relaciones sociales, como es el prejuicio, y, en concreto, la formación de creencias prejuiciosas y estereotipadas en los escolares.

Por último, el tercer capítulo, contenido en este primer bloque, teórico, lo conforma la temática referida a las interacciones sociales en los escolares como base para el desarrollo de la competencia social. Se conceptualiza el término, explicando que serán éstas, las interacciones sociales, las que constituirán el nivel mínimo de análisis, desde las que afrontaremos el fenómeno de integración del alumnado inmigrante. Es decir, analizaremos la situación del alumnado inmigrante desde este enfoque relacional de los iguales, por ser el aspecto que más nos acerca a la realidad que vive el niño/a. La intención de este planteamiento es la de estudiar la situación del alumnado inmigrante desde un punto de vista: acercarse, lo máximo posible, a su situación real. De este modo, conceptualizamos las habilidades sociales, entendidas como códigos culturales que el alumnado debe manejar para la adecuada interacción entre pares. Este capítulo cerraría el primer bloque y daría paso al siguiente, centrado en el trabajo empírico.

El segundo bloque lo constituyen los siguientes seis capítulos, que van del cuarto al décimo. Se trata del grueso de la investigación: el trabajo empírico, formado por dos fases, en cada fase se realiza un estudio de diferente índole. En primer lugar, después de explicar, en el capítulo cuarto, el planteamiento general de la investigación, realizamos un estudio extensivo o cuantitativo titulado: "Evaluación del prejuicio y las relaciones sociométricas del alumnado de $5^{0}$ de primaria de la ciudad de Valladolid", desarrollado en el quinto capítulo, con él obtenemos una primera panorámica general acerca de la situación prejuiciosa y relacional del alumnado.

Una vez expuestos los resultados, la discusión de los datos y algunas conclusiones derivadas del estudio cuantitativo, pasamos a la segunda fase de la investigación. En ella, realizamos una etnografía escolar, siguiendo la orientación del profesor Ángel Díaz de Rada. Las principales cuestiones metodológicas respecto a los objetivos, el análisis de los datos y los criterios de validez, utilizados en este estudio, se explican en el capítulo sexto. 
A partir de este capítulo, del séptimo al décimo, ofrecemos el informe final del segundo estudio. Explicamos, a través de las actas del diario de campo, la información elaborada que obtuvimos durante nuestra permanente presencia en el terreno, a lo largo de un año escolar en un centro, siguiendo el proceso de integración de tres alumnos inmigrantes de diferentes países de procedencia.

Finalmente, dentro del tercer bloque, y en el capítulo once, presentamos las conclusiones finales y las referencias bibliográficas, completando así la presente investigación, que usando dos corrientes metodológicas, la cuantitativa y la cualitativa, utiliza la primera como trampolín para adentrarse en la segunda, más propia de una indagación educativa, como afirma la gran mayoría de los autores que tratan de profundizar en el cuerpo de las ciencias sociales.

A continuación presentamos un cuadro, donde resumimos la estructura conceptual seguida en la presente tesis doctoral.

\begin{tabular}{|c|}
\hline $\begin{array}{l}\text { LA SITUACIÓN DEL ALUMNADO INMIGRANTE EN LOS CENTROS EDUCATIVOS } \\
\text { VALLISOLETANOS Y SU PROCESO DE INTEGRACIÓN ESCOLAR }\end{array}$ \\
\hline BLOQUE I. MARCO TEÓRICO \\
\hline Capítulo 1. Inmigración y escuela en el S.XXI. Estado de la cuestión. \\
\hline Capítulo 2. Las relaciones sociales y el prejuicio. \\
\hline $\begin{array}{l}\text { Capítulo 3. Las interacciones sociales y el desarrollo de la competencia social en los grupos escolares } \\
\text { étnicamente diversos. }\end{array}$ \\
\hline BLOQUE II. TRABAJO EMPÍRICO \\
\hline Capítulo 4. Planteamiento general de la investigación. \\
\hline Capítulo 5. Estudio extensivo. \\
\hline Capítulo 6. Estudio etnográfico. \\
\hline Capítulo 7 al Capítulo 10. Informe final del estudio etnográfico. \\
\hline BLOQUE III. APORTACIONES FINALES \\
\hline Capítulo 11. Conclusiones finales y futuras líneas de investigación. \\
\hline Referencias bibliográficas. \\
\hline ANEXOS \\
\hline
\end{tabular}

Tabla 2. Estructura conceptual de la tesis doctoral. 


\section{Capítulo 1}

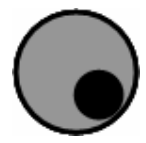

\section{Inmigración y escuela en el siglo XXI. Estado de la cuestión.}

Para estudiar el tema de las relaciones sociales entre escolares en contextos interétnicos, es necesario describir el estado de la cuestión de la inmigración y la escuela. El análisis que exponemos va focalizando progresivamente la situación hasta llegar a los centros educativos más cercanos a nuestra realidad. Es decir, empezamos analizando las migraciones mundiales del siglo XXI, continuamos explicando la inmigración y educación en Castilla y León y concretamos posteriormente con la descripción de este fenómeno en la ciudad de Valladolid, lugar en el que realizamos la presente investigación. Así mismo explicamos las características sociales de los colectivos más numerosos en esta ciudad; los latinoamericanos, los marroquíes y los procedentes de Europa del este. Posteriormente incluimos un epígrafe referido a la inmigración dentro del ámbito escolar, describiendo la situación sociodemográfica de las escuelas, las diferencias existentes en cada uno de los colectivos étnicos que habitan en los colegios y los principales enfoques teóricos desde los que se aborda la integración de los inmigrantes en la escuela. Por último cerramos el capítulo con una sección dedicada a la revisión que la literatura nos ofrece respecto al tema de la inmigración y la escuela en nuestro país desde el año 2000 hasta la actualidad. Toda esta información pretende ubicarnos en el contexto en el que posteriormente llevaremos a cabo nuestra investigación. 


\section{1.- La inmigración en un mundo globalizado}

Resulta útil analizar el fenómeno de la inmigración desde los siguientes datos aportados por diferentes autores y organizaciones: "Durante la década pasada (la de los noventa), 55 Estados, ubicados en África subsahariana y Europa oriental, han visto disminuir sus ingresos. Liberia, Ruanda y Sudán son más pobres hoy que hace 30 años. En Europa del Este la pobreza se ha multiplicado por siete. En el sur de Asia y en el África subsahariana cuatro de cada cinco personas son consideradas pobres. En América Latina, los PAE o Países Altamente Empobrecidos, a lo largo de los años ochenta, acentuaron la concentración económica y elevaron los niveles de pobreza, que alcanza al 50\% de su población. En Ecuador entre 1995 y 2000 el número de pobres aumentó de 3.900.000 a 9.100.000. Actualmente la pobreza afecta al $71 \%$ de sus habitantes. A mediados de los años setenta, siete de cada diez argentinos integraban la franja de ingresos medios. A finales de 2002 la relación había descendido a cuatro de cada diez". (Gil Araujo, 2005, 38).

Según UNICEF, de los 6.000 millones de habitantes que tenía el planeta en 1999, la quinta parte más rica de la humanidad tiene unos ingresos 82 veces más elevados que la quinta parte más pobre, y consume el $85 \%$ de los recursos del planeta.

Ante estas desigualdades existentes en la humanidad, no es de extrañar, que se produzcan cada vez más movimientos migratorios de las zonas más pobres a las más ricas. Además, el intenso desarrollo de las telecomunicaciones y de los medios de transporte facilita las migraciones.

Hoy en día las migraciones tienen un significado diferente al de épocas pasadas. Recogiendo diversos aportes bibliográficos hacemos un repaso de las características actuales de la migración en un mundo globalizado. En primer lugar explicamos las etapas que desde una perspectiva política se han ido dando a lo largo de la historia y en segundo lugar enumeramos las características que explican la peculiar idiosincrasia de la migración del siglo XXI.

En el primer apartado de este capítulo referido a la inmigración en un mundo globalizado vamos a desarrollar los dos epígrafes siguientes:

1.1.- Etapas en el tratamiento político de la inmigración

1.2.- Características de la migración del siglo XXI 


\section{1.- Etapas en el tratamiento político de la inmigración}

Ricardo Zapata-Barrero (2000) afirma que la investigación sobre la migración ha transitado del estudio del inmigrante como actor económico al inmigrante como actor político y como problema estructural. Dice que se suelen distinguir tres etapas en el tratamiento político de la inmigración: Puertas Abiertas desde 1945 a 1973; Puertas Cerradas: desde 1973 a 1990 y Muros de Contención: desde 1990 a nuestros días.

La etapa de Puertas Abiertas se inicia tras la II Guerra Mundial. Europa quedó devastada y necesitaba mano de obra para la reconstrucción económica del Continente. Se pensaba que los inmigrantes regresarían a sus casas y esta consideración hizo que permanecieran en segundo plano los aspectos regulativos de la población que llegaba desde los países emisores de inmigrantes (Gran Bretaña, Alemania, Francia, Italia, Portugal, España, Turquía, Argelia e India). Muchos de estos países no los concebiríamos, hoy día, como emisores, pero durante ese largo período lo fueron. Con estos países se firmaron acuerdos bilaterales. Sin embargo, faltó la planificación sectorial, geográfica, o comunitaria.

La Etapa de Puertas Cerradas se inició con la crisis del Estado de Bienestar. La emigración comenzó a verse como un problema al que había que poner "límites de tolerancia" y para el cual había que pensar en "políticas de cuotas". Se pensó en devolver a los inmigrantes a su tierra o en establecer estrategias rotatorias que regularan los turnos de acceso, según conviniera a la economía del país receptor.

La etapa de "Muros de Contención" es en la que nos encontramos ahora mismo. No se abren las puertas de par en par, tampoco se cierran herméticamente; pero se ponen trabas, se levantan muros, se construyen vallas (entre EE. UU. y México, entre África y Europa; entre Israel y Palestina). Partiendo de que el inmigrante es un problema en sí mismo, se elaboran cupos para restringir la entrada, se planifican políticas de integración para que permanezcan sólo los necesarios a la economía del Capitalismo neoliberal, se observa que no se van, sino que se ahíncan en nuestras culturas sin prescindir de la suya.

Este es el panorama donde el nuevo inmigrante de la época globalizadora se ubica. Bajo ella se cobijan o vagan 150 millones de personas que viven fuera de su lugar de nacimiento, lo que representa el $2,4 \%$ de la población total del mundo. 


\section{2.- Características de la migración del siglo XXI}

1. Los movimientos de población contemporáneos se caracterizan, asevera Sandra Gil Araujo $(2005,13)$, por la diversidad de países involucrados y la complejidad de sus causas: cada vez es más difícil diferenciar entre migraciones forzadas y migraciones económicas.

2. Paulatino proceso de feminización. Vinculado, sin duda con la feminización de la pobreza y de la fuerza de trabajo.

3. En este sentido, las migraciones Sur-Norte pueden ser interpretadas como una estrategia de resistencia a las condiciones de empobrecimiento y desigualdad creciente, resultado de los modelos de desarrollo implantados en las últimas décadas.

4. Los movimientos de población deben analizarse en un contexto más amplio que el de las relaciones internacionales. La explicación de fondo radica en las relaciones socioeconómicas entre Norte-Sur.

5. Desde esta perspectiva, debe entenderse que las migraciones no son un fenómeno autónomo, sino dependiente de procesos económicos, históricos, sociales y políticos de alcance global.

6. Por estas razones, se caería en una interpretación reduccionista del fenómeno migratorio si a éste sólo se le concibe como un simple desplazamiento de la fuerza de trabajo, sin interrogarse sobre las causas de ese excedente dispuesto a emigrar y sobre los mecanismos generadores de esos empleos disponibles para las sociedades receptoras.

7. La geografía de la inmigración está fuertemente estructurada: los imperios coloniales del pasado han creado verdaderos puentes de emigración. Del mismo modo, la moderna estructura económica trasnacional o economía global (Sassen, 1999) está creando otro puente que une a los países emisores de población con los receptores que absorben esa mano de obra. El 60\% de los extranjeros residentes en el Reino Unido proceden de excolonias o protectorados ingleses. Casi todos los inmigrantes originarios de la India 0 del Caribe británico que están en Europa viven en el Reino Unido. El 80\% de los inmigrantes turcos, el $86 \%$ de los griegos y el $76 \%$ de los yugoslavos se concentran en Alemania. La mayor parte de los inmigrantes argelinos residen en Francia junto con el $86 \%$ de los tunecinos. El pasado colonial también se hace presente en el origen de los grupos inmigrantes no comunitarios instalados en territorio español, que provienen principalmente de América Latina y Marruecos. (Gil Araujo, 2005, 19-21). 
8. No es extraño que ante estas características y otras que ellos añaden, al reflexionar sobre las migraciones internacionales, hablen de la "migracionalización" de la sociedad.

9. El fenómeno migratorio, concluyen estos autores, es un fenómeno cotidiano y universal. La migración moderna es una migración compleja. Frente al inmigrante pobre, ignorante y permanente, extraído de un núcleo rural empobrecido, adquiere nueva relevancia la corriente del profesional transeúnte o del emigrante cualificado. Junto a la migración de supervivencia coexiste la migración de promoción.

10. Es necesario pensar que la migración no es sólo efecto de la pobreza (que evidentemente, lo es) y de la trascendencia de la internacionalización de los mercados, sino que también es efecto de la corporatización de las sociedades contemporáneas como la americana, la europea y, por consiguiente, la española.

11. Este reconocimiento de la complejidad y de las diferentes causas de la migración tiene importantes consecuencias, como la necesidad de eliminar ciertos prejuicios, mal cimentados en razones probadas, acerca de: los flujos de inmigrantes, del concepto de extranjero, del miedo al extraño, el "ellos" y "nosotros", de la discriminación que ciertos grupos padecen al ser calificados de intolerables, rechazables, peligrosos, delincuentes 0 ilegales, del inmigrante como portador/creador de problemas sociales, del movimiento inmigrante como un costo social que la sociedad receptora paga a fondo perdido.

En definitiva, el rostro del nuevo emigrante debe superar el esquema reduccionista de la persona hambrienta, pobre, desesperada, temible, ignorante y marginado. Sin negar, de ninguna manera, que muchos de los que ingresan en los territorios del Norte son fruto de condiciones injustas sociopolíticas, imperantes en los países del Sur y, muchas veces, producidas o consentidas por los países del Norte, hay que reafirmar también la novedad coexistente del emigrante culto, arriesgado, profesional, dinámico, curioso-investigador y ejecutivo que traspasa las distintas fronteras del mundo, impulsado por las contemporáneas circunstancias de un mundo global, tecnificado, informatizado y corporatizado. Sin la desaparición de este prejuicio mencionado, las relaciones sociales entre ciudadanos procedentes de diversas culturas no podrán desarrollarse de modo positivo. Debido a la relación con el tema que tratamos en este trabajo, dedicamos un especial apartado al prejuicio en el capítulo siguiente. 


\section{2.- La inmigración en España}

Una vez desarrolladas algunas ideas referidas al proceso migratorio mundial, acercamos las lentes mediante la explicación de dicho fenómeno en nuestro país.

Los epígrafes concretos que trataremos serán los siguientes:

\section{1.- Situación general de la inmigración en España}

\section{2.- Reflexiones sobre las causas sociales de la inmigración en España}

\section{3.- Reflexiones sobre las consecuencias de la inmigración en España}

\section{1- Situación general de la inmigración en España}

Estamos ante un proceso socio-político que se ha iniciado en España aproximadamente hace unos 20 años. Sabemos que las cifras sobre esta situación son difíciles de calcular. La fuente que se utilizaba hasta hace poco era el Registro de Permisos de Residencia del Ministerio de Interior. Ahora estos datos se calculan mediante el Padrón Municipal y para inscribirse en él se tiene que estar en posesión del permiso de residencia. A partir de esta información, según los resultados del padrón del 1 de Enero del 2007, existían 4.480 .000 de extranjeros en la nación, de los 45 millones de habitantes que viven en España. El número de españoles empadronados aumentó en un $0,17 \%$, mientras que el de extranjeros fue de un $8,17 \%$. $Y$ de estos el $49,4 \%$ son varones y el $50,6 \%$ mujeres.

En tan sólo seis años, el porcentaje de residentes extranjeros ha pasado del 2,3\% de 2000 (924.000 personas) al 9,3\% en 2006 (4.145.000). En 2001, los extranjeros inscritos en los padrones giraban en torno a 1.371.000; en el 2002 se situaron en 1.978.000; en 2003 eran 2.664.000; en 2004 sumaron 3.034.000 y en 2005 ascendían a 3.730.000. En el mismo periodo de referencia (2000-2006), los mayores aumentos se produjeron en 2005, con 696.000 nuevos residentes extranjeros, y en 2003, con 686.000.

Estos datos nos sugieren que en un futuro próximo existirá un crecimiento progresivo de la población inmigrante. De no cambiar las tendencias, el volumen de la población extranjera residente en España podría cifrarse para el 2010 en más de siete millones de personas (en torno al 16\% de la población), pudiendo llegar a superar los diez millones en 2015. La concentración de la inmigración en determinadas zonas de España está dando lugar, por ejemplo, a que en la Comunidad de Madrid se haya superado ya la proporción del $16 \%$ de la población, con algunos distritos de la ciudad de Madrid donde reside un 30\% de extranjeros. 


\section{2- Reflexiones sobre las causas sociales de la inmigración en España}

Debe tenerse en cuenta que estamos ante procesos que obedecen a varias razones: no sólo a la capacidad de atracción que ejercen los países desarrollados y a las ofertas específicas de trabajo en determinadas actividades (en la construcción, en el servicio doméstico, en la recogida de productos agrícolas de temporada y en sectores turísticos), sino también al propio efecto de expulsión y abandono desde zonas y países en los que se viven condiciones de grave deterioro económico y social y de falta de perspectivas de futuro. La pobreza y el hambre son factores tan estimuladores de la emigración como la propia oferta concreta de puestos de trabajo. Es decir, estamos ante un fenómeno que no se puede explicar sólo en términos de una racionalidad económica estricta (oferta y demanda de empleos), sino a partir de las situaciones mundiales de dualización y pobreza extrema.

Otra causa por la que la emigración decide venir a España es la afinidad cultural que sienten con este país muchos inmigrantes, en especial los latinoamericanos. Los marroquíes explicarían su llegada a este país, por su cercanía geográfica. La pertenencia a la UE supone otro atractivo para la inmigración, pues nuestro país hace de puerta de entrada a otros países.

\section{3- Reflexiones sobre las consecuencias de la inmigración en España}

La inmigración, en la forma en que está teniendo lugar, desempeña un papel económico y laboral de carácter dual. Por un lado, está contribuyendo al crecimiento económico de España y, de manera particular, está permitiendo cubrir determinadas actividades y servicios, generalmente con notables rebajas en los costes laborales. Lo que permite que algunas empresas resulten muy productivas, al tiempo que otras sufren competencias "desleales" y, a veces, irregulares. De esta manera, se está suscitando un debate sobre el papel que a veces desempeña la inmigración, como nuevo "ejército laboral de reserva". Esto genera una sobreoferta de trabajadores en determinados sectores y a su vez un descenso de los salarios y un empeoramiento de las condiciones laborales.

La presencia de un número importante de inmigrantes no regularizados (más de millón y medio) y la existencia de mayores índices de paro y precariedad social y laboral entre los extranjeros, está traduciéndose en un aumento de los fenómenos desigualitarios y de exclusión social. Un número importante de inmigrantes padecen discriminaciones, y tienen carencias en vivienda, educación y servicios sociales y asistenciales; lo cual, unido a otros factores de segregación y dualización étnica y cultural, está acentuando los rasgos de una sociedad dividida, 
en un contexto en el que el porcentaje del PIB que España dedica a gastos sociales, se redujo, desde 1994, en cinco puntos.

Estas condiciones desiguales en cuanto a los niveles salariales, derechos laborales y sociales, están generando ciudadanos de segunda o tercera categoría. Lo cual está generando un modelo dual de sociedad, con un doble circuito de posibilidades y diferenciándose entre sí los niveles de vida existentes.

$\mathrm{Si}$ se mantienen los intensos ritmos de llegadas, y si continúan los problemas de exclusión, los déficit de integración y el surgimiento de actitudes de rechazo y una diferenciación a la baja en los recursos sociales y oportunidades laborales para esta población de inmigrante cada vez más creciente, puede acabar conformándose un cóctel inflamable que acabe convirtiendo a la inmigración en uno de los principales problemas sociales de España.

Todo esto tiene una clara repercusión en el ámbito educativo. Para el sistema educativo representa un gran reto integrar a los hijos de estos inmigrantes en la sociedad y en la cultura españolas, en igualdad de oportunidades. Los efectos educativos pueden conseguir 0 que se integren en la sociedad receptora y se lleguen a sentir identificados con el proyecto del país que les acoge o que se acumulen odios y rencores, si se producen y perciben procesos de exclusión social.

\section{3.- La inmigración en Castilla y León}

Indagando en las causas la inmigración en esta comunidad autónoma vemos, según un estudio realizado por García Zarza (2003), que es de carácter laboral casi toda ella, como ocurre en el resto del territorio español, pero con mucha más intensidad. Dentro de la diversidad de causas que generan la inmigración, la mayoría se deben a las deficiencias socioeconómicas que existen en sus países de procedencia, todas ellas podrían resumirse en la conocida Teoría de la repulsión atracción, esto es, el rechazo que sienten los inmigrantes hacia lo que conocen, su entorno socioeconómico, presente y futuro, y el atractivo tan fuerte que les produce lo que ven en España. Los medios de comunicación, los inmigrantes que permanecen entre nosotros y los que se han vuelto ya y los turistas contribuyen, en gran medida, a dar a conocer tales diferencias y crear altas expectativas a los que todavía están en sus países de procedencia. Además Castilla y León, en especial, hace tiempo que tiene escaso crecimiento de la población. La tasa de envejecimiento es muy alta y creciente, por lo que la población activa es cada vez menor. Los inmigrantes contribuyen a aumentar la población joven y activa de la comunidad.

La diferencia con el resto del país es que en esta comunidad autónoma existe menor desarrollo económico que en otras autonomías, lo que explicaría la 
menor intensidad de la llegada de personas de otros países, si lo comparamos con otras comunidades como Madrid o Barcelona.

Los inmigrantes que llegan a nuestra comunidad provienen principalmente de los siguientes cuatro ámbitos:

\begin{tabular}{|l|c|}
\hline \multicolumn{1}{|c|}{$\begin{array}{c}\text { NACIONALIDADES DE } \\
\text { PROCEDENCIA }\end{array}$} & PORCENTAJES \\
\hline $\begin{array}{l}\text { Iberoamericanos: Colombia, } \\
\text { Ecuador, República } \\
\text { Dominicana. }\end{array}$ & $30,24 \%$ \\
\hline Bulgaria & $11 \%$ \\
\hline Marruecos & $10,1 \%$ \\
\hline China & $3,1 \%$ \\
\hline
\end{tabular}

Tabla 1.1. Datos obtenidos del CREI Castilla y León 2007.

Esta diversidad en la procedencia nacional de los inmigrantes de Castilla y León, contribuye a acrecentar las múltiples e interesantes repercusiones que este colectivo provoca en la población y en la economía y sociedad regional, es debido a las diferencias que hay entre ellos y las características de Castilla y León.

Otra característica de la inmigración en Castilla y León y de las repercusiones que provoca en la demografía, economía, sociedad y educación es el sexo y edad de los inmigrantes. Estos dos últimos datos suelen guardar relación con el tipo de oferta de trabajo ofrecido a los inmigrantes. En este sentido, vemos que los varones constituyen el $52,4 \%$ y las mujeres el $47,6 \%$ del total. La participación femenina en el sector laboral ha aumentado progresivamente, superando incluso, en el caso de los iberoamericanos, a la participación masculina en el mundo laboral.

Respecto a la edad de estos colectivos hay que decir que se corresponde con la edad más propicia para el trabajo y la procreación, se encuentran en su mayoría entre los 16-65 años, el 84,6\%, mientras que los menores de esta edad sólo son el $12,6 \%$ y los mayores el 2,9\%. Es decir, casi todos se encuentran en edad en la que pueden trabajar y ser activos en la sociedad. En los últimos años se observa un incremento de la natalidad entre los inmigrantes, lo que empieza a repercutir en los alumnos de primaria.

Los sectores de trabajo que suelen ocupar son el sector primario, el servicio doméstico, limpieza, atención a la $3^{\mathrm{a}}$ edad, construcción y hostelería. Por lo general, no se requiere mucho nivel cultural 0 de formación, sino que con unos conocimientos mínimos pueden acceder a dichos trabajos. Por lo tanto, el nivel cultural es bajo, aunque no faltan los que tienen un alto nivel cultural, pero 
desempeñan trabajos inferiores. Es importante resaltar que la tasa de actividad de los inmigrantes es muy alta, precisamente la razón por la que vienen es para trabajar. Según el estudio de García Zarza (2003), los inmigrantes superan el 70\% de la población activa, cuando la de los españoles sobrepasa escasamente el 30\%.

En la actualidad hay, según el Centro de Recursos de Educación Intercultural de la Junta de Castilla y León (2007), 19.125 alumnos inmigrantes escolarizados en la Comunidad, lo que supone alrededor de un $2 \%$ del alumnado total, predominando los alumnos procedentes de Bulgaria, Ecuador, Colombia, Rumania y Marruecos. Respecto a las etapas educativas en las que se inserta este alumnado, el $17 \%$ se encuentran en educación infantil, el $43 \%$ en primaria, el $28 \%$ en la ESO, el 5\% en Bachillerato, el 4\% en ciclos formativos y el $3 \%$ en garantía Social. En las enseñanzas universitarias el porcentaje de inmigrantes se reduce en gran medida, no llegando siquiera al $1 \%$ de la población estudiantil. A la hora de hablar del carácter público y privado-subvencionado de los centros, se corrobora que estos últimos cuentan con una proporción de alumnado inmigrante mucho menor.

Vemos, por tanto, cómo el fenómeno de la inmigración ha sido un fenómeno reciente en todas las provincias de la región. Al igual que en el resto de España, donde tampoco había tradición de recibir extranjeros, los inmigrantes en Castilla y León han contribuido a incrementar el impacto en la sociedad castellanoleonesa. Cuando hablamos de impacto social nos referimos a la influencia de estos colectivos en el funcionamiento más notable de la sociedad como es la ocupación de puestos laborales de máxima necesidad ciudadana como puede ser: las tareas domésticas, los servicios de hostelería, los trabajos agrícolas, etc. Comentamos algunos de esos impactos.

Tradicionalmente, esta comunidad ha tenido una composición étnica poco multicultural. De repente ha visto incorporarse gentes con idiomas, culturas y tradiciones diferentes. Además, muchos de estos inmigrantes se dedican a actividades de escasa importancia real en la economía, pero con bastante impacto social, como es el caso de los que se dedican al servicio doméstico, limpieza y atención a la $3^{\text {a }}$ edad.

Por otro lado, también puede acrecentar el impacto social de los inmigrantes, la diferencia en el aspecto físico de muchos inmigrantes, su diferente modo de vida y de relaciones sociales. Algunas actividades marginales, droga, prostitución, delincuencia han sido, a veces, excesivamente jaleadas y distorsionadas por los medios de comunicación. Este mismo fenómeno mediático ha contribuido, sorprendentemente, a incrementar el impacto social de los inmigrantes en nuestra comunidad regional. 
En el panorama educativo se ha conseguido una progresiva transformación, creando escenarios multiculturales, lo cual supone un giro en los planteamientos y metodologías educativas, a lo que tendrán que enfrentarse los profesionales de la educación.

Muchas veces tales repercusiones quedan reducidas al impacto visual, pero generalmente van más allá, ya que supone un cambio en las relaciones y en el modo de enseñar, al ponerse en contacto gentes de cultura y comportamientos sociales diferentes.

\section{4.- La inmigración en Valladolid.}

Focalizando un grado más nuestra perspectiva sobre el fenómeno de la inmigración llegamos a la ciudad de Valladolid, lugar donde realizamos nuestra investigación. A continuación numeramos los epígrafes de los que constará este cuarto apartado:

\section{1.- Datos sociodemográficos}

4.2.- Características de los principales colectivos inmigrantes en Valladolid

\subsection{1.- Colectivo marroquí}

\subsection{2.- Colectivo de Europa del Este}

\subsection{3.- Colectivo latinoamericano}

\section{3.- Condiciones socioeconómicas de los grupos de inmigrantes}

4.3.1.- Desde un punto de vista personal y familiar

4.3.2.- Desde un punto de vista social y educativo

\section{1- Datos socio-demográficos.}

Según la última lectura de la base de datos del Padrón Municipal de Habitantes, a fecha de 1 de Julio de 2005, había empadronados en Valladolid 13.439 personas extranjeras. Esta ciudad es la que más inmigrantes posee de Castilla y León, seguida por Burgos, Salamanca y León. El crecimiento ha sido espectacular en los últimos tres años. Este colectivo ha pasado de representar menos del $1 \%$ en el 2002, a más del $4 \%$ en esta última revisión del Padrón; 13.439 personas de nacionalidad extranjera.

Valladolid aglutina el $67,54 \%$ de los extranjeros de la provincia, el $12,94 \%$ de la población total castellana y leonesa. Sin embargo, la población inmigrante de nacionalidad extranjera representaba tan sólo el 3,74\% de la total española. Siendo la media nacional el 8,39\%. 
Nos interesa conocer en concreto cuál y cómo es esta diversidad que va dibujando el escenario de esta provincia. Conocer en profundidad las diversas procedencias, así como sus diferencias, sus problemas y necesidades es importante para gestionar unas buenas relaciones sociales.

A partir del año 2001 es cuando Valladolid se convierte en un núcleo económicamente atrayente para la población extranjera. Los franceses constituían la principal fuente de trabajadores asociados a la FASA-RENAULT. Después de este año, la llegada de los latinoamericanos comienza a ser notoria, también los procedentes de Europa del Este: búlgaros y rumanos sobre todo. Los marroquíes, han ido manteniendo un ritmo paulatino pero constante, mientras que los asiáticos (chinos) han ido decreciendo paulatinamente. Por lo general, vemos que son el colectivo latinoamericano y el de Europa del Este los que van aumentando su llegada a Valladolid.

En esta gráfica vemos cuáles son las procedencias de los habitantes extranjeros con las que cuenta esta ciudad.

\begin{tabular}{|l|l|}
\hline \multicolumn{1}{|c|}{ NACIONALIDADES DE PROCEDENCIA } & \multicolumn{1}{|c|}{ PORCENTAJES } \\
\hline Bulgaria & $21,85 \%$ \\
\hline Ecuador & $10,11 \%$ \\
\hline Colombia & $9,86 \%$ \\
\hline Rumania & $8,19 \%$ \\
\hline Marruecos & $8,14 \%$ \\
\hline
\end{tabular}

Tabla1.2. Número de habitantes extranjeros empadronados en Valladolid, según el último Padrón del 2005.

Nuestro estudio se centra en el ámbito educativo de la inmigración. Una vez vistas las principales características sociales que reflejan el estado de la cuestión, nos centraremos en la situación referida a la educación en Valladolid, es decir, en las características que nos pueden aportar una visión educativa general. Para ello, veremos, en primer lugar, las características de los principales colectivos inmigrantes; posteriormente, las condiciones socioeconómicas y educativas de los grupos de inmigrantes.

\section{2- Características de los principales colectivos inmigrantes en Valladolid.}

Conviene conocer las diversas identidades culturales de los alumnos extranjeros. La elaboración de estereotipos, en su mayoría, se consolidan por el 
desconocimiento de las claves culturales que posee el alumno inmigrante. Siguiendo los estudios de García Zarza (2003) y Pajares (1998), vamos a explicar los aspectos culturales de los colectivos principales que existen en Valladolid a los que, además, hemos analizado en nuestro estudio etnográfico.

\subsection{1- Colectivo marroquí}

Este colectivo se caracteriza por tener una gran movilidad espacial. En Valladolid ha ido disminuyendo su llegada en los últimos años. Esto está ligado al hecho de encontrar más dificultades para lograr la integración. Muchos han llegado a la ciudad después de haber recorrido varias comunidades autónomas (Andalucía, Valencia, Murcia, Madrid y, en menor medida, de Cataluña, País Vasco y Castilla La Mancha), según el estudio de García Zarza (2003).

El primer objetivo es enviar dinero a la familia de su país de procedencia, planteándose la estancia en España como algo temporal o como puente para irse a otros países de la Unión Europea.

La familia tradicional marroquí es patrilineal, comunitaria y endogámica. Tiene un carácter comunitario. Está formada por un miembro varón que es el cabeza de familia y los hijos, que en el caso de los varones no se disgregan al casarse. Esto difiere con la familia nuclear española. Dentro de la familia marroquí, los hijos deben mantenerse dentro de la estructura comunitaria y continuar sometidos a la autoridad del padre. En el caso de las mujeres, tampoco se alejan demasiado, pues han de casarse preferentemente con un primo que las seguirá manteniendo en esa comunidad familiar.

Las mujeres están enclaustradas dentro de esta estructura familiar, durante la soltería y al casarse. Pero en la actualidad, estas tradiciones culturales están evolucionando y transformándose de forma acelerada en Marruecos. Mientras en las zonas rurales se mantienen más firmes a estas costumbres; en la ciudad las mujeres cada vez van adquiriendo más libertad e incorporándose poco a poco a la educación y al trabajo fuera de casa.

Los inmigrantes asentados en España y en concreto en Valladolid, también se van haciendo eco de estas transformaciones que suceden en Marruecos. Los que proceden de ciudades vienen adaptados a unas estructuras familiares, unas relaciones hombre - mujer y unos niveles de fecundidad que empiezan a parecerse bastante a los que hay en España.

Según el estudio de Pajares (1998), la cultura árabe tiene otros aspectos que son positivos y pueden servirnos a Europa Occidental como reflexión crítica sobre nuestro comportamiento. Se refiere a la solidaridad orgánica que trasciende los límites de la familia y que lamentablemente se está perdiendo en el mismo 
Marruecos, como consecuencia de los cambios que la ciudad impone a las estructuras familiares.

\subsection{2.- Colectivo de Europa del Este}

Los inmigrantes procedentes de Europa del este son más propensos que los marroquíes a la reagrupación familiar o a la formación de nuevas parejas a medio y largo plazo. Una vez conseguidos los ahorros suficientes, hacen todo lo posible por acercar a su familia a la localidad donde residen y alquilan una vivienda en la que poder vivir todos juntos.

Muchos de ellos han realizado estudios superiores en sus respectivos países y al llegar a España, desempeñan ocupaciones laborales por debajo de su calificación profesional, este hecho puede generar situaciones de frustración personal.

\subsection{3.- Colectivo latinoamericano}

Existe gran variedad de rasgos culturales que aportan cada uno de los países de origen, especialmente si se tratan de caribeños, antillanos 0 suramericanos. También se encuentran diferencias socio-culturales en función de su clase social y de su procedencia urbana o rural. Por otra parte, sus culturas son producto de un prolongado mestizaje: primero entre indígenas y colonizadores europeos, después con los negros trasportados como esclavos desde África, luego con las nuevas migraciones europeas y, por último, con la fuerte influencia de los Estados Unidos de Norteamérica.

Respecto a las diferencias entre los españoles, en concreto, entre los vallisoletanos y este colectivo son menores que en los casos anteriores. Existe una cierta cercanía cultural y esto se debe, en primer lugar, al idioma, pues, a pesar de tener algunas expresiones diferentes que pueden crear cierta desorientación en la comunicación, el idioma es el mismo (salvo en el caso de los brasileños). Además, en segundo lugar, no existen diferencias religiosas, ya que son mayoritariamente católicos. Por último, se valora el hecho de que una gran parte de ellos sean descendientes de españoles. Por todo ello, parece que el diálogo intercultural resulta menos complicado que con otras procedencias.

Sin embargo, a pesar de esta cercanía cultural, existen otros aspectos que pueden llegar a chocar con la cultura española. Veamos cómo pueden influir en el ámbito de la educación.

Un aspecto importante es el papel social que tiene el maestro en los países latinos. Los maestros, sobre todo si se trata de zonas rurales, son verdaderos líderes comunitarios y tienen un gran peso en las decisiones de la comunidad, son 
mediadores sociales. La gente siente respeto y admiración por ellos. El alumnado recién llegado a España muestra esta actitud ante los profesores. Los escolares españoles actuales, sin embargo no poseen los mismos valores sobre la figura del profesorado y esto va "contagiándose" de forma que, con el tiempo esas actitudes del alumnado inmigrante van cambiando, al imitar lo que ven y terminar integrándose en la cultura mayoritaria. Durante la primera escolarización, existe en el comportamiento de estos alumnos un mayor peso de lo afectivo, que a veces dificulta la adopción del rol adecuado entre profesor - alumno.

Otro aspecto diferenciador se refiere a la percepción social que los latinos tienen de las estructuras de poder. Esta comprensión difiere significativamente de la que tienen los españoles. Ellos sienten gran respeto por la autoridad, por los mayores o por personas con determinado nivel académico o estudios universitarios, lo cual repercute en la percepción que el niño latino tiene en las relaciones sociales que establece en la escuela. El sentido de la autoridad está altamente establecido, posiblemente porque la historia de los pueblos latinos está marcada por el respeto al superior. Este aspecto es importante para entender las relaciones sociales que se desarrollarán en la escuela. Será difícil encontrar a niños latinos que respondan agresivamente al profesor y les extrañará, por lo menos al principio, que los alumnos españoles contesten al maestro. Ellos mantienen el "usted" como expresión de deferencia, es signo de respeto hacia el interlocutor, al que se percibe en un escalafón superior.

Estudios realizados por Márquez (2002) nos explican que muchos niños de estas culturas presentan poca expresividad, comparado con los españoles. Muchas veces esto se considera, dentro de la escuela, como retraso o deficiencia de carácter; cuando estas expresiones podrían representar timidez ante la figura del profesor o especial esmero para aceptar las insinuaciones del maestro.

El desconocimiento de todas estas características culturales de los grupos minoritarios suele dar lugar a la formación de estereotipos y prejuicios, desconfianza y rechazos. Muchas veces lo que se conoce de estos grupos es la opinión que el grupo mayoritario tiene de ellos. Estas ideas previas o prejuicio se corroboran en nuestras construcciones mentales cuando los medios de comunicación relacionan muchos sucesos marginales con la inmigración. Conocer las características de cada uno de los colectivos con los que se va a convivir es un aspecto necesario para mejorar las relaciones sociales, sin caer por ello en la consolidación de estereotipos rígidos. 


\section{3- Condiciones socioeconómicas de los grupos de inmigrantes}

\subsection{1- Desde un punto de vista personal y familiar.}

En primer lugar, partimos del hecho que supone para el inmigrante, salir de su país. Romper con numerosos lazos culturales, sociales y familiares y enfrentarse a un nuevo espacio con reglas de funcionamiento diferentes implica un choque cultural que tiene que superar la persona llegada a territorio desconocido.

En la mayoría de los casos, la intención de emigrar a un país es para mejorar su situación económica. Sale primero un miembro de la familia con la intención de reagruparse familiarmente con posterioridad. Si es la madre la que emigra, los hijos suelen quedarse al cuidado de los abuelos y, como pasan bastantes años hasta que consiguen juntarse de nuevo, se produce un desconocimiento mutuo, entre padres e hijos que provoca la falta de costumbres comunes en la dinámica familiar. En muchos casos, estas parejas maritales iniciales se rompen y la madre, quedándose al cuidado de sus hijos, rehace la familia con otro miembro español. Los hijos, producto de estas estructuras familiares, se escolarizan y trasladan todas estas situaciones personales a la escuela. Ésta, por tanto, debe conocer estas desagradables y difíciles situaciones para actuar en consecuencia.

En muchos casos, los trabajos de estos colectivos son bastante precarios y la escasez de recursos económicos de muchos de estos inmigrantes les obliga a someterse a un nuevo trabajo, lo cual produce estar mucho tiempo fuera de casa, con la consecuente pérdida de una necesaria convivencia familiar. Muchas veces vive en habitaciones de 30 metros cuadrados toda una familia, hecho que favorece la creación de hábitos no saludables en la casa. El hacinamiento como forma de vida es un problema que también se traspasará a la escuela mediante la práctica de hábitos insalubres y de escaso reposo, necesario para rendir académicamente.

Esta situación precaria laboral de la que hablamos impide que los padres tengan tiempo para ir a hablar con los profesores del colegio. Existe, por tanto, una descoordinación entre familia y colegio y un desconocimiento mutuo que consigue crear una mala apreciación por parte de algunos profesores que lo consideran como una muestra de desinterés hacia la educación de sus hijos.

\subsection{2- Desde un punto de vista social y educativo.}

Desde el punto de vista social, siguiendo a Pajares (1998) y a Márquez (2002), resumimos algunos puntos que pueden influir en las relaciones 
interculturales. Estos autores nos explican algunas características que resumimos a continuación:

- Miedo a perder o a que se contamine la propia identidad cultural.

- Consideración de que sólo existe una cultura y una visión válida de la vida, que suele identificarse con el de la cultura mayoritaria.

- Tendencia asimilacionista por parte de la cultura mayoritaria.

- Situación de conflicto entre los diferentes grupos por razones históricas (gitanos), razones económicas (clasismo con los pobres), razones sociales (sacar a los niños del colegio para que no estén con minorías étnicas porque aprenden menos).

- Inestabilidad y precariedad laboral.

- Falta de recursos económicos.

- Situación irregular en España.

- Dificultades de acceso a las ayudas sociales.

En el ámbito educativo influyen todas estás características sociales que hemos ido viendo. Veamos más concretamente algunos aspectos culturales de la escuela para entender las relaciones sociales y la socialización escolar desde un punto de vista teórico.

Vásquez y Martínez (1996) recogen algunos de estos comportamientos 0 valores que forman parte de la cultura escolar española. Entre ellos destacan:

- Los rituales de desplazamientos, de entradas y salidas.

- El excesivo tiempo dedicado a conseguir orden y silencio.

- Estructura asimétrica del poder en las interacciones que se establecen entre profesor y alumno. El alumno es el sujeto al que hay que enseñar porque no sabe y el profesor es el que posee todo el conocimiento que debe trasmitir, además es éste el que dirige y controla el rumbo de los procesos de enseñanza y aprendizaje. Del alumno se espera que intervenga sólo cuando se le pregunta.

- Existe una homogenización en las actividades diseñadas para un tipo de alumno medio.

- Se sigue un esquema metodológico rígido que consiste básicamente en la explicación del profesor, el trabajo individual, la corrección del trabajo individual (se prima el trabajo y el éxito individual). 
Estas prácticas son consustanciales a la escolarización. Los alumnos españoles que siempre han estado en estas escuelas no son conscientes de estas prácticas, son consideradas como algo natural. Claro está que esta naturalidad es considerada como tal para los alumnos pertenecientes a la cultura española, los que llegan nuevos de otras procedencias tienen que asimilar estas prácticas para relacionarse socialmente de forma adecuada con los compañeros.

Esto es uno de los obstáculos con los que se pueden encontrar algunos de estos niños. Los patrones de socialización de la escuela a la que se ven obligados a ir no son naturales para ellos, incluso pueden no coincidir y contradecir los valores que definen sus culturas (Vásquez y Martínez, 1996, 87). Se da, consecuentemente, un distanciamiento entre lo que están acostumbrados a hacer y lo que una escuela extraña a ellos les exige hacer. Por ejemplo, como hemos indicado más arriba, algunas culturas están más orientadas a lo colectivo que a lo individual, desde muy pequeños participan en las tareas que en nuestro país relacionamos con los adultos, como es hacer las labores de casa, quedarse al cuidado de otros niños más pequeños, colaborar en la economía familiar. Igualmente, en algunas culturas se da más importancia a las relaciones sociales que a mantener el orden y silencio (Jordán, 2001), como sucede en la nuestra.

La escuela por otro lado, tiene tendencia a la homogeneización. En la escuela tradicional se suele comparar al alumnado minoritario con el resto desde el esquema homogeneizador señalado. Así pues, el fracaso escolar suele atribuirse a un "déficit cultural" que le impide alcanzar el nivel académico adecuado. A veces, el propio sistema escolar se olvida de que su propio escenario es otra forma cultural construida. Vásquez $(1995,67)$ señala: el déficit no necesariamente está en ellos, sino en su enfrentamiento a una cultura muy distinta de aquella donde fueron socializados, al mismo tiempo que la estructura social donde viven los sitúa de facto en una situación de "minoría".

Existen, por tanto, diferencias en cuanto a la definición de escuela, en cuanto a su función y en cuanto a lo que se espera de los distintos grupos. La importancia de escolarizar en edades tempranas a los niños también responde a un hecho cultural. Por ejemplo, en la escuela occidental se delegan responsabilidades que en otras culturas pertenecen a la familia. Otras culturas, sin embargo, por el hecho de encontrarse en situación de pobreza, escolarizan más tarde a los niños, generándose en estos alumnos problemas diferentes, cuando llegan a esta institución académica.

Concluyendo, diremos que las políticas educativas de índole ideológica y estructural que se desarrollan en Valladolid y el territorio nacional, en general, serán las que permitirán a la larga un proceso donde se favorezcan las relaciones sociales 
interculturales en la escuela y donde se podrán crear nuevas formas de ver el mundo, producto de este contacto permanente con grupos humanos diferentes.

\section{5.- La inmigración y la escuela}

\section{1- Situación general. Cifras.}

La población de estudiantes inmigrantes en España está creciendo del mismo modo que lo hace la llegada de estos colectivos al país. Sólo en centros públicos, el total de extranjeros es de 143.610 alumnos, el 80,2\% de este colectivo, mientras que la escuela concertada escolariza a 60.217, el 19,8\%. Un estudio de Comisiones Obreras, citado en la Revista del País Semanal, en el 2004, señala que la escuela pública española ha perdido en los últimos cinco años alrededor de 660.000 alumnos nacionales, y ha ganado 190.000 alumnos de origen inmigrante, mientras que la privada pierde 32.000 alumnos nacionales e incorpora 41.000 extranjeros. En el citado artículo se expresa literalmente que la etiqueta "escuela pública llena de inmigrantes es igual a baja calidad educativa" es causa de que los padres españoles retiren a sus hijos de estas escuelas. Las líneas políticas educativas que organizan esta cuestión están generando serios problemas en el sector educativo público, creando cada vez más escuelas que se asemejan a guetos.

La mayoría de las noticias ponen de manifiesto una falta de estrategias para afrontar la multiculturalidad y conseguir la integración real de todos los estudiantes. Este fenómeno está íntimamente relacionado con el fracaso escolar, tan preocupante para los responsables de medir la calidad del sistema educativo.

\section{2- Principales enfoques educativos teóricos para abordar la integración del inmigrante.}

En el análisis anterior sobre las causas de los movimientos migratorios veíamos cómo el fenómeno generado por la falta de subsistencia en los países en vías de desarrollo crea un mayor número de movimientos migratorios hacia los países más desarrollados económicamente, aumentando así, los conflictos multiculturales, y despertando a veces sentimientos racistas, normalmente unidos a tendencias políticas intolerantes. Todo esto tiene un claro reflejo en la escuela, la cual tiene por tanto, un papel difícil e importante que desarrollar respecto a la integración de inmigrantes.

La educación en el siglo XXI, no sólo está en continua evolución, sino que existen fuerzas contradictorias con los fundamentos de la educación como son las tradiciones economicistas que relacionan comercio-educación. Estas posiciones se 
traducen en corrientes diversas del pensamiento que tienen cada una su fundamento en proposiciones ideológicas sobre la naturaleza de la escuela, el papel del Estado en la gestión de la política social y la relación entre el ser humano y la economía (Haim Gazïel, 2000).

Junto a todas estas fuerzas emerge en las sociedades desarrolladas, la educación multilcutural. El mercado crea una nueva pauta, influyendo principalmente en la educación pública, donde se impone un nuevo diagnóstico, una nueva visión curricular, transformando y flexibilizando la históricamente realizada hasta ahora.

El desafío dentro del ámbito escolar, hasta el momento, era demandado por la educación especial, producto de alumnos con diferencias físicas o psíquicas. La intención era lograr una mejora en el sistema educativo para mejorar su integración social. Entonces, se empezó a hablar de escuelas comprensivas para la formación global de las personas. Estas necesidades y planteamientos en materia educativa van dando lugar al concepto de la escuela inclusiva o escuela para todos. Una escuela que fuera para todos, cabría definirla como un sistema organizado que promueve la colaboración y que busca un sistema escolar más coherente en el que se persigue un beneficio común. Una escuela en donde se comparten conocimientos y experiencias de trabajo, con la finalidad de aprovechar los conocimientos de todos y establecer el clima cultural y colaborativo necesario en el que cada profesor asume la responsabilidad del aprendizaje de todos los alumnos (Arnáiz y Rodríguez, 2001, 271).

Se trata de reconocer las diferencias, valorar a las personas por lo que son y cómo son, creer en sus posibilidades de mejora y darles la oportunidad de desarrollarse con sus iguales, pues todos somos tan iguales como desiguales y hay que aceptar las semejanzas y las diferencias como algo real e inherente al hecho humano (Porras, 1998).

El objetivo de la escuela inclusiva, es cambiar la escuela actual hacia formas educativas donde todos los alumnos tengan cabida, dejando atrás concepciones basadas en la desigualdad y la discapacidad, reconociendo que todos somos diferentes y que eso es lo realmente valioso en los seres humanos. Hoy día se considera este término más pertinente que el de integración (Stainback y Jackson, 1999), ya que va más allá de la mera integración, al entenderse con este término que los alumnos discapacitados, inmigrantes, profesores y miembros de la comunidad escolar son considerados como parte de esta inclusión (Apple 1996, Stainback y Jackson, 1999).

Por lo tanto, vemos cómo el desafío real de la educación del siglo XXI para la escuela es la capacidad para atender la diversidad. Esto supone la igualdad de oportunidades para todos los alumnos, sin distinguir si son "nativos" o inmigrantes, 
ofreciendo una enseñanza de calidad ajustada a las necesidades de cada alumno (Díaz Pareja, 2003).

El concepto multicultural surge, en los años sesenta, en Estados Unidos (Vásquez e Ingle, 1982) como respuesta a la diversidad cultural y a la importancia de responder a las necesidades propias de cada grupo étnico. Banks (1985) la define como el conjunto de programas y prácticas diseñadas para ayudar a mejorar el rendimiento académico de las poblaciones étnicas e inmigrantes y para enseñar a los estudiantes del grupo mayoritario las culturas y experiencias de los grupos étnicos minoritarios existentes dentro de sus naciones.

El proceso de multiculturalidad es un proceso democrático que exige conocer las culturas diferentes con las que se convive y poder convivir con ellas sin que existan tensiones y problemas. Jiménez, (1997) considera algunos tipos de ajuste posibles cuando dos culturas o más se juntan en una misma nación. Estos son: La acomodación paralela: cada grupo mantiene su identidad y coexiste con otras culturas. La eliminación: los grupos minoritarios desaparecen. La dominación: el grupo dominante hace que el minoritario se acomode a su cultura. La integración o asimilación: la minoría debe aprender y asimilar un mismo patrón cultural. Y el ajuste multiétnico: establece similitud entre multicultura e intercultura lo que indica, en el ámbito educativo que cada grupo se siente con derecho a un espacio para coexistir con las demás culturas.

La multicultura conlleva una actitud educativa de respeto a la diversidad y a los derechos de cada cultura participante, que en el transcurso de la convivencia construyen juntos un sentido de multidependencia y multi-identidades.

Sin embargo, el gran reto de la educación, no se encontraría dentro de un paradigma multicultural, sino que el objetivo es acercarse a la "interculturalidad", entendida como diversidad cultural. Esa propuesta plantea una posibilidad de intercambio y de construcción social que genera todo un proceso de interculturalidad, al cual está llamada, principalmente, la escuela desde un sentido global.

Multiculturalidad significa reconocer la existencia, el valor y la autonomía de las diferentes culturas existentes. Significa reconocer el principio de igualdad y el de la diferencia. La interculturalidad, sin embargo, da un paso más allá y se plantea la necesidad de conocer, proponer tratamientos específicos a las culturas diferentes y dialogar entre ellas. Se trataría de convivir en la diversidad y los principios que se reconocen son, además de los dos anteriores (el de igualdad y diferencia), el de interacción positiva, es decir relaciones interétnicas e interreligiosas. La multiculturalidad es un hecho presente en la sociedad española, mientras que la interculturalidad es el proyecto al que se aspira. 
La escuela se perfila como el medio idóneo donde lograr una integración intercultural, pero para ello se requiere de una definición de planes para su desarrollo que se encuentran fuera del ámbito escolar. El reconocimiento de los derechos de los inmigrantes es la base principal para conseguir la integración (Pajares, 2000). Aplicando este concepto al contexto escolar, el tratamiento de la interculturalidad se relacionaría con los siguientes aspectos:

- Elaborar un currículo abierto y flexible, centrado en la diversidad cultural; teniendo en cuenta los contenidos de las diferentes culturas y haciendo más hincapié en lo que nos une y no en lo que nos separa.

- Concebir el proceso educativo como marco para un diálogo igualitario que ayude a transformar el contexto, más que a adaptarse a él. Para ello sería necesario compartir las metas entre todos los miembros de la comunidad educativa.

- Se debe propiciar en la escuela una actitud positiva hacia las culturas diferentes, rechazando toda aquella conducta discriminatoria, intolerante, racista o xenófoba. La educación en valores como el respeto, la tolerancia y solidaridad es el mayor instrumento para conseguir posteriormente individuos tolerantes dentro de la sociedad.

- Para lograr la interculturalidad en la escuela se pueden utilizar tres mecanismos: flexibilidad interna, apertura al entorno y responsabilidad profesional (Jiménez, 2003).

Jiménez (2003), establece un modelo de atención a la diversidad cultural dentro del enfoque de la inclusión que se aproxima a nuestros planteamientos.

\begin{tabular}{|l|l|l|}
\hline \multicolumn{3}{|c|}{ MODELO DE ATENCIÓN A LA DIVERSIDAD DENTRO DEL ENFOQUE DE LA INCLUSIÓN } \\
\hline EXCLUSIÓN & Discriminación (trato desigual) & Social (prácticas discriminatorias) \\
\hline EXCLUSIÓN & Segregación del otro & $\begin{array}{l}\text { Espacial (guetos residenciales) } \\
\text { Institucional (guetización escolar) }\end{array}$ \\
\hline EXCLUSIÓN & Eliminación del otro & $\begin{array}{l}\text { Cultural (etnocidio) } \\
\text { Física (genocidio) }\end{array}$ \\
\hline INCLUSIÓN & Homogeneización & $\begin{array}{l}\text { Asimilacionista } \\
\text { Fusión cultural }\end{array}$ \\
\hline INCLUSIÓN & $\begin{array}{l}\text { Aceptación de la diversidad cultural } \\
\text { como positiva }\end{array}$ & $\begin{array}{l}\text { Pluralismos cultural } \\
\text { Multiculturalismo } \\
\text { Interculturalismo }\end{array}$ \\
\hline
\end{tabular}

Tabla1.3.Modelo de diversidad cultural propuesto por Carlos Jiménez, (2003). 
Por tanto, vemos la escuela como medio principal donde trabajar la atención a la diversidad mediante un enfoque intercultural, ya que el multicultural es el existente. $Y$ la seguimos viendo bajo la perspectiva de un paradigma inclusivo que contempla diferentes a todas y a cada una de las personas que forman la institución, las cuales, siendo diferentes, deben ser iguales. La escuela inclusiva deberá estar atenta a esta doble finalidad: respetar la diversidad y luchar por la igualdad de todos y de cada uno de los seres humanos.

A partir del discurso expuesto en este capítulo, extraemos los factores del contexto social que más relación directa pueden tener con el proceso de integración escolar y los presentamos en la siguiente tabla.

\begin{tabular}{|l|l|}
\hline \multicolumn{2}{|c|}{ FACTORES DEL CONTEXTO SOCIAL Y FAMILIAR INLFUYENTES EN LA INTEGRACIÓN ESCOLAR DEL } \\
ALUMNADO INMIGRANTE
\end{tabular}

Tabla 1.4. Factores del contexto influyentes en la integración escolar del alumnado inmigrante.

\section{3.- Revisión de la literatura sobre inmigración y escuela}

En la última década se ha desarrollado en España una creciente producción científica pretendiendo explicar la situación en la que se encuentra el alumnado inmigrante que se va incorporando a las aulas escolares. Para ello, hemos manejado las publicaciones que dispone el Centro de Documentación de Interculturalidad del Estudios Interculturales de la Universidad de Granada ${ }^{1}$ a través una revisión recientemente publicada: (García, Rubio y Ouafa, 2008).

Este repaso organiza la producción encontrada en cinco campos:

\footnotetext{
${ }^{1}$ Este centro de documentación cuenta hasta (finales del 2007) con: 2.577 monografías, 4.656 artículos de revistas, 1.821 documentos no publicados y 147 tesis doctorales.
} 
1) Estudios que han intentado cuantificar el fenómeno en términos estadísticos y que nos hablan de la concentración de este tipo de escolares en algunos centros.

2) Investigaciones centradas en los programas de acogida y dispositivos especiales creados para estos nuevos escolares.

3) Estudios que han tratado de explicar el funcionamiento de la enseñanza de las lenguas vehiculares de la escuela y la enseñanza y/o promoción de las llamadas lenguas maternas.

4) Trabajos dedicados a las relaciones entre familias y su interacción con la escuela.

5) Estudios sobre el éxito y/o fracaso de estos escolares en el sistema educativo.

La presente tesis doctoral, sin encontrarse alejada de todos estos ámbitos, se posiciona en otra línea, quizá más cercana a la psicología social. Estudiamos la interculturalidad en la escuela desde el análisis de las interacciones sociales. Los siguientes capítulos teóricos nos hablarán de ello.

A lo largo del capítulo hemos intentado ofrecer una panorámica general sobre la inmigración y la escuela. Hemos definido las características sociodemográficas, laborales y educativas principales siguiendo una progresiva concreción en función del contexto geográfico: partimos de las características de las migraciones mundiales en el siglo XXI, continuamos explicando la situación en España, en Castilla León, hasta llegar a la ciudad de Valladolid, donde se desarrolla nuestra tesis doctoral. El discurso del capítulo se encuentra transversalizado por dos ejes que protagonizan nuestra investigación: el social y el escolar. En este último incluimos los principales modelos educativos referidos a la integración escolar del alumnado inmigrante, extraídos de la literatura existente al respecto. Posteriormente, para acercar este marco teórico a la práctica educativa, hemos incluido un cuadro en el que se recogen los factores del contexto social que se han ido describiendo a lo largo de las explicaciones previas y que influyen de forma más notable en la integración escolar del alumnado. Por último, incluimos una breve sección donde resumimos las principales líneas de investigación que han seguido hasta ahora las producciones científicas sobre esta temática en nuestro país. 


\section{Capítulo 2}

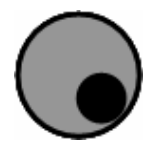

\section{Las relaciones sociales y el prejuicio}

La intención de este capítulo es la de describir el fenómeno de las relaciones sociales desde dos perspectivas diferentes. En primer lugar utilizamos un enfoque histórico, enfatizando el aspecto desigual que las ha ido marcando al fenómeno relacional. La razón por la que incluimos este primer apartado, se debe a la pretensión de resaltar cómo a lo largo de la historia, las relaciones sociales predominantes, han estado marcadas por una gran desigualdad en función de las fuerzas sociales influyentes en cada época. En segundo lugar, desarrollamos un segundo apartado en el que explicamos la influencia del prejuicio y de los estereotipos en el desarrollo de las relaciones sociales actuales y en concreto cómo éstas se suceden en el contexto escolar. 


\section{1.- Las relaciones sociales a lo largo de la historia}

A lo largo de este capítulo vamos a describir desde una perspectiva histórica las relaciones sociales siguiendo una línea transversal, como es la desigualdad social que las ha caracterizado desde su origen. Para ello iremos recorriendo los siguientes epígrafes:

1.1.- Importancia de las relaciones sociales a lo largo de la historia

1.2.- Evolución de las relaciones sociales: ¿cómo la desigualdad social ha ido marcando el rumbo de las relaciones sociales en la historia?

1.3.- ¿Por qué se ha ido consolidando la desigualdad en la forma de entender las relaciones sociales?

\section{1.- Importancia de las relaciones sociales a lo largo de la historia}

A lo largo de la historia de las culturas se observa la presencia de un transversal que ha cruzado los campos del pensamiento. Me refiero al tema de las relaciones sociales. Tanto los sociólogos, como los psicólogos, los filósofos y los pedagogos se han cuestionado este fenómeno. La mayoría de las reflexiones de los pensadores, sean pertenecientes al área de la letras 0, incluso, al área de las ciencias, se han preguntado por las conexiones entre sujeto-sociedad, e individualismo- socialismo.

De una 0 de otra manera, el binomio persona-sociedad ha marcado el balanceo de la filosofía y de la ciencia. La pregunta se ha centrado en la categoría "relación". ¿Cómo se relacionan el individuo y el grupo? ¿Cómo se relaciona la realidad con la idea? ¿Cómo se relaciona el yo con el tú? ¿Cómo se relacionan las cosas y las palabras? (Foucault). ¿Cuál es más importante, la persona 0 la sociedad? (Marx). ¿El yo o el partido político? (Lenin). Miles de interrogantes emergen del problema relacional.

Queremos dar a entender que la temática "relación" no podremos estudiarla desde todos los ángulos desde los que nos gustaría, tendremos que circunscribirnos al círculo acotado ya por esta tesis: las relaciones sociales en contextos escolares interétnicos. Más concretamente, para englobar el tema dentro de una perspectiva general, intentaremos hacer un breve repaso a las relaciones mantenidas entre la cultura y la sociedad. Mejor, entre los intelectuales de la modernidadpostmodernidad y el poder imperante en las sociedades respectivas en las que les ha tocado desarrollar sus reflexiones. Para ello nos vamos a valer, principalmente, de dos libros. Uno del autor H.R. Kerbo titulado: "Estratificación social y desigualdad" 
y otro del profesor A. Ovejero, titulado "La nueva psicología social y la actual postmodernidad", pues encontramos en él un estudio que repasa la historia de la Psicología Social a través del cual se desvelan las relaciones entre, no sólo los psicólogos y la sociedad, sino también entre los principales pensadores occidentales y la sociedad, sean éstos psicólogos, filósofos o sociólogos.

Precisamente, esta última relación entre Psicología y Filosofía marca una primera crítica a la mezquindad de ciertos científicos, encerrados en sus limitados principios, demostrando una raquítica ignorancia. Dice Ovejero $(1999,11)$ : En cuanto la Psicología se independizó como ciencia particular intentó desasirse totalmente de la filosofía, lo que por fuerza le ocasionó serios problemas de constitución, problemas que se agravaron al ir aislándose paulatinamente nuestra disciplina de las demás ciencias sociales. Este aislamiento o falta de contextualización no ha sido sólo una marca de la relación entre áreas y materias de conocimiento, sino también una regla seguida por instituciones, organizaciones y partidos políticos. Se ha preferido el individualismo a la socialización. Por desgracia ésta ha sido la trayectoria más generalizada en el transcurso de la historia humana. Para entenderlo ayudará hacer un pequeño recorrido histórico a continuación.

\section{2.- Evolución de las relaciones sociales: ¿cómo la desigualdad social ha ido marcando el rumbo de las relaciones sociales en la historia?}

Kerbo (2004) estudia la evolución de las sociedades humanas y asigna a cada tipo de sociedad un sistema diverso de estratificación. Desde los inicios de la humanidad ha existido una desigualdad que ha ido caracterizando las relaciones sociales entre los individuos. Así, a las sociedades cazadoras y recolectoras corresponde el sistema de estratificación denominado comunalismo primitivo. Durante cerca de 500.000 años los seres humanos sobrevivieron fundamentalmente con lo que hoy se denomina el modo de producción de caza y recolección. El tipo general de organización social durante este periodo podría denominarse comunalismo primitivo y parece probada la existencia bastante común de una cuasiigualdad durante el mismo. El promedio de miembros de estas tribus era de unas 50 personas, el 90 por ciento de los cuales era nómada o seminómada. Sin embargo empiezan a aparecer ciertos fundamentos de la desigualdad, como por ejemplo, el sexo, la edad y el honor. La mujer no cazaba, sino que se dedicaba a la crianza de los hijos, por lo tanto, al no aportar riqueza material a la comunidad, obtenía menor consideración dentro de la tribu. Un trato desigual debido al sexo en combinación con la participación en el modo de producción. Una segunda y tercera fuente de estratificación era la edad: si bien los jóvenes tenían más resistencia y fortaleza para cazar, la edad proporcionaba mayor astucia y conocimiento de los lugares en que se 
podía encontrar esa caza. Los mayores, pues, obtenían un mayor estatus y un mayor grado de honor, ya que contribuían más al bienestar del grupo.

Las relaciones sociales, en esta lejana época de la historia, fueron de cuasi-igualdad, aunque se vislumbran atisbos de una incipiente estratificación en la distribución de los bienes materiales, si bien éstos apenas eran distintos de los bienes alimenticios.

Un segundo tipo de sociedad han constituido las sociedades agrarias antiguas y tardías, surgidas hace unos 20.000 años. Ya entonces emergen distintas escenificaciones de estratificación, en este caso, la esclavitud y el sistema feudal 0 de castas. En la primera parte de este período aumentaron los recolectores y cazadores, aumentó la población, la tierra firme comenzó a reducirse como consecuencia del final de la última glaciación. Los niveles del mar estaban por debajo de 250 a 500 pies en relación con el nivel actual de las aguas, ya que las capas de hielo ocupaban gran parte del planeta sólido. Escaseaban los alimentos. Las tribus entraron en conflicto. Los yacimientos arqueológicos evidencian, con el descubrimiento de flechas y proyectiles de piedra clavados en los huesos humanos, la existencia de esos conflictos inter-tribales. Menos tierra y más población trajeron el cambio social. Nuestros antepasados descubrieron los métodos agrícolas de producción de alimentos. Había llegado la revolución neolítica, el primer acontecimiento importante de la evolución de las sociedades humanas. Cambió la tecnología de la producción de alimentos, cambió la organización social y sabemos que en los primeros 8000 años de agricultura, que comenzó hace 10.000 aproximadamente, la población humana aumentó de 10 a 300 millones de personas. ¿Cómo influyeron todos estos acontecimientos en la estratificación social? Existen muestras de que existía una desigualdad social creciente. Wenke $(1980,349)$ nos cuenta que algunos cementerios antiguos tienen tres o cuatro clases distintas de tumbas. Algunas están sólidamente construidas en piedra, contienen bienes valiosos y están situadas en lugares centrales, mientras que otras son simples tumbas que no contienen nada salvo el cadáver. $Y$ es razonable inferir de ello que estas divisiones corresponden a la existencia de diferentes clases sociales y económicas.

Al igual que en los enterramientos, existen indicios de desigualdad creciente en los restos arqueológicos de las viviendas, dice Kerbo $(2004,62)$. Con el avance de la agricultura se construyen aldeas con multitud de casas. Pero mientras en el centro de la aldea las viviendas familiares son más grandes y están mejor construidas, en la periferia se levantan casas simples y más pobres. La evidencia de esta desigualdad social continúa en la constatación de los grandes monumentos religiosos. Ejemplo: Stonehenge, en la planicie de Salisbury, Inglaterra, es un edifico religioso tan imponente que se calcula un número de 30 millones de horas de trabajo 
humano para construir esa reliquia arquitectónica. Una conclusión razonable es que tal inversión de trabajo humano requirió desigualdades de poder, y el poder suficiente sobre otros para movilizar semejante esfuerzo laboral. (Pfeiffer, 1977, 95).

Junto a los monumentos religiosos, es necesario subrayar también la importancia de la religión en estas sociedades agrícolas. La religión se convirtió en la base más importante de las desigualdades estructuradas en estas sociedades campesinas (Lenski, 1984, 99). Y añade Pfeiffer (1977, 104): históricamente, la religión ha sido un medio útil para justificar o mantener las desigualdades de poder y riqueza. Detrás de la religión desfilaron las poderosas elites políticas laicas en las sociedades agrícolas avanzadas.

El palo de cavar y la azada dieron paso al arado y al riego. Nuevas técnicas, nuevas transformaciones sociales y, consecuentemente, nuevas relaciones sociales. ¿De igualdad? No. El arado y el riego proporcionaron mayor población. Se podía comer mejor, puesto que con menos esfuerzo de conseguían más y mejores alimentos. Nacen así las ciudades donde habita esa población más numerosa que emplea su tiempo laboral en nuevas ocupaciones: arte, oficios, religión, guerreros para defender la propiedad de la tierra. La primera ciudad conocida se llama Uruk, situada al sur de Mesopotamia, entre los actualmente ensangrentados ríos Tigris y Eúfrates, hace unos 5.500 años. Contaba con 20. 000 habitantes. El mantenimiento de los templos y de los sacerdotes que rendían culto a Dios en ellos exigía el almacenamiento de la mayor parte de las riquezas de esas ciudades y, además, esclavos para mantener esos ingresos. Los yacimientos arqueológicos delatan que esa desigualdad esclavista era una realidad. El ejército de esclavos era necesario para satisfacer el apetito no sólo de la clase sacerdotal, sino también de otras familias acaudaladas independientes que seguían en importancia a las elites religiosas. Aparecieron, pues, funcionarios administrativos y ejércitos que se encargaban del orden social, los proyectos de construcción y la recaudación de impuestos (Kerbo, 2004, 63). Los ideólogos marxistas afirman que la esclavitud fue un invento necesario para mantener la propiedad privada. No les falta razón y su aseveración coincide con una amplia investigación arqueológica que ha descubierto en las ciudades de todo el mundo $y$, por tanto, también en las ciudades centroamericanas surgidas hace alrededor de 3000 años, la existencia de poderosos lideres religiosos, grandes desigualdades materiales y esclavitud. Desigualdades que se hicieron hereditarias. Algunas de estas ciudades son Teotihuacán, la primera gran ciudad, con 125. 000 habitantes, que apareció 100 años a. de C. y que estaba situada donde hoy está ubicada la ciudad de México (Pfeiffer, 1977, 369). Según Lensky (1984) es en esta época de las sociedades agrícolas cuando se dio el gran salto cualitativo en la desigualdad humana. 
En este recuento de desigualdades sociales y de formas de estratificación ocurridas en la historia no deberíamos olvidarnos de los grandes imperios agrarios. Me refiero a los imperios de Egipto, China, Grecia, Roma y el Islámico. Su origen radica en el surgimiento de una clase militar y de un Estado organizado, crucial para el incremento de poder y privilegios. Recoge Lensky $(1966,194)$ que por primera vez en la historia, las diferencias de poder militar basadas en el desarrollo tecnológico se convirtieron en una realidad básica en las sociedades humanas, por lo que aumentaron proporcionalmente las oportunidades de explotación. En efecto, junto a la clase militar y la creación de un Estado, la invención de la rueda y la vela multiplicó la eficacia del transporte y de la comunicación, todo lo cual supuso la aparición de los imperios agrarios y la extensión del poder a territorios más extensos.

Su existencia se remonta a cerca de 5000 años en lugares como Egipto y China. Entre todos estos imperios agrarios resalta la importancia del romano, que nace 300 años a. de C. y termina unos 500 años d.C., a manos de invasores como Atila. Un periodo de 800 años durante el cual Roma es cabeza de Occidente, pero en el que también tendrá que contrastar diferencias y simultanear semejanzas con los otros imperios nominados. En cuanto a las relaciones sociales que se dieron en estos imperios, conviene apuntar las siguientes:

- Relaciones de desigualdad.

- Relaciones de esclavitud.

- Relaciones de conquista, por tanto, de estado de guerra crónico.

- Relaciones de dominio sobre las clases más bajas, como la campesina, que era la más numerosa.

- Relaciones de autoritarismo para ejecutar las funciones del Estado, consistentes en hacer cumplir las leyes, reclutar soldados, recaudar impuestos y obtener tributos de los territorios conquistados.

- Relaciones originadas por la división del trabajo entre artesanos, mercaderes, religiosos, militares y agricultores.

La consecuencia derivada de estas complejas y poco o nada democráticas relaciones entre los sujetos del imperio y entre éstos y sus instituciones se proyecta en la existencia de unas clases sociales caracterizadas por un alto grado de desigualdad y de jerarquía. Así, por ejemplo: en la cima del poder y de la riqueza se situaba una pequeña clase dirigente. La propiedad pertenecía al soberano, quien podía comprar con el excedente de la producción la lealtad de los funcionarios que trabajaban para mantener un sistema de gran desigualdad. La mayor parte de las masas soportaba un nivel de subsistencia. Sólo un pequeño grupo disponía de un 
poco de tierra o un oficio cualificado, constituyéndose así en un puente entre las masas y la clase dominante.

El tercer tipo de sociedad al que alude Verbo son las sociedades industriales y postindustriales. A la caída del feudalismo siguió la burguesía. ¿Qué relaciones sociales se entablaron en este tipo de comunidades humanas? La respuesta en general es que los sujetos de estas sociedades se relacionan en y desde la lucha de clases. Son relaciones de lucha, de dominación, a veces, de expolio, de violencia y, en el mejor de los casos, relaciones de partitocracia, dentro de una democracia débil, formal y representativa; pero no radical ni económica.

Kerbo $(2004,70)$ señala: En todas estas sociedades surgieron elites con nuevas bases de poder. Pero no hay que exagerar las diferencias entre estas nuevas sociedades. A pesar de sus diferencias en cuanto a ideología política, grados de democracia y (hasta cierto punto) niveles de desigualdad y movilidad social, la nueva tecnología industrial y la organización social que surgió impusieron límites generales al tipo de sistema de estratificación que podía existir.

Habría que añadir que las relaciones que se establecen hoy día en las sociedades postindustriales, podrían calificarse de globales e internacionales. Queremos decir que en una sociedad global o globalizada las relaciones en el seno de las naciones pueden ser esas a las que alude Kerbo (2004), menos desiguales que las que se originaban en las sociedades agrarias. Pero, aquellas relaciones que podríamos llamar internacionales o globales siguen siendo tan desiguales o más que las más desiguales de la historia. Nunca ha existido una brecha entre el Norte y el Sur tan grande como la actual. Nunca ha existido una diferencia en el renta de los países tan desiguales como las que hoy se dan entre las rentas de los países desarrollados y la de aquellos que algunos llaman subdesarrollados 0 , más eufemísticamente, países en vías de desarrollo. Y lo que es peor, la distancia entre unos y otros países sigue aumentando progresivamente a partir de los últimos años. Algo está pasando en el actual orden social mundial. Algo que no va bien.

En definitiva, en la sociedad postindustrial del siglo XXI siguen prevaleciendo las relaciones sociales de desigualdad e injusticia, sobre todo si nos fijamos en las relaciones internacionales. ¿La sociedad de economía global proporciona la posibilidad de generar relaciones de justicia?

Visto este somero recorrido por la historia de las sociedades, cabe interrogar: ¿Por qué se han dado y siguen dándose las relaciones sociales que se acaban de enunciar? ¿Qué sucede o qué problemática ocurre en la cultura de nuestro tiempo para que no seamos capaces de cambiar, en el seno de nuestra sociedad actual, el tipo de relaciones sociales descritas? Abordaremos, a continuación el escabroso tema de la legitimación. 


\section{3.- ¿Por qué se ha ido consolidando la desigualdad en la forma de entender las relaciones sociales?}

\subsection{1.- ¿Qué se entiende por legitimación?}

Kerbo $(2004,196)$ lo define así: Método para mantener la obediencia y la desigualdad estructurada. El profesor Ovejero (1999) describe la figura del Nicolás Maquiavelo como un prototipo de su época y como un legitimador de una época histórica que inició la denominada modernidad, posteriormente descrita como una etapa en que el poder y la ilustración se dan la mano para enaltecer el valor de la riqueza, del poder y de la economía, como los grandes fines que justifican cualquier otra acción que a ello contribuya. Pretendemos presentar a este autor como prototipo de otros muchos autores legitimadores del poder y del "statu quo" imperantes. Sirva esta ejemplificación para representar a otros muchos que a lo largo de la historia han hecho acto de presencia y a aquellos de nuestros coetáneos que, aún hoy día, siguen ejerciendo tal pretensión.

Maquiavelo, con su obra El Príncipe, se ha convertido en un símbolo del renacimiento político de la Modernidad. ¿Se puede considerar a Maquiavelo como un legitimador cultural? Se pueden descubrir en su obra, relaciones legitimadoras de los valores de una época. Dicen de él que contó lo que se hacía y no lo que se debía hacer. Intencionadamente o sin intención, a Maquiavelo se le puede interpretar como un legitimador del poder y del sistema político-cultural que por aquel tiempo reinaba.

Las relaciones interpersonales que Maquiavelo establece son aquellas que se derivan del sostenimiento del poder. Los ciudadanos se deben al Estado y las tácticas de actuación del Príncipe respecto a la ciudadanía, han de caracterizarse por lo que se podría llamar personalidad maquiavélica: frialdad emocional, escepticismo sobre el hombre, fuerte motivación por el poder, ausencia de compromiso ético, político y religioso.

¿Existen también los deslegitimadores? Nos fijaremos brevemente en un filósofo, padre de muchos seguidores: Nietzsche (1844-1900). Nietzsche es considerado como un profeta de la Postmodernidad. Su discurso entierra a los moralistas y defiende con gran fervor la vida del hombre, No queda otro remedio para devolver a la filosofía su dignidad que comenzar por colgar a todos los moralistas (Nietzsche, en Ovejero, 2004, 256). Las ideas de Nietzsche suponen una revolución en el pensamiento moderno. Las relaciones sociales por ende también experimentan este cambio. 
Este autor supone un ataque a la modernidad, critica la objetividad científica, considera que el conocimiento de sí es tan engañoso como el de las cosas. Así como las matemáticas o la física, la psicología es víctima del lenguaje. Olvidamos que lo esencial del drama se representa entre bastidores. La categoría de la sustancia, proyección del yo sobre las cosas, es tan ilusoria aplicada al yo, como a las cosas. Creemos que nuestros estados de ánimo son expresión de un mismo sustrato, el yo; pero somos nosotros quienes hemos fabricado la identidad de esos estados llamándolos nuestros. (Ovejero, 2004).

¿Puro nihilismo? No. Más bien, se podría hablar de la necesidad de destruir para construir después. Otros lo llaman el proceso de la "reconstrucción". ¿Cómo? A través del diálogo democrático que podría crear relaciones sociales positivas y enriquecedoras dentro de una sociedad humana (Habermas, 1988, 1989).

Llegados a este punto, recuerdo al lector la introducción de este capítulo. Decía allí que intentaba estudiar las relaciones sociales existentes entre los intelectuales de la modernidad-postmodernidad y el poder imperante en las sociedades respectivas en las que les ha tocado desarrollar sus reflexiones. Véase el siguiente cuadro, antes de llegar a su explicación posterior: 


\begin{tabular}{|c|c|c|c|c|}
\hline & $\begin{array}{l}\text { RELACIONES SOCIALES, } \\
\text { EN GENERAL. }\end{array}$ & AUTORES & $\begin{array}{ll}\text { RELACIONES } & \\
\text { CONTRASTADAS } & \text { POR } \\
\text { LOS AUTORES } & \end{array}$ & \begin{tabular}{l}
\multicolumn{2}{l}{ APORTACIONES } \\
PARA EL \\
FUTURO
\end{tabular} \\
\hline $\begin{array}{l}\text { ANTE- } \\
\text { MODERNIDAD }\end{array}$ & $\begin{array}{l}\text { Verticales. } \\
\text { Sumisas. } \\
\text { Jerárquicas. }\end{array}$ & $\begin{array}{l}\text { Escolásti- } \\
\text { cos. }\end{array}$ & $\begin{array}{l}\text { El hombre es un siervo de } \\
\text { Dios. } \\
\text { "Roma locuta, causa finita". }\end{array}$ & $\begin{array}{l}\text { Búsqueda del } \\
\text { sentido de la } \\
\text { vida. }\end{array}$ \\
\hline MODERNIDAD & 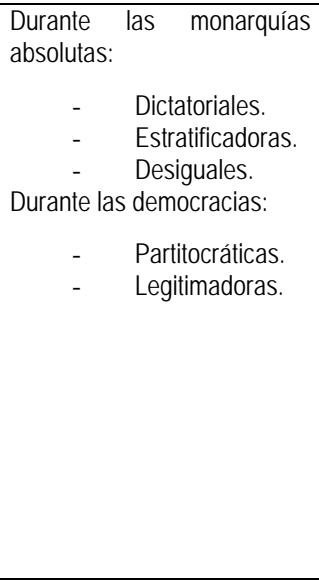 & $\begin{array}{l}\text { Nicolás } \\
\text { Maquia- } \\
\text { velo. }\end{array}$ & 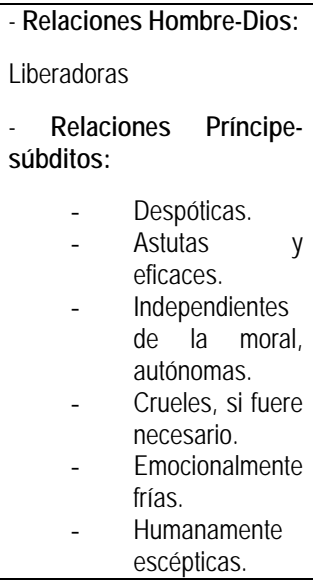 & $\begin{array}{l}\text { - Apuesta por el } \\
\text { hombre, } \\
\text { eliminando la } \\
\text { opresión del } \\
\text { teocentrismo y de } \\
\text { la Iglesia. } \\
\text { - Autonomía de la } \\
\text { ciencia respecto } \\
\text { a la revelación. }\end{array}$ \\
\hline $\begin{array}{l}\text { POSTMO- } \\
\text { DERNIDAD }\end{array}$ & $\begin{array}{l}\text { Se desean relaciones } \\
\text { sociales que sean: } \\
\begin{aligned} & \text { Horizontales y } \\
& \text { democráticas. } \\
\text { - } & \text { Dialógicas. } \\
\text { - } & \text { Deslegitimadoras }\end{aligned}\end{array}$ & $\begin{array}{l}\text { Friedrich } \\
\text { Wilhelm } \\
\text { Nietzsche }\end{array}$ & 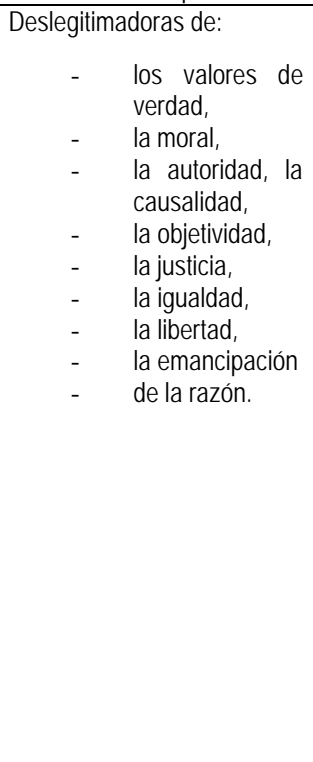 & 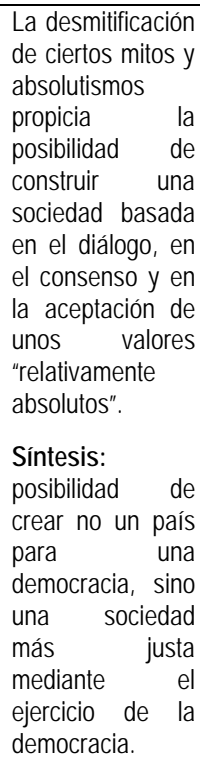 \\
\hline
\end{tabular}

Tabla 2.1. Características de las relaciones sociales a lo largo de la historia. 
A lo largo de la historia de las culturas imperantes en las distintas sociedades hemos asistido a una interpretación de las relaciones sociales muy diversa. Mientras en la edad pre-moderna, existían relaciones de sumisión a la revelación, a los papas, a los emperadores, a los señores feudales; en la edad moderna, el absolutismo monárquico por una parte continuaba con las relaciones despóticas y, por otra, la mentalidad emergente del Renacimiento lograba colocar a la razón por encima de los entes extraterrestres, elaborando la enciclopédica ilustración de las mentes y de los sujetos, aunque no eliminando la estratificación de las clases porque seguían patentes las hirientes desigualdades. El proyecto moderno de la unicidad, de la lógica y del cartesianismo, de la democracia burguesa y de los partidos políticos no ha sido suficiente para construir una sociedad justa. Por el contrario, la razón instrumental, el método hipotético-deductivo, la adhesión al poder y el apego a las riquezas, como valores protagónicos, han herido al proyecto de la llustración, han abierto un camino patológico a la economía de la globalización de los mercados, deteriorando las esperanzas de la igualdad. Se produjeron los genocidios y los campos de concentración, en cambio. Ni el mercado, ni la religión, ni la democracia representativa, ni la autoridad represiva han sido capaces de proporcionar luz a la humanidad.

Consecuentemente, la reacción postmoderna se desinfló tirando por la borda los ideales que promulgaba la revolución francesa. Ni la libertad, ni la igualdad, ni la fraternidad fueron creíbles para muchos postmodernos que condenaron estos valores cayendo en un pasotismo sin alicientes, pasivo y sin ideales. Nadie cree en la verdad, ni en la ciencia, ni en la justicia, ni en la moral. El lenguaje, dice Nietzsche y sus seguidores postmodernos, engaña. Imposible sostener los absolutos. Para prueba nos basta el siglo XX con sus dos guerras mundiales, con el genocidio en los Balcanes, con la guerra del Golfo, con las masacres en Afganistán y en Irak, etc.

A lo sumo queda la vida, el pragmatismo, las experiencias vitales, el utilitarismo. Algunos autores sin embargo, mantienen una cierta esperanza. Nos hablan de la ética de la cordialidad (Cortina, 2007), del conocimiento como producto social (Vigotsky 1986), del interaccionismo simbólico (Blumer,1982) que construye significados con mayor humildad y cautela que el soberbio e hipócrita positivismo. Ovejero $(1999,267)$ lo dice en su libro sobre la postmodernidad. Paso, con permiso, su pensamiento a mis palabras:

Todo vale... menos lo absoluto, todo menos la explotación de unas personas por otras, todo menos la imposición de un discurso sobre otro, pues no existe fundamento ninguno que justifique la imposición, la dictadura ni los abusos. Será, en todo caso, una cuestión de poder, pero no de verdad ni de objetividad, 
puesto que éstas no existen como absolutos: Auschwitz es un crimen típico de la Modernidad. La actitud crítico-relativista es la única actitud democrática y el relativismo la única verdad en democracia. Eso es la postmodernidad. Heidegger sentencia: el todo es falso. Pero la vida queda. La vida universal para todos los seres capaces de vida.

¿Será posible cimentar hoy en día aquellos principios de la modernidad: la igualdad, la libertad y fraternidad? ¿Podrá la postmodernidad, una vez superados los límites de la etapa moderna, construir unas relaciones sociales solidarias?

Las páginas de este capítulo reflejan una descripción histórico - filosófica de las relaciones sociales desde el punto de vista de la diferenciación y estratificación social. ¿Por qué? Encontramos en ello, el denominador común que ha atravesado la historia de la humanidad. Desde las sociedades cazadoras hasta la actual postmodernidad, han existido cruces y diálogos interculturales en las relaciones sociales de los individuos. Si bien es cierto, que tampoco han faltado las consiguientes diferenciaciones y valoraciones sociales. Se han ensalzado a unas clases y oprimido a otras, en función de los poderes legitimadores del momento. Todo este contexto socio-histórico es el que nos permite analizar las relaciones sociales hoy en día, y en concreto, las de los sujetos en sus edades más tempranas.

El discurso prejuicioso cumple una función social de establecer y sostener relaciones de poder opresivas. Este panorama desigual explica muchas de las interacciones sociales que se mantienen entre personas con distintas procedencias sociales y culturales.

El prejuicio y los estereotipos atribuidos como consecuencia de estas valoraciones sociales son las que van modelando las relaciones sociales en nuestra sociedad. Finalizamos pues, el enfoque socio-histórico de las relaciones sociales y damos pie a un nuevo apartado en el que explicamos la importancia del prejuicio y los estereotipos étnicos en el desarrollo de las interacciones sociales.

\section{2.- Influencia del prejuicio hacia otras etnias en las relaciones sociales}

La desigualdad existente en las relaciones sociales reflejada en el apartado anterior se produce debido a procesos psicológicos y sociológicos que van conformando un esquema cognitivo del sujeto. Los estereotipos y los prejuicios son procesos directamente conectados con las relaciones sociales. Para poder describir el fenómeno de la interacción social es imprescindible conocer estos procesos. El desarrollo de las relaciones sociales de la actualidad tiene mucho que ver con la creación de estereotipos y prejuicios cuando generamos valoraciones sociales de 
los demás, sobre todo si nos referimos a los intercambios que se establecen con personas de diferentes étnias.

Explicaremos a continuación los conceptos de prejuicio y estereotipo y su repercusión a la hora de establecer relaciones sociales. Centraremos el desarrollo de este tema en la escuela, contexto en el que basamos nuestra investigación. Para conseguir estos objetivos iremos desarrollando los siguientes epígrafes:

\section{1.- Definición del prejuicio}

\section{2.- Componentes del prejuicio}

2.3.- Nueva manifestación del prejuicio que da forma a las interacciones sociales actuales.

\section{4.- Las relaciones sociales prejuiciosas en la escuela}

2.5.- La reducción del prejuicio en la escuela: la interdependencia y el aprendizaje cooperativo, una posible solución

\section{1.- Definición del prejuicio}

Popularmente, el prejuicio es entendido como "un juicio u opinión formada de antemano, sin el debido examen" (Chambers English Dictionary, 1988). Estas definiciones han llevado a los psicólogos sociales a considerar el prejuicio como un juicio "inexacto", "incorrecto", lo que se ve en definiciones como la siguiente: "el prejuicio étnico es una antipatía basada en una generalización errónea e inflexible". (Allport, 1954,10).

Como veremos el prejuicio es un concepto complicado que necesita ser explicado desde diversas fuentes disciplinarias. La Psicología social, la antropología, la sociología o la filosofía social se han encargado de conceptualizar este término desde diversos enfoques. Esto es debido a que la propia naturaleza de la vida social exige contemplar múltiples perspectivas para poder entender su esencia. Así, en el prejuicio, los procesos implicados no pueden entenderse desde esferas fácilmente disociables sino que están íntimamente imbricados y su articulación es múltiple y compleja; Frente a un problema tan complejo como el racismo, no podemos permitir el constreñirnos por los límites de distintas disciplinas, (Essed, 1991, 31).

La investigación y teorización social sobre el prejuicio y el racismo no forma un corpus teórico unificado, sino que se compone de múltiples aportaciones provenientes de diversas disciplinas y que atañen a distintos niveles de análisis.

En primer lugar delimitaremos conceptualmente este término y posteriormente explicaremos las diversas teorías que explican el fenómeno. 
Los estudiosos del tema establecen diferencias conceptuales entre estereotipo y prejuicio. Estereotipo es una inferencia inspirada en la asignación de una persona a una categoría determinada (Brown 1998, 54). Ovejero $(1998,237)$ lo define como un conjunto de creencias, estrechamente relacionadas entre sí y compartidas por cierto número de personas acerca de los atributos personales que poseen los miembros de ese grupo. Son una serie de expectativas de comportamiento relativas a personas que pertenecen a un determinado grupo.

El prejuicio, sin embargo, es la actitud que se genera a partir de una serie de creencias predeterminadas. Los científicos sociales han definido el prejuicio de diversas formas. El prejuicio étnico es una antipatía basada en una generalización errónea e inflexible (Allport, 1954,10). Una actitud negativa injustificada hacia un individuo, basada únicamente en su pertenencia a un grupo (Worchel y otros, 1988, 449). Aronson ( 2005,283$)$ define al prejuicio como una actitud hostil o negativa hacia un grupo distinguible, basada en generalizaciones derivadas de información imperfecta o incompleta. Cabe también distinguir la existencia de prejuicios positivos y negativos. Podemos manifestar ciertas preferencias a favor de determinados colectivos por asociaciones cognitivas que realicemos. Así por ejemplo, si yo asocio el concepto de futbolista con el comportamiento de superficialidad y poca capacidad intelectual, sentiré hacia ellos cierto desinterés. Sin embargo, si relaciono esta figura con una estrella del deporte que gana mucho dinero, manifestaré cierta atracción y preferencia. En este apartado dejaremos de lado los aspectos referidos al prejuicio "a favor" de la gente.

El siguiente diálogo que aparece en el clásico libro de Gordon Allport, La naturaleza del prejuicio, refleja muy bien el funcionamiento del prejuicio:

Sr. X: El problema con los judíos es que sólo se preocupan por su propio grupo.

Sr. Y: pero las estadísticas de la campaña de beneficencia muestran que, en proporción, han hecho donativos más generosos para las necesidades generales de la comunidad que los que no son judíos.

Sr. X: Eso prueba que siempre están intentando comprar prestigio e introducirse en los asuntos cristianos. Sólo piensan en el dinero; por eso hay tantos banqueros judíos.

Sr. Y: pero un estudio reciente muestra que el porcentaje de judíos en el negocio de la banca es despreciable, muy inferior al porcentaje de los no judíos.

SR. X: Exactamente, no administran negocios respetables. Sólo invierten en la industria cinematográfica o en las salas de fiestas. 
Como vemos, es difícil cambiar los procesos cognitivos que afectan al individuo a la hora de establecer juicios sobre otros colectivos. Las personas con prejuicios muy arraigados son prácticamente inmunes a toda información que discrepe con su juicio no suficientemente fundamentado. Los prejuicios son actitudes y como tales son muy difíciles de erradicar. Esta manera de generalizar las características de un mismo grupo, es lo que se denomina "pre-juiciar" o pre-juzgar.

Estas definiciones transmiten un aspecto esencial del fenómeno de prejuicio: su orientación social. Sin embargo, como dice Rupert Brown no creo que sea necesario considerar al prejuicio como un conjunto de creencias falsas 0 erróneas (Brown, 1995, 26). Este autor continúa diciendo que existen tres razones para oponerse a este planteamiento reduccionista: por no poder establecer un criterio universal para considerar errónea una creencia, por la naturaleza relativista de la percepción intergrupal, no pudiendo crear un valor de verdad único; y, por último, por no considerar la variedad de formas que puede adoptar el prejuicio a lo largo del tiempo. Razones por las cuales prefiere entender el prejuicio no sólo como una creencia estética, ni sólo cargada de componentes cognitivos; sino como un juicio, lanzado sin suficiente base empírica, que integra elementos tanto cognitivos como emocionales y conductuales.

Así pues, llegamos a la obtención de tres componentes del concepto prejuicio: el cognitivo, el afectivo y el conductual, importantes desde el campo de la investigación y porque proporcionan fáciles procedimientos para operativizar y evaluar el fenómeno. Abundemos, aún más, en estos componentes.

\section{2.- Los componentes del prejuicio}

EL prejuicio está compuesto por diferentes componentes que lo conforman (Díaz Aguado, 1998). Hablamos del componente cognitivo, sobre el que actúan fuertemente los medios de transmisión cultural. El componente afectivo, donde aparecen las emociones que suscita al individuo y como consecuencia de los dos anteriores tenemos el componente conductual. Éste último es el que resulta más fácilmente evaluable desde la Psicología social porque se traduce en conductas observables. La investigación empírica a la que precede este marco teórico se centra en este componente.

Sobre el componente cognitivo actúan fuertemente los medios de transmisión cultural. Se trata del conjunto de creencias que un individuo tiene acerca del exogrupo o hacia un miembro de ese exogrupo como consecuencia de su pertenencia al mismo. Enmarcamos dentro de este componente la formación de los estereotipos. Las funciones cognitivas desarrolladas y consolidadas forman el estereotipo. Estereotipar a alguien es atribuir a esa persona algunas características 
que se consideran compartidas por todos o casi todos los miembros del grupo. Dicho de otra forma, un estereotipo es una inferencia inspirada en la asignación de una persona a una categoría determinada.

En el componente afectivo aparecen las emociones que mueven al individuo. Comprende una serie de afectos, en definitiva sentimientos, tales como el rechazo, el desprecio, el desagrado, etc. Estos elementos dan el carácter motivacional al prejuicio.

Como consecuencia de los dos anteriores tenemos el componente conductual. Consiste en la inclinación a actuar de una manera hostil 0 discriminatoria hacia el grupo o individuo objeto del prejuicio. Éste último es el que resulta más fácilmente evaluable desde la Psicología social, como ya hemos indicado más arriba.

El prejuicio se trata de una actitud y como tal resulta muy difícil erradicarla. Los mensajes sociales, los aprendizajes familiares, los medios de comunicación influyen inevitablemente a la hora de formar juicios sobre otras personas procedentes de otras culturas. Convivimos con estas diferencias y a la vez las valoramos, las juzgamos. Como fruto de este intercambio de ideas, pensamientos, tradiciones y mensajes sociales se producen las relaciones interpersonales. Es decir, se trata de algo totalmente contextual. El fenómeno de la interacción social puede empezar a analizarse en función del contexto en el que se encuentre. Este contexto es el que da significado a las relaciones que en él se generan. En él se establecen características y códigos microculturales generado por los agentes que en él influyen.

\section{3.- Nueva manifestación del prejuicio que da forma a las interacciones sociales actuales}

En este apartado queremos expresar la idea de proceso asociada al concepto de prejuicio. El prejuicio adquiere formas diversas en función de los discursos sociales que existan en el momento social. Como fenómeno social del que se trata, evoluciona al compás de las transformaciones sociales. Los códigos culturales que van produciendo esta evolución en los discursos racistas son los que explican las interacciones sociales de los individuos.

Desde los años 70, diversos autores han empezado a ofrecer nombres con los que calificar esta nueva expresión del prejuicio que caracteriza la forma de entender las interacciones sociales entre personas con procedencias culturales diferentes. Sears y Zinder (1971) hablan de "racismo simbólico". Mc Conahay (1981, 1986) utilizan el término de "racismo moderno". Dovidio y Gaertner (1986) hablan de "racismo aversivo". En Europa son varios los autores que piensan que existe un 
modelo del "nuevo racismo". Pettigrew y Meertens $(1992,1995)$ hablan de "prejuico sutil". La idea fundamental de todos estos términos es que existe una nueva expresión del prejuicio, que recibe distintos nombres, pero que se caracteriza por sentimientos y creencias discriminatorias que adquieren matices distintos a las del "viejo racismo". (Navas y otros, 2004 y Rueda y Navas, 1996, 133). Los individuos manifiestan el prejuicio de una forma más sutil, más sofisticada, de acuerdo con los mensajes contradictorios que nos envían desde la sociedad. $Y$ estas manifestaciones se traducen en la forma de interactuar socialmente.

Allport, en 1954, ya respondía a esta cuestión cuando afirmaba:

Cuando existe un conflicto entre, por una parte, la ley y la conciencia y, por otro lado, la costumbre y el prejuicio, la discriminación se practica principalmente por vías indirectas y ocultas, y menos frecuentemente de forma directa, por las consecuencias embarazosas que de ellos se derivarían. (Allport, 1954,57).

El discurso racista va evolucionando, adquiere formas diversas en función de los debates sociales que se establezcan en el momento. Las interacciones sociales van adaptándose de igual modo a los discursos de la época. El punto en común del discurso racista actual es la función social que desempeña. Se trata de justificar, sostener y legitimar conductas que mantienen el poder de unos grupos sobre otros.

Para entender el prejuicio es necesario explicarlo desde el punto más social y éste viene a decir que el prejuicio negativo hacia otras étnias es una expresión de estructuración social de dominación por parte de unos grupos y de opresión de otros. El grupo con poder lo sustenta aquel con mayores recursos económicos, sociales y culturales. Se establecen así diferencias entre las procedencias. Los ojos de un europeo no perciben de la misma manera a un inmigrante procedente de Canadá que al oriundo del África Subsahariana. Más cercano todavía, tampoco es juzgada de la misma forma la llegada de un grupo de individuos procedentes de Europa del Este que la de una familia gitana.

De estas anotaciones expuestas en este apartado extraemos la idea de que las interacciones sociales dependen del contexto social en el que se produzcan. Para entender más el fenómeno deberemos concretar el contexto en el que nosotros desarrollaremos nuestro trabajo. Se trata del contexto escolar. Dentro de este ambiente las interacciones sociales se entienden, se generan y se desarrollan en función de las influencias de las características propias de la cultura escolar. 


\section{4.- Las relaciones sociales prejuiciosas en la escuela}

Dado que nuestra investigación se circunscribe en el ámbito escolar analizaremos el prejuicio desde este contexto, para ello trataremos los siguientes epígrafes:

2.4.1.- Formación del prejuicio en escolares y su influencia a la hora de establecer interacciones sociales en la escuela

\subsection{2.- Causas de la aparición del prejuicio}

No sólo en el ámbito escolar se producen manifestaciones prejuiciosas. Más bien podríamos decir que la escuela es un reflejo de lo que pasa en el resto de instituciones sociales, en los barrios y sobre todo en la familia. Intentaremos comprender cómo se produce el prejuicio a la hora de establecer interacciones sociales en la escuela desde el punto de vista de la psicología social.

\subsection{1. - Formación del prejuicio en escolares y su influencia a la hora de establecer interacciones sociales en la escuela}

- “¿De verdad no odias ser una niña?”, preguntó Jorge.

- "No, claro que no", dijo Ana. "Me encantan los vestidos bonitos y tengo mis muñecas y no puedes tener todo eso si eres un niño."

Enyd Blyton, Los cinco en la isla del tesoro.

(1942; 1989 grabación de EMI Records Ltd.) en Brown, 1995,137.

El prejuicio presupone la conciencia y el uso de categorías sociales en la percepción, el juicio y la conducta. Existen pruebas en las que se demuestran que los niños desde los tres años de edad son conscientes de las categorías sociales más importantes: género y etnia. A partir de los tres años, los niños también se identifican más fácilmente con unas categorías que con otras y demuestran preferencias actitudinales y conductuales claras entre estas categorías. Prefieren a los miembros de su propio grupo (endogrupo) que a los de otros (exogrupo). Esto se ha demostrado muy claramente con el género, pero también con la etnia, la nacionalidad y con grupos discapacitados (Véase los estudios realizados por Thompson (1975), Davey (1983), Yee y Brown (1988), Ferraresi (1988), Fagan y Singer (1979), Goodman (1952), Clark y Clark (1947), en Brown (1995), Tajfel y Turner (1986).

De las preferencias a la consolidación de estereotipos, se suceden múltiples variables que interactúan entre ellas. Unas se refieren a factores 
individuales, como es la capacidad cognitiva para la categorización ${ }^{1}$, la necesidad de formar una identidad social, y otras a factores más sociales como es la influencia familiar, la de sus iguales, los medios de comunicación, etc. La teoría de Aboud (1977) y la de Piaget (1937) son buenos ejemplos para explicar cómo se produce la categorización en función del desarrollo cognitivo. Aboud (1977, 134-146) distingue tres estadios: en los primeros años (hasta los 5), el niño está dominado por procesos perceptivos y afectivos, categorizando el mundo en conjuntos muy amplios (hombres y mujeres, conocidos, desconocidos) y los asocian a respuestas emocionales, derivadas de sus experiencias personales y la observación de lo que hacen los otros. El pensamiento es egocéntrico y está caracterizado por indicios perceptivos (Piaget, 1937). La combinación de estos procesos afectivos y cognitivos proporciona la aparición de preferencias étnicas.

De los 5 a los 7 años ${ }^{2}$, el niño se encuentra en el período pre operacional concreto (Piaget,1937) y las cogniciones profundizan, considerando atributos más abstractos e internos. Los niños en esta edad consideran las categorías sociales como estables y no cambian por alteraciones superficiales como la apariencia o la edad. Al mismo tiempo, las orientaciones sociales de los niños experimentan también un cambio, pasan de la percepción egocéntrica hacia sí mismo a centrarse en el grupo, coincide además con la escolarización reglada. Esta combinación entre cambios sociales y cognitivos, según Aboud (1988), es lo que facilita un alto grado de etnocentrismo.

Por último, cuando el niño adquiere el pensamiento operacional, hay una flexibilidad de pensamiento que permite la posibilidad de variación individual. Dentro de los grupos, los estereotipos empiezan a ser susceptibles de cambiar. Aquí cabría mencionar (aunque Aboud no hace mucha referencia a ello) la importancia de la sensibilidad hacia las normas de la sociedad adulta por parte de los niños a estas edades y por lo tanto la aparición de la conciencia de la "deseabilidad social". Estos últimos cambios producirán una reducción en el prejuicio y en la discriminación, aunque empezarán a consolidarse los estereotipos de forma más encubierta 0 indirecta, como aluden algunos autores cuando hablan de las nuevas formas de

\footnotetext{
1. Un aspecto fundamental de la cognición humana es la necesidad y capacidad de las personas de categorizar al mundo. Esto surge a causa de la enorme cantidad y complejidad de información con la que tenemos que enfrentarnos. Y se da tanto en el mundo social como en el mundo físico. Esta función de simplificación de la categorización supone una serie de sesgos y otros efectos que tienen importantes implicaciones para la comprensión del prejuicio y de cómo debe reducirse. Allport (1954), Bruner (1957) y Brown (1988), entre otros nos hablan de este concepto básico para la comprensión del prejuicio.

2 Existen estudios empíricos que apoyan la existencia de un período crítico en los estereotipos de los 5 a los 8 años, durante el cual el favoritismo hacia el endogrupo alcanza un pico, para después declinar en el período preadolescente. Es decir, la formación de estereotipos adquiere una forma de $\mathrm{U}$ invertida en el devenir evolutivo del niño (Asher y Allen, 1969, 1986; Lambert y Klineberg, 1967; Vaughan, 1964; Yee y Brown,1988).
} 
prejuicio (Brown, 1995, Sears y Kinder, 1971, Mc Conahay, 1981). Como vamos viendo, la formación del prejuicio en el niño se encuentra entre una encrucijada de variables de índole cognitivo, madurativo, afectivo y social. ¿Qué podemos decir entonces del prejuicio en los niños?

Los estudios sobre la evolución cognitiva de las categorías citadas anteriormente, nos impiden afirmar que los niños sean meros receptores de la sociedad adulta. Sin embargo, la socialización directa y primaria del niño se forma con sus padres y con otras fuentes como la influencia de sus compañeros, de sus profesores en la escuela y los canales habituales de transmisión de la cultura. Por lo tanto, cuando hablamos de formación del prejuicio en el niño, nos referimos a un conjunto interrelacionado de factores individuales y sociales. Podemos entenderlo mejor a partir de un texto de Rupert Brown.:

El proceso de desarrollo de los niños es dinámico, precisamente como sus padres, están buscando activamente comprender, evaluar y controlar su mundo social con los recursos cognitivos (a veces limitados) a su disposición. Ya que el mundo está dividido en formas socialmente significativas (etnia, género, edad,...) no debería sorprendernos demasiado que las convicciones y la conducta de los niños se modelen en esa misma línea. Además, los sesgos y preferencia que podemos observar no son el resultado de adoctrinamiento pasivos del mundo adulto, sino el crecimiento natural de una interacción entre el mundo y los procesos psicológicos de categorización, identificación entre el mundo y los procesos psicológicos de categorización, identificación y comparación en las mentes de nuestros niños. (Brown, 1995,177).

Todas estas explicaciones acerca de la formación del prejuicio deberemos tenerlas en cuenta para entender las relaciones sociales en la escuela entre alumnos inmigrantes y españoles. Si como decíamos anteriormente, una de las fuentes de socialización del niño y, por tanto, de su influencia para la formación de su categorización y estereotipo es la interacción entre iguales y entre sus profesores, debemos atender al papel que éstos juegan en el ámbito escolar.

¿Cuáles son las causas que dentro de este contexto pueden producir conductas prejuiciosas en los escolares? Será lo que desarrollaremos a continuación.

\subsection{2.- Causas de la aparición del prejuicio}

Los psicólogos evolutivos han sostenido que los animales sienten preferencia hacia otros individuos de similares características y que tienden a expresar miedo y aversión hacia otros organismos con rasgos diferentes aunque no 
les conozcan. Se habla por un lado de mecanismos biológicos de supervivencia y por otro, se conoce la existencia de la cultura (medios de comunicación, familia, sociedad) como agentes socializadores que pueden enseñarnos intencionadamente 0 no a asignar cualidades y a atribuir rasgos negativos a colectivos diferentes a nosotros.

Desde la Psicología social, se apuesta por el factor aprendizaje como principal medio de adquirir pensamientos y comportamientos prejuiciosos. Esta disciplina explica diferentes factores que explican este fenómeno: la necesidad de autojustificación, la necesidad de estatus y de poder. Aronson (2005, 307-324) analiza cuatro causas importantes para la creación del prejuicio: competencia 0 conflicto económico y político, agresión desplazada, necesidades de personalidad y conformidad con las normas sociales existentes. Causas todas ellas interrelacionadas, de forma que pueden operar todas ellas de manera aislada 0 conjunta en el individuo. Myers (en Ovejero, 1998, 237 y ss) dice que existen factores sociales, emocionales y cognitivos que se dan la mano entre sí. Veamos las explicaciones que nos aclaran este fenómeno. Según Myers (en Ovejero, 1998, 237 y ss.), el prejuicio brota de tres fuentes:

\section{A - Fuentes sociales}

El prejuicio opera como un mecanismo para defender la autoestima del endogrupo y su posición social y económica (o aquella que pretende alcanzar). E conjunto de fuentes sociales se subdivide a su vez en:

\section{a.1) Desigualdades sociales.}

La posición desigual fomenta el prejuicio (Myers, 1995, 356). Cuando un grupo es poseedor de los recursos y percibe una amenaza por parte de otro (en nuestro caso de los inmigrantes), las actitudes prejuiciosas han funcionado a lo largo de la historia como un mecanismo justificador de tal desigualdad.

Las actitudes se manifiestan fácilmente a la conducta, por lo que en situaciones de conflicto es frecuente que el endogrupo mejor posicionado socialmente desarrolle una serie de conductas discriminatorias hacia los exogrupos desfavorecidos con el fin de preservar su estatus social y/o económico. Como señala Brown (1995, 31): Las instituciones y las prácticas sociales pueden generar sus propias situaciones autosatisfactorias para crear prejuicios contra grupos particulares. Pongamos como ejemplo el acceso a puestos de trabajo cualificados. Para conseguirlos es necesaria una formación determinada (normalmente superior). Los inmigrantes que vienen a España en muchas ocasiones tienen un nivel de cualificación superior al de los propios españoles, pero la mayoría de las veces su inserción en el mercado laboral se caracteriza por el subempleo, ya que se suele 
pensar que sus títulos no son homologables debido al bajo nivel educativo de los países de origen, o si lo son no se pueden situar en el mismo plano que los nacionales por la misma razón. Esto en la mayoría de los casos no se contrasta empíricamente. Como vemos, se está justificando una situación de desigualdad en base a un prejuicio.

También el uso de la religión puede ser un arma para respaldar la posición subordinada. Los estudios realizados por Gorsuch (1988) en Norteamérica revelan que: 1) El prejuicio racial era mayor en los miembros de la iglesia que en los no miembros y 2) los que poseen creencias cristianas tradicionales revelan un nivel superior de prejuicio que los que no tienen tales creencias.

a.2) Necesidad del grupo de tener una autodefinición o identidad positiva.

Los miembros del endogrupo tienen una necesidad de responder positivamente a la pregunta "¿Quién soy?". La Teoría de la Identidad Social de Tajel y Turner (1986) afirma, basándose en la Teoría de la Comparación Social de Festinger (1954), que el individuo necesita compararse con otros para valorarse y por ello su pertenencia a un grupo juega un papel fundamental a la hora de efectuar tal valoración.

Una de las motivaciones más profundas del ser humano es la de poseer una autodefinición positiva (Ovejero, 1998, 239), por lo que el individuo tratará de mantener y reforzar su adhesión a un grupo que le proporciona tal autodefinición y sólo intentará unirse a otros, si éstos pueden consolidar los aspectos positivos de su identidad social.

Como ejemplo para este estudio podemos decir que los inmigrantes pueden ser utilizados como medida de comparación por parte de los autóctonos para reforzar su identidad positiva. Para ello son necesarios una serie de engranajes que actúen de tal manera que en esa comparación el endogrupo autóctono salga mejor parado que el exogrupo inmigrante.

Ahí es donde opera el prejuicio y donde surge el sesgo endogrupal, la tendencia por parte de los miembros de un grupo a favorecer, beneficiar o valorar más positivamente a ese grupo con respecto al grupo al que no pertenecen, en comportamientos, actitudes, preferencias y percepciones (Brown (1984), Turner (1980) y Tajfel, 1959).

\section{B.- Fuentes emocionales}

El prejuicio, como actitud que es, posee también raíces emocionales. Como bien dijo Nelson Mandela (El País, 8 de octubre 1995) El racismo es un problema 
muy grave, porque no se basa en la lógica, sino en los prejuicios, en las emociones, por eso nunca puedes derrotarlo con argumentos.

Aunque el origen del prejuicio suele estar en las fuentes sociales, las emociones le dan el carácter motivacional y en muchas ocasiones lo aumentan. Dentro de las fuentes emocionales, dos han sido las variables más estudiadas.

\section{b.1) La personalidad autoritaria}

Los estudios realizados por Adorno y sus colaboradores (Adorno, Brunswik, Levinson y Sanford, 1950) en su libro "The Authoritarian Personality" para tratar de explicar los sucesos ocurridos en la Alemania nazi, constituyen la base del enfoque psicodinámico realizado sobre el prejuicio (véase Ovejero, 1981).

Estos autores parten de la idea de que los individuos que son susceptibles a la propaganda fascista muestran un conjunto de características que configuran un síndrome. Para determinar estas características analizan simultáneamente dos conceptos; la ideología y la personalidad. Relacionándolos, los autores pretenden estudiar las estructuras de personalidad para descubrir las fuentes psicológicas del antisemitismo nazi.

Llegaron a la conclusión de que existe un proceso por el cual los individuos se convierten en personas autoritarias desde niños. Las personas autoritarias fueron a menudo víctimas de una disciplina dura, lo que les hizo reprimir la agresividad intrínseca a ese tipo de educación y por ello la dirigen hacia los exogrupos. Estas personas son obedientes y sumisas con los que ostentan el poder, pero a su vez proyectan su agresividad hacia los grupos discriminados (en el presente estudio, los inmigrantes). No es infrecuente escuchar actualmente en España frases como: Ios niños de hoy en día no tienen disciplina, a mí de pequeño no me dejaban ni decir nada, una bofetada y obedecía. Según esta teoría, este tipo de personas son más propensas a tener prejuicios hacia los inmigrantes.

En un estudio con adultos estadounidenses (Adorno y cols. 1950), los autores encontraron que la hostilidad hacia el exogrupo no era la exclusiva, sino que se simultaneaba con la hostilidad hacia otras minorías.

En resumen, desde distintos puntos de vista, hablar de personalidad autoritaria es casi sinónimo de hablar de personalidad prejuiciosa. (Ovejero, 1998, 241).

b.2) Frustración-agresión. La teoría del chivo expiatorio

Esta hipótesis presupone que las personas frustradas tienen una predisposición emocional hacia la agresión. No implica que la conducta agresiva se 
vaya a producir necesariamente, sino que tendrá más posibilidades de ser llevada a cabo.

Cuando la causa de nuestra frustración es intimidante o vaga, a menudo redirigimos nuestra hostilidad (Myers, 1994, 365). Es lo que se denomina "agresividad desplazada". Si esa frustración surge de una manera espontánea 0 inesperada, más probabilidades habrá de que se produzca esa agresión (Ovejero, 1998, 115).

Podemos entonces suponer que aquellas personas que no consiguen sus objetivos 0 logros, que se sienten frustradas 0 insatisfechas ${ }^{3}$. son proclives a desplazar su agresividad hacia los exogrupos, en nuestro caso hacia los inmigrantes, los cuales se constituirían el chivo expiatorio.

\section{C. - Fuentes cognitivas}

Los estudios sobre las fuentes cognitivas del prejuicio suponen la aportación más novedosa al intento de comprensión del fenómeno. Los prejuicios no sólo nacen de las circunstancias sociales y de las emociones, sino que también existen como "productos secundarios de los procesos normales de pensamiento". (Myers, 1995, 369).

Cuando percibimos a los demás debemos hacer frente a una gran cantidad de información y muchas veces de manera casi inmediata, por lo que resulta inevitable hacer trampas y buscar atajos, lo que produce importantes y frecuentes sesgos, sesgos que, al cumplir también funciones emocionales y grupales, se hacen a menudo incluso sistemáticos (Ovejero, 1998, 243).

Dentro de las fuentes cognitivas del prejuicio destacan tres:

\section{c.1) Los procesos de categorización}

La realidad social a la que hemos de hacer frente a lo largo de nuestra vida nos conduce inexorablemente hacia la categorización. El mundo es un lugar demasiado complejo y por tanto hemos de dotarnos de mecanismos para simplificarlo y darle un cierto orden.

La mente humana tiene que pensar con la ayuda de categorías... el proceso de categorización es imprescindible para la supervivencia (Allport, 1954,

\footnotetext{
${ }^{3}$ Las exigencias que impone el actual neoliberalismo para la satisfacción son cada vez mayores. Una de las razones se debe al contínuo bombardeo de los mensajes publicitarios que relacionan poder social y económico y belleza física con la felicidad. Estas razones lograrán, presumiblemente, que crezca el número de individuos insatisfechos y, por ende, según esta teoría, también aumentará el número de individuos prejuiciosos.
} 
22). No andaremos demasiado desacertados si afirmamos que el ser humano tiene un modelo de pensamiento que se basa de forma natural en categorías.

Los seres humanos no tenemos la capacidad de responder de una forma diferenciada a cada individuo o hecho con el que nos topamos. Es ahí donde establecemos una serie de categorías que pueden llevarnos al prejuicio. El proceso de categorización normalmente produce dos efectos: Por una parte la homogeneización intracategorial o la creencia de que todos los miembros del grupo son iguales y por otro lado la diferenciación intercategorial o exageración de las diferencias entre los miembros pertenecientes a las distintas categorías (Echebarría y otros, 1995, 29). Si enlazamos esto con el sesgo endogrupal visto anteriormente, vemos cómo el establecimiento de categorías puede derivar en prejuicio.

Pero también hay que decir que no toda categorización conduce al prejuicio. Como se observa en los efectos de la misma, subyace un componente emocional o motivacional, por lo que son las necesidades emocionales lo que lleva al prejuicio y no los procesos cognitivos. Estos están al servicio de aquéllas. De ahí que, aunque la categorización es inevitable, el etnocentrismo no lo es. (Ovejero, 1998, 244).

Por tanto, el establecimiento de categorías basadas en estereotipos y el riesgo añadido de sesgo endogrupal pueden reconducir los procesos de categorización hacia el prejuicio. Ante el rápido cambio que están sufriendo nuestras sociedades con la llegada de "nuevas gentes" se establece la categoría de "inmigrantes" a la hora de percibirlas, lo que, si se dan las características que se han descrito, puede desembocar en prejuicio.

\section{c.2) .Los estímulos distintivos}

También conocidos como la saliencia de los estímulos diferenciados (Ovejero, 1998, 244). Las personas distintas, que sobresalen por alguna razón (en nuestro caso por el color de su piel, su vestimenta, su forma de hablar etc.), suponen un extra de atención en el proceso de percepción que distorsiona los juicios. Cuando alguien sobresale en un grupo tenemos la tendencia a creer que es el responsable de aquello que sucede. Por ejemplo, si en un grupo de trabajo hay una persona de color y algo no funciona bien (y no se sabe claramente quién es el causante de tal anormalidad) normalmente se señalará a esa persona como la responsable del problema.

Por otra parte, las ocurrencias vividas y extremas (Myers, 1994, 372) también pueden funcionar de la misma manera que las personas distintas. Todo este proceso cognitivo puede concluir en el sesgo de la correlación ilusoria o la tendencia a percibir una relación de causa-efecto allí donde no existe, ya que 
cuando esperas ver relaciones significativas, con facilidad asociamos acontecimientos azarosos (Ovejero, 1998, 35). No es entonces casualidad que tratemos de establecer una relación de ese tipo entre inmigrante y delincuente ante la lectura de los titulares de las páginas de sucesos de casi cualquier periódico.

c.3) Creencia en un mundo justo

Uno de los principales sesgos que cometemos en el proceso de interpretación de la conducta de los demás es lo que se denomina el error fundamental de atribución (Ross, 1977). Al explicar las acciones de los demás... atribuimos tanto su conducta a sus disposiciones internas que descartamos factores situacionales importantes. (Myers, 1994, 375).

Este error atributivo nos puede llevar hacia el denominado sesgo del mundo justo o la tendencia a creer que el mundo es justo y que, por lo tanto, cada uno tiene lo que merece y merece lo que tiene. (Ovejero, 1998, 245).

Tal conjunto de circunstancias puede justificar, en algunos casos, los pensamientos de algunas personas del ámbito escolar. Pensamientos prejuiciados que justifican el bajo rendimiento académico de los alumnos inmigrantes, por ser considerados peores alumnos, más torpes e incapaces.

Todas estas razones explicadas influyen a la hora de interactuar con otros individuos. La familia es la primera gran fuente de aprendizaje con la que los alumnos adquieren el funcionamiento cognitivo, social y emocional de los que acabamos de hablar. En la escuela, los escolares expresan estos aprendizajes familiares y también aprenden otros nuevos al socializarse con otros compañeros que actúan de forma diferente. Las interacciones sociales en la escuela se desarrollarán por tanto en un vaivén entre lo que traen de casa y los modelos sociales diferentes que ven en el colegio.

La labor de los profesionales de la educación respecto al tema de la diversidad étnica deberá conocer los funcionamientos sociales de los alumnos y trabajar con ellos para reducir el prejuicio si lo que se quiere es convivir armoniosamente con alumnos étnicamente diversos.

A continuación desarrollaremos el tema de la reducción del prejuicio en la escuela. 


\section{5.- La reducción del prejuicio en la escuela: el aprendizaje cooperativo y el entrenamiento en habilidades sociales, una posible solución}

La escuela es un lugar propicio para que interactúen alumnos con orígenes y procedencias culturales diferentes. En este espacio una gran diversidad de alumnado tiene que convivir y estar juntos muchas horas a lo largo del día, por tanto se posibilita la oportunidad de entablar diálogos interculturales si se utilizan las metodologías adecuadas a este objetivo.

Allport (1954) cuando escribía sobre la segregación en los Estados Unidos, advertía que se tenían que tomar las medidas oportunas para equiparar el estatus de grupos diferentes dentro de la escuela y de las aulas. Utilizar la metodología cooperativa en el aula puede ser una de las estrategias más eficaces para este fin.

Los estudiantes trabajan en relaciones de interdependencia cuando están implicados en actividades cooperativas. En los trabajos de aprendizaje cooperativo, los alumnos trabajan en pequeños grupos para alcanzar metas comunes que establece el profesor.

En este subapartado veremos los siguientes epígrafes:

2.5.1.- Efectos del aprendizaje cooperativo: efectos cognitivos y no cognitivos.

2.5.2.- Entrenamiento de las habilidades sociales para obtener eficacia en la colaboración.

\subsection{1.- Efectos del aprendizaje cooperativo}

Las numerosas investigaciones realizadas durante las últimas décadas sobre aprendizaje cooperativo, han permitido demostrar su eficacia para mejorar muchos aspectos escolares. Según Díaz Aguado (1995), la interacción entre compañeros que se produce en situaciones de aprendizaje cooperativo genera los siguientes efectos:

- Al aumentar en la escuela las interacciones sociales con los compañeros, 0 entre iguales, se aprenden habilidades sociales más sofisticadas.

- El aprendizaje cooperativo proporciona un tipo de interacción entre compañeros diferente de la que los alumnos establecen en contextos informales, al estar estructurada intencionalmente en torno al aprendizaje, contribuyendo a aumentar la variedad y riqueza de experiencias que la escuela proporciona a los alumnos para favorecer su desarrollo. 
- En determinadas situaciones, representa un procedimiento compensador de situaciones anteriores de privación social, al garantizar que todos los alumnos interactúen con sus compañeros de forma positiva, incluidos los que habitualmente no lo consiguen en contextos habituales.

Teniendo en cuenta la división que establece Ovejero (1990), clasificaremos los efectos del aprendizaje cooperativo en cognitivos y no cognitivos y dentro de cada uno de estos ámbitos, explicaremos los factores que consideramos más relevantes.

\subsubsection{1. - Efectos cognitivos: el rendimiento escolar}

Numerosos autores afirman que los alumnos que trabajan de una manera sistemática y bajo ciertas condiciones el aprendizaje cooperativo alcanzan mejores resultados a nivel cognitivo que otros alumnos que trabajan en situaciones diferentes (Johnson y Johnson, 1982; Sharan 1980; Slavin, 1985; Ovejero, 1990).

Respecto al lenguaje, Ovejero (1990) lo considera como fenómeno psicosocial que tiene una importancia decisiva en las personas, ya que les va a permitir el dominio o no del mundo exterior.

Webb (1982) sostiene que uno de los factores que más contribuye al propio aprendizaje es el hecho de verse en la necesidad de explicar algo a alguien, de tal manera que se asegure la comprensión del otro.

El uso de la discusión dentro de los grupos de trabajo contribuye a que se desarrollen estrategias de razonamiento superior para convencer y dejarse convencer con un adecuado uso de la palabra.

Ovejero (1990), considera que en estas situaciones entran en juego procesos interpersonales del lenguaje que hacen mejorar la adquisición de conocimientos y la comunicación interpersonal. Al tiempo que las mayores oportunidades de interacción oral refuerzan el aprendizaje de la lengua para los alumnos inmigrantes que no ha adquirido el idioma mayoritario.

Respecto a la asimilación conceptual, Johnson y Johnson (1982), afirman que los alumnos que trabajan con estos métodos mejoran la asimilación de los conceptos estudiados que resultan ser más funcionales y significativos para los alumnos.

Díaz Aguado $(1995,108)$ sintetiza las ventajas cognitivas de la cooperación, ya que, al presentar una oportunidad educativa de primera magnitud, favorece: 
- El aprendizaje observacional, a través de los modelos que proporcionan sus compañeros.

- La reestructuración y el conflicto socio-cognitivo que estimula la interacción entre iguales y la motivación para encontrar nuevas soluciones con las que influir a los demás.

- La mayor dedicación de tiempo activo sobre la tarea a trabajar.

- La ampliación de las fuentes de información y la rapidez de feed-back sobre los propios resultados.

- La atención individualizada que proporciona a los alumnos que más lo necesitan, alcanzando así, en lenguaje de Vigostki, su zona de desarrollo potencial.

- La oportunidad de poder enseñar a los compañeros y así favorecer procesos de asimilación y reorganización de lo aprendido de una forma más significativa.

\subsubsection{2. - Efectos no cognitivos}

\section{A.- El Autoconcepto y la autoestima}

La autoestima es un juicio sobre el valor o la competencia que uno se atribuye a sí mismo (Johnson 1972, 78).

Es en la interacción con los otros donde se desarrollan el autoconcepto de las personas. De ahí la importancia del aprendizaje cooperativo para este factor.

Johnson y Johnson (1982) dicen que los alumnos que trabajan cooperativamente se sienten importantes y útiles para la consecución de las metas que tienen planteadas por el grupo.

La distribución de las oportunidades para obtener éxito hace que todos los alumnos tengan su momento de reconocimiento y al repetirse sistemáticamente se potencia la autoestima de cada uno de ellos.

Slavin (1986), afirma que los efectos de la cooperación en la autoestima se centran básicamente en dos hechos: la mejora de los logros académicos y la mejora de las relaciones interpersonales. En el siguiente gráfico podemos apreciar esta relación. 


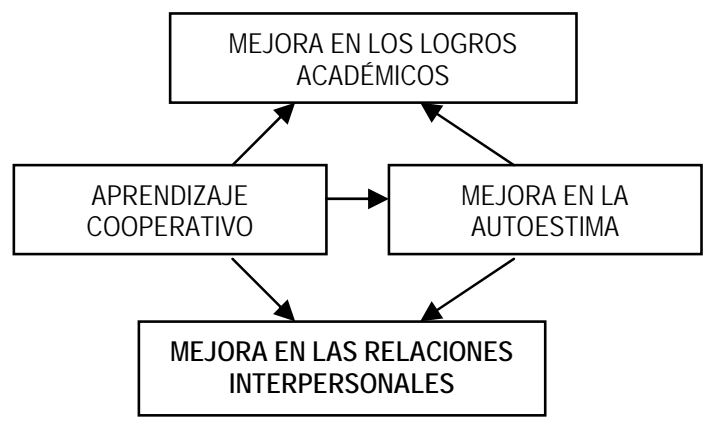

Figura 2.1. Efectos del aprendizaje cooperativo (Adaptado de Slavin, 1985)

\section{B.- Apoyo social}

También son varios los estudios que aseguran que en el aprendizaje cooperativo es mucho más frecuente el apoyo o la ayuda social entre los alumnos.

Según Ovejero, $(1990,197)$, podemos definir la ayuda social como la existencia y disponibilidad de personas en las que poder confiar para una ayuda emocional, instrumental, informativa y de estima.

Parece una parte inherente a las relaciones interpersonales positivas. Johnson y Johnson, (1982), establece como finalidades del apoyo social las siguientes:

- Aumenta la productividad y el rendimiento.

- Mejora la salud física.

- Aumenta el ajuste y la salud psicológica.

- Incrementa la capacidad de combatir el estrés.

Queda claro, pues, que los métodos de aprendizaje cooperativo favorecen el contacto entre los alumnos y, en consecuencia, la aparición de lazos afectivos entre ellos, así como la creación de sentimientos de pertenencia al grupo. Éste, proporciona apoyo, comprensión, normas, favorece las interacciones positivas, de amistad entre sus componentes, respeto mutuo, actitudes solidarias, democráticas y la creación de conductas prosociales. Salas (1998), apoya esta idea y aporta que uno de los efectos que más se destacan en el aprendizaje cooperativo es la potenciación y mejora de las relaciones sociales al darse conductas continuas y recíprocas de ayuda mutua. 
Por lo tanto, vemos que la ayuda social tiene relación con otros factores como el rendimiento académico, la autoestima o salud psicológica, las relaciones sociales y, por ende, la resolución de conflictos.

\section{C.- Resolución de conflictos}

$\mathrm{Si}$ el conflicto tiene lugar en un contexto cooperativo y si es administrado adecuadamente a través de grupos de aprendizaje cooperativo, el conflicto puede ser sumamente útil, pues les permite a los estudiantes y al profesor aprender las habilidades necesarias para vivir en perfecta convivencia con quienes les rodean, a pesar de las diferencias (Ovejero, 1990, 202).

Johnson y Hewstone (1992), afirman que manejando adecuada y cuidadosamente las controversias existentes entre los alumnos se pueden maximizar resultados a nivel de rendimiento académico, de creatividad y de motivación por aprender.

Comprobamos, por lo tanto, que los conflictos, dentro de un ambiente cooperativo, pueden ser muy enriquecedores para conseguir los objetivos que nos planteamos al aplicar la cooperación con los alumnos. También sabemos que son necesarias ciertas habilidades sociales para que esto se produzca.

En sentido bidireccional, vemos cómo no sólo el aprendizaje cooperativo mejora la resolución de conflictos, sino que se produce un proceso recíproco ya que la manera más eficaz de resolver un conflicto es mediante el establecimiento de relaciones interpersonales de cooperación. Sherif llegó a esa conclusión ya desde 1953, realizando investigaciones experimentales que continuaron en 1967. Este autor afirmaba que la manera más eficaz de resolver conflictos era mediante el restablecimiento de actitudes intergrupales favorables consistentes en la participación de todos los miembros del grupo, proponiendo metas que no puedan alcanzar si no es con la ayuda de todo el grupo, es decir, metas que exijan la cooperación intergrupal.

\section{D. - Autonomía}

La autonomía está relacionada con el rendimiento académico y el apoyo social. Mejorando la autonomía, detectamos cambios respecto a:

- Eficacia en la organización de los grupos.

- Mejora de la capacidad con la que defender sus puntos de vista.

- Capacidad de realizar las tareas escolares con menos ayuda del profesor.

- Capacidad de proponer ellos nuevas propuestas de trabajo. 
Tras la explicación de los distintos factores que influyen trabajando el aprendizaje cooperativo, podemos considerar el Apoyo Social, el común denominador del resto de variables.

El espacio escolar quizá sea el único que propicie a algunos alumnos el conocimiento e intercambio con sujetos de otras procedencias culturales. La interdependencia que se genera con este tipo de prácticas cooperativas ayudan al diálogo intercultural y las relaciones sociales van tomando un cariz diverso e interétnico donde se respetan las culturas.

El contacto de apoyo mutuo consigue establecer interacciones y desdibujar los estereotipos que pueden existir sobre los sujetos con otras procedencias. Muchos estudios (Slavin, 1985,1986; Díaz Aguado, 1995) han revelado que las relaciones intergrupales mejoran de forma considerable después de tener experiencias cooperativas en grupos heterogéneos y, además, los efectos en las relaciones interraciales tienen efectos duraderos.

El aprendizaje cooperativo se contempla como la herramienta más adecuada con la que reducir el prejuicio. Introducir esta estrategia en la escuela puede contribuir, al multiplicar las interacciones entre iguales, a mejorar las relaciones sociales entre alumnos étnicamente diversos.

Previamente a estos resultados colaborativos, es necesario entrenar las habilidades sociales en el alumnado para conseguir tales efectos. Será el apartado que desarrollaremos a continuación.

\subsection{2.- Entrenamiento de las habilidades sociales en el alumnado para obtener eficacia en la colaboración}

Como hemos visto en el cuadro adaptado de Slavin, tres páginas atrás; la mejora de las interacciones sociales en el alumnado, supone un efecto notable en el aprendizaje cooperativo. Por eso, el entrenamiento en dichas habilidades lo consideramos un factor importante para tales efectos. Existen muchas conexiones entre las técnicas de aprendizaje cooperativo y las de entrenamiento en habilidades sociales. Para mostrarlo enumero las seis premisas que Curran en Ovejero, (1990, 263 y ss.) establece:

$1^{0}$ - Las relaciones interpersonales son importantes para el desarrollo y funcionamiento psicológicos que se reflejarán en el trabaja colaborativo.

$2^{0}$ - La falta de armonía interpersonal puede contribuir a conducir a disfunciones y perturbaciones psicológicas, pudiendo manifestarse a la hora de trabajar en grupos y propiciando las respuestas negativas de los compañeros. 
$3^{0}$ - Ciertos estilos y estrategias interpersonales son más adaptativos que otros estilos y estrategias para clases específicas de encuentros sociales. enseñarse.

$4^{0}$ - Estos estilos y estrategias interpersonales pueden especificarse y

50- Una vez aprendidos estos estilos y estrategias mejorarán la competencia en esas situaciones específicas y en concreto, en el trabajo en grupos.

$6^{\circ}$ - La mejora en la competencia interpersonal puede contribuir 0 conducir a la mejora del funcionamiento psicológico y por tanto en el trabajo cooperativo.

Además, el entrenamiento en habilidades sociales ha sido relacionado con cuatro ámbitos, coincidentes con los del aprendizaje cooperativo (Michelson et al., 1987). Estos son: las habilidades sociales y funcionamiento adaptativo, las relaciones con los compañeros, el rendimiento escolar y las habilidades sociales e inteligencia.

Para que las relaciones entre el alumnado sean constructivas no deberán fomentar los sentimientos de rechazo y hostilidad, sino todo los contrario; la pertenencia, la aceptación y el apoyo, serán sentimientos necesarios para conseguir tales habilidades. Es decir, para que el aprendizaje cooperativo cumpla sus efectos deberá proporcionarse en un ambiente donde existan interacciones positivas con sus compañeros, y donde el profesorado controle la dinámica colaborativa. Para conseguir el ambiente descrito, es necesario entrenar las habilidades sociales. He aquí el punto de conexión entre ambos aspectos.

Es necesario por tanto, aprender a cooperar. Como dice Slavin en Ovejero, (1990, 256): Learning to cooperate, cooperating to learn. O sea, es necesario cooperar para aprender, pero también hay que aprender a cooperar y es que el éxito del aprendizaje cooperativo se asegura capacitando a los individuos de estrategias y habilidades colaborativas. Ahora bien, ¿cómo generamos habilidades sociales de cooperación?. Johnson, Johnson, Holubec y Roy en Ovejero, $(1990,256,257)$ establecen cinco supuestos subyacentes en la enseñanza de las habilidades sociales necesarias para la colaboración:

1- Es necesario preparar un ambiente cooperativo entre el alumnado antes de enseñar las habilidades de cooperación.

2- Se deben enseñar las habilidades de cooperación. No es suficiente estructurar lecciones cooperativas. El alumnado no nace con estas habilidades aprendidas, ni las aprende de forma automática.

3- Los compañeros serán la clave. Mientras el profesorado define y estructura las situaciones de aprendizaje cooperativo y decide las habilidades 
colaborativas que se van a trabajar, los miembros del grupo determinan si las habilidades son practicadas internalizadas.

4- Las habilidades cooperativas deben siempre verse acompañadas por el apoyo de los compañeros para hacerlo. Siempre que haya un alumno menos capacitado para interiorizar estas habilidades, habrá que proporcionarle el apoyo constructivo necesario.

5- Es importante enseñar las habilidades cooperativas en los momentos iniciales.

Para la práctica educativa, nos resulta interesante el plantearnos cómo enseñar estas habilidades cooperativas. Johnson, Johnson, Holubec y Roy en Ovejero, (1990, 257 y ss.) Establecen cinco pasos:

1- Asegurarse de que los estudiantes vean la necesidad de la habilidad.

2- Asegurarse de que los estudiantes entiendan lo que es una habilidad.

3- Exponer situaciones prácticas.

4- Asegurarse de que los estudiantes procesan su utilización de las habilidades.

5- Asegurarse de que los estudiantes perseveran en su práctica de las habilidades.

El aprendizaje de la mayoría de las habilidades sigue el siguiente curso (Ovejero, 1990): en primer lugar se da un periodo lento de aprendizaje, en el que se argumentan los tipos de habilidades la importancia de las mismas. En segundo lugar se produce un periodo rápido de perfeccionamiento, en un tercer periodo, la ejecución se mantiene, en cuarto lugar se produce una rápida mejora y se finaliza con un periodo de mantenimiento; $y$ así sucesivamente.

Lo importante de este proceso es que el alumnado pase de conocer teóricamente estas habilidades a incorporarlas de forma práctica, y que posteriormente reproduzca de forma automática. El profesorado deberá fomentar una sostenida práctica de estas habilidades durante un largo periodo de tiempo. "El objetivo del aprendizaje de toda habilidad cooperativa es alcanzar el punto en el que los profesores puedan estructurar cooperativamente una lección e implicar automáticamente y de forma natural a los estudiantes en un alto nivel de habilidades de colaboración mientras alcanzan sus metas de aprendizaje" (Johnson, Johnson, Holubec y Roy en Ovejero, $(1990,259)$.

A su vez, si para que el aprendizaje cooperativo funcione eficazmente es necesario el aprendizaje cooperativo, la propia dinámica del aprendizaje cooperativo 
mejora entrenando las habilidades sociales. Los factores responsables de la eficacia del aprendizaje cooperativo son coincidentes con los del entrenamiento en las habilidades sociales (Ovejero, 1990, 261) y para demostrar tal afirmación, describimos algunos factores responsables de la eficacia, tanto del aprendizaje cooperativo, como de las habilidades sociales (Goldstein et al. en Ovejero, 1990, 261 y ss.):

1- Modelado o modelamiento o aprendizaje por medio de la imitación. Es una técnica efectiva y fiable por la rapidez con la que se aprenden conductas nuevas y por el fortalecimiento de las conductas previamente aprendidas.

2- Role-playing o representación de papeles. Técnica en la que se le pide a un individuo que desempeñe un papel. Esta técnica completaría al anterior ya que el hecho de observar lo que el modelo hace, enseña al alumno lo que tiene que hacer. Sin embargo, también necesita la suficiente práctica para aprender cómo y por qué se debe comportar de determinada manera Goldstein et al. en Ovejero, 1990, 261 y ss.), de ahí que se utilice también esta técnica. Sin embargo la representación de papeles, produce efectos no demasiado duraderos porque el individuo todavía necesita saber porqué debe adoptar determinadas conductas.

3- Retroalimentación del rendimiento, es decir, suministrar al alumno información sobre cómo ha representado el papel asignado. Aquí tienen importancia las recompensas, el refuerzo, la crítica, y sobre todo, el refuerzo social.

4- Generalización del adiestramiento, se trataría en último lugar, de extrapolar lo aprendido a nuevas situaciones de aprendizaje y de la vida real.

Como vemos, el parecido entre aprendizaje cooperativo y entrenamiento en las habilidades sociales es grande. Los alumnos se imitan unos a otros, practican realidades sociales aprendidas, habilidades de cooperación, habilidades cognitivas. Es decir, el propio grupo cooperativo funciona como un grupo de entrenamiento de las habilidades sociales.

Una vez expuesta la relación y dependencia entre el aprendizaje cooperativo y las habilidades sociales, y dado que nuestro trabajo pretende servir como reflexión para el trabajo práctico en los colegios de educación primaria, señalaremos a continuación los ámbitos de intervención escolar en las habilidades sociales.

Ovejero (1997) distingue tres niveles diferentes de actuación. Un nivel micro o molecular, otro nivel intermedio y un nivel macro o molar.

- En el nivel macro o molar, las habilidades sociales se consideran como habilidades generales, en el campo escolar, destacarían las siguientes: el 
rendimiento escolar, ya que la inteligencia es un constructor social, que se desarrolla al hilo de la interacción social (Ovejero, 1990). Por lo tanto, cuanto más adaptativas sean las interacciones sociales del alumnado, más y mejor se desarrollará la inteligencia. Además el manejo en estas habilidades, puede tener una fuerte incidencia en la atención el reforzamiento del profesor hacia el niño o la niña, repercutiendo en su motivación, su autoconcepto y su rendimiento, como demuestran las teorías sobre la profecía autocumplida. La cooperación y la conducta prosocial y la integración social, también se encontrarían dentro de este nievel.

- En el nivel intermedio, se enseñarían los componentes específicos de las habilidades sociales. En la infancia se han relacionado las siguientes habilidades con la competencia social: saludos, iniciación social, hacer y responder preguntas, elogios, proximidad y orientación, participación en tareas 0 juegos, conducta cooperativa de compartir, y responsabilidad afectiva (Kelly en Ovejero, 1997).

- En el nivel micro o molecular, se analizan las conductas concretas que componen cada habilidad. De ahí que este nivel y el anterior sean complementarios. En este nivel se distinguen tres tipos de componentes de las habilidades sociales (Ovejero, 1997):

- Componentes conductuales: verbales (la mirada la sonrisa a los gestos expresión facial la postura corporal), paralingüísticos (la voz, el volumen, la claridad la fluidez la velocidad) y verbales (él habla, los saludos, iniciar, mantener y terminar una conversación, aceptar las críticas, pedir disculpas, hacer preguntas, defender los propios derechos)

- Componentes cognitivos: como son las habilidades de percepción social (familiaridad, distancia, etc) y las variables propiamente cognitivas (solución de problemas y conflictos, autocontrol).

- Componentes fisiológicos y afectivos: dentro de los cuales se encontrarían las manifestaciones psicofisiológicas (la presión sanguínea, la tasa cardiaca, la relajación, la respiración) y los componentes afectivosemocionales (expresión de emociones, habilidades de relajación, etc).

Es necesario tener en cuenta y articular de forma adecuada los tres niveles explicados para trabajar las habilidades sociales en el ámbito escolar. 
A lo largo de este capítulo hemos analizado el fenómeno de las relaciones sociales desde una doble perspectiva correspondiente con dos niveles de concreción distintos.

En primer lugar, desde un enfoque algo más general, realizábamos una trayectoria del fenómeno siguiendo como eje transversal la desigualdad social que había caracterizado al hecho relacional.

En segundo lugar, concretábamos algo más el tema y explicábamos un aspecto crucial cuando hablamos de las relaciones sociales en contextos interétnicos y nos referíamos al prejuicio. Conceptualizamos el término, describíamos sus componentes, explicábamos su formación desde las teorías socio-evolutivas, focalizándolo en el contexto escolar. Por último explicábamos algunas orientaciones para reducir el prejuicio en la escuela extraídas de la literatura: el aprendizaje cooperativo y el entrenamiento en habilidades sociales.

Todas estas justificaciones pretenden presentar una cobertura teórica donde introducir el trabajo de campo que realizamos posteriormente. 


\section{Capítulo 3}

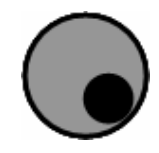

\section{Las interacciones y habilidades sociales para el desarrollo de la competencia social en los grupos escolares étnicamente diversos}

Corsaro (1985) argumenta que los niños llegan a ser miembros de su sociedad a través de la construcción y participación en una cultura de iguales. Esta cultura consiste en un conjunto de significados compartidos entre ellos, que deberán conocer y aprender tanto aquellos procedentes de otros países, como los pertenecientes al lugar receptor.

En este capítulo centramos el tema de las interacciones sociales en el contexto escolar, queremos analizar la importancia que éstas tienen para generar habilidades socialmente competentes cuando se encuentran en contextos étnicamente diversos. Cinco apartados conforman el eje de este capítulo. El primer y segundo apartado nos sirven para ubicarnos en la encrucijada conceptual de los términos: interacción, habilidad y competencia social en contextos étnicamente diversos. En tercer lugar describimos la importancia de estudiar y potenciar en el alumnado la competencia social como facilitador de la integración escolar. En el cuarto epígrafe, explicamos las características y evolución de las interacciones sociales a lo largo de la etapa escolar y por último, analizamos los contextos (familiares, sociales y escolares) influyentes en el proceso de socialización del infante. 


\section{1- Ubicación conceptual de las interacciones sociales y desarrollo de la competencia social en los grupos escolares étnicamente diversos de nuestro trabajo}

El tema de la interacción social se relaciona directamente con dos conceptos: competencia social y habilidades sociales. Estos constructos son estudiados por diversos autores, pensando fundamentalmente en la intervención, (Caballo, 1987, 1989, 2002; Ovejero, 1997; Verdugo 1997; Monjas, 1996, 2007; Díaz Aguado, 1988, 1995).

La orientación que utilizamos en este capítulo y en la tesis en su conjunto, la podemos resumir a través del siguiente esquema:

Para conseguir:
COMPETENCIA SOCIAL EN GRUPOS ESCOLARES ÉTNICAMENTE DIVERSOS
se necesitan:
INTERACCIONES SOCIALES (IS)
y dentro de ellas se requieren:
HABILIDADES SOCIALES ADAPTATIVAS
que dependen de:
FACTORES CULTURALES
que varían en función de los:
CONTEXTOS: sociales, familiares y educativos

Tabla 3.1. Relación conceptual entre los conceptos: competencia social, interacción y habilidad social. Enfoque teórico de la investigación.

Es decir, para que el niño adquiera competencia social, es necesario que éste protagonice y manifieste interacciones sociales adaptativas. A su vez, la interacción social positiva requiere de la adquisición de un buen repertorio de habilidades sociales con las que interactuar con el otro. Estas habilidades dependen fundamentalmente de una serie de factores culturales que podrán variar en función del contexto (familiar, social y escolar) en el que se originen o desarrollen.

En nuestra investigación, nos interesa analizar e incidir en el aspecto cultural de las interacciones y habilidades sociales del alumnado nuevo en el contexto escolar, alumnado procedente de otros países y con otros referentes culturales 0 usos sociales. 
Por lo tanto, competencia, interacción social y habilidad social, son conceptos íntimamente relacionados. En el apartado siguiente analizaremos las diferencias y semejanzas conceptuales y resaltaremos el enfoque que nosotros utilizaremos en nuestra investigación.

\section{2.- Conceptualización de las interacciones sociales y habilidades sociales entre iguales como base para el desarrollo de la competencia social}

En este apartado vamos a realizar un análisis teórico sobre el desarrollo de la competencia social a través de las interacciones y habilidades sociales. Para ello vamos a incluir los siguientes apartados:

2.1.- Conceptualización de las interacciones, habilidades y competencia social.

2.2.- Características de las interacciones y habilidades sociales en contextos étnicamente diversos.

2.3.- Variables de la interacción y habilidad social en contextos étnicamente diversos.

2.4.- Interacciones y habilidades sociales necesarias para el desarrollo de la competencia social.

2.5.- Modelo de las interacciones y habilidades sociales

\section{1.- Conceptualización de las interacciones, habilidades y competencia social}

Conceptualizar estos constructos es tan complejo como intentar definir todas las situaciones sociales en las que el individuo se ve envuelto. Caballo $(1987,7)$ afirma que la carencia de una definición universal acertada, una variedad de dimensiones que no acaban de quedar establecidas, unos componentes seleccionados en base a la intuición de cada investigador y la falta de un modelo que guíe la investigación sobre la competencia social, son problemas actuales que todavía no han sido resueltos.

A pesar de esta complejidad conceptual, intentaremos comprender el concepto de dicho fenómeno a través de la literatura que nos ofrecen diversos especialistas en la materia.

Gresham y Elliot $(1990,12)$ dicen que las competencias sociales vendrían definidas como aquellas respuestas que, en una situación dada, se demuestran efectivas 0 , en otras palabras, maximizan la probabilidad de decir, mantener 0 
intensificar los efectos positivos para la interacción. Pelechado $(1979,15)$ define este concepto como el patrón complejo de respuestas que llevan al éxito individual y social... y resultan eficaces para controlar a los demás como a uno mismo en contextos determinados... Spence $(1987,87)$ lo ve como la conducta social apropiada a la acción social concreta.

Continúa diciendo el último autor, que la competencia social es un constructo formado por dos componentes: la conducta adaptativa y las habilidades sociales. La primera consiste en la habilidad del individuo para alcanzar los estándares de autosuficiencia y responsabilidad personal establecidos por la sociedad. Se compone de habilidades de funcionamiento independiente, autogobierno, responsabilidad personal, etc. Las habilidades sociales, sin embargo hacen referencia a las conductas específicas y observables de una persona, en orden a realizar completamente una tarea en una situación social dada. Se trata de términos difícilmente separables, con matices distintos.

Por último también existen autores que encuentran una tercera diferenciación: las habilidades de supervivencia (Rodrigo 1999) referidas a aquellas conductas juzgadas como aceptables y necesarias para la admisión y permanencia de una persona en un contexto determinado (una escuela, un centro de trabajo, un grupo social, etc.). Desde este enfoque estos autores afirman que la competencia social es un indicador social de salud mental. Esta perspectiva explica el desarrollo saludable de la personalidad y la adaptación a distintos ámbitos.

Moraleda $(1995,9-10)$ encuentra dos tipos de componentes que explican la competencia e interacción pro-social; por un lado, el comportamiento positivo, en el que se ubican tanto el interno (pensamientos, sentimientos, etc) como el externo (conductas que se expresan manifiestamente y posibilitan las relaciones con los otros) y por otro el aprendizaje de estrategias y habilidades de interacción social apropiadas a la situación.

Monjas (1996), diferencia entre el término competencia social y habilidad social, explicando que el término competencia se refiere a una generalización evolutiva, mientras que el término habilidad se refiere a conductas específicas. Las habilidades sociales pueden entenderse como un conjunto de capacidades aprendidas por el sujeto, las cuáles le permiten percibir, entender, descifrar y responder a la gran diversidad de estímulos sociales, y de forma más concreta, a aquellos que provienen del comportamiento de los otros, incrementándose así dentro de un contexto determinado, el reforzamiento social ( Kelly, 1982, 76).

Según estos autores nombrados, entendemos las interacciones y, dentro de ellas, las habilidades sociales como un componente necesario para desarrollar la 
competencia social. Sería la "partícula menor" dentro del engranado social y educativo que envuelve el aspecto relacional del sujeto.

Según el enfoque con el que explicamos las interacciones sociales, tenemos que explicar algunas características que las definen:

- Están en contínua influencia y por tanto en modificación. No estamos hablando de un concepto estático sino que la característica que define el concepto es su continuo cambio y transformación.

- Pueden ser simétricas y asimétricas (con las mismas o diferentes características socio-cognitivas) y a su vez pueden ser influidas por adultos o por el contrario, ser reguladas por ellos solos.

- Dependen tanto en su origen como en su formación del contexto social donde se ubiquen. En este caso, nos encontramos en un contexto escolar español. Desde esta perspectiva cultural resaltaremos la importancia del análisis de los escenarios socioculturales. Es distinto estudiar la interacción entre iguales en situaciones de juego, en situaciones de amistad que en entornos educativos. En este último contexto pueden darse ambas situaciones, pero estarán marcadas por el contexto educativo donde se suceden y, por ende, por el adulto.

Vemos por tanto, que este concepto está muy ligado a la cultura y al contexto donde se desarrollen. Butler y Grudson, en Caballo (1987) afirman que es imposible desarrollar una definición consistente de la competencia social si no consideramos el contexto cambiante. Caballo (1987) continúa diciendo que la habilidad social debe considerarse dentro de un marco cultural determinado y los patrones de comunicación varían ampliamente entre culturas e incluso, dentro de las propias culturas, de la edad, el sexo, la clase social y la educación (Caballo, 1987, 4).

Nuestro trabajo se concreta en un espacio escolar español donde existe alumnado procedente de otros países y en tal ambiente pretendemos analizar las interacciones y habilidades sociales, siempre con la finalidad última de reflexionar sobre la adaptación escolar de este tipo de alumnado. Para conseguir tal objetivo, consideramos los conceptos: interacción social, competencia social y habilidad social, como un conjunto con el que indagar en estas diferencias culturales.

A continuación, vamos a destacar algunos principios básicos que enmarcan teóricamente estos constructos, extraídos de la profesora Monjas Casares, 2007. 


\section{2.- Características de las interacciones y habilidades sociales en contextos étnicamente diversos}

\subsection{1.- Son un conjunto de conductas que se piensan, se sienten, se hacen y se dicen}

Las interacciones y habilidades sociales contienen componentes cognitivos, emocionales y conductuales. Existe un factor social que envuelve a estos tres componentes. Es decir, la cognición, la emoción y por ende, la conducta, dependerán del ambiente social en el que se hayan socializado. De esta manera, el alumnado inmigrante puede realizar cogniciones diferentes entre sí y demostrarlo en sus conductas.

\subsection{2.- Son conductas y repertorios de conducta adquiridos} principalmente a través del aprendizaje

Nos referimos a un conjunto de habilidades que pueden aprenderse a lo largo de toda la vida y estando en contacto con los demás. Los aprendizajes difieren en función del contexto cultural en el que se encuentre la persona. El alumnado inmigrante se ve envuelto en una encrucijada entre los aprendizajes sociales que trae de su país de procedencia y los que se encuentra en el país receptor.

\subsection{3.- Son respuestas específicas a situaciones específicas}

La efectividad de la conducta social depende del contexto concreto y de las normas sociales que se usen en ese contexto específico. De este modo, el alumnado inmigrante puede verse sometido a más situaciones diferentes para él. Debe aprender los códigos que rigen los usos sociales de cada situación. Algunos son universales, pero otros dependen específicamente del momento concreto. Evidentemente, no es lo mismo que un niño esté en el recreo con los compañeros conocidos, jugando a los juegos de siempre, que verse rodeado de niños/as moviéndose por el espacio sin entender las normas que rigen dicho desconcierto.

\subsection{4.- Son conductas que se producen siempre en relación a otra u otras personas}

Lógicamente, la interacción y la habilidad social se ponen de manifiesto con otros interlocotures. Éstos pueden ser adultos 0 iguales. Los códigos utilizados en cada caso variarán en función de quién se trate.

\subsection{5.- Se refieren a conductas de muy distinta complejidad}

Caballo (2002), señala una serie de dimensiones conductuales de las habilidades sociales (hacer y aceptar cumplidos, hacer peticiones, expresar afecto, 
inicar y mantener una conversación, defender los propios derechos, rechazar peticiones, expresar opiniones personales, expresar molestia, solicitar cambios en la conducta del otro, disculparse 0 admitir ignorancia, afrontar las críticas sobre la propia conducta). El alumnado procedente de distintas culturas y contextos usará estos componentes con registros diferentes, estos cambios pueden ser mal interpretados por sus compañeros. Estas diferencias conductuales no tienen por qué ser una fuente de conflicto, sino de aprendizaje intercultural.

\section{3.- Variables de la interacción y habilidad social en contextos étnicamente diversos}

Monjas (2007) nos ofrece una serie de componentes cognitivos que influyen en la interacción y habilidad social. Estos son los siguientes:

- Variables relacionadas con la percepción e interpretación del mundo social; dentro de ellas hablaríamos de la percepción social, las creencias, las atribuciones y la adopción de roles.

- Variables relacionadas con la elaboración y solución de problemas; dentro de las cuales se encontrarían el auto lenguaje y las auto instrucciones, las estrategias de interacción, las habilidades de solución de problemas interpersonales.

- Variables relacionadas con la anticipación de consecuencias; dentro de las cuales estarían las expectativas, la autoeficacia y autoconfianza, la competencia social percibida, los planes, metas y los objetivos sociales.

Todas estas variables están fuertemente influidas por el contexto social en el que se encuentren. El alumnado manifiesta disparidad de registros y de formas de interiorizar estos componentes. Los patrones cognitivos que posee el individuo respecto a estas cuestiones difiere no sólo en el alumnado inmigrante, sino que depende también del contexto familiar y social en que se haya socializado.

\section{4.- Interacciones y habilidades sociales necesarias para el desarrollo de la competencia social}

La interacción social entre iguales es el lugar en el que se construyen los significados y códigos culturales que posibilitarán la competencia social, así como la adaptación escolar.

Recopilamos a continuación algunas habilidades sociales que posibilitan al individuo la interacción competente (Monjas 2007).

- Conocimiento de sí mismo y de los demás.

- Reciprocidad: necesidad de dar para recibir. 
- Empatía: habilidad para percibir situaciones desde la perspectiva del otro.

- Colaboración y ayuda.

- Autocontrol y autorregulación de la propia conducta.

- $\quad$ Apoyo emocional.

- Disfrute, diversión y complicidad.

- Estrategias sociales de negociación y de acuerdos.

- Aprendizaje de aspectos sexuales.

- Desarrollo moral y aprendizaje de valores y normas.

Desde los estudios de Piaget y Vygostky nos informan de los beneficios de la interacción cooperativa con los iguales para conseguir tales habilidades. Piaget subraya que tales interacciones ofrecen beneficios desde el ámbito cognitivo, social y moral. Vygostky apuntaba que, a través de estas prácticas, los escolares realizan aprendizajes, utilizando al compañero como mediador. Más recientemente los trabajos teóricos de Ovejero (1990) y los empíricos de Díaz Aguado (1998) nos ofrecen resultados muy favorecedores en la competencia social, cuando se aplicaban programas de aprendizaje cooperativo en las aulas y sobre todo en aquellas con diversidad étnica.

Nuestro trabajo se acerca a estos dos últimos enfoques. Queremos adentrarnos en los procesos internos que se desarrollan en contextos educativos étnicamente diversos a través de las interacciones sociales entre iguales. Para ello, por un lado necesitamos conocer los contextos influyentes en este fenómeno (Rodrigo 1999) y por otro, necesitamos acercarnos de forma naturalista y ecológica al lugar donde se producen estos procesos de socialización (Corsaro, 1985). Se trata de una visión profunda y minuciosa del problema.

Los estudios psico-socio-educativos realizados enfocan esta temática desde un punto de vista socio-cognitivo. El objetivo último es conocer cómo funciona el conocimiento humano. Es decir, estos estudios pretenden responder a la pregunta: ¿cómo influyen los contextos sociales y de interacción en la cognición del individuo? Nuestro trabajo, sin embargo, toma un ligero matiz, pretende dar respuesta al siguiente interrogante: ¿Cómo son las interacciones sociales del alumnado inmigrante y cómo éstas influyen en el proceso de integración escolar? 


\section{5.- Modelo de las interacciones y habilidades sociales}

Caballo (1987) configura un modelo explicativo de las habilidades sociales adaptado de Mc Fall (1982). Este explica que "una respuesta socialmente habilidosa sería el resultado final de una cadena de conductas que empezaría con una recepción correcta de estímulos interpersonales relevantes, seguiría con el procesamiento flexible de estos estímulos para generar y evaluar las posibles opciones de respuesta, de las cuales se seleccionaría la mejor, y terminaría con la emisión apropiada o expresión manifiesta de la opción escogida." (Robinson y Calhon, 1984, en Caballo 1989, 13).

\begin{tabular}{|c|l|}
\hline Habilidades de descodificación & ¿Quién está en escena? \\
Recepción & ¿Dónde tiene lugar la situación? \\
Percepción & ¿Qué dijeron los demás en la escena? \\
Interpretación & ¿Quién quiere decir de quién? \\
& ¿Qué emoción expresaron? \\
\hline Habilidades de decisión & $\begin{array}{l}\text { Definir derechos, responsabilidades y objetivos a } \\
\text { Búsqueda de la respuesta }\end{array}$ \\
Comprobación de la respuesta & Generar alternativas de respuesta \\
Selección de la respuesta & Anticipar y evaluar las consecuencias a corto y \\
Búsqueda en el repertorio & largo plazo \\
Evaluación de su utilidad & Escoger una respuesta \\
\hline Habilidades de codificación & \\
Ejecución & Contenido verbal \\
Autoobservación & Componentes no verbales \\
& Contexto y ocasión \\
& Reciprocidad \\
\hline
\end{tabular}

Tabla 3.2. Modelo Mc Fall, 1985, adaptado por Caballo (1988) de las habilidades sociales.

Analizando con un poco más de precisión este modelo, podemos extraer algunos factores que nos ayudan a explicar algunas características de las interacciones sociales en contextos étnicamente diversos.

La descodificación de los estímulos situacionales entrantes (input), requiere la interpretación de los códigos culturales de una situación concreta. El alumno inmigrante que desconoce estos usos culturales, puede interpretar de forma errónea o no obtener significado. La toma de decisiones y la codificación posterior podría estar influida por esta percepción inicial. Los usos sociales difieren en función de la 
cultura, y aunque algunos son universales, cada individuo tiene unos patrones culturales adquiridos en sus contextos cercanos de socialización. Es decir, podrían ejecutar sus conductas en función de una interpretación previa confusa, o de una percepción sin significado para ellos.

Los alumnos con procedencias distintas a la mayoritaria deben conocer y aprender los códigos del contexto de acogida, si quieren integrarse. Cuando se enfrentan a esta tarea pueden encontrarse indefensos al no atribuir significados 0 , incluso, al distorsionar los estímulos que reciben del exterior, esto incrementa en gran medida, si además no conocen el idioma del país receptor.

\section{3.- Importancia del desarrollo de la competencia social a través de las interacciones y habilidades sociales entre iguales}

Algunos investigaciones afirman que la habilidad para socializarse y desarrollar habilidades de competencia social supone un importante requisito para su posterior desarrollo adulto, ya que de lo contrario, los escolares tendrían una alta probabilidad de riesgos en diversos ámbitos de su vida adulta (Ladd, 1990; Parker and Asher, 1987). Los niños que no son aceptados por sus compañeros, que son incapaces de mantener una relación estrecha con sus iguales y ubicarse en la cultura a la que pertenecen sus compañeros, son proclives a padecer conductas inadaptadas al medio social (Katz,1976). Hartup (1996) nos explica cómo las interacciones sociales entre iguales influyen de manera notable en el desarrollo socio-cognitivo-emocional del niño y en la eficacia con la que posteriormente, en la edad adulta, nos relacionamos y funcionamos a nivel social. El mejor indicador en la niñez de la adaptación en la vida adulta, no son las notas escolares, ni el comportamiento en clase, sino la capacidad con la que este niño se relaciona con otros niños (Hartup, 1992,1).

En el contexto escolar se desarrollan estrategias de interacción social más elaboradas que en cualquier otro contexto, al estar en continuo contacto con sus compañeros. El juego proporciona un ambiente idóneo para detectar, desarrollar, evaluar y trabajar conductas prosociales en los niños. En este contexto lúdico, el escolar tiene que descubrir una amplia gama de opciones con las que actuar: seleccionar a sus compañeros, desarrollar estrategias para incorporarse en el juego, organizar 0 adaptarse a unas normas lúdicas, tiene que hacer notar sus méritos y convencer a los demás de ello, tiene también que anticipar y aceptar la exclusión (Corsaro, 1986, 207). Es éste un contexto único en cuanto al desarrollo de estrategias sociales complejas y con un alto grado de reciprocidad, entendida como un "toma y daca", donde el niño debe saber dar para recibir, tiene que saber 
anticipar respuestas en los demás y tiene que conocer las consecuencias que sus actuaciones tendrán sobre los demás. Todo un ejercicio de empatía, asertividad y despliege de habilidades sociales.

La interacción entre iguales es una magnífica oportunidad para estimular el proceso de adopción de perspectivas que consigue alcanzar una etapa superior en los conocidos niveles de Kohlberg (1969), donde el niño percibe y construye el conocimiento del otro. Además, esta interacción con sujetos de un nivel inmediatamente superior es ideal para desequilibrar la estructura de razonamiento moral y hacerle avanzar hacia el estadio siguiente (Blatt y Kohlberg, en Díaz Aguado, 1999).

Es evidente el papel que las interacciones entre iguales suponen en la formación de la propia identidad, ya que es el mejor modo de compararse con los otros, de percibir con precisión su propia competencia. Bandura (1981) nos explica cómo el niño puede tener resultados aversivos, si realiza acciones más allá de sus posibilidades; sin embargo, si se infravalora y por tanto evita actividades que le ayudarían a desarrollar su competencia, conseguirá desarrollar sentimientos de deficiencia que bajarán su autoestima. En el contexto escolar culturalmente diverso en el que nuestros centros escolares se encuentran y, en concreto, en el que es objeto de nuestro estudio, esta identidad cultural adquiere relevancia especial.

Los sujetos pertenecientes a una minoría étnica tendrán especial dificultad para que estas conductas sociales estén adaptadas a los códigos culturales del contexto escolar en el que se encuentran. Y no sólo serán ellos los que deberán hacer un esfuerzo por entender las normas culturales con las que integrarse e interactuar en un contexto determinado, sino que los demás, los escolares mayoritarios, también tendrán que desarrollar toda una serie de habilidades relacionadas, como mencionamos anteriormente, con el conocimiento del otro, la empatía, el anticipo de reacciones, la elaboración de estrategias de interacción, etc., para establecer vínculos con estos alumnos. Si a todo esto le sumamos el desconocimiento de la lengua, entonces multiplicamos por cien la dificultad en el manejo de las habilidades sociales, ya que los mensajes corporales, la gestualidad y la comunicación no verbal, en general, es muy susceptible de malos entendidos, de enfrentamientos, de asilamiento, etc., incluso en personas adultas con estas habilidades supuestamente desarrolladas.

Desde la psicología social de la educación las interacciones y la competencia social son importantes para el aprendizaje de las estrategias de negociación. Supone una gran lección social el intercambiar, negociar y llegar a acuerdos entre pares. 
Incluso desde una perspectiva etológica se ha comprobado que los primates adquieren la competencia social que necesitan para su adaptación al medio a través de la interacción con sus compañeros. Todos los elementos del repertorio conductual adulto pueden ser encontrados dentro del esquema de juego entre monos jóvenes. El esquema de las interacciones entre iguales, en el que las conductas más frecuentes son repetidas por los demás y las menos frecuentes son ignoradas, se asemeja al de los primates (Díaz Aguado 1999). Estos demuestran en sus acciones, conductas agresivas, sexuales, de afiliación, coalición y cooperación. La interacción con los compañeros proporciona la oportunidad de practicar y perfeccionar estas conductas y de desarrollar de esta forma el nivel de competencia adulta (Suomi, 1979, 131-133).

Al hablar de interacción social en contextos diversos, como es el caso de este trabajo, encontramos su importancia en el desarrollo y la adquisición de patrones de comportamiento que posibilitan la mejora de la tolerancia hacia lo diferente, hacia la apertura de las costumbres culturales externas y desconocidas por la propia cultura. Esto amplía en el niño el repertorio de habilidades sociales necesarias para convivir o simplemente, tratar en un futuro con personas con otras características culturales.

Por otro lado, el proceso de integración escolar está íntimamente relacionado con la competencia en las interacciones sociales manifestadas entre los iguales y esto será el objetivo práctico de la presente investigación.

\section{4.- Características y evolución de las interacciones sociales en la edad escolar}

Si vamos a investigar las interacciones sociales que se producen en el alumnado, sería conveniente reflejar las tendencias evolutivas por las que se va sucediendo el niño. En esta evolución influyen factores sociales, biológicos, emocionales, cognitivos, contextuales. En el apartado 4 analizamos los contextos que influyen en este desarrollo, pero de momento vamos a describir las características evolutivas de las interacciones sociales en los escolares. Seguiremos el cuadro expuesto por Monjas (2007,68-69).

- Desde el nacimiento a los dos años:

* Las interacciones se desarrollar a través de juegos de imitación.

* Al final del período se hace evidente el refuerzo y modelado de los iguales.

- Desde los dos a los seis años: 
* Al principio usan palabras que inciden en el comportamiento de otros niños ("vamos a jugar a pillar").

* Durante los 3-4 años, lo más frecuente es una actividad no social, juego en solitario.

* Aparece en juego en paralelo que se mantiene estable de los 3 a los 6 años; jugando cerca de otros niños, con materiales similares, pero sin intentar influir en las actividades de otros.

* En el nivel más alto hay dos formas de interacción: el juego asociativo (actividades separadas pero intercambian juguetes y comentarios) y el juego cooperativo (las acciones de los niños van dirigidas a una meta común).

- Desde los 7 a los 11 años:

* Las habilidades de comunicación mejoran, tanto para interpretar como para responder a emociones del otro.

* La mejora de la habilidad para comprender papeles complementarios de varios jugadores favorece los juegos de reglas.

* La interacción se hace más prosocial y se tiene en cuenta las necesidades del otro. Disminuye la agresión física y entre los niños son más frecuentes los insultos y entre las niñas la exclusión social.

* Tomar contacto con una amplia variedad de iguales favorece la comprensión de puntos de vista diferentes al propio.

* Tendencia a la homosociabilidad: las niñas y niños tienden a establecer relaciones de amistad con otros escolares de su mismo sexo. Esta preferencia permanece hasta la adolescencia.

Como ya hemos indicado, la socialización es el proceso por el cual se va produciendo este desarrollo evolutivo, mediante el que adquieren las pautas de comportamiento, las creencias, las normas, valores, costumbres y actitudes propias de la familia, la escuela, el contexto social y cultural y el momento histórico. (Monjas 2007,59).

\section{5.- Influencia de los contextos en el desarrollo de las interacciones sociales entre iguales y la competencia social en contextos educativamente diversos}

Existen diversos escenarios socioculturales en los que se produce la construcción de conocimiento social. En estos contextos las personas establecen 
códigos, significados culturales que se regulan y normativizan, transmitiendo de este modo el conocimiento (Rodrigo, 1999). Cuando observamos con la actitud de extrañamiento (Díaz de Rada, 1996) que señalan los antropólogos, es decir, con un distanciamiento transcultural, nos percatamos de la enorme complejidad que existe en cualquier sistema de organización social. El ámbito escolar, en el que centramos nuestro trabajo, se encuentra influenciado por una encrucijada de factores procedentes de estas diferentes organizaciones sociales (familiares, sociales, profesionales, etc). Vamos a ir viendo los aspectos esenciales de cada uno de ellos para entender el desarrollo de las interacciones entre iguales y la competencia social.

Los epígrafes que vienen a continuación explican la influencia de cada uno de estos contextos.

\section{1.- Contexto familiar}

\section{2.- Contexto social: los medios de comunicación}

\section{3.- Contexto escolar y comportamiento social}

\section{1.- Contexto familiar}

Tradicionalmente, se ha diferenciado entre socialización primaria (procedente de la familia) y la secundaria (procedente de contextos sociales). En este apartado vamos a describir lo que la literatura apunta sobre la temática referida a la influencia familiar en el comportamiento interpersonal del niño.

Es difícil reflejar toda la complejidad del asunto a través de un repaso de la literatura, ya que los conocimientos sobre este tema son abundantes (Pinata, Egeland y Ericsson, 1989). Sin embargo los estudios sobre la materia destacan dos aspectos importantes a la hora de relacionar familia y competencia social. Nos referimos en primer lugar, al tipo de apego que el niño ha vivido en su primera infancia. Las investigaciones longitudinales existentes al respecto generalizaron la idea de que los niños preescolares que en su primera infancia fueron clasificados como de apego seguro, muestran posteriormente más competencia social en las relaciones con sus compañeros: inician frecuentemente interacciones positivas, muestran conductas de cooperación y ayuda, manifiestan afecto y presentan menos conductas agresivas y desajustadas. Por el contrario, los niños de apego inseguro tienden más al aislamiento social y a las conductas inseguras.

En segundo lugar, nos referimos a los estilos de educación familiar. Los datos de investigación parecen apuntar de forma clara hacia las siguientes direcciones. El estilo autoritario de los padres está asociado a conductas agresivas. Al haber recibido pocas expresiones de afecto, estos niños reproducen el patrón con pocas manifestaciones afectivas. Los hijos educados con padres permisivos, 
presentan dificultades en controlar sus impulsos, manifestando una conducta no ajustada. Sin embargo, los padres democráticos contribuyen a una educación de sus hijos que tiende a presentar altos niveles de conducta prosocial. Además los hijos de estos padres han sido los que han tenido más oportunidad de desarrollar conceptos morales más avanzados y una autoestima más fuerte, factores que se relacionan con un ajuste social (Rodrigo, 1999).

Es decir, simplificando, los hijos cuyos padres les han educado a través de unas relaciones positivas y felices tienen muchas posibilidades de tener relaciones positivas con sus compañeros. Se aprenden las estrategias de relación interpersonal y se reproducen los rasgos psicológicos generados durante la primera infancia en el ámbito escolar. Sin embargo, no debe olvidarse que los niños realizan fuera de la familia otros aprendizajes con sus compañeros, con sus profesores y otros agentes diferentes a la familia. Esta interacción puede actuar transformando o modificando ciertos patrones aprendidos.

Ubicándose nuestro trabajo en un contexto étnicamente diverso hay que resaltar la existencia de diferencias culturales dentro del ámbito familiar. Los patrones de agrupamiento y los valores familiares que en ellas se producen difieren incluso dentro de nuestra propia estructura familiar. En nuestro país ha existido una clara evolución a lo largo de los años. Durante siglos, lo que existía era la familia extensa (varias familias emparentadas entre sí compartían un espacio o vivían muy cerca para cuidar los unos de los otros). El tipo de familia actual es la llamada nuclear (compuesta por ambos progenitores y sin descendencia). Más recientemente, las familias monoparentales cada vez tienen más presencia en el panorama familiar debido al alto número de separaciones y divorcios desde que la mujer se incorporó al mercado laboral (Instituto de la mujer, 1990, Yubero, S., Bodoque, A., Larrañaga, E., 2006).

La existencia de diferentes modelos familiares procedentes tanto de las familias de nuestro propio país como las procedentes de otros países, nos informan de dos aspectos importantes para entender el fenómeno de las interacciones sociales, por un lado el carácter dinámico y contextual de la educación familiar, dependiendo de la época social en la que nos encontremos, y por otro, la diversidad de conductas, aprendidas de las familiar correspondientes, que se ponen en juego cuando los iguales interactúan entre sí. El intercambio de patrones culturales diferentes entre compañeros en la escuela constituye una fuente de riqueza y de aprendizajes que favorecen la conducta prosocial.

\section{2.- Contexto social: medios de comunicación}

Otro poderoso agente socializador es el de los medios de comunicación. Estos suponen una potente fuente de influencia en el desarrollo de los niños y del 
individuo durante toda su vida. A través de ellos se perciben realidades creadas por agentes exteriores. Los niños construyen representaciones sociales y visiones del mundo social y generan prejuicios y estereotipos hacia los grupos humanos a partir de lo que ven en este medio.

Además, la televisión, selecciona, define y crea los temas de interés que ocuparán la atención de los individuos. Enseña a necesitar, incluso a desear a personas y a cosas. Muestra estilos de vida, hábitos diversos y alejados y con sutiles valoraciones morales, propias de la cultura "productora" de las imágenes (Rodrigo, 1999, 245). Construye una realidad homogénea y estereotipada, con pocas variantes que se ajusten a la diversidad. Esta homogeneidad cercana al "pensamiento único", que diría Habermas $(1988,1999)$, puede influir de forma clara a la hora de establecer relaciones sociales con compañeros procedentes de otros países, con costumbres distintas a las que están acostumbrados a ver en la televisión.

Sin embargo, al mismo tiempo, la televisión también ofrece un criterio unificador con el que se pueden compartir significados y códigos culturales con personas que viven en la otra punta del planeta. Así por ejemplo, la coca-cola o la hamburguesa del Mc Donald es conocida por cualquier persona del planeta y en un momento determinado puede servir como nexo de unión y de interacción entre dos personas procedentes de países diferentes.

La televisión se mueve por intereses comerciales y este hecho favorece la propagación de valores e imágenes simplificadoras de conflictos o grupos humanos minoritarios o conflictivos. Esta reducción cognitiva beneficia la creación de estereotipos en los individuos, que influirán posteriormente a la hora de interactuar. Los niños, al estar dotados de menos estrategias de análisis, serán los primeros en captar todo este "goteo" de mensajes televisivos.

Un ejemplo de lo que venimos diciendo, se produce con la imagen sobre la mujer que transmite la televisión. A pesar de que la televisión actualmente refleja un estilo de mujer con vida activa dentro la sociedad, sigue siendo desigual cuando se trata de asociar el sexo con imágenes de poder. Tradicionalmente, la imagen que este medio daba de la mujer era de una persona poco independiente, asociada a la crianza de los hijos y de la casa. Actualmente se ha desarrollado un nuevo retrato de "supermujer", atractiva, capaz de simultanear sus tareas tradicionales con un desempeño profesional brillante (Rodrigo 1999, 257).

Algunos datos de investigaciones realizadas sobre la relación entre horas de televisión vistas por el niño y las conductas que demuestran a la hora de interactuar con mujeres reflejan los siguientes resultados (Harris, 1989): 
- Cuantas más horas de televisión vean más actitudes rígidas manifiestan con las compañeras de este género a la hora de interactuar socialmente.

- $\quad$ Niños que vivieron sin televisión en pueblos hasta la mitad de los años sesenta, manifestaron menor rigidez en la concepción de los roles de género.

- Los jóvenes menos tradicionales en su desempeño profesional son más sensibles y críticos a los estereotipos de género que muestra la televisión.

No conocemos investigaciones que relacionen horas de televisión vistas por el niño y estereotipos desarrollados en relación a la diversidad étnica, pero los estudios de género nos avisan de que existe cierta relación entre ambas variables. Es decir, los mensajes que ofrece la televisión son permeables en las mentes de los escolares y a su vez se manifiestan en las interacciones sociales entre iguales. Estas manifestaciones se traducen mostrando comportamientos más rígidos y estereotipados hacia el concepto de mujer. La misma influencia podemos pensar que ocurra respecto a los temas étnicos.

\section{3.- Contexto escolar y comportamiento social}

El contexto escolar está influido por una gran cantidad de aspectos sociales que la rodean: familia, medios, políticas educativas y sociales. En este sentido, podemos decir que los profesores, así como los escolares, también son "prisioneros" de estas redes influyentes en el contexto escolar (Rodrigo 1999).

Existen distintos enfoques que estudian el contexto escolar. Las visiones burocráticas y formalistas de un inicio dieron paso a la investigación socio-ecológica que apuesta por una concepción construida de la escolaridad, activamente negociada entre profesores y alumnos (Rodrigo 1999,194). Estos procedimientos de estudio ofrecen modelos dinámicos con los que obtener una visión compleja del entorno educativo y su influencia en el desarrollo y aprendizaje.

Encontramos una gran variedad de planteamientos metodológicos con los que la literatura se ha acercado al fenómeno del desarrollo del individuo en el contexto escolar (Anderson,1985; Vygostky,1986). Esto nos evidencia la importante incidencia de este contexto en el desarrollo del niño.

Es imposible negar la cantidad inagotable de experiencias sociales con las que el escolar irá desarrollando su competencia social dentro del contexto escolar. Están conviviendo con otros compañeros durante muchas horas al día, viendo otras realidades sociales a las que han vivido en el contexto familiar. Además, el proceso de enseñanza-aprendizaje se desenvuelve mediante relaciones interpersonales y éstas tienen lugar en un contexto socialmente organizado. 
La escuela no es sólo un lugar donde aprender conocimientos conceptuales, sino que tiene una función socializadora que pretendemos resaltar en este epígrafe. Son diversos los estudios que han mostrado la importancia del currículum implícito (Hamilton, Dugan y Troiler, 1985).

Los hallazgos de los estudios referidos a la influencia del contexto escolar en el desarrollo de la competencia social y de las interacciones sociales (Báez y Bethencourt, 1992) nos ofrecen una visión del alumno menos pasiva que la tradicional figura del estudiante, ya que en la primera edad el propio escolar va construyendo de forma activa y con ayuda del profesor sus aprendizajes. En definitiva, al dejar de considerar a los alumnos como meros receptores pasivos de enseñanza, admitimos que las interacciones sociales pueden influir sobre la instrucción y sus resultados tanto como puede hacerlo el propio profesor (Weinstein y Middlestad, 1979 y Hallinan, 1987).

Otra aportación a tener en cuenta consiste en reconocer que la interacción entre iguales es, numéricamente, la fuente de influencia más importante en la infancia. Según va creciendo el niño, la presión grupal puede influir sobre su comportamiento y desarrollo social en mayor medida que el ambiente familiar incluso (Rodrigo, 1999).

Las investigaciones de Báez y Bethencourt (1992) han identificado los efectos de la influencia escolar sobre el desarrollo de los iguales y el proceso de socialización. He aquí, algunos de esos efectos:

- Adquisición de valores, actitudes, competencias y destrezas sociales.

- Valor predictivo sobre la futura salud psicológica.

- Identidad sexual.

- Adopción de la perspectiva del otro, facilitando la superación del egocentrismo.

- Habilidades lingüísticas e intelectuales.

- Aspiraciones educativas y rendimiento académico, etc.

Los efectos que tienen que ver con la adquisición de valores y la adopción de perspectiva del otro, se relacionan directamente con las habilidades para interaccionar con compañeros procedentes de otros países y étnias. El contexto escolar, así como el social, se caracteriza por ser cada vez más diverso, las interacciones competentes con compañeros de otras procedencias es otro aprendizaje al que se enfrentan los escolares y es en el que nos centramos en esta tesis doctoral. 
Una de las aproximaciones metodológicas del análisis de las relaciones sociales, que cuenta con una larga trayectoria, es la sociometría (Cubero y Moreno, 1990; Díaz Aguado, 1986; Justicia, 1986). El valor probado de los datos que ofrecen estas técnicas, nos ha animado a utilizarlas en nuestro trabajo. Algunas aportaciones interesantes de estos procedimientos que conviene revisar a nivel teórico son los siguientes:

- Se han identificado cinco grupos sociométricos claros: alumnos populares, rechazados, ignorados, controvertidos y promedios.

- La sociometría trabaja fundamentalmente con cuatro factores (el saber, la sociabilidad, la agresión y el aislamiento) y éstos han demostrado tener una buena estabilidad y consistencia interna.

- El estatus sociométrico correlaciona de forma clara con rendimiento académico, adaptación emocional y conocimiento social.

- A medida que avanza la escolaridad, los grupos de iguales dejan de tener estructuras inestables y desordenadas de comportamiento social para mostrar cada vez más integración social y menos egocentrismo.

- Los tipos sociométricos, sobre todo los rechazados, manifiestan estabilidad a lo largo de toda la escolaridad.

- Mientras que, al inicio de la escolaridad, la popularidad se relaciona directamente con la adaptación escolar (éxito académico, conformidad, buena conducta, etc.), posteriormente las elecciones sociales de los iguales dejan de coincidir con la estimación del profesor, adquiriendo las relaciones interpersonales y la vida grupal más peso.

- Existen diferencias sexuales. Los niños se agrupan por un lado, mientras que el sexo contrario lo hace por otro.

Existen estudios (Neecomb, Bukowski y Pattee, 1993), que han aplicado y relacionado los tipos sociométricos con diferentes tipos de comportamiento social (agresión, aislamiento, sociabilidad y capacidades cognitivas): Sin embargo, no hemos encontrado ninguna investigación que aplique, de forma directa, estos tipos sociométricos a los alumnos con diferentes procedencias culturales.

Uno de los objetivos del primer estudio cuantitativo que realizamos en esta tesis doctoral y que exponemos en el capítulo que aparece a continuación, consiste precisamente en evaluar, a través del procedimiento sociométrico, la relación existente entre los tipos sociométricos enunciados (populares, rechazados, ignorados y medios) y las diferentes étnias (gitanos/payos, españoles/inmigrantes $y$, dentro de los 
inmigrantes, las procedencias concretas de diferentes países. Para poder responder a la pregunta: ¿qué estatus social ocupa cada una de las étnias existentes en los centros educativos? A su vez, esto nos ayudaría a complementar los datos obtenidos con la evaluación realizada en este mismo estudio sobre el prejuicio de los escolares hacia compañeros de otras procedencias culturales. Este capítulo será el que desarrollaremos a continuación.

Este capítulo es el tercero y último del primer bloque, correspondiente con el marco teórico de la presente tesis doctoral. Con él hemos pretendido acercar al lector los presupuestos teóricos que vamos a manejar en la investigación empírica que viene a continuación. Supone un nivel más de aproximación (respecto a los dos capítulos anteriores), hacia los pilares que vertebran el trabajo empírico del proyecto doctoral.

Empezábamos mediante la conceptualización de las interacciones sociales, ubicándolas como un componente necesario para el desarrollo de la competencia social y por ende, de la integración escolar, así como de las características, las variables y un modelo explicativo de las habilidades sociales. En tercer lugar, justificábamos la importancia de desarrollar esta competencia en los escolares. Continuábamos describiendo las características y evolución de las interacciones sociales en la edad escolar. Y en el último apartado, lo dedicamos a explicar la influencia de los contextos (familiar, social y escolar) en el desarrollo del niño. Dedicamos especial atención, dentro de este último apartado, a las interacciones sociales dentro de este contexto escolar. Todo ello nos acerca al bloque segundo donde exponemos el trabajo de investigación. 


\section{Capítulo 4}

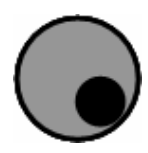

\section{Metodología de la investigación}

El propósito de este capítulo es describir tanto el planteamiento metodológico utilizado en la investigación, como los objetivos o interrogantes generales que nos plateamos al realizar esta tesis doctoral. Estos son redactados en el primer apartado del capítulo y en la tabla 4.1.Podemos estructurar la investigación en torno a dos fases diferenciadas. Cada una de ellas se corresponde con dos estudios. En el primero ofrecemos una visión extensiva y cuantitativa sobre el prejuicio y las relaciones sociométricas en el alumnado de $5^{\circ}$ de primaria de los colegios de Valladolid y en el segundo, realizamos un estudio etnográfico, mediante el seguimiento intensivo de tres alumnos inmigrantes recién llegados a la escuela. 


\section{Planteamiento de la investigación}

El objetivo general que nos planteamos al realizar esta tesis doctoral fue: conocer la situación prejuiciosa y las relaciones sociométricas existentes entre el alumnado de $5^{\circ}$ de primaria y en una segunda fase, analizar el proceso de socialización e integración escolar en el alumnado inmigrante nuevo de este mismo curso. Queríamos responder las siguientes preguntas:

- ¿Existe prejuicio a la hora de establecer relaciones sociales entre los escolares?

- ¿Podemos explicar de alguna manera por qué se produce el prejuicio en este contexto? (Relación de la variable prejuicio con factores socio-demográficos y de integración escolar)

- ¿Qué valoración sociométrica recibe el alumnado evaluado: "buenas", "malas" o "regulares"?

- ¿Qué valoración sociométrica reciben los diferentes colectivos étnicos?

- ¿Qué valoración sociométrica reciben las diferentes procedencias?

- ¿Qué grupo sociométrico tiene más prejuicio; los "populares", los "rechazados", los "ignorados" o los "medios"?

- ¿Cómo son las interacciones sociales entre los iguales y cómo éstas afectan en el proceso de integración escolar?

- ¿Se pueden reconocer fases comunes por las que pasan los diferentes niños y niñas inmigrantes en su proceso de integración?

- ¿Existen factores facilitan este proceso y cuáles lo dificultan?

- ¿Existen choques culturales se observan en este alumnado al acceder a nuestra cultura escolar?

- ¿Podemos explicar cómo se produce la exclusión social en el alumnado?

Debido a la naturaleza de estas cuestiones y a la decisión de estudiar el fenómeno relacional desde dos enfoques complementarios, decidimos indagar en diferentes líneas, de ahí la razón de realizar dos estudios diferenciados, que constituyen las dos fases de la investigación. Las seis primeras preguntas las respondemos a través del primer estudio extensivo y cuantitativo, las cinco últimas mediante la etnografía escolar realizada en segundo lugar.

A continuación incluimos una tabla donde aparecen los objetivos generales de la investigación en forma de interrogante. 


\begin{tabular}{|c|c|c|}
\hline \multirow{2}{*}{\multicolumn{3}{|c|}{$\begin{array}{l}\text { SITUACIÓN DE LAS INTERACCIONES SOCIALES ENTRE IGUALES Y EL PROCESO DE SOCIALIZACIÓIN E INTEGRACIÓN } \\
\text { ESCOLAR DEL ALUMNADO INMIGRANTE } \\
\text { PREGUNTAS/OBJETIVOS GENERALES DE LA INVESTIGACIÓN Y LA UBICACIÓN DE LAS RESPUESTAS EN LA TESIS } \\
\text { DOCTORAL }\end{array}$}} \\
\hline & & \\
\hline INTERROGANTES/OBJETIVOS & $\begin{array}{c}\text { ESTUDIO REALIZADO PARA DAR } \\
\text { RESPUESTA A LOS } \\
\text { INTERROGANTES }\end{array}$ & UBICACIÓN EN LA TESIS DOCTORAL \\
\hline \multicolumn{3}{|c|}{ SITUACIÓN DE LAS INTERACCIONES SOCIALES ENTRE IGUALES } \\
\hline $\begin{array}{l}\text { ¿Existe prejuicio a la hora de establecer } \\
\text { relaciones sociales entre los escolares? }\end{array}$ & \multirow{6}{*}{$\begin{array}{l}\text { ESTUDIO EXTENSIVO/CUANTITATIVO } \\
\text { (Primer estudio de la investigación: } \\
\text { descriptivo y observacional) } \\
\text { (Duración: curso 2004/2005) }\end{array}$} & \multirow{6}{*}{$\begin{array}{l}\text { Capítulo 5: } \\
\text { Estudio extensivo sobre el prejuicio y las } \\
\text { relaciones sociométricas en el alumnado } \\
\text { de } 5^{\circ} \text { de primaria de la ciudad de } \\
\text { Valladolid }\end{array}$} \\
\hline $\begin{array}{l}\text { ¿Podemos explicar de alguna manera por } \\
\text { qué se produce el prejuicio en este } \\
\text { contexto? (Correlación de la variable } \\
\text { prejuicio con factores socio-demográficos } \\
\text { y de integración escolar) }\end{array}$ & & \\
\hline $\begin{array}{l}\text { ¿Qué valoración sociométrica recibe el } \\
\text { alumnado evaluado: "buenas", "malas" o } \\
\text { "regulares"? }\end{array}$ & & \\
\hline $\begin{array}{l}\text { ¿Qué valoración sociométrica reciben los } \\
\text { diferentes colectivos étnicos? }\end{array}$ & & \\
\hline $\begin{array}{l}\text { ¿Qué valoración sociométrica reciben las } \\
\text { diferentes procedencias? }\end{array}$ & & \\
\hline $\begin{array}{l}\text { ¿Qué grupo sociométrico tiene más } \\
\text { prejuicio: los "populares", los } \\
\text { "rechazados", los "ignorados" o los } \\
\text { "medios"? }\end{array}$ & & \\
\hline \multicolumn{3}{|c|}{ PROCESO DE SOCIALIZACIÓIN E INTEGRACIÓN ESCOLAR DEL ALUMNADO INMIGRANTE } \\
\hline $\begin{array}{l}\text { ¿Cómo son las interacciones sociales } \\
\text { entre los iguales y cómo estas afectan en } \\
\text { el proceso de integración escolar? }\end{array}$ & \multirow{5}{*}{$\begin{array}{l}\text { ESTUDIO ETNOGRÁFICO } \\
\text { (Segundo estudio de la investigación: } \\
\text { cualitativo/etnográfico) } \\
\text { (Duración: curso 2005/2007) }\end{array}$} & $\begin{array}{l}\text { INFORME FINAL } \\
\text { Capítulo 8: Situaciones escolares sin la } \\
\text { presencia del adulto } \\
\text { Capítulo 9: Situaciones escolares con la } \\
\text { presencia del adulto }\end{array}$ \\
\hline $\begin{array}{c}\text { ¿Cómo se desarrolla el proceso de } \\
\text { integración de los escolares inmigrantes } \\
\text { nuevos? }\end{array}$ & & $\begin{array}{l}\text { INFORME FINAL } \\
\text { Capítulo 10: Fases comunes en el } \\
\text { proceso de integración del alumnado } \\
\text { inmigrante nuevo }\end{array}$ \\
\hline $\begin{array}{l}\text { ¿Existen factores facilitan este proceso y } \\
\text { cuáles lo dificultan? }\end{array}$ & & $\begin{array}{l}\text { INFORME FINAL } \\
\text { Capítulo 10: Aportaciones finales }\end{array}$ \\
\hline $\begin{array}{c}\text { ¿Exsiten choques culturales se observan } \\
\text { en este alumnado al acceder a nuestra } \\
\text { cultura escolar? }\end{array}$ & & $\begin{array}{l}\text { INFORME FINAL } \\
\text { Capítulo 10: Aportaciones finales }\end{array}$ \\
\hline $\begin{array}{l}\text { ¿Cómo podemos saber si un alumno sufre } \\
\text { exclusión por parte de sus compañeros? }\end{array}$ & & $\begin{array}{l}\text { INFORME FINAL } \\
\text { Capítulo 10: Aportaciones finales }\end{array}$ \\
\hline
\end{tabular}

Tabla 4.1. Preguntas / objetivos generales de la investigación y la ubicación de las respuestas en la tesis doctoral 
La tabla 4.1. nos muestra de forma visual cómo daremos respuesta a los once interrogantes generales planteados en la investigación y dónde ${ }^{1}$ encontrar sus respuestas argumentadas a lo largo de este capítulo.

La primera fase de la investigación se corresponde con un estudio extensivo, de carácter cuantitativo y con un corte descriptivo y observacional. En él, utilizamos una amplia muestra para responder a los seis primeras cuestiones, es decir, las referidas a la evaluación del prejuicio y las relaciones sociométricas del alumnado.

En un segundo momento, realizamos un análisis intensivo, a través de una etnografía escolar, realizada en un colegio donde existían, entre otros, tres alumnos inmigrantes nuevos, de diferentes procedencias, recién llegados al centro y que cursaban quinto curso. Realizamos un seguimiento, durante un año escolar, para estudiar el proceso de integración y de socialización del alumnado inmigrante nuevo de este mismo curso. A continuación, explicamos un poco más en detalle, las características de cada uno de los dos estudios, correspondientes a dos fases diferentes de la investigación.

A) Estudio extensivo sobre el prejuicio y las relaciones sociales en el alumnado inmigrante nuevo en el centro.

En primer lugar realizamos un estudio extensivo, con una muestra de 539 alumnos y alumnas de quinto curso de Primaria, pertenecientes a todos los colegios públicos de la ciudad de Valladolid. El objetivo que pretendíamos era conocer las interacciones sociales existentes entre los iguales en relación con el alumnado inmigrante nuevo en el colegio, mediante la medición del prejuicio manifestado por el alumnado y la valoración sociométrica otorgada a estos colectivos. Para este fin, utilizábamos diferentes pruebas de evaluación, por un lado, unas escalas de disposición conductual e identidad étnica, así valorábamos el prejuicio declarado por el alumnado, influyente en las interacciones sociales y por otro, unas técnicas sociométricas que reflejaban la valoración social recibida hacia el alumnado inmigrante.

Los resultados obtenidos a través de este estudio, nos aportaron los pilares básicos para comprender el fenómeno. Esta perspectiva inicial se refería a las siguientes temáticas:

\footnotetext{
${ }^{1}$ En el apartado de conclusiones ofrecemos nuestras explicaciones a estos interrogantes de forma concreta y resumida, pero es a lo largo del trabajo de campo de la tesis donde se pueden encontrar las argumentaciones de forma detallada. Es decir, desde el capítulo 5 al 10.
} 
- El nivel de prejuicio existente en el alumnado y a su relación con diferentes variables sociodemográficas (sexo, nivel socioeconómico del centro, etnia y procedencia), y otras variables de índole escolar (tiempo de escolarización, existencia de inmigrantes 0 no en el aula y adquisición del idioma).

- Las valoraciones sociométricas otorgadas por el alumnado entre sí, es decir, qué alumnos eran los rechazados, los preferidos, los que poseen mayor estatus social dentro del grupo, qué colectivos étnicos y procedencias culturales eran las preferidas por los iguales.

Toda esta información, obtenida a través de este primer estudio, nos ofrecía un primer acercamiento sobre la situación prejuiciosa y relacional del alumnado étnicamente diverso en los colegios de Valladolid.

Para conocer más en detalle el proceso de construcción de este fenómeno, vimos la necesidad de analizar más de cerca el proceso de integración del alumnado inmigrante, por ello, decidimos realizar un estudio cualitativo, a lo largo de un período largo de tiempo, en un solo centro educativo de educación primaria.

B) Estudio cualitativo sobre el proceso de integración escolar del alumnado inmigrante nuevo.

En segundo lugar, dentro de nuestro diseño de investigación, decidimos realizar una etnografía escolar. Teniendo en cuenta la compleja naturaleza de este fenómeno social, así como el carácter dinámico que define tanto a las interacciones sociales, como a la integración escolar, consideramos necesario realizar un estudio que nos permitiera observar el proceso a lo largo de un período de tiempo suficientemente significativo (un curso escolar). Escogimos para ello, a tres alumnos inmigrantes de quinto curso de primaria de un mismo centro escolar, significativos en nuestro planteamiento por acabar de llegar a España y en concreto, al colegio, y por no tener por tanto, ningún contacto previo con la cultura propia de nuestras escuelas.

Siendo conscientes de la aportación que cada una de las metodologías ofrecería al fenómeno, se formularon objetivos diferentes para cada fase 0 estudio de la investigación, mientras el primero nos ofrecía una relación entre variables y factores escolares en el contexto escolar étnicamente diverso, el segundo, nos describía el proceso de integración de tres alumnos inmigrantes nuevos en un mismo centro escolar.

Por lo tanto, el objetivo del estudio etnográfico, quedó formulado del siguiente modo: análisis del proceso de socialización e integración escolar de 


\section{tres alumnos inmigrantes recién llegados a España y nuevos en el centro escolar.}

La decisión estratégica utilizada para investigar el proceso de integración escolar del alumnado inmigrante, consistió en realizar un seguimiento intensivo durante la jornada escolar a tres alumnos inmigrantes nuevos, procedentes de distintos países. Se observaron diferentes espacios escolares (filas de entrada a las clases, recreo, pasillos, aulas ordinarias, aulas de apoyo). Cada uno de estos lugares, constituían micro-contextos donde se desarrollaban interacciones variadas en el alumnado, todas ellas, fueron la fuente de información, descriptiva y analítica, con la que elaboramos el informe final.

Las técnicas de evaluación utilizadas, a diferencia de las usadas en el estudio anterior, junto con los análisis de la información pertinente, nos sirvieron para extraer información sobre el proceso de integración de estos escolares.

A través de la observación emanada del campo, la información del alumnado y profesorado, obtenida en las entrevistas y en los resultados sociométricos y los relatos del diario personal realizado por uno de los alumnos inmigrantes, obtuvimos una descripción detallada sobre el proceso de integración escolar del alumnado inmigrante en este centro. Además, los temas que fueron emergiendo, nos permitieron extraer algunas aportaciones de interés para la práctica educativa. De este modo, obtuvimos:

- Unas etapas comunes en dicho proceso.

- Unos indicadores con los que valorar si el proceso educativo era favorable o no lo era.

- Los choques culturales sufridos por el alumnado inmigrante nuevo al acceder a la nueva cultura escolar.

- Algunas conductas y factores, extraídos de las interacciones sociales sucedidas en los iguales, que indicaban exclusión y marginación.

Con la intención de otorgar al lector una visión unificada del problema de investigación, exponemos en las páginas siguientes dos mapas conceptuales con sus consiguientes explicaciones. 


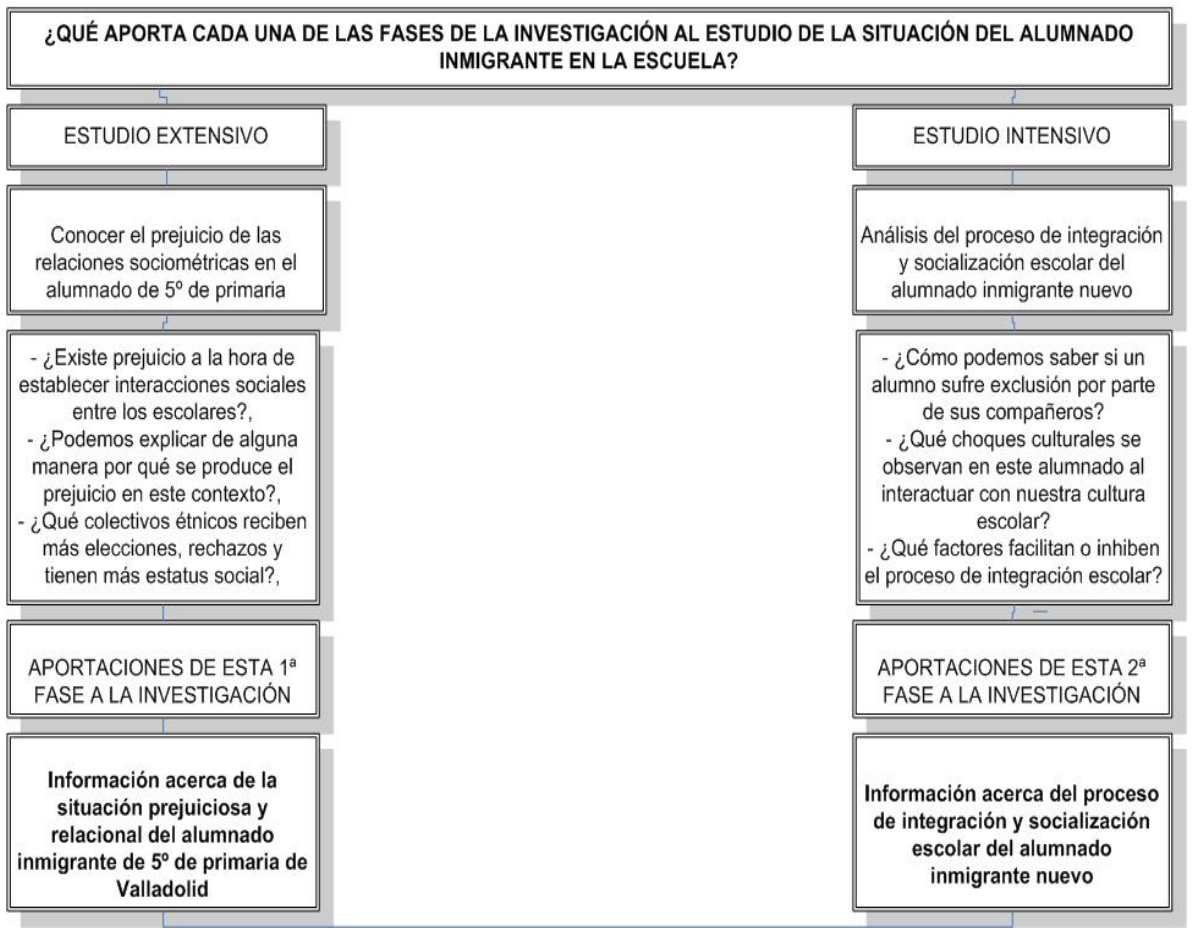

Figura 4.1. Aportaciones de las fases y de los dos estudios a la investigación

En el mapa que acabamos de visualizar, aparecen dos cuadros finales, con las letras en negrita, donde explicamos las aportaciones de cada una de las fases a la investigación. Cada uno de los estudios pretende dar respuesta a unos objetivos determinados y ambos conforman una visión general sobre la situación escolar del alumnado inmigrante desde el punto de vista de las relaciones entre los pares. De este modo, obtenemos información relativa al prejuicio y a la valoración sociométrica del alumnado de $5^{\circ}$ de Primaria de la ciudad de Valladolid, y por otro, en la segunda fase, adquirimos una visión analítica y de proceso sobre la integración escolar del alumnado inmigrante cuando accede por primera vez a la cultura escolar.

Como se puede comprobar, cada estudio requiere un planteamiento metodológico diferente, y por tanto, una formulación específica en cuanto a sus objetivos se refiere. Dado que estamos explicando el diseño general de la metodología de la investigación, adjuntamos a continuación, otro mapa conceptual (figura 4.2), en el que reflejamos las diferencias metodológicas exigidas por cada uno de los estudios. 


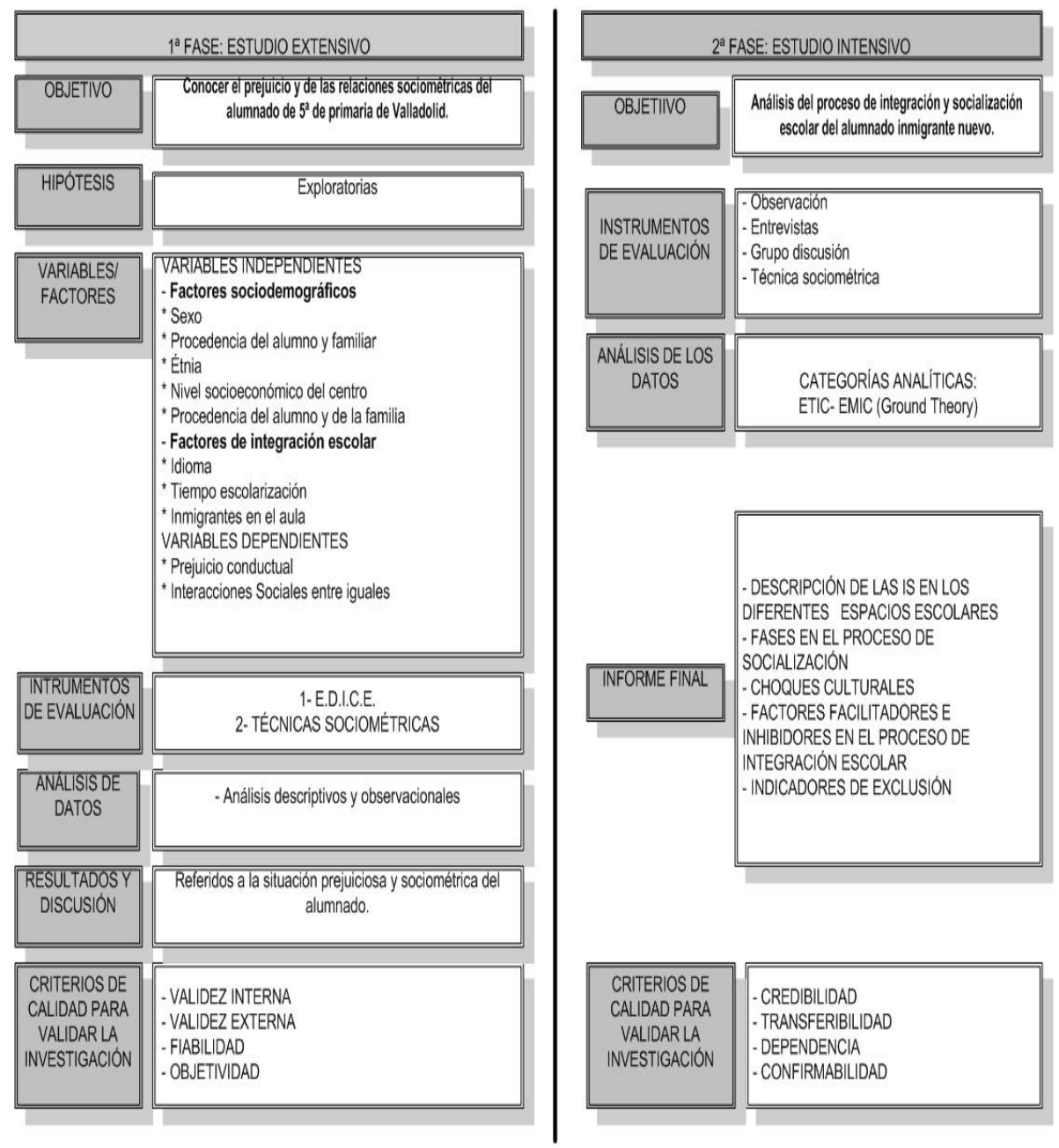

Figura 4.2. Estructura metodológica de la investigación: diferencias en cada uno de los estudios

En el cuadro que acabamos de ver, incluimos el diseño general de cada estudio. Cada uno de ellos tiene un propósito diferente, y se explicitan en los dos objetivos formulados, a pesar de las diferentes intencionalidades de cada uno, ambos intentan dar respuesta a la situación relacional y de integración del alumnado inmigrante en los colegios de Valladolid.

Veíamos en la figura 4.2, que tanto las técnicas de recogida de información, como el análisis de los datos obtenidos, difieren tanto en su enfoque, como en su aplicación. Los primeros tienen que ver con una valoración final (escalas y 
sociometría), mientras que los segundos analizan el proceso (observación, entrevistas, diario personal, grupo de discusión). Quizá la diferencia más notable sea la referida al planteamiento de las hipótesis iniciales. En el primer estudio, partimos de unos factores previos, extraídos de la literatura, éstos serán relacionados con las variables, para obtener la significación de tales correlaciones. En el segundo estudio, sin embargo, no partimos de planteamientos iniciales concretos ${ }^{2}$, sino que llegamos al campo, con la mente abierta y permeable a las nuevas aportaciones que puedan surgir.

Las dos fases de la investigación serán expuestas en los capítulos sucesivos. En el capítulo quinto, exponemos el estudio extensivo sobre el prejuicio y las relaciones sociométricas en el alumnado de quinto de Primaria de Valladolid. En él exponemos los objetivos, las hipótesis, las variables e instrumentos de evaluación utilizados, los resultados obtenidos, la discusión de los datos y las principales conclusiones de esta primera fase de la investigación.

En el sexto capítulo, desarrollamos el planteamiento metodológico del segundo estudio cualitativo, que se corresponde con una etnografía escolar. Explicamos el proceso seguido en la investigación, los instrumentos de evaluación utilizados, el análisis de los datos mediante la ejemplificación y los criterios de validación del estudio.

Los resultados obtenidos mediante el trabajo de campo del estudio de caso, los desarrollamos en el informe final, explicado en los cuatro capítulos siguientes, es decir, del capítulo séptimo, hasta el décimo. La razón de este desglose se debe a que la extensión de la información producida, entorpecía la lectura y claridad de las ideas expuestas en él.

En este capítulo hemos descrito el planteamiento de la investigación, así como la articulación de los dos enfoques utilizados en cada uno de los estudios realizados. Todo ello, pretende ofrecer una visión complementaria del fenómeno de la integración escolar en el alumnado inmigrante

\footnotetext{
2 No queremos decir con esto, que nos hayamos acercado al campo con la mente en blanco, y menos habiendo realizado un estudio extensivo previo, sino que, a partir de nuestra entrada en la escuela, fueron emergiendo temas de interés con los que inicialmente no contábamos. Esto se refleja a través de la elaboración de categorías de diferente índole (etic y emic) detalladas en el capítulo 6.
} 


\section{Capítulo 5}

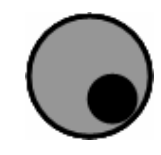

\section{Estudio extensivo/cuantitativo sobre el prejuicio y las relaciones sociométricas en el alumnado de quinto de primaria de los colegios públicos de Valladolid}

El presente capítulo muestra un estudio extensivo sobre el prejuicio y las relaciones sociométricas de los escolares hacia etnias diferentes a la propia en todos los colegios públicos de la ciudad de Valladolid. Para ello evaluamos estas dos variables ("prejuicio" y "relaciones sociales entre iguales"), con dos instrumentos que nos permiten acceder a un alto número de muestra, nos referimos a la Escala de disposición conductual e Identidad étnica (E.D.I.C.E.), (Díaz Aguado,1992) y tres técnicas sociométricas; Sociometría, Adivina Quién y Ranking (Díaz Aguado, 1993). Mediante los análisis estadísticos oportunos relacionamos, las variables anteriormente mencionadas, con los factores sociodemográficos siguientes; la "etnia", la "procedencia del alumnado y de la familia", el "género" y el "nivel socioeconómico del colegio" y los factores relacionados con la integración escolar; el "tiempo de escolarización", la "adquisición del idioma español" y la "convivencia con compañeros de otras etnias en la clase". A partir de estos análisis descriptivos ofrecemos unos resultados y una discusión de los mismos, fundamentados bibliográficamente. A través de este procedimiento intentamos describir las relaciones del alumnado inmigrante y el posible prejuicio existente hacia ellos en los centros de educación primaria de Valladolid. 


\section{1.- Introducción: Metodología descriptiva y observacional}

En este capítulo describimos un estudio extensivo-cuantitativo acerca del prejuicio y de las relaciones sociométricas entre iguales en contextos educativos étnicamente diversos. La metodología responde a un modelo descriptivo-observacional. Se pretende reflejar una radiografía general del fenómeno en los colegios públicos de la ciudad de Valladolid.

Elegimos el curso de $5^{0}$ de primaria ${ }^{1}$ utilizamos diversos instrumentos con los que alcanzar a una amplia muestra: escalas y técnicas sociométricas. Las variables "prejuicio" o también llamado por la autora del instrumento "disposición conductual a compartir experiencias con alumnos de otras etnias" y la variable "interacciones o relaciones sociales entre iguales" se cruzan con distintos factores sociodemográficos y de integración escolar como son el "sexo", la "etnia", la "procedencia del alumno", "procedencia familiar," el nivel socio económico del centro escolar", la "existencia de inmigrantes en el grupo escolar de referencia", la "adquisición de idioma" y el "tiempo de escolarización".

Este capítulo sigue el siguiente guión: en primer lugar, explicitamos los objetivos generales y específicos para entender las líneas básicas que sustentarán el estudio, describimos a continuación el diseño realizado en la investigación, el procedimiento seguido, enumeramos las variables dependientes e independientes que vertebran los ejes temáticos y desarrollamos los análisis estadísticos llevados a cabo, posteriormente presentamos los resultados, la comprobación de las hipótesis y la discusión de los datos.

\section{2. - Objetivos}

Como decíamos, el presente estudio realiza un análisis exploratorio acerca de las relaciones sociométricas y el prejuicio entre los alumnos de $5^{\circ}$ de primaria de los centros públicos de la ciudad de Valladolid. Podemos establecer dos categorías de análisis: una que tiene que ver con el prejuicio, evaluado con las escalas, y otra relacionada con las interacciones o relaciones sociales entre iguales, evaluada a través de las técnicas sociométricas. A continuación numeramos los objetivos de la investigación.

\footnotetext{
${ }^{1}$ Las razones por las que seleccionamos este nivel educativo se encuentran en la edad psicológica y madurativa que poseen estos alumnos en $5^{\circ}$ curso. A los 10 años, el niño manifiesta más estabilidad en las creencias y estereotipos adquiridos a través de la socialización primaria o familiar y secundaria o social que los alumnos de edades inferiores. (Aboud, 1995).
} 
- Objetivo general:

- Evaluar el prejuicio y las relaciones sociométricas en los alumnos de $5^{0}$ de primaria de los colegios públicos de la ciudad de Valladolid.

\section{- Objetivos específicos:}

- Relacionados con el prejuicio:

o Evaluar el prejuicio hacia los alumnos pertenecientes a otro colectivo étnico diferente al propio.

- Evaluar la relación existente entre el prejuicio y algunos factores sociodemográficos, como el "género", el "nivel socio económico del centro", la "etnia", la "procedencia del alumno y la familiar".

o Evaluar la relación existente entre el prejuicio y algunos factores relacionados con la integración escolar como, el "tiempo de escolarización", la "existencia o no de inmigrantes en el aula", la "adquisición del idioma".

- Relacionados con las relaciones sociométricas del alumnado de $5^{0}$ de primaria de los colegios públicos de Valladolid:

- Conocer la valoración social de los grupos de $5^{0}$ de primaria, otorgada por el alumnado entre sí ("buena", "mala" o "regular").

- Evaluar la relación existente entre los grupos sociométricos a los que pertenece el alumnado y los siguientes factores: la "etnia", la "procedencia del alumno", el "tiempo de escolarización" y el "prejuicio".

A través de la investigación empírica, se persigue la obtención de un marco general que arroje luz sobre las especifidades y circunstancias concretas con las que se encuentran los alumnos inmigrantes en el contexto escolar. Mediante este estudio, de carácter fundamentalmente exploratorio, se pretende abrir una vía para una posterior investigación de carácter cualitativo, que ahonde en aquellos aspectos relevantes, explicativos del proceso de la integración escolar del alumnado inmigrante.

\section{3.- Planteamiento y diseño de investigación}

En este apartado vamos describir los siguientes epígrafes: la muestra, las variables e instrumentos de medida, las hipótesis del estudio, el diseño del estudio y el procedimiento.

\section{1.- Muestra}

La muestra estuvo formada por 539 participantes, alumnos que cursaban $5^{\circ}$ de Primaria en colegios públicos de la ciudad de Valladolid. Las edades de los alumnos se 
corresponden con el curso académico al que pertenecen, es decir entre 10 y 11 años. La razón por la que elegimos este curso académico tiene que ver con los procesos de socialización producidos en estas edades. Ya se han establecido los primeros patrones sociales y estereotipos respecto a la diversidad étnica y por tanto, es un buen momento para evaluarlo.

Los 539 alumnos están escolarizados en los 31 C.E.I.P. de Valladolid, de los 40 totales que existen en dicha ciudad. Este número se corresponde con la totalidad de los centros públicos de educación primaria que estuvieron dispuestos a que realizáramos la evaluación. Realizados los análisis de muestreo teórico vimos que las características de esos centros correspondían Los nueve centros restantes de la población total fueron evaluados a partir del censo general y no encontramos razones por las que su ausencia en nuestro estudio pudiera distorsionar los resultados del mismo. Las explicaciones que alegaron para no permitirnos realizar las pruebas a los alumnos estaban relacionadas con la reticencia a la llegada de psicólogos externos al centro. Parece ser que tenían miedo a recibir críticas por parte de las familias, si se enteraban que unos psicólogos habían estado evaluando a sus hijos. Por lo tanto, la población de este estudio, la constituyeron los 40 colegios públicos existentes en Valladolid y la muestra, los 31 que aceptaron, es decir, el $77,5 \%$ del total.

Estos 31 centros fueron divididos para su posterior análisis en dos niveles socio-económicos: "el medio" y "el bajo", siendo el segundo aquel que mayor número de alumnado con mayor desventaja social y económica tuvieran escolarizados. De este modo, 9 colegios se correspondían con estas características, es decir, el 29\% de los centros existentes en nuestra muestra. Los 22 restantes (el 71\%), pertenecían a un nivel socio-económico medio.

Si en vez de contabilizar los centros, tenemos en cuenta el número de alumnado, encontramos, que son 106 alumnos, de los 539 totales, los que están escolarizados en colegios clasificados como centros con bajo nivel socio económico, lo que corresponde al $19 \%$ del alumnado total de la muestra de $5^{\circ}$ de primaria, perteneciendo el resto del alumnado, al 80,3\%, es decir, 433 alumnos se encuentran escolarizados en centros clasificados como de nivel "socioeconómico medio".

Los 539 alumnos, tenían las siguientes características: 42 alumnos eran españoles gitanos, 452 españoles payos, 26 latinoamericanos, 10 de Europa del Este, 6 de Europa Central y 4 de países del Magreb. Es decir, 46 alumnos de los 539 son alumnos procedentes de otros países al español. 5 de los alumnos que faltan para llegar a los 539 totales fueron perdidos por el sistema. Esta pérdida se debe a que faltaban datos por rellenar en las pruebas. Los 5 pertenecía a la etnia gitana. A continuación representamos en una gráfica los datos característicos de la muestra. 


\begin{tabular}{|c|c|}
\hline SEXO & $\begin{array}{l}\text { NINOS }=295 \\
\text { NIÑAS }=244\end{array}$ \\
\hline PROCEDENCIA & $\begin{array}{l}\text { ESPANA }=493 \\
\text { INMIGRANTES }=46 \\
\text { Latinoamérica }=26 \quad \text { Europa Central }=6 \\
\text { Países árabes }=4 \quad \text { Europa del Este }=10\end{array}$ \\
\hline NIVEL SOCIO- ECONÓMICO & $\begin{array}{l}\text { Bajo }=106-19 \% \\
\text { Medio }=433-80,3 \%\end{array}$ \\
\hline COLECTIVO & $\begin{array}{l}\text { PAYOS }=446-83,5 \% \\
\text { GITANOS }=47-7,6 \% \\
\text { INMIGRANTES }=46-8,7 \%\end{array}$ \\
\hline TIEMPO ESCOLARIZACIÓN & $\begin{array}{l}1 \text { año: } 19-6,16 \% \\
1 \text { a } 3 \text { años: } 43 \text { - 13,96\% } \\
\text { Más de } 3 \text { años: } 246 \text { - 79,87\% } \\
\text { Perdidos por el sistema: } 231\end{array}$ \\
\hline INMIGRANTES EN EL AULA & $\begin{array}{l}\mathrm{NO}=493-91,5 \% \\
\mathrm{SI}=46-8,5 \%\end{array}$ \\
\hline DISCAPACIDAD & $\begin{array}{l}\text { No }=531-98,5 \% \\
\text { Si }=8-1,5 \%\end{array}$ \\
\hline TOTAL $=539$ & \\
\hline
\end{tabular}

\section{2. - Variables e instrumentos de medida}

Las variables que utilizamos en este estudio se dividen en cuatro bloques, los cuales se corresponden con las variables dependientes e independientes. En el cuadro que dibujamos a continuación aparecen enumeradas.

\begin{tabular}{|c|c|}
\hline Variables dependientes & Variables independientes \\
\hline 1'a - Componente conductual del prejuicio. & $\begin{array}{ll}3^{a} \text { - Factores socio - demográficos: } \\
0 & \text { Sexo } \\
0 & \text { Nivel Socio-Económico del centro } \\
0 & \text { Etnia } \\
0 & \text { Procedencia } \\
0 & \text { Procedencia familiar } \\
\text { (4- Factores de integración escolar: } \\
0 & \text { Tiempo de escolarización } \\
0 & \text { Existencia o no de inmigrantes en el } \\
& \text { aula } \\
0 & \text { Adquisición del idioma }\end{array}$ \\
\hline
\end{tabular}

Tabla 5.2. Variables del estudio extensivo. 
Somos conscientes de que existen otras variables influyentes en las relaciones sociales escolares ("nivel académico", "estructura familiar", "rasgos físicos", "habilidades sociales del alumnado", etc). Debido a la imposibilidad de recoger más datos sociales ante el elevado número de muestra con el que contábamos, decidimos seleccionar aquellos factores que la literatura considera importantes, (Díaz Aguado,1996; Rodrigo, 1999; Corsaro,1985; Hartup, 1983). En la investigación cualitativa posterior, evaluamos más factores a los que no pudimos acceder en este momento.

\section{A- Variables e instrumentos relacionados con el prejuicio}

El término prejuicio hace referencia a una actitud de los miembros de un grupo generalmente mayoritario hacia los de otro grupo minoritario. Normalmente solemos entender este concepto como una expresión de actitudes negativas, pudiendo ser también positivas (Brown, 1998). Nosotros hablaremos de lo que comúnmente se entiende por prejuicio: actitud negativa injustificada hacia un individuo basada únicamente en su pertenencia a un grupo. (Worschel y otros, 1998,449). Suelen distinguirse tres componentes en su estudio (Asmore, 1970; Pinillos, 1982; Rosenfield y Stephan, 1981):

Componente cognitivo o estereotipo, es el conjunto de creencias sobre los rasgos de los miembros de un grupo que se hacen explícitas a través de etiquetas verbales. El componente afectivo o evaluativo se refiere a la evaluación negativa de un grupo, junto con sentimientos de hostilidad hacia sus miembros (es el componente fundamental del prejuicio). El componente conductual está constituido por una intencionalidad de conducta negativa y/o una tendencia a conductas hostiles (discriminación) y de marginación hacia los miembros del grupo. Este último será el que evaluaremos en nuestro estudio.

Para evaluar el componente conductual del prejuicio suelen emplearse escalas de tipo Likert en las que se pregunta por la disposición a participar en diversas actividades con miembros del otro grupo étnico (Katz y Rosenberg,1978; Rosenfield y Stephan,1981; Schwarzwal y Cohen, 1982; Amir y Sarna,1984). La selección de las actividades por las que se pregunta suelen realizarse teniendo en cuenta su relevancia en las relaciones interpersonales de la población estudiada, así como la conveniencia de incluir actividades tanto de nivel de intimidad moderado (sentarse al lado) como de nivel de intimidad alto (visitar la casa).

Nosotros utilizamos la escala E.D.I.C.E. (Díaz Aguado y Martínez Arias,1991) que consta de 13 ítems que pretenden evaluar la disposición para interactuar en actividades, junto con miembros del otro grupo étnico. La escala es de tipo Likert, con cuatro grados expresados verbalmente (MUCHO, POCO, BASTANTE, NADA). De los 
13 ítems que forman la escala de disposición conductual pueden diferenciarse dos niveles: a) los que implican compromiso interpersonal moderado (elementos 2,3,4,6,7 y 9); b) los que implican un alto grado de compromiso interpersonal (elementos 1,5,8 y 10).

Por último, mencionamos la consistencia interna global de la escala de la autora que es $\&=0.8951$ y la nuestra que es de $\&=0.8846$. Estamos hablando de una consistencia alta en ambos casos, la cual nos permite fiarnos de los datos obtenidos.

\section{B- Variables e instrumentos relacionados con las relaciones sociales entre iguales}

Las relaciones sociales son los lazos que unen a los miembros de un grupo, pueden ser: activas, pasivas, recíprocas, horizontales y verticales. La mayoría de autores que en sus estudios han tratado el tema de las relaciones sociales en escolares lo han hecho para investigar problemas relacionados con la inadaptación escolar Kohn, (1977), el abandono de la escuela (Kuperstmidt, 1983, Parker y Asher, 1987), la delincuencia (Roff, 1972) o más recientemente han surgido muchos estudios que también tratan las relaciones sociales para solucionar problemas de violencia escolar (García-Bacete, Lara Carrión, Monjas y Casares, 2005; Díaz Aguado,1999; Fernández Enguita, 1996, 2001). Nosotros, en nuestro estudio, como ya hemos comentado, analizamos las relaciones sociales entre alumnado étnicamente diverso para analizar cómo influyen en su proceso de integración escolar. Nos interesa saber cómo son estas relaciones y cómo influye el prejuicio para establecer dichas interacciones.

Las relaciones sociales son muy importantes en edades escolares. El mejor indicador en la niñez de la adaptación en la vida adulta, no son las notas escolares, ni el comportamiento en clase, sino la capacidad con la que este niño se relaciona con otros niños. Los niños que generalmente no son aceptados por otros niños, que son identificados como agresivos o destructores, que son incapaces de sostener una relación estrecha con otros niños y de ubicarse en la cultura a la que pertenecen sus demás compañeros corren serios riesgos.(Hartup, 1996). El rechazo en la escuela en estas edades es uno de los predictores de problemas muy graves de adaptación social en edades posteriores como son la inadaptación social (Kohn,1977), el abandono de la escuela (Kuperstmind, 1983; Parker y Asher, 1987), la delincuencia (Roff y Wirt, 1984); el suicidio (Stengle,1971); o la necesidad de recibir asistencia psiquiátrica en la edad adulta (Cowen et al., 1973).

El procedimiento más utilizado actualmente para evaluar las relaciones entre compañeros es la sociometría, que consiste en preguntar a todos los alumnos acerca del resto de los niños de clase. 
Estos instrumentos se utilizan para analizar la jerarquía de situación de los grupos (Hargreaves,1986). Es decir, se trata de una dimensión que intenta descubrir y describir cómo se distribuyen las preferencias dentro del grupo. Esta idea fue bautizada por Moreno en 1934 (Moreno,1965), quien inventó el método de la sociometría. Entre las ventajas de su utilización cabe destacar la facilidad de su aplicación y su alta validez, especialmente cuando se utilizan procedimientos múltiples como es el caso de nuestro estudio. Estas técnicas multivariadas están basadas en estudios previos sobre la interacción de compañeros (Díaz aguado, 1986,1988), en concreto fueron: las nominaciones, los atributos positivos y negativos y el estatus social. Veamos cada una de ellas.

Las nominaciones consisten en pedir que nombren a un número limitado de compañeros (en torno a tres), en función de la preferencia personal para realizar determinadas actividades básicas (jugar, estudiar...). Estas preguntas permiten determinar el número de elecciones y de rechazos recibidos y si existen agrupaciones étnicas dentro de las aulas

En concreto, los métodos sociométricos utilizados en este estudio, se basan en un enfoque múltiple diseñado en estudios sobre interacción entre compañeros (Díaz Aguado, 1986,1988). Consiste en pedir al alumnado que nombre a los tres niños 0 niñas con quien más y menos le gusta jugar con los siguientes procedimientos:

- Elecciones: número de veces que el alumno es nombrado en la pregunta: ¿Quiénes son los tres niños de tu clase con los que más te gusta jugar?

- Rechazos: número de veces que el alumno es nombrado en la pregunta: ¿Quiénes son los tres niños de tu clase con los que menos te gusta jugar?

Con el objeto de obtener información sobre la conducta tal como ésta es percibida por los compañeros, Hartshorne y May propusieron el método del "adivina quién". A partir de este procedimiento general, en las investigaciones anteriormente realizadas (Díaz Aguado,1986,1988) se seleccionaron los adjetivos más utilizados por los niños de los primeros cursos de escolaridad en la descripción de sus compañeros.

Este instrumento es el siguiente procedimiento utilizado en el estudio, el funcionamiento básico consiste en asociar diferentes atributos a cada uno de los compañeros. De este modo obtenemos información, tanto de la conducta percibida por los compañeros, como de las características en las que más destacan los niños populares y los niños rechazados. Además nos permite conocer la naturaleza de las relaciones sociales entre compañeros dentro de la cultura peculiar de cada aula. 
Pueden obtenerse dos índices globales de conducta percibida agrupando todas las nominaciones que cada niño recibe en los atributos de tipo positivo, por una parte, y negativo, por otra.

- Atributos positivos: número de veces que el niño es nombrado por sus compañeros en las categorías descriptivas de carácter positivo (el que tiene más amigos, al que más quiere el docente, el más alegre, el que más ayuda a los otros niños, el que más sabe).

- Atributos negativos: número de veces que el niño es nombrado por sus compañeros en las categorías descriptivas de carácter negativo (el que tiene menos amigos, al que menos quiere el docente, el menos alegre, el que menos ayuda a los otros niños, el que menos sabe).

La mejor evaluación del estatus social (nivel medio de popularidad) se obtiene a partir del método de las puntuaciones, también denominado ranking. Es la tercera prueba utilizada en nuestro estudio. Consiste en pedir a todos los alumnos que puntúen a cada uno de sus compañeros utilizando una escala de cinco grados (MUY BIEN, BIEN, REGULAR, MAL Y MUY MAL), contestando a la pregunta genérica: ¿cómo te cae?, seguida por los nombres de todos los niños de la clase. El estatus sociométrico de cada niño se calcula sumando todas las puntuaciones que recibe y dividiendo el resultado de dicha suma entre el número de compañeros totales que le han puntuado. Este procedimiento permite conocer la aceptación media obtenida por cada uno de los niños de la clase (acerca de cómo cae a los demás).

Al final de este capítulo adjuntamos los cuatro instrumentos originales de evaluación utilizados: escalas de prejuicio, sociometría, adivina quién y ranking.

\section{C.- Variables socio-demográficas}

Hemos incluido las variables referidas al género, nivel socio - económico del centro y etnia debido a la relevancia que a priori pensamos que pueden tener a la hora de asociarse con el prejuicio y las relaciones sociales. Existen autores que nos dicen que existen diferencias en función de estos factores.

Respecto al género, encontramos algunos estudios (Eagly, 1996 y Eagly y Word,1991), cuyos resultados nos decían que las mujeres tendían a manifestar comportamientos que podríamos denominar como más sensibles y amistosos hacia otros compañeros nuevos dentro de un contexto.

El nivel socio económico del centro fue otra variable que correlacionamos en nuestro estudio. Fue categorizada en torno a dos niveles: medio y bajo. El nivel alto fue desestimado por la inexistencia de colegios públicos de "élite" en la ciudad. El 
criterio con el que asignamos a los 31 colegios en cada una de estas categorías tuvo que ver con el siguiente argumento:

- Cuando el 70\% del alumnado escolarizado en el centro provenía de familias desfavorecidas socio-económicamente.

El colectivo étnico fue la tercera variable del estudio. El alumnado de la muestra fue clasificado como: "inmigrante", "gitano" y "payo".

Por otro lado, fueron utilizadas las variables: procedencia del alumno y procedencia familiar, como elementos de correlación. Los alumnos con los que contábamos provenían de los siguientes lugares: "Marruecos", "Latinoamérica" y "Europa del Este" y "Europa". Y las categorías establecidas dentro de las procedencias familiares, se refirieron a: "padres españoles", "padres inmigrantes" y "padres mixtos".

\section{escolar}

\section{D.- Variables e instrumentos relacionados con la integración}

El tiempo de escolarización, la sexta variable del estudio, nos permitía obtener información acerca de la siguiente relación: ¿se reduce el prejuicio al estar más tiempo en contacto con los compañeros? Estudios como los de Allport, (1954) nos explican con su conocida hipótesis del contacto, que al permanecer junto compañeros una larga temporada, se producen beneficios a la hora de compartir experiencias, reducir prejuicios y promover actitudes favorables.

La existencia de inmigrantes en el aula, viene a ser un factor relacionado con el anterior. La teoría psico-social mencionada anteriormente explicaría la influencia positiva de este factor en la integración escolar, si existe un contacto positivo entre grupos heterogéneos.

Respecto a la adquisición del idioma, es predecible pensar que, cuanto mayor sea el conocimiento de la lengua, existirán más posibilidades de contacto para poder interactuar con los iguales y de esta forma influir sobre la calidad de las relaciones sociales.

A continuación presentamos una tabla donde aparecen resumidas las variables dependientes del estudio así como los instrumentos utilizados para evaluar cada una de ellas. 


\begin{tabular}{|l|l|}
\hline \multicolumn{1}{|c|}{ Variables dependientes } & \multicolumn{1}{|c|}{ Instrumentos empleados } \\
\hline Componente conductual del prejuicio & $\begin{array}{l}\text { E.D.I.C.E. (Escala de Disposición Conductual e Identidad } \\
\text { Étnica) }\end{array}$ \\
\hline Interacciones Sociales entre iguales & TÉCNICAS SOCIOMÉTRICAS: \\
& - Sociometría \\
& - Adivina Quién \\
& - Ranking \\
\hline
\end{tabular}

Tabla 5.3. Variables dependientes e instrumentos utilizados en el estudio extensivo.

\section{3.- Hipótesis del estudio extensivo}

Aunque algunos autores cuestionan la posibilidad de plantear hipótesis en investigaciones exploratorias -dado que al tratarse de un objeto de estudio en principio desconocido por el investigador no podrían establecerse hipótesis (Sabino, 1996; Tamayo, 1998)-, otros autores clasifican a estas hipótesis como heurísticas, que están propuestas con el fin de encontrar algo nuevo o descubrir otras hipótesis más generales o sugestivas.

Las hipótesis planteadas en la investigación son de carácter exploratorio, buscan examinar y conocer relaciones y significaciones en base a los datos obtenidos.

Hipótesis 1. Existencia de prejuicio en los escolares de $5^{\circ}$ de primaria de los colegios públicos de Valladolid.

De acuerdo con los resultados obtenidos en investigaciones previas (Díaz Aguado,1992,1996,2000; Pettegrew y Meertens,1995) se espera tener un nivel medio de prejuicio, no demasiado pronunciada, pero tampoco inexistente, cuando se les pregunta por la disposición conductual a compartir experiencias con compañeros de otros colectivos étnicos. En concreto los resultados esperados son:

Hipótesis 1a. Los alumnos de $5^{\circ}$ de primaria de los colegios públicos de Valladolid manifiestan niveles medios de prejuicio cuando se les pregunta por la disposición a compartir experiencias con compañeros de otras etnias. Siendo tres los niveles clasificados de esta variable (alto, medio y bajo).

Hipótesis 2. Relación existente entre los factores sociodemográficos y escolares y el nivel de prejuicio en el alumnado. 
Esta hipótesis se plantea de una forma exploratoria. En concreto, dentro de las clasificaciones obtenidas en el alumnado respecto al nivel de prejuicio, se pretenden analizar los siguientes factores:

- Factores sociodemográficos: "etnia", "país de procedencia", "sexo", "tiempo de escolarización", "procedencia de los padres".

- Factores de escolares: "Tiempo de escolarización", "convivencia con alumnos de otras etnias en su grupo de clase", "adquisición de la lengua del país receptor".

Hipótesis 2a.- Evaluar el nivel de prejuicio que manifiestan los alumnos pertenecientes a diferentes colectivos étnicos, estando clasificados dentro de las categorías: inmigrante, payo y gitano.

Hipótesis 2b.- Evaluar el nivel de prejuicio que manifiestan los alumnos de diferentes países de procedencia, siendo éstas nacionalidades las siguientes: Español, Marroquí, Europa central, Europa del Este, Latinoamericano.

Hipótesis 2c.- Evaluar el nivel de prejuicio existente en función del género.

Hipótesis 2d.- Evaluar el nivel de prejuicio que manifiestan los alumnos en función del nivel socio-económico del centro en el que estén escolarizados, siendo medio y bajo las dos categorías establecidas.

Hipótesis 2.e.- Evaluar el nivel de prejuicio que manifiestan los alumnos en función de la procedencia familiar, siendo estas procedencias las siguientes: padres inmigrantes, padres españoles, padres mixtos y padres con hijos adoptados.

Hipótesis 2.f.- Evaluar el nivel de prejuicio que manifiestan los alumnos en función del tiempo de escolarización, estableciendo los tiempos del siguiente modo: menos de un año, entre uno y tres años y más de tres años.

Hipótesis 2.g.- Evaluar el nivel de prejuicio que manifiestan los alumnos en función de la convivencia en el aula cono otros alumnos inmigrantes, en función de la existencia o no de alumnos inmigrantes cada uno de los grupos de clase de $5^{\circ}$ de primaria.

Hipótesis 2.h.- Evaluar el nivel de prejuicio que manifiestan los alumnos en función de la adquisición o no de la lengua del país de recepción, en este caso la española.

Hipótesis 3.- ¿Cómo son las relaciones sociométricas entre iguales: "buenas", "regulares" o "malas"?.

Esta hipótesis también se formula de forma exploratoria ya que queremos conocer las correlaciones existentes entre los grupos sociométricos del alumnado y 
algunos factores como la etnia, la procedencia, el tiempo de escolarización y el prejuicio. En concreto las hipótesis planteadas son las siguientes: "media"?.

Hipótesis 3.a: ¿Qué etnia es la más "rechazada", "ignorada", "popular" o

Hipótesis 3.b.-¿Qué procedencia es la más "elegida", "rechazada", "ignorada" o "media"?.

Hipótesis 3.c.- ¿Quién pertenece a los "elegidos", los "rechazados", los "ignorados" o los "medios"; los alumnos que llevan más tiempo en el colegio, o los que llevan menos?

Hipótesis 3.d.- ¿Quién tiene más prejuicio, el grupo de alumnos perteneciente a los "elegidos", a los "rechazados", a los "ignorados" o a los "medios"?

\section{4. - Diseño}

El tipo de estudio realizado es de tipo selectivo, puesto que en este tipo de trabajos no existe una manipulación directa de las variables independientes. Teniendo en cuenta los objetivos y la naturaleza de las variables del estudio, el diseño utilizado es descriptivo observacional, lo que significa que se estudiará la asociación entre las distintas variables que forman parte del estudio. Este tipo de diseño es el más frecuente en la investigación de las relaciones interpersonales (Brehm, 1992).

Se pretende recoger una amplia muestra y extender la información obtenida respecto a este fenómeno. Para abarcar toda esta población se necesitan instrumentos de relativamente fácil aplicación. Decidimos utilizar unas escalas y unas técnicas ya elaboradas y validadas previamente por los autores. Estas son las siguientes:

- Escala de Disposición Conductual e Identidad Étnica (Díaz Aguado, 1991)

- Técnicas sociométricas: Sociometría. Adivina Quién y Ranking. (Díaz Aguado 1993)

Como ya hemos dicho, utilizamos un tipo de muestreo incidental ya que evaluamos todos los centros que nos permitieron la entrada. Fueron 31 centros de un total de 40 , es decir, la muestra que evaluamos, se corresponde a un $77,5 \%$ de la población total de centros educativos de la ciudad.

Así mismo, todas las variables son analizadas en un único momento temporal que coincide con el segundo trimestre del curso académico. La razón por la que decidimos realizar las pruebas una vez iniciado el curso académico, se debe a que las relaciones entre los iguales se crean durante los meses escolares iniciales, y una vez pasados unos meses, el alumnado ya puede formarse un juicio sobre el compañero. 


\section{5. - Procedimiento}

Antes de comenzar la evaluación, se realizó un estudio previo a través de los datos ofrecidos por la dirección provincial de Valladolid. Estos datos nos permitieron conocer las direcciones, el número de colectivos escolarizados en cada centro, las minorías existentes, el alumnado con discapacidad. A partir de ahí llamamos por teléfono a todos los colegios y se organizó una agenda para acudir personalmente al centro y pasar las pruebas a los escolares de $5^{\circ}$ de Primaria. Normalmente era el director el que se encargaba de que el alumnado y el profesorado estuviera preparado para contestar los cuestionarios. Previamente se les pedía a los docentes que tuvieran preparada la lista de los estudiantes de la clase y localizado el alumnado no español para conocer sus datos sociodemográficos. De los 40 centros existentes en Valladolid, sólo fueron 9 los que por razones diversas no permitieron que realizáramos pruebas psicológicas a sus estudiantes².

Una vez dentro de las aulas, explicábamos al alumnado en qué consistía la prueba, remarcábamos el anonimato de los resultados y explicábamos mediante la ejemplificación, como contestar cada una de las preguntas. Los escolares con discapacidad, eran ayudados por el tutor/a o por nosotros para que pudieran contestar las preguntas del cuestionario.

Sólo hubo dos niños de etnia gitana que no quisieron contestar estos test. No alegaron ninguna razón, simplemente se negaron. El resto del alumnado, lo rellenaron con bastante agrado, suponiendo para ellos un entretenimiento que rompía con la rutinaria jornada escolar.

Los profesores y tutores de cada clase estaban informados sobre la temática de la investigación y muchos de ellos se mostraron interesados en obtener los datos finales. Por lo tanto, se les prometió devolverles los resultados de las sociometrías por correo ordinario.

Los cuestionarios que contestaron los alumnos fueron los siguientes:

- Una escala - cuestionario tipo Liker que evaluaba la disposición conductual a estar con alumnos pertenecientes a otros colectivos (E.D.I.C.E.) ${ }^{3}$

- Una técnicas sociométricas formadas por: la sociometría, el adivina quién y el ranking. La sociometría pretende evaluar las elecciones y rechazos de los alumnos dentro de la clase. El adivina quién, los rasgos positivos y negativos

\footnotetext{
2 Los colegios que nos cerraron sus puertas, argumentaron al respecto, las siguientes razones: 1: "daban largas" cada vez que llamábamos, 2: mostraban recelo a que los psicólogos entraran al aula a evaluar a los alumnos.

3 Debido a la cantidad de veces que usamos esta variable decidimos simplificar su nominación y llamarla: prejuicio.
} 
que se atribuyen entre ellos. El ranking nos da una valoración general del estatus social que cada alumno ocupa en la clase.

Una vez obtenidos todos estos datos, realizamos una base de datos y procedimos a sus posteriores análisis estadísticos. Todo este proceso duró aproximadamente un curso académico (de finales de Octubre 2005 hasta Julio de 2006).

\section{6.- Análisis estadísticos}

Los análisis estadísticos se han realizado con el paquete estadístico SPSS, versión 14.0. Para analizar la asociación entre las variables del estudio se ha utilizado el test Chi-cuadrado de Pearson o el test exacto de Fisher en el caso de que el número de celdas con valores esperados menores de 5 sea mayor de un $20 \%$.

Se ha utilizado la prueba t de Student para muestras independientes en la comparación de los valores medios, cuando el número de grupos a comparar fuese mayor se ha realizado el ANOVA. Las alternativas no paramétricas utilizadas, en el caso de no ser conveniente la utilización de las anteriores, han sido la prueba $U$ de Mann-Whitney (para dos grupos) o la prueba $\mathrm{H}$ de Kruskal Wallis (para más de dos grupos).

También queremos señalar que hemos empleado un nivel de significación de $p<0,05$, rechazando todas las hipótesis planteadas que superan dicho nivel.

Para evaluar la variable "relaciones sociométricas entre iguales" lo hicimos a través del programa del Excel. Una vez introducidos todos los datos sociométricos en una base de datos, realizamos una agrupación personalizada adaptada a la muestra con la que contábamos. De este modo distribuimos a los miembros evaluados sociométricamente en los siguientes grupos: "Ios preferidos", "Ios rechazados", "Ios ignorados" y "Ios medios". Existían diferencias entre los "medios", por los que decidimos incluir dos categorías más: "medios altos" y "medios bajos". Estos grupos categorizados fueron relacionados con algunos factores seleccionados como la "etnia", la "procedencia del alumnado", el "tiempo de escolarización" y el "prejuicio".

Los criterios utilizados para realizar estas agrupaciones sociométricas no se adaptaron a criterios puramente estadísticos, sino que fueron clasificados en función de una evaluación individual de los resultados globales que obtuvieron cada uno de los alumnos. Los pasos seguidos para realizar estos análisis fueron los siguientes:

- Introducir en la base de datos a los escolares ordenados por grupos clase/colegios.

- Separar en diferentes columnas los resultados obtenidos en la sociometría, en el adivina quién y en el ranking. 
- Valorar cada grupo-clase en función de:

+ La media obtenida en la prueba del ranking

+ El número de elecciones menos el número de rechazos

+ El número de votos obtenidos en los atributos positivos menos el de los negativos.

- En función de esta valoración, los 539 alumnos de la muestra los agrupamos en las categorías mencionadas: "preferidos", "medios altos", "medio bajo", "medio", "rechazado" e "ignorado". 4

\section{4.- Resultados de la investigación}

En este apartado vemos a tratar los siguientes apartados:

\section{1.- Resultados referidos al prejuicio}

4.1.1.- Nivel general de prejuicio existente en el alumnado.

4.1.2.-Relación entre la variable prejuicio con los factores sociodemográficos y de integración escolar.

4.2.- Resultados referidos a las relaciones sociométricas

\section{1.- Resultados referidos al prejuicio}

\subsection{1.- Nivel general de prejuicio existente en el alumnado.}

En primer lugar, con el objetivo de conocer las puntuaciones globales referidas al prejuicio, se hizo una clasificación a partir de la prueba de la mediana, distribuyendo los resultados en tres categorías: "prejuicio alto", "medio" y "bajo".

El dibujo que presentamos a continuación demuestra como quedaría distribuida la manifestación de prejuicio en el alumnado en función de esta segmentación.

\footnotetext{
${ }^{4}$ En los anexos adjuntamos la clasificación de los grupos sociométricos a los que pertenecen cada uno de los 539 alumnos que conformaron la muestra.
} 


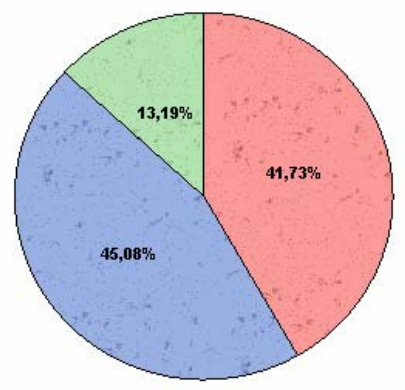

Escala de disposición conductual
$\square_{\text {Bajo }}$
$\square$ Medio
$\square$ Alto

Figura 5.1. Distribución de la disposición conductual a compartir experiencias con otras etnias.

Existe un 13,19\% de los 539 alumnos que han sido clasificados por sus respuestas dentro de una categoría perteneciente a "prejuicio alto". Sin embargo un $41,73 \%$ se ubican dentro de la categoría de "prejuicio bajo" y el 45,08\% restante como alumnos con "prejuicio medio".

A continuación presentamos los datos obtenidos en cada uno de los ítems del cuestionario.

\begin{tabular}{|c|c|c|c|c|c|}
\hline & $\mathbf{N}$ & Mínimo & Máximo & Media & Desv. típ. \\
\hline $\begin{array}{l}\text { 1. ¿Te gustaría invitar a un } \\
\text { niño gitano (payo/inmigrante) } \\
\text { a tu casa? }\end{array}$ & 507 & 1 & 4 & 2,11 & ,890 \\
\hline $\begin{array}{l}\text { 2. ¿Te gusta jugar en el } \\
\text { recreo con niños gitanos } \\
\text { (payos/inmigrantes)? }\end{array}$ & 507 & 1 & 4 & 1,95 & ,876 \\
\hline $\begin{array}{l}\text { 3. ¿Preferirías ir a un colegio } \\
\text { donde todos los niños fuesen } \\
\text { payos (gitanos/inmigrantes)? }\end{array}$ & 499 & 1 & 4 & 1,99 & ,968 \\
\hline $\begin{array}{l}\text { 4. ¿Te gustaría ir de } \\
\text { excursión con niños gitanos } \\
\text { (payos/inmigrantes)? }\end{array}$ & 505 & 1 & 5 & 3,21 & ,870 \\
\hline $\begin{array}{l}\text { 5. ¿Te gustaría contar un } \\
\text { secreto tuyo a un niño gitano } \\
\text { (payo/inmigrante)? }\end{array}$ & 502 & 1 & 4 & 2,61 & 1,085 \\
\hline $\begin{array}{l}\text { 6. ¿Te gusta hablar en } \\
\text { grupos en los que hay niños } \\
\text { gitanos (payos/inmigrantes)? }\end{array}$ & 505 & 1 & 4 & 2,02 & ,917 \\
\hline
\end{tabular}




\begin{tabular}{|c|c|c|c|c|c|}
\hline $\begin{array}{l}\text { 7. ¿En el comedor te gusta } \\
\text { sentarte al lado de un niño } \\
\text { gitano (payo/inmigrantes)? }\end{array}$ & 502 & 1 & 4 & 2,13 & ,945 \\
\hline $\begin{array}{l}\text { 8. ¿Te gustaría ir al } \\
\text { cumpleaños de un gitano } \\
\text { (payo/inmigrante)? }\end{array}$ & 503 & 1 & 4 & 1,79 & ,955 \\
\hline $\begin{array}{l}\text { 9. ¿Te gusta sentarte en } \\
\text { clase al lado de niños gitanos } \\
\text { (payos/inmigrantes)? }\end{array}$ & 496 & 1 & 4 & 1,96 & ,916 \\
\hline $\begin{array}{l}\text { 10. ¿Te gustaría tener a un } \\
\text { niño gitano (payo/inmigrante) } \\
\text { como uno de tus mejores } \\
\text { amigos? }\end{array}$ & 505 & 1 & 4 & 1,87 & ,934 \\
\hline $\begin{array}{l}\text { 11. Si pudieras nacer de } \\
\text { nuevo, ¿te gustaría ser gitano } \\
\text { (payo/inmigrante)? }\end{array}$ & 507 & 1 & 4 & 1,53 & ,974 \\
\hline $\begin{array}{l}\text { 12. ¿Te gustaría que tus } \\
\text { padres fuesen gitanos } \\
\text { (payos/inmigrantes)? }\end{array}$ & 507 & 1 & 5 & 3,30 & 1,051 \\
\hline $\begin{array}{lr}\begin{array}{l}\text { 13. ¿Preferirías tener más } \\
\text { amigos }\end{array} & \text { gitanos } \\
\text { (payos/inmigrantes) } & \text { que } \\
\text { payos (gitanos/inmigrantes)? }\end{array}$ & 508 & 1 & 4 & 2,30 & ,973 \\
\hline N válido (según lista) & 459 & & & & \\
\hline
\end{tabular}

Tabla 5.4. Estadísticos descriptivos

Si agrupamos los ítems en función del grado de compromiso y sumamos todas las puntuaciones, observamos que existe más prejuicio y resistencia a compartir experiencias con alumnos de otras etnias en aquellas preguntas que exigen un mayor grado de intimidad con otros alumnos pertenecientes a otros colectivos étnicos..

\begin{tabular}{|l|l|l|l|l|l|l|}
\hline & $\begin{array}{l}\text { MEDIA } \\
\text { ITEM 3 }\end{array}$ & $\begin{array}{l}\text { MEDIA } \\
\text { ITEM 4 }\end{array}$ & $\begin{array}{l}\text { MEDIA } \\
\text { ITEM 6 }\end{array}$ & $\begin{array}{l}\text { MEDIA } \\
\text { ITEM 7 }\end{array}$ & $\begin{array}{l}\text { MEDIA } \\
\text { ITEM 9 }\end{array}$ & TOTAL \\
\hline $\begin{array}{l}\text { NIVEL DE INTIMIDAD } \\
\text { MEDIO }\end{array}$ & 1,99 & 3,21 & 2,02 & 2,13 & 1,96 & 11,31 \\
\hline & $\begin{array}{l}\text { MEDIA } \\
\text { ITEM 1 }\end{array}$ & MEDIA & MEDIA & MEDIA & MEDIA & TOTAL \\
ITEM 2 & ITEM 5 & ITEM 8 & ITEM 10 & \\
\hline $\begin{array}{l}\text { NIVEL DE INTIMIDAD } \\
\text { ALTO }\end{array}$ & 2,11 & 1,95 & 2,61 & 1,79 & 1,06 & 9,52 \\
\hline
\end{tabular}

Tabla 5.5. Medias de las puntuaciones de los ítems clasificados en función del nivel de intimidad. 
Cuanto menor sea la puntuación total, más cerca se situará de la respuesta de la escala igual a мucHo que puntuaba con un 1. Es decir, cuanta menos puntuación total obtengan los ítems, menor prejuicio existirá. Así vemos en la tabla 2, un 11,31 de media frente a un 9,52. Es decir, cuanta más implicación afectiva existe, mayor prejuicio manifiesta el alumnado.

4.1.2.- Comparación de la variable prejuicio en función de los factores sociodemográficos y de integración escolar.

Posteriormente, adjuntamos los resultados obtenidos al relacionar la variable prejuicio con los factores elegidos en el estudio.

4.A) La primera relación se establece entre "prejuicio" y "etnia", a continuación presentamos los datos obtenidos al respecto.

\begin{tabular}{|l|r|r|r|}
\hline & $\mathrm{N}$ & \multicolumn{1}{|c|}{ Media } & \multicolumn{1}{c|}{$\begin{array}{c}\text { Desviación } \\
\text { típica }\end{array}$} \\
\hline Payo & 450 & 20,56 & 7,757 \\
Inmigrante & 41 & 15,66 & 6,003 \\
Gitano & 47 & 20,04 & 10,620 \\
Total & 538 & 20,14 & 8,021 \\
\hline
\end{tabular}

Tabla 5.6. Relación entre prejuicio y la etnia.

Los inmigrantes son los que presentan menores resultados en la variable prejuicio siendo la diferencia de 4,91 puntos con respecto a los payos $(p<0,001)$ y de 4,38 puntos con respecto a los gitanos $(p<0,001)$. Los alumnos inmigrantes presentan menos prejuicio que los payos y gitanos.

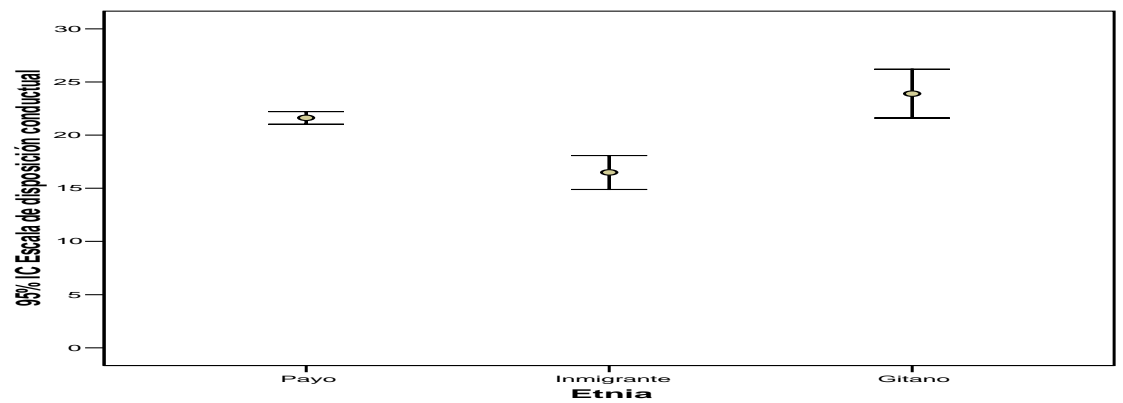

Figura 5.2. Relación en entre prejuicio y étnia 
4.B.- En segundo lugar, relacionamos la variable "prejuicio" con el "nivel socio económico del centro", obteniendo los siguientes resultados.

\begin{tabular}{|l|l|r|r|r|}
\hline & $\begin{array}{l}\text { Nivel } \\
\text { socioeconómico del } \\
\text { colegio }\end{array}$ & N & Media & \multicolumn{1}{c|}{$\begin{array}{c}\text { Desviación } \\
\text { típ. }\end{array}$} \\
\hline $\begin{array}{l}\text { Escala de } \\
\text { disposición } \\
\text { conductual }\end{array}$ & Bajo & 106 & 19,63 & 10,124 \\
\hline & Medio & 433 & 20,29 & 7,430 \\
\hline
\end{tabular}

Tabla 5.7. Relación entre prejuicio y el nivel socioeconómico del centro.

Existen diferencias significativas entre la variable "prejuicio" y "nivel socioeconómico del centro" $(F(1,506)=5,08 . p<.05)$. Los alumnos pertenecientes a un nivel socio-económico bajo puntúan más alto en prejuicio que los de nivel socio económico medio.

4.C.- En segundo lugar, la relación la establecemos con el "género" y los resultados aportados son los que aparecen a continuación.

\begin{tabular}{|l|r|r|r|r|}
\hline Género & $\mathrm{N}$ & \multicolumn{1}{|c|}{ Media } & Desviación típ. & \multicolumn{2}{c|}{$\begin{array}{c}\text { Error típ. de la } \\
\text { media }\end{array}$} \\
\hline Niño & 274 & 22,06 & 6,491 &, 392 \\
\hline Niña & 234 & 20,68 & 6,440 &, 421 \\
\hline
\end{tabular}

Tabla 5.8. Relación entre prejuicio y el género.

El prejuicio obtenido para los niños es mayor que el obtenido para las niñas, 22,06 puntos frente a $20,68(p=0,017)$. 


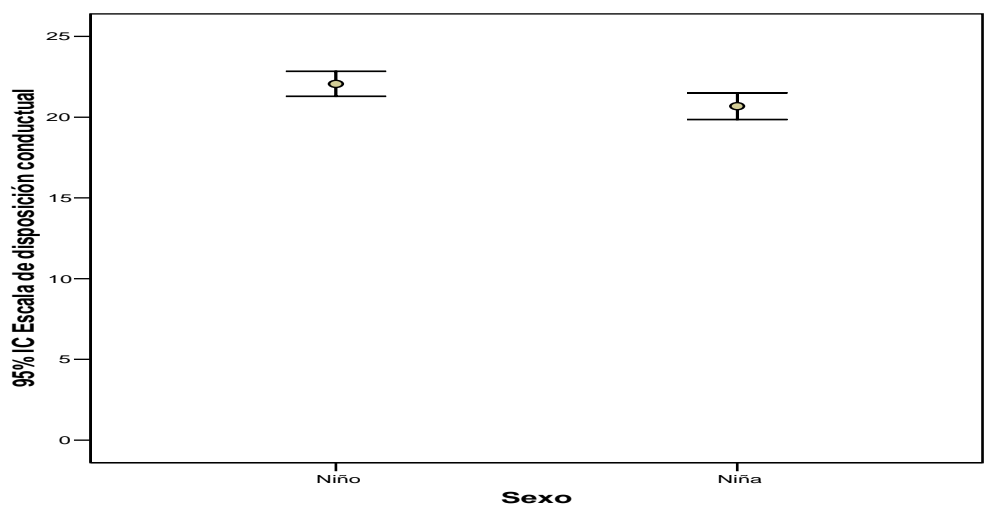

Figura 5.3. Relación entre prejuicio y género

Existen diferencias significativas entre el componente conductual del prejuicio y el género. Los niños obtienen puntuaciones significativamente más prejuiciosas que las niñas.

4.D.- La relación entre "prejuicio" y el "tiempo de escolarización" parece no obtener resultados significativos. $(p=0,204)$.

4.E.- La relación entre "prejuicio" y la "existencia de alumnos inmigrantes en el grupo" obtiene los siguientes resultados.

\begin{tabular}{|c|c|c|c|c|}
\hline $\begin{array}{c}\text { Inmigr en } \\
\text { el aula }\end{array}$ & $\mathrm{N}$ & Media & $\begin{array}{c}\text { Desviación } \\
\text { típ. }\end{array}$ & $\begin{array}{c}\text { Error típ. de } \\
\text { la media }\end{array}$ \\
\hline No & 464 & 21,89 & 6,453 &, 300 \\
\hline $\mathrm{Si}$ & 44 & 16,52 & 4,742 &, 715 \\
\hline
\end{tabular}

Tabla 5.9. Relación entre prejuicio y existencia de inmigrantes en el mismo grupo.

El valor medio del prejuicio es mayor si no hay inmigrantes en el aula, 21,89 puntos frente a $16,52(p<0,001)$. 


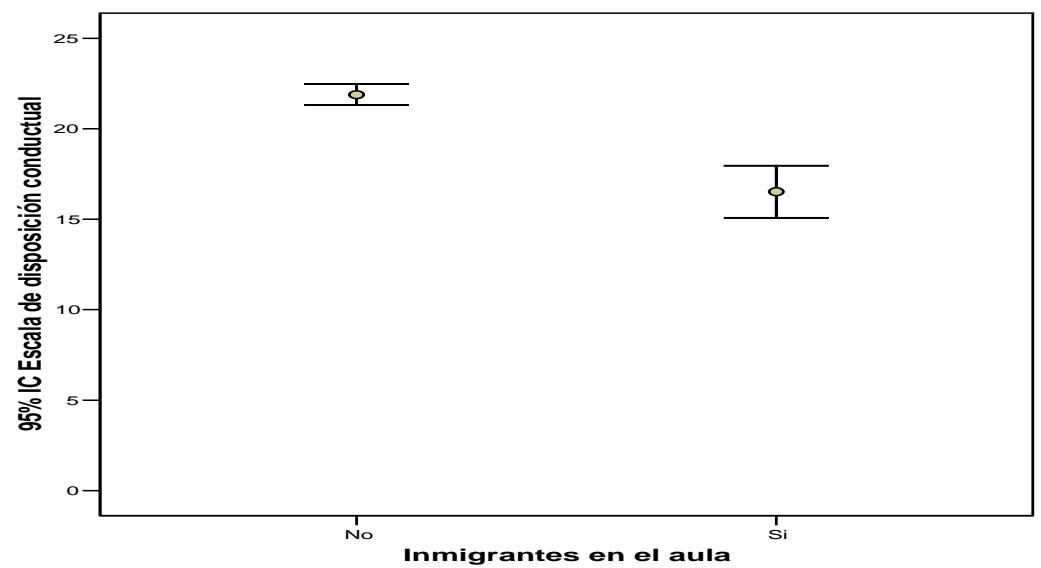

Figura 5.4. Relación entre prejuicio y existencia de inmigrantes en el aula.

Como vemos en la figura 5.4, hemos encontrado diferencias significativas en la variable prejuicio y existencia de inmigrantes en el aula. Existe más prejuicio en el alumnado cuando no hay inmigrantes en su misma aula. indican:

4.F.- Entre "prejuicio" y "procedencia del alumno" los resultados obtenidos nos

\begin{tabular}{|l|c|c|c|}
\hline & $\mathrm{N}$ & Media & $\begin{array}{c}\text { Desviación } \\
\text { típica }\end{array}$ \\
\hline España & 493 & 20,57 & 8,090 \\
\hline Latinoamérica & 26 & 15,50 & 5,163 \\
\hline Europa Este & 10 & 14,50 & 6,687 \\
\hline Europa & 6 & 17,50 & 4,848 \\
\hline Países árabes & 4 & 18,25 & 8,884 \\
\hline Total & 539 & 20,16 & 8,025 \\
\hline
\end{tabular}

Tabla 5.10. Relación entre prejuicio y el país de procedencia del alumnado. 


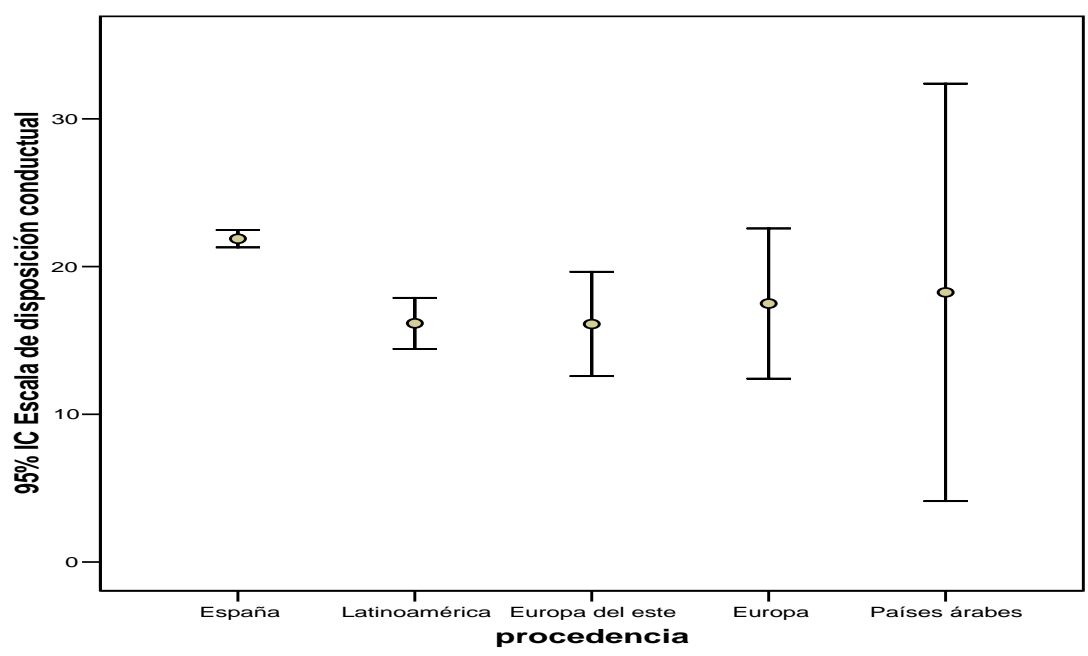

Figura 5.5. Relación entre prejuicio y procedencia.

Existen diferencias significativas $(p<0.16)$, pero debido al bajo $N$ del que disponemos, debemos tener cierta prudencia al establecer tales diferencias. Podemos decir, que parece que los alumnos españoles, que constituyen el grueso de la muestra, tienen una puntuación más elevada (con más prejuicio) que el resto.

4.G.- "Procedencia familiar" y "prejuicio" se relacionan entre sí del siguiente modo:

\begin{tabular}{|c|c|c|c|}
\hline & N & Media & $\begin{array}{c}\text { Desviación } \\
\text { típica }\end{array}$ \\
\hline Padres inmigrantes & 38 & 15,37 & 5,514 \\
Padres españoles & 490 & 20,60 & 8,092 \\
Mezcla & 5 & 15,20 & 6,140 \\
Adoptados & 2 & 15,50 &, 707 \\
Acogidos & 2 & 14,50 & 4,950 \\
Total & 537 & 20,13 & 8,024 \\
\hline
\end{tabular}

Tabla 5.11. Relación entre prejuicio y la procedencia de la familia. 


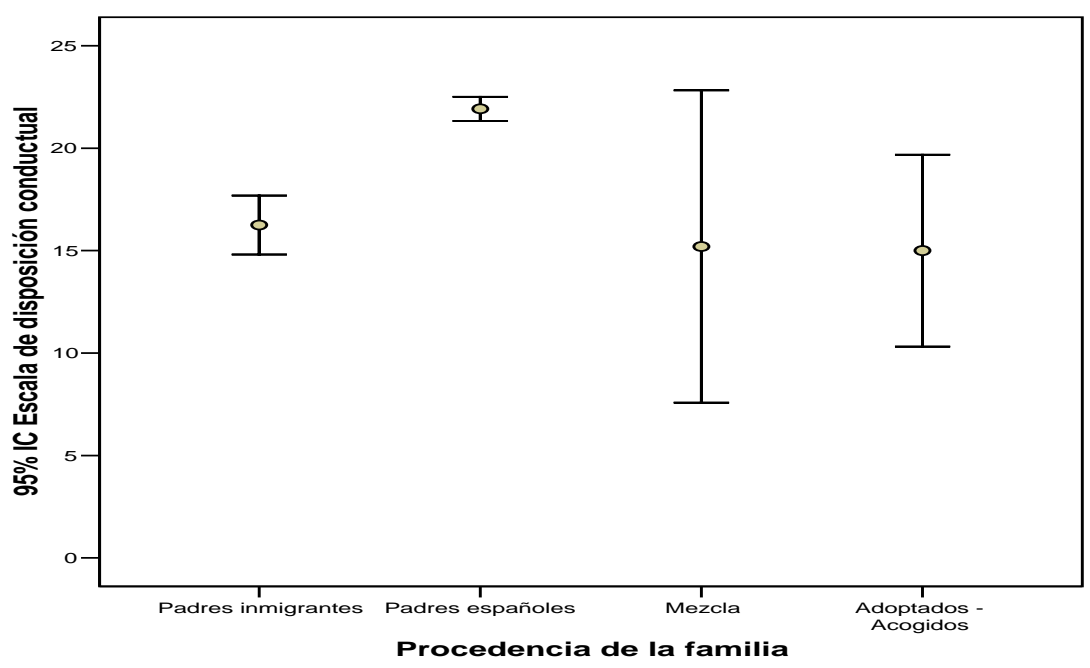

Figura 5.6. Relación entre prejuicio y procedencia de la familia.

Existen diferencias significativas entre el prejuicio y los padres españoles. El prejuicio medio de los que tienen padres españoles es superior al de los niños con padres inmigrantes $(p<.01)$, no existiendo diferencias estadísticamente significativas entre el grupo de padres mixtos (en los que cada miembro pertenece a una etnia diferente).

4.H.- No existen diferencias significativas entre el "prejuicio" y el "tiempo de escolarización". ( $p=0,204)$.

En la tabla que aparece a continuación resumimos los factores que, según nuestros resultados, se relacionan significativamente con el prejuicio. Los círculos que aparecen en color anaranjado son los que han obtenido una correlación estadísticamente significativa. 


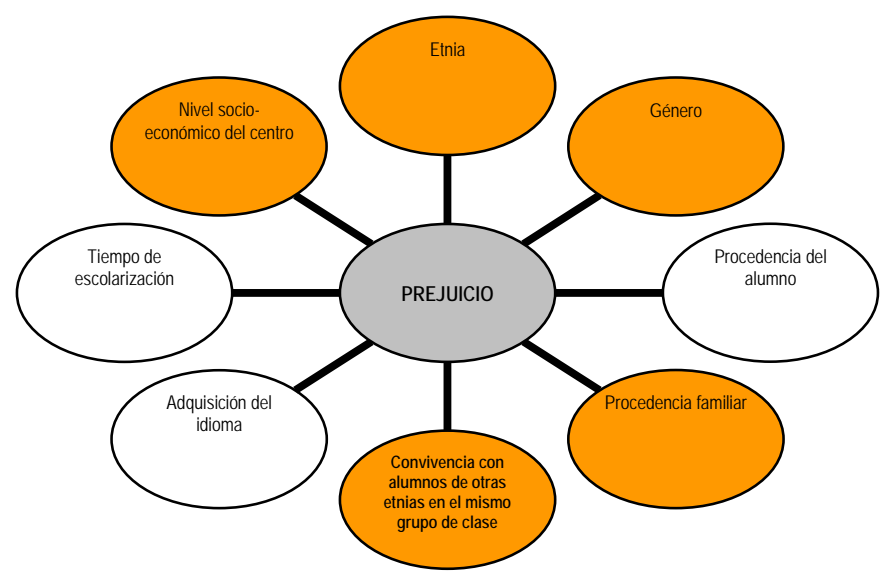

Figura 5.7. Correlaciones estadísticamente significativas.

\section{2.- Resultados relacionados con las relaciones sociométricas}

Presentamos a continuación los datos obtenidos al evaluar las relaciones sociométricas entre los iguales. Para ello establecemos una clasificación a partir de la prueba del ranking. Los resultados de esta prueba nos ofrecen la valoración social global del lugar que ocupa el alumno en el aula. Si hacemos la media de todas las puntuaciones obtenidas por los alumnos en cada grupo, obtenemos una puntuación que oscila entre el 1 y el 5 . Establecemos tres intervalos para clasificar los datos como: "relaciones sociales buenas dentro del grupo", "relaciones sociales regulares" y "relaciones sociales malas".

Los resultados de cada uno de los grupos escolares evaluados aparecen a continuación en la tabla 5.12.

\section{VALORACIÓN SOCIAL DEL ALUMNADO PERTENECIENTE A LOS GRUPOS DE $5^{\circ}$ DE PRIMARIA DE LOS 31 COLEGIOS PÚBLICOS DE VALLADOLID}

$\left(n^{\circ}\right.$ de centros)

$\mathrm{N}^{0}$ de grupos con resultados sociométricos buenos: 15

$N^{0}$ de grupos con resultados sociométricos normales: 16

$\mathrm{N}^{0}$ de grupos con resultados sociométricos malos: 0

Tabla 5.12. Valoración social general del alumnado de $5^{\circ}$ de primara entre sí. 
4.A.- A continuación, describimos las puntuaciones de los grupos formados por alumnos y alumnas pertenecientes en su mayoría a minorías étnicas: gitanos y/o inmigrantes. Hemos denominado a estos centros escolares como: "colegios guetos", dado que el alumnado asistente tiene muchas desventajas sociales si lo comparamos con los escolares que acuden a otros colegios de la misma ciudad.

\begin{tabular}{|c|c|c|c|}
\hline COLEGIO & NO GUETO O SI GUETO & $\begin{array}{l}\text { PUNTUACIÓN } \\
\text { SOCIOMÉTRICA }\end{array}$ & CLASIFICACIÓN \\
\hline 1 & $\mathrm{NO}$ & 2,34 & NORMALES \\
\hline 2 & $\mathrm{SI}$ & 1,9 & BUENAS \\
\hline 3 & $\mathrm{NO}$ & 2,03 & BUENAS \\
\hline 4 & $\mathrm{NO}$ & 2,25 & BUENAS \\
\hline 5 & $\mathrm{NO}$ & 2,6 & NORMALES \\
\hline 6 & $\mathrm{NO}$ & 2,3 & NORMALES \\
\hline 7 & $\mathrm{SI}$ & 2,22 & BUENAS \\
\hline 8 & $\mathrm{SI}$ & 2.02 & BUENAS \\
\hline 9 & $\mathrm{SI}$ & 1.5 & BUENAS \\
\hline 10 & $\mathrm{NO}$ & 2.31 & NORMALES \\
\hline 11 & $\mathrm{NO}$ & 2,3 & NORMALES \\
\hline 12 & $\mathrm{NO}$ & 2,4 & NORMALES \\
\hline 13 & $\mathrm{NO}$ & 2,3 & NORMALES \\
\hline 14 & $\mathrm{SI}$ & 2,17 & BUENAS \\
\hline 15 & $\mathrm{NO}$ & 2,3 & NORMALES \\
\hline 16 & NO & 2,3 & NORMALES \\
\hline 17 & $\mathrm{SI}$ & 1,75 & BUENAS \\
\hline 18 & $\mathrm{NO}$ & 2,35 & NORMALES \\
\hline 19 & $\mathrm{NO}$ & 2,19 & BUENAS \\
\hline 20 & $\mathrm{NO}$ & 2 & BUENAS \\
\hline 21 & $\mathrm{NO}$ & 2,22 & BUENAS \\
\hline 22 & $\mathrm{SI}$ & 1,76 & BUENAS \\
\hline 23 & $\mathrm{SI}$ & 1,95 & BUENAS \\
\hline 24 & $\mathrm{NO}$ & 2,3 & NORMALES \\
\hline 25 & $\mathrm{NO}$ & 1,98 & BUENAS \\
\hline 26 & $\mathrm{NO}$ & 2,3 & NORMALES \\
\hline
\end{tabular}

${ }^{5}$ Los criterios de la clasificación como "colegios guetos", fueron las siguientes: 1) centros situados en los barrios periféricos de la ciudad. 2) Escaso número de alumnado debido al progresivo abandono de los niños. 3) Abandono del centro por parte de los niños mejor situados socialmente. 4) clases formadas en su 90\% por alumnado gitano y algún inmigrante. 


\begin{tabular}{|c|c|c|c|}
\hline 27 & NO & 2,27 & BUENAS \\
\hline 28 & NO & 2,4 & NORMALES \\
\hline 29 & NO & 2,3 & NORMALES \\
\hline 30 & NO & 2,3 & NORMALES \\
\hline 31 & NO & 2,3 & NORMALES \\
\hline
\end{tabular}

Tabla 5.13. Puntuaciones sociométricas por grupo-clase.

4.B.- A continuación presentamos los grupos sociométricos a los que pertenecen cada uno de los diferentes colectivos étnicos del estudio.

\begin{tabular}{|l|c|c|c|c|}
\hline & $\begin{array}{l}\text { ALUMNOS } \\
\text { INMIGRANTES }\end{array}$ & $\begin{array}{l}\text { ALUMNOS } \\
\text { ESPAÑOLES } \\
\text { PAYOS }\end{array}$ & $\begin{array}{l}\text { ALUMNOS } \\
\text { GITANOS } \\
\text { mayoritarios en su } \\
\text { clase }^{6}\end{array}$ & $\begin{array}{l}\text { ALUMNOS } \\
\text { GITANOS } \\
\text { minoritarios en su } \\
\text { clase }^{7}\end{array}$ \\
\hline RECHAZADOS & $18-40 \%$ & $73-15,7 \%$ & $3-11,1 \%$ & $2-66,6 \%$ \\
\hline IGNORADOS & $7-15,5 \%$ & $13-2.8 \%$ & $0-0 \%$ & $0-0 \%$ \\
\hline MEDIOS & $8-17,7 \%$ & $162-34,8 \%$ & $7-25,9 \%$ & $0-0 \%$ \\
\hline MEDIO BAJO & $6-13,3 \%$ & $54-11,6 \%$ & $3-11,1 \%$ & $1-33,3 \%$ \\
\hline MEDIO ALTO & $2-4,4 \%$ & $61-13,11 \%$ & $9-33,3 \%$ & $0-0 \%$ \\
\hline PREFERIDO & $4-8,8 \%$ & $102-21,9 \%$ & $5-18,5 \%$ & $0-0 \%$ \\
\hline TOTAL & $45-100 \%$ & $465-\mathbf{1 0 0} \%$ & $\mathbf{2 7 - 1 0 0 \%}$ & $\mathbf{3 - 1 0 0 \%}$ \\
\hline
\end{tabular}

Tabla 5.14. Grupos sociométricos en función de la etnia

Como se ve en la tabla 5.14, el $40 \%$ del alumnado inmigrante se encuentra en la categoría de "rechazado", los españoles y payos en la de "medios" y los alumnos gitanos rodeados de otros compañeros de su mismo colectivo étnico se incluyen en los "preferidos", mientras que si se encuentran en grupos-clase con compañeros payos, son valorados en un $66 \%$ como "rechazados".

4.C.- Las relaciones entre grupos sociométricos y procedencias de los alumnos inmigrantes son las siguientes.

\footnotetext{
${ }^{6}$ Existen 7 alumnos gitanos minoritarios que no asistieron a clase el día que pasamos las pruebas sociométricas.

${ }^{7}$ Nos referimos al alumnado gitano que en clase constituye una pequeña minoría.
} 


\begin{tabular}{|l|l|l|l|l|l|l|l|}
\hline Procedencia & RECHAZADO & IGNORADO & $\begin{array}{l}\text { MEDIO } \\
\text { BAJO }\end{array}$ & MEDIO & $\begin{array}{l}\text { MEDIO } \\
\text { ALTO }\end{array}$ & $\begin{array}{l}\text { PREFERI } \\
\text { DO }\end{array}$ & TOTAL \\
\hline Marroquí & $2-66,6 \%$ & $1-33,3 \%$ & 0 & 0 & 0 & 0 & $\mathbf{3 - 6 , 8 \%}$ \\
\hline Latinoamericano & $8-33,3 \%$ & $6-25 \%$ & $3-12,5 \%$ & $6-25 \%$ & $2-40 \%$ & $3-12,5 \%$ & $\mathbf{2 4 - 5 4 , 5 \%}$ \\
\hline Europa Este & $5-50 \%$ & 0 & $1-10 \%$ & $2-20 \%$ & $1-10 \%$ & $1-10 \%$ & $\mathbf{1 0 - 2 2 , 7 \%}$ \\
\hline Europa & $4-66,6 \%$ & 0 & $2-33,3 \%$ & 0 & 0 & 0 & $\mathbf{6 - 1 3 , 6 \%}$ \\
\hline
\end{tabular}

Tabla 5.15. Grupos sociométricos en función de la procedencia

Los 3 alumnos de procedencia Marroquí ocupan los puestos de "rechazado" o "ignorado". Los latinoamericanos, son los alumnos que ocupan puestos más valorados socialmente: "preferidos" o "medio alto", no obstante, contamos con un bajo número de muestra para poder llegar a conclusiones firmes.

4.D.- El tiempo de escolarización y los grupos sociométricos se distribuyen como aparece en la tabla que aparece a continuación.

\begin{tabular}{|l|l|l|l|l|l|l|l|}
\hline $\begin{array}{l}\text { TIEMPO DE } \\
\text { ESCOLARIZACIÓN }\end{array}$ & RECHAZADO & IGNORADO & $\begin{array}{l}\text { MEDIO } \\
\text { BAJO }\end{array}$ & MEDIO & $\begin{array}{l}\text { MEDIO } \\
\text { ALTO }\end{array}$ & PREFERIDO & TOTAL \\
\hline Menos de 1 año & $5-71,42 \%$ & $0-0 \%$ & $\begin{array}{l}2- \\
28,5 \%\end{array}$ & 0 & 0 & 0 & $\begin{array}{l}7- \\
15,2 \%\end{array}$ \\
\hline De 1 a 3 años & $8-41,05 \%$ & $4-23,5 \%$ & $0-0 \%$ & $1-5,8 \%$ & $\begin{array}{l}2- \\
11,7 \%\end{array}$ & $2-11,7 \%$ & $\begin{array}{l}17- \\
36,9 \%\end{array}$ \\
\hline Más de 3 años & 0 & 0 & $\begin{array}{l}1- \\
100 \%\end{array}$ & 0 & 0 & 0 & $\begin{array}{l}1- \\
2,17 \%\end{array}$ \\
\hline Toda su vida & $5-23,8 \%$ & $3-14,2 \%$ & $\begin{array}{l}3- \\
14,2 \%\end{array}$ & $\begin{array}{l}7- \\
33,3 \%\end{array}$ & $1-4,7 \%$ & $2-9,5 \%$ & $\begin{array}{l}21- \\
45,6 \%\end{array}$ \\
\hline
\end{tabular}

Tabla 5.16. Grupos sociométricos en función del tiempo de escolarización

No podemos establecer una progresión significativa en cuanto a la aceptación del alumnado en función del tiempo que lleve escolarizado. Sin embargo observamos que el alumnado que lleva escolarizado menos de un año no ocupa ningún puesto alto, ni medio, sino que son rechazados en su mayoría.

4.E.- Las relaciones que se establecen entre los grupos sociométricos y el prejuicio los expresamos con esta tabla. 


\begin{tabular}{|c|c|c|}
\hline GRUPO SOCIOMÉTRICO & PREJUICIO & PORCENTAJE PREJUICIO \\
\hline PREFERIDOS & $\begin{array}{l}\text { Alto }=7 \\
\text { Medio }=52 \\
\text { Bajo }=53\end{array}$ & $\begin{array}{l}6.1 \% \\
45,6 \% \\
46,5 \%\end{array}$ \\
\hline MEDIO ALTO & $\begin{array}{l}\text { Alto = } 8 \\
\text { Medio = } 39 \\
\text { Bajo }=33\end{array}$ & $\begin{array}{l}9,8 \% \\
47,6 \% \\
40,3 \%\end{array}$ \\
\hline MEDIO & $\begin{array}{l}\text { Alto }=30 \\
\text { Medio }=68 \\
\text { Bajo }=78\end{array}$ & $\begin{array}{l}16,7 \% \\
38,4 \% \\
44 \%\end{array}$ \\
\hline MEDIO BAJO & $\begin{array}{l}\text { Alto }=4 \\
\text { Medio =18 } \\
\text { Bajo = } 15\end{array}$ & $\begin{array}{l}11,1 \% \\
50 \% \\
41,7 \%\end{array}$ \\
\hline IGNORADO & $\begin{array}{l}\text { Alto }=2 \\
\text { Medio = } 7 \\
\text { Bajo = } 15\end{array}$ & $\begin{array}{l}8,7 \% \\
30,4 \% \\
65,2 \%\end{array}$ \\
\hline RECHAZADO & $\begin{array}{l}\text { Alto }=13 \\
\text { Medio }=40 \\
\text { Bajo }=49\end{array}$ & $\begin{array}{l}12,7 \% \\
39,2 \% \\
48 \%\end{array}$ \\
\hline
\end{tabular}

Tabla 5.17. Grupo sociométrico en función del prejuicio manifestado

A pesar de que los "alumnos preferidos" obtienen menor porcentaje de prejuicio que los "rechazados", las pruebas realizadas nos indican que tales diferencias no son estadísticamente significativas. Por tanto no podemos establecer diferencias estadísticamente significativas entre el grupo sociométrico y la variable prejuicio $(p=$ 0.214). Aun así consideramos interesante introducir esta tabla para observar la distribución de las puntuaciones y apreciar esos matices.

\section{5.- Comprobación y explicación de las hipótesis exploratorias}

Hipótesis 1. Existencia de prejuicio en los escolares de $5^{\circ}$ de primaria de los colegios públicos de Valladolid.

Podemos confirmar, que los niveles de prejuicio de los escolares, mostrados en los resultados de estas escalas, se encuentran en niveles medios, aumentando en aquellos ítems que requieren un mayor contacto con alumnos de etnias diferentes 
como vemos en la tabla 4.3. y 4.5. Esto se correspondería con las afirmaciones realizadas en otras investigaciones (Díaz Aguado, 1996) y confirmaría la hipótesis de partida en la que presuponíamos que las manifestaciones prejuiciosas por parte de los escolares iban a manifestarse de forma sutil (Pettegrew y Meertens 1995).

Hipótesis 2. Relación existente entre los factores sociodemográficos y escolares y el nivel de prejuicio en el alumnado.

Los factores relacionados con las variables: "prejuicio" e "interacción social" que nos ofrecieron significación estadística ( $p>$.05), fueron los siguientes: la "etnia", la "existencia de inmigrantes en el aula", el "sexo", el "nivel socio-económico del centro", la "procedencia del alumnado" y la "procedencia de los padres". Las hipótesis que siguen a continuación explican cada uno de estos factores.

Hipótesis 2a.- Evaluar el nivel de prejuicio que manifiestan los alumnos pertenecientes a diferentes colectivos étnicos, estando clasificados dentro de las categorías:" inmigrante", "español", "gitano".

Entre payos y gitanos no hay diferencias significativas intergrupales, sin embargo, si consideramos a payos y gitanos como un grupo, sí existen diferencias significativas respecto al grupo de inmigrantes. Es decir, las puntuaciones de payos y gitanos juntas demuestran prejuicio hacia los inmigrantes. Podemos verlos en la tabla 4.6. Por tanto la relación entre prejuicio y colectivo étnico planteada en la segunda hipótesis exploratoria del estudio, nos informa de la existencia de prejuicio hacia los inmigrantes en los grupos escolares.

Hipótesis 2b.- Evaluar el nivel de prejuicio que manifiestan los alumnos de diferentes países de procedencia, siendo éstas las siguientes: "Español", "Marroquí", "Europa del Este", "Europa" y "Latinoamericano".

Respecto a esta variable no pudimos obtener resultados concluyentes debido al bajo número que constituían cada uno de los grupos de las procedencias de los alumnos $(\mathrm{N}=25)$. Sin embargo, los datos parecen indicar que existe una ligera tendencia que apunta a que son los alumnos españoles los que muestran un índice mayor de prejuicio, podemos verlo en la tabla 4.10.

Hipótesis 2c.- Evaluar el nivel de prejuicio que manifiesta en función del "género".

Como vemos en la tabla 4.8, existen diferencias significativas entre el componente conductual del prejuicio y el género ( $p>$.05). Los niños obtienen puntuaciones significativamente más prejuiciosas que las niñas.

Hipótesis 2d.- Evaluar el nivel de prejuicio que manifiestan los alumnos en función del nivel socio-económico del centro en el que estén escolarizados, siendo "medio" y "bajo" las dos categorías establecidas. 
La tabla 4.7 nos indica que los alumnos pertenecientes a un nivel socioeconómico bajo puntúan más alto en prejuicio que los de nivel socio económico medio $(p>05)$. Recordamos que los alumnos escolarizados en los colegios clasificados dentro de la categoría de nivel socio económico bajo, son casi en su totalidad pertenecientes al colectivo gitano.

Hipótesis 2e.- Evaluar el nivel de prejuicio que manifiestan los alumnos en función de la procedencia familiar, siendo estas procedencias las siguientes: "padres inmigrantes", "padres españoles", "padres mixtos" y "padres con hijos adoptados".

Existen diferencias significativas entre el prejuicio y los padres españoles. El prejuicio medio de los que tienen padres españoles es superior al de los niños con padres inmigrantes $(p<.01)$; no existiendo diferencias estadísticamente significativas entre el grupo de padres mixtos, es decir que cada miembro pertenece a una etnia diferente. En la tabla 4.11 aparecen estos resultados.

Hipótesis 2.f.- Evaluar el nivel de prejuicio que manifiestan los alumnos en función del tiempo de escolarización, estableciendo los tiempos del siguiente modo: menos de un año, entre uno y tres años y más de tres años.

No se han encontrado diferencias significativas entre el tiempo de escolarización y el prejuicio manifestado. $(p=0,204)$, aunque se aprecia una leve tendencia al rechazo hacia alumnado recién llegado.

Hipótesis 2.g.- Evaluar el nivel de prejuicio que manifiestan los alumnos en función de la convivencia en el aula con otros alumnos inmigrantes, en función de la existencia 0 no de alumnos inmigrantes en cada uno de los grupos de clase de $5^{\circ}$ de primaria.

Como vemos en la tabla 4.9, hemos encontrado diferencias significativas en la variable prejuicio y existencia de inmigrantes en el aula. Existe más prejuicio en el alumnado cuando no hay inmigrantes en su mismo aula ( $p>$.01). Los resultados de esta hipótesis nos ofrecen importantes implicaciones educativas como ya veremos en el siguiente apartado al discutir los datos.

Hipótesis 2.h.- Evaluar el nivel de prejuicio que manifiestan los alumnos en función de la adquisición o no de la lengua del país de recepción, en este caso la española.

No se han encontrado diferencias significativas entre el tiempo de escolarización y el prejuicio manifestado. $(p=0,204)$.

Las hipótesis que siguen a partir de ahora se refieren a las relaciones sociométricas. En ninguna de ellas se ha podido establecer significación estadística, sin embargo consideramos interesante incluirlas por la información que nos aporta al respecto. Describimos por tanto, a partir de la hipótesis 3 , hacia donde apuntan los resultados obtenidos. 
Hipótesis 3.- Calidad de las relaciones sociométricas entre iguales.

Las puntuaciones sociométricas que aparecen en la tabla 4.12 son todas buenas 0 normales. No existe ningún grupo en el que los alumnos se valoren negativamente entre sí. También el resultado de esta hipótesis tiene consecuencias importantes para el panorama educativo. De momento, para explicar esta hipótesis utilizamos los resultados que aparecen en la tabla 4.12 y 4.13. En la primera, aparecen las puntuaciones medias que obtienen los grupos escolares, categorizados en, "buenas", "malas" y "regulares", predominando las primeras. En la segunda tabla (4.13), aparecen estas mismas valoraciones en función del nivel socio-económico del centro, diferenciando los colegios considerados como "guetos" de los que no lo eran (por las razones ya explicadas), y así curiosamente, observamos que los grupos pertenecientes a "colegios guetos" obtenían mejores puntuaciones sociométricas que los grupos de otros colegios no considerados como "guetos".

Hipótesis 3a.- ¿Qué alumnos categorizados en función de su colectivo étnico de pertenencia es las más "rechazada", "ignorada" o "popular"?

Si analizamos la tabla 4.14, vemos que las puntuaciones sociométricas que obtienen los inmigrantes son peores que las de los españoles. Los alumnos procedentes de otros países suelen estar considerados como "rechazados" 0 "ignorados", de esta forma vemos en dicha tabla, cómo 18 alumnos inmigrantes, de los 45 totales, son considerados "rechazados" y otros 8 "ignorados".

Hipótesis 3b.-¿Qué procedencia es la más "elegida", "rechazada", "ignorada" o "media"?.

A pesar de contar con un número alto de muestra, el alumnado procedente de otros países es todavía muy bajo en los colegios de primaria de esta ciudad. Este número se reduce todavía más si los segmentamos por procedencias.

Revisando la tabla 4.15, vemos que los 3 alumnos de procedencia marroquí, ocupan los puestos de "rechazado" o "ignorado". Los latinoamericanos, son los alumnos que ocupan puestos más valorados socialmente: "preferidos" o "medio alto".

Hipótesis 3c.- ¿Qué grupos sociométricos pertenecen a los elegidos, los rechazados, los ignorados o los medios; los alumnos que llevan más tiempo en el colegio o los que llevan menos?

No podemos establecer una progresión significativa en cuanto a la aceptación de alumno en función del tiempo que lleve escolarizado. Sin embargo, observamos en la tabla 4.16 que los alumnos que llevan escolarizados menos de un año, no ocupan ningún puesto "alto", ni "medio", sino que son "rechazados" la mayoría. 
Hipótesis 3d.:- ¿Quién tiene más prejuicio, el grupo de alumnos perteneciente a los elegidos, a los rechazados, a los ignorados o a los medios?

En la tabla 4.17 podemos establecer diferentes asociaciones respecto a la relación entre grupo sociométrico y prejuicio. El grupo de "preferidos" muestra menos prejuicio que la de "rechazados". Un 6\% del grupo de los "preferidos" muestra prejuicio alto frente a un $12,7 \%$ del alumnado perteneciente al grupo de los "rechazados". El alumnado del grupo de los "ignorados" son los que manifiestan menos prejuicio: un $65,2 \%$ frente al resto de los grupos que rondan entre el 40 y $50 \%$ de bajo prejuicio. Por tanto, podemos decir que existe cierta tendencia (recordamos que sin ser estadísticamente significativa) a manifestar más prejuicio cuanto peor valorado se está.

\section{6.- Discusión de los datos}

El objetivo que perseguimos en este apartado es el de ofrecer explicaciones y reflexiones en base a los resultados obtenidos y descritos en el apartado anterior. Algunas de las ideas que exponemos concuerdan con algunos postulados teóricos de los estudiosos del tema.

Seguiremos la misma estructura que hemos utilizado al formular las hipótesis del estudio. En primer lugar describimos las hipótesis relacionadas con el prejuicio y después las referidas a las interacciones sociales entre los escolares.

Hipótesis 1. Existencia de prejuicio en los escolares de $5^{\circ}$ de primaria de los colegios públicos de Valladolid.

Los resultados nos decían que el porcentaje más alto de alumnos manifiesta disposición media para compartir experiencias con otros grupos étnicos.

A su vez, los interrogantes de los que constan las escalas aplicadas, tienen grados diferentes de compromiso e intimidad. Es diferente preguntar a un niño: " ¿ $T e$ gustaría tener a un niño gitano/inmigrante como uno de tus mejores amigos?"(ítem 10) que: "¿En el comedor te gustaría sentarte al lado de un niño gitano/inmigrante?" (item 7). El grado de implicación afectiva es mucho mayor en el primer caso que en el segundo. Este hecho puede ser relacionado con los conceptos de prejuicio manifiesto y sutil (Pettigrew, y Meertens, 1995), estos autores diferencian entre prejuicio manifiesto (que aparece en percepción de amenaza por parte del exogrupo y en el rechazo al contacto íntimo con sus miembros) y el prejuicio sutil (que se da de una manera escondida a través de la defensa de los valores tradicionales, la exageración de las diferencias culturales y la negación de emociones positivas hacia los miembros del exogrupo). Así, podemos afirmar que el prejuicio se ha vuelto sutil. Se rechazan las formas expresas de racismo, pero a su vez se emite un discurso socialmente aceptado que nos da la posibilidad de marginar y discriminar a los inmigrantes sin tener 
conciencia de que nuestras actitudes y/o comportamientos son prejuiciosos. Esta nueva manifestación del prejuicio explicada parece reflejarse en las respuestas del alumnado, al expresar menos prejuicio ante situaciones con menos compromiso interpersonal.

El tipo de preguntas de las escalas utilizadas en este estudio para evaluar el prejuicio ${ }^{8}$, tratan de comprobar qué posición adoptaría el escolar ante situaciones cotidianas en relación a los colectivos étnicos diferentes al suyo. Davey (1983) se ocupó de cuestiones parecidas relacionadas con la población infantil en contextos multiétnicos, éste concluía su trabajo afirmando que las preferencias intergrupales de los niños estaban influidas por un sentimiento rudimentario de la posición social de los grupos en la comunidad. No diferenciaban en función de sus rasgos fenotípicos, pero sí cuando tenían que elegir llevarlos a su casa a jugar. Su opinión al respecto, coincidente con la nuestra, es que los niños se socializan en los prejuicios que existen en la sociedad. El niño aprende las relaciones que los agentes de su entorno mantienen con los diferentes colectivos (Davey, en Ramírez Goicoechea, 2007).

Por tanto, ante la reflexión sobre el por qué de las respuestas prejuiciosas del alumnado, argumentamos, que los niños reproducen actitudes hacia otras étnias en función de la socialización en la que se han visto envueltos (Davey, 1983; Hirscheld 1988, 1997; Toren 1993; Phylactou y Thoren, 1990). En el estudio cualitativo que desarrollaremos en próximos capítulos indagaremos sobre los mecanismos escolares que actúan en este proceso de socialización del alumnado.

Hipótesis 2. Relación existente entre los factores sociodemográficos y escolares y el nivel de prejuicio en el alumnado.

Los factores relacionados con las variables: "prejuicio" e "interacción social" que nos ofrecieron significación estadística fueron los siguientes: "la etnia", la "existencia de inmigrantes en el aula", el "género", el "nivel socio - económico del centro" y la "procedencia de los padres". A continuación vamos a realizar algunas interpretaciones justificadas bibliográficamente para entender los resultados obtenidos.

Hipótesis 2a.- Evaluar el nivel de prejuicio que manifiestan los alumnos pertenecientes a diferentes colectivos étnicos, estando clasificados dentro de las categorías: inmigrante, payo y gitano.

Los "gitanos" manifiestan más prejuicio hacia los inmigrantes que los "payos" en sus respuestas. Fernández Morate (2003), a partir de diferentes estudios sobre la población gitana en Castilla y León, considera que existen algunos factores que nos pueden servir para explicar esta relación entre prejuicio y etnia gitana. Por un lado, la trayectoria histórica del pueblo gitano ha manifestado cierto desapego a la institución

\footnotetext{
${ }^{8}$ El lector puede observar la escala utilizada en el estudio en la parte final del presente capítulo y/o en los anexos.
} 
escolar de los payos. La ausencia de este colectivo en las aulas está unida a una falta de motivación y desinterés creado por el desfase curricular en el que se encuentran (Fernández Morate, 2003, 261). Este absentismo demostrado en las aulas escolares de la actualidad, fácilmente podría generar una desubicación dentro del contexto escolar y sentirse aislados cuando llegaran al aula después de una larga ausencia. A su vez, este sentimiento de aislamiento puede ser interpretado como una exclusión que generaría sentimientos de rechazo hacia el resto de sus compañeros. Por otra parte la ausencia no permite que los programas de tolerancia y aceptación a las personas nuevas tengan su efecto.

Otro posible argumento que podría explicar las respuestas prejuiciosas del alumnado gitano hacia los inmigrantes, se refiere a la disputa económica ante las políticas sociales de integración. Los gitanos pueden sentirse como desplazados ante la llegada de los inmigrantes. Las ayudas sociales tienen que repartirse entre un colectivo mayor y ello provoca malestar en las familias que a su vez transmiten hacia sus hijos e hijas a través de mensajes negativos hacia el colectivo inmigrante. A partir de estas situaciones, las familias pueden construir valores, opiniones y creencias acerca del colectivo inmigrante que serán transmitidas a los hijos.

Algunos trabajos que nos ayudan a explicar las razones por las que los inmigrantes son los que menos prejuicio conductual manifiestan, son aquellos que justifican que las actitudes del grupo mayoritario hacia la minoría étnica suelen ser más negativas que las de ésta hacia aquél (Brand, Ruiz y Padilla 1974; Clark y Clark, 1939, 1952; Amir, Sharan, Rivner, Ben-Ari, y Bizman, 1979; Amir y Sharan, 1978). En los trabajos de Clark y Clark, (1952), preguntaban a diferentes niños con muñecas de distintos rasgos físicos y color, con quién preferían jugar, y cuál les parecía más bonita; y encontraban que tanto los blancos como los negros elegían la muñeca blanca y cuando se les preguntaba por la muñeca mala o con la que menos jugarían, ambos colectivos decían que la negra. Nuestros datos pueden apoyarse en cierta medida en estas teorías; el sentimiento de algunos inmigrantes de poseer un estatus social inferior, puede conseguir rebajar su nivel de autoestima y como consecuencia intentan equipararse, desprenderse de su grupo étnico para así parecerse al grupo mayoritario y de esta manera integrarse en él.

La identidad social ha servido según Tajeel, (1979), para proporcionarnos una distintividad positiva respecto a otros, hasta tal punto que si un grupo minoritario se define negativamente tenderá a realizar tres tipos de estrategias para modificar nuestro sistema de creencias y ser aceptados por el grupo mayoritario. Estos tres procesos son denominados por el autor como, movilidad individual (se intentaría abandonar el grupo para pasar a otro más valorado socialmente), creatividad social (redefiniríamos 0 modificaríamos las dimensiones comparativas) y competición social (trataríamos de 
superar al exogrupo en la misma dimensión de comparación en la que se percibían superiores). Las puntuaciones menores en prejuicio por parte de los inmigrantes podrían explicarse desde estos argumentos psico-sociales, que encuentran en el deseo de aceptación, la movilidad individual hacia el grupo mayoritario, realizando una selección perceptiva de lo positivo del grupo mayoritario al que van a pertenecer.

Hipótesis 2b.- Evaluar el nivel de prejuicio que manifiestan los alumnos de diferentes países de procedencia, siendo éstas las siguientes: Español, Marroquí, Europa del Este, Latinoamericano.

Respecto a esta variable no pudimos obtener resultados concluyentes debido al bajo número que constituían los grupos de las procedencias del alumnado. Sin embargo, los datos parecen indicar que existe una ligera tendencia que apunta a que son los alumnos españoles, los que muestran un índice mayor de prejuicio. Según las teorías psico-sociales, los grupos mayoritarios suelen mostrar más prejuicio que los minoritarios, ya que estos últimos, pretenden ser aceptados e integrados en un contexto social nuevo para ellos (Ovejero, 1998). sexos.

Hipótesis 2c.- Evaluar el nivel de prejuicio que manifiesta cada uno de los

El género es otro de los factores influyentes en nuestros resultados. Los niños de $5^{\circ}$ de los colegios públicos de Valladolid muestran puntuaciones más prejuiciosas que las niñas. Meaux y Lewis (1984) y sus colegas han mostrado que las mujeres están más predispuestas a cuidar de los demás y son menos autoritarias que los hombres. Ambos factores (ayuda y autoridad) se relacionan con las manifestaciones prejuiciosas (Ovejero, 1998). Los resultados obtenidos en nuestro estudio respecto al género, pueden ser apoyados desde las teorías que explican el papel que tradicionalmente se le ha otorgado a la mujer, se le ha asignado el rol de ama de casa y más dispuesta como consecuencia, a cuidar de los demás. Los psicólogos sociales evolutivos sostienen que las conductas entre sexos se diferencian en aquellos aspectos en los que se han tenido que adaptar. Es decir, desde el punto de vista darwiniano, biológicamente las mujeres se han tenido que adaptar a cuidar a los niños en las primeras edades por cuestiones anatómicas; aquellas mujeres que no tuvieran esta predisposición tendrían menos bebés que sobrevivieran. Así, por ejemplo, vemos en los estudios de Eagly (1996) que las mujeres tienden a manifestar comportamientos que se pueden describir como más sensibles y amistosos desde el punto de vista social y con más preocupación por el bienestar de los demás, mientras que los hombres tienden a comportarse de un modo más independiente, dominante y controlador. Y esto se debe a que los estereotipos culturales, a lo largo de la historia, han ido enfatizando estos patrones. Resumiendo, las puntuaciones obtenidas nos dicen que las niñas tienen menos prejuicio que los niños, pero nosotros añadimos un comentario al respecto: que 
los estereotipos de género se alejan a menudo de la realidad y resultan muy dañinos y son utilizados muchas veces como mecanismos de poder, dado que normalizan a partir de argumentaciones biologicistas estereotipos culturalmente construidos.

Hipótesis 2d.- Evaluar el nivel de prejuicio que manifiestan los alumnos en función del nivel socio-económico del centro en el que estén escolarizados, siendo medio y bajo las dos categorías establecidas.

Los resultados nos informan de la relación existente entre "prejuicio" y "nivel socio-económico" del centro. Los alumnos pertenecientes a entornos socioeconómicos más bajos muestran más prejuicio. Este resultado puede explicarse desde las siguientes teorías.

En primer lugar, consideramos que las clases más altas pueden haber recibido más formación y cultura por parte de sus familias y esto, favorece a que sus hijos no desarrollen categorizaciones cognitivas simples, que relacionen inmigración y delincuencia o peligrosidad. A las clases más bajas, sin embargo, se les atribuye un menor grado de formación y cultura por parte de los padres. Así mismo conceden menos importancia a la formación de sus hijos. Las categorizaciones que estas familias realizan pueden estar más influidas por los medios de comunicación o por los comentarios que se escuchan en la calle. Es decir, tendrán menos estrategias cognitivas para elaborar e interpretar la información que oigan al respecto. Doisey, Mugny y Perret-Clermont $(1975,135)$ muestran a través de estudios de laboratorio altamente validados que los sujetos de alto estatus, tienen criterios más firmes y estables que los de un estatus inferior. Estos individuos poseen por lo tanto, menor vulnerabilidad a las opiniones externas que los individuos con menor poder social.

Así mismo, desde otro punto de vista relacionado con las experiencias vividas, pensamos que las clases bajas suelen habitar en zonas o barrios donde se encuentra el mayor número de inmigrantes, por lo que la problemática se encuentra más cercana y por tanto, los choques también son más directos (Zarza, 2003). Es decir, no lo viven desde un nivel meramente conceptual como los pertenecientes a las clases más acomodadas, sino que es algo que ven a diario en la calle, en las tiendas del barrio, en sus pandillas, etc.

Otra razón por la que el prejuicio puede aumentar en estos centros categorizados como de "bajo nivel socio económico", se debe al alto número de gitanos escolarizados en dichos colegios. Los análisis estadísticos nos indicaron que era este colectivo el que subía en gran medida la media de prejuicio global. Sin embargo, los inmigrantes manifiestan una disposición conductual más alta a compartir experiencias con otras etnias diferentes a la suya. Es decir, son los gitanos los que reflejan tener más prejuicio, seguidos de los payos y/o españoles y por último, los inmigrantes. 
Hipótesis 2e.- Evaluar el nivel de prejuicio que manifiestan los alumnos en función de la procedencia familiar, siendo estas procedencias las siguientes:" padres inmigrantes", "padres españoles", "padres mixtos" y "padres con hijos adoptados".

Los resultados manifiestan que los alumnos cuyos padres son españoles, puntuaban significativamente con más prejuicio que el alumnado con padres procedentes de diferentes países, algo que parece encontrar coherencia con los resultados obtenidos al relacionar el "prejuicio" y la "procedencia del alumnado". Veíamos cómo los alumnos españoles, incluyendo en este grupo a los escolares pertenecientes a la etnia gitana, también presentaban una tendencia a mostrar más prejuicio que los alumnos inmigrantes, aunque no de forma significativa. Es decir, los alumnos españoles, así como los alumnos cuyos padres son españoles, muestran más prejuicio que los alumnos inmigrantes y que los alumnos cuyos padres también proceden de otros países diferentes al español. Lógicamente la familia es el primer contexto de socialización que del niño, es fácil por tanto que los escolares adopten las mismas valoraciones sociales que sus padres en cuanto a la diversidad étnica se refiere. Sabemos que los años escolares se caracterizan por la importancia creciente que cobra el contexto familiar en la socialización escolar. Los valores sobre la diversidad étnica, transmitidos durante la primera socialización, en el seno familiar, se manifiestan en el contexto escolar cuando interactúan con sus iguales (Díaz Aguado y Martínez Arias, 2001).

Hipótesis 2.f.- Evaluar el nivel de prejuicio que manifiestan los alumnos en función del tiempo de escolarización, estableciendo los tiempos del siguiente modo: "menos de un año", "entre uno y tres años" y "más de tres años".

Respecto a esta correlación entre "prejuicio" y "tiempo de escolarización", no obtuvimos resultados significativos. El tiempo que los alumnos llevan en la escuela no explica el prejuicio manifestado en sus respuestas.

Hipótesis 2.g.- Evaluar el nivel de prejuicio que manifiestan los alumnos en función de la convivencia en el aula con otros alumnos inmigrantes, en función de "la existencia o no de alumnos inmigrantes en cada uno de los grupos de clase de $5^{\circ}$ de primaria".

El resultado con mayor calado educativo quizá sea el obtenido al relacionar las variables "prejuicio" y "convivencia con compañeros de etnias diferentes al suyo". Esta relación nos indicaba que cuando los alumnos de etnias diferentes están en contacto, el prejuicio disminuye. La teoría o hipótesis del contacto, desarrollada a partir de Allport (1954), sustenta la idea de que la relación y el contacto con minorías conseguirá reducir el prejuicio de las mayorías, pero este cambio de actitud resultaría sólo, si el contacto interracial es cooperativo. 
Sin embargo, las conclusiones de las primeras investigaciones sobre los efectos de la integración de minorías en las aulas (Gerard y Miller, 1975; Gerard, 1983; Schofield, 1978) muestran una inconsistencia en sus resultados; mientras unos dicen que mediante la inclusión de estas minorías en las aulas, se consiguen mejores actitudes interétnicas (Jansen y Gallager, 1966; Mann, 1959), otros sugieren lo contrario (Dentler y Elkins, 1967; Taylor, 1967), también hay autores que proponen que la inclusión de minorías tiene efectos positivos sobre las actitudes de un grupo étnico y negativos para el otro (Kurokawa, 1971; Crooks, 1970; Mc Whirt, 1967) y finalmente, autores como Lombardi (1962) aseguran que no produce ningún efecto.

Troyna y Hatcher (1992) consideran que en los estudios de diferentes experiencias de campo basadas en la hipótesis del contacto, no es clara la causalidad, sólo la correlación. Indican, que no siempre es la relación de amistad la que contribuye a la erradicación de un prejuicio. Turner (1978) también critica la hipótesis e indica que ha de distinguirse entre atracción interpersonal y cohesión intragrupal.

Parece ser que la desegregación y la existencia física de minorías en las aulas podrían conducir automáticamente a la reducción de prejuicio, pero existen más investigaciones que nos demuestran que es necesario algo más que la inclusión física para que se produzcan efectos favorables (Amir, Sarna, Rivner, Ben-Ari y Bizman, 1979; Gerard, 1983). Existen otros factores de los que dependen los efectos positivos para el cambio de actitud, como son los siguientes:

- El porcentaje de alumnos en cada grupo, siendo el 50\% la óptima para proporcionar oportunidades que incrementen el contacto intergrupal (Dentler y Elkins, 1967).

- El nivel cognitivo superior conceptual ayuda también a conseguir resultados más favorables, ya que favorecen la comprensión de las condiciones sociales, culturales y económicas que subyacen a las diferencias étnicas (Glock et al. 1975).

- Proporcionar situaciones de contacto en las que los distintos grupos étnicos tengan un estatus similar.

- El tipo de relación, siendo los vínculos estrechos conseguidos mediante buenas metodologías cooperativas las que consiguen mejorar las relaciones y reducir el prejuicio (Schofield, 1978).

Estos resultados nos ponen de manifiesto que, si bien el mero contacto puede mejorar las relaciones, no lo asegura sino se tienen en cuenta estos factores mencionados. Según estas teorías podríamos presumir de la acción educativa del profesorado, considerando que si el prejuicio disminuye en los grupos donde existen alumnos inmigrantes, quizá se deba a que las dinámicas escolares dentro de las aulas 
se desarrollan en climas favorables y tolerantes, no existiendo en ellas, discriminación hacia los colectivos procedentes de otros países.

Fernández Enguita, Gaete y Terrén (2008), han publicado recientemente un estudio realizado a través de análisis de redes y mediante la utilización de técnicas sociométricas con alumnado nativo e inmigrante con el que podemos apoyar y matizar estas argumentaciones. En él se observa cómo, efectivamente, influye el número de alumnado inmigrante existente en cada aula, pero de manera compleja: apenas lo hace sobre los nativos, cuyo grado de endogamia no disminuye por ello, pero sí que lo hace sobre la posición y la actitud de los propios inmigrantes, que ven mejorar su estatus sociométrico y también refuerzan, en general, su conducta endogámica y como consecuencia el prejuicio (Fernández Enguita, Gaete y Terrén, 2008, 177). La cuestión es que esto afecta a dos debates frecuentes. El primero se refiere al efecto del aumento de la presencia de cualquier minoría en cualquier contexto, concretamente

Hipótesis 2.h.- Evaluar el nivel de prejuicio que manifiestan los alumnos en función de la adquisición o no de la lengua del país de recepción, en este caso la española.

El bajo número de alumnos con estas características nos impidió establecer alguna conclusión respecto a la relación entre prejuicio y tener adquirido el idioma del alumnado mayoritario, el español, en nuestro caso. Esta variable fue incluida porque pensábamos que el lenguaje podía ser un factor importante a la hora de establecer relaciones sociales. Nos parecía lógico pensar que el prejuicio podía aumentar en el caso de que exista una imposibilidad de comprender y expresar mensajes entre los iguales. La falta de entendimiento debido al desconocimiento del idioma puede provocar interpretaciones prejuiciosas por parte de los alumnos pertenecientes a los grupos mayoritarios, al considerar al alumno "no hablante", como más alejado de lo que para ellos es la normalidad. Esta relación será estudiada en el estudio cualitativo posterior.

Hasta ahora hemos argumentado los resultados que tenían que ver con el prejuicio, pasamos ahora a discutir los resultados referidos a las relaciones sociométricas.

Hipótesis 3.- Calidad de las Interacciones Sociales entre iguales.

Las puntuaciones sociométricas medias que obtuvieron cada uno de los grupos escolares evaluados manifestaban una calidad "buena" o "media". Creemos que existe una relación directa entre estas valoraciones sociales positivas y el clima escolar. Previsiblemente, con puntuaciones buenas, encontraremos un clima escolar positivo que favorecerá prácticas educativas eficaces. 
En la tabla 4.13 diferenciábamos los centros cuyas clases eran mayoritariamente minorías étnicas y los grupos más comunes donde las clases las conformaba alumnado étnicamente variado. Los primeros grupos, fueron los que obtuvieron mejores puntuaciones sociométricas. A continuación explicamos cinco razones desde las que podemos explicarnos este resultado:

La primera tiene que ver con la baja ratio profesor-alumno existente en estos grupos, que permite individualizar los procesos de enseñanza-aprendizaje y adaptarlos a las necesidades de cada alumno. Esto facilita el seguimiento de los procesos personales de los alumnos, así como la adecuación de los contenidos, métodos, estrategias y actividades pedagógicas; favoreciendo la construcción de un clima positivo en la clase (fomento de valores y buenas relaciones entre compañeros).

El segundo argumento es el referido a la intensidad y/o prioridad otorgada en el centro a la educación en valores. Las administraciones proporcionan a los colegios, con más problemática social, más orientaciones relacionadas con la implementación de actividades y programas relacionados con la educación en valores (al ser considerados como escuelas con más riesgo de conflicto). Por lo tanto, si se enfatiza curricularmente sobre el tema de las relaciones sociales, los resultados al respecto pueden verse influidos.

En tercer lugar y como consecuencia del anterior, puede que los profesores, aconsejados por la dirección, apliquen estos programas en mayor medida y se cree un clima escolar que prioricen los contenidos relacionados con la educación en valores sobre los meramente académicos, notándose de nuevo en los resultados.

Esto se relaciona con el cuarto argumento que se refiere a las bajas expectativas del profesorado proyectado en el alumnado, el cual, desmotivado ante la situación educativa en total desventaja en comparación con otros centros, y ante el posible sentimiento de indefensión, decide restar importancia a los contenidos académicos y dedicarse a trabajar otro tipo de aprendizajes más relacionados con las actitudes. Todas estas razones pueden ser las causantes de que se reduzca el nivel de competitividad existente en estos colegios y se cree un clima relajado entre los alumnos.

Por último, existe una razón bastante contundente referida al sentimiento endogámico existente entre el alumnado de estos grupos (al que contribuye la mejora de su estaus sociométrico y popularidad), y la encontramos en la cohesión social demostrada entre los gitanos. La cultura gitana otorga gran importancia a grupos sociales de su misma etnia. Los grupos familiares se extienden hasta cuartos lazos de consaguinidad. Tienen arraigado una vida en comunidad mucho mayor que la de la cultura paya, y aunque también tienen enfrentamientos entre diversas familias, es 
difícil ver a dos gitanos que no sepan a qué familia pertenecen. Además, tienen desarrollado un sentimiento gregario con el que empatizan con otros colegas de su mismo colectivo étnico (Fernández Enguita, 1999, 2008). Esto parece reflejarse en las puntuaciones sociométricas de las aulas formadas mayoritariamente por gitanos.

Hipótesis 3a. Evaluar con qué grupo sociométrico se corresponde cada etnia o lo que es lo mismo: ¿Qué alumnos categorizados en función de su colectivo étnico de pertenencia es las más "rechazada", "ignorada", popular" o "media"?.

Los alumnos inmigrantes y gitanos son los que peores valoraciones sociales obtienen. La mayoría de ellos se encuentran clasificados en la categoría de "rechazados" o "ignorados". Esto no significa que algunos alumnos inmigrantes sean considerados como "preferidos", pero la tabla 4.14 nos indica las proporciones tan desequilibradas en detrimento de las minorías étnicas.

Hablando de la etnia gitana, tenemos que diferenciar entre aquellos que se encuentran en clases donde la mayoría son gitanos (en este caso, la valoración es positiva) o si, por el contrario, el alumnado gitano está ubicado en grupos donde ellos constituyen una pequeña representación (entonces la valoración que reciben es negativa).

Podemos relacionar los resultados encontrados en esta hipótesis y los obtenidos en la hipótesis $2 a$. que nos explicaba la relación entre etnia y prejuicio manifestado. Los alumnos pertenecientes a la etnia gitana eran los que más prejuicio manifestaban $y$, como vemos ahora, también son valorados por los demás negativamente, ubicándose mayoritariamente en la categoría de rechazados en los grupos donde ellos son minoría.

Hipótesis 3b.- Evaluar con qué grupo sociométrico se corresponden los grupos de alumnos categorizados según la procedencia o lo que es lo mismo: ¿Qué procedencia es la más "elegida", "rechazada"," ignorada" o "media"?

La muestra no es suficientemente amplia como para poder establecer conclusiones respecto a la valoración social en función de la procedencia. No obstante, señalamos algún resultado general. Las puntuaciones obtenidas de los alumnos inmigrantes son mayormente negativas, sólo existen cuatro alumnos preferidos de los 46 totales. En concreto, los marroquíes son los que peor puntuados están, sin ser significativos los resultados, debido al escaso número de alumnos con procedencias diferentes del que disponíamos.

A falta de significación estadística, encontramos en los trabajos de Arnáiz y de Haro (2003) algunos datos que se corresponden con los nuestros, encontrando resultados que les llevan a describir al alumnado marroquí como de bajo nivel de integración. En su investigación, sólo el 11\% del mismo se halla en situación de 
integración y un escaso 1,5\% aparece como sujeto popular, al tiempo que tres cuartas partes son rechazadas y el otro $10 \%$ permanece en situación de aislamiento 0 marginación. La tónica general es de desintegración y exclusión debido a que el alumnado magrebí obtiene muchos rechazos y pocas elecciones por parte del grupo. Este resultado también se encuentra en la líneas de los encontrados en EEUU por Jackson et al. (2006), de los que resulta que los niños negros reciben por lo general nominaciones sociométricas más pobres que los blancos.

Algunos argumentos que pueden explicar el rechazo hacia el colectivo Marroquí, se refieren a los choques culturales que se pueden producir mediante la interrelación social entre alumnos con procedencias culturales diferentes. A este respecto Pajares (1998), considera que la cultura Marroquí, se encuentra algo más distante de la española que otras culturas como la latinoamericana, no sólo por la lengua, sino también por la estructura comunitaria, patrilínea y endogámica que consolida en los niños unos valores sociales distintos y a veces chocantes con los de los españoles. Sin embargo, los alumnos sufren en la escuela una resocialización que muchas veces no se ajusta a los patrones generales sociales. Es decir, los niños en la escuela establecen algunos vínculos en los que no se cumplen las creencias estereotipadas de la sociedad. Sobre todo en edades tempranas, la influencia social parece afectar en menor medida a la hora de establecer relaciones. Sin embargo, a medida que el alumnado va creciendo en edad, lo hace también en experiencias e influencias sociales. El contexto social, va adquiriendo un mayor peso en la selección de los vínculos de amistad que el niño establece conforme avanza la edad escolar.

Pensamos que en muchas ocasiones, el rechazo va unido al fracaso escolar. En la cultura escolar se valora positivamente al alumnado con buenos resultados académicos, quien no los tenga tiene más posibilidades de ser excluido por sus compañeros. De esta forma vemos como algunos estudios (CIDE 2003) apuntan que el colectivo Marroquí es el que demuestra menos éxito académico, seguido del dominicano. En palabras textuales leemos alguna de las conclusiones del estudio recién citado: "...Esta situación sugiere una especial problemática de los y las inmigrantes marroquíes para su inserción exitosa en el sistema escolar, que puede estar relacionada con unas mayores dificultades idiomáticas y de encaje cultural, así como con un mayor rechazo, marginación o prejuicios por parte del profesorado y del resto del alumnado".

Hipótesis 3c.- Evaluar qué grupo sociométrico se corresponde con los grupos de alumnos categorizados en función del tiempo de escolarización o lo que es lo mismo: ¿Qué grupos sociométricos pertenecen a los elegidos, los rechazados, los ignorados o los medios; los alumnos que llevan más tiempo en el colegio o los que llevan menos? 
El bajo número de alumnos inmigrantes de la muestra impide obtener conclusiones contundentes en cuanto a la relación entre tiempo de escolarización y aceptación. Sin embargo, a pesar de la inexistencia de significatividad estadística, extraemos alguna relación de interés que podemos observar en la tabla 4.16. Parece que la progresión en el tiempo responde al siguiente ciclo: la valoración social del alumnado que lleva menos de un año de escolarización se corresponde fundamentalmente con la categoría de "rechazado". A medida que el alumno va pasando más tiempo escolarizado en el centro, la situación social se va difuminando algo más y ocupa algún puesto en la categoría de "preferido" o "medio alto", pero siguen sin ocupar el puesto de "preferido". Algunos estudios (CIDE 2003) encuentran una alta correlación entre tiempo de escolarización y éxito escolar. Los escolares que llevan toda su escolarización en España tienen mucho menos fracaso que aquellos que realizaron los primeros cursos en sus países de procedencia y finalizan la primaria en nuestro país, esto se demuestra con el número de veces que repiten curso, siendo los recién escolarizados los que más repiten. El alumnado inmigrante necesita un período de adaptación para acomodarse a la nueva cultura y realizar algunos ajustes cognitivos. Este tiempo difiere en función de las características personales y del choque cultural que cada alumno encuentre en el país receptor.

Por otro lado es curioso observar cómo la categoría de "ignorado", es ocupada fundamentalmente por los alumnos inmigrantes que llevan más de un año en el centro (tal y como se verá de forma ejemplificada en el estudio etnográfico). Esto significaría que en un principio, la llegada del alumno nuevo al grupo produce un efecto novedoso en sus compañeros. Una vez pasado un curso escolar, estos alumnos parecen perder interés y se refleja en la valoración sociométrica obtenida al convertirse en "ignorado". Ante la imposibilidad metodológica del estudio para demostrar este asunto, decidimos analizarlo en el estudio cualitativo realizado posteriormente.

A partir de esta conclusión, destacamos la importancia de realizar seguimientos a estos alumnos inmigrantes a lo largo del tiempo, y reflejar además, dicho seguimiento en el plan de acogida que elabora cada centro. Sería un error dar por concluido el proceso de integración, una vez aprendido el idioma del país receptor.

Hipótesis 3d.- Evaluar qué grupo sociométrico se corresponde con los grupos de alumnos categorizados en función los resultados obtenidos en las escalas de prejuicio o lo que es lo mismo: ¿Quién tiene más prejuicio, el grupo de alumnos perteneciente a los elegidos, a los rechazados, a los ignorados o a los medios?

La categoría de alumnos "medios" y "rechazados" es la que más prejuicio manifiesta, seguidos de los clasificados como "medio bajo". Es decir, parece existir una relación lineal entre el grupo sociométrico y el prejuicio del siguiente tipo: cuanto más rechazado esté el alumnado por sus compañeros, más prejuicio manifiesta. Sin 
embargo, si el alumnado es considerado como "preferido", el prejuicio disminuye. Pareciera como si alrededor de los alumnos "elegidos" se generara un círculo positivo y sin embargo los "rechazados" se rodearan de lo contrario; cuanto más rechazo reciben, más prejuicio proyectan a los demás. Díaz Aguado (1988) establece un modelo explicativo en el que relaciona el rechazo de los compañeros con el aprendizaje de conductas desadaptadas y de baja competencia social del niño que lo recibe. La autora viene a decir, por tanto, que el niño que recibe rechazo o que es ignorado por parte de sus compañeros, es privado de las experiencias necesarias para su desarrollo y además contribuye al establecimiento de conductas y percepciones negativamente distorsionadas. Esta distorsión es la que pude explicar la relación entre alumno rechazado y prejuicioso.

\section{7. - Conclusiones}

La investigación llevada a cabo fue realizada con dos objetivos básicos: a) conocer el prejuicio hacia otras etnias por parte del alumnado de $5^{\circ}$ de primaria de los colegios de Valladolid y b) evaluar las relaciones sociométricas entre alumnos de diversas etnias y procedencias. Esta información nos ayuda a comprender el proceso de integración escolar del alumnado inmigrante, que estudiaremos en el estudio cualitativo.

Como se ha observado a lo largo de la exposición de los resultados, tanto el prejuicio como las relaciones sociométricas, se relacionan con factores como la etnia, la procedencia de los padres, el sexo, el nivel socioeconómico del centro y el hecho de convivir en el mismo aula con alumnos de diferentes colectivos étnicos.

El carácter exploratorio del estudio nos ofrece información sobre el prejuicio y las relaciones sociométricas existentes en los contextos educativos. Estas características tienen implicaciones importantes en el ámbito educativo, entre ellas podemos destacar las siguientes:

- Existen ciertas respuestas prejuiciosas en los escolares de $5^{\circ}$ de primaria de los colegios públicos de la ciudad de Valladolid, sobre todo cuando las preguntas se refieren a situaciones de interacción social más íntima.

- Los centros con un nivel sociocultural más bajo manifiestan más prejuicio que los centros con un nivel medio.

- Los alumnos que comparten experiencias en el mismo grupo-clase con compañeros de otras etnias diferentes a la suya, manifiestan menos prejuicio que los alumnos en cuyas clases no existen alumnado diverso.

- El alumnado gitano manifiesta considerablemente más prejuicio que los inmigrantes o los españoles. La mayor dificultad en cuanto a la diversidad étnica 
escolar se encuentra en este colectivo. Manifiestan más prejuicio ante los compañeros procedentes de otros países. Cuando están en clases donde ellos son una pequeña minoría, suelen ser considerados como rechazados, sin embargo, cuando en las clases donde apenas existen alumnos payos y ellos son la mayoría, las valoraciones sociométricas que se otorgan entre ellos son bastante buenas.

Las reflexiones más destacadas en el ámbito educativo referidas a las puntuaciones sociométricas, podemos resumirlas en las siguientes conclusiones:

- Las relaciones sociales, manifestadas en la sociometría, están asociadas al clima escolar y a la afabilidad existente en el ambiente de la clase. En general las puntuaciones de los centros de Valladolid demuestran que este clima es aceptable.

- El alumnado gitano e inmigrante ocupa categorías sociométricas de "rechazados" o "ignorados", mientras que los alumnos españoles y no gitanos tienen mejores valoraciones sociales ubicándose, en mayor proporción, en los grupos sociométricos de "preferidos" o "medios".

- Conforme va pasando el tiempo de escolarización, los alumnos inmigrantes van cambiando en la jerarquía sociométrica. En muchos casos, conforme pasa la "novedad inicial", pueden llegar a caer en el olvido, pasando a la categoría de "ignorados".

- El alumnado "rechazado" manifiesta más prejuicio que el alumnado "preferido". Existe una relación entre la aceptación de los iguales y la manifestación de prejuicio. Pudiéramos pensar que los iguales valoran de forma más positiva a aquellos compañeros respetuosos con los demás. Dicho de otra forma: los iguales toleran al que tolera.

- Según los análisis de nuestros resultados podríamos describir (prudentemente) un alumno "prototipo" que presenta posibilidades de mostrar un perfil socialmente menos competente, y es el alumno con índice alto de prejuicio, de sexo masculino, perteneciente a un centro de nivel socioeconómico bajo, que lleva más de unos meses escolarizado en el centro, que se encuentra en un grupo de clase homogéneo sin contacto con compañeros de otras etnias y perteneciente a la etnia gitana. Este perfi, no constituye, de ninguna manera, un modelo con el que clasificar la competencia social en las relaciones sociales, simplemente hace referencia a la tendencia hacia la que apuntan los resultados obtenidos en esta muestra y en este contexto.

Otras conclusiones, extraídas de las observaciones realizadas al acudir personalmente a lo colegios, han sido las siguientes: 
- Constatamos con preocupación que algunos colegios públicos, por lo general, los situados en los barrios obreros de la ciudad, se están o se han convertido en colegios "guetos" exclusivos para gitanos y minorías culturales desfavorecidas socialmente. En Valladolid, los colegios públicos que concentran en sus aulas un alto porcentaje de alumnado gitano, van camino de convertirse en colegios exclusivos para gitanos. Paradójicamente, es en estos centros, donde se encuentran los mejores resultados sociométricos. Pero lo más curioso de este hecho, es el escaso número de alumnado gitano existente en las aulas ordinarias. Las familias van sacando al alumnado payo cuando ven que se van escolarizando cada vez más gitanos. Podemos decir por tanto, que el sistema público educativo de esta ciudad, poco a poco está creando centros de gitanos y otros de payos. Los padres medianamente preocupados por la formación de sus hijos no quieren llevarles a estos centros donde serían la minoría. Esta es una nueva manifestación de la vieja segregación que ha existido durante toda la vida.

- El absentismo del alumnado gitano es uno de los principales problemas con los que nos hemos encontrado a la hora de evaluar al alumnado. Este problema, constituye también, una gran dificultad para trabajar con este colectivo en la escuela. Las causas de este fenómeno las encontramos al profundizar en las raíces de esta cultura: la incompatibilidad de las ocupaciones familiares con la asistencia regular a la escuela, la necesidad de las familias de que el hijo contribuya al sustento económico familiar, la ayuda en las labores del hogar, la participación en acontecimientos familiares y comunitarios, la falta de hábitos horarios para establecer rutinas cotidianas, la excesiva permisividad con lo que le apetece al hijo/a, la participación en las convenciones de jóvenes de la Iglesia Evangélica, las reuniones de oración en las casas de culto, etc. Todo esto desemboca en la poca importancia que tradicionalmente las familias gitanas han dado a la escuela. Así, (Ramírez Goicoechea, 2007, 224) señala que la apatía con la que el pueblo gitano ha mirado desde siglos todo lo que huele a escuela, disciplina, orden y obligaciones concretas de tipo escolar. El tanto por ciento elevadísimo de analfabetos que hoy día tiene el pueblo gitano de todo el mundo es un índice demostrativo de la poca importancia que los padres gitanos han dado tradicionalmente a la escuela. En este mismo libro, se expresa la siguiente afirmación: la escuela tradicionalmente ha sido considerada por mi pueblo como una cárcel. Actualmente se ha producido un avance en la escolarización del pueblo gitano, pero este problema sigue siendo el principal causante del desfase escolar, de unas malas relaciones con los compañeros (que no entre ellos), de la indisciplina y de las dificultades de integración en la comunidad educativa con alumnado "no gitano". 
- Los grupos escolares donde hay inmigrantes obtienen significativamente puntuaciones que reflejan menos prejuicio. Esto puede atribuirse a las buenas prácticas educativas de los docentes que crean climas favorables para la diversidad étnica y benefician las interacciones sociales entre alumnado étnicamente diverso. El contexto escolar es un ambiente favorable para trabajar la interculturalidad, la dificultad empieza cuando este colectivo sale del colegio. Consideramos favorable, por tanto, que existan grupos heterogéneos en cuanto a la etnia en los grupos escolares.

A lo largo de este capítulo hemos descrito algunos aspectos relacionados con el prejuicio y las relaciones sociométricas en el alumnado de $5^{\circ}$ de primaria de la ciudad de Valladolid. La razón por la que hemos decidido evaluar dichas cuestiones se encuentra en que los resultados obtenidos nos proporcionan información, desde el punto de vista de los escolares, sobre la integración escolar del alumnado inmigrante, que es el objetivo de esta tesis. A partir de aquí, analizaremos el proceso de esta cuestión, mediante un estudio cualitativo realizado en un centro educativo de primaria, durante un año escolar.

En este capítulo se ha expuesto el estudio extensivo o cuantitativo de la investigación. El esquema que hemos seguido para la explicación sigue el siguiente guión: primero formulamos los objetivos, describimos el planteamiento y diseño seguido en la investigación, concretando dentro de él, las variables y las hipótesis formuladas, así como los análisis estadísticos utilizados. Continuamos explicando los resultados de la investigación, comprobando las hipótesis, discutiendo los datos obtenidos y finalizamos con unas últimas conclusiones.

Las aportaciones de este primer trabajo nos sirvieron para obtener una primera aproximación acerca de las relaciones sociales en el alumnado inmigrante de quinto de primaria de los colegios públicos de Valladolid. A partir de esta información descriptiva y observacional (a modo de foto fija) decidimos realizar un segundo estudio cualitativo que nos acercara al problema de investigación desde otra perspectiva que tuviera más en cuenta el proceso del fenómeno. 


\section{Capítulo 6}

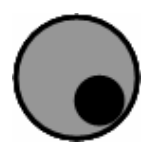

\section{Estudio etnográfico}

El propósito de este capítulo es describir la metodología utilizada en el segundo estudio llevado a cabo en un centro escolar de Valladolid durante el curso académico 2006/7. Se corresponde con la segunda fase de la investigación marcada por un carácter cualitativo. En la primera sección, exponemos el planteamiento general de la investigación, continuamos explicando la estructura conceptual de la etnografía con ayuda de una representación gráfica. Una vez que conocemos los pilares en los que se fundamenta el estudio, describimos las fases seguidas en el transcurso del trabajo, así como el procedimiento utilizado para analizar los datos y los criterios de calidad que validan el estudio. Por último, describimos la forma en la que decidimos estructurar y elaborar el informe final. 


\section{1.- Planteamiento de la investigación. Necesidad de realizar un estudio cualitativo}

Recordamos que el problema que pretendíamos analizar en esta investigación es el referido a la situación del alumnado inmigrante en el contexto escolar desde el punto de vista de los iguales. Con el estudio exploratorio inicial obteníamos una amplia visión de cómo este fenómeno se desarrollaba en los grupos escolares de $5^{0}$ de Primaria de Valladolid. Las escalas sobre prejuicio y la sociometría nos aportaron una panorámica general sobre cómo se producía el fenómeno prejuicioso y relacional en el alumnado.

Cuando conceptualizábamos la compleja naturaleza de las relaciones sociales dábamos cuenta del marcado carácter dinámico que las definía. El estudio descriptivo extensivo/cuantitativo previo nos impedía captar estos matices junto a otros que se suceden durante el proceso. Esto es lo que pretendemos estudiar en esta segunda fase.

En este segundo estudio analizamos el fenómeno de la interacción e integración escolar desde otro enfoque totalmente diferente. Pretendíamos conocer y comprender de cerca el proceso de integración y de socialización escolar de tres alumnos inmigrantes recién llegados a España y nuevos en el centro escolar.

\section{2.-Planteamiento metodológico: estudio etnográfico}

Se hacía necesario por tanto utilizar otra metodología que nos acercara a la esencia interna del problema, que nos describiera los detalles sobre la socialización y la integración escolar de las minorías étnicas. Para ello optamos por un enfoque cualitativo con el que observar la realidad educativa, indagando en el mundo personal de los sujetos, interpretando y acercándonos a las construcciones personales y sociales mediante las que los sujetos confirman la realidad educativa en contextos de interacción social y de relaciones con el entorno (Santos, 1998, Escudero, 1990).

En este marco y teniendo en cuenta nuestros objetivos, hemos optado por la realización de un estudio etnográfico (Hammersley y Atkinson, 1994; Díaz de Rada 1996, Velasco y Díaz de Rada, 1997,2004). En concreto, nos basamos en las líneas que plantean los profesores A. Díaz de Rada y $\mathrm{H}$. Velasco para las etnografías escolares. Estas líneas son plateadas desde un enfoque naturalista donde se consideran, además del contexto escolar, las influencias externas que atraviesan dicho contexto. 
Decidimos ubicarnos dentro de este paradigma más naturalista para realizar la investigación, porque queríamos conocer un fenómeno social dentro de un contexto concreto donde los sujetos se relacionan y en el que construyen sus significados de forma personal. Para conseguir esta perspectiva era necesario utilizar un enfoque cualitativo porque trabajar de este modo es entrar en la vida de otras personas con el sincero interés por aprender qué y por qué hacen o dejan de hacer ciertas cosas y qué piensan y cómo interpretan el mundo social en el que viven y se desenvuelven (Vázquez y Angulo, 2003). Además como indican Cohen y Mahion (1990,164), el investigador de un estudio cualitativo y etnográfico observa las características de una unidad individual, un niño, una pandilla, una clase, una escuela 0 una comunidad con el propósito de probar profundamente y analizar intensamente el fenómeno diverso que constituye el ciclo vital de la unidad. Arnaus $(1999,629)$ explica que los estudios cualitativos de enseñanza describen ejemplos prácticos de la realidad a enseñar. Provienen de la práctica educativa observada, documentada, sistematizada y presentada con más o menos extensión -relato, narración, exposición, descripción, etc. Son textos de mucha riqueza porque presenta un rostro humano de la realidad educativa y porque se relacionan claramente con la experiencia diaria. Cuentan situaciones e historias de lo que ocurre en las aulas e incluyen lo que dicen, hacen o piensan y sienten los protagonistas implicados -profesorado y estudiantes-.

Consideramos a esta metodología idónea para acercarnos a la naturaleza del estudio porque como afirma Martínez Bonafé (1990, 59): la observación sobre el terreno y la profundización en situaciones y campos particulares abre la posibilidad de obtener un conocimiento exhaustivo y cualitativo de fenómenos, hechos y problemas, sobre los cuales la tradición positiva, por su preocupación generalizadora, ofrece un tipo de información mucho menos significativa.

En este apartado veremos los siguientes epígrafes:

2.1.- Descripción de la estructura conceptual del estudio etnográfico

2.2.- Reconstrucción del proceso: antecedentes, diseño y trabajo de campo.

\section{1.- Descripción de la estructura conceptual del estudio etnográfico}

En este apartado describiremos la estructura general de los elementos que definen el estudio etnográfico. Para ello nos serviremos de una representación gráfica en la que hemos integrado todos los componentes que configuran el engranaje de dicho estudio. Puede ayudar al lector visualizar el esquema de la figura 6.1 mientras realiza la lectura de este epígrafe. 
En el cuadro que aparece en la parte inferior del dibujo reflejamos los objetivos del estudio, que van concretándose desde el general hasta las categorías analíticas, con enfoques distintos en cuanto a su precedencia: las etic ${ }^{1}$ y las emic. Las flechas ubicadas en el centro del esquema reflejan la porosidad o intercambio existente entre la información obtenida en el trabajo de campo y la reelaborada en el trabajo de mesa. Es en este último momento, cuando se reformulan las categorías extraídas de los observables y donde a su vez va tomando forma el discurso final del informe.

El objetivo o problema de investigación de nuestro estudio, formulado en forma de interrogante, es el siguiente:

- ¿Cómo es el proceso de socialización e integración escolar en el alumnado inmigrante nuevo?

Este planteamiento general se concreta en unos objetivos específicos, que fueron los siguientes:

- ¿Cómo influyen los códigos de la cultura escolar en el desarrollo de las interacciones sociales entre el alumnado inmigrante nuevo?

- ¿Qué choques culturales encuentra el alumnado inmigrante nuevo, cuando accede a nuestra cultura escolar?

- ¿Qué factores favorecen o inhiben el proceso de socialización y la integración escolar del alumnado inmigrante?

- ¿Qué momentos o fases comunes nos encontramos en el proceso de integración de tres alumnos inmigrantes nuevos en el centro escolar?

- ¿Podemos extraer algunos indicadores que reflejen el grado de integración-exclusión del nuevo alumnado?

En tercer lugar, describimos las categorías analíticas, denominadas por los etnógrafos. Estas nos ayudan a concretar y a focalizar las preguntas anteriores y además nos van aportando una guía con la que ir elaborando el discurso final. Como veníamos diciendo, a su vez, algunas de estas categorías fueron emergiendo durante el transcurso de la investigación (emic) y otras fueron establecidas desde el

\footnotetext{
1 Términos tomados del inglés. Etic: Discurso que basa su racionalidad fuera de un sistema. Emic: Discurso que basa su racionalidad dentro de un sistema particular. (Velasco y Dïaz de Rada, 1997, 35). Es decir, mientras el primero proviene de un planteamiento externo, que tiene en su mente el investigador, el emic, es aquel que va emergiendo del campo de trabajo. El intercambio y reformulación de las categorías de ambos enfoques, son las que va creando el discurso final de la investigación.
} 
principio (etic). Las categorías analíticas fueron surgiendo de una serie de preguntas que fuimos realizando en el transcurso del trabajo "mesa-campo-mesa", reformulando y extrayendo un discurso, siguiendo las líneas de la Graunded Theory o teoría enraizada ${ }^{2}$ de Glaser y Strauss, (1967). Estas categorías fueron las siguientes:

\section{¿Qué aspectos personales influyen en el proceso de integración escolar del alumnado inmigrante?}

- Situaciones familiares (etic): cultura, nivel económico, situación laboral y legal (emic), inserción en un grupo cultural cerrado (emic), participación en la vida del centro (emic)

- Rasgos de personalidad (etic): aquellos que ayudan o dificultan en el proceso de integración

- Habilidades sociales (etic)

- Habilidades motrices (etic)

- Rasgos físicos (etic)

- Rasgos culturales propios. (etic)

\section{¿Qué códigos culturales existen dentro de la cultura escolar?}

- Los códigos verticales (emic): organización de tiempos y espacios, comportamiento esperado en cada tiempo y espacio, normas académicas, exigencias académicas, protocolos de interacción docente-discente.

- Los códigos horizontales (emic): tipos de interacción entre iguales (contactos, bromas, tono de voz), oportunidad para cada acción ("qué acción y cuándo hacerla"), prácticas corporales dominantes y valoradas, condicionantes estructurales de los juegos para la integración, agrupamientos, interacción con personas de otro sexo o edad, jerarquías, uso de espacios, indumentaria.

- El aprendizaje de los códigos y de la predominancia de unos u otros según los momentos o la presión del grupo de iguales o de los adultos (emic).

- Los choques entre los códigos del centro (verticales y horizontales) y la socialización primaria del alumnado nuevo. Implicaciones para la integración (emic).

\footnotetext{
${ }^{2}$ Teoría que explica el itinerario de la información final que se obtiene en una etnografía. El proceso es el siguiente: en primer lugar, se rescata el observable (dato empírico), después se realiza una aproximación, incluyéndola en una categoría analítica, posteriormente, se reformula, comprobándolo de nuevo en el campo, de esta forma tendríamos la categoría analítica final y, en último lugar, se extrae la teoría final de todo este proceso.
} 
- Prejuicios y estereotipos; conflictos entre iguales por prejuicios; la fuerza de los grupos formados en el centro y la de los grupos formados fuera del centro (emic).

¿Cómo influyen en las interacciones sociales del alumnado inmigrante la presencia 0 ausencia del adulto en los diferentes contextos escolares: recreo, filas, servicios, clases formales, clases de apoyo?

- Espacios sin presencia directa del adulto (recreo, filas, servicios):

- Diferentes tipos de comunicación (emic).

- Aspectos, rasgos aprendidos en la cultura de la que proceden (emic).

- Relaciones sociales en función de la edad (emic).

- Relaciones sociales en función del sexo (emic).

- Acciones violentas (emic).

- Acciones prejuiciosas (emic).

- Espacios con presencia directa del adulto (clases formales y de apoyo):

- Aprendizaje de los códigos utilizados en las clases formales y en las de apoyo (emic).

- Relación con el profesorado (emic).

- Significado de la autoridad (emic).

¿Cómo influyen las acciones de atención al alumnado inmigrante en las interacciones sociales entre iguales? (plan de acogida)

- Procedimiento y protocolo seguido (etic).

- Agentes implicados y responsabilidades (etic).

- Viabilidad (etic).

- Posibilidades y limitaciones (emic): creencias y cultura profesional docente, choque entre demandas institucionales y práctica habitual: aspectos no abordados (recreos, actividades extraescolares, salidas).

¿Cómo influye la acción de los docentes en la integración escolar y en las interacciones sociales entre los iguales?

- Características generales de las interacciones sociales que se producen en las clases formales (emic). 
- Dependencia y autonomía del adulto (emic).

- Comprensión de los significados de los diferentes significados de los espacios físicos del centro escolar (emic).

- Idioma, lengua española (emic).

- Coordinación entre el profesorado (emic).

- Expectativas y prejuicios (emic).

- Agrupamientos y metodología cooperativa (emic).

¿Qué proceso sigue cada escolar nuevo en su proceso de integración? ¿Qué aspectos facilitan o dificultan el mismo? ¿Existen fases comunes a todos los procesos personales?

-El proceso de integración personal y las fases del mismo (emic).

-Fases comunes a los diferentes procesos (emic).

-Aspectos que facilitan o perjudican el proceso de integración (etic).

Por otro lado, nos encontramos con el contexto en el que se asienta la realidad del estudio. Resulta importante profundizar en las raíces individuales del estudio, pues es la manera de poder analizarlo y entenderlo desde el entorno en el que surge y se desarrolla. Por ello hemos tenido en cuenta tres aspectos: por un lado la historia de los padres, la familia, los alumnos de $5^{0}$ de primaria y los alumnos inmigrantes nuevos de este mismo curso; por otro, la legislación que regula el sistema educativo de educación primaria y por último, las investigaciones 0 estudios previos que hemos tenido en cuenta a la hora de elaborar este estudio de caso. Estos son los tres cuadrados que aparecen en la parte superior del esquema.

Dentro de este cuadro central, incluimos cuatro apartados que configuran el procedimiento del estudio. En primer lugar, los lugares físicos donde se realizó la investigación, fueron espacios, todos ellos escolares y pretendieron diversificar los lugares donde obtener información. Cada uno de ellos tiene significados diferentes tanto para el alumno como para el profesor. Estos fueron los siguientes: el recreo, las filas, los pasillos, las clases formales y las clases de apoyo.

Las técnicas de recogida de información y los documentos utilizados fueron los siguientes: la observación, que se plasmó en un diario de campo, las entrevistas y un diario personal de un alumno inmigrante que nos permitió contrastar la información desde el punto de vista de los sujetos investigados, y, por último, la sociometría en las clases donde se encontraban los tres alumnos inmigrantes del seguimiento. 
La estrategia metodológica que utilizamos se corresponde con el seguimiento de tres alumnos inmigrantes nuevos de $5^{\circ}$ de primaria de procedencia y sexo diferentes. Estas diferencias (género y procedencia) y semejanzas (mismo nivel educativo, situación de novedad en el centro y procedencia diferente a la mayoritaria) nos sirvieron para extraer una serie de reflexiones acerca de la cultura escolar y de la integración del alumnado inmigrante en este contexto. 


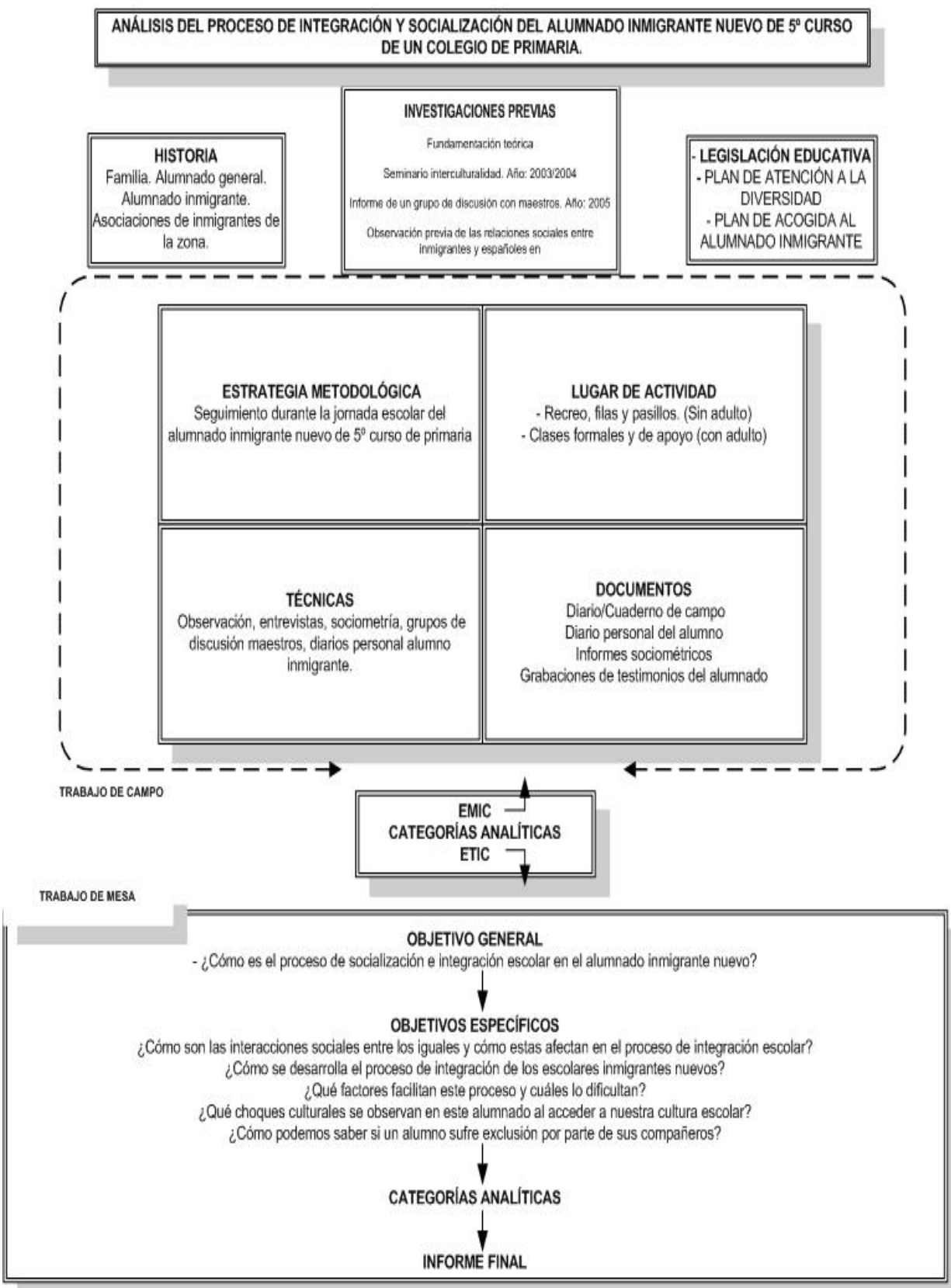

Dibujo 6.1. Estructura conceptual del estudio etnográfico. 


\section{2.- Reconstrucción del proceso}

A continuación pasamos a reconstruir el proceso que fuimos siguiendo en la elaboración del estudio etnográfico. Hemos establecido tres momentos en dicho proceso. Primero, donde narramos los antecedentes de la investigación. Segundo, donde describimos el diseño: la elección del centro educativo y la utilidad de los instrumentos de evaluación utilizados para el análisis de nuestro problema de investigación. En tercer lugar describimos el trabajo de campo realizado: el acceso al campo, los espacios y momentos para la recogida de la información y las técnicas e instrumentos de evaluación.

Los epígrafes en los que explicamos esta información se corresponden con:

2.2.1.- Primer momento: Antecedentes de la investigación

2.2.2.- Segundo momento: Diseño de investigación

\subsection{3.- Tercer momento: Trabajo de campo}

\subsection{1.- Primer momento: antecedentes de la investigación}

Antes de la realización del presente trabajo, existió un previo acercamiento al tema de estudio a través de diferentes actividades que tuvieron como denominador común el conocimiento de experiencias educativas con alumnos inmigrantes y en el análisis de las características encerradas en las relaciones sociales que establecían sujetos de diversa procedencia cultural. En la página siguiente adjuntamos una tabla donde se reflejan las actuaciones que se llevaron a cabo antes de la elaboración de este trabajo y que sirvieron como fuentes de conocimiento previo para la posterior formulación del problema de investigación. 


\begin{tabular}{|c|c|c|c|}
\hline \multicolumn{4}{|c|}{ ANTECEDENTES } \\
\hline$\underline{\text { ACTIVIDAD }}$ & $\underline{\text { TEMPORALIZACIÓN }}$ & $\underline{\text { CONTENIDO }}$ & $\begin{array}{l}\text { TÉCNICA } \\
\text { METODOLÓGICA }\end{array}$ \\
\hline TRIT & Curso escolar 2001/2002 & $\begin{array}{l}\text { Experiencia educativa } \\
\text { de aprendizaje } \\
\text { cooperativo en un } \\
\text { grupo escolar con un } \\
\text { alto número de } \\
\text { minorías étnicas. }\end{array}$ & $\begin{array}{c}\text { Aplicación y evaluación } \\
\text { de un programa } \\
\text { educativo }\end{array}$ \\
\hline $\begin{array}{c}\text { SEMINARIOS } \\
\text { PROFESORADO DE } \\
\text { PRIMARIA }\end{array}$ & Curso escolar 2003/2004 & $\begin{array}{c}\text { Compartir experiencias } \\
\text { educativas por parte de } \\
\text { los maestros con } \\
\text { alumnado inmigrante y } \\
\text { gitanos. }\end{array}$ & $\begin{array}{c}\text { Grupos de discusión } \\
\text { Observaciones en clases } \\
\text { de primaria con alumnos } \\
\text { inmigrantes }\end{array}$ \\
\hline $\begin{array}{c}\text { SEMINARIO } \\
\text { INTERCULTURALIDAD CON } \\
\text { PROFESIONALES } \\
\text { RELACIONADOS CON } \\
\text { COLECTIVOS } \\
\text { INMIGRANTES }\end{array}$ & Curso escolar 2003/2004 & $\begin{array}{l}\text { Exposición de diversas } \\
\text { experiencias no } \\
\text { formales con población } \\
\text { inmigrante por parte de } \\
\text { profesionales en } \\
\text { diversos ámbitos de } \\
\text { trabajo. }\end{array}$ & $\begin{array}{l}\text { Actas transcritas } \\
\text { Grupo de discusión }\end{array}$ \\
\hline $\begin{array}{l}\text { GRUPO DISCUSIÓN CON } \\
\text { PROFESORES DE } \\
\text { PRIMARIA EN CONTEXTOS } \\
\text { EDUCATIVOS RURALES }\end{array}$ & Noviembre 2005 & $\begin{array}{l}\text { Discusión sobre temas } \\
\text { relacionaos con la } \\
\text { integración de } \\
\text { inmigrantes en el } \\
\text { colegio }\end{array}$ & $\begin{array}{c}\text { Grupo discusión } \\
\text { Grabación de opiniones } \\
\text { de los maestros }\end{array}$ \\
\hline $\begin{array}{l}\text { OBSERVACIONES EN LAS } \\
\text { CLASES DE EDUCACIÓN } \\
\text { FÍSICA EN UN C.E.I.P. }\end{array}$ & $\begin{array}{c}2^{0} \text { trimestre. Curso escolar } \\
2005 / 2006\end{array}$ & $\begin{array}{c}\text { Compartir los } \\
\text { comentarios extraídos } \\
\text { de las actuaciones } \\
\text { educativas para } \\
\text { trabajar con alumnado } \\
\text { inmigrante. }\end{array}$ & $\begin{array}{c}\text { Observación } \\
\text { Entrevistas grabadas a } \\
\text { diferentes niños }\end{array}$ \\
\hline
\end{tabular}

Tabla 6.1. Antecedentes a la investigación.

\subsection{2.- Segundo momento: diseño de la investigación}

Tras la realización del trabajo extensivo, explicado en el apartado anterior, obtuvimos una panorámica sobre el problema de investigación. Pero, como ya hemos referido, necesitábamos indagar en otra dirección para conocer detalles más concretos del proceso que sigue una persona que llega nueva a un centro. La estrategia escogida para acceder a este tipo de información consistió en la realización de un seguimiento durante un curso escolar (septiembre-junio) a tres alumnos inmigrantes recién llegados a España, en un centro educativo determinado. Diseñamos un plan que consistía en observar la jornada escolar de estos tres alumnos de una forma intensiva durante el curso académico 2006/2007. Una vez elegido el centro, realizamos una selección de los instrumentos etnográficos básicos 
que nos podían servir para recoger la información: la observación y las entrevistas. Más adelante también decidiríamos utilizar otras técnicas como fueron; el grupo de discusión, la sociometría y el diario personal de un alumno inmigrante nuevo.

\subsubsection{1.- Elección del centro}

En primer lugar, antes de decidir en qué centro educativo realizar el estudio de caso, nos dirigimos a la Dirección Provincial de Valladolid y un inspector de educación nos ofreció la posibilidad de revisar las listas donde aparecían los niños escolarizados en los centros públicos de Educación Primaria. Buscamos un centro que tuviera las siguientes características:

- $\quad$ Al menos con dos alumnos inmigrantes de diferentes nacionalidades en el mismo curso, en $5^{\circ}$ de Primaria.

- Alumnado con procedencias diferentes, a ser posible que alguno no hablara español y fueran de diferentes sexos.

- $\quad$ Alumnado que acabara de llegar a España.

- Que hubiera alumnado gitano en el mismo grupo.

Uno de los centros reunía estas condiciones, con la ventaja adicional del conocimiento personal del director y del centro (por la labor educativa que desarrollé como maestra interina unos años atrás). Esta situación facilitó el acceso al centro y me concedieron libertad y autonomía para entrar en las aulas y presenciar las reuniones de padres y profesores.

2.2.2.2.- Instrumentos de recogida de información y su finalidad.

La observación de las relaciones sociales de estos tres alumnos en el centro escolar, las entrevistas a escolares y docentes, la sociometría en el momento inicial y final del curso académico y un diario personal de un alumno inmigrante nuevo fueron los instrumentos que seleccionamos a la hora de diseñar el estudio. Las dos primeras técnicas utilizadas protagonizan la metodología etnográfica. Ambas se complementan y contribuyen al control, fiabilidad y significatividad de los datos.

La observación proporciona el contraste objetivo con la realidad para compensar lo que subjetivamente a veces se dice en la entrevista. A su vez, la entrevista proporciona sentido a las acciones a veces incomprensibles que se observan, o corrige las inferencias a veces precipitadas a las que se llega tras la observación. Pero ambas técnicas hablan especialmente de dos tipos de información en el trabajo de campo. Éstas son: las descripciones y discurso del investigador (mediante la observación) y el diálogo proporcionado por el discurso 
ajeno de los sujetos del estudio (mediante las entrevistas). Las técnicas sociométricas se asemejan al tipo de información que nos ofrecen las entrevistas pero de una forma global. Nos permite contrastar los discursos entre los propios sujetos. Existe una heterogeneidad de accesos para obtener información, ya que la intención del estudio de caso es la de aprehender la totalidad y objetivarla.

Estos dos tipos básicos de información producida mediante las técnicas comentadas son indispensables para poder aludir a las categorías etic y emic. El resultado producido es una interacción de ambos tipos de discurso que pretende alcanzar un difícil y doble objetivo de comprensión: el de la comunidad científica y la de la población objeto de estudio.

El cuadro 6.3 resume el diseño de investigación explicado y los instrumentos utilizados para la recogida de información.

\begin{tabular}{|c|c|c|c|}
\hline \multicolumn{4}{|c|}{ DISEÑO DE LA INVESTIGACIÓN } \\
\hline$\underline{\text { ACTIVIDAD }}$ & TEMPORALIZACIÓN & CONTENIDO & $\frac{\text { INSTRUMENTOS DE }}{\text { EVALUACIÓN }}$ \\
\hline $\begin{array}{l}\text { ESTUDIO EXTENSIVO: } \\
\text { Evaluación del prejuicio e } \\
\text { interacciones sociales } \\
\text { entre el alumnado. }\end{array}$ & Noviembre-Febrero 2005 & $\begin{array}{l}\text { Evaluación del prejuicio } \\
\text { conductual } \\
\text { Evaluación de las } \\
\text { relaciones sociales en } \\
\text { contextos educativos con } \\
\text { minorías étnicas. }\end{array}$ & $\begin{array}{c}\text { Escalas } \\
\text { Técnicas sociométricas }\end{array}$ \\
\hline $\begin{array}{c}\text { ESTUDIO INTENSIVO: } \\
\text { Etnografía escolar. }\end{array}$ & Curso académico 2006/07 & $\begin{array}{l}\text { Análisis del proceso de } \\
\text { socialización escolar de } \\
\text { tres alumnos inmigrantes } \\
\text { de } 5^{\circ} \text { de primaria recién } \\
\text { llegados a España y al } \\
\text { centro educativo. }\end{array}$ & $\begin{array}{c}\text { Observación } \\
\text { Entrevistas a niños } \\
\text { Comentarios profesores } \\
\text { Técnicas sociométricas }\end{array}$ \\
\hline
\end{tabular}

Tabla 6.2. Diseño de la investigación

\subsection{3.- Tercer momento: trabajo de campo}

\subsubsection{1.- Acceso al campo y rol de la investigadora}

Una vez elegido el centro nos pusimos en contacto con su director. Mantuvimos una entrevista con él y le explicamos el propósito de la investigación y las necesidades de la misma. Mi propuesta tuvo una acogida muy favorable y ese mismo día, el director del centro, me presentó a los maestros tutores de $5^{\circ}$ curso y a las profesoras de compensatoria (a las que ya conocía personalmente). Unas 
semanas más tarde dio comienzo el curso y una vez en el centro fui presentada a otros docentes y familias.

El rol que adquirí en el centro fue evolucionando y adquiriendo significados diferentes para cada uno de los miembros que componían el centro educativo. En un primer momento fui presentada como una maestra que había trabajado en el centro y que iba a realizar un estudio con los alumnos inmigrantes de $5^{\circ}$. Fue curioso observar cómo cada uno de los componentes de la comunidad escolar se iba construyendo una idea diferente respecto al porqué de mi presencia en el centro. Las atribuciones realizadas tanto por el profesorado como por los estudiantes se manifestaban a través de las interacciones que mantenían conmigo.

Por un lado, los docentes-tutores identificaron mi papel en el aula como una ayuda para traducir la lengua del español al inglés. Después atribuyeron mi labor a la cooperación con las profesoras de compensatoria en los procesos de aprendizaje dentro de los apoyos. Las dos profesoras de compensatoria atribuían mis intenciones al deseo de conocer los progresos educativos del alumnado inmigrante, mientras que los alumnos, en un inicio, percibieron mi estancia en el centro como un agente evaluador hacia los alumnos que no tenían adquirido el español. Después empezaron a verme como una persona más del centro y esto ayudó a que la influencia en sus conductas se fuera diluyendo progresivamente. El alumnado inmigrante, en un principio, me veía como alguien a quien recurrir cuando no entendían alguna cuestión referida al idioma.

La forma verbal con la que me denominaba cada miembro de la comunidad escolar era significativa a este respecto. Los profesores tutores me llamaban por mi nombre, las de compensatoria me trataban como "la investigadora", de forma jocosa y los niños hablaban entre ellos refiriéndose a mí como "la traductora". A todos les sorprendía que no me separara de mi cuaderno de notas, de hecho, siendo esto motivo constante de comentarios jocosos. Puede que alguno de ellos estuvieran condicionado por esta imagen. Observar y apuntar notas en un cuaderno puede generar sospechas e inseguridades en los sujetos observados. Estos condicionantes, lejos de impedirnos observar la realidad tal y como es, nos sirvió para reflexionar acerca de las causas de estos comportamientos. Estas influencias en el modo de actuar explican los entresijos de la cultura escolar y contribuyen a la reflexividad ${ }^{3}$. Así por ejemplo, el dar la mano a una niña inmigrante nueva cuando la investigadora la está mirando, implica dos cosas: que el contexto escolar otorga importancia a que los alumnos ayuden al nuevo y/o indefenso y que esta alumna

\footnotetext{
${ }^{3}$ Contribuir a la reflexividad está relacionado con suministrar contexto. Son conceptos aportados desde la etnografía que enfatizan la idea de conocer toda la información que rodea al fenómeno de investigación para aprehender todos sus significados.
} 
conoce este discurso manifiesto en la cultura escolar, sabe que esta acción agradará a los profesores que lo vean.

\subsubsection{2.- Espacios y momentos para la recogida de la información}

La observación se realizaba durante la jornada escolar del centro, de 9:00h a $14 \mathrm{~h}$, salvo en el horario de verano en el que el colegio se cerraba una hora antes. Los primeros días acudíamos al centro diariamente y permanecíamos toda la jornada escolar. Conforme iba pasando el tiempo, fuimos adquiriendo ciertas rutinas y seleccionando de forma más precisa la información que nos aportaban ciertos momentos, por lo que el tiempo de observación se fue reduciendo. Los espacios que observamos fueron los siguientes: las aulas de clase donde se impartían las asignaturas, el gimnasio durante la clase de educación física, el aula de informática donde tenían la clase de alternativa a la asignatura de religión, el recreo, las filas y en alguna ocasión asistimos por la tarde, a una asociación de inmigrantes, ubicada en el mismo barrio, donde trabajan con estos mismos alumnos para reforzar las materias académicas. Los diferentes significados que la cultura escolar otorga a estos espacios nos ayudaron a ir organizando los datos y a ir elaborando las categorías analíticas con las que posteriormente analizaríamos la información.

\subsubsection{3.- Técnicas e instrumentos de recogida de información}

A continuación incluimos las técnicas utilizadas en el trabajo de campo. Estas fueron la observación (plasmada en el cuaderno y diario de campo), las entrevistas y/o comentarios de profesores y alumnos, el diario personal de un niño inmigrante y las técnicas sociométricas.

\section{A.- Observación: del diario al cuaderno de campo}

La observación realizada en el centro escolar podemos clasificarla como "no participante" y esta disposición tiene mucho que ver con la decisión del rol que adopté como investigadora en el colegio y a su vez con los objetivos del estudio. Si reprodujéramos en una gráfica los tipos de observador etnográfico y los situáramos en un continuo que va desde el totalmente observador hasta el totalmente participante, cada investigación se encontraría en un lugar aproximado dentro de este continuo. Mi intención era conocer y describir más que diagnosticar e influir, por tanto, no queríamos interferir en el desarrollo de los acontecimientos. Sin embargo, la "no participación" en determinados momentos se hacía imposible por cuestiones relacionadas con la ética del investigador. Así por ejemplo, en alguna ocasión se dio algún consejo que pudo haber influido en el objeto de estudio. Aunque estas ocasiones fueron muy escasas, creemos que simplemente la presencia del investigador en el campo ya es un modo de influir en el suceso de los acontecimientos. ¿Cómo?- Por las expectativas que se generan en el profesor 
observado, en la percepción del alumnado por sentirse evaluados, en el director que piensa en la imagen del centro hacia el exterior. Sin embargo, esto, lejos de desvirtuar nuestra investigación, lo utilizamos como medio para suministrar contexto, es decir, de explicar los significados, las razones y los modos en los que los sujetos son influenciados por la observación.

Todas estas observaciones las íbamos tomando a lo largo de la jornada escolar en un cuaderno de campo, aunque la premura con la que se sucedían determinados hechos, en ocasiones nos dificultaba tomar las notas. Al llegar a casa transcribíamos las anotaciones del cuaderno y realizábamos las consiguientes reflexiones, conformando de este modo, el diario de campo. Las anotaciones del día las copiábamos en letra negra y las reflexiones, análisis y orientaciones para las nuevas observaciones las escribíamos en letra roja para distinguirlas del material de campo.

En principio, las observaciones estaban principalmente centradas en los tres alumnos sobre los que hacíamos el seguimiento, apreciando sus interacciones 0 sus actitudes y gestos. Tal y como se recomienda en algunos manuales de investigación etnográfica (Velasco y Díaz de Rada, 1997), "nos dejamos perder" en el campo, empapándonos de lo que allí sucedía sin orientar demasiado nuestra observación. Son muchos los detalles a los que atender que se complican dado que se realiza el seguimiento a tres niños en dos grupos-clase diferentes, de manera que se llega a sentir cierta sensación de angustia por no poder recoger todos los detalles. En principio, orientamos nuestra mirada hacia los detalles que tenían que ver con "cómo se podía sentir la persona nueva" y "qué factores les ayudaban 0 dificultaban en su integración".

Durante los primeros días, el seguimiento de los tres alumnos elegidos nos fue llevando a otros niños y niñas inmigrantes, de manera que fuimos ampliando nuestra red de observación. Estas nuevas personas (hermanos y hermanas de los escolares elegidos, niños y niñas de la misma procedencia, niños y niñas que compartían con ellos las clases de apoyo, etc.) nos fueron mostrando más detalles sobre los diferentes procesos de integración.

Estos primeros días adoptamos una rutina de observación estructurada por tiempos y espacios. Recogíamos la información sobre la llegada al colegio y lo que ocurría en las filas de acceso al centro; acompañábamos en la subida a las aulas; observábamos el desarrollo de las clases ordinarias alternando entre los dos grupos de $5^{\circ}$ en los que había escolares nuevos; se acudía a las clases de apoyo y a las de educación física; durante los recreos, dado que cada grupo de escolares tendía a ocupar los mismos espacios, estructuramos un recorrido de observación para seguir a los diferentes niños y niñas inmigrantes nuevos y a algunas otras personas que 
iban cobrando importancia en la observación (principalmente alumnado gitano 0 personas rechazadas en el grupo); y también acudimos a las reuniones de profesorado con las familias.

A medida que avanzaba el curso se fueron añadiendo nuevos puntos de observación como los servicios, las reuniones informales de docentes o las sesiones de una asociación de ayuda a los inmigrantes que trabaja en aquel barrio y a la que acudían algunos de los niños observados.

En general, apreciamos que los momentos en los que los alumnos formaban las filas, subían o bajaban a clase 0 al recreo, cambiaban de aula 0 esperaban a que llegara el profesor nos aportaban interacciones sociales interesantes que debíamos observar. Sin embargo, las clases formales cada vez nos aportaban menos información debido al escaso protagonismo para interactuar con sus iguales que en este momento tiene el alumno. Era importante por tanto estar presente y alerta en esos momentos y por el contrario, ir recortando el tiempo de las observaciones en las clases formales. Otro suceso que ejemplifica la progresiva selección de los momentos de observación fue el de colocarnos unos minutos antes de que sonara la sirena (fin del recreo) en las filas que los alumnos realizaban para subir a clase. Así podíamos ver quiénes llegaban los primeros y quiénes los últimos, cómo se relacionaban en este lugar en el que no estaba el adulto directamente y qué significados tenían los códigos ${ }^{4}$ que utilizaban.

La reflexión tras la observación diaria va abriendo ciertos núcleos de interés que poco a poco se van convirtiendo en las líneas que orientan la búsqueda de información tanto a través de la observación como a través de entrevistas.

B.- Entrevistas. Información desde el punto de vista de los alumnos.

Las entrevistas se realizaron de dos formas: en el recreo o en momentos libres, aquí, preguntábamos sobre diversos aspectos acontecidos de los que requeríamos más explicaciones, de esta forma podíamos conocer la opinión de los niños y profesores y los contrastábamos con nuestras anotaciones. Era importante conocer las distintas perspectivas del triangulo profesor-alumno-investigador, para que las interpretaciones ganen en matices y se ajusten mejor a los significados dados por los protagonistas.

Muchas de estas informaciones las obteníamos a través de preguntas informales realizadas al hilo de algún hecho concreto (niños y niñas jugando con el

\footnotetext{
4 Un código es un sistema de reglas convencionales que se dan dentro de una relación social y cultural determinada. Entender los significados de estos códigos significa entender la cultura en la que se desenvuelven estos sujetos, las formas de hacer, incluso de sentir o de pensar.
} 
profesorado durante una clase o durante los cambios de materia) sobre el que intentábamos recoger la perspectiva de sus protagonistas.

Por otro lado, realizamos entrevistas formales, semiestructuradas a los alumnos de $5^{\circ}$ para conocer algunos aspectos relevantes de las relaciones sociales entre diversas étnias: elecciones, rechazos, amistades, causas de sus conflictos, etc.

C.- Sociogramas. Información de los alumnos para la evaluación global.

Los sociogramas se realizaron a los grupos de $5^{\circ}$ de Primaria en los que se encontraban ubicados los niños inmigrantes. Esta prueba nos servía para triangular los datos obtenidos con la observación y las entrevistas.

Fueron pasados al principio y al final del curso. La primera sociometría se pasó la cuarta semana de curso, de esta manera podíamos comprobar los primeros vínculos que se habían establecido entre los componentes de cada grupo. La segunda se pasó el $7^{\circ}$ mes con el fin de comprobar los cambios producidos a lo largo del curso.

Estas pruebas eran las mismas que se habían utilizado en el estudio extensivo (ya explicado) y que se pueden ver en los anexos incluidos en el CD.

D. - Diario personal de un alumno inmigrante nuevo de $5^{\circ}$

Las primeras semanas animamos a uno de los niños nuevos a que realizara un diario personal en el que fuera recogiendo sus apreciaciones sobre los primeros días de escolarización. El niño en cuestión sabía hablar inglés, de manera que utilizamos esta lengua como mediadora, él lo escribía en inglés y yo se lo iba traduciendo al español durante las clases en las que no tenía tarea. De esta forma él podía ir practicando con nuestro idioma.

En este diario escribía cómo se sentía, cuáles eran las principales barreras que se encontraba para integrarse en el grupo y poderse relacionar con sus compañeros. Las palabras en primera persona del sujeto investigado nos permitía acercarnos a la realidad que él mismo estaba viviendo, alejándonos así, de la realización de posibles interpretaciones subjetivas de nuestra parte.

Sin embargo, interpretamos que la limitación del idioma y nuestra presencia tan directa suponían una barrera a que él pudiera explicar en profundidad todas sus sensaciones y sentimientos. A pesar de ello obtuvimos algunas informaciones interesantes con las que completar la perspectiva de una persona nueva en un grupo. 
Intentamos poner en práctica este procedimiento con otra de las niñas evaluadas, pero los problemas de comunicación las primeras semanas eran muy grandes (no entendía ninguna lengua que nosotros conociéramos: francés o inglés) y tuvimos que desestimar esta opción.

La razón por la que tampoco se realizó el diario personal con los otros alumnos inmigrantes a los que evaluamos, se debió a su carácter tímido e introvertido, éste rehuía de cualquier acercamiento durante los primeros días. Con nuestra estancia prolongada y nuestro acercamiento progresivo logró que a mediados de curso nos contestara alguna pregunta.

\section{E..- Grupo de discusión previo al trabajo con maestros}

Previamente al trabajo de campo, realizamos un grupo de discusión con los maestros pertenecientes a un grupo de trabajo estable de la universidad. El objetivo era conocer la situación educativa de los inmigrantes en sus clases. Estos grupos de discusión fueron grabados en casete y con ello conocimos la visión del maestro respecto a este fenómeno. Recogimos información acerca de los siguientes aspectos:

3. Situación de los inmigrantes en sus colegios: grado de integración.

4. Principales dificultades educativas que encontraban los alumnos inmigrantes en el centro escolar y en concreto en sus clases.

5. Causas por las que ellos consideraban que los inmigrantes eran rechazados.

Esta información nos sirvió para enfocar la mirada los primeros días de acceso al campo.

\section{3. - Análisis de los datos}

A partir de la información obtenida diariamente se realizaba un proceso de contraste y análisis de la misma que nos llevaba a una reformulación de las categorías analíticas. El análisis de la información se producía mediante una interacción de trabajo de campo y de mesa. En esta interacción entre el trabajo de campo y la "mesa de trabajo" se van generando y transformando las ideas que van conformando el discurso final en un entramado de datos y argumentos.

En este tercer apartado veremos los siguientes epígrafes:

3.1.- Trabajo previo: antecedentes

3.2.- Sobre la mesa de trabajo 


\subsection{1.- Cuaderno y diario de campo}

\subsection{2.- Elaboración de categorías de análisis}

3.2.3.- Ejemplos de la evolución de un observable a una categoría analítica

\section{1.- Trabajo previo. Antecedentes}

Las actividades previas a la investigación y las lecturas bibliográficas sobre la temática configuraron y orientaron los interrogantes que guiarían el trabajo de campo. Este bagaje con el que la investigadora acude al campo supone una guía que orienta la mirada, tamiza la realidad a la que se presta atención, selecciona y condiciona los datos recogidos y supone una red de categorías (etic) con las que se ordenan y enfrentan dichos datos para realizar un proceso de análisis. Ello supone una primera "transformación" (Velasco y Díaz de Rada, 1997) de los fenómenos en datos. Así pues, el análisis de los datos iniciales no se hace "en vacío", sino guiado por una red de significados a veces restrictiva, otras orientadora, siempre condicionante.

\section{2.- Sobre la mesa de trabajo: como trabajo global}

\subsection{1.- Cuaderno y diario de campo}

La reflexión diaria sobre las notas de campo iba creando el diario de campo. Esto es un registro secundario realizado en la mesa de trabajo; sistemático, reflexivo e inteligible de lo que anotábamos de modo apresurado en el cuaderno de campo. Es aquí donde, la interacción entre trabajo de campo y de mesa iba produciendo la transformación del discurso. Aunque en el diario de campo, copiaba a veces literalmente lo que había escrito previamente en el cuaderno de campo, el diario implicaba, ya en el ejercicio de esta copia, una nueva captación de lo registrado, sin las urgencias de la observación sobre la marcha. Por otro lado, se construía un texto más elaborado que el registro inmediato. La etnografía exige llevar ambos tipos de registro para ir configurando el discurso etnográfico (Velasco y Díaz de Rada 1997, 98).

\subsection{2.- Elaboración de categorías analíticas}

Una vez transcritos los observables ${ }^{5}$ y realizadas las reflexiones oportunas en el cuaderno de campo, disponíamos de mucha información secuenciada en actas que correspondían a los días en los que realizamos las observaciones en el colegio. Después de leerlas varias veces, íbamos anotando en los márgenes, el tema al que

\footnotetext{
5 Un observable es un dato anotado durante el trabajo de campo. Este dato sin ser clasificado dentro de una categoría analítica no nos aporta información teórica, es un "dato mudo".
} 
pertenecía. Conforme íbamos leyendo las anotaciones y reflexiones del cuaderno de campo, estos temas se iban refinando hasta que pudimos establecer las categorías con las que organizaríamos la información y las que constituirían el eje transversal del estudio y del informe final. La evolución y depuración de las categorías analíticas $^{6}$ se fue produciendo conforme nos introducíamos en el campo, progresivamente íbamos conociendo la realidad del objeto de estudio. Estas categorías procedían de las lecturas teóricas y de los observables registrados en nuestro diario de campo. Es decir, cuantas más lecturas realizábamos del tema de estudio, más fertilidad se producía en la elaboración de categorías analíticas, esto se debía a la calidad de los significados que podíamos otorgar a estos datos observados. Velasco y Díaz de Rada $(1997,2004)$ nos dicen que la clave del proceso etnográfico es realizar profundamente un trabajo de ida y vuelta entre estas categorías analíticas y el campo. De manera que las categorías, que son interpretantes teóricos de la realidad, van siendo reformuladas, enriquecidas, corregidas, eliminadas 0 añadidas conforme producimos nuevos datos (Díaz de Rada, 2005,155).

Para enriquecer y contrastar con otras opiniones esta selección de categorías analíticas, fueron sometidas a una verificación de expertos. En este caso, nos aportaron una información complementaria los doctores Ángel Díaz de Rada, profesor de la asignatura "etnografía y técnicas de investigación antropológica" en la licenciatura de Antropología social y cultural (UNED) y autor de varios libros y artículos sobre esta temática y Alfonso García Monge, investigador que ha ido siguiendo este proceso de investigación y experto en investigaciones basadas en estudios cualitativos.

Para elaborar el discurso final fuimos siguiendo una secuencia que consolida la metodología etnográfica. Posteriormente exponemos un cuadro en el que resumimos las fases seguidas durante el análisis de los datos y posteriormente, ejemplificamos cómo se fueron elaborando las categorías analíticas hasta llegar a la elaboración del discurso e informe final.

\begin{tabular}{|l|l|}
\hline $\begin{array}{l}\text { 1- PROBLEMA QUE NOS } \\
\text { PROPONEMOS } \\
\text { INVESTIGAR }\end{array}$ & $\begin{array}{l}\text { - Antecedentes: TRIT, seminarios de maestros, seminario de expertos en } \\
\text { interculturalidad. }\end{array}$ \\
\hline $\begin{array}{l}\text { 2- TRABAJO DE } \\
\text { CAMPOICUADERNO DE } \\
\text { CAMPO }\end{array}$ & $\begin{array}{l}\text { - Utilización de técnicas para recoger información desde perspectivas ETIC y } \\
\text { EMIC: observación, entrevista y sociometría. } \\
\text { - Distribución y selección de espacios y tiempos en la observación. }\end{array}$ \\
\hline
\end{tabular}

\footnotetext{
${ }^{6}$ Las categorías analíticas expresan las intenciones teóricas del investigador, además reordenan o recodifican el flujo de los datos u observables y permiten comparar datos concretos producidos en otras situaciones (Hammersley y Atkinson, 1994).
} 


\begin{tabular}{|l|l|}
\hline $\begin{array}{l}\text { 3- REFLEXIÓN SOBRE EL } \\
\text { TRABAJO DE CAMPO. } \\
\text { DIARIO DE CAMPO * }\end{array}$ & $\begin{array}{l}\text { - Trascripción de las observaciones en actas diarias. } \\
\text { - Reflexiones sobre los observables en las actas transcritas. } \\
\text { - Asignación de temas a cada uno de estos observables en los márgenes de las } \\
\text { actas. }\end{array}$ \\
\hline $\begin{array}{l}\text { 4- ELABORACIÓN DE LAS } \\
\text { CATEGORÍAS } \\
\text { ANALÍTICAS* }\end{array}$ & $\begin{array}{l}\text { - Trabajo de ida y vuelta: del trabajo de campo al de mesa y viceversa. } \\
\text { - Verificación de expertos. }\end{array}$ \\
\hline $\begin{array}{l}\text { 5- ELABORACIÓN DEL } \\
\text { DISCURSO* }\end{array}$ & - Trama argumental \\
\hline
\end{tabular}

Tabla 6.3. Fases seguidas en el análisis de los datos.

\subsection{3.- Ejemplos: evolución de un observable a una categoría analítica}

En el subapartado que sigue ejemplificamos el proceso de ida y vuelta entre el trabajo de mesa y el de campo con el que elaboramos las categorías analíticas hasta llegar a la trama argumental. Por la gran extensión que supondría plasmar todos los observables del estudio, para que el lector se pueda hacer una idea del proceso seguido se han elegido dos observables sobre los que se desarrolla el itinerario que va siguiendo hasta convertirse en una categoría analítica. En los textos de las actas y diarios hemos añadido unos números entre paréntesis y negrita: "(1)" a modo de llamadas sobre las que realizar diferentes comentarios.

\subsubsection{1..- Ejemplo 1}

\section{A) Observables extraídos del acta}

Me voy entonces a la fila donde los de $5^{\circ} \mathrm{B}$ se colocan para entrar a clase. La gorra beige me ayuda a localizar fácilmente a Joseph (1). Allí está serio, tranquilo, aguardando su sitio en la fila sin hablar con nadie (2). Me acerco a él y le pregunto por qué ayer no estaba al terminar el colegio, su padre le estaba buscando. Él me dice que le esperó un rato y como tardaba se fue el sólo a casa porque se sabe el camino. Amani también va sola al colegio y se encarga de su hermano pequeño, son los únicos niños observados cuyos padres no están. Sin embargo Willy y su hermana pequeña Lisbet que va a $2^{\circ}$ de primaria, lleva tres años en España y su madre les acompaña al colegio (3).

(Diario, 12 de septiembre 2006)

B) Reflexión sobre el observable

Joseph parece un chico autónomo. Seguimos observando diferencias respecto a los alumnos españoles. Ninguno de ellos va solo al colegio, los padres les dejan en la puerta, algunos incluso entran para verles colocados en las filas y esperan a que suban. Sin embargo este alumno búlgaro va y vuelve solo al colegio. Amani también 
es una alumna nueva de Marruecos y va sola al colegio y se encarga de dejar en la fila correspondiente a su hermano pequeño. Otros alumnos búlgaros de $6^{\circ}$ curso también van solos al colegio, mientras que sus compañeros españoles son acompañados por algún adulto en su mayoría. Por el contrario, Willy, alumno procedente de la República Dominicana que lleva dos años en el colegio, es acompañado por un adulto. Quizá sea la distancia espacial o quizá el aprendizaje socializador de estos dos años, al ver que todos los niños son acompañados por sus padres, los causantes de que les acompañen. A esto unimos la información obtenida por la profesora de compensatoria con la que deducimos una alta responsabilidad en las tareas del hogar por parte de Amani y de otras niñas inmigrantes procedentes de Marruecos. Por tanto podemos pensar que muchos de los alumnos inmigrantes de este colegio manifiestan más autonomía en las actividades diarias que los españoles.

En la observación diaria surgen múltiples detalles que son apuntados, cada uno de ellos sugiere un tema. En ocasiones esos temas son retomados y van consolidando una línea de observación y análisis. En el fragmento de diario apreciamos tres temas:

(1) La indumentaria: puede dar origen a una línea de observación sobre los contrastes culturales de la indumentaria, la modificación de ésta para adaptarse a los usos de sus compañeros, la posible discriminación o bromas surgidas a partir de la misma, etc.

(2) Sugiere esa observación varios temas para el análisis y el seguimiento tales como la evolución de la actitud del niño; la obediencia a las normas verticales u horizontales; 0 su actuación en momentos en los que las normas no son claras.

(3) La autonomía y responsabilidad dada al alumnado por las familias de diferentes culturas.

Apreciamos que la reflexión de aquel día se centraba en este tercer aspecto. Ello nos habla sobre los énfasis que la investigación puede ir cobrando a ritmo diario. En ocasiones, la observación y la reflexión pueden verse condicionadas y orientadas en una dirección, abandonando otras líneas del fenómeno. Sobre ello nos gustaría hacer dos apreciaciones en torno a nuestro estudio:

Conocedores de estos condicionantes, optamos desde el primer momento por intentar apuntar todos los detalles, frases y situaciones. De esta manera, aunque en un primer análisis (diario, a ritmo de observación) no hiciéramos referencia a ciertos temas, contábamos con la información para un segundo análisis. De hecho, los temas (1) y (2) del ejemplo citado fueron objeto de seguimiento y análisis posteriormente. 
Cuando el trabajo de observación y reflexión es sistemático y prolongado hay ciertos núcleos que van cobrando importancia y otros que se van descartando.

La observación continuada va aportándonos múltiples temas. Su agrupamiento y el contraste con las categorías etic formuladas en la planificación del estudio nos van sugiriendo las categorías analíticas finales. Así, en el ejemplo anterior los temas mencionados terminarían perteneciendo a las siguientes categorías:

(1) - Códigos horizontales y verticales

- Choques o diferencias culturales

(2) - Fases del proceso de integración

- Códigos horizontales y verticales

(3) - Choques o diferencias culturales

\subsubsection{2.- Ejemplo 2}

A) Observables extraídos del acta

Suena la sirena: Joseph está en la fila enredando con el balón de fútbol (1). Willy va al servicio, pasa delante de mí y me saluda. Las niñas juegan a las palmitas, Rodrigo es el único niño que se ha implicado a fondo en el reto de conseguir jugar bien a las palmitas (2a). Joseph, Willy y Pablo por detrás poniéndole los cuernos y haciéndole burla (2b). Este intenta asustarles con un gesto violento para que dejen de hacerle burla, pero no se dan por aludidos, sigue jugando con Sofía. Suben las escaleras: Sofía y Rodrigo siguen jugando a las palmitas haciéndolo cada vez más deprisa y sin importarle lo que digan de él (2c).

Willy está al lado de Joseph (3). Joseph abre una ventana pequeña del pasillo y la deja abierta (sabiendo que no debe hacerlo) y se ríe (4). Entre ellos se pegan pataditas al subir las escaleras para tropezar (5a). Amani sube tranquila sin hablar con nadie (5b).

(Diario, 6 de noviembre 2006)

B) Reflexión sobre los observables

Vemos cómo sólo hay un niño que participa en la cultura lúdica femenina con el juego de las palmitas. Esta acción es objeto de burla por el resto de niños que están a su alrededor porque jugar a juegos de niñas es considerado dentro de los códigos de la cultura escolar del alumno masculino como algo mal visto.

Por otro lado, Willy va aprendiendo de los códigos de sus compañeros de clase a los que quiere integrarse. Él ha aprendido que infringir la norma del profesor 
puede ser causa de admiración, por eso realiza pequeñas "travesuras" como lo de abrir la ventana mientras estos compañeros le miran.

En la narración aparecen varios detalles que van definiendo tanto la "cultura escolar" y sus "códigos y usos" como el proceso que siguen los críos observados para adaptarse a ello. Así tenemos:

(1) Nos habla este tema sobre la evolución del alumno nuevo y sus formas de estar en cada lugar, cada vez más acordes con lo que ha ido viviendo en las primeras semanas de clase.

(2) Las prácticas corporales y su división por géneros (2a); las formas de presión para que nadie se aleje de la norma horizontal establecida (2b), así como la unión de los nuevos a estos grupos de presión (es decir, cómo los nuevos se convierten en defensores de la pureza de las normas); y el grado de seguridad que los niños del grupo tienen como para salirse de las normas establecidas (2c) (una seguridad aún no alcanzada por los nuevos).

(3) Las uniones y dependencias entre los nuevos.

(4) El juego con la norma vertical como código horizontal (satisfacción de los iguales burlando la norma del adulto).

(5) Los usos de interacción entre iguales (5a) y las diferencias en función del género (5b).

Como se aprecia en el tema (2) cada situación presenta múltiples caras. Un mismo hecho nos habla de cada uno de sus protagonistas, del contexto cercano en el que se inscriben las acciones (y las normas que lo regulan), así como del contexto cultural que cruza dicha situación y que marca y condiciona lo sucedido (escolarización, cultura lúdica tradicional en función de géneros, modelos familiares, agentes de socialización extraescolares...). De hecho, el observable del ejemplo se presta a múltiples categorizaciones. Este es un problema con el que nos hemos enfrentado continuamente en este trabajo (al igual que otros etnógrafos 0 investigadores naturalistas). En el ciclo de observación-análisis-categorizaciónnueva observación hemos precisado de una doble estructura:

3. Por una parte seguíamos una estructura prefijada que atendiera a aspectos formales (etic) y que nos ayudase a orientarnos minimamente y a organizar tanto la observación como el análisis. En el ejemplo mostrado, el tema (2) se situaría dentro de una de estas categorías etic: las interacciones del alumnado sin la presencia del adulto -los tiempos de filas y subida a clase-.

4. Por otra, manteníamos una estructura abierta a los temas y categorías emergentes (emic) que nos fuesen mostrando nuevos matices y significados 
del proceso de integración de este alumnado. En el ejemplo mostrado, el tema

(2) pertenecería a una categoría sobre los códigos horizontales que regulan las interacciones entre iguales.

La evolución que hemos plasmado del observable a la categoría analítica responde a la posición social del investigador etnógrafo. Debe ubicarse en un lugar intermedio entre el campo donde observa y la reflexión teórica posterior. Una posición "dentro - fuera" entendida del siguiente modo: el etnógrafo no sólo ha de estar dentro estando en parte fuera, sino que, estando dentro del campo, ha de saber mantener una identidad variable y diversa. Cualquier posición que rompa este equilibrio de fuerzas debe ser advertida inmediatamente en el ejercicio reflexivo que se hace al redactar el diario, pues de ese equilibrio depende buena parte de la calidad etnográfica de la información que registramos (Velasco, y Díaz de Rada, 1997,109).

Así pues, la combinación de la estructura, tanto de categorías preestablecidas como de categorías emergentes, fue constituyendo el entramado argumental sobre el que componer nuestro análisis y elaboración del informe final. En el cuadro siguiente se muestra la relación de temas y categorías fruto de la interacción trabajo de campo y de mesa.

\section{OBJETIVO GENERAL DEL ESTUDIO CUALITATIVO.}

¿Cómo es el proceso de socialización e integración escolar del alumnado inmigrante de $5^{\circ}$ de primaria nuevo en el colegio?

\subsection{OBJETIVOS CONCRETOS (específicos)}

- ¿Cómo son las interacciones sociales entre los iguales y cómo éstas afectan en el proceso de integración escolar?

- ¿Cómo se desarrolla el proceso de integración de los escolares inmigrantes nuevos?

- ¿QQué factores facilitan este proceso y cuáles lo dificultan?

- ¿Qué choques culturales se observan en este alumnado al acceder a nuestra cultura escolar? ¿Cómo podemos saber si un alumno sufre exclusión por parte de sus compañeros?

\subsubsection{NUCLEOS TEMÁTICOS DEL ESTUDIO (que nos aproximan a las categorías analíticas).}

- Aspectos personales influyentes en el proceso de integración del alumnado inmigrante.

- Códigos culturales escolares existentes en el alumnado y en el profesorado.

- Interacciones sociales entre iguales en los diferentes contextos escolares: recreos, filas, clases, apoyos.

- Influencia en las interacciones sociales, entre iguales, de las acciones del centro para atender al alumnado inmigrante: plan de acogida. 
- Influencia en las interacciones sociales, entre iguales, de las acciones educativas de los docentes en el aula.

- Choques culturales encontrados en el alumnado inmigrante al acceder a nuestra cultura escolar.

- Características de las interacciones sociales, entre iguales, que reflejan si se produce adaptación escolar o no.

\subsubsection{CATEGORÍAS Y SUBCATEGORÍAS ANALÍTICAS.}

- ¿Qué aspectos personales influyen en el proceso de integración escolar del alumnado inmigrante?

- Situaciones familiares (etic): cultura, nivel económico, situación laboral y legal (emic), inserción en un grupo cultural cerrado (emic), participación en la vida del centro (emic)

- Rasgos de personalidad (etic): aquellos que ayudan o dificultan en el proceso de integración

- Habilidades sociales (etic)

- Habilidades motrices (etic)

- Rasgos físicos (etic)

- Rasgos culturales propios. (etic)

¿Qué códigos culturales existen dentro de la cultura escolar?

- Los códigos verticales (emic): organización de tiempos y espacios, comportamiento esperado en cada tiempo y espacio, normas académicas, exigencias académicas, protocolos de interacción docente-discente.

- Los códigos horizontales (emic): tipos de interacción entre iguales (contactos, bromas, tono de voz), oportunidad para cada acción ("qué acción y cuándo hacerla"), prácticas corporales dominantes y valoradas, condicionantes estructurales de los juegos para la integración, agrupamientos, interacción con personas de otro sexo o edad, jerarquías, uso de espacios, indumentaria.

- El aprendizaje de los códigos y de la predominancia de unos u otros según los momentos o la presión del grupo de iguales o de los adultos (emic).

- Los choques entre los códigos del centro (verticales y horizontales) y la socialización primaria del alumnado nuevo. Implicaciones para la integración (emic).

- Prejuicios y estereotipos; conflictos entre iguales por prejuicios; la fuerza de los grupos formados en el centro y la de los grupos formados fuera del centro (emic).

¿Cómo influyen en las interacciones sociales del alumnado inmigrante la presencia 0 ausencia del adulto en los diferentes contextos escolares: recreo, filas, servicios, clases formales, clases de apoyo?

- Espacios sin presencia directa del adulto (recreo, filas, servicios):

- Diferentes tipos de comunicación (emic).

- Aspectos, rasgos aprendidos en la cultura de la que proceden (emic).

- Relaciones sociales en función de la edad (emic).

- Relaciones sociales en función del sexo (emic).

- Acciones violentas (emic).

- Acciones prejuiciosas (emic).

- Espacios con presencia directa del adulto (clases formales y de apoyo): 
- Aprendizaje de los códigos utilizados en las clases formales y en las de apoyo (emic).

- Relación con el profesorado (emic).

- Significado de la autoridad (emic).

¿Cómo influyen las acciones de atención al alumnado inmigrante en las interacciones sociales entre iguales? (Plan de acogida)

- Procedimiento y protocolo seguido (etic).

- Agentes implicados y responsabilidades (etic).

- Viabilidad (etic).

- Posibilidades y limitaciones (emic): creencis y cultura profesional docente, choque entre demandas institucionales y práctica habitual: aspectos no abordados (recreos, actividades extraescolares, salidas).

¿Cómo influye la acción de los docentes en la integración escolar y en las interacciones sociales entre los iguales?

- Características generales de las interacciones sociales que se producen en las clases formales (emic).

- Dependencia y autonomía del adulto (emic).

- Comprensión de los diferentes significados de los espacios físicos del centro escolar (emic).

- Idioma, lengua española (emic).

- Coordinación entre el profesorado (emic).

- Expectativas y prejuicios (emic).

- Agrupamientos y metodología cooperativa (emic).

¿Qué proceso sigue cada escolar nuevo en su proceso de integración? ¿Qué aspectos facilitan o dificultan el mismo? ¿Existen fases comunes a todos los procesos personales?

-El proceso de integración personal y las fases del mismo (emic).

-Fases comunes a los diferentes procesos (emic).

-Aspectos que facilitan o perjudican el proceso de integración (etic).

Tabla 6.4. Estructura conceptual del estudio etnográfico.

\section{3.- Elaboración del informe}

La siguiente fase de la etnografía fue la elaboración del informe. Para ello debíamos reorganizar toda la información obtenida y plasmarla en un informe legible para el lector. Las categorías analíticas nos fueron guiando y ayudando a estructurar las líneas argumentales del informe. Nuestra intención era acoger toda la complejidad de la información obtenida, pero atendiendo a la necesidad de ser inteligible. Como señalan Taylor y Bogdan (1992, 179): el propósito de la investigación no es sólo incrementar la comprensión de la vida social por parte del investigador, sino también compartir esa comprensión con otras personas. 
Es difícil transmitir al lector lo mismo que sabemos o hemos visto nosotros, por lo que necesariamente, mostraremos una disección de la realidad en la que quedan señalados unos aspectos y omitidos otros, tal y como señalan Taylor y Bodgan (1992, 153): en todos los estudios los investigadores presentan y ordenan los datos de acuerdo con lo que ellos piensan que es importante. Esta posible subjetividad debe ser entendida por el lector, ya que como señalan Reason y Rowan (cit. en Pérez Serrano, 1994b, 131): Mi postura es algo que yo aprecio, es parte de mí como investigadora. Mientras es importante para mí y para otros el reconocer que esa es mi postura personal, es conveniente enfatizar que eso es, en realidad, lo que yo puedo dar como investigadora, que esa es mi contribución, que es coherente sentirla como tal y que tiene otras muchas características que me hace valorarla más que un esfuerzo distanciador con el fin de ser objetivo. Yo trabajo desde una posición particular, aprecio las otras posiciones y sé que cada una tiene su propia integridad y su propia validez.

Compartir el trabajo de campo es complejo, la información se carga de sentimientos y valores difíciles de trasladar a otras personas. El valor que nosotros atribuimos puede ser interpretado de forma diferente por otras personas y no provocar los mismos efectos. Además es complejo intentar sumergir al lector en los contextos, situaciones y tiempos que nosotros hemos vivido. Las decisiones que hemos tomado para organizar la información y que esta cobre más fuerza y sentido se refieren a: la elección de una estructura para organizar y presentar la información, y decidir el nivel de profundidad y detalle de la narración.

\subsection{1.- Elección de una estructura para organizar y presentar la información.}

Como hemos ido explicando, no partíamos de ninguna estructura prefijada puesto que estábamos abiertos a lo que fuera surgiendo de la experiencia. Los temas y categorías iban agrupándose en subtemas y pequeños apartados estrechamente interrelacionados entre ellos. Estos eran "temas emergentes", en palabras de Taylor y Bodgan $(1992,161)$ y en ellos íbamos viendo cierta lógica con la que presentar la información. Así pues, la información nos permitía hablar de: un contexto educativo y unos espacios diferentes dentro del mismo, de interacciones sociales con y sin presencia del adulto, de aspectos culturales y del proceso de socialización de los alumnos nuevos en el centro escolar.

Estos títulos fueron la línea básica para estructurar el informe y los epígrafes y detalles correspondientes se fueron introduciendo dentro de estos apartados que conformaron la estructura básica. A partir de esta idea general de la estructura del informe se fue distribuyendo la información recogida en el diario de campo, en las entrevistas y en las sociometrías. Un proceso de etiquetado, corte y 
pegado, de forma agrupada, de lo más rudimentario, tal y como describen Taylor y Bodgan (1992) o Pérez Serrano (1994b). Se optó por esta forma manual y no utilizar ningún programa informático pues como sugieren Guba y Lincon (cit. En Pérez Serrano, 1994b, 127) lo que se gana en mor de una supuesta objetividad, se pierde en capacidad de respuesta; en adaptabilidad para recoger información de forma simultánea sobre múltiples factores y a diversos niveles; en la perspectiva global; la adquisición de una mayor amplitud de conocimientos; en la oportunidad de depurar y sintetizar los datos en el acto y volver a ellos ante una demanda de clasificación, corrección o ampliación y en un análisis en estrecha relación con otras fases del proceso de investigación. En definitiva, pensamos que al manejar directamente los datos, el investigador toma más consciencia del "mapa general" de la investigación, de los caminos que sigue y de las interrelaciones y significados que subyacen de los mismos.

\subsection{2.- Decisiones sobre el nivel de profundidad y detalle de la narración.}

Para elaborar una tesis doctoral no es suficiente el saber cómo organizar la información, sino que hay que saber qué registro se usará. Esto nos pone en una disyuntiva muy bien descrita por Sicilia $(2004,62)$ cuando explica: el período de escritura de una tesis doctoral encierra, según mi experiencia, un dilema importante, al tener que presentar un trabajo que cubra las expectativas de "objetividad" de una comunidad científica, pero al mismo tiempo no apague las vivencias que son ya parte del investigador. Para nosotros es un placer sumergirnos en las narraciones que recuerdan los momentos de la experiencia en el campo, cada vez que se releen salen nuevos detalles, pero este entusiasmo es difícil transmitirlo al lector. La realidad es imposible de repetir y para compartirla hay que retocarla como sugiere uno de los personajes de la obra de Simenon "las memorias de Maigret" $(2004,40)$ : La verdad nunca parece verdadera. Y eso ocurre no sólo en la literatura o en la pintura. No le citaré tampoco el caso de las columnas dóricas cuyas líneas nos parecen rigurosamente perpendiculares, pero que producen esta impresión porque están un poco curvadas, ¿me entiende?...cuéntele usted cualquier historia a alguien. Si no la retoca, le parecerá artificial y poco creíble. Retóquela, y será más auténtica que la realidad. Debíamos elegir una forma de presentar lo ocurrido sin repetir todo lo ocurrido. Se ha optado por usar un registro que se mueve entre lo particular y lo genérico, en el que se han ido tomando algunos ejemplos significativos de los que se intentan deducir situaciones más amplias y extrapolables. Se han utilizado en la construcción del informe elementos de distinta índole, como los descritos por Ericsson (1989): asertos empíricos, viñetas narrativas, citas del diario de campo, de las entrevistas, comentarios de profesores, de la investigadora, de los alumnos, descripciones generales, descripciones teóricas e 
informaciones sobre el proceso de estos alumnos inmigrantes. Según este autor, estos elementos permitirán a la persona que se acerque a los datos: experimentar de forma vicaria el medio que se describe y comparar prototipos de asertos fundamentales y de constructos analíticos; examinar todo el espectro de pruebas sobre las que se base el análisis interpretativo; y considerar los fundamentos teóricos y personales de la perspectiva de la autora.

Veamos más detenidamente la estructura que adoptó el informe final del estudio de caso.

\section{ANÁLISIS DE LAS INTERACCIONES SOCIALES ENTRE IGUALES EN DIFERENTES ESPACIOS ESCOLARES.}

1- INTERACCIÓN ENTE IGUALES SIN LA PRESENCIA DIRECTA DEL PROFESOR EN LA CULTURA ESCOLAR. LAS FILAS DE SUBIDA A LAS AULAS Y EL RECREO. CHOQUES CULTURALES DE LOS ALUMNOS CON OTRAS PROCEDENCIAS: COMUNICACIÓN, GÉNERO, AGRESIVIDAD, PREJUICIOS Y CULTURA LÚDICA EN DIFERENTES ESPACIOS ESCOLARES.

a. Análisis de las interacciones sociales entre iguales en el recreo: procesos sociales del juego.

b. Análisis de las interacciones sociales entre iguales en las filas de subida a clase: choques culturales, prejuicio, agresión.

2- INTERACCIONES ENTRE IGUALES CON LA PRESENCIA DIRECTA DEL PROFESOR. EL PLAN DE ACOGIDA, CLASES FORMALES, CLASES DE EDUCACIÓN FÍSICA Y LOS APOYOS DE COMPENSATORIA: ¿CÓMO INFLUYEN LAS ACTUACIONES DEL CENTRO Y DEL PROFESORADO EN LAS INTERACCIONES SOCIALES CON ALUMNOS INMIGRANTES NUEVOS.

a. Análisis del Plan de Acogida y su influencia en las interacciones entre iguales: organización escolar.

b. Influencia de las metodologías, utilizadas en las clases, en las interacciones sociales entre iguales: aprendizaje cooperativo.

ANÁLISIS DEL PROCESO DE SOCIALIZACIÓN ESCOLAR DE TRES ALUMNOS INMIGRANTES NUEVOS EN EL CENTRO.

3- ACERCAMIENTO A LA CULTURA ESCOLAR DESDE TRES SITUACIONES DIFERENTES: FASES EN LAS INTERACCIONES SOCIALES DE TRES ALUMNOS INMIGRANTES NUEVOS.

a. Narración de las fases seguidas en los procesos personales

b. Explicación de los factores que intervienen en los procesos personales de los tres alumnos.

C. Acciones educativas realizadas durante el proceso.

4- CHOQUES CULTURALES EN EL ALUMNADO INMIGRANTE AL ACCEDER A LA CULTURA ESCOLAR

5- ASPECTOS QUE FACILITAN Y DIFICULTAN EL PROCESO DE INTEGRACIÓN ESCOLAR

6- INDICADORES DE EXCLUSIÓN

Tabla 6.5. Estructura del informe final 


\section{4.- Los criterios de calidad para validar el estudio etnográfico}

El observador se acerca a la realidad y transforma los fenómenos en datos. A su vez los datos son analizados, agrupados e incorporados a un discurso argumental para ser presentados. ¿Qué procedimientos aseguran que en este proceso la información que recibe el lector no es una construcción completamente alejada de la realidad de la que se partió?

Repasaremos las cualidades esenciales del procedimiento e instrumentos utilizados para valorar si la investigación ha sido desarrollada adecuadamente y si sus resultados se pueden considerar legítimos y merecedores de confianza. Explicaremos los criterios de calidad de ambos estudios según la clasificación que establecen algunos autores.

De entre las propuestas que diferentes autores han abordado dentro del ámbito metodológico de la investigación cualitativa (Guba, 1983; Goetz y Le Compte, 1988; Santos Guerra, 1990; Arnal, Del Rincón y Latorre, 1992; Colás y Buendía, 1992; Pérez Serrano, 1994b; Del Rincón et. al., 1995), tomamos la propuesta realizada por Guba (1983). Este autor traduce como credibilidad (la validez interna de los estudios analíticos) al criterio regulativo del valor de verdad 0 veracidad; como transferibilidad (validez externa o generalización de las investigaciones cuantitativas) a la aplicabilidad del estudio; dependencia (fiabilidad en términos cuantitativos) a la consistencia de las aportaciones; y confirmabilidad (paralela a la objetividad de los estudios empírico analíticos) que aseguraría la neutralidad de los descubrimientos. Adaptamos un cuadro resumen de Colás y Buendía $(1992,274)$ para expresar el paralelismo entre los criterios de calidad de ambos estudios realizados en esta investigación.

\begin{tabular}{|c|c|c|}
\hline $\begin{array}{l}\text { CREDIBILIDAD } \\
\text { (Validez interna) }\end{array}$ & $\begin{array}{l}\text { Valor de verdad: Isomorfismo } \\
\text { entre los datos recogidos por } \\
\text { el investigador y la realidad }\end{array}$ & $\begin{array}{cc}\text { - } & \text { Observación persistente } \\
\text { - } & \text { Triangulación } \\
\text { - } & \begin{array}{c}\text { Recogida de material } \\
\text { referencial }\end{array} \\
\text { - } & \text { Comprobaciones con los } \\
\text { participantes }\end{array}$ \\
\hline $\begin{array}{l}\text { TRANSFERIBILIDAD (Validez } \\
\text { externa) }\end{array}$ & $\begin{array}{l}\text { Aplicabilidad: Grado en que } \\
\text { pueden aplicarse los } \\
\text { descubrimientos de una } \\
\text { investigación a otros sujetos y } \\
\text { a otros contextos. }\end{array}$ & $\begin{array}{l}\text { - Muestreo teórico intencional } \\
\text { - Descripción exhaustiva } \\
\text { - Recogida de abundantes datos }\end{array}$ \\
\hline
\end{tabular}




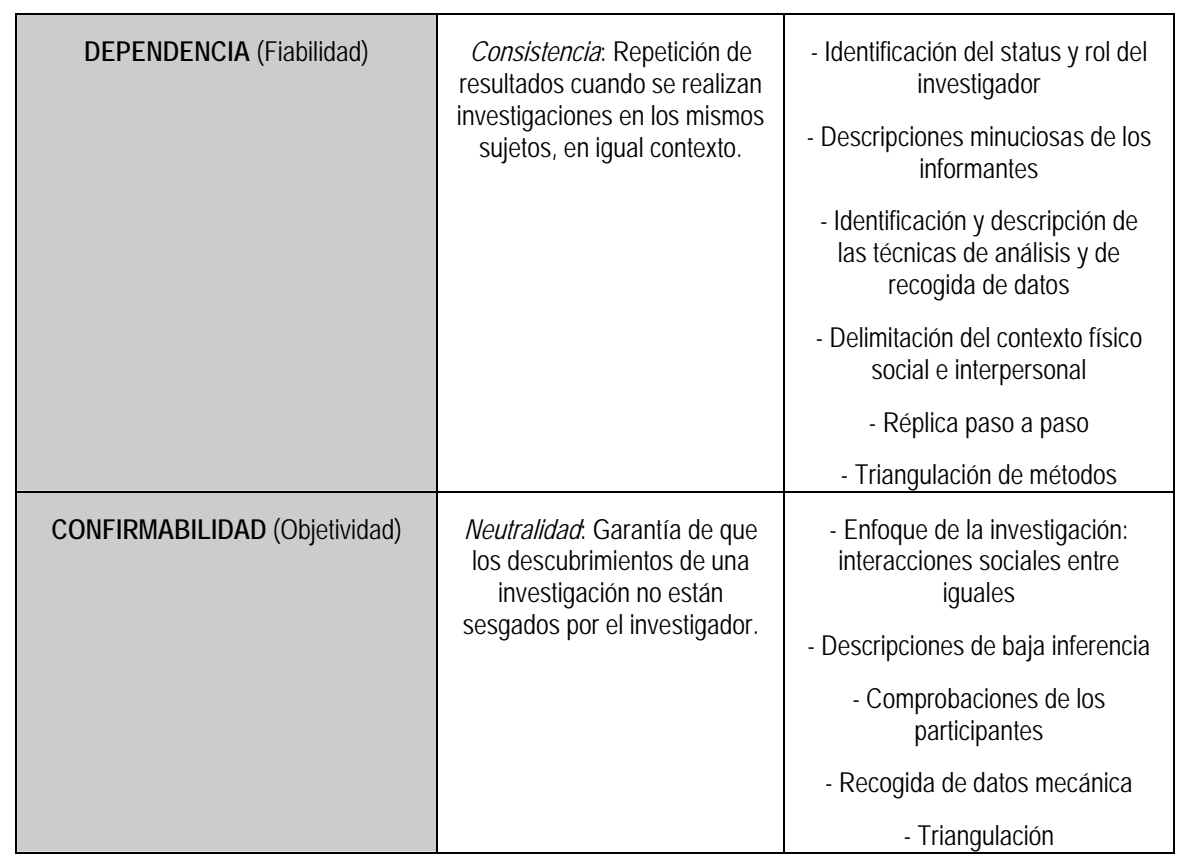

Tabla 6.6. Adaptado de Colás y Buendía (1992, 274).

Veamos punto por punto en qué medida esta investigación reúne estos criterios de calidad. Es decir, expliquemos los criterios por los que creemos que esta investigación se acerca a la realidad y no responde a una invención.

\section{1- Credibilidad. Validez interna}

El objetivo es demostrar que la investigación se ha realizado de forma pertinente, garantizando que el tema fue identificado y descrito con exactitud (Del Rincón et al. 1995, 225), es decir, se comprueba que los datos obtenidos son representaciones auténticas de la realidad.

En cuanto a los procedimientos descritos por Colás y Buendía en el cuadro anterior para garantizar la credibilidad de la información obtenida en nuestra investigación, tenemos:

- Trabajo prolongado y observación persistente: Consideramos que el seguimiento se ha realizado durante un tiempo suficiente como para asegurar la credibilidad de los datos. Se ha llevado a cabo una observación persistente y un trabajo durante un curso escolar que han ayudado a ir conociendo en profundidad el contexto. 
- Triangulación: Según Kemmis (1981) se trata de un control cruzado entre diferentes fuentes de datos: personas, instrumentos, documentos o la combinación de éstos; Elliot (1993) explica que no es tanto una técnica de supervisión como un método más general cuyo principio básico subyacente es el de recoger observaciones de una situación, de algún aspecto de ella, desde una variedad de ángulos 0 perspectivas, utilizando distintos tipos de pruebas, de manera que después se puedan comparar y contrastar; Dezin (cit. en Santos Guerra, 1990) lo define como la combinación de metodologías en el estudio de un mismo fenómeno. En nuestro caso se han procurado diferentes formas de triangulación:

- De métodos: utilizando narraciones de las actas y reflexiones de las mismas por el investigador, comentarios de los profesores, entrevistas con el alumnado, técnicas sociométricas.

- De momentos: analizando tras la práctica en reuniones con la maestra especialista, analizando al día siguiente de la práctica, analizando posteriormente con la revisión de los vídeos.

- De expertos: poniendo a juicio de otros colegas de la Escuela Universitaria de Educación nuestra experiencia.

- Recogida de material de adecuación referencial: Durante todo el proceso se han dejado abundantes pistas e informaciones como para comprender las situaciones concretas en las que se generaron: vídeos, diapositivas, narraciones desde diferentes perspectivas, comentarios posteriores y entrevistas nos han permitido volver una y otra vez a confirmar o detallar lo sucedido.

- Comprobación con los participantes: Las situaciones de comprobación que se han realizado tienen que ver con la verificación de expertos a la hora de ir generando las categorías analíticas.

\subsection{Transferibilidad. Validez externa}

Refleja la posibilidad de aplicar los resultados a otros contextos, aunque lo contextual y particular de las investigaciones cualitativas llevan a establecer cautelas, evitando las generalizaciones. Guba $(1983,150)$ plantea la disyuntiva entre la posibilidad de generalización, pero cayendo en la falta de relevancia, o la búsqueda de un rigor interno que por referirse a algo más real no pueda ser trasladado a otras realidades:

Los que proponen el planteamiento racionalista han insistido en que el criterio más importante para medir la calidad de una investigación es su rigor, mientras que los que defienden el naturalismo afirman que es relevante. La distinción se ha caracterizado a veces como la diferencia entre decir: "no importa lo 
que hagas, en tanto que lo hagas bien" en contraposición con decir: "algo que no valga la pena hacer en absoluto no vale la pena hacerlo bien". Estos dos criterios merecen atención, pero desgraciadamente se encuentran enfrentados: cuanto más insiste uno sobre el rigor (validez interna), y lo asegure mediante el tipo de control posible en el laboratorio, menos relevancia (validez externa) puede esperarse, ya que los resultados se aplicarán sólo en otro laboratorio.

Sin embargo, estos estudios, aunque no se traduzcan en aplicaciones instantáneas a otros contextos, sí pueden servir para iluminar otras realidades en la medida que sugieran ideas a personas con problemas o sensibilidades afines, tal y como indican Ebbut y Elliot $(1985,14)$ : Los lectores de un estudio de casos pueden indentificarse con el problema del investigador y de este modo conseguir nuevas comprensiones sobre sus propios problemas. A este proceso de validación es al que Stake (1998) denomina "generalización naturalística".

En nuestro caso hemos visto que esta experiencia puede ser una buena referencia para maestros y maestras por acercar la perspectiva del alumno, conocer sus problemas, sus puntos fuertes, sus necesidades educativas. Así mismo puede servir para la organización de los centros educativos a la hora de elaborar el plan de acogida de los alumnos inmigrantes.

Siguiendo el guión propuesto por Del Rincón et. al.(1995), sobre las estrategias que aseguren la transferibilidad, tenemos que en esta investigación se ha adoptado:

- Muestreo teórico: Como señalan Del Rincón et. al. $(1995,257)$ se busca maximizar la cantidad de información recogida para iluminar los hechos o situaciones a la hora de comparar escenarios y contextos múltiples para descubrir lo que es común y específico. En este caso se aportan abundantes datos sobre diferentes aspectos del proceso para que el lector se haga una idea más clara de las peculiaridades de nuestro caso y de cómo se han producido los hechos.

- Descripción densa: De igual forma se realizan exhaustivas y minuciosas descripciones del contexto que pueden ayudar a establecer correspondencias con otros contextos y hacer así más extensivas las generalizaciones.

- Recogida de abundante información: Los fragmentos de narraciones, actas, comentarios de los profesores, entrevistas a los alumnos, sociogramas, pueden permitir que las personas que se acerquen a los datos que se presentan se hagan una idea ajustada de lo ocurrido, las decisiones tomadas, los problemas surgidos, las reflexiones asociadas, y las nuevas hipótesis surgidas. 


\subsection{Dependencia. Fiabilidad}

Con el fin de garantizar que los resultados se pudieran repetir, si se volviese a realizar la investigación con los mismos sujetos en idéntico contexto se establecieron varios procedimientos. Siguiendo a Goetz y Le-Comte (1988), se realiza una descripción de las relaciones entre el investigador principal y los participantes que clarifique para nuevos investigadores el status y rol del mismo; se ha aportado una descripción de la forma en la que se llevó a cabo la investigación. Describir en detalle cómo se realizó el trabajo puede ayudar a conseguir este criterio de calidad. Sin embargo, el objetivo de este estudio es describir una realidad y compararlo con otras lecturas realizadas para poder acercarnos a un modelo explicativo del fenómeno. Esto dificulta conseguir resultados idénticos si aplicáramos otro estudio semejante

\subsection{Confirmabilidad. Objetividad}

Del Rincón et. al. $(1995,258)$ dicen que la confirmabilidad consiste en confirmar la información, la interpretación de los significados y la generalización de las conclusiones. Es decir, se trataría de mostrar la objetividad de los datos y de las interpretaciones que de ellos se derivan, algo complejo en la investigación cualitativa en la que la realidad es analizada por unas lentes concretas que a su vez van cambiando a medida que se van obteniendo nuevos datos. Sin embargo, hay ciertos procedimientos que pueden asegurar que el informe presentado no surge de una visión única sino que nace de la intersubjetividad y, por tanto, se encuentra algo más desligado del sesgo que el investigador puede introducir. Entre estos procedimientos seguidos, tenemos:

- Aproximación a la realidad del alumnado: El hecho de evaluar las interacciones sociales entre iguales, de fijarnos en el proceso de integración desde las propias experiencias del alumnado, nos permite acercarnos a este criterio.

- Auditoría de confirmabilidad: En ella se controlaría la correspondencia entre los datos y las inferencias e interpretaciones que el investigador ha ido extrayendo de ellos. En este caso se podría considerar como tal la verificación que algunos compañeros y expertos han realizado sobre nuestro proceso.

- Triangulación: Como ya se ha descrito, se ha realizado una triangulación de métodos, momentos y expertos que tal y como señalan autores como Guba (1983) o Woods (1987) aseguran la credibilidad y la confirmabilidad de la información.

- Ejercicio de reflexión: El cuestionamiento de los análisis realizados ha sido una constante a lo largo del proceso. De este estudio etnográfico surgen 
hipótesis generales que intentan iluminar nuestra comprensión de lo ocurrido. La particularidad de este proceso irrepetible pensamos que no es óbice para que el lector que se acerque al mismo vea en él perspectivas que le interesen y le brinden nuevas lentes con las que apreciar los hechos que acontecen a los alumnos inmigrantes y no inmigrantes en las escuelas.

En este capítulo, hemos descrito los principios metodológicos del estudio etnográfico. Empezábamos repasando el planteamiento general de la investigación para no olvidar el hilo conductor de la misma. Se trataba de estudiar la situación del alumnado inmigrante en la escuela. Y para ello, nos introdujimos en esta segunda fase cualitativa, con el que queríamos analizar el proceso de integración que sufren tres alumnos inmigrantes recién llegados a un colegio español.

En el segundo apartado explicábamos la estructura conceptual de la etnografía escolar, sirviéndonos del diseño metodológico propuesto por un experto en este enfoque: A. Díaz de Rada. De este modo formulamos los objetivos generales, específicos hasta llegar a las categorías analíticas.

En el tercer apartado, describimos, los análisis de los datos, aspecto fundamental del estudio. Para entender mejor este procedimiento, ilustramos la explicación mediante dos ejemplos.

Por último, incluimos, en el cuarto apartado, los aspectos de calidad para validar el estudio, repasando los cuatro criterios que la aseguran: credibilidad, transferencia, dependencia y confirmabilidad. 


\section{Capítulo 7}

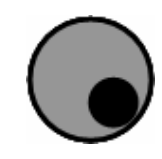

\section{Aspectos introductorios referidos al contexto escolar y a los tres alumnos inmigrantes, protagonistas del estudio}

La intención de este capítulo consiste en explicar, por un lado la estructura conceptual que va a tomar el informe final, y por otro, describir las características principales del centro educativo en el que realizamos el trabajo de campo, así como los aspectos fundamentales de los tres protagonistas de nuestro estudio a los que realizamos el seguimiento durante un año académico. 


\section{1.- Estructura conceptual del informe final}

Los apartados que vamos a ir desarrollando en el informe final se corresponden con los bloques temáticos obtenidos como fruto del desarrollo del estudio etnográfico, explicitados en el capítulo anterior. La estructura que hemos decidido utilizar en el informe ha sido extraída de los objetivos específicos y de las categorías analíticas extraídas del trabajo de campo. Algunas de ellas, fueron establecidas previamente (etic), otras sin embargo fueron emergiendo según transcurrió el proceso de investigación (emic). Todas ellas van dando respuesta al objeto de nuestro estudio, es decir, describir el proceso de socialización e integración de tres alumnos inmigrantes nuevos en el contexto escolar.

El tono que utilizamos en la explicación de este informe final intenta acercar, en la medida de lo posible, al lector, a la realidad de la cultura escolar que hemos ido presenciando, por eso se incluyen los pasajes reales del diario de campo con sus respectivas reflexiones para ir dando respuestas a los temas de nuestra investigación.

El informe final consta de cuatro apartados, debido a su extensión, hemos decidido secuenciarlo en cuatro capítulos diferenciados. Los títulos de los capítulos, apartados y epígrafes del informe final serán los siguientes:

- Capítulo 7: Aspectos introductorios referidos al contexto escolar y a los protagonistas del estudio.

- Estructura conceptual del informe final

- Contexto del centro y del alumnado inmigrante nuevo de $5^{0}$ de primaria al que realizamos el seguimiento

- Capítulo 8: Situaciones escolares sin la presencia del adulto: influencia de las acciones educativas en el proceso de integración escolar del alumnado inmigrante nuevo.

- Características de las interacciones sociales producidas en las filas de entrada y subida a las clases.

- Características de las interacciones sociales producidas en el recreo.

- Capítulo 9: Situaciones escolares con la presencia del adulto: influencia de las acciones educativas en el proceso de integración escolar del alumnado inmigrante nuevo

- El plan de acogida:

- ¿Qué es el plan de acogida?. 
- Fases y actuaciones dentro del Plan de Acogida.

- Clases de apoyo.

- Expectativas que el alumnado nuevo genera en el profesorado.

- Distancia cultural que el alumnado inmigrante nuevo encuentra en los contenidos académicos.

- Respeto hacia los diferentes ritmos de aprendizaje.

- Interacciones entre el propio alumnado inmigrante.

- Motivación del alumnado inmigrante en las clases de apoyo.

- Clases ordinarias:

- Características generales de las interacciones sociales en las clases formales.

- De la dependencia a la autonomía en el funcionamiento del alumnado nuevo.

- Conocimiento y comprensión del significado de los espacios físicos del centro escolar.

- La relación del alumnado nuevo con el profesorado y la coordinación en las acciones docentes.

- Expectativas y prejuicios del profesorado y alumnado expresado en el aula hacia el alumno inmigrante nuevo.

- Procesos pedagógicos que se desarrollan en el aula y su influencia en las relaciones con las minorías culturales.

- Agrupamientos y metodología cooperativa.

- Metodología y sensibilidad docente hacia la problemática del alumnado nuevo.

\section{- Capítulo 10: Fases finales en el proceso de integración del alumnado inmigrante}

- $1^{\text {a }}$ fase: Desconocimiento, inseguridad y receptividad

- $2^{\mathrm{a}}$ fase: Conocimiento de las rutinas básicas

- $3^{\mathrm{a}}$ fase: Fase de aprendizaje de los códigos verticales y horizontales

- $4^{\mathrm{a}}$ fase: Fase de primera definición del estatus dentro del grupo 
- $5^{a}$ fase: Fase de consolidación del estatus dentro del grupo

La estructura, por tanto, empieza a partir de un capítulo inicial que sitúa al lector en el contexto de estudio; los dos siguientes capítulos se estructuran atendiendo a las diferentes situaciones que a lo largo de una jornada escolar se viven en un centro educativo. Esta es la estructura que nos ayudó a organizar nuestra observación en el campo y es la que guía las rutinas por las que debe pasar y aprender un niño o niña nuevos en el colegio para integrarse en el contexto escolar.

Con este recorrido por las situaciones con y sin presencia del profesorado pretendemos mostrar los múltiples aspectos que influyen en el proceso de integración del nuevo alumnado. El conocimiento de esos aspectos que salpican la vida cotidiana del centro nos permite en el último capítulo de este informe llegar a una formulación de las fases por las que pasa el alumnado inmigrante en su proceso de escolarización; los aspectos que facilitan y dificultan su integración; y los choques culturales con los que se enfrenta este alumnado.

\section{Contexto del centro y del alumnado inmigrante nuevo de $5^{\circ}$ de primaria al que realizamos el seguimiento}

En este apartado del informe comenzamos explicando la situación contextual del centro en cuanto al tratamiento de la diversidad. En primer lugar describimos la proporción y las características del alumnado con el que cuenta el colegio, así como las ayudas y modelos de integración de los que disponen para atender a la diversidad. En segundo lugar, presentamos las características de los tres alumnos inmigrantes a los cuales realizamos el seguimiento.

\section{1.- Características principales sobre las medidas del centro referidas a la atención a la diversidad.}

El centro en el que desarrollamos el estudio se ubica en un barrio obrero de la ciudad de Valladolid. En la misma zona existen otros dos centros educativos, uno imparte enseñanzas primarias y el otro es un instituto donde se imparte Educación Secundaria Obligatoria y Formación Profesional. Las minorías étnicas se encuentran irregularmente distribuidas. Mientras en este centro existen escolarizados un número normalizado de inmigrantes, en el otro se encuentra concentrado la mayoría del alumnado gitano. Esto se debe a la progresiva desescolarización del alumnado payo en el centro, convirtiéndose al fin en un colegio únicamente para gitanos y población socialmente desfavorecida. 
Nuestro colegio cuenta con una plantilla bastante grande de profesorado y se realizan numerosas actividades con asociaciones y organismos del exterior. En concreto, el plan de acogida es mostrado como ejemplo en diversos cursos organizados en la comunidad educativa a través de la elaboración de un CD interactivo que ya conocen muchos otros colegios de primaria.

El colegio en el que trabajamos presenta un modelo normalizado de integración al inmigrante. Existen 800 alumnos matriculados, y aproximadamente 100 de ellos pertenecen a minorías étnicas (37 de ellos son inmigrantes y 63 son gitanos). Resulta difícil estimar el número exacto porque la incorporación de este tipo de alumnado se produce de forma progresiva a lo largo del curso escolar.

Las ayudas al centro se establecen de una forma gradual y controlada. El profesorado de compensatoria es el que se encarga de elaborar estos planes de acogida. Estas pruebas alternativas se diseñan tanto para el alumnado inmigrante como para los que requieren algún tipo de atención especial.

Existen dos profesoras de compensatoria, una de ellas acaba de llegar de otro colegio de la misma ciudad con características muy diferentes. Estas maestras elaboran las pruebas de competencia curricular y determinan quiénes necesitan esta ayuda. El número es demasiado alto para contar sólo con dos profesoras, por lo que a veces la individualización de los procesos es menor de lo que se desearía.

La orientadora del equipo perteneciente a este centro me explicó los modelos existentes en los centros públicos de la ciudad de Valladolid.

"Existen tres modelos de funcionamiento respecto al plan de acogida de los inmigrantes en los centros de Valladolid y esto se establece en función del número de inmigrantes que tenga el centro.

Por un lado está el modelo "gueto", donde los alumnos que van mejor académicamente se van a otros centros para aprender más, ya que las aulas están formadas por gitanos e inmigrantes con situaciones familiares especiales en su $99 \%$ y el nivel es muy bajo.

En oposición está el modelo normalizado, que sería este, donde existen 37 alumnos inmigrantes de un total de 800 que tiene el centro. Las ayudas se establecen de una forma más graduada y controlada y los diseños dentro del centro para adaptar a esta población se controlan mejor.

El caso medio, es aquel, en el que existe una población alta inmigrante (33\%), pero no llega a ser "gueto". 
Estas declaraciones nos hicieron reflexionar sobre la importancia de elaborar proyectos curriculares adaptados a las necesidades del alumnado por parte del centro. Cada centro escolar es reflejo y consecuencia de una determinada situación social y ante ello se deben tomar las medidas educativas correspondientes.

\section{2.- Presentación de los personajes protagonistas de nuestro estudio}

Joseph y Amani. Un niño y una niña inmigrantes recién llegados a España acaban de ser escolarizados en este colegio público de Valladolid un 11 de Septiembre de 2006. El centro está ubicado en un barrio obrero de clase media. Dos procedencias distintas. El primero de Bulgaria, la niña de Marruecos. Los dos tienen 10 años y serán escolarizados en quinto curso de primaria, aunque cada uno en una clase diferente para equilibrar el número de inmigrantes por aula: $5^{\circ} \mathrm{A}$ y $5^{0} \mathrm{~B}$ respectivamente. En la clase de $5^{\circ} \mathrm{B}$ podremos observar a Joseph durante la jornada escolar junto a otros 25 niños, todos son españoles salvo un niño algo mulato llamado Willy. Éste procede de la República Dominicana. Es el segundo año que está en el colegio, pero el ser repetidor lo convierte también en un miembro nuevo del grupo de la clase de $5^{\circ} \mathrm{B}$. Joseph, Amani y Willy. Partimos, pues, de tres situaciones diferentes desde las que analizar el proceso de socialización y el acceso a la cultura escolar. Todas ellas comparten un rasgo común: su novedad en el grupo escolar.

Empecemos por Amani. Amani es una niña. Procede de Marruecos. No habla español. A simple vista parece una niña tímida, introvertida y seria.

Su situación familiar no es todo lo satisfactoria que se desearía. El padre ha sido repatriado a Marruecos por algún enfrentamiento con la justicia que desconocemos. Los miembros restantes de la familia lo forman, la madre, el hermano mayor que tiene 18 años, dos niñas de 14 y 10 años y Maluf, el hijo pequeño de 7 años, que nunca hasta ahora ha ido a ningún colegio y también está escolarizado en este mismo centro. El único que habla español es el hermano mayor, porque lleva más tiempo en el país. La madre viste con ropa negra y tiene la cabeza cubierta con un velo del mismo color, la cara permanece al descubierto. Según avanzan los días en el colegio vamos conociendo más detalles de su situación familiar y en alguna de las informaciones a la que accedemos por parte de la trabajadora social, nos enteramos de que se encuentran en una situación ilegal, no tienen los papeles en regla, viven de los ingresos que un hermano de la madre les da de vez en cuando. La intención es que el hermano empiece a trabajar cuando acabe el módulo de formación profesional que está realizando. La madre no 
tiene intención de trabajar en un principio, aunque la situación económica la obliga a insertarse en el mundo laboral, limpiando un asilo de ancianos.

Respecto a la situación escolar de esta niña sabemos que cursó en Marruecos tres cursos de educación obligatoria, desconocemos el rendimiento obtenido en dichos estudios. La situación económica desfavorecida de la familia obliga a Amani a trabajar cuidando a una niña pequeña, esto la hace perder algún día de clase, la carga de responsabilidad para esta niña es muy grande. Las profesoras avisan a la madre de que la niña no puede faltar al colegio para trabajar. La información entre la familia de esta alumna y el colegio es insuficiente y confusa, debido al miedo de la familia a dar información y ser desvelada su situación ilegal en el país. Nos enteramos también de que el hermano no deja a Amani hablar español en casa y si lo hace le amenaza con pegarla. Alguna vez se la ve a las 12 del mediodía, en el recreo, arrodillarse para hacer unos rezos de forma rápida.

Joseph es el siguiente alumno que presentaremos, procede de Bulgaria, no habla español, pero habla inglés a un nivel en el que se entendería perfectamente si los alumnos españoles lo hablaran. No obstante, no deja de ser una primera vía para comunicarse, además de ser un aspecto valorado y admirado sobre todo por el profesorado (quien reflejará a través de palabras, gestos y conductas en las clases cierta admiración ante esta habilidad). Esto, unido a su carácter extrovertido y socialmente habilidoso, conformará un cúmulo de expectativas docentes muy positivas.

Su situación familiar es bastante diferente de la de Amani. Su padre habla español, la madre está aprendiéndolo. Ambos tienen estudios superiores en sus respectivos países. En casa recibe ayuda para aprender español y hacer los deberes. La situación económica, aunque escasa, es más estable.

En tercer lugar hablaremos de Willy, un niño que pasó desapercibido hasta para la investigadora durante los primeros días. En un principio eran los dos alumnos anteriores los que iban a ser investigados. Unos días más tarde nos percatamos de que existía otro escolar repetidor y procedente de la República Dominicana que había llegado hacía un año a España. Decidimos considerarle como otro alumno a observar, dado que presenta un perfil que introduce al objeto de estudio algunas variables interesantes, por ejemplo; es un alumno inmigrante y a pesar de no ser nuevo en el colegio, sí lo es en el grupo de clase.

Las maestras de compensatoria me informan de su situación familiar y personal. Willy tiene una lesión en la rodilla, la familia lleva un año esperando para operarle por la Seguridad Social española. Los padres están separados y la madre comparte piso con un nuevo compañero sentimental. Este niño tiene una hermana pequeña, que cursa segundo de primaria en este mismo colegio y otra de quince 
años que es la que acude a las reuniones de padres en el colegio, justifica la ausencia de la madre argumentando que trabaja todo el día y no tiene tiempo para ir. En una primera reunión, la hermana de Willy manifiesta de forma privada a la tutora del curso que tiene mucho complejo, tanto ella, como el resto de la familia, porque no posee mucho nivel académico

La situación escolar de Willy es algo diferente respecto a sus compañeros de clase. Lleva dos cursos de retraso, porque repitió curso en el colegio de su país de procedencia y también en el actual, por no superar los objetivos académicos del curso. Tiene por tanto doce años. El idioma no supone una barrera para relacionarse con sus iguales. Las expectativas académicas hacia este alumno no son, por tanto, muy positivas. Además, no posee demasiadas habilidades sociales, es tímido, callado e inseguro. A esto añadimos la lesión de la pierna que intenta disimular al andar. Físicamente ninguno de los tres niños poseen ningún rasgo que llame negativamente la atención, sus rasgos son agradables.

Willy ya conoce el funcionamiento general del centro, lleva un año en él, pero los niños del grupo de $5^{\circ}$ en el que está este año son desconocidos 0 , como mucho, conocidos de vista. La situación de partida por tanto es distinta. Tiene la ventaja de conocer físicamente el centro, domina la lengua española, sin embargo, cuenta con alguna dificultad, como por ejemplo ser un alumno nuevo en el grupo, ser doblemente repetidor, tener una lesión en la pierna que le impide ser igual de habilidoso motrizmente que los demás y presentar cierta timidez e inseguridad en las relaciones con los demás.

Estas son, a grandes rasgos, las situaciones personales de los tres alumnos a los que realizamos un seguimiento intensivo durante un curso académico. Con ello pretendemos describir el proceso de socialización escolar que tres alumnos recién llegados a España experimentan al escolarizarse en un centro educativo español. Esta descripción nos permitirá analizar temas importantes referidos a la integración escolar de las minorías étnicas.

En los capítulos que comienzan a continuación empezaremos describiendo los apartados numerados en el capítulo, que a su vez, van dando forma al informe final. 
El objetivo de este capítulo ha sido describir la situación contextual que rodea y explica el objeto de estudio. Constituye la primera parte del informe cualitativo, donde presentamos los resultados o información obtenida a partir del trabajo de campo. Pretendemos acercar al lector, de la forma más cercana posible, a la realidad que vivimos en esta escuela, sin olvidar las reflexiones que de ello se derivan.

La información que explicamos en los próximos tres capítulos, es el fruto del análisis de los datos obtenidos mediante los diferentes instrumentos de evaluación (observación, entrevistas, sociometría, diario personal de Joseph, grupos de discusión), todo ello anotado en el diario de campo, lugar del que extraemos los pasajes que incluimos durante la narración del informe. 


\section{Capítulo 8}

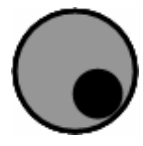

\section{Situaciones escolares sin la presencia del adulto: el alumnado nuevo ante los códigos de la "cultura escolar" utilizados en las filas de entrada a clase y en el recreo}

En este capítulo perteneciente al informe final de la etnografía, presentamos la información obtenida a partir de la observación de las interacciones sociales entre iguales en situaciones donde el adulto no está presente. El discurso que exponemos está diferenciado en función de dos espacios escolares: las filas de entrada y subida a clase y el recreo. El análisis de dichas relaciones entre alumnado nativo e inmigrante nuevo nos permite extraer unos códigos culturales que van definiendo tanto las interacciones entre pares como la cultura del contexto en la que están inmersos. 


\section{1- Características de las interacciones sociales producidas en las filas de entrada y subida a las clases}

Las filas escolares suponen una transición de espacios, tiempos y códigos. Constituyen una organización entre el "tiempo del escolar" y el "tiempo controlado por adultos", de ahí que en ellas se pongan de manifiesto muchos aspectos de interés tanto de los códigos formales de la institución como de los códigos de interacción utilizados entre iguales.

Este es uno de esos protocolos de transición entre microsistemas que marca y facilita la disposición del alumnado a entrar en un nuevo marco de referencia. A través de un ritual de organización, los cuerpos "libres" son contenidos en un orden espacial antes de traspasar las puertas del centro y ser "silenciados" (Vaca Escribano, 2001).

Las filas que los escolares realizan para subir a las clases ordenadamente se ubican en una zona cubierta del patio del colegio, cerca de la puerta de entrada, en un soportal sustentado por unas columnas de ladrillo naranja característico de la construcción de los centros de Educación Primaria vallisoletanos. En cada columna se coloca un curso, en las más cercanas a la puerta de entrada se colocan los cursos inferiores, los cursos mayores, sin embargo, se sitúan a mayor distancia de la entrada. Pareciera como si al avanzar en edad lo hicieran también en autonomía y en capacidad de espera y de ahí, la distancia en el espacio respecto a la puerta. El establecimiento de esta norma parte del adulto, del profesorado del centro, aunque no es exclusivo de este colegio, es una norma bastante extendida que conforma una "cultura escolar". Sin embargo esta norma o "código vertical"1, perteneciente a una

${ }^{1}$ Códigos horizontales y verticales. Esta terminología intenta remarcar cómo los seres humanos transforman la formalidad en informalidad. Se trata de prácticas humanas continuamente transformadas. Así, en la cultura escolar, vemos cómo los docentes establecen unas normas generales como hacer unas filas de subida a las aulas (códigos verticales) y el alumnado las transforma con otros códigos horizontales como: llegar el primero o el último, darse golpecitos en la espalda, realizar juegos de manos. Reconocemos algunas similitudes con conceptos descritos por otros autores. Erikson utilizaba los conceptos conocimiento reificado para el formal o los verticales y regenerativo para el informal u horizontal. Berstein habla de códigos elaborados y códigos restringidos. Esos códigos tienen que ver con las redes que influyen y desbordan la escuela, con el tejido de redes sociales que se dan de manera tácita en este contexto y que hay que inducirlas a través de un proceso etnográfico. Por eso autores como Velasco y Díaz de Rada y Velasco (1997) encuentran en la etnografía, la herramienta perfecta para disolver la barrera y ver la circulación de cómo uno se va transformando en otro. Encontramos alguna relación con las ideas de Weber cuando habla de "racionalidad que se orienta a fines vs. racionalidad que se orienta a valores". En nuestro trabajo optamos por hablar de códigos verticales, los establecidos por la institución y sus docentes y por otro lado los horizontales, los que va creando el alumnado. Recurrimos a esa metáfora espacial (vertical-horizontal) para remarcar la idea adulto-escolar (vertical) y la idea relación entre iguales (horizontal). Sabemos que incurrimos en cierta imprecisión al asociar las normas y usos de los docentes a las normas institucionales (dado que las primeras 
cultura escolar general, adquiere características específicas en función de los protagonistas, es decir, del alumnado. Éstos obedecen la norma pero, a la vez, la rellenan de otros significados ("códigos horizontales"), por ejemplo con el tipo de interacciones, comunicación y acciones que establecen entre ellos.

Las observaciones que de este espacio realizamos las consideramos importantes a la hora de analizar las interacciones entre iguales, por las siguientes razones:

- Es un lugar en el que el alumnado se comunica e interacciona sin la supervisión y control directo del profesorado del colegio. Ellos obedecen la norma establecida por los adultos, llegan a la hora y se colocan donde les han enseñado a hacerlo (códigos verticales), pero una vez allí, establecen sus propios usos y códigos (códigos horizontales). El análisis de estos códigos horizontales nos aporta abundante información acerca de cómo son las interacciones entre iguales.

- Como se ha comentado, ésta es una situación en la que confluyen códigos verticales y horizontales, de ahí que alguien que se introduzca por primera vez en ella tendrá cierto conflicto al no saber cómo atender a ese doble código y mantener un equilibrio entre lo que "agrada al adulto" y lo que "agrada a los compañeros y compañeras". Al observar en ella al alumnado recién escolarizado podemos atender a aspectos interesantes como el proceso de aprendizaje de estos códigos, su preferencia por atender a la norma del adulto 0 a la impuesta por iguales, el alumnado que va marcando los códigos, las consecuencias de no obedecer, entender o participar de las normas entre iguales, o la identificación de posibles diferencias culturales que impidan participar 0 entender esos códigos.

Es decir, las interacciones que se producen en este lugar y momento de la jornada nos aportan información interesante para descifrar cuáles son esos códigos escolares con los que los alumnos inmigrantes nuevos, con otras procedencias culturales, tendrán que enfrentarse para integrarse en el contexto educativo. A su vez este análisis nos permite dibujar un panorama general de nuestra cultura escolar.

suponen también una forma de código restringido), pero dado que este estudio intenta enfatizar el proceso que vive el escolar, nos ha parecido más adecuada esta división (dado que el niño o niña no sabe diferenciar entre lo que le imponen, ya venga de una ley, de una norma del centro o de un uso del docente en particular). 
Los docentes utilizan esta organización como forma de control y organización para regular la entrada y salida de las aulas. Existen tres momentos en los que se realizan estas filas, a las 9:00 de la mañana para empezar las clases, a media mañana para subir del recreo y para ir al pabellón adyacente al centro los días que tienen clase de Educación Física. Estas filas empiezan a moverse en cuanto suena una sirena, trayéndonos a la memoria escenas militares 0 penitenciarias. En cada momento podemos observar diferentes conductas en los chavales. Sin duda el momento de mayor intensidad en las interacciones, como veremos, es después del recreo, posiblemente debido a la fatiga de haber acumulado tres horas escolares y a la alteración producida por sus juegos.

Para el alumnado, sin embargo, cobra otros significados. Para el alumnado de las edades observadas (10-11años) se trata de un lugar en el que pueden "desfogarse", demostrar cómo son, hacerse notar ante sus compañeros, jugar con los límites de lo permitido 0 autoafirmarse ante el grupo burlando la norma vertical.

A través de los siguientes epígrafes mostraremos diferentes aspectos sobre el proceso de integración del alumnado nuevo que se hacen visibles en estos tiempos de espera a la entrada a las aulas:

\section{1.- Cultura de procedencia y situación familiar}

\section{2.- Manifestación de los códigos horizontales en las filas}

\section{1.- Cultura de procedencia y situación familiar}

Los primeros días de los alumnos inmigrantes nuevos en el colegio nos permitieron observar algunos choques o diferencias culturales que pueden influir en las interacciones sociales. Conforme pasan los días, estas diferencias se van diluyendo a favor de la progresiva asimilación escolar. En estos pasajes recogidos a principios de curso, notamos algunas diferencias culturales en cuanto a la tolerancia al volumen del ruido, los contactos corporales y la autonomía para ir al colegio.

Suena la sirena. Todo el mundo se dirige hacia la fila. Joseph va corriendo. Se pone el primero. Tres niñas hablan con él muy alto. Él hace un gesto de aturdimiento debido al volumen del ruido existente. Un profesor de otro curso le da una palmada fuerte en la espalda, mientras dice mirándome a mí: "éste se integra en dos días". Los contactos corporales del profesor le llaman la atención. Son aspectos diferentes para este alumno nuevo en nuestra cultura escolar. Recordamos las observaciones realizadas en otros colegios europeos y los comentarios de compañeros que han permanecido allí una temporada y nos permiten entender que quizá en el colegio de Joseph los contactos corporales entre profesorado y 
alumnado sean más fríos, incluso inexistentes. Esto puede resultarle extraño los primeros días.

(Diario 11 de Septiembre 2006)

Al día siguiente vuelvo a atravesar las mismas verjas verdes que ayer para entrar en el colegio. Desde lejos ya empiezo a oír el bullicio característico de los niños y niñas [...]. Sólo cuando pasamos ajenos y cerca de un colegio nos percatamos del ruido existente. Esto mismo parece pasarle a Joseph el primer día. El umbral de tolerancia al ruido de Joseph es diferente al de sus compañeros.

(Diario 12 de Septiembre 2006)

Podemos imaginarnos la saturación perceptiva a la que está sometido Joseph en estos primeros días. Intentando percibir todo, seleccionando aquellos datos de importancia, y esforzándose por comprender aquello que choca con su socialización. Interpretamos que este niño debe tener mucha seguridad personal para no verse intimidado por una invasión sonora y corporal tan grande. No apreciamos que se refugie en lugares marginales, ocupa aquellos espacios con sentido institucional (el lugar en el que se formará la fila) de lo cual podemos deducir el valor de los rituales para las personas nuevas en un contexto y de cómo éstos les pueden ayudar a irse incorporando a él. De ello también deducimos cómo los códigos verticales, quizá por ser más explícitos o porque emanan de alguien al que se atribuye una autoridad, son adoptados más rápidamente que los horizontales. Apreciamos que no se refugia tampoco en objetos (video juegos, reloj, libros u otros objetos personales), sino que observa tranquilamente lo que ocurre a su alrededor, parece que tuviera una gran apertura al entorno y una búsqueda de aprender sus usos rápidamente.

Los momentos de entrada y salida del centro nos dejan vislumbrar algunos otros aspectos de los usos familiares de este alumnado inmigrante:

Me voy entonces a la fila en la que los de $5^{\circ} \mathrm{B}$ se colocan para entrar a clase. La gorra beige me ayuda a localizar fácilmente a Joseph. Allí está, serio, tranquilo, aguardando su sitio en la fila sin hablar con nadie. Me acerco a él y le pregunto por qué ayer no estaba al terminar el colegio, su padre le estaba buscando. Él me dice que le esperó un rato y como tardaba se fue el sólo a casa porque se sabe el camino. Parece un chico autónomo, no hay problema, pensé yo. Seguimos observando diferencias respecto a los alumnos españoles. Ninguno de ellos va solo al colegio, los padres les dejan en la puerta, algunos incluso entran para verles colocados en las filas y esperan a que suban.

Amani también va sola al colegio y se encarga de su hermano pequeño. De los niños o niñas que se observan son los únicos cuyos padres no están. Sin 
embargo Willy y su hermana pequeña Lily ${ }^{2}$ que va a $2^{\circ}$ de primaria, llevan tres años en España y su madre les acompaña al colegio. La distancia o la asimilación cultural que en tres años ya se ha introducido en sus vidas de manera notable, esto puede ser la causa de este hecho.

(Diario 12 de septiembre 2006)

La autonomía de los niños puede estar ligada con la percepción de inseguridad social que tengan las familias. Posiblemente, nuestra sociedad no sea más insegura que la que han vivido estos niños y niñas en sus países de origen o la que se vivía en nuestro país hace no muchos años cuando los escolares iban solos al colegio. Sin embargo, posiblemente en la imaginación de todas las familias han arraigado múltiples miedos (accidentes de tráfico, secuestros, robos...) que llevan a una sobreprotección.

La tolerancia al ruido, los contactos corporales y la autonomía en aspectos cotidianos son algunas diferencias culturales observadas en este espacio entre el alumnado español y estos tres alumnos inmigrantes como vemos en estos fragmentos. Pero estas diferencias se observan también entre los propios inmigrantes en función de sus diferentes procedencias. Esto nos demuestra que existe tanta diversidad como alumnado escolarizado. A los inmigrantes se les considera como un colectivo, pero este colectivo en sí mismo, como veremos más adelante, también encierra mucha diversidad (personal, familiar y cultural) y, por lo tanto, medidas de atención diferente. No es lo mismo un inmigrante árabe que uno búlgaro u otro latinoamericano, cada uno tiene sus necesidades específicas. Empezando con el idioma hasta su condición personal y familiar. Por ejemplo, Amani tardará mucho más en aprender español que Joseph y, a su vez, Willy ya lo tiene adquirido, pero le costará más comunicarse por falta de habilidad personal.

Apreciamos que las diferencias culturales se difuminan al introducirse en la cultura escolar. La cultura de procedencia que este alumnado trae apenas llega a manifestarse en estos contextos. Hemos detectado que el deseo de los niños y niñas nuevos es integrarse y ser uno más. Como comenzaremos a ver a continuación, ello les supondrá entender y aprender lo que les marca la cultura escolar receptora.

\section{2.- Manifestación de los códigos horizontales en las filas}

Como ya se ha indicado, en este tiempo, la actividad del alumnado está levemente contenida por la organización escolar, esto supone un momento interesante para detectar algunos de los usos y códigos que regulan las relaciones

\footnotetext{
2 Lily, es la hermana pequeña de Willy, la incluimos en nuestras observaciones porque nos aporta información acerca de la relación que tiene con su hermano y por encontrarse a veces sola en el recreo.
} 
entre el alumnado. Entre estos usos hablaremos de algunos de los que deben ser aprendidos por los nuevos escolares:

1.2.1.- La evolución de las filas a lo largo de la jornada escolar y las acciones permitidas en cada momento

1.2.2.- Relativizar los códigos verticales y primar los códigos horizontales

1.2.3.- El orden de llegada a las filas

1.2.4.- La salvaguarda de los códigos horizontales: definición de prácticas adecuadas según el género

1.2.5.- La trasgresión del código vertical como código horizontal de los niños

1.2.6.- Interacción agresiva entre niños y roles en el grupo

1.2.7.- Broma-agresión como "prueba de iniciación y clasificación"

1.2.8.- Las interacciones entre las niñas

\subsection{1.- La evolución de las filas a lo largo de la jornada escolar}

No todas las filas son vividas por el alumnado de igual forma. A lo largo de la jornada escolar, éstas evolucionan y nos dejan ver diferentes matices.

Apreciamos diferencias entre la fila de entrada, a las 9 de la mañana, y la de subida después del recreo. Estas diferencias nos hacen reflexionar sobre algunos aspectos importantes para las relaciones sociales. En la fila de entrada, por lo general, los niños suelen estar más tranquilos y surgen menos discusiones e interacciones entre ellos. Pensemos que llegan de casa y necesitan un tiempo de adaptación para comenzar la jornada escolar. Este es un código horizontal a aprender: estaría fuera de lugar que un alumno bromease en exceso 0 entrase en contactos violentos con otros a estas horas del día, posiblemente, lo que en otros momentos sería permitido aquí supondría una ofensa. Este es uno de los primeros códigos que el alumnado debe aprender: la adecuación de los diferentes tipos de interacciones según el momento del día.

A medida que transcurre la jornada, aumentan las interacciones, los contactos corporales, las broncas, las bromas, el bullicio y el desorden. Ya ha habido contacto e interacciones entre el alumnado y eso se nota en la fila tras el recreo. Estos indicadores nos hacen plantearnos hasta qué punto esta agresividad en los contactos es producida por una jornada escolar en la que se da una continua contención corporal y una limitación de los contactos e interacciones en el aula. 


\subsection{2.- Relativizar los códigos verticales y primar los códigos horizontales}

Conforme va pasando el tiempo en el colegio del alumnado nuevo, las interacciones van cambiando de intensidad y éstos alumnos van buscando formas de ser tenidos en cuenta por el resto del alumnado. El código vertical que les brindaba un lugar en el que estar y una tarea a realizar (ordenarse en fila), al cabo de unos días, comienza a ser relativizado:

Ahora hay un grupito hablando con Joseph, a diferencia de esta mañana que estaba en la fila sin hablar con nadie. Es el centro de atención. Willy, también nuevo en el grupo, está sin hablar con nadie. Con las manos en la boca y las rodillas juntas, mirando alrededor como pensando qué puede hacer. La novedad de Joseph, las estrategias del niño para relacionarse incluso sin saber el idioma, consiguen que sea el protagonista. Willy sin embargo, hablando español perfectamente, no recibe atención alguna. En otro momento observamos lo siguiente: En la fila Willy está el primero, Joseph de los últimos riendo con distintos compañeros de su clase. [...] Ahora interactúa en la fila más que por la mañana. A lo largo de la jornada escolar las interacciones se intensifican.

(Diario 13 de Septiembre 2006)

Hoy Willy emprende estrategias para intentar integrarse en el grupo, empieza a utilizar los códigos horizontales y habilidades sociales que considera necesarios para conseguir tal objetivo. Primero comienza juntándose a Joseph, llevando la pelota a la fila. Willy llega con Joseph a la fila y trata de interactuar con un balón con algunos de los que están allí, pasándolo con la mano. Al igual que otros días Willy aprovecha este momento para jugar con los de su clase [...] Se pasan el balón en un pequeño corro dirigido por Willy. Resulta el momento que más atención ha recibido en todo el recreo.

(Diario 14 de Septiembre 2006)

Apreciamos que Willy atiende en primer lugar el código vertical (colocarse el primero de la fila). Este espacio le permite observar lo que ocurre a su alrededor y "aprender" los códigos horizontales, los usos de interacción de los niños de su grupo. En cuanto conoce algunas claves de este funcionamiento, pone en marcha una estrategia para ser tenido en cuenta. Cuando se pone a jugar con el balón en la fila, posiblemente poco le importa la reprobación de los adultos. El fin prioritario es la integración, es decir, de alguna manera los códigos horizontales llegan a prevalecer sobre los verticales. Situaciones como estas, nos muestran la necesidad de los niños de interactuar entre ellos, de ser aceptados, de poder jugar con otros, y ser valorados por ellos. 
Estas situaciones también nos permiten vislumbrar hasta qué punto tienen calado los mensajes y fórmulas de interacción que el profesorado intenta transmitir al alumnado (modales, respeto, turnos de intervención, inclusión...). Son aprendizajes contextuales que 0 bien quedan desdibujados 0 sobre los que el alumnado hace torpes ensayos en situaciones de interacción informal como éstas. Es decir, los códigos verticales presentan una influencia limitada y relativa en los usos horizontales. En el primer ejemplo se aprecia que el alumnado se muestra cordial con Joseph (de acuerdo con las directrices del profesorado), pero ignora a Willy (más adelante mostraremos algún caso, identificado en las relaciones entre niñas, en el que se ve una mayor influencia de los mensajes emanados de los adultos).

\subsection{3.- El orden de llegada a las filas}

Otro significado interesante que observamos en este momento, es el referido a la rapidez de llegada a las filas cuando se acaba el recreo y suena la sirena para "formar filas". Después de encontrar a varios niños y niñas en los primeros puestos de la fila, sabiendo que son rechazados/as en sus correspondientes grupos, empezamos a sospechar que podría existir algún tipo de relación entre rechazo en el juego y colocación en la fila. Los niños y niñas que más disfrutan o que más integrados se les ve en el juego durante el recreo, aprovechan hasta el último segundo de juego y ocupan los últimos puestos de las filas. Entendemos que los niños y niñas encuentran en sus iguales un lugar de refugio adaptado a sus necesidades y regido por sus propios códigos. Posiblemente, en la medida que se sumergen en él, relativizan el valor de las normas verticales. Ello les llevaría, como en este caso, a demorar la incorporación a las filas.

En torno a estos temas son interesantes los siguientes pasajes:

Ya empezamos a notar el rechazo que sufre Willy por sus compañeros de clase y el protagonismo que Joseph ocupa en este grupo. Willy se queda vagando por ahí durante el recreo. Suena la sirena: "liberación para Willy", va corriendo a la fila. Observo a algunos de los que ocupan los primeros puestos. En algunos detecto una cierta búsqueda de agradar a los maestros. Se colocan formalitos, casi teatralizando su disposición a la obediencia (cara seria con una ligera mueca de sonrisa, mirada dirigida al adulto, manos juntas a la altura de la cadera, pies juntos como en posición de firmes, y a veces haciendo rápidas subidas y bajadas de talones no sé si por nerviosismo o como para recalcar su posición).

(Diario del 18 Septiembre 2006) 
Me acerco a las filas dos minutos antes de que suene la alarma para ver qué niños ya están colocados en ellas y quiénes son los que llegan primero. De nuevo notamos cómo unos alumnos disfrutan más del tiempo de recreo que otros. Mientras algunos se colocan antes de que empice la sirena, otros aprovechan a jugar hasta que las filas empiezan a avanzar hacia las clases. Lily (la hermana de Willy que observamos que no tenía con quién jugar) y Maluf (el hermano de Amani que no juega, ni interactúa con nadie) siempre se encuentran los primeros en la fila, incluso sentados a veces esperando a que se acabe el recreo.

(Diario del 2 de Octubre 2006)

Este otro testimonio de Lily nos confirma nuestras sospechas al respecto de la relación entre grado de disfrute en el recreo y momento de llegada a la fila: Lily y Esperanza están las primeras en la fila. Les pregunto: "Os gusta llegar las primeras a la fila ¿eh?" Lily responde: "es que como no jugamos a nada". Pregunto: "¿con quién habéis jugado hoy?" Lily: "Yo, si no juego con Esperanza, juego con la pared".

(Diario del 2 de Octubre 2006)

En función de las observaciones y comentarios escuchados, reflexionamos sobre el momento de llegada a la fila y establecemos una serie de relaciones. Reflexionamos sobre los posibles significados del momento de llegada a la fila. Sobre los que llegan los primeros apreciamos un alto deseo de agradar a los maestros y maestras, demostrando mucho interés en cumplir las normas que ellos establecen. Es su oportunidad de ser valorados. El primer puesto de la fila, aún a estas edades, sigue siendo un lugar disputado. De alguna manera, todos buscan colocarse en esa posición, aunque la mayoría sabe que ocuparla supone renunciar a unos minutos de juego. Sin embargo, aquellos que durante el recreo no encuentran un lugar para disfrutar con otros, les sobra tiempo para ocupar ese primer puesto en la fila. En caso de que esta situación se repita recreo tras recreo, podríamos decir que es un indicador de rechazo o exclusión. Imaginamos que para estos niños y niñas el sonido de la sirena que marca el fin del recreo supone un alivio, supone el cese de la pelea por ser considerado, por ganarse el favor de otros, o por poder participar en algún juego. El final del recreo les permite entrar en un espacio en el que la primacía de los códigos verticales les favorece la adopción de un rol más claro y no tener que pelear por buscar su lugar en el grupo. La organización del espacio personal (pupitres), de los tiempos y de las tareas a realizar puede suponer un respiro para estos niños y niñas con más problemas de integración.

Dado que el primer puesto es observado y deseado por todos, su ocupación puede remarcar la distancia entre los grupos de niños o niñas que se juntan en el recreo con aquellos que son marginados. 
Como ya se ha señalado, aquellos que llegan los últimos a la fila suelen ser los que quieren aprovechar hasta el máximo en el juego. Están disfrutando de la actividad y no quieren que se acabe. Suelen ser los niños y niñas más integrados en los juegos. En el caso de los tres niños inmigrantes a los que seguimos, vemos cómo corresponde la llegada a la fila con las observaciones, con los resultados en las sociometrías y con las entrevistas de los alumnos. Joseph llega de los últimos una vez integrado en el grupo de fútbol, Willy de los primeros y Amani por el medio, cuando llegan las demás niñas con las que juega en el patio. Concluimos diciendo, por tanto, que la rapidez repetida en el tiempo con la que llegan a la fila es un indicador y un primer diagnóstico del grado de integración del alumno en el grupo.

\subsection{4.- La salvaguarda de los códigos horizontales: definición de prácticas adecuadas según el género}

Se aprecia una clara diferencia entre las interacciones y los códigos utilizados por los niños y por las niñas, incluso existe una clara separación física entre ellos y ellas. Los niños demuestran, por lo general, unas formas de comunicación verbal y gestual más violentas. Las niñas muestran menor agresividad física en sus interacciones. Las habilidades sociales manifestadas difieren en función del género del alumnado (Monjas 2000).

Se puede apreciar que cada uno de los grupos funciona con códigos horizontales propios. Sin embargo, cuando están juntos, el código común dominante es el de los chicos. Ello se manifiesta, por ejemplo, en el establecimiento de los patrones para definir el estatus en clase 0 en la determinación de las prácticas apropiadas para cada uno y la exclusión de aquellos 0 aquellas que practiquen juegos que no les "corresponden".

Veamos a través de algunos fragmentos de observaciones ciertos detalles sobre estos aspectos.

Suena la sirena:[...]

Unas niñas juegan a las palmitas, Rodrigo es el único niño que se ha implicado a fondo en el reto de las palmitas. Joseph, Willy y Pablo, por detrás, le ponen cuernos y le hacen burla. Éste les asusta para que le dejen y sigue jugando con Sofía.

Suben las escaleras: Sofía y Rodrigo siguen jugando a las palmitas haciéndolo cada vez más deprisa.

(Diario 6 de noviembre 2006)

El código horizontal establece que ciertas prácticas son masculinas 0 femeninas. Las dos personas nuevas en el grupo (Joseph y Willy) lo entienden 
rápido y se apresuran a apoyar a aquellos censores que sancionan el código. La inseguridad de las personas nuevas, posiblemente les lleve al "integrismo" y la defensa de las normas de las facciones con más poder aparente de decisión.

\subsection{5.- La trasgresión del código vertical como código horizontal de los niños}

Hemos ido recogiendo varias situaciones en las que los niños se mueven al borde de lo permitido para granjearse la aprobación de sus iguales. Son pequeños gestos y acciones (tolerados en su mayoría por los docentes, pero muy significativos para los escolares). El alumnado nuevo, en su intento por agradar a los iguales buscará oportunidades de jugar con las normas verticales:

Willy al lado de Joseph. Joseph abre una ventana pequeña del pasillo y la deja abierta y se ríe. Entre ellos se pegan pataditas al subir las escaleras para tropezar. Amani sube tranquila sin hablar con nadie

(Diario 6 de noviembre 2006)

Apreciamos el intento de Joseph por buscar la integración a través de la trasgresión de aquello que él imagina como un código vertical. Dado que el código horizontal de los niños establece el moverse en el límite de las normas verticales, Joseph intentará hacer pequeños gestos (abrir una ventana y dejarla abierta) que sean apreciados por sus iguales. Observamos la sutileza de las acciones y la configuración en estos niños de sus diferentes roles en el centro, así como los esquemas de valores sobre lo correcto e incorrecto en función de sus roles como alumnos o como compañeros. Suponemos que al abrir la ventana Joseph ha tenido que hacer un cálculo de las repercusiones que puede tener tanto en su rol de alumno como en el de compañero. Dentro del primero no pasaría de una leve llamada de atención, incluso menos, dentro del segundo le puede granjear la complicidad de los que le hayan visto. Una falta inapreciable en el código vertical, pero muy valorada en el horizontal. La acción es claramente rentable. No es de extrañar que días más tarde pudiéramos ver a Willy repitiendo la misma acción. La diferencia entre ambos, está marcada por la capacidad de Joseph para comprender los esquemas de valores que rigen en ese lugar y jugar con ellos en su proceso de integración.

\subsection{6.- Interacción agresiva entre niños y roles en el grupo}

Los niños nuevos van asimilando las formas violentas de interacción (golpeos, patadas, zancadillas...), pero además de este código de interacción deben aprender cuándo y con quién usarlo. Esta expresión agresiva puede ser la manifestación de un déficit de habilidades sociales que impide comunicarse de 
forma adecuada a los escolares. En el siguiente pasaje se aprecia la sutileza de su uso en función del estatus en el grupo:

Un niño juega a las palmitas con las chicas, los demás se ríen pero a él le da igual. Los otros empiezan a burlarse de él y a separarle agarrándole del cuello para que no juegue, todos se ríen. Willy lo hace también (el separarle del cuello), mientras mira a los demás, como buscando su risa, pero en este caso no hay tanto regocijo y el niño se enfada con él por agarrarle.

(Diario 24 de Septiembre 2006)

Apreciamos los diferentes estatus en el grupo y la tolerancia a las bromas en función de quién las realice. Willy se apresura a repetir lo que ha visto, pero parece que el código horizontal no le permite tomarse esas libertades. Ni su acción es valorada por los instigadores de la chanza, ni tolerada por el que la sufre. Comprender el frágil equilibrio del uso de estos códigos horizontales requiere de mucha habilidad social. Cuándo, quién, con quién y cómo aplicar cada acción es un aprendizaje complejo para el que no todo el alumnado demuestra la misma habilidad. Estos datos van perfilando una de las ideas que extraemos de este estudio: el valor de las habilidades sociales de cada persona como condicionante clave de su integración.

En la siguiente escena apreciamos las presiones continuas que se establecen entre el alumnado para demostrar fidelidades y definir el estatus.

Subimos con la fila hacia el aula:

- Joseph coge del hombro a un niño de su clase

- Willy está arrastrándose por la pared y mirándome continuamente para ver cuándo le miro. Voy viendo que los niños inseguros se percatan con mayor facilidad de la mirada del mayor. Joseph por ejemplo apenas se da cuenta de cuándo le miro y si lo ve le da igual. También él me miraba más los primeros días de colegio que ahora.

- Willy da golpecitos en la cara a Joseph riéndose, tal y como hacen los demás entre ellos. Joseph se enfada y le empuja dos veces. Los otros (Diego, David y otro) se ríen, animan a Joseph para que siga haciéndolo, le dicen que le haga burla a Willy. Joseph no lo entiende, ellos insisten y le hacen un gesto como de gallina para picarle. Él no se entera o no se quiere enterar.

- Entran en clase y no se desarrolla más la idea pero ahí queda latente. Joseph ya sabe que a Willy le discriminan, él no le discrimina, pero ya no le 
hace tanto caso. Ser amigo de Willy significa no estar con los líderes y eso lo aprende sin saber español.

(Diario del 2 de octubre 2006)

A estas alturas del curso (recién comenzado) ya comienzan a fijarse ciertos roles. Joseph va consolidando un estatus entre los líderes y ya no tolera la interacción con Willy. Podemos imaginar lo que esto significa para Willy. Joseph constituía una puerta para introducirse en el grupo de los chicos, y ahora no sólo se va cerrando esa posibilidad, sino que él está pasando a un rol de marginado. Estas situaciones nos describen una lucha diaria por integrarse. Una trama de equilibrio frágil en la que en cualquier momento puede cambiar el estatus ante los demás y la actitud del grupo hacia uno.

En este fragmento vemos también el tipo de interacciones que mantienen los niños durante la espera de las filas y durante la subida por las escaleras. Todas estas acciones van dejando posos de aprendizaje en los alumnos que llegan nuevos al grupo, irán interiorizando el tipo de comunicación que se da en el grupo nuevo en el que se quieren integrar. Comunicación e interacciones que encierran unos valores determinados (burla, jerarquías, agresión) y que, en este caso concreto, están marcados por tres niños (una "minoría ruidosa" en palabras de Bores Calle, 2006), considerados los líderes dentro del grupo de los chicos. La necesidad de sentirse integrado que todo niño tiene, llevará a Willy y a Joseph a repetir aquellas acciones mejor valoradas por el grupo de líderes: comunicarse con golpecitos, hacer burla a las niñas, unirse para despellejar al rechazado, tener más tiempo el balón 0 cualquier otro material susceptible de juego en la fila, hacer bromas tirándose por el suelo, poner la zancadilla, hacer el payaso armando bulla cuando no está el profesor. Muchas de estas acciones que van componiendo los códigos horizontales se definen en contraposición con los códigos verticales.

A su vez, el conjunto de habilidades sociales que los escolares van desarrollando, incrementará la calidad de las interacciones sociales de los mismos. Se produce una relación dialéctica entre ambos términos: la posesión de las habilidades sociales mejora la interacción social de los escolares, así como la propia interacción mejora las habilidades sociales.

\subsection{7.- Broma-agresión como "prueba de iniciación y clasificación"}

De lo expuesto arriba nos resulta preocupante la agresividad que muchas conductas reflejan. Gran parte de las acciones descritas dejan entrever una agresividad latente que se aprecia en todos los intercambios entre estos niños.

Entendemos que puede haber múltiples causas, entre ellas podemos 
apuntar la competitividad constante y la presión que sufren estos niños para mantener o ganar un puesto en el grupo, un grupo que para probar a sus componentes juega constantemente con los límites de la tolerancia a la agresión.

Toda broma (hablamos de golpecitos, zancadillas, empujones, collejas, pellizcos...) tiene una carga de agresión que será vivida como tal en función del momento, de quién provenga, y de quién la reciba. La misma acción puede originar múltiples respuestas en función de las anteriores variables, un empujón puede ser devuelto entre risas, puede convertirse en el inicio de una pelea o puede acabar con el agredido acusando ante un docente el hecho. No debe resultar fácil para un niño comprender todas estas variables e imaginamos que para un recién llegado aún resultarán más complejas, máxime si como en el caso de Willy se cae en el papel del marginado. Podemos deducir lo complejo de su situación. Él busca integrarse y agradar, pero se convierte en blanco de las bromas. Posiblemente se pueda plantear cuestiones como: ¿hasta qué punto puede tolerarlas sin enfadarse?, ¿en qué medida constituyen una prueba iniciática que "merece la pena" aguantar durante un tiempo?, ¿es mejor enfadarse y quedarse solo o aguantar y estar un poco integrado?.

En cualquier caso, este tipo de interacciones supone un polvorín en constante peligro de explosión tal y como nos muestra la siguiente situación.

Están en las filas. Joseph está junto a un grupo de niños sin hablar pero muy sonriente. Ibor, Búlgaro de $6^{\circ} B$, se acerca a mí para decirme que un niño le ha pegado. Me acerco a ese niño, le pregunto por qué pega y me dice que era en broma. Pero Ibor no se lo ha tomado en broma. Estamos viendo que existe un doble significado: por un lado pegan al débil, al rechazado de la clase y luego se escudan en que es broma. Es cierto que los niños se relacionan a base de toquecitos y agarrándose a diferencia de las niñas, pero casualmente suelen aliarse para hacerle las bromas al marginado con lo que él no se lo toma así y se enfada. [...] Unos minutos después, veo que hay una pelea entre las dos filas de $6^{\circ} \mathrm{A}$ y $6^{\circ} \mathrm{B}$. Me acerco a separar a los niños. [...] El niño que ha pegado a Ibor está metido en la pelea ahora con otro niño del otro $6^{\circ}$. Dicen que se estaba metiendo y pegando a Ibor $y$ por eso J. Carlos le ha pegado.

(Diario 10 de Octubre 2006)

Comprobamos que lo que empieza siendo broma acaba en bronca, incluso en pelea. Los niños agredidos suelen contestar con más agresión y así se va generando un ciclo que se cortará normalmente con la intervención de un adulto. En el aula este tipo de conflictos no llegan a estos extremos, cuando alguien se siente agredido éste recurre al docente para que intervenga. No siempre es fácil la mediación. Muchos de estos conflictos no tienen un origen claro, a veces surgen 
entre bromas, otras enmascaran problemas más profundos de rechazos 0 enemistades. En cualquier caso, suponen un ambiente de constante crispación.

Si interpretamos estas interacciones como una fórmula para medir las reacciones en otros y, en consecuencia, otorgarle un estatus en el grupo, tendremos los siguientes patrones de acciones-reacciones y consecuencias:

- Si la broma es tomada como agresión y se produce un enfrentamiento, el alumno será valorado como agresivo y por tanto poco deseable para los intercambios y será excluido del grupo.

- Si la broma es aceptada de forma sumisa, el alumno es valorado como blanco de nuevas bromas.

- Si ante la broma se reacciona con un enfrentamiento simulado, se interpreta como indicador de complicidad y el alumno será aceptado en el grupo.

\subsection{8.- Las interacciones entre las niñas}

Las niñas constituyen un grupo aparte, con sus líderes propios y sus normas que difieren en gran medida de las de los niños. Así, por ejemplo, vemos como Amani, a diferencia de Joseph y Willy, interactúa de otro modo con sus compañeras (aunque también obedece a un patrón de imitación). Sus acciones son más sumisas, más obedientes, dependientes de que alguien haga algo por ella. Vemos en el siguiente fragmento cómo los primeros días necesita seguir, estar encima e imitar a una niña para acceder al grupo.

Los primeros acercamientos de Amani al grupo son diferentes. Observamos mayor ansiedad y dependencia de otros para interactuar con los demás. Tarda más en entender el significado de los sucesos que acontecen en la jornada escolar. Como vemos, desconoce lo que tiene que hacer para bajar al recreo, es más, ni siquiera sabe a dónde van los niños cuando se agolpan para ponerse en fila y bajar al patio. Necesita la ayuda directa de alguien para poder funcionar. Por ejemplo, tiene más dependencia que Joseph para desenvolverse.

En su primer día de clase los niños se ponen en fila en el aula para salir cuando la profesora dé la orden. Amani no conoce estas normas, está parada de pie esperando a que alguien la diga algo. Pero nadie se lo dice, ella no está tan atenta a las oportunidades para relacionarse como Joseph, sino que parece bloqueada.

Salgo con ella al recreo, parece que se quiere quedar conmigo. Pero de repente, por detrás aparece una niña de $5^{\circ} \mathrm{A}$ y dice: "que venga con nosotras que es de nuestra clase y que juegue al escondite con todas". "Vale, perfecto" digo yo. Justo en ese momento aparece su hermano pequeño de la mano de Ayud. Ella 
sonríe levemente. Ayud nos ayuda a traducir: "Ellas quieren jugar contigo al escondite". Amani sonríe. Yo le comento a la niña: "cógela de la mano y así sabrá que te tiene que seguir porque no entiende nada de Español, pero pronto lo hablará. Tened paciencia ¿vale?". Se la llevan de la mano y desaparecen. Cuando vuelven para hacer la fila de subida a clase, Ana sigue de la mano de Amani, se pone en la cola y me mira para que yo la vea.

Es curioso que este papel de "madre-protectora" con los nuevos, lo observamos solo en las niñas, en los niños no vemos conductas de este tipo. Los niños realizan este proceso paralelo a través del balón jugando al fútbol, las niñas a través de cuidar de la otra persona.

(Diario 12 de Septiembre 2006)

Como se ha ido viendo, la integración supone un proceso de aprendizaje de códigos y usos en el cual la imitación se muestra como uno de los procedimientos habituales. Vemos que mientras los niños aprenden la interacción brusca, la burla y la jerarquización, las niñas van aprendiendo el cuidado, la responsabilidad, la obediencia, el agradar al adulto 0 el carácter tranquilo.

\section{2- Características de las interacciones sociales producidas en el recreo}

En un horario dominado por tiempos de silenciamiento corporal, el alumnado puede llegar a ver en el recreo una válvula de escape, un tiempo suyo en el que se siente protagonista y dueño de su acción (Vaca Escribano, 2002). Es por ello por lo que supone un lugar idóneo para observar la actividad libre de los niños y niñas, su cultura lúdica, sus afinidades y rechazos, sus rituales y usos, sus formas de comportarse, en definitiva, podemos observar de forma más integral al niño. El patio es un momento ideal para observar al niño, no al alumno (De la Lande, 2007, 5). Seguiremos viendo en este apartado más detalles sobre las interacciones entre el alumnado, sus usos y códigos horizontales y el proceso por el que el alumnado nuevo se va incorporando a sus grupos de iguales. Para comprender y poder participar de estos códigos es necesario entender una serie de normas y rituales tan arbitrarios como los que produce el sistema educativo. En palabras de Geertz $(1975,12)$ : Dado que la cultura infantil está contextualizada por el mundo adulto, es también dentro de este contexto donde las criaturas se socializan mutuamente.

Las observaciones en el patio también nos informan de que existen diferentes formas de acceder a ese entramado, es diferente si eres niño o niña, si eres mayor o de los cursos inferiores, si eres repetidor, si eres nuevo en el colegio y todavía más si eres nuevo, procedes de otra cultura de origen y no hablas el español, como es el caso de Joseph y Amani. 
Antes de pasar a exponer este entramado de interacciones y usos nos parece interesante que el lector se haga una idea general de la estructura de este patio. El patio está distribuido en varias zonas, y, en función de su edad y sexo el alumnado se distribuye por ellas:

- El alumnado de $1^{0}$ y $2^{0}$ de Primaria ocupa las zonas cercanas a la puerta de entrada, los espacios reducidos alrededor de las canchas de deporte, zonas de paso y la zona trasera del colegio (un talud de césped y tierra). Por allí juegan a diversos juegos más o menos estructurados (perseguirse, recoger piñas o piedras) y simbólicos ("a comprar y vender"). Algunos de estos juegos perduran durante el tiempo, asociados a los mismos espacios y son practicados por grupos mixtos.

- Los niños de $3^{0}$ y $4^{0}$ juegan al fútbol en zonas pequeñas cercanas a la puerta de entrada. Las niñas de estos mismos cursos juegan a "comercios", pasean, están sentadas hablando o se persiguen.

- Principalmente los niños mayores son los que ocupan las canchas de fútbol y baloncesto. Las niñas de $5^{\circ}$ y $6^{\circ}$ que no pasean juegan al "escondite pillapilla" y al baloncesto cuando les toca. En ocasiones están cerca de los chicos para llamar su atención o intentar intervenir en sus juegos.

A veces se aprecian enfrentamientos entre niños por la disputa del espacio. Las zonas más demandadas son los espacios deportivos reglados. El profesorado decidió establecer unos turnos entre las clases para que cada día de la semana estos espacios fueran utilizados por un grupo-clase. En la práctica, los grupos-clase pueden juntarse entre ellos para jugar contra otro grupo. De esta manera desaparecieron algunos de los conflictos sobre este aspecto. El estatus de los espacios parece que viene dado por la reglamentación de la zona. Es decir, las zonas pintadas y con canastas o porterías son más deseadas y están restringidas para los cursos superiores y fundamentalmente son utilizadas por niños, aunque a veces (cuando les toca el turno) son utilizados por las niñas. Son las zonas más amplias y la densidad de ocupación es la menor (aunque se trata de un patio grande en el que no hay problemas de espacio).

Dentro de este apartado realizaremos un recorrido por los siguientes temas:

2.1.- Jerarquía y segregación en función del género y la edad.

2.2.- Influencia de la tipología de las actividades lúdicas en las interacciones sociales de los iguales.

2.3.- Acciones prejuiciosas y violentas producidas en los juegos. 


\section{1.- Jerarquía y segregación en función del género y la edad}

Hablaremos en primer lugar de algunos de los códigos horizontales que apreciamos en estos recreos. Estos códigos (que serían una suerte de "esquemas culturales de orientación", D’Andrade, 1995 en Velasco, 2004, 483) establecen una jerarquización por edades en el uso del espacio y una segregación por géneros en la realización de prácticas. Con el fin de comprender mejor los códigos que debe aprender y en los que se debe introducir el alumnado que llega nuevo al centro, nos detendremos en este apartado a describirlos.

Como apuntábamos en la introducción de este punto, el espacio está sujeto a una jerarquía y a unas normas. Los niños mayores acceden a espacios mucho más amplios, mientras que las niñas y los pequeños se ven relegados a zonas reducidas, marginales o cercanas al profesorado.

Joseph suele situarse en un espacio de los más deseados. Allí juega a fútbol, la actividad de más prestigio entre los niños. Hemos apreciado cómo, en ocasiones, las niñas intentaban introducirse en este juego, pero la ausencia de atención recibida por parte de los niños (no les pasaban el balón), hacía que poco a poco fueran abandonando la actividad.

Amani sin embargo, no dispone de un espacio fijo en el que jugar. Tiene establecido el grupo de niñas con las que juega y también la actividad ("el escondite pilla-pilla"). Este juego no requiere de un espacio concreto, ya que pueden esconderse por cualquier parte del patio, sobre todo aquellas que no están ocupadas por otros grupos.

Por otro lado, los niños de cursos inferiores, como Maluf, permanecen o bien pegados a las filas de subida a las clases (cerca de la puerta y de los profesores) o bien jugando a los "comercios" en zonas reducidas y cercanas a la puerta de entrada a las aulas. En esta actividad las niñas buscan material por el suelo como hojas, piedras o palitos y simulan venderlos (en las actas de noviembre se describen con detalle estas situaciones).

Como vemos, los espacios se distribuyen de forma jerárquica. Si el adulto no interviene, los niños en general y los mayores en particular tienen más posibilidades de disponer de los mejores espacios y de realizar los juegos más prestigiosos dentro de los códigos elaborados por el alumnado. Esta segregación y jerarquización en los espacios se recoge también en trabajos como los de Geertz (1975) o Martínez y García (1997). Algunas explicaciones de esta invasión espacial hacen referencia a la reproducción en el juego de ciertos rasgos culturales reforzados en función del género. Siguiendo a Martínez y García (1997), en el proceso de socialización de las mujeres se remarcaría su preparación para 
desarrollarse en espacios pequeños, íntimos y para asumir una jerarquía, mientras que a los hombres se les prepara para el "espacio público", demostrar su competencia y dominio. Estos rasgos se aprecian en los juegos tradicionalmente practicados por niños y por niñas. Mientras que los juegos de niñas llevaban al recogimiento espacial, la intervención rítmica y controlada (comba, bailar el aro, goma, tirar la pelota a la pared...); los de niños necesitaban de espacios amplios, una intervención individual más libre y mayor competitividad (correr con el aro, fútbol...).

Esta segregación por sexos va aumentando conforme van avanzando de nivel escolar y de edad. Observamos en nuestro recreo que los niños de los primeros cursos juegan juntos sin importarles el sexo, todavía no se ha producido esta segregación, comparten actividades y espacios diversos. Sin embargo, a partir de $4^{\circ}$ de primaria, se van agrupando los niños por un lado y las niñas por otro, paralelamente a la selección de un espacio. Autoras como Badinter (1992) nos hablan de que esta separación unisexual es común en todas las sociedades humanas, viendo en ello una necesidad para consolidar la identidad sexual.

Esta situación remarca valores como la competitividad en los niños, la licitud de que utilicen los mejores espacios, o el refuerzo de su competencia motriz. Las niñas, sin embargo, van asumiendo su papel secundario y van entrando en la inactividad 0 en la práctica de actividades poco complejas (en cuanto a normativa y a dificultad motriz). Estos modelos se perpetúan gracias a la imitación de los más pequeños de las prácticas vistas a los mayores (Elkonin, 1985). Así vemos cómo los niños de $3^{0}$ juegan a lo que ellos llaman fútbol, pero sin cumplir todas las normas que los mayores establecen cuando juegan al mismo juego ${ }^{3}$ (de perseguir y golpear un balón van pasando a comprender progresivamente todas las reglas que conforman la estructura del juego).

Las niñas intentan introducirse en estos espacios de niños, pero poco a poco, se van desinteresando ante la falta de atención recibida y van ocupando las zonas marginales del patio. Veamos algunos pasajes de las actas que reflejan estas ideas.

Hoy tienen pista asignada para jugar al baloncesto. Las chicas que se han chivado son expulsadas del juego. No les dejan jugar. (Ante la regla vertical de "todos juegan", ellos tienen la suya que es "al chivato ni agua"). Diego, Pablo y David son los niños que expulsan a los demás y que animan a rechazar, a los demás parece que les da lo mismo. Joseph agarra por la espalda a uno para quitarle el balón como si fuera Rugby. Álvaro le dice: "pero

\footnotetext{
3 En el trabajo de J. Linaza y A. Maldonado (1987) podemos encontrar un estudio detallado de la evolución de la comprensión de las normas en este juego.
} 
¿qué haces?", él dice: "vale, vale" (enérgicamente).Las chicas poco a poco van saliendo del juego y se dirigen a una esquina del patio, una se acerca a mí y dice: "ies que los chicos nunca nos pasan el balón!

(Diario 24 Noviembre 2006)

Las chicas tienen interés en participar (algunas practican deportes extraescolarmente), pero la segregación se muestra como una regla inviolable de su código horizontal. Vemos en el pasaje anterior que algunos niños (la "minoría ruidosa" de la que hemos hablado) se convierten en los guardianes de ese código, los defensores de una "tradición" (machismo) a preservar. Realmente a la mayoría de los chicos les daría lo mismo jugar con unos que con otras, pero esos pequeños grupos de poder regulan e imponen las fórmulas de interacción. Así las cosas, si eres un chico nuevo en el grupo, sólo tendrás oportunidad de integrarte si logras "caer bien" a estos líderes. Algo de esto es lo que le ha debido suceder a Joseph. Como se aprecia en el fragmento anterior, aunque él se emplea de manera poco ortodoxa en el juego, los líderes no le recriminan o le rechazan. Por el contrario, sus maneras en ocasiones radicales y algo bruscas puede que sean apreciadas por esa "minoría ruidosa". Nos aventuramos a interpretar que su apariencia física (bien

parecido y fuerte) y sus maneras (apacible en general, pero mostrando tajantemente los límites) hayan sido interpretados por esos líderes como señales de alguien a quien respetar y con el que aliarse.

Por otra parte, podemos imaginar que un escolar inmigrante que llega nuevo al colegio y desconoce cómo será la cultura escolar a la que se enfrenta, aprenderá y asumirá rápidamente estos códigos sexistas. En este pasaje Joseph está jugando y aprendiendo todos los códigos que en el juego se están dando. Cada vez irá viendo más normal que las niñas no jueguen a este deporte y que, si lo hacen, apenas reciban pases. Es decir, irá asumiendo que las personas del otro género no son del mismo nivel y que deben asumir un papel secundario.

\section{2.- Influencia de la tipología de las actividades lúdicas en las interacciones sociales de los iguales}

Cada juego supone un texto que transmite unos valores a aquellos que participan en él (Renson, 1991; Pelegrin, 1996, Reboredo, 1983; García Monge, 2001). La propia actividad lúdica constituye un momento idóneo donde observar, no sólo, las habilidades sociales que los niños y las niñas poseen y manifiestan, sino la forma en la que se van adquiriendo.

Al introducirnos en el análisis de los juegos podemos ir viendo, además de estos mensajes que emanan de ellos, las posibilidades que brindan sus estructuras para provocar unas acciones u otras en los participantes. Hay juegos cuya 
escenografía supone una presión para los participantes, otros invitan a la agresividad, otros al individualismo, otros brindan tempos lentos con oportunidades para que cada uno decida cuándo y cómo interviene, otros son selectivos y ponen en evidencia las carencias de algún jugador. El análisis que a continuación haremos nos permitirá ver las posibilidades que ofrecen los juegos practicados en el patio del centro estudiado a la integración del alumnado nuevo. Observaremos como existe una bidireccionalidad en cuanto al juego y la construcción de habilidades e interacciones sociales. Las características y normas de los juegos propician la manifestación de determinadas habilidades sociales y, a su vez, las propias interacciones y habilidades de los escolares van construyendo y dando forma a las dinámicas lúdicas.

Haremos un recorrido por los juegos observados en los recreos, deteniéndonos especialmente en los casos de los niños y niñas inmigrantes sobre los que realizamos el seguimiento. En el análisis de estos juegos seguiremos un orden en función de las edades de los practicantes: primero las actividades lúdicas de Maluf y de los alumnos más pequeños ("pillar" y "los comercios"), para pasar a las de los mayores (primero la de las niñas: "escondite pilla-pilla" y luego los deportes practicados principalmente por los niños: fútbol y baloncesto).

\subsection{1.- "Pillar"}

Este juego consiste en perseguir y ser perseguido. Es practicado por dos 0 más jugadores. Normalmente, los niños y niñas más pequeños desarrollan una versión poco estructurada en la que un grupo huye de una persona y una vez que alguien es atrapado o bien el juego muere con un forcejeo entre perseguidor y perseguido 0 el capturado se convierte en un nuevo perseguidor. También hemos visto persecuciones entre dos que no terminan en nada. A partir de estas líneas básicas a veces vemos versiones más elaboradas como la de ir sumando perseguidores en una "cadeneta" o la de salvarse cuando se huye subiéndose a algún lugar interpretado como "casa" ("alturitas").

Ser atrapado, al igual que esconderse, o rescatar y ser rescatado son actividades que tienen mucho que ver con ser el objeto de deseo (Lapierre y Acouturier, 1985), de hecho, tradicionalmente se realizaban a la caída de la tarde, en verano, en lugares y horas determinados y en grupos mixtos (García Monge, 2004). En las actas vemos cómo es la actividad fundamental de Maluf. Busca el contacto a través de ser perseguido. Al no poder hablar con nadie y necesitar sin embargo, ser tenido en cuenta por algún compañero, busca el contacto mediante esta acción fácilmente entendida por otros. Cuando se acerca alguien para hablar con él o para mirarle el bigotillo, él huye. Al ver que los demás (sobre todo niñas) le persiguen, lo vuelve a hacer repetidamente hasta consolidarlo como juego cuando 
sale al recreo. Sin mediar palabra con nadie, la escucha corporal ha creado en este caso una interacción básica de perseguir y sobre todo ser perseguido. Eso sí, corre siempre cerca de la fila de subida a las aulas, como le indica su hermana. Conforme pasa el tiempo se va alejando de esta zona, pero teniendo como referencia este punto cercano a la puerta. Esta actividad es realizada por casi todos los niños en algún momento del recreo. A modo de juego estructurado o de "jugueteo de interacción". Lo curioso es que un niño que no tiene cultura escolar de ningún tipo, ya que en su país todavía no había sido escolarizado y además no habla ni una palabra de español, haya establecido su primera y casi única interacción con sus iguales mediante el juego y en concreto con la actividad de pillar.

Maluf se encuentra cerca de la entrada como acostumbra a hacer desde que su hermana le dejó algo más de autonomía en el recreo. Dos niñas de su curso empiezan a jugar con él, él se escapa y las niñas le persiguen. Esta es la forma en la que ha aprendido a interactuar, él corre y los demás le persiguen. No necesita hablar, sólo gestos y acción. Los demás entienden rápidamente la norma y él se siente atendido.

Se añade otro niño y todos le persiguen. El es hábil y más pequeño que los demás y se logra escapar todo el rato.

Cinco minutos antes de que suene la sirena, Maluf está colocado en la fila para subir. Los niños se han cansado de perseguirle. Algunos niños y niñas que pasan a su lado le cogen, le dan toquecitos en la cabeza.

(Diario 13 de Noviembre 2006)

Se sitúan en el sitio de siempre, previa visita de su hermana Amani para asegurarse de que está allí. El almuerzo ya lo traen independiente. Otro paso de autonomía. Antes el almuerzo les unía por lo menos en la hora del recreo. Ahora ya no. Aun así, Amani le mira y se asegura de que está al empezar el recreo y al acabar.

Mira a ver a qué niñas conoce y va a pillarlas detrás de ellas. Hasta ahora venían a pillarle a él, ahora sabe que tiene que empezar él si quiere jugar con alguien y así lo hace. Dos niñas juegan con él y le persiguen, le atrapan, le abrazan. Le cogen para meterlo dentro del colegio, pero él no quiere, les dice que no con el dedo y se va corriendo en busca de otros niños/as con quien jugar.

Vuelve a la zona de la fila, se mueve, mira alrededor a ver a quién ve. No ve a nadie. Se dirige hacia donde está su hermana pero sin acercarse, sólo mira de lejos. Coge una hoja del suelo y empieza a darle vueltas mientras corretea, pasa cerca de mí, le saludo pero él huye y se va en otra dirección. 
Le enseña a una niña la hoja para que juegue con él. Huye de la interacción de mayores, sólo quiere la de los niños que se relacionan sin hablar con él, porque ya saben que no habla.

Llega el balón de fútbol con el que juegan Joseph y Willy a su zona y él lo coge y se lo pasa pero sin moverse de esa zona.

Sigue buscando cómo interactuar. Ya se le ven gestos de relación con los demás aunque sea sin hablar. Se acercan otra vez las dos niñas. Le hacen burla con las manos en buen tono para incitarle a que vaya a pillarlas. Él quiere que le pillen a él. Las otras quieren que él las pille. Se acercan a él, le dicen "píllame". Él no entiende, entonces ella le coge la mano y se la pone encima de ella misma. Él ya lo entiende $y$ va a por ellas.

(Diario del 17 de Noviembre 2006)

En estos relatos vamos apreciando varios detalles interesantes:

- Observamos la actividad constante que mantiene Maluf buscando contactos con otros niños y niñas. Sus ganas de comunicación parecen inmensas. El resto de la jornada escolar (durante las clases y los apoyos) apenas mantiene contactos con sus compañeros, o sea, que este es el momento que Maluf tiene para crear su círculo social y no desperdicia ni un minuto interactuando con los adultos.

- Un niño como Maluf, recién llegado a un lugar extraño, recurre a las fórmulas elementales de interacción para llamar la atención de otros. Sin embargo, su consistencia es frágil. Le faltan recursos para introducirse en un grupo, para continuar la actividad durante un tiempo (cambian los niños y niñas con los que interactúa y el tiempo máximo de un juego ronda los cinco minutos) y para consolidar la relación. Siendo más mayores algunos de estos problemas pueden suplirse, pero a esta edad las relaciones son más frágiles y las alianzas se deshacen con la misma facilidad que se forman.

- El recurso elemental de interacción que utiliza está en la persecución. La simplicidad de la línea básica del juego permite a Maluf entender y ser entendido por los demás rápidamente y establecer un juego al momento. Sin embargo, esta misma sencillez es la que impide que el juego dure mucho tiempo, ya que no existe un reto con el que engancharse. Él opta por ser perseguido, lo interpretamos como un indicador de inseguridad. Cuando eres perseguido te sientes "objeto de deseo", sientes que los demás te están atendiendo.

- La mayor receptividad de las niñas para abrirse a nuevas personas e integrales en sus juegos. No resulta extraño ver que, en general, o bien niños más pequeños (acogidos por grupos mixtos o de niñas) o bien niñas en edades mayores (acogidas por grupos de niñas como en el caso de Amani) viven procesos de integración más fáciles que los niños mayores (caso de Willy). 
Por otro lado, esta actividad es buscada por las niñas mayores para conseguir la atención de los niños. A los 11, 12 años las niñas ya empiezan a sentir y a hablar de atracciones por el sexo contrario, los niños, sin embargo, parecen no estar en la misma onda, aunque, a todos ellos les agrada gustar a otros.

Algunas niñas de la clase de Joseph están al lado de donde ellos juegan al fútbol. Van corriendo hacia Joseph y le hacen cosquillas. Él corre detrás de ellas saliéndose del partido unos segundos, pero vuelve rápido al juego.

No realizan ninguna otra actividad concreta salvo la mencionada.

Les pregunto qué hacen y me responden: "estamos picando a los chicos para que corran detrás de nosotras", "en concreto a Joseph", dice otra niña riéndose. Me mira y me dice a carcajadas: "es que está muy bueno, ¿a qué si?

(Diario 13 Noviembre 2006)

Mientras que los chicos siguen desarrollando una actividad reglada y motrizmente compleja, las niñas han asumido su papel de ser relegadas a un segundo plano, desempeñando un rol en función de los chicos (buscar su atención), sin generar una actividad propia. Es curioso comprobar que dos décadas de escuela mixta han acentuado algunos estereotipos de género: los chicos activos, demostrando su competencia y las chicas a su alrededor buscando su aceptación 4 .

En ambos ejemplos hemos visto que buscar ser atrapado es una forma básica de reclamar la atención de otros, que varía en fines y maneras en función de la etapa evolutiva del individuo.

\subsection{2.- "Los comercios"}

Las alumnas de los primeros ciclos inventaron un juego que consistía en recoger objetos del patio, como piedras, palitos, hojas y objetos similares, unirlos creando adornos (por ejemplo: piedras rodeadas de hojas), exponerlos en una zona reducida del espacio y ponerlo a la venta simbólica mediante el intercambio de otros objetos similares.

Esta actividad es realizada fundamentalmente por niñas, aunque aparece alguna vez algún niño de cursos inferiores como comprador o como recolector de objetos, las que organizan y gestionan son niñas.

\footnotetext{
${ }^{4}$ Es fácil reconocer en esta escenografía estereotipos que se reproducen en otras situaciones: chicos practicando un deporte mientras las chicas hacen de animadoras. Este es un modelo posiblemente reforzado por las prácticas deportivas (asociadas socialmente a un género u otro) y por los medios de comunicación (películas, dibujos animados, anuncios de juguetes...).
} 
Este juego recoge todos los roles de la cultura tradicional femenina: recolección, reproducción de modelos observados en los mayores, asimilación de roles asociados en la tradición a las mujeres (hacer la compra). Y también reconocemos valores nuevos como el de la iniciación en la sociedad de consumo (compra-venta de objetos de adorno). Se trata de un juego simbólico, pautado por guiones de actuación dirigidos por las niñas que lideran el grupo. Son juegos de alto contenido verbal y escaso contenido motriz. Se desarrollan en una zona espacial reducida, cercana a la puerta de entrada y al profesorado. Conlleva un "tempo" de acción lento en el que cada jugadora puede establecer su momento de intervención, se adapta, por tanto, a diferentes tipos de ritmos individuales.

Teníamos la idea de que las niñas aceptarían en todos sus juegos a los niños. Sin embargo en este juego, vimos cierto grado de selección de los participantes. Los niños apenas jugaban, ni ellos querían, ni a ellas parece que les gustase mucho que ellos jugasen. A veces se acercaba algún niño, pero al ser ignorado terminaba abandonando el grupo. Algún niño más pequeño, si llevaba objetos bonitos, era aceptado pero sólo con el rol de recolector y de comprador, nunca podía gestionar y menos vender.

Lo mismo ocurre con las niñas nuevas. Las niñas que decidían hacer los cambios y vender a los demás, eran las que decidían también quién jugaba y quién no, utilizando como excusas frases del tipo "es que somos muchos ya", o "es que no sabe como es el juego". Veamos en el siguiente fragmento el rechazo que sufre Esperanza por este grupo en sus primeros días de escolarización en el centro:

Veo a unas niñas de clase de Esperanza. Me comentan que están jugando a "Ios comercios". Les presento a Esperanza y les digo que como es nueva y no conoce a nadie todavía, no tiene a nadie con quien jugar. Les pregunto si quieren jugar con ella, ya que son de su clase. Me responde una en representación que no puede, porque tienen los puestos justos en la tienda y que además no sabe jugar. Al instante aparece una niña al lado y dice: "yo también soy de su clase, que juegue conmigo". Esperanza se acerca y se queda con ella jugando

(Diario 25 Octubre)

Para el alumnado inmigrante nuevo, este tipo de juegos requiere un gran esfuerzo de comprensión, no sólo del lenguaje sino de las reglas y códigos internos entre iguales: objetos que son apreciados por las líderes, respeto a sus opiniones (no se aceptan las improvisaciones dentro del guión básico o la "libre competencia de mercado"), asumir los roles asignados, o el respeto de los espacios, turnos y rituales. La comprensión de estos códigos horizontales no resulta fácil, dada su aleatoriedad. Se trata de guiones cambiantes en pequeños matices en función de las opiniones de las niñas que dirigen el grupo. Posiblemente 
por todo ello es difícil encontrar a niñas inmigrantes jugando a este juego y si a pesar de todo se acercan, reciben pocas interacciones y terminan abandonando.

Lily y Esperanza (las dos niñas de la República Dominicana, una de ellas nueva) están jugando a los comercios en un grupo de unas 10 niñas de $2^{\circ}$. Ellas dos están en el juego, pero no interactúan demasiado con las demás, no hablan con nadie salvo entre ellas. Las niñas que protagonizan el juego tienen cada vez más piedras que ponen en un bordillo de piedra a modo de expositor y no dirigen ninguna interacción (verbal, gestual o visual) hacia Esperanza y menos a Lily. Ante el aburrimiento por ser ignoradas se van a otra zona ellas dos solas y empiezan a subirse a caballito una encima de la otra. Parece ser que es la solución que toman ante el rechazo del gran grupo. Cada vez se acercan más niñas incluso algún niño. Ese juego tiene mucho tirón y sólo consiste en recopilar piedrecitas y ponerer las hojas encima, adornarlas y exponerlas a la visión de los demás..

(Diario 24 Noviembre 2006)

Nos resulta difícil decir con claridad cuál es la razón de estos rechazos. Tenemos algunos datos que pueden orientar alguna explicación. Por ejemplo, sabemos que Lily (que lleva un año en ese grupo) es considerada desorganizada y algo "mandona" (de hecho una vez que tomó bajo su cuidado a Esperanza ya no le dejaba hacer otra cosa que no fuera estar con ella). Esa consideración de "mandona" viene dada por un grupo de niñas a las que les gusta imponer su criterio, así que en realidad cuando la definen como "mandona" podrían decir "poco sumisa". Al comparar este caso con el de Amani (obediente, se deja llevar por las otras niñas) vislumbramos un posible rasgo de las personas nuevas valorado por los receptores: la sumisión y aceptación de lo establecido.

Si el juego de pillar que vimos anteriormente es el que tiene una línea más fácil de entender, este constituiría el polo opuesto, siendo el guión de difícil acceso para los alumnos inmigrantes nuevos, dado que se compone de normas no explicitadas, no se trata de un código universal (fútbol, baloncesto...), y depende de decisiones personales de las directoras del juego.

\subsection{3.- "Escondite pilla-pilla"}

Esta actividad tiene el siguiente desarrollo: mientras uno cuenta, los demás se esconden por todas las zonas del patio, al terminar de contar deberá no sólo verles, sino atraparles persiguiéndoles por todo el espacio.

Este juego es practicado por Amani y las niñas de su clase. En ocasiones hay dos niños (no demasiado integrados en el grupo líder masculino) que juegan con ellas. La actividad resulta algo dispersa porque al ser el patio tan grande, se pasan todo el recreo buscándose sin tener demasiado reto. Por eso a veces tienen 
ciertas disputas para ver quién "se la queda", ya que saben que quien lo haga posiblemente se la "quedará" durante todo el recreo.

Siguiendo el análisis de rasgos de los juegos propuesto por García Monge (2004), nos encontramos que en este juego:

- La participación del jugador viene regulada por uno mismo, cada uno decide qué hacer, cuándo y cómo (esconderse, huir, seguir al perseguidor, arriesgarse para ser perseguido, unirse a otro, dónde esconderse, cuándo salir...). Por tanto, se ajusta a diferentes ritmos personales de funcionamiento.

- Las acciones de los jugadores quedan casi en el anonimato y del resultado de las mismas no se deduce un beneficio o perjuicio para los otros. Esto hará disminuir la presión sobre las intervenciones. Cualquier escolar nuevo en el grupo puede encontrarse más relajado en un juego como este 5 .

- Es una actividad poco exigente en cuanto a la habilidad requerida y en cuanto a la comprensión de la normativa. Puede acoger a niños y niñas con diferentes niveles de habilidad y comprensión.

- Se basa en códigos universales básicos de juego infantil: perseguir y ser perseguido, esconderse y ser buscado. Por ello puede resultar atractivo para cualquier niño o niña nuevo en el grupo.

- Las interacciones con otros no suponen conflicto de intereses (la actuación individual no choca con los intereses de un equipo, el guión de un grupo de líderes o los intereses de los adversarios), cada uno decide con quién ir y cómo hacerlo. En todo caso, cualquier jugador puede decidir aliarse o beneficiar a otros (avisándoles del peligro por ejemplo), brindando así pequeños resquicios para que alguien nuevo en el grupo se gane la amistad de los demás. Por otra parte, alguien nuevo, una vez que es aceptado en el juego, puede decidir libremente cómo y con quién participar sin verse juzgado en sus acciones, sin tener que medirse con otros, 0 demostrar una habilidad especial.

- Pone en funcionamiento muchos mecanismos de toma de decisiones en los participantes que se enfrentan libremente al espacio.

Todos estos rasgos nos muestran una actividad interesante para acoger a niños y niñas nuevos en el centro. El caso de Amani es un ejemplo de ello. Esta niña ha sido muy bien aceptada en el grupo. Los primeros días la cogían de la mano y

\footnotetext{
${ }^{5}$ En el extremo contrario se encontrarían juegos como "el pañuelito", de intervención obligada, expuesta a la mirada de todos y con un resultado que afecta a todo el grupo.
} 
ella repetía todo lo que veía. Al poco tiempo aprendió las normas y se la veía avisando a las demás para que no las pillaran.

\subsection{4.- "Fútbol"}

El fútbol es la actividad protagonista de los recreos de los centros escolares. Su popularidad nos permite saltarnos la descripción del juego. Sin embargo, es importante realizar el análisis de sus rasgos por las implicaciones educativas y sociales que de él se derivan.

Esta actividad es realizada por niños y se complica en función de la edad, las normas y el nivel técnico. La línea básica del juego consiste en la disputa por un móvil y ello conlleva situaciones egocéntricas de posesión del mismo.

El tempo de acción es muy rápido y viene marcado por compañeros y adversarios por lo que los niños que no se ajusten a este ritmo quedan excluidos del juego. Este es el caso de Willy que los primeros días era rechazado alegando que jugaba mal al fútbol. Muchas veces no se trata de un nivel de habilidad objetivo sino de la seguridad en los contextos, niños que en su barrio o con otros niños juegan perfectamente al fútbol en el patio del recreo se ven más torpes debido a la inseguridad producida por el espacio reducido, por el desconocimiento de los jugadores, etc. (Martínez Álvarez y García Monge, 1997). Este puede ser el caso de los alumnos inmigrantes nuevos, llegan con otros ritmos y desconociendo el contexto y lógicamente su actuación es más torpe. Sin embargo, en el caso de Joseph esto no fué así. El primer día de clase para él, de alguna manera fue puesto a prueba por sus compañeros metiéndole en su grupo de fútbol. Éste, deseoso de agradar y de mostrar lo mejor de sí metió un gol aplaudido por los demás. Fue un gol metido en buen momento, porque a partir de entonces aunque realizara malas jugadas éstas no eran reprochadas. Posiblemente no se trate tanto del hecho en sí sino de las expectativas que los demás depositaban en él. Veamos en el siguiente ejemplo cómo son valorados de forma diferente los goles de Joseph y los de Willy.

En este grupo que juega al fútbol están Willy, Joseph y 8 niños más. Joseph interactúa cada vez más con sus compañeros durante el juego y se le oyen sus primeras palabras en español: "pasa". Está claro que el fútbol supone un código compartido que une a niños de diferentes procedencias, a la vez que los separa de las niñas.

Al rato, Joseph mete un gol. Todos le felicitan, sonríen, muchos hacen con él un choque de manos. A partir de este momento cada vez pasan más el balón a Joseph. 
Willy está casi todo el tiempo algo apartado en el grupo. Apenas interactúa con sus compañeros. Un rato después, mete un gol, pero nadie salvo Joseph le felicita con un choque de palmas.

(Diario 14 de Septiembre 2006)

Vemos cómo la suerte de Willy se encaminó por otro lado. Posiblemente su lesión en la pierna que le dificultaba, pero no impedía jugar, su condición de repetidor y su ritmo de acción bastante más lento que el de Joseph y de los demás compañeros hizo que los demás se formaran una idea de él como torpe en el fútbol. Ser rechazado en este juego va mucho más allá de no jugar en una actividad. Supone un claro ataque al estatus social en el grupo, tal y como las pruebas sociométricas realizadas los primeros días demostraron. Las excusas para no permitirle jugar aludían a razones como: "somos muchos", "eres malo". Posteriormente estas excusas se iban refinando y le incluían en el juego, pero en papeles secundarios como el "portero", "el recoge pelotas". Las estrategias que Willy desarrolló para ser integrado las veremos en el apartado de evolución y fases de estos tres alumnos inmigrantes a los que realizamos el seguimiento.

Los contactos que se realizan en el fútbol son bruscos y la agresividad puede ir aumentando a medida que avanza el juego, llegando un punto en el que es difícil distinguir juego de agresión. Así vemos cómo algunos niños acusan a otros de pegar patadas. Las niñas y los niños más relajados desaparecen de estos momentos y deciden realizar otra actividad ante los continuos enfados.

Para un alumno nuevo este grado de agresión puede ser chocante, incluso puede tomárselo como una agresión personal como es el caso de Joseph. Los primeros días se enfadó varias veces por creerse insultado, cuando las palabrotas que los otros niños proferían no iban dirigidas a él, sino que eran una forma violenta de expresarse. Las entrevistas realizadas a los niños de esta clase nos confirmaron esta observación: "En el recreo una vez Álvaro decía: "hijos de puta", "cabrones", pero lo decía en general no a él y Joseph se enfada". Otro niño de su clase confirmaba la misma idea y nos permitía contrastar nuestras observaciones: " $A$ veces se enfada porque se cree que le insultan, ahora parece que se está calmando".

Esta violencia verbal es más acusada en juegos como el fútbol, siendo casi inexistente en otros juegos en los que los espacios son mayores. En otras actividades no se hacinan todos luchando por una pelota en pocos metros cuadrados, el tiempo de acción es más tolerante con todo tipo de ritmos y la intervención del niño no está valorada por todos mientras la realiza, sino que se diluye su protagonismo. 
Estos análisis nos ponen de manifiesto que se trata del juego que marca el estatus social entre los niños y que a su vez más rechazos y marginaciones genera. A pesar de ello, Joseph y Willy pelean por tener su puesto reconocido dentro de él. Las niñas del grupo organizan la actividad alrededor de este espacio y muchas veces (como señalamos al hablar de los juegos de persecución) lo único que hacen es buscar el contacto y atención de los niños.

\subsection{5.- "Baloncesto"}

Esta actividad, al igual que el fútbol, tiene unos referentes sociales claros, una normativa estandarizada y una demanda técnica más alta que otros juegos infantiles. Aunque los modelos de referencia de la misma en los medios de comunicación suelen ser masculinos, es una actividad muy difundida entre las niñas (por ejemplo, en Castilla y León, en categorías inferiores el número de niñas supera al de niños). Algunas niñas de los últimos cursos del centro ocupan el espacio de las canchas de baloncesto para jugar, cuando les corresponde el turno (turnos asignados por los maestros para la ocupación de espacios). En este caso, la norma vertical ha facilitado que las personas con menor capacidad de imponer sus criterios puedan disfrutar de estos espacios. De todas formas, apreciamos también ciertos códigos horizontales por los que el fútbol es considerado una práctica de mayor estatus por el grupo de chicos dominantes, de manera que las canchas de baloncesto son ocupadas por las niñas y por los niños más tranquilos o rechazados en el fútbol.

La relación espacio-participantes es mayor que en el fútbol y quizás por ello, en general, se aprecia un ambiente más sosegado que en aquel.

En ocasiones también apreciamos rechazos. Cuando el grupo quiere excluir a alguien sólo tiene que recurrir a las normas del juego (cinco en cada equipo). Esto es utilizado de nuevo para no dejar jugar a los niños de menor estatus en el grupo 0 a aquellos que desconozcan las normas del juego. En este caso, la clara reglamentación del juego le resta flexibilidad y se convierte en una coartada para la exclusión.

El manejo del móvil con las manos permite un mayor control y ello posibilita parar para mirar y pasar, con lo cual el juego puede ser menos individualista y el móvil se puede repartir más entre todos. Si seguimos los trabajos de García Monge (2004) y tomamos el número de pases recibidos por un niño como un indicador de su consideración dentro del grupo obtendríamos que dentro del juego se pueden apreciar a muchas personas rechazadas que solicitan la pelota todo el tiempo y, aun estando bien situadas para el lanzamiento a canasta, no reciben ningún pase. El siguiente pasaje recoge una situación de este tipo: 
Me encuentro a Crassy y a otro niño búlgaro llamado Ibor. Están apoyados en la pared mientras ven jugar a baloncesto a los de sus clases respectivas. El Director que andaba por allí, me saluda y vamos los dos a hablar con ellos. Les preguntamos que por qué no juegan. Nos dicen que no les dejan. El director interrumpe el partido y les dice que por qué no le dejan jugar. Les meten a cada uno en un equipo y apenas les dejan tocar el balón. Ibor se esfuerza bastante por conseguir el balón, no parece malo, se mueve bien buscando los huecos. Bastantes veces está situado debajo de la canasta, él solo y no recibe ningún pase. Al poco coge dos rebotes y tira a canasta, falla las dos veces. Se le oye a otro niño decir: "Eres un chupón Ibor, no tires, pasa". Unos minutos más tarde ese mismo niño tira dos triples de los cuales ninguno llega ni al tablero. Crassy no coge el balón apenas. Continúa el juego y ellos dos apenas tocan bola. Está visto que a algunos se les permite "chupar" del balón y a otros ni tocarlo.

(Diario 11 de Diciembre 2006)

Otro día, en este mismo espacio observamos a la clase de Joseph jugando al baloncesto y vemos cómo Willy, a pesar de tener un ojo morado y la pierna con la lesión latente, está dándolo todo en el partido de baloncesto. En las clases de Educación Física se demostró que era bastante bueno jugando, pero nadie pareció valorarlo, tal y como se apreció en aquel partido en el que apenas le pasaban el balón, incluso estando muy bien situado.

Están jugando al baloncesto junto con Adrián M y Adrián S, Israel, Pedro y Diego. Willy tiene guantes, cojea por la pierna que tiene mal y va con gafas de sol. Lis le pregunta por qué las lleva. Me dice que es que tiene el ojo morado porque se chocaron Adrián S y él jugando al fútbol la semana pasada. A pesar de ello, está entregado al partido dándolo todo, cogiendo balones cuando puede y participando como los demás. Hay jugadas en las que Willy está solo y Diego prefiere pasar a Joseph que se encuentra peor situado. Willy ha demostrado varias veces en Educación Física que se le da bien el baloncesto, pero en los recreos no podrá demostrar su valía.

Israel (el niño gitano), sin embargo, no tiene preferencias al pasar el balón en este rato. Pasa al que mejor está situado.

En general todos buscan la manera de poder tirar ellos a canasta y llevarse ellos el mérito.

(Diario 25 octubre 2006)

Si hiciéramos un estudio pormenorizado de la cantidad de pases que recibe cada niño en todo juego en donde existan pases y recepciones de balón, podríamos realizar un auténtico sociograma en vivo y nos ofrecería mucha información del 
estatus social de cada alumno. Por lo general hemos observado que los alumnos inmigrantes nuevos reciben menos pases.

En resumen, hemos ido viendo cómo la cultura lúdica tradicional, factores institucionales (diseño de los espacios, organización de turnos de uso), y las prácticas sociales dominantes (fútbol y baloncesto) configuran la estructura básica sobre la que se asientan los fenómenos de jerarquización, segregación y rechazos. Este análisis nos permite conocer mejor los problemas y posibilidades para la integración que tendrá un nuevo escolar en situaciones en las que no haya una presencia marcada del adulto. Tras esta exploración de la cultura lúdica de este centro, apreciamos, con respecto a la integración del alumnado inmigrante, lo siguiente:

En general hemos apreciado una gran pobreza lúdica y una homogeneización de prácticas. A esta simplicidad en la variedad se le une una simplicidad en las normas y organizaciones. Salvo el caso de los deportes, el resto de los juegos son poco estructurados ("pilla-pilla") o de estructuras muy sencillas ("escondite pilla-pilla"). Nos encontramos, por tanto, con dos polos opuestos que pueden suponer problemas a la hora de acoger a alguien nuevo en el grupo:

- De un lado, las actividades sencillas que con la misma facilidad que surgen y permiten entrar a alguien, se disuelven (caso de Maruan y el "pilla-pilla") 0 actividades simbólicas de norma tan aleatoria que depende de la decisión de un grupo pequeño de participantes ("comercios").

- De otro lado, los deportes de equipo. Competitivos, selectivos y segregadores. El ambiente de rivalidad y la presión hacia sus participantes no supone un ambiente relajado en el que una persona nueva pueda integrarse tranquilamente siguiendo su ritmo.

La falta de oferta lúdica puede suponer, por tanto, un problema para la integración. Cuando el grupo practica actividades diferentes (un día juegos de puntería como los tazos o las canicas, otro día juegos de persecución por equipos como "polis y cacos", otro día juegos de habilidad como juegos de saltar a burro 0 comba...) puede haber más posibilidades de que alguna de ellas cuadre con los intereses y habilidades de la persona nueva. Esta homogeneización conlleva, además, el refuerzo de unos únicos valores (segregación, jerarquización, selección, competitividad, individualismo...).

Por otra parte, el diseño de los patios condiciona las actividades que se podrán desarrollar en él. La codificación referida a prácticas corporales dominantes de gran parte del espacio invita a su uso restrictivo por unos pocos. Como señala Faleroni (1999,137): La forma de apropiación del espacio queda fuertemente 
legitimizada por el modelo deportivo dominante, y quien no se ajuste a su simbología, queda excluido. De esta forma, esta inducción al juego deportivo que suele ser, como vimos en el análisis anterior, más agresivo y competitivo, fomenta un tipo de relaciones sociales marcadas por estos valores. En estas situaciones de competitividad los niños (más educados en rasgos competitivos y agresivos) tienden a imponer sus formas de hacer: un ritmo rápido de actuación, disputa por el móvil, presión de compañeros y adversarios para no fallar, o agresividad verbal y física. Todo ello puede ser vivido por muchos alumnos inmigrantes nuevos como algo tenso, incluso traumático, si no se adaptan a este ritmo marcado. Esta puede ser la causa por la que Amani no se acerque a ningún niño ni para jugar, ni para trabajar en clase. O más claramente, por la que Willy sufre exclusión por parte de sus compañeros al jugar al fútbol.

Por tanto, esta forma de organización de los espacios conlleva unas prácticas. Esas prácticas arrastran unos modelos con ciertos valores. Esos modelos se caracterizan por una selección (de aquellos más hábiles o luchadores), una segregación por sexos y una especialización que lleva a no compartir el espacio y a buscar los mejores escenarios de juego. Ello supone que los mayores ya no se conformarán con una improvisación de límites y porterías e impondrán su mayor poder físico para ocupar toda una cancha. Así se van asimilando y normalizando valores como la jerarquización por sexos y edades, y aprendiendo que las actividades de más valor están reservadas a los varones de más edad.

En este ambiente selectivo, las niñas, los pequeños y los nuevos se pueden ver relegados a espacios y actividades peor consideradas, incluso a la inactividad total. Nos choca que estos grupos no desarrollen otras actividades paralelas del mismo nivel de organización que estos deportes (caso de muchos juegos tradicionales de persecución por equipos, puntería o habilidad).

Vemos que el sexo, la edad, la división y codificación de los espacios, las características de las actividades practicadas y las características de los niños y niñas que componen cada grupo van definiendo los rasgos de la cultura lúdica escolar, es decir, las normas que el alumnado nuevo inmigrante, deberá conocer, entender y aprender para ser uno más en el colegio. Podrán desobedecer algunas normas del profesorado, incluso de los padres, pero lo que no podrán hacer, si quieren ser valorados positivamente entre ellos, es no cumplir estos códigos que hemos llamado horizontales. Estos códigos establecidos entre ellos están influidos y marcados por una encrucijada de redes como son: la tradición escolar, las actuaciones educativas del profesorado y los valores que traen provenientes de familias, medios de comunicación y sociedad. El alumnado 
inmigrante que se enfrenta a un contexto nuevo se percata y asimila estas normas internas establecidas.

\section{3.- Acciones prejuiciosas y violentas producidas en los recreos}

En tercer lugar, explicaremos las interacciones entre iguales en las que se produce rechazo o violencia entre etnias, así como el prejuicio presente en estas acciones. Dado que pretendemos estudiar el tema de las relaciones entre alumnado inmigrante nuevo y alumnado español, consideramos interesante y necesario destacar cómo se realizan los agrupamientos, quiénes se agrupan, así como los rechazos y filiaciones que entre iguales se producen. Ya hemos visto que la gran separación en el recreo es la referida a la edad y al sexo, sobre todo en el alumnado de cursos superiores. Sin embargo, existen otros agrupamientos en los que nos fijamos con atención. Estos son los referidos a las etnias. Respecto a esta categorización observamos dos núcleos de agrupamientos, por un lado podríamos hablar de los gitanos y por otro de los inmigrantes. Dentro de estos últimos, existen diferencias en cuanto a su agrupación, en función de si llevan más o menos tiempo en el centro y en función de la procedencia, siendo los árabes los alumnos que más tendencia tienen a la agrupación entre sí, y los de Europa del Este los que más facilidad tienen para mezclarse con los españoles. Comprobamos cómo estas observaciones se corresponden con los resultados que obteníamos en el estudio extensivo/cuantitativo, en concreto, cuando relacionábamos las valoraciones sociales con las procedencias de los alumnos. Allí observábamos, sin establecer significación estadística debido al bajo número de inmigrantes, que los magrebíes no recibían ninguna valoración como "preferidos" y bastantes como "rechazados". Sin embargo, observamos que los alumnos búlgaros se integraron con más rapidez a los grupos de españoles como también confirmaron algunos comentarios de varios profesores.

Este hecho indica que, aunque se tiende a buscar la interacción con los compañeros de la misma clase, los que son rechazados por su propio grupo de referencia buscan otros compañeros alternativos. Éstos suelen ser los niños que disponen de mayor afinidad en la situación escolar. En el caso de los inmigrantes, se juntan con otros inmigrantes, pero de la misma procedencia, en el caso de los gitanos se unen entre ellos. Respecto a estas filiaciones de las minorías, existen matices dentro de las diferentes procedencias. Por ejemplo, es más difícil ver a un alumnado marroquí jugando con alumnado inmigrante de otras procedencias los primeros días. Sin embargo, el alumnado búlgaro y latinoamericano interactúa con mayor facilidad (como es el caso de Joseph y Willy). 
En los diarios de los primeros días se recogen muchas situaciones que refrendan estas apreciaciones. En ellos vemos cómo Amani, Maruan y otros niños marroquíes de segundo y tercer curso permanecían unidos en una reducida zona del espacio protegiéndose unos a otros ante la supuesta adversidad que ellos sentían las primeras semanas de escolarización. Colocaremos números al final de algunas frases que luego comentaremos.

Ayud está en tercero y su hermano pequeño en $2^{\circ}$. El primero le dice a su hermano que no se vaya de su vista y éste a su vez, como se encarga del hermano de Amani y tampoco le quiere perder de vista para protegerle, no le deja moverse de una esquinita para estar en el ángulo de visión de Ayud que está jugando al fútbol con los de su clase (1). Maluf (hermano pequeño de Amani) se escapa de las manos del hermano de Ayud, éste corre detrás de él y le trae consigo. Así continuamente. En cuanto se separan un poco de esa esquinita desde donde pueden ser controlados, Ayud se enfada y le grita a su hermano. Éste se encuentra en un dilema: o cuido a Maluf o hago caso a mi hermano y no me muevo. Como quiere las dos cosas, atrapa a Maluf para que no se vaya. (2)

Le digo a Ayud que le deje moverse que vienen conmigo. Se vienen a dar un paseo por el patio para que Maluf lo conozca. El hermano de Ayud se asegura diciéndome si su hermano le deja ir (2). Yo le digo que sí, que no hay problema. Aún así el paseo es bien rápido, apenas recorre 50 metros y vuelve a la esquina. Durante este breve paseo le digo a unos de su clase que le pregunten si quiere jugar con ellos y contestan:

"Es que es marroquí", dice un niño. (3)

"Y qué más da" digo yo.

"Bueno" responde él. (3)

El niño que iba al lado le pegunta: "¿Quieres jugar al "pilla-pilla" con nosotros?" (4)

Baja la cabeza, huye en dirección a la esquina y dice: "no, no". (5)

(Diario 20 de Septiembre)

"¿Porqué no quieres jugar con los de tu clase?" Le pregunto a Salá, un niño marroquí de $4^{\circ}$. Él me responde: "Porque tengo a un niño pequeño y él no sabe jugar, entonces yo tampoco juego". (6)

(Diario 24 de Octubre 2006)

(1) Parece que es frecuente que los niños de más edad, que llevan unos años en el centro (Ayud lleva 3 años) se hayan integrado en el grupo y participen con ellos de sus juegos. Sin embargo, el llevar más tiempo en el centro no siempre indica mayor integración en el grupo mayoritario, tal y como reflejan los resultados obtenidos en el 
estudio extensivo o cunatitativo. Estos datos nos decían que no existía relación entre tiempo de escolarización y mejor valoración social del alumnado inmigrante. El estudio etnográfico nos permitió explicar este asunto matizando que, aunque no implique mejoría en cuanto al estatus social, sí conlleva la mezcla interétnica a la hora de compartir actividades y experiencias en el contexto escolar.

(2) Este sentimiento de protección de los hermanos menores no lo observamos ni en los búlgaros ni en los latinoamericanos. Los hermanos mayores tienen una gran autoridad y la ejercen. En el pasaje podemos apreciar el respeto que los hermanos pequeños tienen por ello. No sabemos si esta estructuración jerárquica es uno de los factores que lleva a la unión mayor entre el alumnado marroquí o es un reflejo de ese código restringido.

(3) En ocasiones encontramos estas respuestas que obedecen claramente a estereotipos, a respuestas escuchadas en otros momentos y a otras personas (quién sabe si a niños mayores 0 a sus familias). No suponen creencias arraigadas como se demuestra en el ejemplo. Lo mismo que dicen que no, un segundo más tarde le aceptan. El problema es que estos pequeños estereotipos se pueden consolidar en actitudes y creencias más arraigadas. Por otra parte, un niño inseguro no insistirá mucho ante una primera negativa. Como se ve, la intervención del adulto es clave para normalizar las relaciones y dar oportunidades a todos estos niños de interactuar con otros. No basta en este sentido el trabajo en el aula. El patio es un lugar muy importante en lo referente a interrelaciones y pertenencia a un grupo que no debe ser abandonado en los planes educativos del adulto.

(4) Este es un protocolo habitual en la cultura lúdica tradicional. Los grupos de niños y niñas, normalmente estaban ávidos de ampliar el número de participantes en un juego sin importar mucho la procedencia o idioma. Esto no ocurre en todos los juegos. En aquellos más codificados, que requieren una especialización y en los que se disputa un móvil (caso del fútbol) no siempre es bien vista una persona nueva.

(5) Imaginamos la inseguridad de este niño en esos momentos. A la timidez normal que produce entrar en un grupo nuevo se le une en este caso el verse sometido al criterio de su hermano mayor. No sabemos si éste le habrá advertido incluso sobre no juntarse con otros niños.

(6) Este ejemplo nos aporta nuevas interpretaciones del sentimiento de protección del que hablábamos en el caso anterior. No sabemos si esa protección no será utilizada como excusa. Un niño no muy integrado en su grupo, se autoimpone el cuidado de un menor, de esta forma no se enfrentará a la integración en su grupo y a la posible frustración ante un rechazo. 
Estos pasajes reflejan la situación del alumnado marroquí los primeros días de clase. Conforme transcurría el tiempo, las relaciones entre ellos iban distanciándose en el recreo y daban paso a la interacción con los compañeros de su clase, en su mayoría españoles. Sin embargo, comprobamos que si sufrían rechazo en algún momento por parte de sus respectivos grupos de referencia, se buscaban entre ellos para no estar solos. Esto nos muestra varias cosas:

- La primera es que cualquier niño desea estar integrado. Lo peor que le puede pasar es estar solo sin jugar con nadie. No recibir ninguna aceptación de los otros supondría un serio ataque a su autoestima.

- En segundo lugar vemos que los inmigrantes se juntan entre ellos cuando no pueden hacerlo con su grupo de referencia. Así, los argumentos populares que escuchamos con frecuencia referidos a la falta de intención por parte del inmigrante a integrarse con el grupo mayoritario, parece no cumplirse en este caso. Estos alumnos prefieren jugar con los niños de su clase. Otra cosa distinta es lo que ocurre fuera del espacio escolar. Probablemente las procedencias de las amistades que se intensifiquen no sean las mismas. Fuera del centro la realidad es muy diferente. El discurso intercultural está muy arraigado en la escuela y ello hace que en este ambiente los escolares inmigrantes tengan más oportunidades de establecer relaciones.

- Parece que los niños y niñas, en el colegio, a la hora de hacer amistades, si no están influidos por los adultos, no tienen razones para rechazar 0 discriminar.

- Los gitanos es el otro grupo que demuestra bastante gregarismo. Éstos permanecen en el recreo agrupados entre ellos y parecen tener menos necesidades que el resto de alumnado para mezclarse con otros niños y niñas que no sean gitanos. En los cursos inferiores esta diferencia es menor, pero conforme avanzan en edad vemos a los gitanos jugando entre ellos.

En este grupo, a diferencia de los payos, no se da tanta separación entre niños y niñas. Sí que existe una tendencia a que las niñas gitanas paseen juntas y los niños gitanos corran juntos, pero demuestran muchas menos reticencias a la hora de juntarse entre ellos.

Ismael (el niño gitano de la clase de Joseph) a veces juega al baloncesto con los payos de su clase, pero muchas veces acaba enfadado porque no le pasan el balón y termina abandonando. Es más notable, por tanto, la segregación entre gitanos que entre inmigrantes.

Resumiendo, los agrupamientos de las minorías étnicas observados en el recreo son los siguientes: 
1.- El alumnado búlgaro juega con el resto de los compañeros de clase desde el principio de curso y se les ve juntos frecuentemente, cuando salen del colegio para ir a casa.

2.- El alumnado marroquí empieza el curso juntándose entre ellos y conforme pasa el tiempo se acerca al resto del grupo teniendo siempre como referencia a sus compañeros marroquíes y acudiendo a ellos con cierta frecuencia cuando son rechazados.

3.- El alumnado gitano es el que más se agrupa entre sí y buscan la interacción con los payos en grupo, no por separado. Estos intentos de interacción a veces acaban en enfrentamientos entre payos y gitanos.

Las entrevistas que realizamos a los niños y niñas también nos demostraban que las interacciones más tensas se producían entre payos y gitanos, siendo mucho menor en el caso de los inmigrantes. Así, por ejemplo, vemos algunos testimonios que reflejan la existencia de algunas situaciones agresivas con el alumnado gitano.

"Muchas gitanas te pegan si no juegas con ellas"6, decía una niña de la clase de Amani (5aB). Otra comentaba:"Unos gitanos les dio por quitarme el bocadillo una temporada", se quejaba otra niña de la misma clase. "Unos niños gitanos me tiraban piedras desde la montaña de atrás del patio", contaba un niño de $5^{0}$ de la clase de Joseph.

Desde el punto de vista del gitano, la versión era diferente: "Hay algunos gitanos que no pegan, no todos pegamos" alegaba un niño gitano de $5^{\circ}$ curso. "¿Tú has pegado alguna vez?", continuaba preguntando yo. Él respondía: "Sí, el año pasado porque tiraban piedras a mi hermano el Jonny unos niño, y yo les pegué". Parece un hecho constatable que estos gitanos han agredido físicamente, pero también hemos visto cómo lo hacen alumnos payos entre sí también. Hay una especie de generalización (todos los gitanos) y un subrayado (se tienen más en cuenta que las de otros niños o niñas) de las acciones provenientes de algún niño gitano.

A veces es difícil saber quién es el que empieza la acción violenta, quién arremete porque es agredido o porque se siente amenazado o desubicado en el grupo y quién lo hace porque quiere llamar la atención. Una posible causa de la agresión puede ser la falta de estrategias sociales que a veces pone en marcha

\footnotetext{
${ }^{6}$ Entrevistas realizadas y grabadas a los alumnos de $5^{0}$ de primaria durante el curso escolar 2006/07del colegio donde realizamos el estudio intensivo.
} 
conductas violentas cuando se sufre agresión por parte de los compañeros (Díaz Aguado, 2001).

Influyen también los códigos de comunicación y la apreciación de señales. A través de las observaciones vimos que la forma de interactuar de los gitanos, siendo igual de violenta, podía ser percibida como más amenazante que la de los payos, incluso entre ellos la forma de comunicarse es más agresiva. Algunos relatos como el siguiente recogen estas ideas:

El gimnasio es compartido por dos grupos a la vez [...] Uno de los niños de un grupo de $5^{\circ}$ (gitano) se dirige a una de las niñas del otro 50: "iAnda, fea!", a lo que ella le responde airada: "iy tú, subnormal! ¿te has mirado al espejo?". Parece que son amigos por las conductas observadas en otros momentos. Pero el tono utilizado en sus interacciones suele ser algo agresivo.

(Diario 6 de Noviembre 2006)

Esta secuencia, representativa de muchas otras, nos indica que la forma de comunicarse puede ser percibida como amenazante por otros niños payos con lo que a la hora de valorarles, la idea de "chulos" y "pegones", que veíamos en las entrevistas de los niños, hace que se incremente, creándose opiniones y valoraciones generales sobre ellos bastante desfavorables.

Todos estos detalles pueden ir consolidando una incomunicación que genera opiniones en los niños que, junto a las de las familias y medios de comunicación, se consolidan en prejuicios hacia todos los pertenecientes a esta etnia.

Lo curioso es que los alumnos españoles también demuestran una agresividad en su comunicación (como desarrollamos en el apartado de las filas), sin embargo, ésta es interpretada como broma o juego. Este relato de una observación en el recreo lo refleja:

Cuatro niños están jugando a "policías y ladrones". Uno de ellos está debajo y los demás están encima pegándole, el niño llora, se enfada, empieza a defenderse de todos y a sacudir empujones diciendo que le dejen en paz. Yo me acerco y les digo que no le peguen. Ellos dicen que están jugando y que él es el ladrón, que le están cacheando y que es un juego7. El niño va a decírselo a la profesora. La profesora de apoyo habla con ellos, les separa en el espacio del patio.

7 Cada vez es más fácil ver en nuestros patios a niños de entre 9 y 10 años desarrollando juegos simbólicos que emitan alguna serie televisiva y que suponen una forma de interacción violenta. En observaciones de otros centros hemos apreciado que la persona agredida no siempre es la misma. De hecho, la persona que hace de prisionera no lo vive como tal. Sin embargo, estos juegos sin normativa clara tienen un umbral, pasado el cual, el juego se desvirtúa, el niño en el rol de prisionero sale de la ficción y comienza el conflicto. 
Al rato vuelven otra vez a la misma situación. La maestra les vuelve a separar. Suena el timbre y se acaba la historia.

(Diario del 11 de Diciembre 2006)

Este relato, como muchos otros que podemos sacar de diversos momentos de la jornada escolar, nos demuestra que la agresividad está latente en los centros. Ésta se manifiesta de diferentes formas y con distintas excusas. Tanto los alumnos payos como los gitanos lo manifiestan en sus conductas. Sin embargo, los prejuicios enraizados en la cultura dominante consiguen que la versión ante un mismo hecho sea peor interpretada si lo hace un gitano a si lo hace un payo. Ya veíamos cuando discutíamos los datos en el estudio extensivo o cuantitativo, las características que se producían en las dinámicas de los grupos. Éstos demostraban que los miembros de los grupos tendían a subestimar las habilidades de los sujetos de baja situación sociométrica y que, por tanto, para ser tenido en cuenta había que estar bajo la expectativa positiva del otro. Inevitablemente, el alumnado gitano, ante estas situaciones, puede generar conductas violentas que llegan a registrarse como patrones automáticos en determinadas situaciones. Se hace evidente por lo consiguiente, las diferencias culturales del alumnado gitano, como la existencia de un déficit de habilidades sociales adaptadas a la situación escolar.

Resulta difícil hallar las causas que justifiquen esta agresividad. Tedeschi, Lindskold y Rosenfeld (1985) distinguen siete factores que aumentan la probabilidad de que aparezcan amenazas y castigos en las interacciones sociales entre iguales. Se refieren a: normas de defensa propia, reciprocidad y justicia distributiva, desafíos a la autoridad, conflicto intenso por los recursos, autorepresentación y protección de la propia imagen, necesidad de atención, deseo de controlar las conductas inmediatas de otros y falta de consideración de las conductas futuras. En los casos descritos interpretamos que se pueden dar varias de ellas: desde el conflicto por los espacios a la necesidad de atención, pasando por las normas de defensa propia. En algunos casos apreciamos que el origen está en el uso de unos formatos de interacción bruscos que llevan a malas interpretaciones y a un aumento de la agresividad. En otros casos apreciamos que el rechazo sufrido por algunos escolares les puede provocar un estado de ansiedad que les lleva a respuestas poco adaptadas. También interpretamos que cuando un grupo tiende a cerrarse (caso de los gitanos), los demás les perciben como grupo (no como acciones individuales de personas concretas) y atribuyen expectativas sobre ellos. Estas generalizaciones pueden llevar a que las personas de ese grupo se revelen contra esas expectativas y, por una parte, actúen de forma más agresiva, y, por otra, se refugien en su grupo, generando un ciclo que confirmaría y perpetuaría el estereotipo. La teoría de la identidad social de Tajfel $(1979,1986)$, completada con la de Turner $(1978,1980)$ y ambas basadas en la de Sherif $(1953)$ nos explican que 
el proceso de identidad social se va formando en los grupos mediante el desarrollo de mecanismos cognitivos en cada sujeto que van adaptándose a las expectativas del grupo. El experimento de Avigdor realizado en 1953, explica cómo el estereotipo es generalmente desfavorable, cuando las relaciones entre los grupos son conflictivas, y generalmente favorable si esas relaciones son amistosas o tienen carácter cooperativo y que si un grupo está interesado en ayudar o en combatir a otro grupo, atribuirá a este último las características que justifiquen el comportamiento favorable o desfavorable respecto al mismo (Doise, Deschamps y Mugny, 1980, 18). Éstas teorías explicarían en gran medida, el por qué de las Interacciones desajustadas entre el alumnado perteneciente a diferentes etnias.

Por lo general, las personas preferidas se relacionan entre ellas con conductas de cooperación, amistad, ayuda mutua, participación en los juegos y con el cumplimiento de las normas establecidas. El alumnado rechazado, sin embargo, es descrito como más agresivo, hiperactivo, instigador de peleas, violador de normas sociales e irrespetuoso. Desgraciadamente, parece ser que este patrón es el que más estabilidad en el tiempo presenta. Esto parece normal si entendemos que el alumnado agresivo recibe ante sus conductas más agresión, configurando así un círculo de difícil salida.

Respecto a las creencias, estereotipos y prejuicios formados por el alumnado pudimos detectarlo más claramente mediante la triangulación metodológica realizada entre el diario de campo, las entrevistas realizadas al alumnado durante el transcurso del curso académico y la sociometría. Las opiniones que demostraron los alumnos en estas entrevistas difieren considerablemente en función de si se trata de un inmigrante o de un gitano, siendo los primeros mucho mejor considerados. Cuando se les preguntaba a los payos quién creían que eran mejores los payos, los gitanos o los inmigrantes, ellos respondían:

"Los inmigrantes son iguales que nosotros, los gitanos depende...hay algunos que pegan mucho.... son un poco brutos." Contestaba una niña de $5^{\circ}$.

Otro niño, líder de la clase de $5^{\circ}$, decía al respecto: "Los gitanos son igual que nosotros sólo que se creen un poco más listillos porque les ves por ahí y...hombre....sí que son un poco así, como que se ponen chulitos, gallitos... Los inmigrantes son igual, igual que nosotros, lo único es que no saben el idioma porque vienen de otro país, se tienen que acostumbrar y ya está."

Una niña de la misma clase que el niño anterior aseguraba que: "Los gitanos son peores que nosotros porque pegan y se hacen los mayores...los inmigrantes no, son iguale a nosotros. Yo no he tenido ningún problema con ellos, pero son así". 
A continuación, la entrevista de otro escolar decía: "Los gitanos te quitan las cosas, se enfadan más. Sólo les gusta jugar con sus amigos".

Una alumna con más discurso (parece que aprendido) parecía ir un poco más allá en cuanto a las razones que ella atribuía hacia la agresividad de los gitanos y decía: "los gitanos son igual que nosotros, pero no han tenido la misma educación y por eso son peores ahora".

De las treinta entrevistas realizadas, 18 manifiestan abiertamente que los gitanos eran peores sobre todo porque "pegan" y "se hacen los chulos", 6 de ellas guardaban silencio cuando se les preguntaba por los gitanos, 4 alumnos gitanos entrevistados decían que no pegaban y si lo hacían era "para defenderse" y 2 niñas no gitanas abogaban por la igualdad de todos, pero no daban ninguna explicación al respecto, daba la impresión de haber utilizado un lenguaje políticamente correcto aprendido "todos somos iguales, seamos de donde seamos, da igual la raza ante la ley".

En general, en los sociogramas se valoraba a los gitanos con puntuaciones muy bajas. Todos estos datos contrastados nos muestran (coincidiendo con lo recogido en el estudio extensivo/cuantitativo) que, independientemente de las causas, la problemática de segregación existe en mayor medida con los gitanos que con los inmigrantes.

Indudablemente la influencia familiar se hace patente en estos testimonios. Ante la pregunta: "¿Qué te dicen tus padres de los niños inmigrantes y de los gitanos?" Las respuestas, en coherencia con las anteriores, manifestaban lo siguiente: "Mis padres me dicen que tengo que jugar con los inmigrantes, porque a mí no me gustaría que me dejaran solo....con los gitanos me dicen también que me lleve bien con ellos". Otro decía: "mis padres dicen que es mejor que me lleve bien con los gitanos para no meterme en líos, porque pegan mucho y no quieren líos". Otro comentaba: "me dicen que tengo que ayudar a los inmigrantes con el idioma porque no entienden español y tengo que decirle lo que significan algunas palabras...con los gitanos no me dicen nada". Es de esperar que los niños que escuchan a sus padres comentarios del tipo, "ten cuidado con los gitanos", tengan percepciones similares hacia los compañeros gitanos.

Respecto a los inmigrantes, los discursos de los niños y de los padres demuestran otro tono más tolerante; aunque, si analizamos en profundidad, vemos ciertos matices que manifiestan un tono más sutil, expresando un discurso socialmente más deseable; como por ejemplo: "todos somos iguales ante la ley", dijo un niño de carrerilla al entrevistarle, "tenemos que ayudarles", "Ios inmigrantes trabajan mucho, nosotros tenemos que esforzarnos". Sin embargo algunos testimonios reflejan que de fondo existen una serie de prejuicios enraizados, como 
se ve en comentarios como: "tenemos que trabajar, porque hasta los inmigrantes van a sacar mejores notas que nosotros".

Cuando se trata de dar la opinión sobre los gitanos, desaparece la sutileza utilizada al hablar de los inmigrantes. El rechazo al gitano parece estar socialmente más aceptado. Los medios de comunicación y la familia juegan en este aspecto un papel difícilmente salvable por la escuela.

Tanto las observaciones realizadas en el recreo (recordemos el caso contado de Ismael, al que apenas le hacían pases en el baloncesto), como las entrevistas y las pruebas sociométricas (en las que el alumnado gitano de las dos clases de $5^{\circ}$ era el peor puntuado en los dos momentos del curso en los que se realizaron estas pruebas) nos confirman que la problemática más notable en la escuela se encuentra en el alumnado gitano. Tanto los prejuicios como los rechazos se dan mayoritariamente hacia este alumnado.

Reflexionando sobre las posibles circunstancias por las que se han configurado estas ideas previas y estereotipos culturales en el alumnado, nos encontramos con circunstancias escolares, familiares y personales. Nos centraremos en las primeras, dada la temática de este estudio.

Con respecto al ámbito escolar, notamos cierta influencia de las acciones educativas del centro respecto a la labor integradora del alumnado inmigrante. Este centro presume de tener un plan de acogida bastante elaborado (prueba de ello es el CD sobre la acogida de inmigrantes elaborado para darlo a conocer a otros centros educativos).

Desde los primeros días, el centro realizó diferentes reuniones y actividades sensibilizadoras con los diferentes agentes de la comunidad escolar (familias, profesorado, alumnado) ${ }^{8}$. Estas acciones han contribuido en gran medida a tener un discurso más tolerante con los inmigrantes, por lo menos dentro del colegio, como vemos en los testimonios de los niños. Sin embargo, la situación con los gitanos es diferente. En lo que hemos podido observar, no se les ha hablado al resto de alumnos sobre la cultura gitana y sobre las diferencias que demuestran.

Para el alumno es difícil entender las diferencias entre las personas, existen razones evolutivas que explican una tendencia a buscar la norma común en estas edades escolares (Aboud, 1988). Para el niño o la niña todo aquello que se salga de la norma cultural es fácilmente objeto de rechazo. Esto encuadra con la buena aceptación de Joseph. Éste se adapta rápidamente a los códigos escolares establecidos y eso es la causa de la fácil integración: habilidades sociales para

${ }^{8}$ En el apartado siguiente desarrollaremos con detalle el Plan de Acogida del centro. 
comunicarse, dibuja bien, buen rendimiento académico, físico agradable, refuerzos y valoración positiva de los profesores, etc. Todo está dentro de los marcos establecidos escolar y socialmente. Sin embargo, Willy o Maluf no cumplen todos estos requisitos integradores. El primero es repetidor, tiene una lesión en la pierna, tiene un mal rendimiento académico, no tiene demasiadas habilidades sociales, etc. Maluf no habla español, ni entiende nada, tienen un color de piel más oscuro que el resto, es mucho más pequeño que los niños de su edad, no interactúa con casi nadie, no recibe refuerzos de su tutora, tiene un bigotillo no correspondiente con su edad sino a alguna alteración hormonal, etc. Esto último es lo más destacable para los demás y es curioso observar cómo lo que para él no supone ningún problema, para los demás es objeto de burla. Esta característica física del pequeño, pronto supondrá un motivo de vergüenza. En cuanto entienda el idioma y comprenda los mensajes de burla que le lanzan los niños y niñas, el alumno marroquí deberá desarrollar fuertes mecanismos psicológicos para que su autoestima no se vea comprometida. Extraemos de las actas uno de los pasajes en el que las niñas se ríen del bigotillo del Maluf:

Unas niñas se ríen del bigotillo del hermano de Amani[...]. Al principio el niño no se entera y se ríe por ser el centro de atención. Luego empiezan a tocárselo y empieza a no gustarle, moviéndose hacia los lados para que le dejen y huyendo, correteando por los alrededores. El hermano de Ayud le dice al rato: "córtatelo", se lo dice en español y en árabe, Maluf no dice nada. Además de los problemas hormonales y de crecimiento que parece que tiene este niño, considero muy interesante resaltar una reflexión acerca de cómo la cultura de estas niñas (en el contexto español, en un colegio, mujeres,...), reflejo de una realidad, va a conseguir que lo que para él no suponía ningún problema, "su bigotillo", empiece a serlo. En cuanto aprenda español y entienda los comentarios se dará cuenta de esas burlas ¿cómo le afectarán?. En un futuro próximo su bigotillo será objeto de burla y una barrera para integrarse en un grupo.

(Diario 13 de Septiembre 2006)

Apreciamos cómo cualquier alteración de la "normalidad" puede ser una excusa para el rechazo. Sin embargo, esto es una contradicción si pensamos en la diversidad y originalidad de cada niño o niña. Puede que la mejor forma de combatir escolarmente estas burlas sea normalizar la situación. Esta normalidad es la que existe en centros donde todos tienen alguna desventaja socio-cultural, en los llamados "guetos". Entre ellos se llaman: "el ciego", "el subnormal" o el "moro" sin atribuir ninguna valoración a tal diferenciación, como explicamos en el estudio cuantitativo, cuando evaluábamos las relaciones sociométricas de los colegios de Valladolid. Existen algunos centros educativos donde a pesar de la desventaja socio-laboral que posteriormente tendrán, entre ellos no hay un clima segregador y 
las diferencias son toleradas mejor. Se llevan bien entre ellos y de hecho, si les sacan del centro y les meten en otros socialmente más deseables y con menos minorías, lo pasan mal y desean volver al anterior'. No se trataría de omitir la diferencia, sino de no atribuirle valoraciones diferenciadas en tales clasificaciones. Esto no significa que defendamos el desarrollo de "guetos" escolares, sino la creación de ambientes favorables a la integración donde no se establezcan valoraciones clasistas en función de las diferencias de cada alumno. Pretendemos hacer ver que lo que es normal en unos contextos no lo es para otros y que existen lugares donde estas anormalidades son más toleradas por los iguales y producen menos segregación, siendo la base de este hecho la normalidad ante la diferencia. Una normalidad que debería impregnar las prácticas cotidianas.

Como señala Corsaro (1986), la capacidad de los grupos de iguales para admitir a otros nuevos es un rasgo cultural que se manifiesta de forma diferente en cada contexto, según se trate de sociedades más permeables o cerradas. Al mismo tiempo, la posición del individuo dentro del grupo de pertenencia será un factor decisivo a la hora de admitir 0 excluir a otros miembros. Es decir, cuanto más aislado esté un alumnola dentro del grupo, mayor posibilidad existirá de que acepte a otros individuos pertenecientes a otros grupos distintos (Doise, Deschamps y Mugny, 1980,86).

Nos podemos apoyar en las teorías de Merton (1957), para explicar cómo los individuos se posicionan en un grupo de referencia u otro. Este autor analiza los factores que, a nivel del individuo, del grupo y del sistema social más global, hacen que una persona se vea conducida a tomar unos grupos a los que pertenece. En concreto analiza los factores que hacen que el alumnado elija un grupo de referencia u otro. En nuestro caso concreto, las teorías de este autor nos podrían dar algunas explicaciones referidas a cómo se realizan los grupos de referencia entre el alumnado perteneciente a diferentes colectivos étnicos. Este autor nos explica que si un grupo de no pertenencia ofrece al individuo más prestigio social, tenderá a elegir a aquel como grupo de referencia (Merton en Doise, Deschamps y Mugny, 1980,86 y ss.). Por tanto, el alumnado verá reforzado su prestigio en los grupos de la misma pertenencia étnica, ya que existe entre ellos más proximidad cultural y, por tanto, se desenvolverán socialmente de forma más cercana, propiciando, de este modo el prestigio deseado. Esto también explicaría que el alumnado más discriminado dentro de su grupo de referencia pueda unirse a otros grupos, como es el caso de algunos niños o niñas inmigrantes, unidos al alumnado más discriminado de cada grupoclase.

\footnotetext{
${ }^{9}$ Argumento extraído de un comentario realizado por una orientadora y de la investigación desarrollada en el centro donde se desarrolló el trabajo de investigación tutelado previo a la tesis doctoral.
} 
Las culturas de iguales integran una serie de rutinas (segregación sexual, grupos de juego de diferentes edades, admisión de nuevos jugadores, admisión de compañeros con diferentes rasgos físicos y de distintos niveles de eficacia, contacto corporal, individualismo o acción colectiva...) que reflejan diversas características del mundo adulto, de manera que, participando en ellas, los niños desarrollan sus destrezas comunicativas y el conocimiento social que les permitirán integrarse en el mismo. De esta manera, los niños se convierten en activos constructores de su propio mundo social, el cual reproducirá las características más salientes del mundo adulto en el que se desarrollan.

Este capítulo forma parte del segundo capítulo del informe final y en él nos hemos referido a las situaciones escolares sin la presencia del adulto, observadas en dos espacios: las filas de entrada y salida a las clases y el recreo. En estos lugares se producen interacciones sociales entre los iguales que van describiendo el proceso de adaptación escolar de la forma más cercana a la realidad vivida por el alumnado. Los principales análisis, deducidos de estas observaciones, se refieren a los epígrafes que hemos ido describiendo en el capítulo.

En primer lugar, realizamos una aportación a la hora de afrontar el estudio de estas interacciones. Esta consiste en la introducción de lo que hemos denominado códigos "verticales" y "horizontales".

Posteriormente, hablamos de algunas situaciones referidas a los choques culturales que pueden sufrir en este proceso inicial. En el segundo apartado describimos las características de las interacciones sociales producidas en las filas de entrada a clase. En concreto, aspectos relacionados con el género, la edad, las actividades lúdicas y sus relaciones dentro de ellas, así como las acciones prejuiciosas, incluso violentas, observadas en estos espacios. 


\section{Capítulo 9}

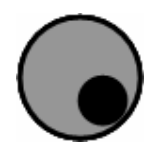

Situaciones escolares con la presencia del adulto: influencia de las acciones educativas en el proceso de integración escolar del alumnado inmigrante nuevo

En este capítulo perteneciente al informe final, desarrollamos el proceso de integración escolar del alumnado inmigrante mediante la descripción de las situaciones escolares con la presencia del adulto. En concreto, utilizamos los escenarios formales del colegio para analizar este proceso. Los apartados que incluimos hacen referencia al plan de acogida del centro, a las clases de apoyo y a las clases ordinarias. Primer, segundo y tercer capítulo respectivamente. 
En este capítulo analizamos las relaciones sociales de los alumnos con la presencia directa del adulto. Las intervenciones educativas por parte de los docentes toman en este momento mayor visibilidad que en el apartado anterior. Las interacciones sociales del alumnado estarán determinadas en gran medida por estas actuaciones docentes. A través del análisis de los datos recogidos en las observaciones, las entrevistas a docentes y escolares, y las pruebas sociométricas se mostrará la relación entre el discurso educativo sobre la integración y su puesta en práctica en la rutina diaria del aula. De igual forma, iremos vislumbrando aquellas actuaciones que facilitan o dificultan el proceso de integración escolar del alumnado nuevo así como las interacciones sociales que se producen entre el alumnado.

Se ha estructurado la información en torno a tres formas y momentos de intervención educativa:

1.- El plan de acogida al alumnado inmigrante nuevo en el Centro.

2.- Clases de apoyo a las que acude el alumnado objeto del seguimiento.

3.- Clases ordinarias en las que participa el alumnado observado.

\section{1- El plan de acogida}

Para comprobar el desarrollo del Plan de Acogida se ha dispuesto del centro como un espacio de observación. Con este término nos referimos a todos aquellos lugares por donde los inmigrantes nuevos circulan durante la jornada escolar, salvo el patio y las aulas que, por su importancia, se considerarán en apartados propios.

Pretendemos explicar en este apartado las actuaciones educativas que acontecieron durante el desarrollo del Plan de Acogida. Estas acciones no se circunscriben a un lugar específico (como en el caso del trabajo diario en las aulas 0 las clases de apoyo), sino que se desarrollan por todo el centro. Este plan establece las directrices del proceso de integración del alumnado inmigrante y por lo tanto su estudio resulta fundamental para nuestro tema de estudio.

A lo largo de este apartado se explicará brevemente qué es el Plan de Acogida, las fases que lo desarrollan y, por último, a través del análisis de algunos pasajes de lo ocurrido, reflexionaremos sobre las implicaciones que algunas de las acciones tienen en el proceso de integración del alumnado inmigrante nuevo.

\section{1.- ¿Qué es el Plan de Acogida?}

El 18 de Diciembre de 2003 la Junta de Castilla y León aprueba el Plan Marco de la Atención a la Diversidad para esta comunidad y en 2005 se elabora ya 
un plan de atención al alumnado extranjero y minorías en todos los centros educativos. Esto supone una cobertura legislativa con la que los centros marcarán de forma común pautas para atender estas necesidades. Por tanto, todos los centros educativos deberán tener elaborados estos planes e incluirlos en sus programaciones anuales.

En estos planes aparece prefijada la actuación con los tres ámbitos que componen la comunidad educativa y que afectan a estas minorías: profesorado, padres y alumnado. Sus acciones pasan por tres fases: la informativa, la de acogida en el centro y en el aula y la de acogida en la comunidad educativa. Estos momentos se realizan mediante reuniones con las familias y con el alumnado, en claustros del profesorado y mediante la organización de apoyos por parte de los docentes de compensatoria.

Existe un seguimiento a lo largo de todo el curso para evaluar la eficacia y calidad de las respuestas a estas minorías. Se entrelazan la evaluación inicial, la procesual y la final. Veamos a través de nuestro proceso etnográfico cómo se fueron sucediendo estas actuaciones.

\section{2- Fases del Plan de Acogida y actuaciones dentro de cada una de ellas}

A continuación enumeramos las fases y actuaciones que dentro del Plan de Acogida se llevaron a cabo. En este repaso por las fases sintetizaremos primero en un cuadro aquellos aspectos que facilitan o dificultan la integración escolar del alumnado inmigrante nuevo; para luego, a través de la reflexión sobre diferentes pasajes de lo ocurrido, resaltar algunos detalles del desarrollo práctico del Plan y su influencia en el proceso de integración.

A lo largo de este proceso, hubo actuaciones que, desde nuestra perspectiva como investigadora, marcaron el rumbo del alumnado inmigrante en el centro escolar. Las actuaciones educativas, además de influir en la integración escolar, lo hicieron, como consecuencia, en las interacciones sociales de los iguales.

A continuación, presentamos un cuadro que muestra las actuaciones educativas durante este proceso escolar, marcado por el plan de acogida. 


\begin{tabular}{|c|c|c|}
\hline $\begin{array}{c}\text { FASES DEL PLAN DE } \\
\text { ACOGIDA }\end{array}$ & $\begin{array}{l}\text { FACILIDADES PARA LA } \\
\text { INTEGRACIÓN Y PARA EL } \\
\text { FOMENTO DE LAS } \\
\text { RELACIONES SOCIALES }\end{array}$ & $\begin{array}{c}\text { BARRERAS A LA } \\
\text { INTEGRACIÓN Y A LAS } \\
\text { RELACIONES SOCIALES }\end{array}$ \\
\hline 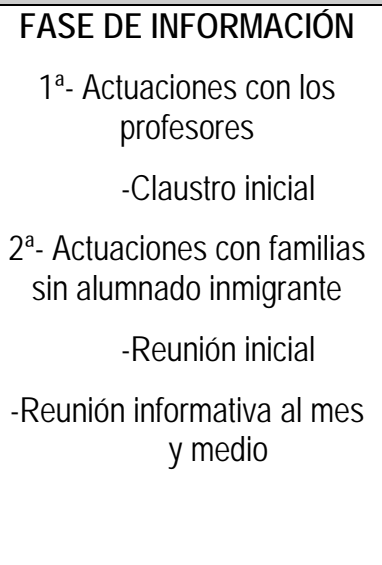 & $\begin{array}{l}\text {-El profesorado se informa } \\
\text { acerca de la llegada del } \\
\text { alumnado inmigrante a sus } \\
\text { clases. Preparan su } \\
\text { actuación. } \\
\text {-Se intenta sensibilizar a los } \\
\text { padres españoles para } \\
\text { ayudar a acercar la cultura } \\
\text { escolar a los inmigrantes. }\end{array}$ & $\begin{array}{l}\text {-El material para los } \\
\text { alumnos: los materiales con } \\
\text { los que trabajar en clase no } \\
\text { están estructurados. Se } \\
\text { utilizan espontánea y } \\
\text { aleatoriamente. } \\
\text {-En las reuniones de los } \\
\text { padres no se produjo } \\
\text { comunicación entre las } \\
\text { familias españolas y } \\
\text { veteranas con las de los } \\
\text { nuevos inmigrantes }\end{array}$ \\
\hline $\begin{array}{c}\text { FASE DE ACOGIDA EN EL } \\
\text { CENTRO Y EN EL AULA } \\
\text { 1ª- Actuaciones con la }_{\text {familia y el alumnado }} \\
\text { inmigrante nuevo. } \\
\text {-Presentación del } \\
\text { alumnado mediador. } \\
\text {-Reunión de } \\
\text { profesorado, familia y } \\
\text { alumnado. } \\
\text {-Enseñar el espacio } \\
\text { físico del colegio. } \\
\text {-Presentación pública } \\
\text { ante el grupo de } \\
\text { referencia }\end{array}$ & $\begin{array}{l}\text {-Seguridad y autonomía del } \\
\text { alumnado inmigrante nuevo, } \\
\text { proporcionada al conocer el } \\
\text { espacio físico escolar, el } \\
\text { funcionamiento básico del } \\
\text { centro y al establecer } \\
\text { vínculo con el alumnado } \\
\text { mediador a quien acudir. }\end{array}$ & -No encontramos ninguna. \\
\hline $\begin{array}{l}\text { FASE DE ACOGIDA EN LA } \\
\text { COMUNIDAD ESCOLAR } \\
\text { 1- Actividades con alumnos }^{\text {veteranos. }} \\
\text {-Charla sensibilizadora con }\end{array}$ & $\begin{array}{l}\text {-Los comentarios positivos } \\
\text { del profesorado a sus } \\
\text { respectivos grupos crean } \\
\text { expectativas positivas en el } \\
\text { alumnado veterano. } \\
\text {-Los contenidos del CD }\end{array}$ & $\begin{array}{l}\text {-EI CD se trabaja en la clase } \\
\text { de religión. El alumnado } \\
\text { inmigrante no cursa esta } \\
\text { asignatura, por lo tanto, no } \\
\text { presencian este gesto de } \\
\text { atención hacia ellos. }\end{array}$ \\
\hline
\end{tabular}




\begin{tabular}{|c|c|c|}
\hline $\begin{array}{c}\text { el alumnado. } \\
\text {-CD sensibilizador con } \\
\text { el que trabajan en una } \\
\text { sesión. } \\
2^{\mathrm{a}} \text { - Actuaciones directas con } \\
\text { el alumnado inmigrante. } \\
\text {-Presentación en el } \\
\text { grupo. } \\
\text {-Ayudas en } \\
\text { coordinación con la } \\
\text { asociación del barrio. } \\
\text {-Apoyos }\end{array}$ & $\begin{array}{l}\text { acercan las culturas } \\
\text { diferentes al alumnado } \\
\text { veterano. } \\
\text {-La presentación oficial del } \\
\text { alumnado inmigrante nuevo } \\
\text { en el grupo clase hace } \\
\text { sentir protagonismo al } \\
\text { mismo y como miembro de } \\
\text { la comunidad educativa. } \\
\text {-Los alumnos inmigrantes } \\
\text { sienten que son tenidos en } \\
\text { cuenta en las clases. } \\
\text { - Los apoyos ayudan a } \\
\text { individualizar y a mejorar el } \\
\text { proceso de enseñanza- } \\
\text { aprendizaje del alumnado } \\
\text { inmigrante nuevo. } \\
\text {-La coordinación entre las } \\
\text { asociaciones externas al } \\
\text { centro y las profesoras de } \\
\text { compensatoria ayudan al } \\
\text { proceso de integración } \\
\text { escolar, provocando } \\
\text { coherencia en los } \\
\text { microsistemas donde el } \\
\text { alumnado se desenvuelve. } \\
\text { (Por ejemplo; les permite } \\
\text { mejorar el conocimiento de } \\
\text { las normas escolares). }\end{array}$ & $\begin{array}{l}\text {-Las clases de apoyo restan } \\
\text { la posibilidad de contacto } \\
\text { interactivo. } \\
\text {-Descompensación entre el } \\
\text { gran número de alumnado } \\
\text { de compensatoria y el } \\
\text { número de profesoras (sólo } \\
\text { 2). }\end{array}$ \\
\hline
\end{tabular}

Tabla 9.1. Fases en el plan de acogida.

El cuadro sintetiza los hechos, así como algunos de los efectos que hemos deducido de ellos. Sin embargo, dado el carácter de este estudio, no nos gustaría dejar pasar algunos de los múltiples detalles que conforman estos procesos de integración. Hemos seleccionado algunos pasajes de las actas para mostrar la complejidad que conlleva la puesta en práctica de un Plan de este tipo, las continuas decisiones que se deben tomar, los significados de cada hecho, los diferentes intereses que se entrecruzan en la acción educativa y las implicaciones de cada actuación docente. 


\section{PASAJE 1: Primera reunión de las profesoras de compensatoria con los padres y el alumno inmigrante nuevo procedente de Bulgaria: Joseph. (Fase de información).}

Poco a poco van desfilando y subiendo todos los niños por las escaleras. Finalmente queda una familia y un niño con una gorra que parece su hijo. Supuse que era el alumno nuevo búlgaro. En efecto, de eso se trataba.

Las dos profesoras de compensatoria, una nueva y otra con más años en el centro, se acercan a la familia, en especial al padre que es el que habla algo de español. La profesora de compensatoria (Laura) les indica que le sigan, que van a atenderles en una sala.

Subimos las escaleras, entramos en el aula de apoyo las siguientes personas: el niño búlgaro, los padres, las dos profesoras de compensatoria, Crusty un alumno búlgaro que lleva más años en el colegio y que hará de intérprete y yo.

9:15h: Una vez aquí empieza hablando Laura: "Sentaos, poneos cómodos". Presenta a los que allí estamos, salvo a mí. Interrumpen la reunión unas madres gitanas preguntando por Laura (la profesora de compensatoria), sale un minuto y les dice que está ocupada que esperen un rato y que bajen a la sala de espera. En este intervalo, Carmen, la otra profesora de compensatoria, continúa hablando con ellos. Proseguimos la reunión. La principal barrera es el lenguaje, por lo que Laura se dirige a ellos de forma pausada y utilizando vocabulario sencillo. Los padres escuchan con atención, el niño mira al vacío porque no se entera de nada, la madre mira fijamente, pero no entiende, el padre muestra asentimientos gestuales ante las palabras de Laura.

La información que se les ofrece a ellos se refiere a datos personales de la familia para rellenar ficha de escolarización, entrega de documentos informativos sobre las normas del colegio, información sobre las reuniones de padres, tutorías, actividades que se ofrecen a los padres para aprender el idioma. Por otro lado, la información que se les demanda a ellos se refiere al nivel de español del niño, otros idiomas que habla, nivel académico en Bulgaria y datos personales tales como fecha de nacimiento y ocupación. Respecto al nivel académico el diálogo se sucede del siguiente modo:

Laura: "En Bulgaria, ¿el niño qué tal iba en el colegio?, ¿bien o mal?"

Padre: "Bien, muy bien"

Laura: "Perfecto. Además decís que el inglés muy bien, ¿no?"

Padre: "Si, habla mucho de inglés" 
Laura: “Pues qué bien! ¿eh?!”

En el último momento se le pregunta al niño si quiere saber algo sobre el colegio o si tiene alguna duda en especial para que se lo traduzca Crusty. La conversación se interrumpe con otra llamada a la puerta. Cuando se retoma, esto último se olvida

(Diario, 12 Septiembre 2006)

\section{PASAJE 2: Conocimiento del espacio físico de Joseph. El alumno mediador entre la cultura familiar y escolar.}

9:30h: Salimos de la sala para hacer el recorrido físico que el niño debe realizar desde que entra por la puerta hasta que llega a su aula para que lo memorice. Los padres le quitan la gorra al niño, éste hace ademán de no querer, finalmente el padre se la da y él la guarda en la mochila. Quizás, con estos gestos pretendieran igualarse a los demás, abrirse a otros y no ocultarse.

Por el camino nos encontramos con el director y éste se une a nosotros. Nos acercamos al aula de $5^{\circ} \mathrm{B}$ donde el niño se escolarizará. Sale la tutora Marta, previamente José Luis habla con ella para comentarle mi entrada en el aula, yo le aclaro que entraré sólo si ella no tiene inconveniente. La respuesta de ella es favorable: "No, no pasa nada, de momento todo perfecto. ¿Hablas inglés para ayudarme con él?"(Parece ser que este es el rol que en un primer momento se me atribuye)). El director dice al padre del niño: "Esta chica está haciendo un estudio sobre cómo llegan los niños de otros países al colegio, estará con él en el aula y le podrá ayudar si tiene cualquier problema". El padre asiente muy sonriente y me pregunta cómo se llamaba la tutora de su hijo. Yo le respondo. Despedimos a Crusty para que entre a su clase y Laura le dice que vaya a buscar a Joseph para ir al recreo. Resaltamos la importancia del niño mediador para introducir al alumno nuevo con el resto de compañeros). El padre pregunta que si no puede ir a la clase de Crusty para poder hablar con él. La otra profesora de Compensatoria dice que no: "es preferible separarlos porque así aprenden antes a hablar español y se integran antes en el grupo". El padre asiente. (Muestra de preocupación porque su hijo se sienta bien, no lo pase mal el primer día).

(Diario, 12 Septiembre 2006)

PASAJE 3: Reunión con las profesoras de compensatoria, la familia y la alumna inmigrante nueva, procedente de Marruecos.

10:00h: Nos encontramos en el recibidor, esta familia está compuesta por una madre con un velo sobre la cabeza que deja ver su cara, un chico de unos 1617 años, un niño pequeño con apariencia infantil y dos niñas una de 10 y otra de 13. El niño y la niña son los que van a ser escolarizados en el centro: la niña en $5^{\circ} \mathrm{A}$ y el niño pequeño en $2^{\circ}$. Nos asombra que tenga 7 años, porque no aparenta más de 5. Nos aseguramos del año de nacimiento. Laura pregunta si tiene algún problema de 
alimentación o de algún tipo, el hermano, que es el único que habla español, dice que no. Les pregunto si hablan francés. El hermano me dice que la niña de $5^{\circ}$, llamada Amani sí. Le hablo en francés y no entiende nada, ni dice nada. Con nosotros está otro niño de $2^{\circ}$, marroquí, que lleva dos años en el centro y hace de intérprete entre la familia y nosotros (Ayuf).

10:10h: Subimos a la misma sala de ayer. Nos sentamos los ocho. Tenemos algunos datos de interés al respecto:

$1^{\circ}$. Acuden a DESOD para recibir ayuda respecto a cómo desenvolverse en la ciudad y al idioma.

$2^{\circ}$. Ellas llevan dos meses en España. El hermano mayor, más tiempo, por eso habla más.

$3^{0}$. Ellas no hablan nada de español. Las pocas palabras que saben, supongo yo, las habrán adquirido por la ayuda proporcionada en DESOD. El nivel en el lenguaje también es una muestra de la existencia o no de socialización y de contacto con otros españoles.

Laura les da la bienvenida, les dice que van a estar muy a gusto aquí. Les presenta a Ayuf, el niño marroquí de $2^{\circ}$ que hará de intérprete, pregunta si conocen a la familia de él. Estos dicen que sí.

El procedimiento formal es como el del día anterior con Joseph. Se les entrega la carpeta con la información básica del colegio, esta vez traducido al árabe: normas, días de fiesta, consejos acerca de la alimentación más apropiada para que acudan con fuerzas, y sugerencias a los padres para que les ayuden con los deberes.

Ayud espontáneamente les dice algo en árabe. Laura pregunta qué le ha dicho: Ayud dice: "que les ayuden, tenemos un cuaderno donde tenemos que hacer los deberes para casa”. Laura dice: "iay!, ipero qué rico eres!", y le da un beso. Ellos sonríen pero no acaban de entender la espontánea expresión de afecto. Laura ha estado trabajando con Ayud en los apoyos todo el año pasado, le ha enseñado a hablar español, le tiene mucho cariño y eso se nota. Además, éste es un momento de protagonismo para él, sin él no podríamos comunicarnos. En estos dos años pocos momentos de sentirse tan útil habrá tenido, ya que hace poco que aprendió el español.

La profesora de compensatoria les habla de la importancia de que hablen con españoles, porque si no, no aprenderán el español. El hermano dice: "claro, como yo que me junté a unos marroquíes y estamos todo el rato hablando en marroquí". Todos los demás asienten salvo la niña de $5^{\circ}$ y el niño de $2^{\circ}$. La primera 
está inmóvil, con la mirada fija, muy seria, con timidez y miedo. El de $2^{\circ}$ está moviendo los brazos por la mesa en círculo, mirando para todos los lados de modo disperso, sin fijar su atención en nada y cansándose cada vez más de oír palabras en otro idioma. La madre está con un móvil en las manos y sonriendo con cara sumisa.

Les habla también de la importancia de que la madre se apunte a las clases de español que en el centro se ofrecen: "es muy importante que ella (todo va dirigido al hermano para que se lo diga a la madre) vaya a clases de español porque muchas veces vosotros aprendéis español porque trabajáis, los niños lo aprenden en el colegio y las madres, al estar en casa, no hablan; yo soy mujer, ella también (señalándome a mí) y a todas nos gusta estar a gusto y bien, ¿entendéis?". Vemos cómo Laura insiste en este tema a diferencia de ayer con la familia búlgara, a quien sólo se lo dijo una vez. La insistencia nos causa la sensación de que la madre de estos dos niños no irá a las clases de español, dada su experiencia con otras familias marroquíes y por el conocimiento previo de la cultura machista de esos países en la que las mujeres no suelen hacer muchas actividades fuera de casa.

Posteriormente, esta misma profesora les comenta que ha estado en Marruecos, que le parece muy bonito, les nombra algunos sitios en los que estuvo, él le pregunta sobre el país con una expresión muy sonriente. Se nota un deseo por agradar al colegio en los dos casos (el de ayer y éste).

Les entrega un formulario y les pregunta si tienen problema para rellenarlo, ellos dicen que no. Laura se asegura diciendo que, si no, se lo rellenamos aquí o en DESOD.

Les explica en qué consiste la agenda en la que el profesor apunta las notas que considera importantes para que los padres se enteren de aspectos como salidas del centro, enfermedades, faltas, etc. Esta agenda es un recurso del centro utilizado como herramienta y estrategia de enlace entre el centro y la familia.

De repente me doy cuenta de que apenas hemos observado ni nos hemos dirigido a la niña (Amani). Al hacer consciente la transparencia de esta niña me doy cuenta de que puede suponer un importante problema para su integración en el centro. La expresión y la ausencia de gestos de la niña transmiten sumisión, timidez. No interacciona con nadie ni siquiera con la mirada. Si no se es consciente de esto, se puede convertir en una alumna invisible a los ojos del profesor y de sus compañeros y compañeras.

Me doy cuenta de que la madre apenas mira a la niña; sin embargo, al niño pequeño sí. Constantemente lo mira, se ríe, nos mira a nosotras después, sobre todo a mí, expresando con su sonrisa el agrado hacia al niño. (Interpreto el hecho de 
varias formas: revalorización del sexo masculino en coherencia con su cultura, personalidad responsable y tranquila de la niña que hace que su madre esté segura de que no va a hacer nada malo, ...)

Continúa la reunión pidiendo los datos a la familia. Ellos entregan los pasaportes, todos menos el del padre que está en Marruecos. Algunos datos de interés:

- Estudios primarios de la madre. Es ama de casa.

- Padre: albañil

- Son cuatro hermanos: dos niñas y dos niños

- Viven cerca del centro escolar

Cuando Laura les pregunta acerca de la profesión de la madre, el hermano salta muy rápido: "En nada, en nada, por supuesto, es ama de casa", haciendo gestos contundentes con las manos.

El niño empieza a mover los brazos en círculo por la mesa, la madre le hace un gesto como para que pare y luego se ríe y me mira como diciendo: "qué traviesillo".

Laura incide en que tendrá que traer el chándal y playeros para las clases de Educación Física. El hermano asiente. Ahora le pregunta qué tal iba la niña en el colegio en Marruecos. Él dice que bien, pero acompañando sus palabras con un gesto con la mano que expresa regular. Respecto al niño nos dicen que él nunca ha ido al colegio porque allí se escolariza a partir de los 7 años, los que tiene él. Tanto en esta entrevista como en la de ayer vemos que las familias quieren causar una buena impresión al colegio. Lo ven como una institución con cierta autoridad y a las personas que la conforman también. Esto no significa que luego hagan caso a todo lo que se les dice, a veces por olvido, por desconocimiento de la cultura escolar, por contradecirse con su cultura o por dejadez en el peor de los casos.

Laura continúa explicándoles los servicios que ofrece el colegio y de los cuales ellos pueden disfrutar: el de madrugadores, el comedor. Ante esto último hacen un gesto claro como que no lo iban a usar, dicen: "no, come en casa, es que en España la comida es muy diferente". Todos asentimos exageradamente: "claro, claro, por supuesto, sólo lo digo por si alguna vez lo necesitáis, que sepáis que existe". Nuestra respuesta espontánea y comprensiva en cuanto a la alimentación musulmana constituye no sólo una muestra de respeto ante esta cultura, sino que deja ver que los profesionales que estábamos allí somos conscientes (quizá por la experiencia, quizá por los medios de comunicación, quizá por ambos motivos) que estamos al tanto de la problemática que generan aspectos culturales relacionados 
en concreto con la comunidad musulmana (como por ejemplo, el uso de velo). En este hecho se aprecia una "hipersensibilidad comprensiva" y también un prejuicio cultural al asociar procedencia con religión y cultura.

Hablan ahora del tema de la compra de los libros de texto. Dicen que si es poco dinero lo pagarán ellos, si no pedirán ayuda al colegio. Laura les comenta que, si no pueden, el centro se los proporciona.

(Diario, 13 Septiembre 2006)

Analizando las acciones educativas que acabamos de describir, observamos algunos factores relacionados con las actuaciones del centro que pueden facilitar la entrada en la cultura escolar y otros que, sin embargo, pueden dificultarla. El caso de Joseph promete tener mayor facilidad para integrarse y para relacionarse con sus compañeros que el de Amani, la alumna inmigrante marroquí. Resumiré estos factores a continuación.

\section{En el caso de Joseph:}

- Las profesoras manifiestan mayores expectativas que en la reunión con la familia de Amani. Estas primeras percepciones se transmitirán al resto del profesorado. Las razones pueden encontrarse en: el alto rendimiento académico manifestado y demostrado en el colegio de Bulgaria, el conocimiento de la lengua inglesa, la simpatía manifestada por el alumno, el nivel cultural medio-alto de la familia al tener ambos miembros de la misma estudios universitarios. Todo esto son factores que pueden permitir al alumno ser visto con buenos ojos.

En el caso de Amani:

- En la reunión con esta alumna y su familia, a pesar de seguir el mismo protocolo, hemos encontrado diferencias sutiles que pueden dificultar la integración en la cultura escolar. Estas son: sólo habla el árabe, la familia está desestructurada, el padre ha sido repatriado a su país, el nivel cultural de la madre es bastante bajo, los gestos y actitud de la alumna son serios y tímidos.

Facilitadores y dificultadores escolares en ambos casos:

- Facilitador: La figura del alumno mediador supone un punto de referencia al que acudir en caso de incertidumbre. Soluciona los aspectos del idioma. Este es el primer nexo con el que comenzar a interactuar socialmente con el resto de los compañeros.

- Inhibidor: El profesorado tiene ideas previas y conoce otros casos en los que ha existido alguna dificultad con el alumnado marroquí del centro. 
- Inhibidor: No conocer el idioma mayoritario con el que interactuar.

PASAJE 4: Presentación de Joseph y Amani en su correspondiente grupo de clase.

\section{Joseph (Fase $2^{\text {a: }}$ Acogida en el centro y en el aula)}

9:40h: Entramos en el aula Joseph y yo. Los pupitres del aula están colocados en forma de $U$ para tener un mayor contacto visual y de acceso tanto del profesorado con el alumnado como del alumnado entre sí. La profesora presenta al resto del grupo: "Mirad, este es Joseph, ya os había dicho anteriormente que iba a venir un niño nuevo de Bulgaria, él no habla español pero sí inglés, así que tenemos que ayudarle y enseñarle cosas para que hable pronto español, ¿vale?" Todos responden: "vale". Continúa diciendo al grupo: "En el recreo le podéis enseñar cosas ¿A ver qué cosas podemos enseñarle?" levantan la mano: "estuche, goma". Profesora: "¿Qué más cosas?". Niños: "Jugar al fútbol". La profesora se dirige a Joseph y le dice en inglés: "¿Do you know play football?" Joseph: "yes". Profesora: "dice que sí, pues en el recreo jugáis con él al fútbol ¿de acuerdo?" Todos: "vale". Un niño dice: "puede jugar con las chicas". Profesora: "de acuerdo, que juegue con las chicas o con quien quiera" (no sabemos si tal comentario indicaba que ese niño pretendía quitarse de encima a Joseph porque las niñas juegan peor al fútbol, pero la respuesta de la profesora hizo disuadir la intención de discriminación al no decir: hombre no con las niñas no. En el recreo lo comprobaremos). Joseph mira expectante todo lo que pasa. La profesora le explica en inglés una serie de frases de saludo en español: "Hola, adiós, mi nombre es...". Joseph las repite con mucha facilidad y bien pronunciadas. Los niños medio aplauden cuando Joseph habla en español. Los niños le preguntan a través de la profesora cuántos años tiene (muestra de la existencia del miedo a hablar inglés por parte de los niños españoles, así como de su incompetencia lingüística en este idioma). La profesora lo traduce al inglés. Joseph responde: "eleven". La profesora dice: "como el resto de los niños 10 u 11 ".

\section{Amani}

10:30h: Hacemos el recorrido desde las filas hasta la clase para que se lo aprendan tanto el niño como la niña. La madre está pendiente continuamente del niño para que se aprenda las cosas.

10:35h: Dejan a Amani en su aula: $5^{\circ} \mathrm{A}$, yo entro con ella. En este momento está la profesora de matemáticas, pero no el tutor, Ovidio.

La profesora la presenta al grupo, dice al grupo cómo se llama y que tienen que jugar con ella en el recreo para no dejarla sola. "Tenéis que jugar en el recreo 
porque a ninguno de vosotros os gustaría que os dejaran solos, ¿no? Hay que acoger a los nuevos, ¿de acuerdo?".

Le pregunta cuántos años tiene, ella no entiende nada, me mira, yo le digo números: 10,11. Ella intuye la pregunta y responde: "10".

10:37h: Se sienta en un pupitre libre y yo a su lado. Todo ha sido muy breve. Los profesores hasta ahora observados dicen más o menos lo mismo al grupo de clase, pero los que no son tutores interactúan menos con ellos. Dicen eso al principio, se acercan una o dos veces a lo largo de la hora de clase y nada más. Las tutoras sin embargo muestran algo más de preocupación.

Intento hablar con ella, es imposible, no entiende nada de nada, ni francés, ni español, al igual que y tampoco árabe. Me pongo a hacer cuentas con ella: multiplicación y suma. La multiplicación no la sabe y en la suma se equivoca.

La profesora sigue dándole clase sin decir nada al respecto y es aquí cuando empiezo a pensar que mi papel se ha convertido en una excusa para los profesores para delegar en mí y traspasar el problema a otra persona.

10:55h: Empiezo a trabajar con ella los días de la semana, copiamos el horario de clase en el cuaderno. A Joseph también le dije que lo copiara y me dijo que para qué si ya lo tenía en los papeles que le habían entregado en la reunión inicial. Aquí aprecio una sutil diferencia: a pesar de querer agradar ambos, Joseph, más práctico, se revela ante cosas que le parecen nimias. Sin embargo la niña cumple todo lo que le digan. Dice mucho de la autoestima y seguridad de ambos.

(Diario, 12 Septiembre 2006)

La presentación individual del alumno nuevo a su grupo de clase, favorece la creación de expectativas positivas en sus compañeros.

Existen diferencias notables entre la presencia de Joseph y Amani ante sus condiscípulos. El primero se muestra extrovertido, seguro y tiene una buena base académica. Amani, por el contrario, muestra timidez, introversión y otro ritmo académico más lento.

Parece evidente que el punto de partida del alumnado para aceptar a un escolar nuevo cambia sustancialmente si previamente se ha hablado positivamente de él. En este caso así fue, la tutora había preparado a los alumnos veteranos informándoles de lo positivo que será la llegada de un alumno de Bulgaria. La idea previa y positiva que se había formado el grupo con estos comentarios se reforzó al conocerlo personalmente y ajustarse a esa imagen. Además, las habilidades personales de comunicación son diferentes en estos dos casos. 
Facilitadores:

- Habilidades Sociales, demostrar intención comunicativa.

- Hablar inglés como alternativa a no saber español.

- Hablar positivamente y crear expectativas de la llegada del alumno nuevo previamente, al grupo de referencia.

Inhibidores:

- $\quad$ Timidez, no demostrar habilidades sociales para comunicarse.

- No hablar ni preparar previamente la llegada de un alumno nuevo al grupo de referencia.

PASAJE 5: Reunión de sensibilización con las familias para informar sobre la escolarización de alumnos nuevos de otras procedencias. (Fase 2a: Acogida en el centro y en el aula).

16.30h: Estoy en la sala sentada como si fuera una madre más, lo que me facilita escuchar sus comentarios.

En total hay 27 personas; de ellas, cinco son padres, el resto madres. El padre de Joseph está sentado el solo, al lado de la pared, apartado de los demás, ha llegado de los primeros.

No hay ningún familiar de Amani. Empieza Laura justificando la razón de la convocatoria de la reunión, explica en qué ha consistido el plan de acogida que el centro ha realizado para atender a los alumnos inmigrantes.

Se les pone un vídeo de sensibilización con imágenes de alumnado inmigrante del colegio.

Luego suben a sus respectivas clases con sus tutores: Marta y Ovidio.

En este transcurso, algunas madres se saludan, se saludan y comentan. El padre de Joseph y la hermana de Willy al no conocer a nadie permanecen al margen de cualquier conversación.

(Diario, 12 Septiembre 2006)

Con esta reunión se pretende sensibilizar a las familias para que tengan buena disposición con el alumnado nuevo inmigrante y que hablen bien en sus respectivos hogares. Además, la idea de juntarles en el centro también podrá producir contactos entre ellos para que establezcan lazos. Sin embargo, esta reunión no produjo contactos entre las familias veteranas y las nuevas. La 
organización de la actividad, tiempo y estructura, no permitió establecer interacciones.

Facilitadores:

- Preparar a las familias para la llegada de alumnos nuevos.

- Fomentar el conocimiento mutuo de las familias nuevas y veteranas.

Inhibidores:

- La estructura de las reuniones no permite establecer contacto entre familias: organización, escasa duración, distribución de la sala, tipo de actividades.

PASAJE 6: Reunión entre la tutora de cada curso y las familias del alumnado del mismo. (Fase $3^{\text {a: }}$ : Acogida en la comunidad escolar).

Son trece en total: doce madres y el padre de Joseph, más la hermana de Willy. Marta se presenta. Explica las asignaturas que da ella y el nombre de los profesores que imparten las demás.

Explica el objetivo de la reunión:

- Informe general, no particular, de la dinámica de las clases.

o Horario de tutorías con ella y con otros a través de ella.

o Manera de trabajar: "Cada maestrillo con su librillo". Ella explica la suya.

Dice que hay poca coordinación entre el profesorado porque no disponen de mucho tiempo para poder hablar entre ellos y así ver entre todos los deberes que se mandan a los niños, pero que ella cree que tampoco son demasiados y que, trabajando un poquito de cada materia cada día en casa, se puede avanzar mucho (el propio profesorado reconoce la falta de coordinación y, por tanto, la imposibilidad de interdisciplinariedad).

Pide colaboración a las familias para que supervisen los deberes de sus hijos e hijas, para asegurar que los hacen de una manera activa, buscando información en otros libros, en internet, etc.

Pide, además del trabajo activo, que repasen en unos minutos lo que han hecho ese día en clase para que no se les olvide al día siguiente.

Expone también el funcionamiento de la biblioteca escolar. La elaboración de un catálogo de préstamos. Se explica la dinámica para animarles a leer. 
- Comenta la distribución del espacio en el aula: las ventajas y los inconvenientes.

- Los apoyos.

- Las actividades extraescolares.

- La Agenda escolar como vehículo de comunicación entre familias y profesorado.

17h: Entra Carmen, la profesora de música. Con gesto serio, pide por favor a las familias que se tomen en serio la asignatura. "No vamos a entrar en detalles de si la asignatura es importante o no, la tienen que cursar en Secundaria, por lo tanto no hay más que hablar" (discurso que denota el valor instrumental que se concede a algunas del currículum).

Pide a las familias que por favor le ayuden y se aseguren de que los críos se saben las notas musicales.

Dice que no hay problema por los nuevos, porque el libro empieza desde cero otra vez, aunque luego avanza más rápido para llegar al nivel siguiente, y que se pueden ajustar a los que ya han cursado la asignatura en los cursos anteriores de Primaria. Reto para los nuevos no reconocido por los docentes: además de ser nuevos y de no haber visto nunca esta materia, deberán ajustarse a un ritmo más rápido aunque empiece de cero para ajustarse al nivel de los demás.

Solicita que, por favor, practiquen en casa y que repasen lo que hacen en clase, que los ejercicios de ritmo no los evalúa, pero que necesita que el alumnado participe en las actividades al respecto. Se evalúa lo objetivo: que sepan las notas musicales.

Tranquiliza a las familias diciéndolas que no existen problemas graves en la clase de sus hijos, pero que si algún alumno molestara, se avisará a los padres, porque "están privando del derecho de aprender a otros compañeros" (utilizando su discurso de forma textual).

17:07h: Carmen se va. Continúa hablando Marta sobre las autorizaciones de las excursiones, de la evaluación y de algunos problemas concretos como las faltas de ortografía.

Respecto a la evaluación, dice que es continua. Hará un examen cada tema o dos temas, pero se valorará además el trabajo de todos los días. En Francés sólo hace un examen al trimestre, porque da prioridad al aprendizaje oral de la lengua, ya que es inicial. 
Comenta que cometen muchas faltas de ortografía y algunos necesitan mejorar la caligrafía. Mandará comprar unos cuadernillos especiales para ello porque necesitan un extra. Pide ayuda para que colaboren en esta labor.

También menciona otros aspectos que deberían mejorar, como el hábito de la lectura. Dice que no leen casi nada, que les animen desde casa a hacerlo.

Recalca la ayuda y la colaboración de los padres para trabajar en la misma línea entre todos a favor de una educación para sus hijos e hijas. En concreto resalta las siguientes ideas:

- fomentar hábitos de estudio activo y no mecánico

- que antes de juzgar al docente hablen con él

- que fomenten la lectura

- la idea de colaboración familia-escuela

Les comenta que los niños y niñas están en una edad preadolescente y que se encuentran en un momento de reafirmar su personalidad, que son muy críticos con todo, que son más vulnerables a lo que se les dice.

Por último lee una serie de consejos para educar a los escolares en la misma línea que el centro.

(Diario, 10 Octubre 2006)

Esta reunión pretende conseguir una mayor coordinación entre la labor de la escuela y la familiar. La familia constituye la primera fuente de socialización del escolar y en este ambiente se desarrollarán los primeros patrones cognitivos y sociales del alumnado. Los estereotipos y prejuicios por tanto, también se formarán en este ambiente. De ahí la importancia de coordinar la acción educativa y la familiar.

Facilitadores:

- Esta reunión permite el conocimiento de la profesora y de su metodología.

- Información importante para conseguir coordinación entre familia y escuela. Inhibidores:

- Rigidez en la aplicación de los contenidos que vienen marcados por la administración, muchas veces condicionados por el desarrollo curricular de los libros de texto. No se atiende a las necesidades del alumnado nuevo.

- Falta de asistencia de los padres cuyos hijos presentan más dificultades escolares: madres de los alumnos gitanos y algunos inmigrantes. 
- Muy centrada en contenidos de materias clásicas. Falta de referencia a temas transversales como la educación para la tolerancia, o la importancia de hacer comentarios favorables a la integración de los nuevos en el seno familiar.

En general, podríamos decir que existe una preocupación en el centro por el tema de la integración de los nuevos escolares. El diseño nos parece interesante y cargado de detalles que pueden ayudar mucho a la integración de los niños y niñas recién llegados.

Sin embargo, su aplicación se difumina cuando se llega al nivel del detalle. El ritmo diario de las clases; la atención a multitud de problemas cotidianos por parte de los maestros y maestras; 0 el elevado número de escolares a los que tiene que atender cada docente y que no permite dedicarse detenidamente a cada caso, suponen distorsiones a la aplicación cotidiana del plan. Por otra parte, vemos que el peso de los contenidos tradicionales (lecto-escritura, matemáticas...), así como las exigencias futuras (que lleguen con nivel a Secundaria) encorsetan las prácticas y determinan las prioridades del sistema. Todo ello demanda o bien un cambio en la sensibilidad del profesorado hacia estos temas transversales o bien más docentes que vigilen estos procesos personales.

Encontramos, además, algunas limitaciones en estos planes, referidas a la dificultad de hacer llegar sus intenciones y su valor a las familias de los escolares más necesitadas de esta relación familia-escuela. ¿Cómo hacer ver la importancia de ir a las reuniones a estas familias que no acuden a ellas?, ¿cómo llenarlas de contenidos que les interesen?, ¿cómo hacerles ver el valor de la escolarización? Son preguntas que definen un campo sobre el que seguir habilitando estrategias que posiblemente superen las competencias del centro escolar. Miguel Ángel Essombra $(2008,15)$ establece en su reciente libro las bases para la transformación hacia un plan de acogida que recoja un currículo intercultural. Estas bases tendrían que ver más con aspectos cualitativos, donde se produzca una verdadera transformación de la naturaleza etnocétrica previa de sus contenidos y una participación y complicidad del conjunto de la comunidad educativa del centro.

\section{Las clases de apoyo}

Las clases de apoyo son gestionadas por el profesorado de compensatoria y están formadas por alumnos que han manifestado un desfase académico en las pruebas de nivel de competencia curricular que se realizan a principios de curso. Los alumnos inmigrantes nuevos no realizan esta prueba, pero van a estas clases para aprender la lengua o para adaptarse a los contenidos escolares en un primer 
momento y ajustar su nivel académico al demandado por el centro, diferente en los distintos países.

Joseph y Amani necesitan estas clases para adquirir el conocimiento de la lengua. Willy en cambio, a pesar de hablar español, necesita los apoyos por tener un desfase curricular de tres cursos académicos. Estos alumnos salen de sus aulas ordinarias para ir a estas clases. Se pretende conseguir que avancen lo antes posible para que puedan volver a su clase de referencia a fin de no crear un grupo segregado.

La intención al describir y analizar lo que ocurre en las clases de los apoyos es entender los procesos individuales tanto sociales como de aprendizaje que vive el alumnado inmigrante nuevo. Esto es posible gracias al reducido número de alumnos que conforman estas clases. Por tanto, hablaremos en este momento sobre las interacciones sociales del alumnado inmigrante en este lugar alternativo al aula ordinaria. Estas clases permiten reducir el número de alumnos en una clase, se facilita por tanto el seguimiento del proceso individual de cada sujeto y se adapta mejor la respuesta educativa a las necesidades de cada uno. Al mismo tiempo, en este lugar se crean climas de mayor intimidad y confianza, con lo que sale a la luz información que en otros lugares resultaría imposible obtener.

También en este espacio fuimos testigos de diferentes informaciones que circulaban entre los profesionales que trabajaban con el alumnado inmigrante del centro. Comparamos la información entre las profesoras de compensatoria, los tutores, los monitores de las asociaciones que trabajaban con la población inmigrante de la zona y los orientadores del equipo psicopedagógico que acudían una vez al mes al centro.

La información obtenida en estas situaciones la organizamos en torno a los siguientes temas:

2.1.- Expectativas que el alumnado nuevo genera en el profesorado.

2.2.- Distancia cultural que el alumnado inmigrante nuevo encuentra en los contenidos académicos.

2.3.- Respeto hacia los diferentes ritmos de aprendizaje.

2.4.- Interacciones entre el propio alumnado inmigrante.

2.5.- Motivación del alumnado inmigrante en las clases de apoyo.

\section{1.- Expectativas que el alumnado nuevo genera en el profesorado}


En primer lugar, apreciamos que las informaciones transmitidas entre el profesorado están cargadas de expectativas generalmente positivas. Los docentes construyen creencias a partir de la información familiar, académica y social que reciben. Veamos un ejemplo:

Una trabajadora social está hablando con la profesora de compensatoria en el aula donde se realizan los apoyos sobre el caso de Lily, una niña Dominicana de $2^{\circ}$ de Primaria que también es nueva en el centro. Comentan: "Su madre ha venido al centro porque la hemos llamado. Es una niña muy maja y su madre parece preocupada por ella. Tiene un poco de retraso curricular pero en poco tiempo se igualará. Hay que darle un poco de tiempo para que se adapte, por ahora todo es muy nuevo para ella, pero tiene habilidades suficientes como para superarlo, yo creo."

(Diario 12 diciembre 2006)

En ocasiones se aprecian algunas opiniones que generalizan atributos sobre los alumnos de alguna procedencia concreta. Hemos recogido a lo largo de esta estancia frases del tipo: "A los árabes les cuesta más que a los de otros países adaptarse en el colegio"; "Los inmigrantes del Este (refiriéndose a los de Europa del Este) no tienen problema para integrarse, se esfuerzan mucho. A los latinos, sin embargo, les cuesta mucho más, son más vaguetes..."; "Los inmigrantes del Este aprenden rápido el idioma". A pesar de las ideas reflejadas en algunas frases como éstas, en general, apreciamos la utilización de un lenguaje políticamente correcto que no deja traslucir sesgos racistas.

Posiblemente toda esta red de informaciones tejida entre profesorado, familia y otros agentes va construyendo unas expectativas en los docentes sobre el alumnado inmigrante que condicionará sus refuerzos, gestos y comentarios hacia este alumnado. Veremos más detalles sobre el tema más adelante al hablar de la metodología utilizada por los docentes.

\section{2.- Distancia cultural que el alumnado inmigrante nuevo encuentra en los contenidos académicos}

El trabajo con pequeños grupos permite sacar a la luz algunos detalles en el proceso de aprendizaje que en las clases ordinarias pasan desapercibidos. Es el caso del choque cultural que producen algunos contenidos académicos para los alumnos que proceden de otros países (de otras culturas escolares). Por ejemplo, en el caso de Joseph, que había aprendido a realizar las operaciones matemáticas como la división con otro método diferente, ahora debía aprender el procedimiento utilizado en este centro. En general, apreciamos que si el alumnado posee las habilidades (como en el caso de Joseph), se adaptan rápidamente a las diferencias, pero en el caso contrario sufren un retraso que arrastrarán a lo largo de la 
trayectoria escolar. Mostramos un pequeño fragmento del diario de campo para resaltar estas diferencias de partida entre escolares.

9:05h: Entramos en la clase de compensatoria. Están cuatro niños: Joseph, Amani, Jose Carlos y Raquel. Empiezan a trabajar las matemáticas. Datos referidos al nivel académico:

- Joseph aprendió a dividir con otro método distinto en Bulgaria. Le están enseñando el método de aquí y eso requiere un ajuste cognitivo. A algunos alumnos les costará más que a otros realizar este ajuste y eso influirá en los resultados académicos. Vemos con este ejemplo, el componente cultural que tienen los contenidos del currículum, incluso las matemáticas.

- Joseph entiende fácilmente las explicaciones y la división la hace bien, a Amani le cuesta algo más.

- Joseph termina antes los ejercicios que el resto, mira a Amani cuando acaba y me mira con gesto de: "ésta no se entera de nada".

- A Amani le tienen que explicar los ejercicios más veces que a los demás. Le cuesta más entender lo que le explican. Es normal, ha experimentado más dificultades de tipo académico como escribir de derecha a izquierda y aprender un idioma más distante léxicamente del español que el búlgaro.

(Diario 29 de Septiembre 2006)

Estos procesos de individualización del aprendizaje nos permiten observar las diferencias entre el alumnado con competencias académicas y el alumnado sin ellas, siendo el primero, capaz de salvar de forma más rápida este choque cultural, reajustándose de manera adecuada a las nuevas exigencias académicas. En este proceso adaptativo, algunas veces se olvida o se desconoce la distancia cultural que supone el paso de unas culturas a otras. En este caso existe mayor distancia cultural entre el árabe y el español que entre el búlgaro y el español. Algunos ejemplos de estas diferencias son el alfabeto árabe, el orden espacial al escribir. Estos ejemplos observados se alejan más del español que la lengua búlgara. Amani, por tanto, se verá envuelta en un proceso adaptativo más exigente que el de Joseph. Entre otras cosas, el tiempo que tarden en adaptarse a las exigencias académicas y a las normas del contexto, determinarán la valoración que de ellos tengan los otros compañeros y compañeras.

Una de las finalidades con la que los centros realizan los apoyos es para que el alumnado inmigrante nuevo disponga de un tiempo y espacio individualizado de transición para ajustar el funcionamiento académico que traen de sus respectivas procedencias al que está instaurado en el centro educativo español de recepción. En 
el caso de Joseph, requerirá de menos esfuerzos que Amani para lograr este ajuste adaptativo. Autores como Pérez Gómez (1992), Santos Guerra (1994) y Rodríguez Rojo (1997) manifiestan sus ideas teóricas al respecto de la integración escolar de inmigrantes, expresando que la cultura mayoritaria impone sus normas y usos a las minorías étnicas, consiguiendo en muchos casos una asimilación más que una verdadera integración. Resulta imprescindible para conseguir la integración de inmigrantes plantear debates interculturales que modifiquen la práctica educativa para atender a las necesidades culturales que se demanden; sin embargo, observamos en nuestro estudio que resulta difícil conseguir una operatividad educativa, si no se parte de unos mínimos organizativos asumibles por todo el alumnado.

\section{3.- Respeto hacia los diferentes ritmos de aprendizaje}

Otro aspecto diferenciador de estas clases respecto a las ordinarias es el respeto existente hacia la diversidad de los ritmos de aprendizaje. Cada niño tiene un ritmo diferente, un nivel académico distinto, unas necesidades específicas. La naturalidad ante esta situación por parte de la profesora facilita que no se hagan bromas, ni burlas cuando uno no sabe hacer algo, cuando no sabe responder en público o cuando hace mal un ejercicio. Esta idea puede caer en el riesgo de legitimizar los reductos de minorías, justificando que funcionan académicamente mejor juntos que integrados en las aulas normales. Por eso mencionamos la idea con cierta prudencia y resaltando que estas clases suponen un trampolín desde el cual volver a su grupo de referencia en cuanto tenga adquiridas las habilidades académicas básicas.

Se oye decir a Elisa dirigiéndose a Willy: "Cada uno va a su ritmo. Él lo sabe hacer (refiriéndose a Joseph), tú ya aprenderás, vamos".

Elisa está repasando una división con Raquel: "A ver, Raquel, si divides entre 5, "¿a dónde vas?". Joseph utiliza la última frase de Elisa y dice como si la frase fuera para él: "A Bulgaria, vamos a Bulgaria". Raquel continúa haciendo la división, pero no le sale. Willy hace un gesto a Elisa como avisándola de que ayude a Raquel a terminar la división.

Raquel, se entretiene un rato y comenta a Elisa que Amani cruza la carretera con el semáforo en rojo. Elisa le pregunta a Amani, ella dice: "rojo no, verde sí".

Joseph me enseña el rostro que ha hecho, yo le pongo una flor. Me pide que se lo firme. Me dice: "Tú dibujas muy bien". 
Joseph me hace un juego con la mano, luego se lo hace a Raquel, ella pasa del tema, le pregunta otra cosa diferente.

(Diario, 8 Diciembre 2006)

No es éste el único relato en el que se observa un clima distendido y tolerante en estas clases. Además de existir muchas más interacciones entre el alumnado y la maestra, vemos cómo no es objeto de burlas o de juicios negativos el no saber hacer una división. Además, la niña que no sabe hacerla no tiene ninguna vergüenza de tal desconocimiento. Por otro lado, el hecho de que exista falta de tensión ante el desconocimiento, lo valoramos positivamente porque a su vez, la mayoría del alumnado que acude a los apoyos se esfuerza por llenar las lagunas académicas que posee.

\section{4.- Interacciones entre el propio alumnado inmigrante}

Este lugar también es un espacio óptimo para observar comentarios y situaciones referidas a la interacción interétnica, es decir, si demuestran prejuicio hacia otros alumnos inmigrantes y de qué manera. Estos comentarios extraídos del análisis del proceso permitirán complementar la panorámica general obtenida al respecto, en el estudio cuantitativo.

El suceso que incluimos a continuación, ocurrido en las clases de apoyo, nos demuestra los prejuicios demostrados hacia el alumnado marroquí. La rapidez con la que se ha formado ese estereotipo nos informa de que existen creencias previas con las que llegan a la escuela.

Elisa me cuenta que esta semana Joseph y Amani se han enfrentado, que se insultan entre ellos. Parece ser que han discutido por un pegamento. (Veremos qué hay detrás del pegamento). Después de esto se sienta cada uno en una parte del aula.

Versión de Joseph: En su español incorrecto, pero ya muy avanzado me dice: "Ella dice "tontos búlgaros" y yo digo "tontos marroquís, mierda de marroquís".

Yo le pregunto: "A ver Joseph, explícame, ¿qué pasó?".

Él me dice: "yo tenía pegamento y la dije es mío, ahora espera. Ella hacerme gestos con la mano y decir familia búlgara loca".

Yo le digo: "Pero si ella no habla español. ¿En qué idioma lo dijo?"

"En Marroquí", responde él.

"¿Y tú entiendes marroqui", le digo a Joseph.

"Eso sí lo entendí", contesta él. 
(Diario, 13 Enero 2007)

Un pasaje como éste nos permite atisbar la presencia de estereotipos y prejuicios hacia otras etnias entre los inmigrantes, que pueden dificultar las interacciones sociales positivas entre iguales. Los argumentos que Joseph utiliza en este caso para explicar el enfrentamiento con Amani tienen un marcado carácter racista. Este hecho no nos permite aventurar ninguna conclusión respecto a la diferencia existente en el prejuicio por parte del alumnado inmigrante o el español. Pero sí consideramos oportuno señalar algún argumento en esta línea defendido por (Ovejero, 2004), éste entiende que puedan existir más conductas racistas entre los propios inmigrantes por ser contrincantes directos en la integración de la cultura mayoritaria.

Los cuestionarios realizados en el estudio previo cuantitativo nos avisaban de que, sin ser exagerado, existía cierta intolerancia a realizar actividades conjuntas con alumnado de étnias diferentes. Con el presente estudio cualitativo, observamos ciertos matices ante esta afirmación general. El prejuicio se muestra de forma más sutil o indirecta entre el alumnado ya que están inmersos en un discurso educativo de tolerancia a la diversidad. En otros apartados desarrollaremos este tema con más profundidad. Ahora nos centramos en describir la influencia de determinadas situaciones personales en las interacciones sociales y en la integración escolar (los enfrentamientos de tinte racista son parte de ello).

\section{5.- Motivación del alumnado inmigrante en las clases de apoyo}

Las clases de apoyo provocaban un estado en el alumnado muy diferente al que mantenían en las clases ordinarias. Algunos diálogos de los escolares en estas clases lo demuestran:

Amani está concentrada sin decir nada, ni interactuar con nadie, pero tranquila y sonriendo de vez en cuando.

Joseph, mientras recorta y pega, no para de contar cosas y de hacer gracias.

Ahora dan lengua y la profesora se encarga de que aprendan los saludos y las primeras frases de contacto con los demás. Joseph ya se las sabe: las dice todas de golpe, tiene ganas de hablar. Se nota un cambio entre la primera clase en la que estaban todos más callados y esta hora donde ya se comunican entre ellos. Joseph dice: "ella es mi amiga Henar", "ella es Amani", todo muy sonriente y alegre. 
Podemos imaginar que en medio de la exigencia que produce el proceso de adaptación a este nuevo contexto escolar (aprendizaje de códigos verticales y horizontales, deseos de agradar e integrarse, esfuerzos por comprender y ser comprendidos...), estas clases suponen un paréntesis de tranquilidad, que les permite sentirse más cómodos, tranquilos y atendidos.

En el caso de Amani apreciamos que esta seguridad se incrementa cuando tiene cerca a "alguno de los suyos":

Esta vez, en clase de compensatoria están sólo Amani, Joseph y el hermano de Amani. La encontramos mucho más suelta, más alegre, interactuando más con los compañeros y con la profesora. Hace preguntas, intercambia el material, sonríe, se sienta junto a los demás compañeros. Vemos en este caso, que la puesta en práctica de las habilidades sociales no sólo dependen de poseerlas 0 no, sino del contexto y de las características del ambiente en el que se desarrollan.

(Diario, 14 Diciembre 2007)

No sabemos si esta tranquilidad le viene de tener oportunidad de controlar a su hermano pequeño. Entendamos que, posiblemente, esta niña ve más natural un centro en el que acuden los niños y niñas de diferentes edades a la misma clase, que uno tan grande como este en el que hay una separación por cursos. De ser así sería comprensible que lejos de valorar la presencia de su hermano menor como un síntoma de excepcionalidad (y por tanto de desprestigio hacia ella) lo tomase como una oportunidad tranquilizadora al poder tenerle cerca. Pueden darse también prioridades en esta niña, es decir que le parezca secundario el aprendizaje escolar al cuidado de su hermano (no sabemos si puede haber de fondo un tema cultural sobre el valor de la escolarización en las mujeres marroquíes).

Algunas observaciones realizadas sobre Willy nos aportan más matices sobre el estado de estos niños y niñas en estas clases:

Willy: "ijo! sólo quedan dos minutos aquí"

(Diario, 20 Enero 2007)

Demuestra con el "sólo" que le gusta estar en esta clase. Es normal, es la única en la que tiene oportunidad de que se ajusten a sus necesidades, en la que le hacen algo de caso y en la que puede hablar con sus compañeros sin que se metan con él.

Wallinton está concentrado en los problemas de matemáticas, cuando no sabe hacerlos pregunta a Elisa. 
Apreciamos que en este entorno se encuentra más seguro y concentrado. En este ambiente distendido no se bloquea, no tiene reparo en hacer preguntas (posiblemente, porque sabe que otros no se meterán con él), y no le importa equivocarse. Por otra parte, todas las energías que habitualmente gasta en preocuparse por los demás (cómo caerles bien, cómo agradarles, qué pensarán de él...), las puede utilizar aquí para centrarse en la materia y progresar. Es posible que él vea también una oportunidad de progreso para ponerse al nivel de los otros compañeros y que se reduzcan sus críticas hacia él.

Estos pasajes, entre otros, nos permiten llegar a la conclusión de que las clases de apoyo suponen un lugar donde conocer los procesos personales (académicos, familiares, sociales y emocionales) del alumnado con más dificultades de integración escolar. A su vez esto permite ajustar las respuestas educativas de los profesionales de forma más adecuada y coordinada. La percepción del alumnado que acude a estas clases es positiva. Esta motivación manifestada, la atribuimos a los siguientes factores:

- Sentimiento de seguridad por parte del alumnado ante la ayuda individualizada recibida por la profesora.

- Estas clases suponen un paréntesis de claridad y tranquilidad entre la gran exigencia que supone el resto de la jornada escolar (aprendizaje de códigos, esfuerzo por interactuar con otros, por hacerse entender...).

- Los críos pueden vivir estos momentos como una oportunidad de ponerse al ritmo de los demás, pero sin verse sometidos al juicio del resto.

- $\quad$ Respeto y normalización del ritmo personal con el que cada uno asimila los aprendizajes.

- Existencia de más cantidad e intensidad de interacciones sociales entre los compañeros.

- Los niños y niñas reciben más oportunidades de ser tratados como personas individuales. Se ve reconfortado su ego, al ser tratados como únicos.

- Estos escolares experimentan menos tensión al no tener que ser evaluados continuamente ante contenidos que no controlan. En estas clases se parte de sus conocimientos previos.

El análisis de las interacciones sociales producidas en este espacio nos permite realizar las siguientes reflexiones. 
Al agrupar a todos los escolares con bajo nivel académico en una clase de apoyo, se corre el riesgo de crear un reducto considerado por el resto de la comunidad escolar como "alumnado de segunda". Los niños y niñas que acuden a estas clases se sienten bien en este lugar, pero ¿qué pasa cuando salen de este aula y se incorporan con su grupo ordinario?, ¿se establece algún tipo de segregación o exclusión entre el alumnado que necesita apoyo y el que no?.

Algunos cometarios escuchados a los alumnos en los pasillos nos dan orientaciones sobre ello.

"¿Dónde va Jonny?" (refiriéndose a una alumno gitano de su clase con el que han estado interactuando en las filas de subida a clase), le pregunta un alumno a otro, uno de las primeras semanas de colegio.

"Va a clase de los que no se enteran" (refiriéndose a "apoyo").

Sin embargo, otros niños cuando hablan de estas clases y es un adulto el que se lo pregunta se refieren a estas clases diciendo: "Está con Elisa" (la profesora de apoyo) o "va a apoyo".

(Diario, 25 Enero 2007)

Estas expresiones del alumnado reflejan dos hechos: por un lado, que el alumnado que va a clases de apoyo posee menor estatus académico y a veces social, y, por otro, que los escolares poseen un conocimiento elevado sobre el discurso que deben manejar ante el profesorado (deseabilidad social).

- Encontramos un paralelismo entre las clases de apoyo y los centros en los que la mayoría de la población que los forman son minorías étnicas y sociales. En ambos casos, estos grupos conforman una burbuja dentro de la cual tienen un ambiente agradable y perfecto, pero al salir de él se encuentran con la realidad con la que tendrán que convivir.

Al respecto, escuchábamos un día a una orientadora comentándole a la profesora de compensatoria:

Muchos niños que están en colegios "gueto", que son los mejores de la clase y son sacados por sus padres a otros más normalizados donde la población está más equilibrada, luego quieren volver a su centro inicial. Puede ser porque allí al ser menos de 10 en las clases, reciben un trato más individual, pues al llegar a otros centros son los que están en compensatoria y de sentirse inferiores a los demás, prefieren ser "Ios listos dentro de los tontos" que "Ios tontos dentro de los listos". 
A pesar de encontrar muchas ventajas a la organización de los apoyos para mejorar la integración del alumnado inmigrante, enumeramos resumidamente algunas ideas que creemos pueden rentabilizar los fines de tales clases:

- Conocimiento de las funciones de los apoyos por parte de los docentes.

- Tener material general y específico de cada área preparado y sistematizado para el alumnado inmigrante.

- Coordinación entre el profesorado de las áreas y la de compensatoria.

- Trabajar para hacer entender y normalizar la diversidad a través de metodologías que promuevan la responsabilidad en el proceso de ayuda, la enseñanza recíproca o el aprendizaje cooperativo.

El siguiente apartado que desarrollamos a continuación tiene que ver con las interacciones sociales observadas en las clases ordinarias. En este apartado analizamos cómo la metodología docente influye en las interacciones sociales del alumnado y en concreto en aquellos en los que la cultura escolar resulta novedosa.

\section{Las clases ordinarias}

Las relaciones que se generan en la clase son diferentes de las que surgen en ambientes naturales como en la pandilla de amigos. Éste es un contexto artificial, organizado externamente para conseguir unos fines educativos concretos. En este lugar se crea un ambiente formado por un conjunto de factores psico-sociales que afectan al comportamiento y a las relaciones interpersonales entre docentes y alumnado. Estas relaciones no se producen libremente, sino que están sujetas a un orden y a unas limitaciones normalmente propuestas por el profesorado.

Las relaciones personales que se dan en el aula se producen de diferentes formas. Según Rivas (1997), la estructura de las interacciones durante las clases son por un lado diádicas, las que se establecen entre el docente y el escolar (en ellas existe un desnivel y cada uno ostenta un rol diferente) y otras son múltiples, del mismo nivel, establecidas por los compañeros entre sí. A su vez, dentro de estas últimas, unas son espontáneas, como las que vimos en el apartado anterior en el recreo, y otras son artificiales, como la realización de trabajos en grupo en el aula. En éstas últimas nos centraremos en este momento.

Las relaciones de las que hablaremos a continuación son bidirecionales. Unas son producidas por el docente hacia los escolares y viceversa, aunque estas últimas tienen mucha menos trascendencia. Rivas (1997) califica a las relaciones profesor-escolar como interacciones de primer orden; interacciones de segundo nivel a las producidas entre compañeros; y las de tercer nivel, aquellas que ocupan 
un lugar intermedio, las llama relaciones funcionales sintagmáticas, que serían manifestaciones de interacción mutua como la forma de relacionarse del profesor con los alumnos, la confianza que éstos depositan en él, la implicación o no del profesor en los problemas de clase, etc.

Los epígrafes temáticos que trataremos en este capítulo responden a un orden temporal que respeta el proceso de integración observado en los alumnos nuevos inmigrantes a los que realizamos el seguimiento. Algunos tienen que ver con las relaciones de primer orden (relación profesor-alumno, coordinación entre el profesorado que atiende a un mismo grupo, disciplina y control), otros con las de segundo (efecto novedad del alumnado nuevo en el grupo, expectativas generadas en el grupo) y otras que se encuentran en un lugar intermedio denominadas por el autor, relaciones funcionales sintagmáticas, como dependencia y autonomía escolar del alumno inmigrante nuevo, o los agrupamientos y metodologías cooperativas.

En primer lugar y como fruto de las reflexiones realizadas tras las observaciones, desarrollamos un apartado sobre las características generales de las interacciones horizontales en las clases formales escolares para ir definiendo al mismo tiempo algunas características de la cultura escolar que se desprenden. En segundo lugar, describimos algunos aspectos que consideramos relevantes dentro del proceso de integración de los tres alumnos inmigrantes a los que seguimos como son su dependencia y autonomía en el funcionamiento en el centro; las expectativas y prejuicios del profesorado y alumnado hacia los niños y niñas inmigrantes; y finalmente, los procesos pedagógicos que se desarrollan en el aula y su influencia en las minorías culturales. En concreto, el orden de epígrafes será el siguiente:

3.1.- Características generales de las interacciones sociales en las clases formales

3.2.- De la dependencia a la autonomía en el funcionamiento del alumnado nuevo.

3.3.- Expectativas y prejuicios del profesorado y alumnado expresado en el aula hacia el alumno inmigrante nuevo.

3.4. - Procesos pedagógicos que se desarrollan en el aula y su influencia en las relaciones con las minorías culturales.

\section{1.- Características generales de las interacciones sociales en las clases formales}

Al reflexionar sobre los relatos tomados de la observación en este lugar surgen varios temas que definen el marco de intereses en el que se establecen las interacciones entre el alumnado y las relaciones docente-discente. En relación con 
el tema que nos ocupa (la integración del alumnado inmigrante nuevo) extraemos los siguientes temas:

-La flexibilidad que permite al alumnado estar atento a la lección al mismo tiempo que entablan interacciones entre ellos

-La implicación afectiva de este tipo de interacciones entre iguales

-Los continuos esfuerzos del alumnado por mantenerse sentados y controlando el cuerpo en las clases

-Las oportunidades que brinda el profesorado para favorecer las interacciones entre iguales

Una de las primeras reflexiones que nos suscitan nuestras observaciones durante el transcurso de las clases fue la referida a la flexibilidad que permite al alumnado estar atento a la lección al mismo tiempo que entablan interacciones entre ellos. Es decir, las interacciones didácticas de primer orden (docentediscente) y las múltiples de segundo nivel (alumno-alumno) podían desarrollarse paralelamente ${ }^{1}$. Las observaciones realizadas en el conjunto de las clases nos permiten afirmar que la mayoría del tiempo hay alumnado interactuando entre sí. Por tanto, debido a la cantidad de interacciones de este tipo observadas en las clases podemos decir que son más importantes de lo que podría creerse. La institución escolar, por lo general, no sólo no otorga importancia a estas interacciones sino que las descalifica utilizando para referirse a ellas términos peyorativos (como distracciones, indisciplina, barullo, chascarrillos, jaleo). Además, el concepto que se tiene del buen maestro es el que mantiene a los niños alejados de estas interacciones. Son consideradas, por tanto, por la institución escolar como negativas. En nuestro estudio nos parecen interesantes por constituir una de las estrategias de interacción entre el alumnado y, por tanto una situación importante para el alumnado nuevo.

En estas interacciones, los escolares desafían lo prohibido, se trata de un desafío disimulado (Vásquez y Martínez, 1996). Los escolares utilizan técnicas de disimulo debido al carácter de privacidad sin el cual estas interacciones no podrían desarrollarse. De esta manera, el modo de expresión suele ser codificado en gestos, mímica, lenguaje escrito con abreviaturas, lenguaje oral con significados contextuales implícitos, etc. Estos modos de comunicarse dificultan el acceso a la socialización del alumnado nuevo inmigrante, el cual, no conoce la lengua y menos

\footnotetext{
${ }^{1}$ Así, por ejemplo, vemos en las actas como muchos alumnos pueden contestar correctamente a las preguntas del profesor o corregir los ejercicios mientras interactúan (moderadamente) con otros compañeros que tienen al lado, pasándose material o realizando algún comentario.
} 
la simbología de estos atajos lingüísticos. Esta puede ser una de las razones por las que los niños y las niñas inmigrantes a los que seguimos se centraron los primeros días en escuchar al profesor y no interactuar entre iguales, ya que no sabían de qué manera hacerlo. Joseph intenta dar una buena imagen a la profesora las primeras horas de clase, intenta responder cuando ella le hace alguna pregunta y sonríe continuamente. Amani no para de rellenar las hojas de vocabulario que le entregan los maestros en clase.

En segundo lugar, reflexionamos sobre la implicación afectiva de este tipo de interacciones entre iguales, de forma especial en el que llega nuevo a un grupo. Cuando a un niño o niña se le pregunta "¿cómo te va en la escuela?" lo normal es que la respuesta se refiera a los aspectos relativos a la vida escolar. Suelen hablar del recreo, de las clases de educación física, de las "fechorías" que realizan en los pasillos cuando el docente no está. Woods (1990) dice que cuando a los niños se les pregunta "¿por qué les gusta el colegio?" se refieren a los juegos y deportes que se practican en la escuela. En nuestro estudio detectamos lo mismo respecto a este aspecto. Los chavales aceptan que el colegio sirve para aprender, sin embargo, en lo cotidiano, sienten que lo más importante es la vida social que desarrollan allí. Estas respuestas encuentran su explicación en la aparición del placer y de la emoción de las relaciones en un marco restrictivo para las mismas. Montandon (1992) habla del atractivo de la interacción prohibida, ya que fuera de clase estas interacciones no tendrían el mismo valor. De esta manera, el autor explica que estas interacciones entre iguales que ocurren en clase (a pesar del adulto), contribuyen a la socialización de las emociones, poniendo en práctica otros modelos que aquellos que la institución impone expresamente. Vásquez e Martínez (1996) aventuran una hipótesis al realizar varias etnografías escolares en diferentes lugares. Ésta se refiere a que las relaciones de poder provocan, entre aquellos que no poseen el poder, un cierto placer en desafiar ese mismo poder, pero a condición de que no parezca que lo están haciendo (Vásquez e Martínez, 1997, 130). Se trataría entonces de pequeños tanteos que permiten probar hasta qué punto el profesor no se entera de que lo están desafiando. Desde la teoría del interaccionismo simbólico se podría decir que los iguales están reconstruyendo los modelos impuestos por la institución y al llevarlos a cabo los están modificando a su manera.

Estas interacciones horizontales permiten al alumnado inmigrante construir nuevas relaciones y lazos entre pares. Estos tres alumnos nuevos se sienten más vulnerables a la autoridad, se sienten desposeídos de poder y, además, al ser de otro país, les cuesta más comprender las normas y códigos de la escuela. Las interacciones entre iguales suponen, de alguna manera, una vía de salida ante esta tensión. Necesitan compartir estos códigos con sus compañeros y compañeras para 
ir formando lazos afectivos y sabemos que la amistad se genera participando de estas interacciones entre iguales. Este tipo de relaciones despierta seguridad en los alumnos nuevos al sentirse partícipes del entramado relacional que les rodea. Además, en estas situaciones suele aparecer el humor que puede aliviar el estrés que los primeros días pueden llegar a sentir. Así, por ejemplo, vemos cómo Joseph una vez pasado el primer día de clase, se esfuerza por participar en estas relaciones horizontales, dibujándose monigotes en la mano para enseñárselo a los niños, haciendo cosquillas a las niñas y repitiendo las acciones que ve que hacen gracia en otros compañeros. Unos días después empezó a realizar los rótulos de los carteles con los nombres de los niños. De alguna manera lo que Joseph estaba haciendo era darse a conocer. Por un día se había sentido "invisible" y de repente, en la medida que los demás le pedían rótulos, comenzaba a sentirse valorado y a construir un papel en el grupo. En todos los casos observamos el despliegue de diferentes estrategias por parte de los niños y niñas nuevos para conseguir una existencia social dentro del grupo.

En tercer lugar, constatamos los continuos esfuerzos del alumnado por mantenerse sentados y controlando el cuerpo en las clases. Ya explicábamos en el apartado sobre los recreos la represión corporal que tenía su válvula de escape en el patio. En las clases observábamos continuas muestras del esfuerzo que esto les exigía y los movimientos compensatorios a los que recurrían: dejar caer lápices al suelo, ir a sacar punta a la papelera continuamente, estirarse, rascarse, mover las piernas, los pupitres, etc. Podemos decir, por tanto, que las interacciones horizontales surgen también como respuesta al aburrimiento y cansancio, donde la regla social impuesta por la institución escolar es la inmovilidad.

Los alumnos inmigrantes nuevos de nuestro estudio observan estas acciones los primeros días con un asombro posiblemente proporcional al umbral de tolerancia que los maestros de los colegios de sus países tuvieran. En el caso de Amani, las clases en su colegio de Marruecos eran mucho más estrictas que las españolas. Incluso se utilizaban castigos violentos a los escolares que no se sometían a la disciplina establecida por el superior ${ }^{2}$. El choque cultural respecto a este aspecto fue más notable para esta alumna que para Joseph (el cual encontraba más similitud con las clases recibidas en Bulgaria).

Otro tema emergente al que llegamos tras el análisis de muchas sesiones en la escuela es el de las oportunidades que brinda el profesorado para favorecer las interacciones entre iguales. En general, apreciamos que domina la

\footnotetext{
2 Esta información la obtuvimos de la propia alumna en una de las sesiones compartidas con ella en la asociación de inmigrantes DESOD.
} 
creencia de que el alumnado sólo puede aprender del adulto. Esta creencia se basa en la vieja idea de cómo adquirir el conocimiento. Se ha tendido a pensar que en la escuela sólo se producen aprendizajes académicos procedentes del profesorado. Hoy en día sabemos que para la adquisición de conocimientos es imprescindible el papel activo del alumnado. Un escolar aplica los conceptos que se le transmiten a través de la interacción con el entorno social, tal y como vienen constatando diferentes estudios desde el trabajo de Vygostky.

En los casos observados apreciamos que dominan las organizaciones clásicas y son poco habituales otro tipo de metodologías que propicien las relaciones entre el alumnado. En este ambiente, los niños y niñas inmigrantes tienen menos posibilidades en el aula de interactuar con otros y verse acogidos por sus iguales. Este es un ejemplo de cómo los códigos y usos verticales no facilitan la integración.

En los pocos casos en que hemos visto tareas en grupo hemos podido apreciar el valor de las mismas y cómo los estudiantes se organizaban y compartían información de forma más rápida y eficaz que cuando el peso de la tarea recaía sobre el adulto. En estos trabajos hemos comprobado cómo niños como Joseph aprovechaban para mostrar sus capacidades, constituyendo oportunidades de ser valorados por el resto.

Consideramos importante, el otorgar importancia a estas interacciones dentro de la institución escolar. Éstas coexisten inevitablemente de forma paralela a la relación docente-discente, suponen una fuente afectiva necesaria para el desarrollo del alumnado y contribuyen a la socialización escolar del mismo. Sin embargo, la institución escolar actúa como si no existieran, como si fueran invisibles, minimizando su importancia. Quizá sea necesario que el adulto fije la mirada en ellas, les preste atención y no las elimine dentro de sus categorías de aprendizaje establecidas.

La escuela podría enfocar la socialización y la integración escolar de manera más global si tuviera en cuenta el potencial de estas interacciones y no actuara pensando que éstas apartan al alumnado de los "verdaderos aprendizajes". Sería bueno que percibiera el significado de estas relaciones, sus matices, su amplitud, los roles que ocupan los diferentes protagonistas de la escena escolar y cómo manejarlo para mejorar la integración escolar de los alumnos que llegan nuevos al centro.

\section{2.- De la dependencia a la autonomía en el funcionamiento del alumnado nuevo}


Si analizamos las relaciones de primer grado (profesorado-alumnado como mediador instruccional y del escolar como aprendiz) vemos que se trata de una relación profesional en la que se establecen dos roles personales que cada uno ocupa en el proceso de enseñanza-aprendizaje. Lo que se intenta es que exista una relación educativa eficaz con la que conseguir su integración social y rendimiento académico dentro del grupo. Esta relación va volviéndose cada vez más academicista conforme aumenta la edad y el nivel escolar, es decir la relación personal va disminuyendo a medida que se sube de nivel educativo.

Los niños y niñas nuevos procedentes de otros países necesitan ayuda personal y afectiva del docente y ésto va creando cierta dependencia socioemocional en estos escolares los primeros días de clase. Esta dependencia con el adulto va desapareciendo de forma paralela a la adquisición de otros lazos con sus iguales. La intensificación de la amistad con sus compañeros y compañeras disminuye la necesidad de atención del adulto.

Existen múltiples factores que influirán en el grado de esta dependencia. En nuestro caso hemos apreciado que los escolares inmigrantes nuevos demuestran una autonomía diferente. Los tres necesitan recibir respuestas de aprobación por parte del adulto, pero de formas diversas:

- Los relatos de las actas nos informan de la necesidad constante de Joseph de agradar a sus compañeros y compañeras, incluso inflingiendo algunas normas leves establecidas por el adulto.

- Nos alertan también de la búsqueda de aprobación del profesorado por parte de Amani, importándole más la valoración de éstos que la de sus iguales.

- Nos explican también la autonomía de Willy en el funcionamiento rutinario escolar. La diferencia de este alumno respecto a la de los anteriores se encuentra en su situación de repetidor que hace que se mueva por las instalaciones con mayor agilidad que los anteriores y que domine el idioma por ser latino, pero a su vez, demuestra menos habilidades sociales para integrarse en el nuevo grupo donde le ha tocado permanecer. Demuestra necesidad y dependencia tanto de sus compañeros como de los adultos, sobre todo de los primeros.

Todos ellos van ganando en autonomía a medida que avanza el curso. Entendemos que debido al progresivo conocimiento, adaptación y comprensión de significados de las normas y rutinas de la cultura escolar.

Las reflexiones realizadas al desarrollar este estudio, nos permiten establecer como facilitadores de la autonomía de estos alumnos inmigrantes tres factores fundamentales que serán desarrollados en los siguientes tres subapartados: 
3.2.1.- El conocimiento del espacio físico y de los significados atribuidos por la cultura de los iguales a los mismos (las filas, el patio, los servicios, las aulas, los pasillos).

3.2.2.- La lengua y los códigos culturales utilizados por los profesores y por los iguales (bromas, abreviaturas, motes, etc).

3.2.3.- La relación del alumnado nuevo y el profesorado y la coordinación en las acciones docentes.

\subsection{1.- Conocimiento y comprensión del significado de los espacios físicos del centro escolar}

Como se ha explicado en el apartado dedicado al Plan de Acogida, una de las primeras acciones que las profesoras de compensatoria desarrollan con los alumnos que llegan nuevos al centro, es recorrer el camino desde la entrada del colegio a la clase. Con ello pretenden que memoricen el trayecto para que puedan realizarlo ellos solos. Acto seguido se les presenta a un estudiante veterano procedente del mismo país que él, para que se entienda con el idioma y le tenga como punto de referencia. El progresivo conocimiento de los espacios donde se tiene que desenvolver permite al alumnado nuevo moverse con más seguridad (así lo hemos constatado atendiendo a la evolución de su gestualidad durante los primeros días).

De forma algo más lenta al conocimiento físico de los diferentes lugares escolares, el alumnado va atribuyendo significados a cada uno de estos espacios. Así, por ejemplo, los servicios no sólo son un lugar en el que ir a hacer necesidades, sino también es un espacio donde ver a los alumnos de otras clases, donde juguetear con el agua y en el que infringir los códigos verticales de los adultos. Esta infracción permite intensificar interacciones de los niños que van al servicio. A su vez, no todo el alumnado va al aseo con este fin. Las niñas y los niños más formales suelen utilizarlo sólo para usos convencionales. Los que van a enredar suelen ser los que presentan menos tolerancia a la norma del adulto. Amani no usaba el servicio como espacio donde relacionarse con otros. Sus conductas en el centro se sometían obedientemente a la norma establecida por el adulto. Sin embargo, Willy y Joseph, conforme pasaba el tiempo, se iban acercando a este espacio con el fin de interactuar con algunos alumnos de otras clases. Interpretamos que algunos relacionan, infringir la norma leve del adulto, con realizar una "heroicidad" de cara a sus compañeros. Quien incumple alguna de estas normas del adulto será considerado como "uno de los nuestros". Esto lo vemos en frases extraídas de las actas como esta: 
9:45h: Cambio de clase para ir a Educación Física. Como el profesor tarda un poco, se queda encargada la misma niña de siempre. Empiezan a armar bulla, a hacer bromas y a tirar algún papel a lo lejos. De repente se oye: "cuidado que hay una profesora" (refiriéndose a mí).

(Diario 2 de Octubre 2006)

Vemos cómo en algunos casos se generan lazos de camaradería contra el adulto, se sienten identificados entre los iguales y tienen una fuerte necesidad de ser considerados por los demás como miembros importantes del grupo. La consolidación de estas relaciones supone una fuente de desarrollo de la autoestima del niño. Podemos imaginar que la necesidad de aprobación aumenta en el caso del alumnado recién llegado al grupo. Las acciones para agradar en ocasiones se intensifican y se reflejan en comportamientos como los de ir a los servicios entre clases a enredar con otros, lanzar papeles desde lejos en el aula, tirar cosas al suelo para al recogerlas hacer alguna señal a otros o pasarse notas en clase; en general acciones que sean consideradas como de rebeldía hacia el superior. Joseph y Willy, siendo nuevos, han aprendido estos códigos rápidamente, incluso antes de aprender el idioma, como es el caso de Joseph.

A medida que estos alumnos nuevos se van incorporando a la cultura escolar van usando los diferentes espacios en función de la necesidad de interacción con sus compañeros.

\subsection{2.- La lengua y los códigos culturales utilizados por los profesores y por los iguales (bromas, abreviaturas, motes, etc).}

Existe una diferencia cualitativa entre conocer el idioma de la población mayoritaria donde uno va a integrarse y el conocimiento de los códigos de comunicación de esa cultura. Los estudiosos del análisis del discurso como Iñiguez (2003), nos informa de las implicaturas en el lenguaje. Éstas conllevan una intención comunicativa que es imposible conocer si no conocemos los rasgos sociales y culturales que rodean al lenguaje. Este es el caso de nuestros alumnos inmigrantes nuevos. No sólo les bastará con conocer la lengua para integrarse sino que deberán hacerse cómplices de estos aspectos contextuales de la comunicación.

Observamos diferencias en cuanto a los tres alumnos que seguimos. En este aspecto, Willy, ya conocía el idioma por ser hispanohablante; Joseph, no hablaba español, pero sí inglés, y su padre le ayudaba en casa a aprender el español; Amani, en cambio, se encontraba en una situación de desventaja debido a que no hablaba español y su familia le castigaba si lo hacía. Por tanto, el conocimiento del idioma y de los aspectos culturales de la lengua se desarrollaron antes en el caso de Joseph, que en el de Amani. Existen, como vemos, ventajas familiares, académicas, incluso de habilidades personales que lo favorecen. A pesar 
de las ventajas de este chaval, Joseph vivió situaciones en las que no podía participar debido al desconocimiento de los códigos culturales de la escuela y de los iguales. Veamos algún ejemplo ilustrativo de esta reflexión.

9: 50h: Cambio de clase. En el intervalo de tiempo que transcurre en la clase entre la salida de un profesor y la llega del siguiente, la profesora deja encargada a Elena (una alumna de la misma clase) para que el resto de los alumnos no se alboroten. Se pone de pie en el encerado con una tiza en la mano para apuntar a quien hable. Los niños empiezan a gastar bromas, ella se ríe y entre risas dice: "Un poquito de Fujitsu en la sala, por favor", los demás se ríen. Ella empieza a imitar a la profesora como para conseguir que se callen: dice: "Callaos todos o os separo". Joseph mira y sonríe, pero no entiende el sentido de estas risas. Elena tiene interiorizados los códigos internos del grupo, sabe cómo decir que se callen, pero sin quedar como la "empollona" aliada con la profesora. Todavía tiene que pasar bastante tiempo para que Joseph entienda, no sólo el significado de "Fijitsu", sino todo este "argot" intragrupo, que, mucho más que un lenguaje, es una construcción de códigos sociales, culturales, generacionales que tejen los nexos entre iguales. Posiblemente, esta integración sucede de repente, un día, como por arte de magia, llegas al aula y el niño es partícipe de todos estos símbolos culturales que unen si los compartes y separan si no participas de ellos.

(Diario 13 septiembre 2006)

Este relato nos muestra cómo la comunicación que existe entre iguales va mucho más allá del simple conocimiento de la lengua, es un hecho profundamente cultural en el que las bromas y los dobles sentidos sólo son entendidos por los que conocen esta cultura, y aún más, esas bromas sirven para establecer jerarquías, generar una imagen ante los demás, mantener alianzas 0 afianzar nexos. Joseph en esos primeros momentos estaba fuera de todo ello.

La forma de acceder a estos intracódigos se va produciendo mediante la imitación y el uso adecuado de las habilidades sociales de cada persona. Los refuerzos 0 castigos sociales constituirán un verdadero aprendizaje para las interacciones sociales mediante el ensayo-error. Así por ejemplo vemos cómo Joseph intenta participar en las interacciones entre iguales mediante el despliegue de las habilidades sociales que posee, gastando bromas e imitando las conductas que ve de los otros compañeros.

Joseph, los últimos cinco minutos de la clase, se ha dibujado un monigote gracioso en el dedo. Llegada la hora de cambiar de clase y bajar al gimnasio para ir a la clase de Educación Física se quedan unos minutos solos sin profesor. Joseph se levanta y le enseña el monigote que se había pintado en la mano a una niña que 
se sienta a su lado. Ésta se ríe. Instantáneamente, al ver que hace gracia, se 10 enseña a un niño al cual no le hace gracia, lo mira y pasa de él sin decirle nada. Acto seguido deja de enseñarlo a más gente. Llega el profesor y se ponen en fila dentro de la clase, dispuestos para salir.

Joseph se pone en la fila de los primeros y empieza a atrapar a un compañero por la espalda en forma de juego. Ha visto que es lo que hacen ellos los otros días para quitarse el primer sitio de la fila. Él le atrapa pero sin saber que es para quitar el sitio de la fila. De hecho luego se coloca más atrás. Otro código que ha entendido: para integrarse en el grupo de los chicos hay que relacionarse con contacto corporal, normalmente a golpecillos. Lo del monigote no hizo gracia a los niños pero sí a las niñas y lo de atrapar por la espalda hace gracia a los niños, pero no al revés. Todo este aprendizaje intragrupal, contextual, acuciado por una necesidad en el chaval no aparece en los manuales.

(Diario 19 de Septiembre 2006)

Este fragmento nos muestra detalles de cómo se va produciendo la socialización escolar en este alumno nuevo. Vemos que el ensayo-error, la risa ofrecida por sus compañeros como refuerzo a sus acciones e indicador del efecto de las mismas, o la imitación de las conductas aprobadas por otros niños o niñas son los mecanismos con los que el alumno nuevo va integrándose en la cultura de iguales.

\subsection{3.- La relación del alumnado nuevo con el profesorado y la coordinación en las acciones docentes}

Este aspecto es muy importante también para el funcionamiento autónomo del alumnado nuevo. Conocer el rol que desempeña cada docente ayuda al niño o niña a saber dirigir las interacciones adecuadas. En un primer momento, es necesario, que los escolares nuevos conozcan quiénes son los profesores y profesoras y qué función desempeña cada uno de ellos y ellas dentro de su proceso de enseñanza-aprendizaje.

En nuestras observaciones apreciamos que las primeras semanas existía un poco de confusión para los dos alumnos inmigrantes nuevos en el centro sobre el rol que ocupaba cada uno de los docentes. Al principio no sabían a quién pedir ayuda y, en caso de hacerlo, acudían a mí. Después, conforme me fui alejando, fueron pidiéndosela a la profesora de compensatoria que era la que llevaba un seguimiento más detallado de estos alumnos. En el caso de Joseph y Amani pasaban buena parte del día en las clases de apoyo con esta maestra, tenían una relación más cercana. Ella mantenía un mayor seguimiento de su proceso de aprendizaje y una atención mayor a los aspectos relacionales que el profesorado de 
otras áreas. No es de extrañar que se diera una relación de dependencia de estos escolares. Apreciamos que el trato que esta maestra mantenía con ellos favorecía los vínculos afectivos. Así, pudimos observar cómo el alumnado de otros años abrazaba a la profesora por el pasillo cuando la veían.

Los tutores respectivos eran el segundo conjunto de adultos con el que más confianza fraguaron, apreciando que con el resto de docentes apenas entablaban relación más allá de lo relativo a la materia impartida.

En los casos observados hemos apreciado que la diversificación y la existencia de muchos docentes facilitan la descoordinación y las lagunas en el proceso de enseñanza aprendizaje de cada uno. Desarrollaremos con más detalle esta idea en el apartado siguiente. interesantes:

De lo descrito anteriormente extraemos dos ideas que nos parecen

- La búsqueda por parte de los niños y niñas nuevos de un adulto que les acoja, le sientan cercano, les dé seguridad y les permita establecer un nexo de confianza suficiente como para preguntarle cosas o acudir en caso de problemas.

- Por otra parte, nos encontramos que, dada la estructura organizativa de los centros (distribución del profesorado por materias, aulas de apoyo, espacios especiales...), suficientemente compleja para un niño o niña nuevos, se hace necesaria una mayor coordinación entre el profesorado para simplificar este proceso y atender a estos casos personales. Sobre este tema nos detendremos a continuación.

Observamos que la coordinación entre el profesorado para atender los procesos de enseñanza-aprendizaje del alumnado nuevo podía ser un aspecto crucial en cuanto a la calidad de la enseñanza que los alumnos nuevos podían recibir. Presentamos a continuación algunos casos que reflejaban la existencia de un vacío de funciones entre tutores y la maestra de compensatoria.

En diciembre, el centro organizó una excursión para visitar la biblioteca de la ciudad. Yo llegué al colegio. Las clases de $5^{\circ}$ estaban vacías. Decidí entonces buscar a la profesora de compensatoria para que me diera alguna información de los alumnos nuevos. Me sorprendió ver a Amani y a Joseph en la clase de apoyo. Eran los únicos que no habían ido a la excursión. Amani, porque su madre no la había dejado y no había llevado el dinero necesario para realizar la salida. Joseph, porque el autobús salió sin que él estuviera montado. La profesora interpretó su ausencia como que el alumno no deseaba ir. Fue un malentendido entre Joseph, la profesora de compensatoria y la tutora. Cada una delegó en la otra la tarea de informarle de la excursión. La conclusión fue que se quedó sin ir y él se sintió ofendido. Sucedió algo 
parecido el día que el centro organizó una visita al dentista. Joseph y Amani de nuevo estaban en el centro y no acudieron a tal evento.

Estos sucesos reflejan cómo los aspectos organizativos pueden influir en que se reduzcan los momentos en que los alumnos nuevos podrían establecer vínculos e interacciones horizontales más fuertes con sus iguales. Por otra parte, suponen mensajes de diferenciación que son claramente interpretados por estos escolares como de minusvaloración.

Veamos algunos detalles más que nos muestran esos pequeños vacíos:

9:50h: Cambio de clase. Tienen Religión. Marta se lleva a los de alternativa. Me pregunta qué hace con Joseph. Le digo que en la reunión de acogida con los padres se quedó en que iría a alternativa, porque su religión es la ortodoxa.

(Diario 14 Septiembre)

12h: El profesor entrega unas fichas para que las rellenen. Amani las mira y las vuelve a dejar en la mesa porque no sabe cómo hacerlo. Ana, la niña que jugó con ella en el recreo, dice al profesor: "Y ella qué hace, si no sabe rellenarlo". El profesor: "pues nada, no puede hacer nada, isiéntate anda!". Se oye un alboroto general, los niños están alterados. El profesor se acerca a mí unos minutos más tarde y dice: "¿con esta niña qué hay que hacer?"

(Diario del 14 Septiembre 2006)

\section{3.- Expectativas y prejuicios del profesorado y del alumnado expresados en el aula hacia los estudiantes inmigrantes nuevos}

Este es otro aspecto influyente en las relaciones sociales más relacionado con procesos internos psico-sociales. Las expectativas en la clase tienen una doble vertiente: la que tienen los escolares del profesorado, y a la inversa, la del profesorado sobre el alumnado. Las primeras forman parte de la percepción que tiene el alumnado del profesorado, se producen a partir no sólo de las experiencias vividas sino de la "leyenda" que exista de cada uno. Las segundas, hemos apreciado que tienen una gran influencia en la opinión que unos escolares se van conformando de otros. Así, las entrevistas, observaciones y resultados sociométricos nos permiten llegar a afirmar que el estatus social de cada escolar está marcado en gran medida por las expectativas que el docente deposita en ellos.

Las expectativas depositadas en Joseph fueron mucho mayores que las depositadas en Amani y en Willy. ¿A qué se deben estas diferencias en las atribuciones perceptivas? Hemos interpretado que pudieron influir los siguientes factores: 
- En primer lugar la disposición de cada uno de los alumnos, las habilidades sociales y el carácter abierto mostrado al exterior son muy importantes para generar y recibir valoraciones positivas. Joseph cuenta con un amplio repertorio de recursos para hacer amigos, de lo que carecen tanto Willy como Amani.

- Otro aspecto que pudo influir fue el hablar inglés. Esto fue muy valorado por los docentes que admiran a un niño que hablaba una segunda lengua, ya que ninguno de sus alumnos 0 alumnas lo hace.

- El saber que en su colegio de procedencia obtenía buenos resultados académicos fue decisivo para que el profesorado le mirara con buenos ojos desde el principio.

- La presentación previa de Joseph, realizada por los profesores al grupo de referencia, creó cierta expectación por la llegada de un alumno nuevo.

- El efecto novedad que se produce en un grupo al recibir a alguien nuevo también produjo una curiosidad que causó cierto protagonismo del niño las primeras semanas. Además, esta expectación positiva generada por la profesora se vio correspondida con la respuesta habilidosa de Joseph. La entrada de Amani y Willy al grupo de iguales, sin embargo, no fue tan "exitosa". En el caso de la alumna, por la timidez e inexpresividad demostrada con los demás. En el caso de la alumna, dominicano repetidor, Willy, por el olvido por parte del profesorado de presentarle al grupo.

Posiblemente, todas estas impresiones fueron generando en los docentes una concepción positiva hacia este alumno. A su vez, los refuerzos utilizados por el profesorado a este alumno durante las clases van generando y contagiando al alumnado una valoración también positiva.

Como se podrá observar en los ejemplos que a continuación se citarán, Joseph ha podido seguir un ciclo de expectativas positivas que retroalimentaban las actitudes que hacia él tenían docentes y compañeros, cosa que no pasó con Willy. Éste vivió un ciclo totalmente diferente. Para empezar, no fue presentado por los profesores en su grupo de referencia, es repetidor, no tiene demasiadas habilidades de comunicación, es un niño tímido. Sin embargo, conoce la lengua y la cultura escolar porque éste será su segundo año en el centro. Esta situación de partida le hace recibir menos refuerzos positivos por parte de sus compañeros y docentes.

El caso de Amani es totalmente distinto. No conoce la lengua, es bastante tímida, su situación familiar es inestable y desestructurada, y procura actuar con cierta desconfianza a la hora de establecer relaciones sociales. Además, su familia 
no otorga demasiada importancia a la escuela y le limita en el aprendizaje del idioma.

Veamos algunos ejemplos en los cuales los compañeros o compañeras y docentes reflejan expectativas distintas hacia estos alumnos.

11:10h: Se colocan en fila para salir al recreo. Un niño se acerca y me dice: "icuánto ha mejorado Joseph!, ¿eh?"

(Diario 28 de Septiembre 2006)

Joseph se cae al salir del salto de la cuerda. Las niñas gritan: "Joseph se ha hecho daño", pero a él se le pasa enseguida, no se recrea en la atención que se le podría dar si se queja más.

Los niños están juntos por un lado y las niñas por otro. En la fila están todas las niñas juntas y todos los niños juntos. Las niñas pelean para que Joseph se ponga en su equipo. Los niños también intentan conseguir a Joseph en su equipo. Willy, sin embargo, está al final, sin recibir atención de nadie, ansioso por ver dónde se pone. En este caso las niñas tienen más poder en la actividad (dominan más el salto a la comba) y se salen con la suya.

(Diario 2 de Octubre 2006)

El profesor está explicando una actividad que deberán realizar en grupo. Un niño pregunta en alto: “¿Joseph también va a hacer la actividad?". Responde afirmativamente el profesor. "iiBien!!", dice el niño.

(Diario 13 de Septiembre)

10:10h. El profesor de Conocimiento del Medio está explicando una actividad que deberán realizar. Dice que lo hagan con el compañero que tienen al lado. El compañero de Willy hace un gesto con la cara y la mano pareciendo estar bastante desconforme. Dice al profesor: "iEs que él no sabe hacerlo!" El profesor no le hace caso y continúa explicando.

(Diario 23 de Septiembre 2006)

13:15h. El profesor está preguntando sobre el tema que vieron el día anterior. Alguno levanta la mano. El profesor va nombrando a algunos niños para que contesten. Willy no recibe ninguna mirada, ni realiza intervenciones en toda la hora de clase.

(Diario 14 de Septiembre 2006)

Las expectativas de los docentes sobre el alumnado son conocidas como el "Efecto Pigmaleón" y se relaciona con la "profecía autocumplida" como se demostraría a partir de los trabajos de Rosenthal y Jacobson (1968), en el sentido de que las expectativas que tiene el profesorado de los escolares suelen cumplirse por sí mismas aunque no guardan, en principio, ninguna relación con la realidad. No 
es sólo la expectativa la que actúa, sino el mantenimiento de la misma, y la percepción que tienen los escolares sobre que esa atribución sea congruente con su propia imagen. Algunas actuaciones de los docentes que pueden ser asimiladas por el alumnado son: la diferencia de atención que presta a unos alumnos u a otros, la dificultad de las preguntas que dirige dependiendo del niño o niña que se trate, el tiempo que les deja para responder, la adecuación del refuerzo otorgado a cada uno. Todas estas conductas educativas van configurando un currículum oculto que el alumnado irá introduciendo de forma inconsciente en sus aprendizajes.

Los prejuicios constituyen una fuente principal para generar en el profesorado expectativas hacia su alumnado. El discurso que los escolares reciben en la escuela es bastante favorable si lo comparamos con los mensajes con los que posteriormente son bombardeados en la sociedad. En este contexto, podríamos decir que los mensajes, en general, son favorables para la interacción cultural. Sin embargo, también se dan conductas que reflejan que este debate intercultural no está del todo superado. Dentro de la institución escolar existe también una gran diversidad en cuanto al profesorado. Nos encontramos con diferentes años de experiencia entre los docentes, con varias generaciones, diversas formaciones iniciales y continuas y distintas concepciones de la educación. Todas estas cuestiones van formando al profesional de la educación unas ideas acerca de los temas escolares y, consecuentemente, de la integración de las minorías culturales.

En nuestro caso, en general, podemos decir que existe una buena predisposición del profesorado para recibir inmigrantes. Tienen preparado un buen plan de acogida y esto produce una sensibilización. Sin embargo, es difícil luchar con las ideas que algunos se hayan podido formar acerca del alumnado inmigrante. Veamos algún relato en el que los prejuicios hacia un determinado colectivo cultural pueden dirigir las interacciones, refuerzos y expectativas hacia determinados alumnos durante las clases.

Los alumnos están en clase de Educación Física jugando al Badminton. Unos monitores especialistas en este deporte están enseñándoles a los dos grupos de $5^{\circ}$ juntos a jugar a este deporte. Los profesores están presentes en la clase pero no intervienen en la enseñanza del deporte, únicamente controlan la disciplina para ayudar a los monitores a que realicen su tarea. Describimos un suceso en el que se demuestra la idea preconcebida de este maestro acerca de los alumnos inmigrantes latinoamericanos, como es el caso de Willy.

Se ponen de pareja Joseph y Willy para jugar al badminton. [...] La dinámica es la misma que la anterior: juego libre por parejas al badminton sin que nadie les diga nada. 
Joseph choca la mano con Willy cuando hacen una buena jugada. Vemos más arranque y determinación que Amani para interaccionar con los demás y caer bien a los demás. Joseph juega haciendo el tonto, sin tomárselo en serio, sabe que no es una actividad en la que se juega la aceptación de todos como en el caso del fútbol (en el que se lo toma muy en serio). Ahora está haciendo equilibrios con la raqueta (pienso que para ser observado). Los golpeos que da, los da sin pensar en que el otro los reciba, tira muy fuerte y alto. Willy no puede dar ninguna en esas condiciones de pase.

La niña que está en el otro campo, sin querer le da con la raqueta. Le suplica perdón, él se enfada, la riñe y se va a su sitio a seguir jugando. Unos minutos más tarde pasa por allí de nuevo y hace ademán de darle con la raqueta como para vengarse.

Willy no lo hace mal, da bastantes toques, trabaja mucho cada devolución (teniendo en cuenta los pases tan malos y difíciles de Joseph) y mira al profesor para ver si le mira cuando lo hace bien.

El profesor se acerca a mí y me pregunta en qué consiste exactamente el estudio que yo estoy haciendo, se lo explico, me hace las siguientes aportaciones: "Los inmigrantes del Este no tienen problemas para integrarse, se esfuerzan mucho. A los latinos, sin embargo, les cuesta mucho más, son más "vaguetes"'.

Al instante, Willy y Joseph, que están al lado nuestro jugando, están peleando a modo de juego para coger el volante. Joseph viene hasta su zona y con la raqueta lo intenta coger. El profesor le dice: "Willy, tienes que agacharte a por el volante, que por ahora no tienes mando a distancia". Willy asiente y sigue jugando.

Yo, que he estado viendo toda la acción de Joseph y Willy y sé que Willy se ha esforzado mucho más que Joseph a la hora de pasar y de recoger el volante imagino que a Willy ese comentario le deja tocado. ¿Será el prejuicio acerca de los latinos lo que le ha hecho presuponer al profesor que no se molestaba en recoger el volante cuando sí lo estaba haciendo durante toda la clase?

(Diario 19 de Septiembre 2006)

Este es un caso claro en el que la expectativa está marcada por el prejuicio. Tanto es así que su idea le impide ver y valorar en su justa medida la situación real sucedida respecto a este alumno Dominicano. La consecuencia de ello será que los refuerzos e interacciones que utilice con el alumno durante el horario escolar irán dirigidos conforme a esa idea previa. Esto, a su vez, también es percibido por el resto de niños y niñas que acabarán por creérselo y podrá incluso convertirse en realidad. Por supuesto este es un hecho aislado, las teorías psicológicas nos explican que sólo mediante la persistencia en el tiempo de este tipo 
de refuerzos se convertirá en realidad esta percepción del profesor. La realidad es que los alumnos tienen más de un docente y por consecuencia, más oportunidades de crear imágenes diferentes. Así, por ejemplo, en el aula de compensatoria los estímulos que recibe son totalmente diferentes. Algunas situaciones educativas consiguen sacar lo peor de los estudiantes: inseguridad, ansiedad, torpeza, lentitud en sus respuestas. Otras, sin embargo, favorecen el rendimiento y las interacciones sociales.

Observando al hermano pequeño de Amani en su clase, vimos que los marroquíes tampoco gozaban de muy buena fama entre algunos docentes. Las expectativas lanzadas hacia ellos en este caso no fueron nada favorables.

Están en clase cogiendo pegatinas y poniéndolas en unos huecos dedicados para ello en el libro que todos, salvo Maluf, tienen. Este niño lleva todo el día coloreando dibujos que la maestra le va pasando continuamente para que no esté sin hacer nada. Después de acabar un dibujo se para antes de empezar otro y mira a los demás, señala el trabajo de la niña de su lado como queriendo pegar él también y cambiar de actividad.

Señala a la niña el hueco para pegar la pegatina, la niña no hace ni caso (se tiene que sentir diferente por fuerza al no hacer lo mismo que los demás, incluso lo que puede hacer sin necesidad de conocer el idioma, al no tener libro, al sacarle luego a apoyo a él solo).

Maluf hace un gesto hacia la profesora señalando un dibujo en blanco, no sabe si tiene que colorearlo o no. Como no habla, sólo hace gestos, ella no se entera, así que se queda sin hacer nada esperando. Al rato, cuando pasa la profesora ve que le falta uno por colorear y hace el siguiente comentario: "Este hace honor a su raza: se cansa enseguida. Era más trabajador al llegar que ahora."

(Diario 2 de Octubre 2006)

Por supuesto, éste es un hecho aislado, con el que no pretendemos asumir que el prejuicio hacia los árabes sea general. Existieron otras situaciones en las que se lanzaban refuerzos totalmente distintos. Sin embargo, ejemplos como éstos nos siguen chocando mucho, máxime al compararlos con los refuerzos que continuamente recibían niños como Joseph:

Están en clase de francés. Repiten la actividad de ayer en círculo con alguna variante. Tienen que decir su nombre en francés y preguntar el de otro compañero o compañera mientras le lanzan una pelota. La maestra dice: "Ianzadle la pelota a Joseph que lo sabe decir muy bien, ya veréis". Una niña se la lanza y Joseph lo dice bien. “¿Véis?”, dice la profesora: "ique rápido aprende y sin saber 
español todavía, ¿eh?", dice mirándome a mí.

(Diario 14 de Septiembre 2006)

Ya decimos que no podemos concluir rotundamente que exista un ambiente de prejuicios en el centro, todo lo contrario. Insistimos en este tipo de ejemplos para que el lector entienda lo que supone para un niño o niña nuevos en un centro, recibir un tipo de expectativas y refuerzos u otros. Se les puede hacer caer en una espiral descendente de desatención, desmotivación y marginación o en un ambiente de protección, seguridad y motivación.

Las técnicas sociométricas realizadas en el inicio y final del curso académico, las entrevistas a los niños y niñas de los grupos observados y las observaciones nos permitieron comparar la información referida a las expectativas. Si tenemos en cuenta que las expectativas y el estatus social están íntimamente relacionados (de alguna manera, el estatus reflejaría las expectativas existentes hacia los niños y niñas nuevos), los resultados de las técnicas sociométricas nos pueden aportar información sobre estos aspectos. Seleccionamos en los siguientes apartados algunos de los resultados de las técnicas sociométricas ${ }^{3}$ y de las entrevistas para indagar sobre estas ideas (en los anexos podemos encontrar los resultados generales de estas técnicas).

Los alumnos inmigrantes nuevos a los que realizamos el seguimiento obtuvieron los siguientes resultados sociométricos que adjuntamos a continuación. Estos datos fueron triangulados ${ }^{4}$ con el resto de instrumentos de evaluación (observación y entrevistas).

\section{Joseph}

- Joseph obtiene cuatro elecciones y ningún rechazo. De los 22 alumnos, sólo hay 4 que no tengan ningún rechazo y uno de ellos es Joseph.

- En el "adivina quién" es uno de los considerados como que más amigos tiene junto con Adrián, que le supera en dos votos.

- También tiene varios votos (3) respecto a la alegría, es decir es uno de los considerados más alegres de la clase. Joseph está considerado como un niño alegre, esa característica es muy valorada para ser aceptado.

- Estas calificaciones positivas las podemos confirmar en el ranking, en el que todas las puntuaciones que obtiene son muy buenas, salvo la de Pablo, que le ha puntuado con un 4 , es decir que le cae mal.

\footnotetext{
${ }^{3}$ Sociometría (detecta los más elegidos y rechazados), Adivina Quién (evalúa los rasgos positivos y negativos atribuidos a los compañeros) y Ranking (evalúa el estatus social que ocupa el alumnado dentro del grupo).

${ }^{4}$ Nos referimos a la triangulación de métodos realizada en la investigación.
} 
- Por otro lado, en el ranking, él también ha puntuado a todos los niños con un 1 , es decir, todos le caen muy bien, salvo Diego que le cae regular.

\section{Willy}

- A Willy apenas le votan para nada, salvo dos para rechazarle: los dos Adrianes y Joseph por preferencia de elector.

- Willy es rechazado sólo por dos personas pero justo por las dos más elegidas de la clase, por lo que lo tiene más difícil para acceder a los demás. Willy se ha acercado desde el principio a los líderes y ha hecho mucho esfuerzo por agradar, pero no le ha salido bien.

- Willy tiene muy pocas elecciones en el adivina quién. Sólo Blanca y Helena se han dado cuenta de que es el que menos amigos tiene o el más triste. Los demás no han caído en que existe para votarle, ni siquiera en lo malo.

- Willy apenas sale votado y, si sale, es para algo negativo. Ocupa uno de los peores puestos en el ranking.

\section{Amani}

- Amani obtiene dos elecciones y ningún rechazo.

- En el adivina quién es la considerada como la que menos amigos tiene, con 6 votos. 3 personas piensan que es la más triste, 2 que es a la que más quiere el profesor y 3 la que menos sabe.

- Ningún voto en lo demás.

- Los atributos no son muy positivos pero tampoco negativos. Lo podemos contrastar con la sociometría en la que no obtiene ningún rechazo. No es rechazada por ahora, pero tampoco se la considera con habilidades notables para integrarse en el grupo.

- En el ranking vemos que no cae muy mal a nadie. Sólo Alberto la pone mal, el resto muy bien, bien y algún escaso regular.

\section{(Extraído de las técnicas sociométricas realizadas con los tres alumnos a los que realizamos el seguimiento. Resultados obtenidos de: Joseph, Willy y Amani en la $1^{\mathrm{a}}$ prueba (a finales de Octubre 2006).}

En las entrevistas recogimos argumentos que explican los resultados de la sociometría y del cuaderno de campo. Estas declaraciones nos demuestran los diferentes juicios que tienen acerca de los alumnos inmigrantes nuevos. 
- Niña de $5^{\circ}$, compañera de clase de Joseph: "Joseph es muy majo. Además es muy listo, nos va a adelantar a todos en las notas del colegio... aunque a veces pega un poco cuando juega al fútbol."

- Niño de la clase de Willy: "Willy, ¿cómo te cae?, ¿qué piensas de él? "Ummm...bien. Casi no hablo con él, pero bueno, es que es muy tímido casi no habla".

- Niña de la clase de Amani: "¿Cómo te cae Amani, qué piensas de ella?". "Bien, es buena, yo juego siempre con ella en el recreo".

- Niño de la clase de Amani: "¿Cómo te cae Amani, qué piensas de ella?". "Bueno, nunca la he oído hablar y bebe cosas muy raras en el recreo. Bebe un zumo de un color y sabor muy raro...es un poco rara, yo creo."

(Extraído de las entrevistas realizadas el 17 Noviembre 2006)

Los procesos educativos se caracterizan por ser dinámicos. La estabilidad en la interacción social no existe. Durante el transcurso del curso escolar observado se produjeron cambios en cuanto al estatus social del alumnado. En el caso de Willy, estos cambios se hicieron más notables que en el caso de los otros dos. ¿Hacia dónde y por qué se produjeron dichos cambios?

A lo largo del curso escolar, las expectativas de estos tres alumnos fueron marcadas principalmente en los primeros meses. Sin embargo, conforme pasó el tiempo se sucedieron algunos cambios detectados con la observación y las técnicas sociométricas. Los cambios más notables se produjeron en Willy. Este alumno era bastante rechazado en los comienzos del curso. No le dejaban jugar al fútbol, se reían de él porque llevaba la misma camiseta que los días pasados, intentaban excluirle acusándole a la profesora de cosas que no había hecho, etc. Willy no sólo resistió todas estas conductas sin agredir a nadie, sino que sus esfuerzos y estrategias continuos por ser aceptado le permitieron ser uno más del grupo. A los tres meses, Willy jugaba en el equipo de fútbol, participaba en los trabajos de grupo y mejoró considerablemente sus resultados sociométricos. No llegó a ser un niño popular, pero sus puntuaciones sociométricas reflejan un gran avance en el estatus social. Joseph sin embargo, experimentó un cambio a la inversa, es decir, pasó de ser el niño más elegido durante el primer mes, a ocupar un lugar medio en el estatus social de la clase. Amani experimentó una mejoría leve en cuanto al estatus social a lo largo de los meses. Lo podemos ver en el anexo de la sociometría y en concreto en estos fragmentos seleccionados.

Joseph ha disminuido su popularidad. Temas relacionados: "efecto novedad", "despliegue de estrategias iniciales por parte de Joseph", "mal temperamento", "influencia del Plan de Acogida". 
Willy ha aumentado su popularidad significativamente, aunque no es popular, está mejor considerado que las primeras semanas de clase. Temas relacionados: "la constancia de querer ser aceptado", "el buen carácter", "el olvido de la influencia del nulo plan de acogida que tuvo".

Las puntuaciones respecto a Amani han mejorado levemente. Tiene una amiga segura que es Natalia. En un principio empezó siendo Ana Lucía, ahora está más con Natalia. Está bastante bien considerada por el resto de sus compañeros, pero tampoco la eligen para jugar o compartir tiempo.

(Análisis de los resultados del sociograma)

Para concluir este bloque sobre las expectativas resumimos en el siguiente cuadro los factores con los que estos tres alumnos fueron formando una imagen decisiva en las interacciones sociales y en la integración escolar.

\begin{tabular}{|c|c|}
\hline \multicolumn{2}{|c|}{ JOSEPH } \\
\hline $\begin{array}{l}\text { Aspectos que generaron expectativas } \\
\text { positivas }\end{array}$ & $\begin{array}{c}\text { Aspectos que generaron expectativas } \\
\text { negativas }\end{array}$ \\
\hline Hablar inglés & No hablar español \\
\hline Poseer habilidades sociales y de comunicación ${ }^{5}$. & $\begin{array}{l}\text { Conocimiento, pero no obediencia a los códigos } \\
\text { de la cultura de iguales. }\end{array}$ \\
\hline Extroversión, alegría y apertura a los demás ${ }^{6}$. & $\begin{array}{l}\text { Malentendidos con respuesta agresiva por no } \\
\text { conocer la lengua y algunos códigos. }\end{array}$ \\
\hline $\begin{array}{l}\text { Disposición para aprender códigos de la cultura } \\
\text { receptora. }\end{array}$ & $\begin{array}{l}\text { Acciones descoordinadas del profesorado que } \\
\text { dificultan la interacción. }\end{array}$ \\
\hline $\begin{array}{l}\text { Facilidad para entender algunos códigos de los } \\
\text { iguales para caer bien. }\end{array}$ & \\
\hline $\begin{array}{l}\text { Familia estructurada de la que, además, recibe } \\
\text { apoyo para las tareas escolares. }\end{array}$ & \\
\hline $\begin{array}{l}\text { Consideración dentro del Plan de Acogida: } \\
\text { Presentación previa por parte del profesorado al } \\
\text { resto del grupo. }\end{array}$ & \\
\hline
\end{tabular}

Tabla 9.2. Aspectos que formaron las expectativas de Joseph.

\section{WILLY}

\section{Aspectos que generaron expectativas positivas}

Aspectos que generaron expectativas

5 Pudimos comprobarlo a través de la sociometría.
6 Pudimos comprobarlo a través de la sociometría. 


\begin{tabular}{|l|l|}
\hline Hablar español & \multicolumn{1}{|c|}{ negativas } \\
\hline Buen carácter, agradable y tranquilo & Ser repetidor \\
\hline Conocimiento de los códigos de los iguales & $\begin{array}{l}\text { Timidez. No muchas habilidades sociales y de } \\
\text { comunicación. }\end{array}$ \\
\hline Obediencia y sumisión a los códigos de los iguales & $\begin{array}{l}\text { Baja competencia motriz por una lesión en la } \\
\text { pierna }\end{array}$ \\
\hline & Familia desestructurada \\
\hline & $\begin{array}{l}\text { Olvido de este alumno dentro del Plan de } \\
\text { Acogida: no se le presentó al resto del grupo } \\
\text { como compañero nuevo al inicio del curso. }\end{array}$ \\
\hline
\end{tabular}

Tabla 9.3. Aspectos que formaron las expectativas de Willy

\begin{tabular}{|c|c|}
\hline \multicolumn{2}{|c|}{ AMANI } \\
\hline Aspectos que generaron expectativas positivas & $\begin{array}{l}\text { Aspectos que generaron expectativas } \\
\text { negativas }\end{array}$ \\
\hline No sobresalir, no llamar la atención por nada & No hablar español \\
\hline Carácter tranquilo & $\begin{array}{l}\text { No interactuar con nadie que no se acerque a } \\
\text { ella e insista en ayudarla }\end{array}$ \\
\hline $\begin{array}{l}\text { Obediencia y sometimiento a adultos } \text { y } \\
\text { compañeros y compañeras }\end{array}$ & $\begin{array}{l}\text { Timidez. No habilidades sociales y de } \\
\text { comunicación. }\end{array}$ \\
\hline \multirow[t]{2}{*}{$\begin{array}{l}\text { Consideración dentro del Plan de Acogida: } \\
\text { Presentación previa por parte del profesorado al } \\
\text { grupo al inicio del curso. }\end{array}$} & $\begin{array}{l}\text { Falta de apoyo en casa en tareas escolares } \\
\text { (impedimentos a hablar español). }\end{array}$ \\
\hline & $\begin{array}{l}\text { Familia desestructurada, situación ilegal. Exceso } \\
\text { de responsabilidad de la alumna en casa }\end{array}$ \\
\hline
\end{tabular}

Tabla 9.4. Aspectos que facilitaron las expectativas de Amani.

Analizar los factores que generan un cambio de estatus social en estos niños y niñas significa buscar las claves de éxito de la integración escolar del alumnado inmigrante nuevo. A su vez nos da pistas para entender algunos sucesos que ocurren en las aulas.

Esta creación de expectativas y la construcción de un buen clima en el aula favorecedor de relaciones sociales positivas, depende en gran medida de los 
procesos pedagógicos que en el aula se desarrollan. A su análisis dedicaremos el siguiente apartado.

\section{4.- Procesos pedagógicos que se desarrollan en el aula y su influencia en las relaciones con las minorías culturales}

En este subapartado encontramos dos temas de interés que serán desglosados en los siguientes epígrafes:

3.4.1- Metodología cooperativa y manifestación de determinadas interacciones y habilidades sociales entre el alumnado.

3.4.2.- Metodología y sensibilidad docente hacia la problemática del alumnado nuevo

\subsection{1- Metodología cooperativa y manifestación de determinadas interacciones y habilidades sociales entre el alumnado}

Dentro de los procesos pedagógicos que influyeron en las interacciones y habilidades sociales entre iguales, dedicamos un apartado especial a los agrupamientos realizados en las clases por el profesorado para organizar los procesos de enseñanza-aprendizaje.

Estos agrupamientos tienen que ver con el estilo de enseñanza en que cada maestro haya sido formado al inicio o durante su trayectoria profesional. En nuestro estudio observamos cómo determinados tipos de agrupamientos, condicionados por la metodología utilizada, influían en la calidad de las interacciones sociales entre el alumnado.

Podemos establecer tres categorías generales de agrupamientos que corrobora la literatura al respecto. Por un lado la organización individualista, por otro la competitiva y la cooperativa por último (Infante Rejano et al., 2002).

La distribución del mobiliario de la clase es un indicador del tipo de dinámica que se desarrolla en el aula. Cada organización favorece un tipo de metodología u otra. Las aulas de nuestro colegio y, en concreto, las de los tres alumnos inmigrantes nuevos de $5^{\circ}$ tenían su mobiliario de pupitres colocados en forma de $\mathrm{U}$ invertida. De este modo, todos podían verse las caras y dirigirse el uno al otro. Algunas temporadas, el tutor decidía cambiar esta organización y ponerlas 
en filas de dos y otras veces se realizaban trabajos en grupo, normalmente en las áreas de plástica, inglés y religión o alternativa ${ }^{7}$.

De los diferentes tipos de organizaciones, nos centraremos en las interacciones generadas a partir de las distribuciones en grupos por facilitarnos el análisis de las relaciones sociales producidas entre escolares.

Las metodologías cooperativas son consideradas por numerosos estudios (Johnson and Johnsony y Holube, .E.J., 1999; Slavin, 1983; Kagan, 1986) como un fuerte instrumento didáctico con el que trabajar además de conocimientos académicos, temas referidos a valores, respeto por otras culturas, habilidades sociales y de comunicación, etc. El problema de este método reside en que su aplicación requiere de la asimilación, por parte del profesorado, de una serie de principios conceptuales que definen la esencia del aprendizaje cooperativo. Estos principios pretenden que las herramientas didácticas, utilizadas para aplicar la cooperación en los grupos, sean capaces de establecer vínculos de manera que cada uno de los participantes sienta que su éxito personal ayuda a los compañeros o compañeras con los que están unidos a alcanzar el suyo, es decir, que exista interdependencia en las metas $y$, de este modo, que los resultados de cada miembro del grupo sean beneficiosos para los restantes miembros con los que está interactuando cooperativamente. Johnson and Johnson et al.,(1982, 60) establecen esta relación de claves para llevar a la práctica esta metodología: Interdependencia positiva entre los miembros de los grupos, responsabilidad individual, grupos heterogéneos, compartir liderazgo por parte de todos los miembros del grupo, enseñar las habilidades sociales necesarias para trabajar en colaboración, estructuración de los procedimientos

Si no se integran estos principios en la práctica educativa, podrá desvirtuarse y conseguir todo lo contrario a las intenciones educativas planteadas en un principio. Así, por ejemplo, algunas prácticas que observamos en la clase de inglés en la que estaba Willy, lejos de promover la integración de este alumno nuevo al grupo, consiguió todo lo contrario, siendo objeto de burlas y agresiones verbales por parte de sus compañeros, como vemos en el siguiente relato extraído en el primer mes.

Están en clase de inglés. El profesor ha encomendado una actividad que consiste en hacer por grupos de cuatro un mural en el que pongan datos principales en inglés de un personaje famoso que previamente hayan recortado de alguna revista. Joseph está en un grupo difererente al de Willy pero ambos grupos están

\footnotetext{
7 Existe una cierta relación entre trabajo en grupo y áreas consideradas popularmente "marías", mientras que el trabajo individual parece estar unido a las materias consideradas "serias" como matemáticas y lenguaje.
} 
situados en el aula uno al lado del otro. Vamos alternando las observaciones entre cada uno de los dos grupos. Empezamos observando el grupo de Joseph y después el de Willy.

Grupo de Joseph:

Al principio, antes de empezar a trabajar, interactúan con él, le dicen alguna cosa en español. Cuando empiezan a trabajar, uno de ellos lleva la voz cantante, organiza el trabajo: pregunta a los demás qué piensan, escucha y da órdenes de qué tiene que hacer cada uno. Los demás se dejan llevar muy bien. A todo esto, con la emoción de hacer el trabajo, Joseph cae en el olvido. Él bosteza, se medio tumba en la mesa. No dice nada a los demás y los otros tampoco a él. Esto son indicadores de que no es un trabajo cooperativo, sino trabajo en grupo y que si no se elabora la actividad metodológicamente bien, no ayuda a integrar ni a colaborar, sino todo lo contrario. El grupo ahora está decidiendo quién será el que escriba el título, hacen una prueba para ver quién lo hace mejor. Es en este momento cuando veo que Joseph va a estar así a menos que alguien haga algo. Les digo a los niños de su grupo que le expliquen lo que están haciendo. Ellos dicen: "iAh! isi!" y empiezan a explicarle en español, les ayudo. Joseph lo agradece y lo capta enseguida. El niño que organiza todo en el grupo dice: "y Joseph ¿qué podría hacer?..." Yo les acerco el cartel donde tiene sus letras y dice: "iAh! Ya está, déjalo, ya no hacemos más pruebas, lo hace Joseph, imirad qué letras tan chulas!", todos se asombran y se lo hacen saber a Joseph, éste sonríe. Joseph las dibuja, le sale muy bien. Su grupo se las enseña a otros grupos, dicen: "Con Joseph vamos a ganar, vamos a ser los que mejor lo tengamos". Nadie les ha dicho que ese trabajo vaya a competir con otros, pero ellos crean competición donde no la hay (¿ello nos puede hablar de que tienen asumidos unos patrones competitivos en otros trabajos?).

Se siguen oyendo comentarios como: "Joseph quiere estar en nuestro equipo siempre, se lo he preguntado", "tenemos que tener cuidado, porque las chicas se lo quieren llevar", "¿de qué equipo eres, Joseph?", me dicen que se lo traduzca, él dice: "del Barca”, algunos exclaman: "iBien!". Otros, nada. Joseph está al tanto de los aspectos culturales de España. Probablemente su padre le haya dicho algo al respecto. Mientras a Joseph se lo rifan, Willy está en el equipo de al lado haciendo las letras mientras los demás hablan entre ellos. Él intenta dibujar, mirarles y escuchar lo que dicen. Termina y continúa haciendo las letras otro niño. Cada uno hace una letra con los consiguientes saltos de tamaño y espacio (esta es otra idea errónea sobre el aprendizaje cooperativo: cada uno hace una cosa, mientras los demás están a otro tema). 
Al terminar la clase los del equipo de Joseph enseñan al resto de la clase las letras que ha dibujado. Las niñas se maravillan. Están como locas con él. Los otros le felicitan, chocan la mano. Willy le mira de reojo desde unos metros.

Grupo de Willy:

Hablan acerca de que Joseph es muy bueno pintando carteles, que dibuja muy bien. Después empiezan a tontear haciendo como que tienen un chicle imaginario y se lo pasan entre ellos, a todos menos a Willy

Willy mira continuamente al grupo de Joseph para ver qué y cómo lo están haciendo. El resto del grupo comparan continuamente su trabajo con el del grupo de al lado en el que está Joseph: "Nuestras letras son una mierda comparadas con las de Joseph", insiste uno de ellos. Willy vuelve a mirar el cartel de Joseph y su grupo.

Todos hablan entre ellos, Willy intenta meter baza, pero no sabe cómo. Se queda callado y mirando al otro grupo cada poco.

Le preguntan a Willy qué es un "pin", él no lo sabe y se calla ante su pregunta, los demás insisten, él dice que no sabe, haciendo un gesto con los hombros, ellos se ceban preguntando y dice uno: "Se ha quedado en el limbo", "no dice nada".

Willy no tiene estrategias para salir del paso, se queda parado, medio bloqueado. Es cierto que tiene un retraso académico bastante grande. Según Laura su nivel curricular es de $1^{\circ} 02^{\circ}$ de primaria y tiene edad cronológica de 60: 11 años.

Los niños machacan al débil que no sabe defenderse. No sólo aísla el hecho de ser repetidor y la falta de habilidades académicas, sino también la falta de estrategias de interacción, de liderazgo. Esto le causa a Willy una especie de bloqueo que no sabe gestionar y lo que hace es callarse, no suele responderles nunca de malas maneras por ahora, no sabemos si es porque quiere pertenecer al grupo y no se lo puede permitir o porque no es nada violento, ni asertivo.

Esta parálisis es interpretada por los de su grupo como falta de interés y empiezan a decirle: "Willy, si no vas a hacer nada, te vas de este equipo". Él no dice, ni hace nada al respecto, sigue callado y con una postura corporal cerrada, de protección, con los brazos recogidos encima del pupitre. Le dicen: "alelao", "este no quiere hacer nada". Willy se empieza a cansar y hace un intento de levantar la mano como amenazando de que se chivará de que le insultan como sigan haciéndolo. Cambian de tema ante este gesto, se distraen con otra historia y cambian de tema. Los alumnos tienen idea de que el profesor protege a todos y defiende lo justo. Sin embargo, Willy no se atreve, sabe que si lo hace pararán en un momento de insultarle, pero luego se acrecentará todavía más su rechazo. 
Willy está cada vez más cerca del grupo de Joseph; tanto es así, que Adri, le dice: "ipero tú qué haces aquí!, no nos copies, ¿eh?". Y a otro niño de su propio equipo no se le ocurre defenderle como miembro del grupo, sino que le dice: "tú no copies, ¿eh?".

El profesor se acerca a mí, me pregunta qué veo, le digo lo que le ocurre a Willy, él se queda al lado de ese grupo y a partir de ahí a Willy no le dicen más cosas, pero tampoco le hacen caso. Los niños saben lo que está bien y lo que está mal. Conocen el discurso de los mayores. Tienen mucha deseabilidad social.

(Diario, 20 de Septiembre 2006)

Estos pasajes nos demuestran que las interacciones que se establecen durante el trabajo en grupo van sucediéndose a golpe de impulso. La expectativa atribuida a Willy por parte de sus compañeros no es nada favorable. Esto hace que no le den ninguna oportunidad para integrarse de forma adecuada. De forma contraria, en el caso de Joseph, la habilidad de pintar rótulos con calidad le ha permitido confirmar la expectativa positiva que de él ya tenían sus compañeros. Sin embargo, como podemos comprobar tras la lectura del acta, el líder de este grupo que organizó el trabajo no se hubiera acordado de la habilidad pictórica de Joseph, si un adulto no la hubiera sugerido al enseñarle el cartelito con las letras bonitas. Esto nos habla de la necesidad de la intervención docente a la hora de estructurar y gestionar estas actividades. Es necesario que las dinámicas que éste proponga constituyan una meta común para el alumnado y donde el intercambio entre los compañeros genere y consolide interacciones y habilidades sociales adaptadas a las situaciones.

Algunas sugerencias que proponemos para mejorar las interacciones sociales son: incentivar al alumnado para que dentro de cada equipo existan diversos roles, crear un sistema de refuerzos en el que se les haga ver que el éxito de su compañero/a es el suyo también, estructurar la actividad con pasos para que se distribuyan las funciones, reforzar las conductas de participación positiva en el grupo, exigir que cada miembro del grupo participe de alguna manera en el cometido de la actividad y que no haya niños/as abandonados, reforzar negativamente o sacar a la luz para debatir las conductas de burla y/o agresión hacia otros, realizar pequeñas acciones previas al trabajo en grupo donde se entrenen las habilidades sociales. Todas estas acciones contribuirían a que se adecuaran en mayor medida a los principios del aprendizaje cooperativo. Podemos decir que lo que reflejan las viñetas anteriores no responden a un trabajo cooperativo, sino a trabajo en equipo en el que la cooperación no está asegurada.

Existe mucha literatura respecto al tema del aprendizaje cooperativo (Johnson and Johnson, 1982, Slavin, 1999; Díaz Aguado, 1993; Díaz Aguado y 
Baraja, 1993; Díaz Aguado y Martínez Arias, 2001). Son investigaciones aplicadas que apoyan estas teorías que venimos explicando. De acuerdo con lo establecido por Allport (1954) con su teoría del contacto, para favorecer la superación de este problema es necesario promover actividades que no se den de forma espontánea. Habría que controlar variables como el tiempo, para que exista el suficiente contacto y la intensidad necesaria intergrupal como para que se establezcan relaciones sociales estrechas. También nos dice que para conseguir estas metas cooperativas, los miembros de los distintos grupos deberían tener un estatus heterogéneo y cooperen en la consecución de los mismos objetivos. La heterogeneidad en los grupos nos asegura la posibilidad de trabajar con alumnado de diferentes ritmos, procedencias, sexo, y así favorecer la tolerancia. Además, la metodología cooperativa, genera un ambiente relacional de respeto e intercambio donde se generan y aprenden a usar habilidades sociales necesarias para interactuar con alumnado con otras procedencias culturales.

El entrenamiento en habilidades sociales por tanto, se considera un requisito previo al desarrollo de las metodologías cooperativas, así mismo estas habilidades podrán mejorarse durante el proceso y es que, como dice Ovejero, (1990, 245), el aprendizaje cooperativo funciona como una técnica o programa de entrenamiento de las habilidades sociales porque aunque son muchos los factores responsables de la eficacia del aprendizaje cooperativo, muchos de ellos son claramente grupales e interpersonales (imitación, percepción social adecuada, apoyo social, refuerzos grupales, etc) y coinciden en gran medida con los factores responsables de la eficacia del entrenamiento de las habilidades sociales.

Ahora bien, para que las habilidades de colaboración, se desarrollen adecuadamente, es necesario crear un contexto educativo adecuado. Johnson, Johnson, Holubec y Roy, en Ovejero (1990) establecen cinco supuestos que deben tenerse en cuenta para la enseñanza de las habilidades sociales. Todas ellas tienen que ver con la necesidad de que el profesor enseñe cuanto antes dichas habilidades, ya que el alumnado no nace con ellas aprendidas, ni las adquiere de forma automática. Además necesitan la ayuda constructiva de sus compañeros para proporcionarse entre sí los apoyos necesarios, cuando hay algún estudiante menos capacitado para la adquisición de las habilidades colaborativas.

\subsection{2.- Metodología y sensibilidad docente hacia la problemática del alumnado nuevo}

Como hemos visto en el epígrafe anterior, no resulta fácil para un docente atender a las múltiples situaciones relacionales que surgen minuto a minuto, máxime cuando su atención se dispersa en los numerosos detalles a los que debe dar respuesta (organización de la tarea, control de grupos, atención a casos 
particulares, preocupación por controlar ritmos diversos, preparación de las siguientes tareas, evaluación de los resultados que el alumnado va teniendo en la tarea propuesta...). La mirada y preocupaciones del maestro o maestra están condicionadas, entre otros factores, por su formación y experiencias previas, de ahí que si estas han estado centradas en un tipo de desarrollo de los contenidos curriculares, les resulte difícil tener otras perspectivas sobre lo que está ocurriendo en el proceso educativo. En ocasiones, cuando alguien nos brinda otra mirada sobre una situación que se considera "normal", se pueden generar nuevas perspectivas. Uno de los propósitos de este informe es ofrecer otra perspectiva al profesorado que les permita sensibilizarse sobre los procesos personales que vive un escolar y la influencia de las decisiones docentes en ellos. Con esa intención hemos escogido el análisis de tres situaciones observadas en las clases de Educación Física. En ellas el movimiento (la mayor presencia de los cuerpos y de sus actuaciones) pone aún más en evidencia los procesos sociales, las interacciones y las implicaciones de las decisiones docentes (su efecto se puede observar mejor en los gestos de los niños y niñas).

La lógica interna (Parlebás, 2001) de las actividades propuestas condiciona las actuaciones de los participantes y determina sus actitudes en esa situación. Por tanto, cada actividad establece un marco formal que favorecerá 0 dificultará la integración del alumnado nuevo. Un ejemplo de ello lo encontrábamos en la primera sesión de Educación Física que tenía el grupo de Willy y Joseph. El profesor propuso el siguiente juego: dos equipos, colocados en dos filas frente a la canasta, el primero de cada fila tenía un balón, a la señal debían salir con su balón hacia la canasta para intentar encestar antes que el del otro equipo, el que lo lograba se incorporaba de nuevo a la fila (al final de ésta), el que no encestaba era eliminado. En su desarrollo se podía apreciar la excitación que el juego provocaba en participantes y espectadores. Los primeros actuando rápido, nerviosos, con múltiples errores; los segundos animando, gritando y saltando. Si realizamos un análisis de esta actividad descubriremos algunos ingredientes interesantes:

- La escenografía de este juego nos recuerda a un duelo, un duelo contrareloj, angustioso; dado que de él se derivará una "muerte" simbólica (quedar apartado, dejar de jugar).

- Esa acción rápida lleva a múltiples errores, lo cual puede angustiar aún más, dado que se está siendo observado por los demás, y se está poniendo en juego la valoración de la propia competencia.

- Igualmente, esa acción rápida no permite que cada uno pueda actuar según su ritmo y sus posibilidades. 
- Al plantearse un reto común a todos, sin respetar los diferentes niveles de habilidad, se pone más de manifiesto la incompetencia motriz. En ésta influyen factores de seguridad personal, de ahí que las personas nuevas en el grupo tengan muchas posibilidades de fracasar en esta tarea.

- La escenografía lleva a una exposición ante los demás y, por si esto no supusiera suficiente presión, el resultado de la acción individual conlleva un beneficio 0 perjuicio para el grupo. Ello supone una situación que puede ser vivida con mucha angustia.

Es fácil concluir que no resulte la tarea más idónea para recibir a un niño 0 niña nuevos en el grupo. Posiblemente esta exposición ante los demás sea lo menos apropiado para un escolar nuevo que aún está inseguro en el contexto, intenta pasar inadvertido, y busca dar una buena imagen para ser aceptado.

Sin embargo, no sólo es importante la lógica interna de las actividades. La tolerancia al error y el ambiente de aceptación por parte de los niños y niñas veteranos juega un papel fundamental en estas situaciones. Hemos podido observar que estos factores personales son completamente aleatorios y dependen de las expectativas que se hayan generado hacia cada persona. En el caso que se expone, pudimos apreciar cómo Joseph era animado por todos sus compañeros y compañeras de equipo y cuando fallaba era recibido por el resto de eliminados entre saludos y abrazos. Por el contrario, Willy (que demostró un buen nivel de habilidad) no recibía tantos ánimos durante su intervención y sus triunfos pasaban inadvertidos (otros niños y niñas que metían canasta eran ostensiblemente felicitados).

Ello nos habla de la complejidad de este tema para los docentes. Mientras que algunos aspectos como la elección de propuestas son controlables, otros como las actitudes del alumnado son difícilmente previsibles, aunque en este caso sí podemos vislumbrar una relación entre las expectativas que el profesorado ha generado en el alumnado de cara a su acogida de una persona nueva (Joseph) y su actitud hacia ella.

Sin embargo, es posible que esta relación causal no sea tan simple y se vea condicionada por otros aspectos. Al contrastar este caso con el de Amani obtenemos otros factores relacionados con las habilidades sociales de la persona nueva, su apertura al grupo y quizás su sexo y apariencia física. Relataremos a continuación otras dos situaciones que ilustren estas ideas, sin perder de vista el tema de la organización y la sensibilidad docente hacia la integración.

Las situaciones están tomadas de una sesión especial de Educación Física en la que una monitora y un monitor de bádminton habían ido al centro a "enseñar" un poco de este deporte: 
Empieza la clase, explicando una chica de la Fundación de Deportes teoría sobre el bádminton. A los niños parece que les da igual (hacen burla, se pinchan entre ellos, se ríen...).

Amani se ha sentado en el corro de las primeras, después lo hacen los chicos, por lo que ella queda al lado de ellos, alejada de Ana (la niña que más se ocupa de ella).

Tras la explicación les dicen que cojan las raquetas. Van todos en tropel. Amani queda algo retrasada, va despacio, pero con decisión (posiblemente al ver a los demás tan rápido).

Se vuelven a sentar en el corro. Amani intenta hacerlo al lado de Ana, pero no puede, antes se han situado otros. Ella busca otro sitio.

La monitora les dice: "Que levante la mano quien no tenga raqueta". Amani levanta la mano. Va entendiendo las órdenes por el contexto, de ahí que se aprenda lo que se ve.

(Diario 19 de Septiembre 2006)

Ana (la niña que está más pendiente de Amani) se acerca a Amani y le explica lo que tiene que hacer. Se ponen a jugar al badminton todos. El campo está dividido por una cuerda, el volante tiene que pasar por encima, pero están todos apelotonados. Difícilmente podrán jugar. banco.

Amani se queda sin pareja, me mira y se acerca a mí que estoy en un

Hay otro niño sentado, él solo, y tampoco tiene pareja y está como enfadado. Parece que prefieren no jugar a interactuar entre ellos. La actividad es totalmente libre, no hay consignas por parte del profesor. Les animo a que se emparejen y se pongan a jugar.

Se ponen a jugar y apenas dan al volante, porque ninguno de los dos sabe jugar. [...] El poco espacio que tienen para moverse tampoco facilita las cosas. El niño que está al lado de Amani jugando, la empuja aludiendo que no cabe. Ella sonríe con un gesto de no entender lo que le dice. El compañero de Amani decide cambiarle el sitio para que no tenga problemas con ese niño.

Fallan casi todas, pero nadie les da indicaciones de cómo hacerlo mejor. [...] Amani corre a recoger todos los volantes que se les escapan.

(Diario 19 de Septiembre 2006)

Estas escenas ponen de manifiesto varios aspectos: 
- En estas actividades esporádicas, el profesorado que acude al centro no puede llevar un control de las necesidades y evolución de cada niño o niña. Habría que tener cuidado con que la escuela se convierta en un lugar de "momentos especiales", alejados del proyecto educativo del centro en los que se deja al alumnado en manos de personas con poca sensibilidad educativa.

- Es normal que un profesorado joven, que debe recorrer todos los colegios de la provincia y estar una hora en cada uno, no se preocupe demasiado de la estructura de la participación social (Erickson, 1993). En estos casos se hace necesario que el docente del centro que acoge esta sesión esté pendiente del control del grupo, de que se respete la normativa de funcionamiento habitual, 0 de que las personas con más problemas se encuentren atendidas.

- La falta de organización (cuando los códigos verticales se relajan) deja salir a la luz los códigos horizontales (caracterizados por la competitividad y el individualismo) y se ponen de manifiesto las desigualdades existentes en el grupo. No es de extrañar que cuando el docente no habilita una estructura clara de acción, en este caso para repartir el material o formar parejas, aquellas personas más inseguras o con más dificultades, como es el caso de los niños y niñas nuevos, se vean atropellados, en este caso, sin raqueta y sin pareja.

- Quedarse sin raqueta o sin pareja supone subrayar la condición marginal y de rechazo que el alumnado nuevo puede sentir. Por ello, estos momentos son especialmente delicados y precisan de toda la atención del docente. El reparto del material o la confección de los agrupamientos son temas trascendentes en el proceso educativo, no se pueden dejar al azar. Cuando hablamos de despertar la sensibilidad pedagógica del profesorado nos referimos a detalles como éstos en los que los maestros o maestras deberían poner en primer orden de su atención la solución de estos problemas.

- Cuando no existe una preocupación por los temas pedagógicos, las personas (los nuevos, los de menor nivel de habilidad, los más rechazados...) más necesitadas de mejores condiciones para la práctica (mejores materiales, ponerse con personas con nivel de habilidad, con personas más comprensivas...) son las que más sufren las consecuencias (peores condiciones para la práctica, más posibilidades de fracaso y por tanto de caer en un ciclo de indefensión aprendida).

- Igualmente, cuando no existe preocupación didáctica (un contenido claro, una estructura de enseñanza, una progresión para adquirir la habilidad, unas estrategias para que cada escolar trabaje según sus posibilidades...), los problemas de los niños y niñas menos competentes 0 inseguros quedan más subrayados. En este caso, vemos que por mucho que se esforzara Amani en dar bien al volante, sería muy difícil que llegase a aprender algo. 
- A pesar de las condiciones desfavorables de la práctica, apreciamos continuos detalles de la lucha de esta niña por adaptarse a su situación actual (intentos de acercarse a su amiga, práctica de una actividad para la que le han rechazado y que no comprende muy bien, sonrisa constante,,..$)$.

Estos pasajes también nos han permitido ver cómo el trato que recibe Amani es muy diferente del que recibe Joseph. Aquí es donde surgen nuestras dudas sobre los factores que contribuyen a formar las expectativas hacia el alumnado nuevo entre sus compañeros y compañeras. En cualquier caso, en los tres pasajes, se pone en evidencia la influencia de las acciones docentes sobre el proceso de integración del alumnado inmigrante nuevo. Nos hablan también estas situaciones de la dificultad de plasmar en el día a día las intenciones del proyecto educativo del centro.

En este capítulo, que constituye el tercero del informe final, hemos ido desarrollando el proceso de integración escolar del alumnado inmigrante a través de la descripción de situaciones escolares con la presencia del adulto. En concreto, hemos explicado las acciones educativas, observadas en los espacios formales del centro, influyentes en este proceso de adaptación.

En el primer apartado, describimos este proceso a través del plan de acogida del colegio. En segundo lugar, a través de las observaciones extraídas de las clases de apoyo, hablamos de las expectativas del profesorado hacia el alumnado inmigrante, de la distancia cultural encontrada en los contenidos académicos, del respecto hacia los diferentes ritmos de aprendizaje, de las interacciones de los inmigrantes entre sí y de la motivación del alumnado.

En tercer lugar, narramos los aspectos pedagógicos observados en las clases ordinarias. En concreto, describimos las características de las interacciones dentro de este espacio, de las implicaciones tanto del funcionamiento dependiente y autónomo del alumnado nuevo, como de la comprensión del significado de los espacios físicos del centro escolar y de la relación establecida con el profesorado.

Al mismo tiempo también dedicamos un apartado para explicar las expectativas y prejuicios manifestados por el profesorado hacia el alumno inmigrante y los procesos pedagógicos desarrollados en las aulas, como son los referidos a los agrupamientos, la metodología cooperativa y la sensibilidad del docente hacia esta problemática. Todo ello mediante la combinación de pasajes extraídos de la realidad vivida en la escuela y de la reflexión sobre la misma. 


\section{Capítulo 10}

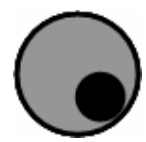

Fases comunes en el proceso de integración del alumnado inmigrante nuevo

En este capítulo vamos a exponer una serie de fases comunes en el alumnado inmigrante nuevo, extraídas de la síntesis del proceso de integración escolar. Mediante los cinco momentos que encontramos en dicho proceso, pretendemos extraer una secuencia común que pueda servir de utilidad a otros contextos educativos. 


\section{1.- Fases comunes en la socialización escolar del alumnado inmigrante nuevo.}

A lo largo del trabajo etnográfico en el centro escolar fuimos observando el proceso por el que los tres alumnos inmigrantes nuevos se fueron acercando a la cultura escolar. A través de un trabajo de síntesis y reflexión se extrajeron cinco fases comunes en los tres procesos. Las hemos denominado de la siguiente forma:

$1^{\mathrm{a}}$ fase: Desconocimiento, inseguridad y receptividad.

$2^{\mathrm{a}}$ fase: Conocimiento de las rutinas básicas.

$3^{\mathrm{a}}$ fase: Fase de aprendizaje de los códigos verticales y horizontales.

$4^{a}$ fase: Fase de primera definición del estatus dentro del grupo.

$5^{\text {a }}$ fase: Fase de consolidación del estatus dentro del grupo.

Al detallar el itinerario socializador de estos escolares, estamos accediendo al mismo tiempo a la cultura escolar en la que se desarrolla este proceso. A continuación, desarrollaremos cada una de estas fases siguiendo una estructura común. En primer lugar, mencionamos los aspectos que la definen. En segundo lugar, las acciones educativas que acaecieron en este momento. $Y$ por último, las reflexiones sobre la influencia de algunos de estos aspectos en la integración de cada alumno.

\section{Fase 1': Desconocimiento, inseguridad y receptividad.}

- Descripción de la $1^{\mathrm{a}}$ fase

\begin{tabular}{|l|}
\hline PROCESO DEL ALUMNADO INMIGRANTE NUEVO \\
\hline Desconocimiento del espacio físico y de los significados de los mismos. \\
\hline Desconocimiento de las rutinas escolares: filas, recreo, horarios, material escolar... \\
\hline $\begin{array}{l}\text { Inseguridad, ansiedad y dependencia. Búsqueda de protección espacial. } \\
\text { Recogimiento corporal. Búsqueda con la mirada de adultos conocidos. }\end{array}$ \\
\hline Falta de autonomía para funcionar por el centro. \\
\hline ACCIONES EDUCATIVAS \\
\hline Enseñarle los espacios físicos. \\
\end{tabular}




\begin{tabular}{|l|}
\hline Presentarle al alumno mediador. \\
\hline Presentación individual al grupo-clase (salvo a Willy). \\
\hline $\begin{array}{l}\text { Crear expectativas positivas al grupo-clase respecto de la llegada de un alumno } \\
\text { nuevo (salvo sobre Willy). }\end{array}$ \\
\hline Presentarle a los diferentes profesores y profesoras. \\
\hline $\begin{array}{l}\text { Reunión con la familia y el alumno para explicarles las normas básicas de } \\
\text { funcionamiento del centro escolar. }\end{array}$ \\
\hline
\end{tabular}

Tabla 10.1. $1^{\text {a }}$ fase: desconocimiento, inseguridad y receptividad.

En esta primera fase los alumnos inmigrantes a los que realizamos el seguimiento muestran y sienten inseguridad ante el desconocimiento total del contexto nuevo en el que se encuentran. Este es el momento en el que más ayuda del adulto parecen necesitar. Su presencia en un contexto totalmente nuevo produce manifestaciones de ansiedad y dependencia.

Los primeros días de Joseph y Amani se encuentran bastante desorientados espacial y emocionalmente. Imaginemos la situación: no conocen el idioma, ni las normas del centro, ni la ubicación física de las salas, menos conocimiento disponen todavía de las rutinas escolares típicas, como el horario de clases, cuándo y qué calzado traer a las clases de educación física o de la existencia de actividades extraescolares.

Las profesoras de compensatoria, siguiendo el plan de acogida que tiene elaborado el centro, les enseñan las instalaciones, hacen el recorrido de la fila del patio a su clase, le presentan a otro niño del mismo país de procedencia para que haga de traductor y se conozcan, se reúnen con la familia para explicarle las normas y el funcionamiento básico del centro.

Estos primeros días se les ve deambulando por el centro con cierta inseguridad. En el caso de Amani, la vemos siguiendo a otros, imitando conductas, juntándose a niños/as procedentes de su mismo país. A Willy se le ve saludando a algún niño de su clase del año pasado, pero no uniéndose a ellos. Se junta a los de su clase actual sin demasiado éxito. A Joseph, sin embargo, se le ve con los de su clase desde el primer momento, en el recreo juega con ellos al fútbol, las niñas buscan el contacto con él. El niño mediador se ofrece a ayudarle en el recreo. Joseph, sin embargo, no parece necesitar su ayuda. Muestra bastante autonomía y 
seguridad en las relaciones sociales con sus compañeros. No obstante todavía las sensaciones de inseguridad son manifiestas: deseo continuo de querer agradar, se pone rojo cuando no entiende lo que le dicen, etc. Así vemos en el diario que iba realizando cada día, las siguientes palabras ${ }^{1}$ con las que expresaba estas primeras sensaciones:

"El primer día en el colegio. El principal problema es el lenguaje. Me sentía mal porque no podía hablar con los niños. Los niños me decían cosas y yo no podía responder. Yo creo que los profesores son majos. Lo que más me gustó fue jugar al fútbol, porque estaba con los niños y yo era el jefe."

(Diario Joseph, primer día de clase. Septiembre 2006)

"El segundo día de clase yo me he sentido "super", porque yo me he comunicado con más niños en inglés y en español. Lo que más me gustó otra vez fue jugar al fútbol. Yo creo que juego normal al fútbol. Los otros niños juegan muy bien. Dos niños querían hablar conmigo y yo no entendía nada. En mi casa hice algunos deberes, como por ejemplo repasar el vocabulario de español. "

(Diario Joseph, segundo día de clase. Septiembre 2006)

"Este día he empezado a comunicarme con los niños de clase. Pero ayer uno de los niños de clase me dijo que me pusiera en el equipo de cuatro personas contra el otro equipo que tenía diez personas. Los profesores son majos conmigo. Las otras clases están enfadados conmigo y creo que es porque soy búlgaro y no hay otros niños búlgaros, o sólo uno más"

(Diario Joseph tercer día de clase. Septiembre 2006)

"Ayer fue un buen día porque ya han pasado cuatro días en el colegio. En el recreo volví a jugar al fútbol. Esta vez los equipos estaban mejor hechos. Con los profesores...pues...normal".

(Diario Joseph, cuarto día de clase. Septiembre 2006)

"Ayer Lunes fue un buen día porque los niños se dieron cuenta de que pintaba muy bien. Todos se quedaron asombrados por el título que hice en el cartel de los personajes famosos. Adri es el mejor jugando al fútbol. La asignatura que más me gusta es Educación Física..., porque es en la que más juego."

(Diario Joseph, sexto día de clase. Septiembre 2006)

"Yo jugué al baloncesto. Willy rompió mi dedo. Con las otras clases no juego, sólo con los de mi clase. Este fin de semana he estado en mi casa tranquilo

\footnotetext{
${ }^{1}$ En la elaboración de este diario seguíamos el siguiente protocolo: el me lo decía en inglés, yo se lo traducía al español y él lo escribía en el cuaderno en español. Este trabajo lo mantuvimos durante los primeros meses.
} 
con mis padres. He jugado al ordenador, al dominó con mi padre, también he visto la televisión. Iván y Willy son mis mejores amigos porque quieren jugar más conmigo y me pasan mucho el balón. Pablo no quiere jugar conmigo porque no quiere jugar al fútbol, ni jugar a nada y se ríe de algunos niños. Yo me siento mucho mejor en el colegio que la primera semana porque hablo cada vez más.

(Diario, 26 de septiembre 2006. Septiembre 2006)

"Ayer tuve clases de apoyo. Tengo dos tipos de clase; con los de clase en grupo y con los de apoyo para aprender español. Yo prefiero estar con todo el grupo porque en clase con todos tengo amigos y en la otra no tengo. En el recreo no tuve ningún problema con nadie. En la clase de Educación Física jugué al baloncesto. En mi equipo estaba Willy y las chicas, el resto en otro equipo."

(Diario, 27 de septiembre 2006. Septiembre 2006)

Vemos que los primeros problemas que surgen tienen que ver con el lenguaje. No hablar español es la principal barrera para interactuar con los demás. Sin embargo, la necesidad de integrarse y ser aceptado por el grupo hace que Joseph despliegue todas sus estrategias corporales, muestre sus habilidades para llamar la atención y dejar constancia de que quiere ser uno más. En este caso, Joseph tiene suficiente competencia social como para conseguir integrarse.

En sus declaraciones personales del diario vemos que el fútbol es el principal elemento socializador. El valor dado a este juego no sólo es una impresión subjetiva de este niño, realmente hemos podido apreciar que el papel en esta actividad marca el estatus dentro del grupo de los chicos.

Por otro lado, bajo la seguridad externa mostrada en las relaciones sociales con sus compañeros se intuye cierta fragilidad en algunos momentos. En algunas ocasiones, Joseph realiza atribuciones erróneas acerca del comportamiento de algunos compañeros, pensando que su procedencia es la causante de que los niños de otras clases no jueguen con él. Joseph no conoce la subcultura de la escuela. Todavía no sabe que los grupos más cercanos en la escuela se establecen por clases y que lo normal es que en el recreo jueguen por grupos. Ante este desconocimiento de la cultura escolar salen a relucir los miedos e inseguridades que rondan por su mente.

Las declaraciones realizadas en el diario nos permiten percibir cierta actitud familiar respecto a la escuela. Nos dice que juega al dominó con su padre, que ve la televisión y que repasa vocabulario español con él. Apreciamos entonces, que existe cierta preocupación de su familia por la formación del niño. 


\section{Acciones educativas en la $1^{\text {a }}$ fase}

- Los tutores respectivos de Joseph y Amani habían preparado la llegada de estos alumnos nuevos al grupo de referencia. Les habían presentado como alumnos de otros países que no hablan español y requerían la ayuda de sus compañeros para que consiguieran integrarse rápidamente y no se sientieran mal.

Esta simple preparación de los maestros al grupo fue suficiente para conseguir que los niños y niñas depositaran ciertas expectativas sobre la llegada de estos alumnos. En cierta medida, podemos decir que provocó un efecto novedad que consiguió aumentar la cantidad de interacciones con Joseph y Amani.

- Las respuestas sociales iniciales de los tres alumnos y la competencia social mostrada con sus iguales en esta primera fase fueron las siguientes:

Joseph responde habilidosamente a este primer acercamiento: sonriendo, haciendo gestos, riendo, diciendo su nombre, etc. Esto produjo que se fueran acercando cada vez más niños y niñas. Sus respuestas eran agradables. Los refuerzos sociales que recibían mutuamente (grupo-Joseph) eran positivos y esto iba reforzando la competencia social del alumno nuevo.

Amani, sin embargo, empieza mostrando un perfil social totalmente diferente. Su carácter tímido y reservado dificultó el primer acercamiento al grupo. Apenas interactuaba con ningún miembro del grupo, miraba continuamente al suelo y no manifestaba agrado cuando se acercaban a ella. Sus conductas conseguían el aislamiento del grupo; sin embargo se acercaba a dos niñas en particular con las que buscaba el trato más íntimo. La aceptación de Amani por estas dos niñas fue más bien, un acaparamiento. De tal forma que la tutela de Amani, llegó a ser objeto de competición entre ambas. Cuando se le acercaba algún niño de su clase a decirle algo, ella bajaba de nuevo la mirada. Acotó su círculo de amistades a esas dos niñas. Por tanto, las interacciones eran menos variadas que en el caso de Joseph. La competencia social aprendida será más reducida en este caso.

Willy difiere bastante de los dos casos anteriores en cuanto al acercamiento social con sus iguales. Se acercaba a ellos pero no hablaba demasiado. Además, no entendía todas las bromas del grupo a pesar de hablar español. Procesaba mucho más lento la información que el resto de niños. Este alumno tampoco interactuaba con el sexo contrario. Los compañeros no interaccionaban demasiado con él, por lo cual se disminuían las posibilidades de obtener refuerzos sociales $y$, consecuentemente, mejorar su competencia social.

- Otro suceso que influyó de manera más notable en este momento fue mi presencia en el centro. Fui presentada como una profesora de apoyo a los alumnos inmigrantes nuevos de quinto curso. Algunos se pensaron que yo era una 
traductora, otros una especie de profesora de compensatoria, otros que yo ponía notas y evaluaba las conductas de los niños y otros pensaban que era una persona extraña que mira y apunta continuamente. Este rol difuso que adquirí durante mi permanencia en el centro favoreció el anonimato y me dio libertad para entrar y observar todas las clases que quisiera.

Cada niño se hacía una idea de lo que significaba mi papel. Una vez pasados los días mi presencia fue siendo cada vez más invisible para los niños. Incluso realizaban acciones no permitidas por los profesores en mi presencia. Sin embargo, tanto Joseph como Willy y Amani sentían mi presencia con mayor intensidad que el resto. Sabían que yo estaba allí por ellos y esto pudo causar en algún momento cierta influencia en sus comportamientos.

\section{Reflexiones sobre la primera fase}

Por un lado, el bajo número de profesores de compensatoria para el número tan elevado de alumnos/as que deben incluirse en esta modalidad supone una dificultad para llevar a cabo procesos de enseñanza-aprendizaje individualizados. Esta dificultad puede incluso derivar en el olvido de algún alumno, como sucedió con Willy. Al ser repetidor, no se le consideró como alumno nuevo y por tanto no se le presentó en el grupo como tal. Este alumno no vivió, a diferencia de los otros dos, un momento de protagonismo en el aula, ni se habló de él previamente. Por tanto, no se generaron expectativas hacia este alumno. En cierta medida este olvido fue intuido inconscientemente por el alumnado que apenas interactuaba con él. Fue Joseph quien captó toda la atención de los compañeros, mientras que Willy caía en el olvido.

Por otro lado, observamos que en las primeras impresiones al llegar a un colegio nuevo pueden aparecer sentimientos de aventura y optimismo, como es el caso de Joseph, sintiendo que podrán iniciar una fase nueva de su vida, mejor que la que dejan atrás. Al mismo tiempo, existen sentimientos de ansiedad ante la novedad a la que se enfrentan. Coelho (2006) encuentra, en estos primeros momentos, un sentimiento que incluye sensaciones de incomodidad y confusión, cuando los alumnos empiezan a identificar en el entorno educativo aspectos intimidatorios y opuestos a la experiencia previa de sus países. Otros escolares (como es el caso de Amani) pueden comportarse en situaciones de clase como observadores, en lugar de participantes. Se puede llegar a crear una fluctuación emocional entre los sentimientos de curiosidad y emoción a la tristeza o sentimiento de pérdida de identidad. Disman (1983) compara este sentimiento de los inmigrantes con el que sufre un sujeto con un impacto traumático. Conforme pase el tiempo en el centro escolar, se irá reduciendo este estrés inicial. Entendemos que en esta primera fase aún no se da un choque cultural. Para que este dé, la persona debe 
poner en contraste sus códigos de porigen con los códigos del lugar. En estos primeros momentos, esta persona aún no ha podido deducir ningún código, posiblemente se encuentra saturada de estímulos a los que debe atender e interpretar. Ante esa maraña, aventuramos que cada persona establece unas prioridades. En los casos vistos, la preferencia de Joseph es abrirse y conocer a otros niños; la de Amani se rige por intentar mantener su intimidad, aunque abriendo un pequeño puente a las relaciones con un par de niñas. Ambos casos nos muestran como prioritario la búsqueda de nexos con iguales.

Fase $2^{\mathrm{a}}$ : Conocimiento de las rutinas básicas.

- Descripción de la segunda fase

\begin{tabular}{|l|l|l|}
\hline \multicolumn{2}{|c|}{ Proceso de integración de los dos alumnos inmigrantes nuevos y del alumno } \\
\multicolumn{1}{|c|}{ repetidor } \\
\hline JOSEPH & \multicolumn{1}{|c|}{ AMANI } & \multicolumn{1}{c|}{ WILLY } \\
\hline $\begin{array}{l}\text { Conocimiento del espacio } \\
\text { físico. }\end{array}$ & $\begin{array}{l}\text { Conocimiento del espacio } \\
\text { físico. }\end{array}$ & (repetidor) \\
\hline $\begin{array}{l}\text { Autonomía para moverse } \\
\text { por el centro. }\end{array}$ & $\begin{array}{l}\text { Autonomía para moverse por } \\
\text { el centro. }\end{array}$ & (repetidor) \\
\hline $\begin{array}{l}\text { Conocimiento de las } \\
\text { normas básicas del centro y y } \\
\text { de las rutinas escolares: } \\
\text { filas, vestuario, recreo, } \\
\text { horarios, espacios }\end{array}$ & $\begin{array}{l}\text { Conocimiento de las normas } \\
\text { básicas del centro y de las } \\
\text { rutinas escolares: filas, } \\
\text { vestuario, recreo, horarios, } \\
\text { espacios. }\end{array}$ & (repetidor) \\
\hline $\begin{array}{l}\text { Primeras palabras de } \\
\text { interacción: saludos, } \\
\text { nombres de sus } \\
\text { compañeros y profesores, } \\
\text { algún taco, alguna broma, } \\
\text { etc. }\end{array}$ & $\begin{array}{l}\text { Primeras palabras de } \\
\text { interacción: referidas a la } \\
\text { cultura escolar: goma, } \\
\text { estuche, papelera,... }\end{array}$ & $\begin{array}{l}\text { Ya tiene adquirida la lengua: } \\
\text { saluda a algunos } \\
\text { compañeros del curso } \\
\text { superior con los que estuvo } \\
\text { el año pasado. }\end{array}$ \\
\hline $\begin{array}{l}\text { Desconocimiento de los } \\
\text { códigos utilizados entre los } \\
\text { compañeros de su grupo. }\end{array}$ & $\begin{array}{l}\text { Desconocimiento de los } \\
\text { códigos utilizados entre los } \\
\text { compañeros de su grupo. }\end{array}$ & $\begin{array}{l}\text { Desconocimiento de los } \\
\text { códigos utilizados entre los } \\
\text { compañeros de su grupo. }\end{array}$ \\
\hline $\begin{array}{l}\text { Autonomía para } \\
\text { relacionarse. No acude al }\end{array}$ & $\begin{array}{l}\text { Protección absoluta de su } \\
\text { hermano pequeño en los }\end{array}$ & $\begin{array}{l}\text { No interacciona con su } \\
\text { hermana pequeña en los }\end{array}$ \\
\hline
\end{tabular}




\begin{tabular}{|l|l|l|}
\hline $\begin{array}{l}\text { alumno mediador, salvo } \\
\text { para ir a casa juntos. }\end{array}$ & $\begin{array}{l}\text { tiempos compartidos: recreo } \\
\text { y apoyos. }\end{array}$ & espacios comunes. \\
\hline $\begin{array}{l}\text { No va nadie a buscarle. A } \\
\text { veces va con otro alumno } \\
\text { búlgaro. }\end{array}$ & $\begin{array}{l}\text { No va nadie a buscarla al } \\
\text { terminar al colegio. Va ella } \\
\text { con su hermano pequeño a } \\
\text { casa. }\end{array}$ & $\begin{array}{l}\text { No va nadie a buscarle al } \\
\text { terminar al colegio. Va él solo } \\
\text { con su hermana pequeña. }\end{array}$ \\
\hline \multicolumn{2}{|c|}{ ACCIONES EDUCATIVAS } \\
\hline Material específico en las clases para trabajar vocabulario español con Joseph y Amani. \\
\hline $\begin{array}{l}\text { Reunión de sensibilización sobre las diferentes procedencias del alumnado con todos los } \\
\text { padres. }\end{array}$
\end{tabular}

Tabla 10.2. Fase $2^{\mathrm{a}}$ : conocimiento de las rutinas básicas.

Con el paso de tan sólo dos semanas, los alumnos van conociendo los primeros aspectos que constituirán el inicio de su socialización escolar: los espacios físicos, las normas básicas de funcionamiento del centro, los nombres de los profesores/as y alumnos/as, o el conocimiento del significado de los códigos básicos compartidos entre los iguales (palabras o gestos de iniciación a la conversación, con quién y a qué jugar, diferenciación en la interacción en función del sexo). Estas son algunas de las interacciones manifestadas que caracterizan la segunda fase del proceso de socialización escolar que hemos denominado "conocimiento de las rutinas básicas".

Una vez orientados en el espacio y conocidas las normas básicas del centro, los alumnos objeto de nuestro estudio pudieron centrarse más en su grupo de referencia. En una semana ya habían calmado la ansiedad y desorientación inicial, y ahora, este estado se transforma en un acercamiento hacia sus compañeros/as de clase para conseguir su aceptación. Identificamos que éste se convierte en el objetivo principal para el alumnado nuevo a partir de esta fase: ante la pérdida de seguridad se ponen en marcha todos los mecanismos de los que el niño o la niña disponen para lograr la aceptación y recobrar la seguridad. Un aspecto que caracterizaría esta fase es la búsqueda de personas ("porteros" en palabras de Hammersley y Atkinson,1994) que faciliten el acceso al grupo. Joseph intenta acercarse a los niños líderes del grupo; Willy, viendo el éxito de Joseph, le utiliza a él de portero; y Amani es recibida por un grupo pequeño de niñas. En este primer acercamiento, dado el desconocimiento del contexto y sus códigos, algunos niños y niñas corren el peligro de ser recogidos por las personas que a su vez sufren una 
marginación (normalmente son las más receptivas). Es el caso que hemos apreciado en Esperanza, acogida por Lily (niña excluida del grupo).

En esta fase ya conocen los trayectos para moverse con autonomía por el centro, por lo menos los sitios de uso frecuente (aulas, patio, servicios y filas de entrada) y tienen el horario apuntado, porque los profesores/as se lo han facilitado. Saben qué días y qué tipo de calzado deben traer para la clase de educación física. Esto da bastante seguridad al alumno y le permite poder centrarse más en la interacción con sus iguales.

Los apoyos se empiezan a organizar, por lo que deberán salir de algunas clases para estar con la profesora de compensatoria y trabajar específicamente con ella. Por tanto, se desdoblan las clases y con ello el tipo de interacción en cada una. La clase de apoyo es más personal, se establecen lazos más íntimos con la profesora y con los compañeros y compañeras que en las clases formales. Este doble código es aprendido rápidamente por los tres alumnos nuevos.

Nos fijamos en las primeras palabras que aprenden y usan para establecer contacto con sus compañeros. Lo primero que aprende Joseph es a saludar, a decir tacos del tipo: "coño", "joder", los nombres de sus compañeros y profesores, y a llamar a cada uno por su nombre cuando se dirige a ellos.

Amani sin embargo, aprende las palabras de las fichas que los profesores le dan: "estuche", "goma", "papelera". Todo con un tono muy bajito. Mientras Joseph prefiere asegurar la interacción con la simpatía, la broma, el humor, el destacar para ser observado y valorado por sus compañeros, Amani se aferra a la obediencia de los mayores, a cumplir las normas de la autoridad, a no destacar ante los demás (ni para bien, ni para mal) y se junta a una niña para ir introduciéndose y no estar sola. Encontramos en los niños una necesidad de estar presentes en el grupo, de ser valorados y tenidos en cuenta. Esta será la primera necesidad de estos tres niños inmigrantes.

Willy, a pesar de hablar español, todavía no conoce los códigos sutiles 0 usos sociales que los alumnos de su grupo utilizan para reírse, para gastarse bromas, para comunicarse. Se acerca físicamente, sonríe, imita conductas, pero no establece diálogo. Mientras todos los alumnos se acercan a Joseph, Willy cae en el olvido. Él lo percibe y desarrollará una serie de estrategias para conseguir la atención de los demás. Las veremos más adelante.

Es en este momento en el que los espacios escolares (recreo, filas, servicios y clases) empiezan a cobrar significado para los alumnos nuevos. Como hemos visto en epígrafes anteriores, en estos lugares se desarrollan usos y códigos verticales y horizontales influyentes entre sí. Las observaciones realizadas en estos 
espacios y lugares durante esta segunda fase nos ponen de manifiesto que Joseph, Amani y Willy no participan todavía de los códigos que el grupo tiene respecto a bromas entre sexos. No conocen aún algunas características que definen las relaciones sociales entre los alumnos como la jerarquía o estatus social establecido en el grupo, quiénes son los marginados, quiénes son gitanos y qué atribuciones le otorgan a este colectivo los alumnos del centro. Sin embargo, van ganando en autonomía para desenvolverse en el centro y conociendo las formas básicas de acercarse a los iguales para jugar o trabajar juntos en clase. Esto será un primer paso para profundizar en las relaciones con sus compañeros y compañeras.

\section{- Acciones educativas y reflexiones sobre la segunda fase}

Al igual que en la fase anterior, comentamos algunos aspectos escolares que, según los datos obtenidos, nos indican que han influido en la construcción de las relaciones sociales de estos alumnos. Nos referimos en este momento a:

- Descoordinación entre tutora y profesora de compensatoria.

- Desconocimiento de las funciones de cada una respecto a los alumnos inmigrantes.

- Profesora de compensatoria nueva en el centro, recién llegada de otro colegio.

- Seguimiento del Plan de Acogida en general, pero con detalles que se olvidan. De ahí la importancia de escribirlo para seguirlo. Por ejemplo, no asegurarse el primer día de con quién juegan en el recreo.

- Gran ayuda al presentar a los mediadores para que ellos tengan un punto de referencia y sepan dónde acudir a preguntar en su idioma.

- Gran ayuda a fin de no ponerlos en la misma clase para que así se abran a los niños y niñas de su clase y no se junten entre ellos y hagan guetos.

- Hablar a los niños/as en clase previamente ayuda a que quieran acercarse al nuevo. Por el contrario, no hacerlo consigue lo opuesto, como ocurrió con Willy, pues los niños/as se olvidaron de él.

La situación familiar de cada alumno o alumna también influye en el modo en el que éstos se muevan por el medio educativo. En estos momentos, las familias suelen estar muy ocupadas con problemas básicos de asentamiento como la vivienda, las ayudas sociales, los papeles para obtener la legalidad, encontrar trabajo, etc. Este estrés puede repercutir en la situación educativa del alumnado manifestando éste más inseguridades para establecer vínculos con sus compañeros y compañeras. Estos factores institucionales y familiares van influyendo en la adaptación del alumnado inmigrante nuevo. 
Fase $3^{a}$ : Aprendizaje de los códigos verticales y horizontales.

- Descripción de la tercera fase

\begin{tabular}{|l|l|l|}
\hline \multicolumn{2}{|c|}{ Proceso de integración de los dos alumnos inmigrantes nuevos y del alumno } \\
repetidor \\
\hline \multicolumn{1}{|c|}{ JOSEPH } & \multicolumn{1}{|c|}{ AMANI } & \multicolumn{1}{c|}{ WILLY } \\
\hline $\begin{array}{l}\text { Primeros acercamientos } \\
\text { a los códigos utilizados } \\
\text { por los iguales: bromas, } \\
\text { motes, tacos. }\end{array}$ & $\begin{array}{l}\text { No conoce los códigos } \\
\text { utilizados por los iguales. }\end{array}$ & $\begin{array}{l}\text { Conoce los códigos de los } \\
\text { iguales porque ya lleva un } \\
\text { año en el centro. }\end{array}$ \\
\hline $\begin{array}{l}\text { Muestra habilidades para } \\
\text { que se fijen en él: pintar, } \\
\text { hacer bromas, reír,... }\end{array}$ & $\begin{array}{l}\text { No se junta a los niños, } \\
\text { sólo a las niñas. }\end{array}$ & No le dejan jugar al fútbol. \\
\hline $\begin{array}{l}\text { Imita conductas que ve } \\
\text { en sus compañeros: } \\
\text { risas, empujones, }\end{array}$ & $\begin{array}{l}\text { Una niña se ofrece a } \\
\text { ayudarla, la coge de la } \\
\text { mano para que la siga. }\end{array}$ & $\begin{array}{l}\text { Le acusan a la profesora de } \\
\text { cosas que no ha hecho. }\end{array}$ \\
\hline $\begin{array}{l}\text { Los profesores y } \\
\text { alumnado descubren las } \\
\text { habilidades y rasgos } \\
\text { personales de los niños } \\
\text { nuevos. }\end{array}$ & $\begin{array}{l}\text { Obediencia en todo lo que } \\
\text { le dicen. }\end{array}$ & $\begin{array}{l}\text { Se burlan de él y le agreden } \\
\text { verbalmente. Sufre exclusión } \\
\text { por parte de sus } \\
\text { compañeros. Los niños } \\
\text { prueban los "límites" del } \\
\text { nuevo. }\end{array}$ \\
\hline $\begin{array}{l}\text { Admiración de los niños } \\
\text { por: transmisión de los } \\
\text { refuerzos del } \\
\text { profesorado, por sus } \\
\text { habilidades de } \\
\text { comunicación, } \\
\text { extroversión, capacidad } \\
\text { de adaptación. }\end{array}$ & $\begin{array}{l}\text { No habla, sólo mira, } \\
\text { asiente e imita } \\
\text { tímidamente. Mira al suelo } \\
\text { cuando alguien le dice } \\
\text { algo. }\end{array}$ & $\begin{array}{l}\text { No responde con violencia o } \\
\text { agresión ante esta } \\
\text { discriminación. Se calla, } \\
\text { pone gesto triste. }\end{array}$ \\
\hline $\begin{array}{l}\text { Los niños se lo rifan para } \\
\text { jugar al fútbol, las niñas } \\
\text { para que juegue con } \\
\text { ellas. }\end{array}$ & $\begin{array}{l}\text { Sólo habla en las clases de } \\
\text { apoyo cuando la profesora } \\
\text { le pregunta expresamente. } \\
\text { Responde bajito. }\end{array}$ & $\begin{array}{l}\text { Desarrolla estrategias para } \\
\text { ser aceptado: imitar las } \\
\text { broma que los líderes } \\
\text { realizan, juntarse a los } \\
\text { líderes, imitar a Joseph, } \\
\text { meterse en el juego sin que }\end{array}$ \\
\hline
\end{tabular}




\begin{tabular}{|c|c|c|}
\hline & & $\begin{array}{l}\text { se den cuenta, ocupar el rol } \\
\text { del juego que nadie quiere } \\
\text { (ser portero), traer material } \\
\text { de juego (guantes),... }\end{array}$ \\
\hline $\begin{array}{l}\text { En clase todos } \\
\text { interaccionan con él en } \\
\text { los descansos. }\end{array}$ & $\begin{array}{l}\text { Muestra continua } \\
\text { preocupación por su } \\
\text { hermano pequeño. }\end{array}$ & $\begin{array}{l}\text { Muestra inseguridad y } \\
\text { ansiedad en las interacciones } \\
\text { con los iguales. }\end{array}$ \\
\hline $\begin{array}{l}\text { Muestra seguridad en las } \\
\text { interacciones sociales. }\end{array}$ & & \\
\hline $\begin{array}{l}\text { Mejora rápidamente el } \\
\text { idioma, pero todavía no lo } \\
\text { domina. }\end{array}$ & & \\
\hline $\begin{array}{l}\text { En clase de educación } \\
\text { física todos se quieren } \\
\text { poner con él. }\end{array}$ & $\begin{array}{l}\text { En clases de educación } \\
\text { física alguna vez se queda } \\
\text { sola cuando se tienen que } \\
\text { poner en parejas. }\end{array}$ & $\begin{array}{l}\text { En clase de educación física } \\
\text { se queda solo cuando se } \\
\text { tienen que poner en parejas. }\end{array}$ \\
\hline $\begin{array}{l}\text { Resultados sociométricos } \\
\text { muy buenos. Sale como } \\
\text { uno de los líderes. }\end{array}$ & $\begin{array}{l}\text { Resultados sociométricos } \\
\text { situados en la media-baja. } \\
\text { La consideran una alumna } \\
\text { triste. }\end{array}$ & $\begin{array}{l}\text { Resultados sociométricos } \\
\text { muy bajos. }\end{array}$ \\
\hline \multicolumn{3}{|c|}{ ACCIONES EDUCATIVAS } \\
\hline \multicolumn{3}{|c|}{ La tutora refuerza las acciones de Joseph en clase. Le hace participar. } \\
\hline \multicolumn{3}{|c|}{ Empiezan los apoyos para estos alumnos. } \\
\hline \multicolumn{3}{|c|}{$\begin{array}{l}\text { Se comparte información con la monitora de la asociación de inmigrantes que } \\
\text { colabora en la integración de estos alumnos. }\end{array}$} \\
\hline \multicolumn{3}{|c|}{$\begin{array}{l}\text { Cada profesor prepara algún material alternativo adaptado para que realice cuando } \\
\text { está en clase. }\end{array}$} \\
\hline
\end{tabular}

Tabla 10.3. Fase 3a: aprendizaje de los códigos verticales y horizontales.

En este momento notamos un salto cualitativo en las interacciones entre los alumnos inmigrantes nuevos y los veteranos. Así como en la fase anterior los nuevos comprendieron la dinámica general del centro, ahora paralelamente, van profundizando en el conocimiento del funcionamiento del aula donde se desarrollan 
procesos psico-sociales sutiles entre los iguales. Ello les lleva a relativizar el valor de los códigos verticales para ponerlos en función de los horizontales. Se aprecia, por tanto, en esta fase algunos juegos con la norma del adulto para agradar a los iguales.

En este proceso toman relevancia aspectos tales como las habilidades sociales y de comunicación, la seguridad y autoestima, la situación personal y familiar, el rendimiento académico y el estatus social que cada alumno o alumna ocupa dentro del grupo.

Cada uno de estos tres alumnos sigue procesos algo diferentes. Veamos uno por uno.

Joseph, el alumno búlgaro, como vemos en el cuadro, muestra una integración más llamativa que los otros dos alumnos. Las interacciones sociales son más ricas y abundantes gracias a sus habilidades sociales. Además, su situación familiar y académica lo facilitan también. Ello le coloca en una situación de seguridad personal percibida por sus compañeros/as, de los que a su vez recibe feedbacks positivos: los niños lo admiten fácilmente en los juegos del recreo, las niñas se acercan constantemente a él y en las clases de Educación Física no le faltan parejas de juego (los resultados sociométricos reflejan esta popularidad).

Amani interacciona de forma diferente con sus compañeros y compañeras. En principio sólo lo hace con las niñas de su clase. Está pendiente en todos los momentos libres de su hermano, dándole prioridad incluso sobre sus iguales. A veces esto le impide jugar con sus amigas. Sin embargo, sus compañeras de clase la aceptan y la integran en sus grupos de juego, haciéndose cargo incluso de su hermano pequeño para que no abandone estos momentos de ocio compartido. Durante las clases formales, apenas se acerca a sus compañeros ni hace nada por conseguirlo, sino que permanece estática, mirando a un punto fijo 0 realizando la tarea que la encomiendan. En las clases de apoyo, en cambio, establece más comunicación corporal con la profesora, mostrándole las tareas que realiza y trabajando obediente y cuidadosamente en ellas. Durante las clases de educación física suele estar con las niñas con las que juega en el recreo, o sola, o al lado de quien se le acerque.

En este momento Willy sufre ataques directos por parte de sus compañeros, se meten con él, se ríen de él y no le dejan jugar en los juegos del recreo en los que ellos protagonizan y dirigen la acción. Sus respuestas, con todo, no son agresivas, sino que intenta a través de diversas estrategias acercarse al grupo líder de la clase. Algunas de estas estrategias sociales utilizadas son: juntarse e imitar a Joseph, acercarse al juego cuando ya están hechos los equipos para no tener que sufrir la exclusión, ocupar los puestos dentro del juego que nadie quiere 
ocupar, traer material para que le permitan jugar aunque sea por el interés de los objetos que trae. Todas estas acciones manifiestan cierta ansiedad al rechazo. Los resultados sociométricos realizados en esta época reflejan estas relaciones explicadas. Las estrategias de interacción que este alumno tiene que desarrollar, debido a su bajo estatus social, son más afanosas que las de los dos alumnos anteriores, puesto que parte de una situación de inferioridad considerable.

\section{- Acciones educativas y reflexiones sobre la tercera fase}

- La acción educativa más significativa de esta etapa es la organización de los apoyos. Transcurrido casi un mes, empezaron las clases de apoyo para los alumnos que las necesitaban. Entre ellos estaban estos tres alumnos, dado el déficit lingüístico y curricular (caso de Willy). Lo más destacable respecto a las interacciones que encontramos en estas clases fue el clima de seguridad y protagonismo de los alumnos que se creó en este ambiente. Como hemos detallado en apartados anteriores, estas clases crearon un clima de confianza con la profesora. Al ser pocos en la clase participan e interactúan en mayor medida, al tiempo que existe un seguimiento más intenso e individualizado de cada uno.

- Cuando estos alumnos están en las clases normales, los maestros y maestras les dan alguna tarea alternativa para que no estén ociosos. En muchos casos, estas actividades eran improvisadas. No existe un material específico, planificado y programado para estas clases. El profesorado delega en la labor de las clases de apoyo y la maestra de apoyo se queja de que no exista colaboración entre ambos en el proceso de aprendizaje de estos niños y niñas.

- Por otro lado, consideramos necesario mencionar la coordinación entre profesorado de las diferentes áreas y los de compensatoria para que se produzca aprendizaje, rendimiento académico y mejora en las interacciones sociales entre iguales como consecuencia.

Tal y como nos indica Coelho (2006), una vez superado el shock cultural ${ }^{2}$ de la fase inicial, observamos cómo se produce un sentimiento renovado de optimismo y autonomía. Además superar las fases anteriores con cierta solvencia desarrolla estrategias y habilidades sociales que mejoran la competencia social y esto podrá hacerles salir adelante en otras ocasiones a lo largo de su vida. Una clave para el progreso del alumnado nuevo inmigrante que detectamos en este momento es el del aprendizaje de la lengua a un nivel medio con el que entenderse con sus compañeros. Esto va proporcionando al alumnado un estado de seguridad,

\footnotetext{
2 Ya indicábamos antes, que a nuestro modo de ver el choque cultural no se produce en los primeros compases del proceso, sino más bien a lo largo de las fases $2^{\mathrm{a}}$ y $3^{\mathrm{a}}$ dado que en ellas las personas nuevas han reducido sus niveles de ansiedad, y pueden centrar su percepción en el descubrimiento de los códigos que contrastan con los de su socialización primaria.
} 
al sentirse competente frente a diferentes situaciones sociales, al ser capaces de comunicarse de forma adecuada en muchas situaciones cotidianas y sentir que realizan progresos en el aprendizaje.

Hemos apreciado en los tres casos cómo su mayor afán se centra en la integración en los grupos de iguales. Cada uno despliega sus propias estrategias y lucha contra los condicionantes, tanto personales como los relativos a las expectativas de los demás hacia ellos. En todos los casos, la imitación y la actitud afable y sumisa se constituyen en las herramientas básicas a las que van recurriendo para aprender los códigos horizontales y verticales. Una actitud agresiva, prepotente o impaciente podría dar al traste con el frágil proceso de aceptación en el grupo de iguales.

\section{Fase $4^{\text {a: }}$ Primera definición del estatus dentro del grupo.}

\section{- Descripción general de la cuarta fase}

\begin{tabular}{|l|l|l|}
\hline \multicolumn{2}{|c|}{ Proceso de integración de los dos alumnos inmigrantes nuevos y del alumno } \\
repetidor \\
\hline \multicolumn{1}{|c|}{ JOSEPH } & \multicolumn{1}{|c|}{ AMANI } & \multicolumn{1}{c|}{ WILLY } \\
\hline $\begin{array}{l}\text { Interpreta mal algunos } \\
\text { comentarios de los niños y } \\
\text { se enfada, se piensa que le } \\
\text { insultan. Se le pasa rápido. }\end{array}$ & $\begin{array}{l}\text { Muestra autonomía en el } \\
\text { movimiento por el centro } \\
\text { escolar. }\end{array}$ & $\begin{array}{l}\text { Imita cada vez más las } \\
\text { conductas de los líderes: } \\
\text { reírse de otros, } \\
\text { empujoncitos en las filas } \\
\text { para hacer gracia. }\end{array}$ \\
\hline $\begin{array}{l}\text { Pierde el marcado } \\
\text { protagonismo del principio } \\
\text { ante sus compañeros. }\end{array}$ & $\begin{array}{l}\text { Sigue pendiente de su } \\
\text { hermano pequeño } \\
\text { aunque le da un poco } \\
\text { más de libertad. }\end{array}$ & $\begin{array}{l}\text { No juega, ni se acerca a las } \\
\text { niñas. }\end{array}$ \\
\hline $\begin{array}{l}\text { Enfrentamiento con Amani. } \\
\text { Comentarios racistas } \\
\text { acerca de los árabes. }\end{array}$ & $\begin{array}{l}\text { Las niñas de su clase } \\
\text { juegan con ella en el } \\
\text { recreo y están } \\
\text { pendientes también de } \\
\text { su hermano. Cada vez } \\
\text { hay más niñas en el } \\
\text { grupo. La utilizan como } \\
\text { instrumento de disputa } \\
\text { en sus rencillas entre los } \\
\text { bandos. }\end{array}$ & $\begin{array}{l}\text { Tira piedritas a su hermana } \\
\text { en el recreo para que no } \\
\text { se acerque a él. }\end{array}$ \\
\hline
\end{tabular}




\begin{tabular}{|c|c|c|}
\hline $\begin{array}{l}\text { Trae pastas por su } \\
\text { cumpleaños. }\end{array}$ & $\begin{array}{l}\text { Obedece y cumple todas } \\
\text { las normas que los } \\
\text { profesores y } \\
\text { compañeras establecen. }\end{array}$ & $\begin{array}{l}\text { Ya no le echan del fútbol } \\
\text { en el recreo. Sigue } \\
\text { utilizando estrategias para } \\
\text { conservar su puesto en el } \\
\text { juego: trae guantes } \\
\text { profesionales de portero, } \\
\text { pasa el balón a los líderes, } \\
\text { imita sus conductas, ... }\end{array}$ \\
\hline $\begin{array}{l}\text { En clase de educación } \\
\text { física se pone con Willy de } \\
\text { pareja. }\end{array}$ & $\begin{array}{l}\text { Imita las acciones de sus } \\
\text { compañeras en el juego. }\end{array}$ & $\begin{array}{l}\text { Está pendiente de mi } \\
\text { mirada continuamente. Se } \\
\text { siente observado. }\end{array}$ \\
\hline & $\begin{array}{l}\text { Tras el enfrentamiento } \\
\text { con Joseph, se sienta } \\
\text { ella sola, apartada de } \\
\text { todos en la clase de } \\
\text { apoyo por decisión } \\
\text { propia. }\end{array}$ & \\
\hline & $\begin{array}{l}\text { Se esfuerza mucho por } \\
\text { aprender. }\end{array}$ & \\
\hline & $\begin{array}{l}\text { Profundiza más en la } \\
\text { relación con una de las } \\
\text { niñas del grupo. }\end{array}$ & \\
\hline \multicolumn{3}{|c|}{ ACCIONES EDUCATIVAS } \\
\hline \multicolumn{3}{|c|}{$\begin{array}{l}\text { En la clase de Joseph y Willy cambia el orden de los pupitres. Willy se sienta al lado } \\
\text { del líder de clase (según los sociogramas). }\end{array}$} \\
\hline \multicolumn{3}{|l|}{ Siguen con los apoyos. } \\
\hline \multicolumn{3}{|c|}{ Reunión de los padres con cada tutor de curso. } \\
\hline \multicolumn{3}{|c|}{$\begin{array}{l}\text { Trabajan un CD para sensibilizar a los alumnos/as de las diversas culturas de } \\
\text { procedencia del alumnado inmigrante nuevo. }\end{array}$} \\
\hline \multicolumn{3}{|c|}{$\begin{array}{l}\text { A Willy le dejan ir a la misma clase de apoyo que Joseph y los de su curso aunque } \\
\text { su nivel curricular es de } 3^{0} \text { de Primaria. }\end{array}$} \\
\hline
\end{tabular}

Tabla 10.4. 4ª fase: primera definición del estatus dentro del grupo. 
Esta fase se caracteriza por la finalización del período que hemos llamado "efecto novedad" que producen los alumnos nuevos al llegar al grupo. Han pasado dos meses desde que empezó el curso y las interacciones sociales entre los escolares sufren un punto de inflexión en cuanto a la intensidad. En el caso de Joseph pasan de ser extraordinarias, a cobrar un tono de normalidad. En el caso de Amani, se caracteriza por el mantenimiento y la estabilidad de las mismas relaciones con las que empezó. En el de Willy, por la constancia en el despliegue de estrategias para no seguir sufriendo exclusión por parte de sus compañeros de clase y su paciencia ante los rechazos. Las acciones educativas que se encargan de mantener la atención sobre estos alumnos son las que a partir de ahora empiezan a cobrar importancia.

Las situaciones personales de cada uno acontecen del siguiente modo. A Joseph le ha costado muy poco comprender cuáles son los códigos con los que sus compañeros se comunican, a pesar de que a veces se producen malentendidos que reflejan que no ha aprendido todavía los giros de la lengua y que tiene ciertas inseguridades por ser nuevo e inmigrante (en esta fase se ponen de manifiesto más claramente los choques culturales). Ejemplo de esta afirmación es el "enfado" que se produjo en estas semanas por parte de este alumno al creer que le llamaban "hijo puta" sus compañeros. Se producen enfrentamientos entre dos alumnos inmigrantes nuevos: Joseph y Amani. En este encuentro Joseph manifestó argumentos racistas sobre los árabes. Sin embargo, este alumno comprende muy bien cuáles son las conductas que debe realizar para integrarse e interactuar en el grupo. Así pues, el día de su cumpleaños trajo pastas para compartirlas con sus compañeros.

Por otro lado, vemos cómo las relaciones con sus compañeros se han reducido en gran medida. Él ya no necesita demostrar continuamente sus habilidades, se le ve más seguro, y a la vez sus compañeros tampoco están tan pendientes de él.

Amani, continúa jugando con las niñas de su clase que se acercaron a ella un primer día y de las que no se separa. Con los niños apenas tiene relación. Sigue prácticamente sin hablar. Sus amigas la aceptan casi muda y la cogen de la mano cuando quieren que haga algo. Ella aprende imitando, respeta las normas que ellas establecen y a veces es objeto de disputas entre bandos de niñas. Es decir, la hacen elegir para que juegue con unas u otras, ella no quiere hacerlo y dice que quiere jugar con todas. Parece ser que el posicionamiento en un bando u otro supone una fuerza para intensificar lazos entre cada grupito. Amani ni entiende esto ni quiere hacerlo, cuando hay malentendidos se va con su hermano y vuelve a incorporarse cuando el embrollo se ha resuelto. 
Willy, empieza a ver recompensada su insistencia en ser aceptado por los líderes del grupo-clase. Le dejan jugar en el recreo al fútbol, aunque casi siempre esté de portero. En un momento determinado consigue que esta figura, en vez de ser la última opción, sea disputada entre ellos. Esto lo logra con los guantes profesionales que trae para jugar, lo cual revaloriza la figura del portero en el fútbol. Este alumno, al igual que Amani, tampoco interactúa con el sexo opuesto. Pero creemos que por razones distintas: ella por timidez y quizá por cuestiones relacionadas con su cultura; él por cuidar una de las reglas básicas que los niños tienen establecidas entre ellos para ser populares: no jugar con las niñas y menos con las pequeñas. De ahí que cuando ve a su hermana pequeña por el patio acercarse a él, le lance piedritas en los pies para que se aleje y no destruya todos los esfuerzos realizados por conseguir un cierto estatus en el grupo.

\section{- Acciones educativas y reflexiones sobre la cuarta fase}

- La tutora establece contacto con las familias de sus alumnos y alumnas para colaborar juntos en el proceso de aprendizaje de los niños y niñas.

- Se realiza una evaluación curricular adaptada en estos escolares al finalizar el primer trimestre. Los resultados son positivos, salvo en el caso de Willy en el que valoran positivamente la actitud, pero no el rendimiento obtenido.

- La tutora de la clase de Joseph y Willy interviene en algún caso en el que ve exclusión en el recreo.

- En este mes trabajan con la tutora en un CD de sensibilización hacia la cultura búlgara y marroquí en la clase de informática, considerando aspectos relacionados con el conocimiento de estos alumnos y el respeto por ellos.

- En un principio a Willy le colocaron en el grupo de apoyo de los niños de $3^{0}$ de Primaria por ser el nivel curricular que le pertenecía, una vez hecha la prueba. A él no le gustaba estar con los más pequeños y poco a poco se fue colando en las clases con Joseph y Amani hasta que la profesora lo permitió (siguió la misma estrategia utilizada para "colarse" en los partidos de fútbol del recreo). En estos momentos Willy interactuaba más que en fases anteriores y su rendimiento académico, dentro de su bajo nivel, era más activo y eficaz. Esto nos advirtió de que quizá las pruebas curriculares en determinados casos se deberían poner en un segundo plano, siendo más importante para el aprendizaje crear un clima socioemocional agradable.

Estas clases permitieron establecer vínculos de amistad entre Joseph y Willy. Compartiendo experiencias semejantes se acercaron algo más (observamos detalles como intercambiarse las direcciones de correo electrónico para escribirse). 
- Realizar actividades extraescolares comunes une a los padres, estrecha los vínculos y consigue introducir en la comunidad en su totalidad. Ninguno de estos tres alumnos participan de ello.

- Hasta ahora los códigos y usos horizontales, entre iguales, que van aprendiendo en el contexto escolar les permiten dar calidad en las interacciones sociales en el grupo. Estos serían:

o Diferencias en la comunicación y cultura de los niños y las niñas. Los primeros valoran aspectos como la broma, unirse para reírse de alguien escudándose en que es broma, no ser violento durante el juego, hacerse favores como pasarse el balón, ponerse juntos de pareja, o colarse en la fila para estar de los primeros. Las niñas, en cambio, valoran la fidelidad en el juego, es decir, no cambiar de pareja o grupo de juego, el buen carácter (no ser agresivo), cumplir las normas de los juegos, no hacer trampa, 0 acompañar a ir a los sitios.

o Rechazo a los gitanos.

o Jugar con los de la misma clase.

o Desafiar en su justa medida al docente: metiéndose en los servicios entre horas y jugar con el agua, levantarse y tirar papeles en los cambios de maestros, saludar a los de otra clase, etc.

o Participar de ciertas gracias que entre ellos tienen en común (algunas muy contextuales, basadas en la televisión: "un poquito de fujitsu").

Una vez pasado un tiempo de escolarización, en nuestro caso fueron cuatro meses, empezamos a presenciar cómo los alumnos nuevos empiezan a adquirir una definición dentro del grupo, ocupan un estatus social dentro de él, de ahí que determinemos la cuarta fase denominada "definición del estatus dentro del grupo". La adquisición de la lengua a un nivel medio les permite hacerse entender sin demasiadas complicaciones con sus compañeros/as, pero hay problemas que van más allá de lo lingüístico. El resto del alumnado suele establecer vínculos con otros niños o niñas del entorno próximo fuera del colegio. Estos lazos se refuerzan y se manifiestan posteriormente en el centro formando grupos de más difícil acceso. El alumnado inmigrante nuevo no tiene la misma facilidad para construir estos contactos y si lo hace es con otros de su misma procedencia, producto de las actividades de los centros sociales de la zona en la que viven. 
Más difícil todavía lo tienen los familiares de este alumnado nuevo. La comunicación entre familias de diversas procedencias se establece en el trabajo 0 en el ámbito de la educación de adultos. Algunas culturas tienen más arraigada la tradición de que la mujer realice las tareas domésticas, lo que dificulta el establecimiento de vínculos con el exterior. Dado que muchas de estas familias mantienen prioritariamente relaciones con familias de su misma procedencia, se da un cierre social que puede ser transmitido a hijos e hijas. Por tanto, se hace necesaria la colaboración entre escuela y asociaciones sociales que faciliten el establecimiento de vínculos entre las familias de diversas procedencias y las autóctonas.

\section{Fase $5^{a}$ : Consolidación del estatus dentro del grupo. Aculturación}

\section{- Descripción general de la quinta fase}

\begin{tabular}{|l|l|l|}
\hline \multicolumn{2}{|c|}{ Proceso de integración de los dos alumnos inmigrantes nuevos y del alumno } \\
\multicolumn{1}{|c|}{ repetidor } \\
\hline \multicolumn{1}{|c|}{ JOSEPH } & \multicolumn{1}{|c|}{ AMANI } & \multicolumn{1}{c|}{ WILLY } \\
\hline $\begin{array}{l}\text { A veces en las clases de } \\
\text { educación física no tiene } \\
\text { pareja o se pone con Willy. }\end{array}$ & $\begin{array}{l}\text { Tiene momentos de } \\
\text { tristeza. Llora en clase } \\
\text { de apoyo. }\end{array}$ & $\begin{array}{l}\text { Juega con sus compañeros } \\
\text { de clase al fútbol. }\end{array}$ \\
\hline $\begin{array}{l}\text { En el recreo le pasan } \\
\text { menos que antes el balón } \\
\text { durante el juego. }\end{array}$ & $\begin{array}{l}\text { Rictus serio. Apenas } \\
\text { sonríe. No expresa } \\
\text { nada. Se cierra a los } \\
\text { demás. No se deja } \\
\text { ayudar. }\end{array}$ & $\begin{array}{l}\text { Muestra continuos deseos } \\
\text { de agradar, pero sin llamar } \\
\text { la atención. }\end{array}$ \\
\hline $\begin{array}{l}\text { Los profesores también le } \\
\text { refuerzan menos. Incluso le } \\
\text { riñen a veces. }\end{array}$ & $\begin{array}{l}\text { Sólo se relaciona con un } \\
\text { grupito de niñas de su } \\
\text { clase. Se separa de los } \\
\text { demás (posiblemente su } \\
\text { situación familiar } \\
\text { irregular le haga no } \\
\text { querer abrirse mucho). }\end{array}$ & $\begin{array}{l}\text { No se enfada por nada. No } \\
\text { responde mal ante } \\
\text { comentarios que no le } \\
\text { gustan. }\end{array}$ \\
\hline $\begin{array}{l}\text { Rendimiento académico en } \\
\text { clase de apoyo muy bueno. }\end{array}$ & $\begin{array}{l}\text { Se une a un niño } \\
\text { marroquí nuevo que } \\
\text { llega a mitad de curso. }\end{array}$ & $\begin{array}{l}\text { Sigue mostrando } \\
\text { inseguridad y ansiedad en } \\
\text { sus movimientos. }\end{array}$ \\
\hline $\begin{array}{l}\text { Rápido aprendizaje de la } \\
\text { lengua, Gran mejoría. }\end{array}$ & $\begin{array}{l}\text { Trabaja los contenidos } \\
\text { con esfuerzo e interés. }\end{array}$ & \\
\hline
\end{tabular}




\begin{tabular}{|l|l|l|}
\hline $\begin{array}{l}\text { Entiende casi todo y se } \\
\text { expresa bastante bien. }\end{array}$ & \\
\hline $\begin{array}{l}\text { Establece lazos más } \\
\text { estrechos con Willy en las } \\
\text { clases de apoyo }\end{array}$ & \\
\hline $\begin{array}{l}\text { Resultados sociométricos: } \\
\text { medios. Ha bajado su } \\
\text { estatus respecto a la 1a } \\
\text { prueba, considerablemente. }\end{array}$ & $\begin{array}{l}\text { Resultados } \\
\text { sociométricos: medios. } \\
\text { Su estatus ha subido } \\
\text { levemente. Permanece } \\
\text { casi igual. }\end{array}$ & $\begin{array}{l}\text { Resultados sociométricos: } \\
\text { medios. Su estatus en el } \\
\text { grupo ha subido } \\
\text { considerablemente. }\end{array}$ \\
\hline \multicolumn{2}{|c|}{ ACCIONES EDUCATIVAS } \\
\hline Seguimiento individual curricular de los alumnos. \\
\hline Tutores/as hablan especialmente con padres de algunos alumnos/as inmigrantes. \\
\hline
\end{tabular}

Tabla 10.5. $5^{a}$ fase: consolidación del estatus dentro del grupo. Aculturación.

Los resultados sociométricos realizados en esta fase demuestran lo que las observaciones nos venían diciendo. Se producen cambios en sus interacciones sociales de forma paralela a la modificación de su estatus social. Joseph empeora, pero sigue siendo aceptado. Amani se mantiene y atisba una leve mejoría de integración y Willy mejora considerablemente respecto a su grupo-clase. Las causas de esta inflexión se deben al tiempo de escolarización, a la constancia de las estrategias utilizadas por Willy para ser aceptado por sus compañeros, al carácter tranquilo y agradable de Amani y Willy y, por fin, al despliegue continuo de estrategias para ser aceptado por Joseph.

\section{- Seguimiento individual}

Ya veníamos haciéndonos eco de los cambios que la trayectoria de estos alumnos inmigrantes experimentaron pasado el primer trimestre. En esta fase se consolida el estatus de cada uno de ellos en su grupo respectivo. A partir de ahora los cambios existentes en las interacciones responderán en mayor medida al comportamiento de cada uno. La influencia escolar seguirá siendo muy importante, pero al poder los alumnos desenvolverse con cierta autonomía, la dependencia del adulto será menor y esto permitirá que el niño organice y dirija sus propias interacciones con los demás. La relación con los compañeros y compañeras se va asentando y éstos y éstas van tratando más a la "persona" y no tanto al "personaje", etiquetado al inicio de curso ("el nuevo", "la niña a proteger", "el repetidor"); de manera que el "colchón" que amparaba sus errores (en el caso de Willy, el prejuicio 
que multiplicaba sus defectos) y que condicionaba las interacciones, va cayendo, y éstas comienzan a regirse por las normas habituales de interacción entre iguales (por ejemplo, a Joseph se le perdonan menos cosas y a Willy se le tienen un poco en cuenta sus detalles o su disposición).

Los resultados de cada alumno podemos resumirlos en estos epígrafes.

\begin{tabular}{|l|l|l|}
\hline \multicolumn{2}{|c|}{$\begin{array}{c}\text { Resultados del proceso de integración de los dos alumnos inmigrantes } \\
\text { nuevos y del alumno repetidor }\end{array}$} \\
\hline \multicolumn{1}{|c|}{ JOSEPH } & \multicolumn{1}{|c|}{ AMANI } & \multicolumn{1}{c|}{ WILLY } \\
\hline Integración & Integración & Integración \\
académica alta. & académica media. & académica baja. \\
Integración social & Integración social con & Integración social \\
entre iguales. & iguales: existe cierto & entre iguales baja: \\
Interacciones & aislamiento. & sufre rechazo en un \\
positivas con ambos & Interacciones & principio aunque \\
sexos. & sociales, con alumnos & luego mejora algo. \\
Interacciones & de sexo masculino, & Interacciones \\
positivas con alumnos & inexistentes. & inexistentes con \\
y profesores. & Algún olvido dentro de & niñas. \\
Algún olvido dentro de & las actividades de la & No hay olvido en las \\
las actividades de la & comunidad escolar. & actividades de la \\
comunidad escolar. & Dentro del grupo & comunidad escolar al \\
Dentro del grupo & clase podríamos decir & no ser nuevo. \\
clase podríamos decir & que, aunque mantiene & Dentro del grupo \\
que su trayecto se & un grupo de amigas, & clase podríamos decir \\
acerca más a la & su trayectoria se & que, aún con una leve \\
integración. & acerca más al & mejoría, su trayectoria \\
& aislamiento. & se acerca más a la \\
& & \\
& & \\
& & \\
& & \\
& & \\
& & \\
& & \\
& & \\
& & \\
& & \\
& &
\end{tabular}

Tabla 10.6. Resultados del proceso de integración de los dos alumnos inmigrantes nuevos y del alumno repetidor. 


\section{- Acciones educativas y reflexiones sobre la quinta fase:}

Las acciones educativas en esta fase de consolidación obedecen a las necesidades coyunturales que van surgiendo. La tutora actúa en caso de que observe altercados de interacción conflictiva entre Joseph y otros compañeros. Algunas veces los niños se quejan de que Joseph pega o se enfada. La profesora interviene riñendo a Joseph y explicándoles a los demás que a veces se enfada porque malinterpreta palabras de los otros. Con Willy se preocupa de que la familia participe en la actividad escolar, dado su bajo rendimiento académico. El tutor de Amani espera a que la profesora de compensatoria le explique el seguimiento individual que ha realizado de ella. Una vez finalizado el protocolo oficial del Plan de Acogida, a los tres meses, las acciones educativas que se desarrollan son individuales e improvisadas en función de las necesidades que cada uno manifieste.

A los siete meses, ya en el tramo final del curso, el alumnado nuevo empieza una fase de aculturación aceptando las normas que la escuela les ha establecido. Coelho $(2006,44)$ dice que este momento puede crear algún conflicto interno recreando sus identidades, llegando incluso a rechazar la cultura original y a hablar sólo, y en todos los lugares, en la lengua del país receptor. Esta asimilación completa puede crear conflictos personales rechazando su antiguo yo y negando la identidad. No es éste el objetivo de la educación, ciertamente.

Sin embargo, nuestros ejemplos reflejan que se produce un esfuerzo para integrarse en el centro, aunque en el contexto familiar conservan el idioma y es de suponer que sus costumbres.

La aculturación, o mejor, esta socialización secundaria, implica aceptar la nueva cultura, pero no tiene porqué significar un desarraigo total de la de procedencia. Muchos niños hacen suyos estilos culturales distintos, dependiendo del contexto y de las relaciones entre ellos y los demás en ese contexto. Esto, además, puede desarrollar capacidades socio-cognitivas flexibles y altamente favorables para la convivencia intercultural.

Hemos secuenciado en este capítulo las cinco fases o momentos comunes encontrados en el proceso de integración del alumnado inmigrante nuevo. Joseph, Amani y Willy, los tres protagonistas de este trabajo. Ellos nos han servido para indagar en la integración escolar a partir de las interacciones sociales desarrolladas entre los iguales. Las reflexiones, extraídas de estos personajes, nos han permitido describir algunas características generales de este proceso de integración del que hablamos. Nos gustaría además, que esta descripción analítica pudiera ser útil para los profesionales de al educación que quieren conocer el escenario (desde el punto de vista del alumnado) en el que van a trabajar. 


\title{
Capítulo 11
}

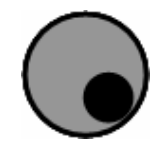

\section{Conclusiones: Aportaciones finales y futuras líneas de investigación.}

\begin{abstract}
En este último capítulo respondemos a los once interrogantes planteados en el capítulo cuatro, en el que exponíamos los objetivos generales de la tesis doctoral. Incorporamos en él, las principales aportaciones de los dos estudios, correspondientes a las dos fases de la investigación. Estas ideas se encuentran desarrolladas y analizadas de forma extensa en los capítulos anteriores, ahora nos limitamos a extraer las conclusiones que consideramos más relevantes. En la segunda sección de este mismo capítulo, describimos las futuras líneas de investigación que se desprenden de la presente tesis doctoral.
\end{abstract}




\section{1.- Aportaciones finales}

Empezamos el capítulo con la tabla que visualizamos al final del párrafo, en ella recordamos los interrogantes que nos plateábamos al comenzar la investigación. El contenido de las páginas que vienen a continuación tratan de responder, de forma sintética, las once preguntas iniciales distribuidas a través de los dos estudios realizados. Recordamos al lector, que los detalles de las explicaciones correspondientes, podrán encontrarse en los capítulos anteriores, aquí sintetizaremos las ideas fundamentales y resaltaremos las principales aportaciones que se extraen de tales respuestas.

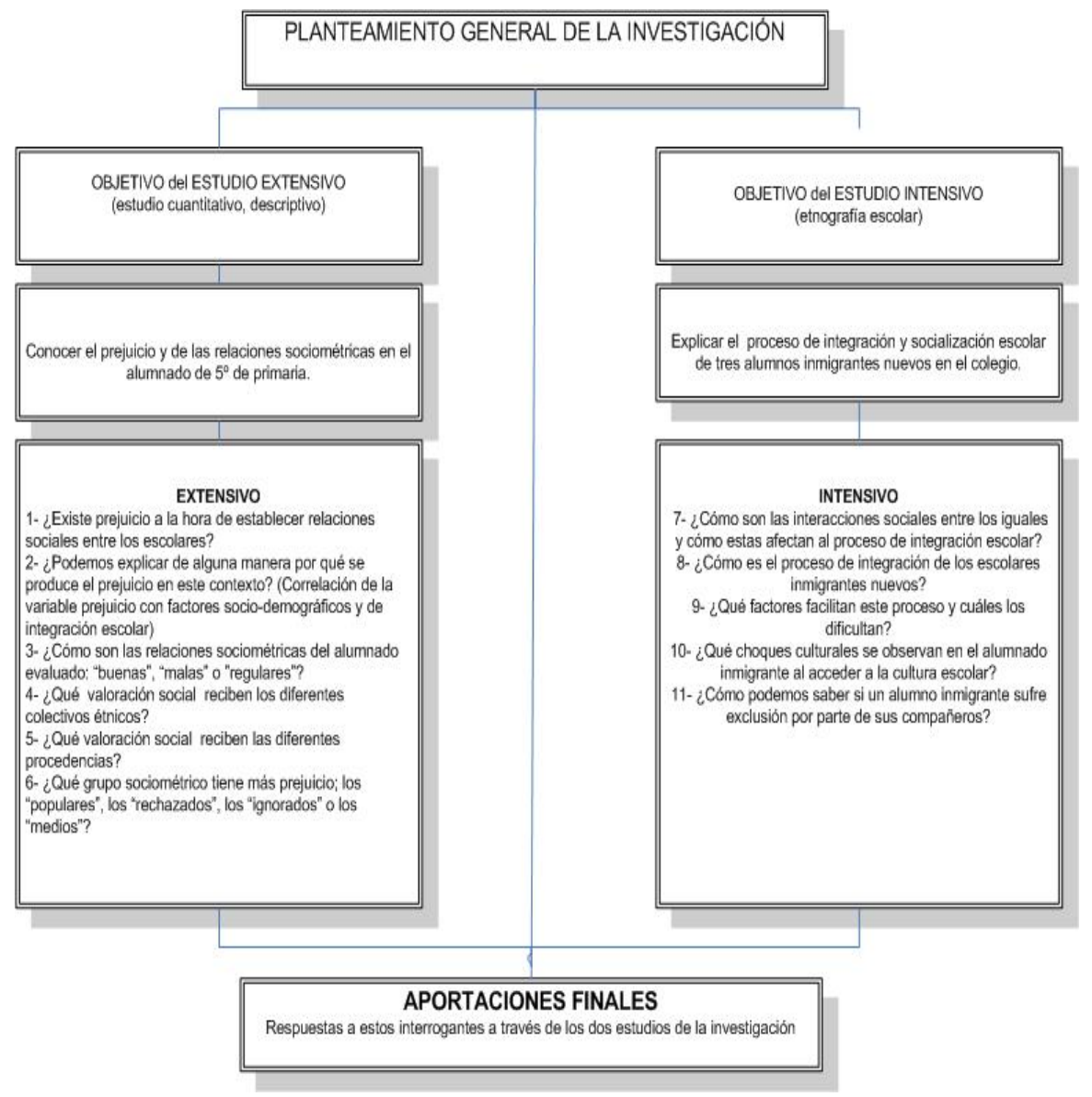

Figura 11.1. Aportaciones finales de la investigación. 


\section{1.- ¿Existe prejuicio a la hora de establecer relaciones sociales entre los escolares?}

Podemos afirmar que los alumnos pertenecientes a los centros educativos de la ciudad de Valladolid poseen ciertas creencias y estereotipos prejuiciosos hacia los sujetos pertenecientes a etnias diferentes a la propia. La expresión de dicho prejuicio se produce de forma sutil y no manifiesta (Pettigrew, y Meertens, 1995). Con esto nos referimos a que los centros educativos evaluados presentan ciertas características que les hacen particulares. Nos explicamos.

De la educación pública siempre se ha esperado que acepte e integre a todos los escolares sin importar la condición social, económica, familiar y étnica que envuelva a cada sujeto. El contexto escolar que analizamos está cubierto de un discurso intercultural que lo diferencia de otras instituciones donde las creencias se manifiestan de forma distinta. A su vez, estos argumentos educativos referidos a la tolerancia y a la inclusión se encuentran marcados por potentes interferencias sociales, familiares, religiosas y publicitarias. Es de esperar, por tanto, que los alumnos, apropiados de este discurso escolar, no expresen en los cuestionarios respuestas racistas abiertas, como muestran los datos. Sin embargo, no todo el alumnado se encuentra en el mismo escalafón de socialización. Los escolares pertenecientes a la etnia gitana parecen no tener igualmente arraigado este discurso intercultural del que puede presumir la escuela y por eso, sus respuestas presentan menos disposición a compartir experiencias con compañeros de otras etnias diferentes a la suya. Además, comprobábamos cómo se han ido generando colegios exclusivos de gitanos, por la progresiva desescolarización de los payos al llegar los primeros. Sería interesante analizar las actuaciones de las políticas educativas ante este fenómeno segregador.

El prejuicio constituye un claro condicionante en la interacción social de los iguales y ésta, a su vez, influye en el proceso de integración escolar en el que se verá inmerso el alumnado inmigrante. De ahí, la decisión de evaluar la situación prejuiciosa, en primer lugar. Si el objetivo del primer estudio fue obtener una radiografía relacional del alumnado entre sí, en el segundo, fue el análisis de la complejidad de matices que recoge el fenómeno de la interacción, entre ellos, el relacionado con el prejuicio, con el estereotipo, con las expectativas otorgadas al escolar que llega nuevo a un centro educativo, procedente de otra nacionalidad. De este modo, el porcentaje global de prejuicio que manifiesta el alumnado se complementa o se incrementa con la multitud de circunstancias y ropajes cualitativos que explican las consecuencias de la actitud prejuiciosa en el proceso de integración escolar. En la siguiente pregunta podemos profundizar más en el tema, ya que se buscan factores explicativos acerca del prejuicio en el entorno educativo. 


\section{2.- ¿Podemos explicar de alguna manera por qué se produce el prejuicio en este contexto? (Relación de la variable prejuicio con factores socio-demográficos y de integración escolar).}

En el marco teórico recogíamos las principales teorías psicosociales, las cuales explicaban la aparición del prejuicio en las personas. Los estereotipos eran transmitidos por fuentes sociales, emocionales y cognitivas. En las primeras se incluían aquellas que tienen que ver con la familia y los medios de comunicación. Éstas son de gran importancia, tratándose de escolares que pasan con sus familias y con la televisión una gran parte del tiempo. En nuestro estudio relacionábamos la variable prejuicio con algunos factores sociodemográficos como el sexo, la etnia, el nivel socioeconómico del centro y la procedencia familiar del alumnado. También relacionábamos el prejuicio con otros factores relativos a la existencia o no de inmigrantes escolarizados en el aula y con la adquisición del idioma.

Estas relaciones apuntaban a que un alumno de sexo masculino, de etnia gitana, escolarizado en un colegio de bajo nivel socioeconómico y que no comparta clase con ningún alumno de otra etnia diferente a la suya, es más proclive a manifestar respuestas prejuiciosas. Expliquemos cada uno de estos factores.

Respecto al género, veíamos como el alumnado masculino mostraba más prejuicio que el femenino. En el colegio donde realizamos el estudio etnográfico comprobamos, al respecto, que las niñas tenían una actitud más abierta y acogedora hacia las personas nuevas, y en muchas ocasiones se hacían responsables de los compañeros inmigrantes que llegaban nuevos a sus clases. Ellas eran las que se preocupaban para que no estuvieran solos en el recreo los primeros días de clase, mientras que los niños estaban más centrados en las actividades lúdicas (fútbol fundamentalmente) con sus amigos de siempre.

Los gitanos, como ya comentamos anteriormente, eran el colectivo étnico que más prejuicio mostraba, seguido de los españoles no gitanos y por último los inmigrantes. Completábamos esta información con los matices que nos ofrecía el estudio etnográfico, en donde veíamos, que éstos últimos, al pertenecer al colectivo minoritario, se esforzaban por integrarse incluso desprendiéndose de algunas normas culturales propias como indica Tajfel en su teoría de la identidad social (explicada en la discusión de los resultados del estudio extensivo). Esto, inevitablemente, nos lleva a realizar una inferencia en cuanto a estos dos colectivos étnicos minoritarios. Mientras los inmigrantes necesitan sentirse aceptados por el grupo mayoritario, los gitanos se muestran autosuficientes con ellos mismos. Parece como si tuvieran cubiertas todas sus necesidades afectivas dentro de su propio 
endogrupo y les importara menos sentirse excluidos por el resto. Con esto no queremos decir que los gitanos se autoexcluyan, pero sí percibimos ciertas muestras que denotaban menor necesidad de ser aceptados por los compañeros pertenecientes a otros colectivos étnicos.

En España, Sánchez i Perris et al. (2004) detectan que los índices de aceptación o rechazo del alumnado no autóctono no son diferentes a los del resto del alumnado y que incluso obtienen un índice de aceptación mayor que los alumnos autóctonos de etnia gitana, por lo que entienden que el hecho de ser inmigrante no es la causa de mayor o menor socialización en el aula. Estas conclusiones apoyan y matizan nuestros resultados, donde veíamos cómo los gitanos (valorando las dos fases de la investigación) eran los más rechazados.

De gran calado para la intervención educativa nos resulta la aportación obtenida al relacionar en el estudio extensivo el prejuicio con la existencia de inmigrantes o no en el grupo-clase. La significación estadística obtenida pone de manifiesto lo que todas las teorías cooperativas nos afirmaban ya desde los estudios de Allport en 1954, confirmados por Johnson en 1982 con su teoría del contacto: los agrupamientos heterogéneos permiten al alumnado comprobar que el contacto con otras etnias no es una cuestión tan complicada como pueden transmitirles algunos mensajes procedentes de otros ámbitos extraescolares como el familiar o el mediático. Este acercamiento permite reducir los estereotipos adquiridos en otros contextos e interaccionar de forma más democrática.

Otra conclusión a la que llegamos, pone sobre aviso a las políticas educativas llevadas a cabo en esta ciudad. Veamos por qué. Nos decían los datos del primer estudio que los centros con alumnado procedente de un nivel socioeconómico y cultural bajo (fundamentalmente "gitanos") eran los que mostraban, significativamente, más prejuicio. A su vez, los gitanos habían obtenido puntuaciones más altas en prejuicio que los otros dos colectivos considerados ("payos españoles" e "inmigrantes"). Por lo tanto, la relación se ve clara: los escolares de estos centros tenían más prejuicio en sus respuestas, porque era el colectivo de "gitanos" los que respondían los cuestionarios.

Con esto resaltamos dos ideas. La primera la explicábamos anteriormente al comprobar que las respuestas de los gitanos indicaban una tasa más alta de prejuicio. La segunda se refiere a la progresiva marginación que algunos colegios públicos están sufriendo al concentrarse en ellos todas las minorías étnicas, sobre todo gitanos, y es aquí donde vemos las consecuencias de las acciones en política educativa de la ciudad. Esto dificulta enormemente la labor educativa integradora, no sólo por el aislamiento social que reciben estos colectivos, al separarlos en centros cada vez más marginales, sino porque los recursos con los que se dotan a 
estos centros para atender a la diversidad resultan muy escasos, si los comparamos con el resto de colegios donde la población escolarizada responde a un alumno medio mejor situado social y curricularmente. Es difícil atender bien a la población escolar si ésta, en su mayoría, presenta necesidades curriculares especiales; se necesita una heterogeneidad en cuanto a la procedencia social en los grupos escolares. Este hecho supone un creciente y notable acontecimiento que favorece la segregación en función del nivel social del que procedan los escolares. A este sentimiento de marginación por parte del personal que trabaja en este tipo de colegios se le unen los bajos presupuestos para realizar proyectos, el bajo número de personal de compensatoria junto con las desmotivaciones profesionales. Un panorama desfavorecedor para trabajar la integración intercultural del que fuimos testigos al realizar esta investigación.

Sin embargo, estos centros que podríamos denominar "marginales", también eran los colegios cuyo alumnado mejor se valoraba mejor entre sí. Las puntuaciones sociométricas reflejaban mayor aceptación entre los miembros de los grupos que constituían las aulas. Es decir, el clima existente entre compañeros de clase podríamos decir que era más relajado y con menos tensiones. Es de suponer cierto énfasis endogámico al juntarse alumnado de la misma procedencia étnica, lo que explica el aumento del estatus sociométrico y el refuerzo de este sentimiento.

Encontramos cierto paralelismo entre este resultado sociométrico y el ambiente observado en las clases de apoyo del colegio en donde realizamos el estudio etnográfico, en las cuales también existía un ambiente de confianza. En ambos contextos se creaban ambientes agradables que favorecían la individualización de los procesos de aprendizaje. La causa de este clima favorecedor la atribuimos al bajo número de alumnado que conformaba ambas clases, al trato individualizado que los profesores ofrecen cuando trabajan con un grupo reducido y a la solidaridad emergente en grupos donde el nivel académico es tan bajo que el ambiente competitivo desaparece. Además, este hecho nos permite realizar dos reflexiones: una, que el alumnado que protagoniza estas situaciones es en su mayoría gitano; y dos, que las valoraciones que se atribuyen entre ellos son más positivas que la de los alumnos no gitanos. Parecen tener un sentimiento de colectividad mucho más marcado que cualquier otro colectivo étnico. Tienen arraigados sentimientos de identidad étnica mucho más fuerte que el colectivo payo. Estos últimos ven a sus compañeros como sujetos individuales, mientras que los gitanos valoran a su compañero primero como perteneciente a su misma etnia y luego como persona individual. Este fuerte sentimiento endogámico también puede ser el que explique las mayores puntuaciones en el prejuicio. Quizá al desarrollar fuertes creencias positivas dentro del endogrupo y para mantener esta valoración, tiendan a buscar a otro exogrupo con el que rivalizar y así justificar su endogamia. 
La cuestión es que esto afecta a dos debates habituales. El primero se refiere al efecto en cualquier contexto del aumento del número de población perteneciente a otro colectivo étnico diferente al socialmente mayoritario, concretamente a lo que el nuevo racismo denomina umbral de tolerancia, que nos explica que la proporción de extranjeros no debe ir más allá de cierto límite, que algunos cifran en el 120 el 15\%, sobrepasado el cual actuaría el imperativo territorial, es decir, la defensa del territorio contra los nuevos. Y el segundo es el relacionado con la distribución de los inmigrantes en las aulas y, en particular, en estos colegios que hemos denominado marginales. Si por el motivo que sea, la concentración de inmigrantes en un aula conlleva un aumento de sentimientos endogámicos, y si consideramos que en el espacio público estas prácticas no son deseables desde el punto de vista de la educación intercultural, encontraríamos aquí una razón para replantearnos desde la educación la distribución equilibrada de minorías étnicas en las aulas.

Respecto a las procedencias de los escolares, observamos en la etnografía escolar que el alumnado procedente de Marruecos es el que tiene un grupo de referencia al que acudir en los momentos de indefensión ante situaciones de rechazo o conflicto con otros compañeros. Además, veíamos cómo los mayores cuidaban de los pequeños de forma a veces excesiva. Por los datos recogidos, podemos interpretar que se puede deber a un rasgo cultural referido a la idea de familia-pertenencia-protección. Por tanto, podemos concluir diciendo que existen diferentes grados de cohesión e identidad dentro de los diferentes grupos étnicos. Los gitanos y los marroquíes son los que más sentimiento de colectividad manifiestan y gracias a esto han creado su propio grupo al que acudir cuando las cosas no van bien con el grupo mayoritario. Sin embargo, el resto de procedencias y el alumnado español-payo, no poseen un grupo alternativo al que acudir si sufren exclusión. Esta imposibilidad de ser protegido por otros compañeros de su misma etnia implica el tener que desarrollar constantemente estrategias de interacción con el grupo mayoritario, porque de lo contrario, estarían totalmente excluidos. Por tanto, podemos inferir dos ideas: una, que el sentimiento de identidad étnica favorece la creación de grupos por colectivos, ofreciendo un colchón en el que refugiarse en el caso de sufrir rechazo por el grupo mayoritario y dos, que, por lo general, se desea, en primer lugar, ser aceptado por el grupo mayoritario, y sólo se acude al propio grupo étnico, en el caso de ser marginado.

Los tipos de agrupamientos que el alumnado realiza en el recreo, observados en la etnografía escolar, indican cierta coherencia con estas respuestas prejuiciosas manifestadas en los cuestionarios. Existe una tendencia bastante marcada a formar grupos diferenciados entre el alumnado gitano y el payo. Estos escolares pueden enfatizar fácilmente ciertas creencias, revalorizando las 
características propias del endogrupo e infravalorando las del exogrupo, de ahí la importancia que los profesionales de la educación otorgan en la formación de grupos heterogéneos para realizar diversas actividades escolares y desterrar los prejuicios mediante la convivencia de la diversidad. Pero este dato, nos hace pensar que los programas de convivencia deberían extenderse a otros tiempos escolares en los que parece que rigen otras normas (recreos, tiempos de llegada y salida del colegio, tiempos de cambio de clases o de subida y bajada al aula...).

\section{3.- ¿Cómo son las relaciones sociométricas del alumnado evaluado: "buenas", "malas" o "regulares"?}

Por un lado, al realizar las sociometrías en las clases de $5^{\circ}$ de los colegios de Valladolid nos percatamos de que las valoraciones que los niños realizan entre ellos son, por lo general, positivas o medias. Esto nos dejaba entrever la interiorización del discurso tolerante de la escuela por el alumnado. Éstos saben que deben llevarse bien con todos sus compañeros y lo reflejan en sus puntuaciones sociométricas.

Al evaluar la calidad de las relaciones sociométricas observamos un dato curioso, nos referimos a la diferencia existente entre los resultados de los grupos denominados "guetos", es decir, aquellos donde el $90 \%$ del alumnado procedía de colectivos étnicos desfavorecidos socialmente. Estos grupos se puntuaban entre sí de forma más positiva que el resto de los grupos de otros centros. Exponemos con cierta prudencia esta idea, ya que puede utilizarse como justificación política para la consolidación de contextos segregados, argumentando sus beneficios relacionales.

\section{4.- ¿Cómo es la valoración sociométrica que reciben los colectivos étnicos y las diferentes procedencias étnicas?}

El estudio, realizado en la primera fase de la investigación, nos indicaba que las minorías étnicas (inmigrantes y gitanos) se ubicaban mayoritariamente en el grupo sociométrico de "rechazados".

Las observaciones realizadas durante el trabajo cualitativo, sin embargo, nos ofrecían más matices respecto a esta cuestión. Por un lado, es cierto que observábamos al alumnado inmigrante y gitano ocupando las zonas espaciales menos deseadas en los recreos. Y dentro de ellas, eran los marroquíes y gitanos los peor situados. Sin embargo, también existían niños y niñas de diferentes procedencias étnicas que estaban perfectamente adaptados e integrados dentro de su grupo-clase.

Existen muchos factores a la hora de hablar de esta exclusión y antes de atribuir las razones a cuestiones racistas, dentro del contexto escolar, pueden 
encontrarse otras como la desadaptación a las normas y a los usos sociales de los grupos mayoritarios, la procedencia de un ambiente familiar problemático, la falta de habilidades sociales para interaccionar con los compañeros, la manifestación de agresividad, la timidez. También sabemos, como explicamos en la pregunta 1.8, que cada escolar sigue un proceso personal, de forma que algunos superan las fases del proceso de integración más rápidamente y otros se quedarán anclados más tiempo en alguna de ellas. La valoración sociométrica que reciban de sus compañeros también dependerá de la habilidad con la que el alumnado transcurra por este proceso, así como de la distancia cultural con la que lleguen al centro.

Estaríamos hablando de una cuestión multicausal. En las preguntas 1.9 y 1.11 explicaremos más detenidamente las causas y el proceso de la exclusión, así como algunos factores indicativos de la misma.

\section{5.- ¿Qué grupo sociométrico tiene más prejuicio: los "populares", los "rechazados", los "ignorados" o los "medios"?}

El estudio cuantitativo nos proporcionaba un resultado interesante para explicar la exclusión étnica. Nos referimos a la relación entre prejuicio y grupo sociométrico. Los alumnos ubicados en el grupo sociométrico "rechazado", manifestaban más prejuicio que los considerados "populares". Este resultado lo incorporamos en una reflexión más global que utilizamos en el siguiente apartado, en él describimos un modelo que intenta explicar cómo se produce este rechazo y qué lugar ocupa el prejuicio en el proceso de integración.

\section{6.- ¿Cómo son las interacciones sociales entre los iguales y cómo éstas afectan al proceso de integración escolar?}

Este trabajo nos ha ayudado a poner de relieve los procesos por los que pasa una persona nueva en un contexto escolar, sacando a la luz las redes que regulan la interacción entre iguales, así como la ideología que sustentan y que reproducen. Estas redes de significados representan ideologías más o menos explícitas sobre temas como las jerarquías, la división por sexos y las atribuciones a cada género y a étnias como la gitana, o las prácticas y usos corporales adecuados según edad y sexo.

En el siguiente cuadro se sintetizan lo que hemos denominado códigos horizontales (aquellos que regulan la interacción entre iguales) y verticales (los emanados de la institución escolar y sus docentes) a los que el alumnado nuevo se enfrentará y deberá ir asumiendo en su proceso de integración. Algunos de estos usos serán favorecedores de la integración (por ejemplo, la actitud de las niñas 
respecto a la apertura y cuidado hacia las personas nuevas en el grupo) y otros supondrán una barrera contraintegradora (por ejemplo, la participación de los niños en actividades de carácter competitivo en las que prima la acción individualista y la agresión).

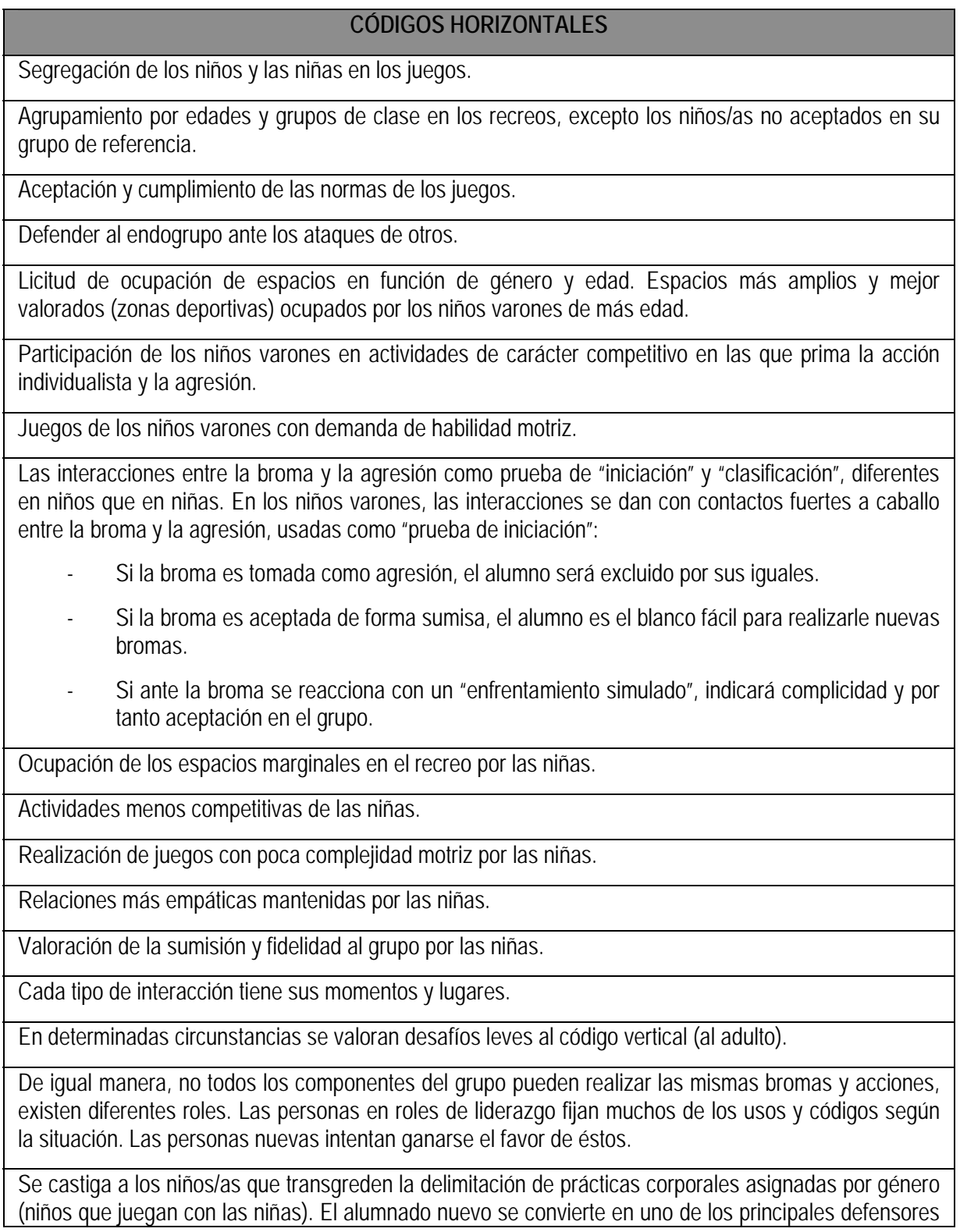




\begin{tabular}{|l|}
\hline de estos códigos- \\
\hline En el aula buscan estrategias para interactuar con los iguales, sin que el adulto se dé cuenta. \\
\hline \multicolumn{1}{c|}{ CóDIGOS VERTICALES } \\
\hline Regulación de tiempos de trabajo, recreo y transiciones. \\
\hline Búsqueda de un relativo orden en los momentos de transición de los espacios. \\
\hline Protocolos de actuación en clase. \\
\hline Distribuciones y agrupamientos. \\
\hline Cumplimiento de tareas académicas. \\
\hline Contención corporal en las clases. \\
\hline Trabajo predominantemente individualista. \\
\hline Metodología que establece comparaciones. \\
\hline División de grupos en espacios, en función de su nivel académico (clases de apoyo). \\
\hline Limitación de las interacciones sociales entre pares, interpretado como molestia o pérdida de tiempo. \\
\hline Discurso favorable a la tolerancia a la diversidad. \\
\hline Enseñanza entendida de forma vertical. \\
\hline Prioridad del cumplimiento del programa curricular sobre el desarrollo del alumno. \\
\hline
\end{tabular}

Tabla 11.1. Códigos verticales y horizontales de la cultura escolar.

A través de estos códigos y usos se va regulando la vida del centro y las relaciones entre iguales. Se regulan las jerarquías (por edades y sexos), el estatus dentro de cada grupo (a través de las pruebas de broma-agresión), los contactos e interacciones, las prácticas corporales apropiadas a cada género, las acciones adecuadas y permitidas en cada momento (en las filas, en los tiempos con adultos, en los tiempos libres, según el momento del día...), la legitimidad en el uso de los espacios, la valoración de las diferentes actitudes (consideración de la sumisión, la alegría y la ironía-broma, y rechazo de la agresividad y la pasividad-tristeza).

El alumnado inmigrante se enfrenta a estas tramas de significados cuando accede a la escuela, y su éxito dependerá en parte de su capacidad para reconocer, aprender y adaptarse a estas redes de usos y códigos. Estos códigos, que hemos ido explicando e ilustrando con ejemplos en las actas, aparecen en los capítulos del informe final (del siete al nueve). Ese entramado de usos y normas irá marcando el proceso de integración del alumno inmigrante y a su vez describirá las características de la cultura escolar a la que accede: 
En primer lugar, durante las observaciones de los recreos y de las filas de entrada a clase constatábamos un ambiente de constante agresividad en la interacción entre iguales, sobre todo entre niños. Veíamos, en el relato etnográfico, los empujones entre los niños para situarse los primeros en la fila, los "golpecitos" en la espalda, las burlas, los juegos simbólicos de "polis y cacos" que acababan en agresión, las patadas fuertes en el fútbol,... Intentábamos explicar estos sucesos a partir de aspectos pedagógicos (organización de los tiempos escolares, falta de sosiego en la jornada escolar, jornada larga, exceso de contención corporal...); sociales (medios de comunicación, cultura competitiva, selectiva e individualista); familiares (formatos de interacción basados en relaciones de poder); y personales (impulsividad, falta de recursos para buscar otros tipos de interacción, inseguridad, necesidad de pertenencia...).

Otra característica que veíamos, al analizar la cultura lúdica de los chavales, fue el marcado carácter competitivo e individualista desprendido de los modelos deportivos con los que organizaban sus juegos. La aceptación dependía en gran medida del grado de éxito demostrado en los juegos y lo que rodea su aplicación: la aceptación de las normas, conseguir goles o puntos para su equipo, defender al endogrupo ante los ataques de los otros. Se prima la acción individual y el éxito final y esto supone una barrera difícilmente franqueable por el alumnado inmigrante nuevo que necesita tiempos flexibles en los que no sienta tensión por estar siendo evaluado, en los que su estatus social no dependa del gol que meta 0 de la canasta que enceste. Necesita un ambiente relajado en el que la acción de cada uno sea menos observada y donde exista un tiempo con el que el chaval pueda ir adaptándose a los nuevos códigos culturales a los que se enfrenta. Por otra parte, ese ambiente competitivo está sometido al flujo cambiante de preferencias personales, expectativas manifestadas entre el alumnado y creencias personales depositadas en los otros. Todo ello va constituyendo un panorama relacional regido muchas veces, por reglas azarosas que dificultan el entendimiento.

También veíamos que existe una diferencia bien marcada entre los valores desprendidos de la actividad lúdica de los diferentes sexos. Las niñas configuraban su jerarquía social en función de; la aceptación a las reglas de funcionamiento establecidas, de la obediencia a las normas existentes en su grupo, de la fidelidad mostrada hacia los miembros del grupo, de la muestra de afecto de forma constante. La escala social de los niños, sin embargo, se establecía por otros factores relacionados con el éxito individual y la competición. Ambos coincidían en la aceptación de las normas como clave para ser aceptado dentro del grupo. Y esto es lo primero que debe hacer un alumno nuevo para tener un lugar social dentro de un grupo. 
A pesar de existir esta diferenciación por sexos, veíamos cómo muchas actividades de las niñas se formaban en torno a la de los niños, llegando a veces incluso a depender de las mismas. Los espacios más deseados en el patio también eran para los niños, y algunas alumnas permanecían todo el recreo al lado del campo de fútbol, esperando interactuar con ellos en los descansos. La cultura masculina, por tanto, protagoniza la cultura escolar en el patio.

Hasta ahora no vemos más que el reflejo de los valores que caracterizan a la sociedad en la que vivimos, marcada por la competición, el individualismo y el machismo. Al observar este microsistema reconocemos los valores sociales que caracterizan esta cultura. El alumnado inmigrante nuevo observará, imitará, e interiorizará los mensajes transmitidos. Son como esponjas que absorben todos los estímulos que la cultura escolar les ofrece.

Parece como si todo el panorama que dibujamos fuera negativo $\mathrm{y}$, sin embargo, existen otras razones para considerar lo contrario. Ya decíamos que dentro de las instituciones que se relacionan de forma más o menos directa con los niños, es la escolar la que posee un discurso explícitamente más tolerante hacia la diversidad étnica y esto tiene un calado en el alumnado. La intensidad de esta interiorización estará influenciada, sin duda, por el refuerzo posterior que el escolar reciba en su entorno social y familiar.

Desde este apartado referido a las conclusiones finales, quisiéramos dejar constancia de la importancia que adquieren en el alumnado las interacciones sociales entre iguales y de las interesantes aportaciones que desde este fenómeno se pueden realizar a la comunidad educativa. Comprender de cerca cómo funciona la estructura relacional del alumno es conocer el funcionamiento sociocognitivo con el que poder mejorar la integración escolar, supone también la posibilidad de ajustar los métodos educativos con los que conseguir este mismo fin, así como conocer los procesos culturales que envuelven las relaciones para saber cómo puede un inmigrante integrarse en estos grupos escolares. Hemos apreciado a través de la etnografía escolar el valor que para el alumnado nuevo tiene su integración y la relación con sus iguales. Este potencial debería ser atendido en los procesos educativos demasiado centrados en una enseñanza individualista y jerárquica (docente-discente), en la que se aprecian pocas oportunidades a la interacción y aprendizaje entre iguales.

A continuación incorporamos un cuadro que resume las características de la cultura escolar mencionadas y, que explican algunas de las interacciones sociales de los iguales, observadas en ellos mismos. 


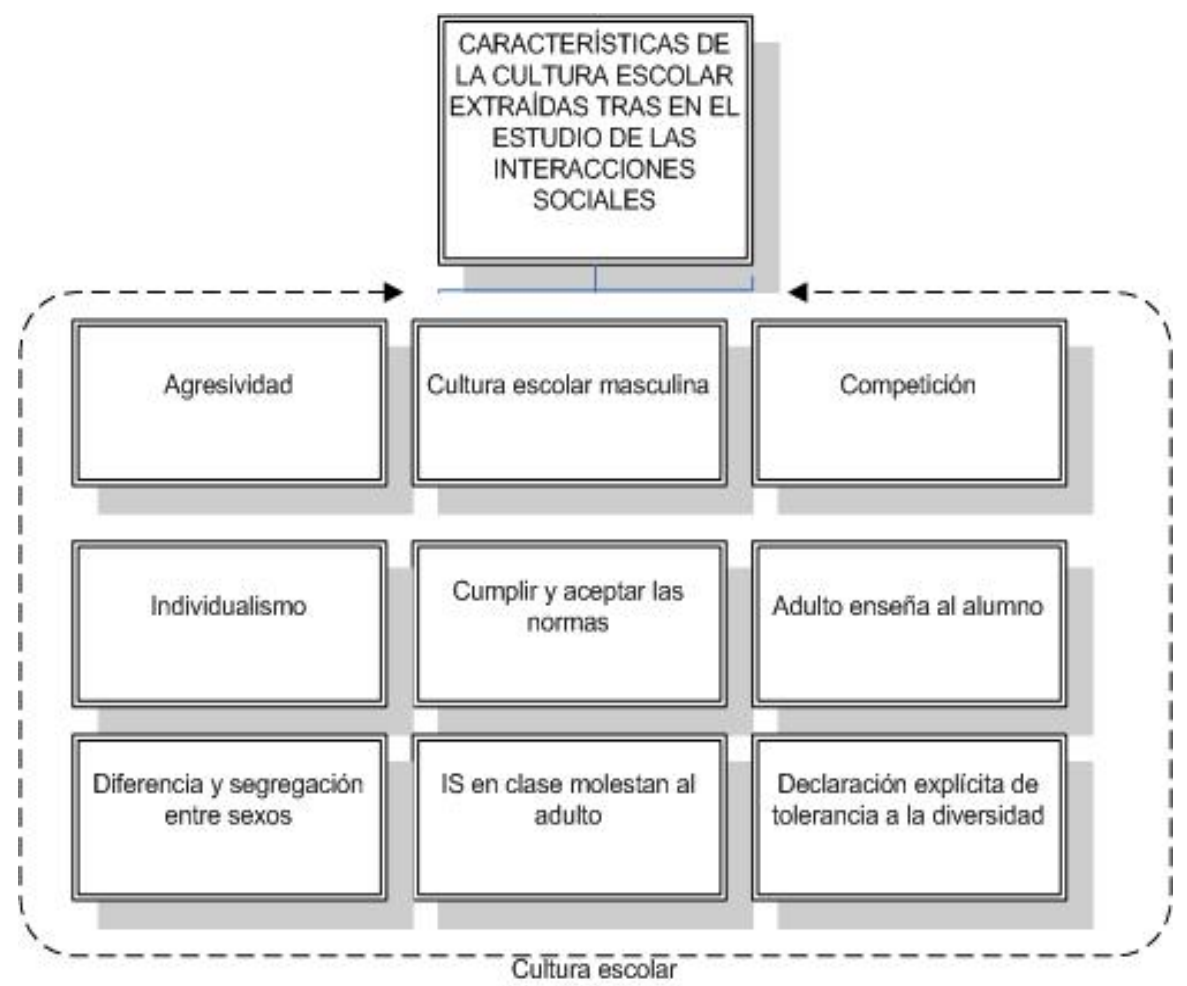

Figura 11.2. Características de la cultura escolar.

\section{7.- $¿$ Se pueden reconocer las fases comunes por las que pasan los diferentes niños y niñas inmigrantes en su proceso de integración?}

Obteníamos, al analizar el proceso de integración escolar, una serie de fases comunes en los alumnos inmigrantes observados:

$1^{\text {a }}$ fase: Desconocimiento, inseguridad y receptividad.

$2^{\mathrm{a}}$ fase: Conocimiento de las rutinas básicas.

$3^{\mathrm{a}}$ fase: Fase de aprendizaje de los códigos verticales y horizontales.

$4^{\mathrm{a}}$ fase: Fase de primera definición del estatus dentro del grupo.

$5^{a}$ fase: Fase de consolidación del estatus dentro del grupo. 
Se observan fases comunes por las que pasan cada uno de estos alumnos y alumnas nuevos en el proceso de socialización e integración escolar. Todos estos momentos tienen como denominador común la adquisición de los significados de la cultura escolar. Para el alumnado veterano, los espacios, las rutinas y el profesorado son conocidos y saben las implicaciones de cada uno de estos aspectos. Sin embargo, los alumnos nuevos necesitan un proceso de adaptación para adquirir este conocimiento.

Podemos hablar de integración superficial, producida cuando estos escolares han adquirido la autonomía suficiente como para moverse por el centro y entenderse con sus compañeros y compañeras. Por otro lado, encontramos una integración más sutil que sucede después de pasados unos cuantos meses en el colegio, se produce cuando los escolares interactúan con sus iguales, compartiendo códigos horizontales.

Dentro de cada una de las fases, los alumnos utilizan estrategias sociales diferentes que indican una mayor o menor competencia social para relacionarse con sus iguales. A lo largo de la jornada escolar hay diferentes tiempos y espacios que van marcando y condicionando las diferentes interacciones. Cada momento exige al alumnado nuevo la utilización de diferentes estrategias y actitudes, así como el aprendizaje de los usos más apropiados en esos lugares. Algunos de esos lugares (servicios, filas, patio) nos resultan interesantes, porque en ellos suceden interacciones sin la influencia directa del adulto, y por tanto mostrándonos valiosa información sobre la competencia social de estos escolares a la hora de establecer vínculos con los iguales.

En estos procesos personales influyen factores culturales, educativos, familiares y personales. Culturales, por la repercusión que puede tener el introducir a un alumno educado en una cultura escolar determinada en un contexto nuevo. Familiares, por la transmisión de valores e importancia que éstos atribuyen a la escuela. Educativos, por la influencia de las acciones y prácticas educativas desarrolladas en los centros y en las clases. Personales, referidos a las habilidades sociales, personalidad, seguridad personal, 0 actitud ante los demás de cada niño 0 niña.

\section{8.- ¿Qué factores facilitan este proceso y cuáles lo dificultan?}

El alumnado inmigrante pasa diferentes fases en su proceso de adaptación. Cada escolar sigue un proceso personal, de manera que algunos superarán estas fases de forma más rápida y otros se podrán quedar anclados más tiempo en alguna de ellas. Esta singularidad de cada proceso se mantiene incluso entre personas 
pertenecientes al mismo entorno cultural de procedencia. Entendemos que ello es debido a la influencia de múltiples factores. En nuestro caso podemos apuntar aquellos que hemos analizado en el ámbito educativo del estudio etnográfico. En la siguiente tabla los agrupamos en torno a aquellos que favorecen las interacciones sociales y el proceso de integración ("facilitan") y a los que lo perjudican ("dificultan").

\begin{tabular}{|c|c|}
\hline FACILITAN & DIFICULTAN \\
\hline \multicolumn{2}{|c|}{ Relacionados con aspectos del centro educativo } \\
\hline $\begin{array}{l}\text { Nombrar a alumnado mediador de la misma } \\
\text { procedencia que el alumno inmigrante nuevo. }\end{array}$ & $\begin{array}{l}\text { Descoordinación entre las acciones educativas } \\
\text { del profesorado del centro. }\end{array}$ \\
\hline $\begin{array}{l}\text { Realizar una buena bienvenida al centro: ofrecer } \\
\text { toda la información necesaria sobre el } \\
\text { funcionamiento del centro y acompañarle por los } \\
\text { espacios físicos. }\end{array}$ & $\begin{array}{l}\text { Vacío legal y desconocimiento de algunas } \\
\text { funciones de la profesora de compensatoria y } \\
\text { tutor. }\end{array}$ \\
\hline $\begin{array}{l}\text { Crear expectativas positivas en el alumnado } \\
\text { veterano para que ayuden al nuevo niño o niña. } \\
\text { Presentarle al grupo-clase }\end{array}$ & $\begin{array}{l}\text { No hablar al alumnado veterano del nuevo } \\
\text { escolar antes de su llegada al grupo. } \\
\text { No presentarle al grupo. }\end{array}$ \\
\hline $\begin{array}{l}\text { Realizar un seguimiento individualizado del } \\
\text { alumnado en los apoyos. }\end{array}$ & $\begin{array}{l}\text { No hacer seguimiento de las relaciones que } \\
\text { mantienen en los recreos (no animar a que les } \\
\text { incluyan en los juegos, no seguirles en esos } \\
\text { tiempos fuera de las aulas...). }\end{array}$ \\
\hline $\begin{array}{l}\text { Realizar un seguimiento una vez finalizado el } \\
\text { plan de acogida de los primeros meses. }\end{array}$ & $\begin{array}{l}\text { No dotar de una cultura lúdica amplia para que } \\
\text { los niños diversifiquen sus actividades en el } \\
\text { recreo. }\end{array}$ \\
\hline $\begin{array}{l}\text { Planes de sensibilización sobre la llegada del } \\
\text { alumnado inmigrante, dirigido a padres y } \\
\text { alumnos. }\end{array}$ & $\begin{array}{l}\text { No fomentar en las actividades de padres, } \\
\text { estructuras que posibiliten el intercambio de } \\
\text { familias de diversas procedencias. }\end{array}$ \\
\hline \multirow[t]{2}{*}{$\begin{array}{l}\text { Coordinación con asociaciones de ayuda al } \\
\text { inmigrante. }\end{array}$} & $\begin{array}{l}\text { No participación en actividades extraescolares } \\
\text { con compañeros y compañeras del colegio. }\end{array}$ \\
\hline & $\begin{array}{l}\text { No modificar el proyecto educativo de centro, } \\
\text { cuando éste no atiende a la diversidad de los } \\
\text { alumnos. }\end{array}$ \\
\hline \multicolumn{2}{|c|}{ Relacionados con acciones docentes en el aula } \\
\hline $\begin{array}{l}\text { Utilización de metodologías cooperativas, } \\
\text { facilitando intercambios socioafectivos. }\end{array}$ & $\begin{array}{l}\text { Metodologías que no favorecen las } \\
\text { interacciones entre iguales. } \\
\text { Trabajo en grupos, pero no cooperativo. }\end{array}$ \\
\hline $\begin{array}{l}\text { Utilización de refuerzos adecuados al alumnado } \\
\text { nuevo. }\end{array}$ & $\begin{array}{l}\text { Currículum alejado de las experiencias vitales } \\
\text { de los alumnos inmigrantes nuevos. }\end{array}$ \\
\hline
\end{tabular}




\begin{tabular}{|c|c|}
\hline $\begin{array}{l}\text { Expectativas positivas depositadas y } \\
\text { manifestadas sutil o explícitamente }\end{array}$ & Prejuicios manifestados de forma sutil. \\
\hline $\begin{array}{l}\text { Metodologías que diversifiquen los retos para } \\
\text { que cada escolar pueda trabajar a su ritmo } \\
\text { dentro de temas comunes y permitan que el } \\
\text { alumnado nuevo sienta su progresión. }\end{array}$ & $\begin{array}{l}\text { Tareas que no respeten los ritmos personales y } \\
\text { supongan un riesgo o discriminación del } \\
\text { alumnado nuevo. } \\
\text { Tareas sin contenido claro y sin una estructura } \\
\text { didáctica de enseñanza-aprendizaje. }\end{array}$ \\
\hline $\begin{array}{l}\text { Sensibilidad hacia los problemas de cada niño o } \\
\text { niña. Estar pendiente de ellos y priorizar su } \\
\text { participación en clase sobre otros aspectos de la } \\
\text { enseñanza. }\end{array}$ & $\begin{array}{l}\text { No cuidar los aspectos organizativos de cada } \\
\text { tarea escolar (emparejamientos, reparto del } \\
\text { material, explicación de la tarea...). }\end{array}$ \\
\hline \multicolumn{2}{|c|}{ Relacionados con las interacciones entre iguales } \\
\hline $\begin{array}{l}\text { "Efecto novedad" (expectativa positiva que } \\
\text { despierta el alumnado nuevo en los veteranos) }\end{array}$ & $\begin{array}{l}\text { Expectativas negativas depositadas en los } \\
\text { escolares que salen del aula a clases de apoyo. }\end{array}$ \\
\hline $\begin{array}{l}\text { Práctica de juegos universalmente conocidos } \\
\text { (persecución), de normativa sencilla, con } \\
\text { posibilidades de intervención individual y con } \\
\text { poca exigencia de habilidad. }\end{array}$ & $\begin{array}{l}\text { Uso de juegos simbólicos de normas aleatorias, } \\
\text { dictadas por una minoría. } \\
\text { Uso de juegos de cooperación.-oposición que } \\
\text { requieran un alto nivel de habilidad y en los que } \\
\text { el grupo disputa un objeto único (fútbol, } \\
\text { baloncesto). }\end{array}$ \\
\hline $\begin{array}{l}\text { Implicación afectiva depositada en las } \\
\text { interacciones y vínculos sociales. }\end{array}$ & $\begin{array}{l}\text { Expectativas negativas depositadas en los } \\
\text { alumnos con bajo nivel académico, repetidores, } \\
\text { etc. }\end{array}$ \\
\hline $\begin{array}{l}\text { Actitud de acogida y apertura hacia las personas } \\
\text { nuevas. }\end{array}$ & $\begin{array}{l}\text { Ambientes de interacción caracterizados por } \\
\text { códigos horizontales en los que prima el } \\
\text { individualismo y la competitividad. } \\
\text { Pruebas entre la broma y la agresión para ver el } \\
\text { "límite" de los nuevos y otorgarles un rol en el } \\
\text { grupo }\end{array}$ \\
\hline $\begin{array}{l}\text { Rebajar la rigidez de los códigos horizontales y } \\
\text { comprender las peculiaridades de la persona } \\
\text { nueva. }\end{array}$ & $\begin{array}{l}\text { Crisparse ante aspectos que resulten } \\
\text { chocantes: apariencia, gestos, malentendidos. }\end{array}$ \\
\hline \multicolumn{2}{|c|}{ Relacionados con las características individuales del alumnado inmigrante nuevo } \\
\hline Hablar inglés además de su lengua materna. & $\begin{array}{l}\text { No hablar ningún idioma con el que se le } \\
\text { entienda en el país de recepción. }\end{array}$ \\
\hline $\begin{array}{l}\text { Poseer habilidades sociales con las que } \\
\text { interactuar. }\end{array}$ & $\begin{array}{l}\text { No manifestar competencia social en la } \\
\text { interacción. }\end{array}$ \\
\hline $\begin{array}{l}\text { Manifestar agrado y alegría al interactuar con } \\
\text { compañeros. }\end{array}$ & $\begin{array}{l}\text { Aislarse y huir del intercambio social con } \\
\text { iguales. }\end{array}$ \\
\hline
\end{tabular}




\begin{tabular}{|c|c|}
\hline $\begin{array}{l}\text { Poseer competencia motriz y habilidad en juegos } \\
\text { o deportes culturalmente valorados. }\end{array}$ & Limitaciones o torpeza motriz \\
\hline $\begin{array}{l}\text { Apariencia y usos corporales cuyos rasgos sean } \\
\text { interpretados como afables por el grupo de } \\
\text { acogida. }\end{array}$ & $\begin{array}{l}\text { Apariencia y usos corporales que sean } \\
\text { interpretados como intimidatorios o agresivos } \\
\text { por el grupo de acogida. }\end{array}$ \\
\hline Carácter extrovertido y alegre. & Carácter tímido y aislado. \\
\hline Sumisión y paciencia. & Agresividad y respuestas violentas. \\
\hline Atribuciones positivas y autoestima. & Atribuciones negativas y autoestima baja. \\
\hline \multicolumn{2}{|c|}{ Relacionados con las situaciones familiares personales } \\
\hline Estructuración y unión del núcleo familiar & Desestructuración y disgregación familiar \\
\hline Situación regularizada familiar en el país receptor & Situación ilegal en el país receptor \\
\hline Nivel económico sostenible y estable & Nivel económico insostenible o inestable \\
\hline \multirow[t]{2}{*}{ Convivencia con familias del país receptor } & $\begin{array}{l}\text { Aislamiento con grupos culturales de su misma } \\
\text { procedencia }\end{array}$ \\
\hline & $\begin{array}{l}\text { Tensiones generadas por la nueva situación de } \\
\text { vida: adaptación a un nuevo espacio, piso } \\
\text { reducido con pocos metros... }\end{array}$ \\
\hline \multirow[t]{2}{*}{$\begin{array}{l}\text { Implicación activa de los padres en la escuela. } \\
\text { Ayuda en las tareas escolares y en el aprendizaje } \\
\text { del idioma. }\end{array}$} & $\begin{array}{l}\text { Poca importancia otorgada por los padres a la } \\
\text { función de la escuela. } \\
\text { Prohibición de practicar el idioma fuera de la } \\
\text { escuela. }\end{array}$ \\
\hline & $\begin{array}{l}\text { Frustración de las familias por sentirse } \\
\text { atrapadas en trabajos de cualificación inferior a } \\
\text { la suya. }\end{array}$ \\
\hline \multicolumn{2}{|c|}{ Relacionados con la "cultura escolar" } \\
\hline Nivel académico ajustado al centro de recepción. & $\begin{array}{l}\text { Desfase notable en el nivel académico respecto } \\
\text { al que pide el centro }\end{array}$ \\
\hline Conocer los significados de los códigos escolares & $\begin{array}{l}\text { Desconocimiento de los significados de los } \\
\text { códigos escolares }\end{array}$ \\
\hline \multirow[t]{2}{*}{$\begin{array}{l}\text { Proximidad en cuanto a los conocimientos } \\
\text { previos académicos. }\end{array}$} & $\begin{array}{l}\text { Distancia en los conocimientos previos } \\
\text { académicos }\end{array}$ \\
\hline & $\begin{array}{l}\text { Experiencia educativa previa inexistente o muy } \\
\text { diferente }\end{array}$ \\
\hline
\end{tabular}

Tabla 11.2. Aspectos que facilitan y que dificultan la integración escolar. 
Se debe interpretar este cuadro en función de los casos observados. Muchos de estos factores cobran un significado muy contextual. Por ejemplo, el desconocimiento del idioma, en función de cómo sea asumido por el resto de actores en el proceso de integración, puede llevarles a una actitud de ayuda o a una de rechazo. En este caso, se ha visto que suponía una limitación relativa y que Joseph (desconociendo el idioma) tenía menos problemas que Willy (dominándole) para interaccionar con los demás. Invitamos a realizar una interpretación global del cuadro, valorando los factores no de forma aislada, sino como un conjunto interrelacionado en el que unos aspectos influyen y compensan a otros. Por ejemplo, un rasgo aislado, como la forma de vestir, en un ambiente de tolerancia puede pasar desapercibido, pero en otro de rivalidad entre iguales puede resultar una excusa detonante de burlas y rechazos.

Respecto a los aspectos relacionados con las medidas que tomó el centro con el alumnado inmigrante nuevo, vemos cómo se relaciona directamente con las acciones reflejadas en el plan de acogida. Respecto a este tema resaltamos la importancia de plasmar por escrito todas estas actividades en el plan de acogida del centro, realizar seguimientos individualizados a cada alumno a lo largo de todo el año académico. La adquisición de la lengua del grupo mayoritario es el primer objetivo que se marca la comunidad educativa respecto a este alumnado nuevo. Una vez adquirido un cierto dominio lingüístico es importante no dar por finalizado el proceso de integración del alumno y realizar seguimientos progresivos a lo largo del curso académico. También la presentación, al grupo clase, del alumno en el primer día de su ingreso y la asignación de un mediador es una buena estrategia que permite acercarse a los códigos horizontales de los iguales.

Las acciones docentes, dentro del aula, que favorecen las interacciones sociales de forma más duradera entre el alumnado son las metodologías cooperativas. Es el método más eficaz para que se produzcan interacciones positivas entre alumnado de etnias diferentes y, por tanto, se produzcan los aprendizajes sociales necesarios para integrarse en la cultura escolar, pero para ello el método debe aplicarse de forma correcta para no producir los efectos contrarios.

Entre los iguales, veíamos cómo todas las interacciones sociales se producían, se regulaban y transcurrían en función de la aleatoriedad de las expectativas que entre ellos se atribuían. Estas expectativas en gran medida eran condicionadas y transmitidas por el currículum oculto presente en las acciones docentes.

Las manifestaciones de los caracteres individuales del alumno inmigrante nuevo permiten al profesorado y a sus compañeros mantener las expectativas depositadas o cambiarlas, si su actitud personal demuestra lo contrario. Lo más 
destacable respecto a las características individuales necesarias para integrase en el grupo mayoritario es la de aceptar las normas que existen en el grupo. Si un alumno nuevo se sale de la norma común, corre el riesgo de no ser aceptado por el grupo, incluso en aspectos tan superficiales como la apariencia física.

Somos conscientes de que existen otros muchos factores de índole familiar y social que influyen en las interacciones sociales. A la escuela la atraviesan muchos ejes sociales que influyen en las prácticas educativas y en la formación de una cultura escolar que hemos descrito gracias a este trabajo etnográfico.

\section{9.- ¿Qué choques culturales se observan en este alumnado al acceder a nuestra cultura escolar?}

Consideramos interesante analizar los aspectos culturales que chocaban 0 que diferenciaban al alumnado de otras procedencias culturales y nuevo, del español y veterano. Quizá estas aportaciones puedan servir para conocer y así planificar las prácticas educativas coherentes con los procesos sociales reales que ocurren entre el alumnado inmigrante.

Es relativamente fácil para los niños y niñas de otros países cambiar aspectos externos de su propia cultura, como pueden ser la forma de vestir, los juegos de interacción con sus compañeros/as, incluso el idioma. Pero es más difícil que prescindan de sus creencias arraigadas.

Algunos aspectos pueden llegar a suponer verdaderos conflictos culturales con los que tienen que enfrentarse, cuestionando su identidad. Uno de los objetivos de nuestro trabajo consiste precisamente en sacar a la luz algunos de ellos. Con ello esperamos aportar algún indicador a los profesionales de la educación que trabajen en procesos de integración étnica.

\begin{tabular}{|l|}
\hline \multicolumn{1}{|c|}{ CHOQUESI DIFERENCIAS CULTURALES } \\
\hline - Diferencia en el respeto demostrado hacia la figura del docente \\
\hline - Diferencia en el respeto por la autoridad y por las personas mayores \\
\hline - Diferencia en el significado de disciplina escolar \\
\hline - Diferencia en la autonomía para funcionar en la vida cotidiana \\
\hline - Diferencia en la responsabilidad ante la vida (más cercanas a las de un adulto) \\
\hline $\begin{array}{l}\text { - Experiencia cultural previa: diferencia en los contenidos, metodología y evaluación del } \\
\text { currículum }\end{array}$ \\
\hline - Diferencias en la comunicación: volumen de la voz, ironía, agresividad. \\
\hline
\end{tabular}




\begin{tabular}{|l|}
\hline - Gregarismo familiar vs. individualidad \\
\hline - Estilos familiares de autoridad más severos \\
\hline $\begin{array}{l}\text { - Diferencia en los valores, en los temas de conversación y en las actitudes de la } \\
\text { preadolescencia }\end{array}$ \\
\hline - Perturbación familiar ante los valores transmitidos por los medios de comunicación: libertad \\
sexual, agresividad, modelos sexuales, etc. \\
\hline $\begin{array}{l}\text { - Problemas de identidad en el contexto familiar, al sumergirse en la lengua del país de } \\
\text { acogida }\end{array}$ \\
\hline
\end{tabular}

Tabla 11.2. Choques y diferencias culturales.

Veíamos en el trabajo cualitativo que existían diferencias culturales que afectaban por un lado, al aprendizaje de los contenidos académicos y por otro, a los aprendizajes sociales. Sin olvidarnos de los primeros, nosotros nos centramos en aquellos que tienen que ver con los procesos sociales. Queremos resaltar que cuando hablamos de diferencias culturales nos referimos a las características propias de la cultura escolar de la que provienen. De esta forma, quizá, puedan darse más diferencias entre alumnos procedentes de diferentes clases sociales que otros alumnos inmigrantes donde sus colegios poseen una cultura escolar parecida. La cultura escolar posee rasgos universales globalizados y otros contextuales. Por tanto, también pueden diferir culturalmente dos centros que se encuentran en el mismo país. Hablamos de contextos escolares que poseen características que les hacen individuales. Sería interesante en futuras líneas de investigación estudiar los aspectos escolares comunes de varias procedencias.

Por tanto, en cada microcontexto escolar existen unas normas, unos códigos y unos matices diferentes que dan forma a la cultura escolar propia de cada centro educativo. Nosotros nos centramos en los aspectos sociales relacionados con la integración del alumnado inmigrante y para entenderlos hemos intentado sumergirnos en la cultura escolar del centro. De ahí la necesidad de introducirse en el campo de un modo intensivo, conociendo las variables contextuales sobre el fenómeno de las relaciones sociales.

\subsection{0.- ¿Cómo podemos saber si un alumno sufre exclusión por parte de sus compañeros?}

A partir del trabajo de campo intensivo podemos presentar una serie de indicadores que ayuden a detectar problemas en el proceso de integración del alumnado nuevo. Mostramos estos indicadores de exclusión en la siguiente tabla: 


\section{INDICADORES RELACIONADOS CON LA EXCLUSIÓN DEL ALUMNADO}

Sale a clase de apoyo

No participa nunca en clase

En el aula, no participa de interacciones sociales con nadie

Cuando se hacen agrupamientos libres dentro de clase se queda sin pareja o grupo. No es elegido/a

Excesiva obediencia al adulto. Está más pendiente de los códigos verticales que de los horizontales

Antes de que acabe el recreo ya se encuentra en la fila

Regularmente no interactúa en la fila de subida a clase con nadie

Cuando sale al recreo tarda en comenzar a jugar. Tiempo lento en el cambio de microsistema.

En los tiempos libres está pendiente de la mirada del adulto. Ésta le cohíbe

No participa en las bromas y en la comunicación que se establece en los pasillos, servicios...

No conoce la jerarquía social existente entre el alumnado: sexo, edad, espacios, juegos.

No cumple las normas de los juegos

Muestra agresividad hacia los compañeros/as

Juega con otros niños o niñas que también están marginados

Juega sólo con los niños o niñas de la misma procedencia

Ocupa los espacios del recreo que nadie quiere

No recibe pases en los juegos de pelota o de objeto a recibir. No es perseguido/a en los juegos de persecución. Es relegado/a a puestos secundarios (portero/a, defender a los capturados en juegos de persecución...)

Permanece en el recreo al lado del adulto o de la puerta de entrada. Juega en solitario, buscando refugio en objetos o juguetes que trae de casa.

Nunca participa en los juegos deportivos

No participa en las actividades extraescolares del colegio

No habla con los compañeros al salir del colegio

No realiza ninguna actividad voluntaria del colegio

Los padres no pertenecen ni ayudan al AMPA

Los padres no saludan a ningún otro padre cuando van a buscar a sus hijos

Malas puntuaciones sociométricas

Tabla 11.3. Indicadores relacionados con la exclusión del alumnado 
Cada uno de estos factores aparece explicado de forma detallada a lo largo de los capítulos 7, 8, 9 y 10. En ellos se relata de qué forma cada una de estas manifestaciones supusieron causas de exclusión en el alumnado.

Otra aportación con la que continuamos respondiendo a este interrogante, es la aproximación de un modelo cíclico con el que explicar el proceso de rechazo y la exclusión étnica, dentro de esta cultura escolar explicada. Este modelo seguiría las siguientes fases:

$1^{0}$ - La diferencia en cuanto a la identidad y la cohesión que manifiestan algunos colectivos étnicos (que según lo observado suelen ser gitanos y marroquíes) genera agrupamientos en colectivos étnicos diferentes en los momentos y espacios escolares en los que no existe influencia directa del adulto.

$2^{0}$ - Estos agrupamientos pueden ser temporales (en los momentos en los que se sienten excluidos del grupo mayoritario) y por tanto serían como grupos de referencia a los que acudir. O podrán ser continuados (acuden a este grupo al salir de las clases y siempre que pueden).

$3^{0}$ - En el caso de que los agrupamientos sean continuados, se empieza a producir una segregación entre las diferentes etnias. Esta segregación impide que se conozcan los códigos culturales necesarios para interactuar con los iguales y para integrarse en la cultura escolar.

$4^{0}$ - Este desconocimiento puede crear malos entendidos, desconfianzas, prejuicios y malas expectativas respecto al grupo étnico contrario. Incluso puede terminar en episodios agresivos que confirmen estos prejuicios y se consoliden estereotipos negativos hacia las etnias diferentes a las propias. Estas expectativas pueden crear situaciones y sentimientos de indefensión en el alumno nuevo que no sabe cómo actuar, al verse sometido a juicios azarosos. No aprende los patrones de interacción adecuados y, sin embargo, se fomentan sentimientos de indefensión.

$5^{0}$ - Este proceso es bidireccional, puede empezar con la automarginación de los grupos étnicos minoritarios o con la agrupación étnica producida por el rechazo del mayoritario, constituyendo de esta manera una espiral.

$6^{0}$ - Esta espiral puede ser cortada por la acción educativa que favorezca la interacción entre alumnado de diferentes etnias. Por ejemplo, a través de los grupos heterogéneos, asegurando la mezcla con etnias diversas durante el recreo de los primeros días de clase, mediante reuniones que fomenten el contacto familiar, organizando actividades extraescolares, etc. 

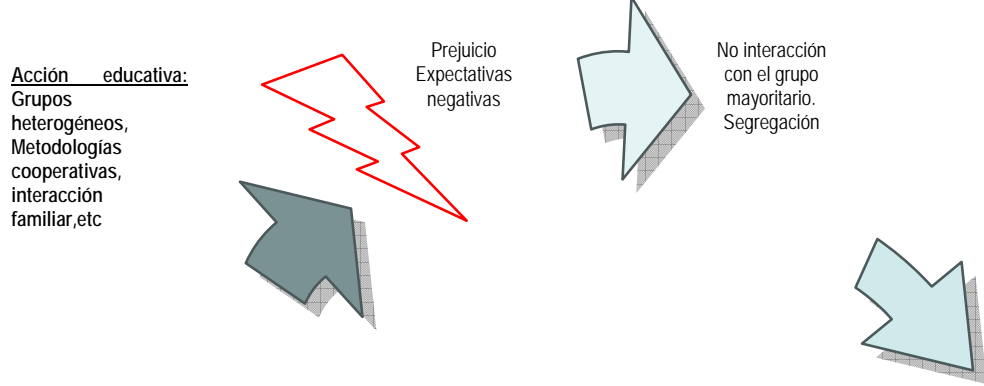

Intensifica el

sentimiento de

identidad étnica

Desconocimiento

de los códigos de

la cultura

mayoritaria.

Carencia de

CÓMO SE

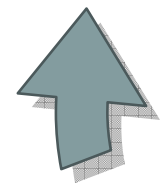

PRODUCE LA

EXCLUSIÓN

ÉTNICA

$$
\begin{gathered}
\text { Agrupamientos } \\
\text { en colectivos } \\
\text { étnicos } \\
\text { minoritarios }
\end{gathered}
$$

habilid. sociales.
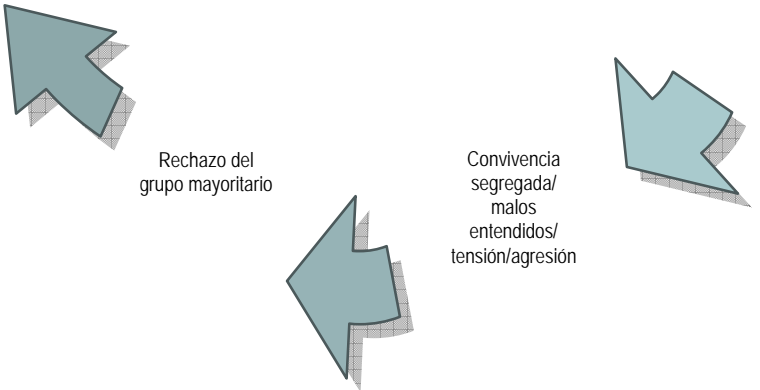

Figura 11.3. Aproximación a un modelo acerca de cómo se produce la exclusión étnica.

\section{2.- Posibles líneas de investigación futuras}

La realización de esta tesis doctoral abre las puertas a posteriores líneas de investigación desde diferentes ámbitos.

Por un lado, encontramos una relación directa con el tema de las interacciones y habilidades sociales desde un enfoque cultural. Nos resultaría interesante continuar el estudio mediante la evaluación comparada de las habilidades sociales manifestadas por el alumnado procedente de distintas 
nacionalidades y el español. Extraer los factores culturales que diferencian tales interacciones y los rasgos institucionales que condicionan los usos y códigos sociales. Este análisis podría ser de utilidad para los profesionales de la educación que trabajen en contextos interétnicos, ya que el conocimiento de estos procesos socio-escolares desde la perspectiva del alumno, puede ser un buen medio para construir prácticas educativas ajustadas a las necesidades reales, y, sin duda, la actualidad educativa se ve inmersa cada vez más, en ambientes interculturales.

Directamente relacionado con el tema anterior, se encuentra el tema del aprendizaje cooperativo como metodología educativa que fomenta la integración escolar especialmente en contextos interétnicos. El análisis etnográfico realizado desde el punto de vista del alumnado nos ayuda a diseñar prácticas pedagógicas que recogen las necesidades reales detectadas, creando de este modo procesos de enseñanza-aprendizaje ajustadas a tales demandas.

Por otro lado, al evaluar el proceso de integración escolar del alumnado inmigrante, estamos poniendo de manifiesto las necesidades institucionales que se hacen patentes para este fin, por tanto desde el área de la pedagogía, en concreto, de la organización escolar, sería interesante analizar si se proporcionan las medidas adecuadas en los centros de educación primaria y si las políticas educativas contribuyen a tales propósitos.

Tanto el análisis de las interacciones sociales como el proceso de integración escolar del alumnado inmigrante, nos lleva a indagar sobre los procesos de socialización que sufren al escolarizarse y al acceder a una cultura nueva. Seguramente, si pudiéramos continuar el estudio etnográfico en diferentes contextos educativos y con un mayor número de alumnado inmigrante, extraeríamos más focos desde los que vislumbrar los códigos culturales constituyentes de las relaciones interpersonales de los escolares y que se ponen en entredicho durante el proceso de integración. Al mismo tiempo, el tema de la violencia escolar, surge de forma inevitable, al observar las interacciones de los niños y las niñas en las situaciones en las que el adulto tiene menos influencia. Desde esta perspectiva relacional también sería interesante estudiar este fenómeno, el cual está últimamente dando bastante que hablar.

Relacionado con esta última idea, las cuestiones referidas a género también nos resultan de interés por manifestarse como una cuestión de exclusión 0 marginación. A lo largo del estudio cualitativo, fueron emergiendo temas relacionados con este tema debido a la relevancia que adquiría este aspecto en las relaciones interpersonales observadas en el alumnado. A nivel transcultural, nos resultaría interesante analizar si las diferencias por cuestión de género se producen de igual modo en otras nacionalidades, incluso en otros contextos. 
Salir del contexto escolar, también puede ser interesante para analizar estos aspectos culturales. Muchos de ellos se manifiestan de forma más clara cuando se sale del centro educativo. El trabajo con asociaciones de los barrios, ONGs y diferentes organizaciones sociales que trabajan con estos colectivos sería una interesante manera de enriquecer a la escuela. Estos análisis tienen cabida desde la antropología social y cultural.

A partir de este primer acercamiento al tema de las interacciones sociales en contextos interétnicos hemos podido extraer, de forma colateral, algunas teorías explicativas acerca del modo en el que se produce la exclusión en el alumnado inmigrante que nosotros hemos observado. En el apartado 1.10 de las aportaciones finales y en el dibujo 11.3 del mismo, incluíamos un modelo con el que explicábamos esta cuestión. Como línea futura de investigación, nos gustaría ampliarlo, evaluarlo y complementarlo, a través de la información obtenida en otros contextos educativos. 


\section{REFERENCIAS BIBLIOGRÁFICAS}

- ABOUD, F.E. (1977): "Interest in ethnic information: a cross-cultural development study." Canadian Journal of Behavioral, 9, 134-146.

- $\quad$ ABOUD, F.E. (1988): Children and Prejudice. Basil Blackwell. Oxford.

- $\quad$ ADORNO, T.W.; BRUNSWIK, D.J.; LEVINSON, R.N. y SANFORD (1950): The Authoritarian Personality. Nueva York. Harper.

- $\quad$ ALLPORT, G.W. (1954): La naturaleza del prejuicio. Buenos Aires. Eudeba.

- $\quad$ AMIR, Y. y SHARAN, S. (1978): "Attitude change in Desegregated Israelí" Israelí High Schools. Journal of Educational Psychology. 70 (2), pp. 129136.

- $\quad$ AMIR, Y. y SHARAN, S.; RIVNER, M.; BEN-ARI, R. y BIZMAN, A. (1979). "Group status and attitude change in desegregated classrooms". International Journal of Intercultural Relations. 3, pp. 137-152.

- $\quad$ AMIR, Y. y SHARAN, S. (1984): School Desegregation. Hilldale. Erlbaum.

- ANDERSON, C.S. (1985): The investigation of school climate. En G. R. AUSTIN y H. GARBER (Eds.).Research on exemplary schools. New York. Academic Press.

- $\quad$ APPLE, M. (1996): Política cultural y educación. Madrid. Morata

- $\quad$ ARNÁIZ, P. y DE HARO RODRÍGUEZ, R. (2001): Análisis de la realidad educativa desde una perspectiva intercultural. Servicios de publicidad de la Universidad de A Coruña, pp. 271-283.

- $\quad$ ARNÁIZ, P. y DE HARO RODRÍGUEZ, R. (2003): Alumnos magrebíes en las aulas: analizar y comprender el presente para transformar y mejorar el mañana. Educación, Desarrollo y Diversidad, 6 (3), pp. 63-82.

- ARNAL, J.; del RINCÓN, D. y LATORRE, A. (1992): Investigación educativa: Fundamentos y metodología. Barcelona. Labor.

- ARNAUS, R.(1999): "La formación del profesorado: un encuentro comprometido con la complejidad educativa". En PÉREZ GÓMEZ, A.; BARQUÍN, J. y ANGULO, J.: Desarrollo profesional del docente: política, investigación y práctica. Barcelona. Akal, pp. 599-635.

- ARONSON, E. (2005): El animal social (8a edición). Madrid. Alianza editorial, pg. 283. 
- ASHER, S.R. Y V. L. ALLEN (1969). "Radical preferent and social comparision processes". Journal of Social Issues, 25, pp. 157-166.

- ASHMORE, R.D. (1970). Solving the problem of prejudice. En B. H. COLLINS (Ed), Social Psychology: Social influence, attitude change, group process and prejudice. Reading, Mass. Addion - Wesley.

- AZMITIA, M. y PELMUTER, M. (1989): "Social influences on children's cognition: State of the art and future directions". En H. REESE (Ed.). Advances in development and behaviour. New York. Academic Press.

- BADINTER, E. (1992): X Y La identidad masculina. Madrid. Alianza Editorial.

- BÁEZ, B. F. y BETHENCOURT, J.T.(1992): Psicología escolar. Madrid. Cincel.

- BANDURA, A. (1981): "Self-referent thought." En FLAVELL, J. y ROSS, L.(Eds.) Social cognitive development. Cambridge University Press.

- $\quad$ BANKS, J. (1985): Multicultural Education. Husen y Postlethwait (Ed).

- BELMONTE, M. (1998): Atención a la diversidad. Diseño de estrategias y evaluación formativa basada en el análisis de tareas. Bilbao. Mensajero.

- BLUMER, H.(1982): Interaccionismo simbólico. Perspectiva y método. Barcelona. Hora.

- BORES CALLE, N. (2006): El cuaderno del alumno en el área de Educación Física en la Enseñanza Secundaria Obligatoria. Tesis Doctoral. Universidad de Valladolid.

- $\quad$ BRAND, E.S., RUIZ, R.A. y PADILLA, A.M.(1974): "Etnhic identification and preferent: A review". Psychological Bulletin. 81, pp. 860-890.

- BREHM,S. (1992): Intimate relationships. Nueva York: Mc Graw -Hill.

- $\quad$ BROWN, A. L. y PALINCSAR, A. S. (1989): "Guided, cooperative learning and individual knowledge adquisition". En RESNICK, L. B.(Ed.). Knowing, Larning and Instruc-tion. Hillsdale, New Jersey: Erlbaum.

- BROWN, R.J. (1984): "The effects of intergroup similarity in intergroup relations". En TAJFEL, H. (ed.), The Social Dimension. Vol.2, Cambridge. Cambridge University Press. 
- BROWN, R.J. (1988): "Group Processes: Dynamics within and between groups." Oxford: Basil Blackwell. En HERNÁNDEZ GRANDA, E. (2001). Agresividad y relación entre iguales en el contexto de la enseñanza primaria. Estudio piloto. Trabajo de Investigación. Oviedo.

- BROWN, R.J. (1988): Group Processes. Dynamics within and between groups. Oxford. Basil Blackwell.

- BROWN, R.J. (1995): La naturaleza del prejuicio. Madrid. Ed. Buenos Aires.

- $\quad$ BRUNER, J.S. (1957): "On perceptual readiness". Psychological Review, 64, pp. 123-151.

- $\quad$ BUSS, D.M. y KENRICK, D.T. (1998): "Evolutionary Social Psychology". En D.T. Gilbert, S.T. Fiske y G. Lindzey (eds.), The Handbook of Social Psychology, $4^{a}$ edición, Vol. 2, pp. 982-1.026. Boston, MA: Mc Graw Hill.

- CABALLO, V.E. (1987): Evaluación y entrenamiento de las Habilidades Sociales: una estrategia multimodal. Tesis doctoral. Universidad Autónoma de Madrid.

- CABALlO, V.E. (1989):Teoría, evaluación y entrenamiento de las habilidades sociales. València. Promolibro.

- CABALLO, V.E. (2002): Manual de evaluación y entrenamiento de las habilidades sociales (1 ${ }^{\mathrm{a}} \mathrm{ed}, 5^{\mathrm{a}} \mathrm{imp}$.). Madrid: Siglo Veintiuno.

- CARBONELL, F. (2005): "Educar en tiempos de incertidumbre, equidad e interculturalidad en la escuela". Cuadernos de educación intercultural. Madrid. La Catarata.

- CANO. R. (2006): "Valoración de las actuaciones de atención educativa al alumnado inmigrante en Castilla y León". Contextos educativos 8,9, pp. 109-134.

- CHAMBERS ENGLISH DICTIONARY (1988).

- CIDE, (2003): La escolarización de hijas de familias inmigrantes. Edita: instituto de la mujer. Madrid.

- $\quad$ CLARK, K.B. y CLARK, M. (1939): "Development of conciousness of self and the emergence of racial identification in Negro children". Journal of Social Psychology. 10, pp. 591-599. 
- $\quad$ CLARK, K.B. y CLARK, M. (1939): "Development of conciousness of self and the emergence of racial identification in Negro children". Journal of Social Psychology. 10, 591-599.

- $\quad$ CLARK, K.B. y CLARK, M. (1952): "Racial identification and preferent in Negro children". En: T. M. NEWCOMB y E.L. HARTLEY (Eds.), Readings in social psychology (Rev. ed.). New York Holt.

- CLARK, K.B. y CLARK, M. (1952): "Racial identification and preferent in Negro children". En: T. M. NEWCOMB y E.L. HARTLEY (Eds.), Readings in social psychology (Rev. ed.). New York Holt.

- $\quad$ CLARK, K.B. y M.P. CLARK (1947): "Racial identification and preference in Negro children". En PROSHANSKY, H. y B. SEIDENBERG (Eds.) Basic Estudies in Social Psychology, Nueva York: Holt Rinehart y Winston (Edición de 1995).

- COELHO, E. (2006): "Enseñar y aprender en escuelas multiculturales. Una aproximación integrada". Cuadernos de educación. Madrid.

- $\quad$ COHEN, L. y MANION, L. (1990): Métodos de investigación educativa. Madrid. La Muralla.

- COLÁS, M.P. y BUENDÍA, L. (1992): Investigación educativa. Sevilla. Alfar.

- CONSEJERÍA DE LA JUNTA DE CASTILLA Y LEÓN, (2002). Plan marco de atención educativa a la diversidad para Castilla y León, (2002). Editado por la Junta de Castilla y León. Valladolid.

- CORSARO, W.A. (1985): Friendship and per culture in the early years. Norwood, New Jersey: Ablex.

- CORSARO, W. A. (1986): "Routines in peer culture". En J. C. GUMPERZ, W. A. CORSARO y STEECK (Eds.). Children's Worlds and Children Language. Berlin: Mouton de Gruyter.

- CORTINA, A. (2007): Ética de la razón cordial. Oviedo. Nobel.

- $\quad$ COWEN, E.; PEDERSON, A.; BABIGIAN, H.; IZZO, L; TROST, M. (1973): Long Term followup of early detected vulnerable children. Journal of Consulting and Clinical Psychology. 41, pp. 438-446. 
- $\quad$ COWEN, E.; PEDERSON, A.; BABIGIAN, H.; IZZO, L; TROST, M. (1973): "Long Term followup of early detected vulnerable children". Journal of Consulting and Clinical Psychology. 41, pp. 438-446.

- CROOKS, R.C. (1970): "The effects of an interracial preschool programs upon racial preference, knowledge of racial differences and racial identification". Journal of Social Issues. 26 (4). pp. 137-144.

- CUBERO, R. y MORENO, M. C. (1990): "Familia, escuela y compañeros durante los años escolares". En J. PALACIOS, A. MARCHESI y C. COLL (Eds.). Desarrollo psicológico y educación, Vol. I. Madrid: Alianza.

- DAMON, W. y PHELPS, E. (1989): "Critical distinctions among three approaches to peer education". International Journal of Educational Research, 13 (1), pp. 9-37.

- DAVEY, A. (1983): "Learning to be Prejudiced. Growing Up". En Multi-Ethic Britain. Londres. Edward Arnold.

- DEAUX, K. y LEWIS, L. (1984): "Structure of gender stereitypes: Interrelationships among components and gender label". Journal of Personality and Social Psychology, 46, pp.991-1004.

- DELORS, J. (1996): Informe Delors. La educación encierra un tesoro. Madrid. UNESCO. Santillana.

- DENTLER, R.A. y ELKINS, C, (1967): "Intergroup attitudes, academic performance, and racial composition". En DÍAZ AGUADO, M.J. et cols. (1998). Educación y desarrollo de la tolerancia. Programas para favorecer la Interacción Educativa en contextos étnicamente heterogéneos. Vol. IV. Instrumentos de evaluación. Madrid. Ministerio de Educación y Ciencia.

- DÍAZ DE RADA, A. (1996): Los primeros de la clase y los últimos románticos. Una etnografía para la crítica de la visión instrumental de la enseñanza. Madrid. Siglo XXI.

- DÍAZ PAREJA, E. (2003): "Atención a la diversidad: condiciones de la escuela para todos. Diversidad de Jaén". Revista Bordón. 55 nº 2.

- $\quad$ DÍAZ-AGUADO, M.J. (1986): El papel de la interacción entre iguales en la adaptación escolar y el desarrollo social. Madrid. CIDE. 
- DÍAZ-AGUADO, M.J. (1988): La interacción entre compañeros: un modelo de intervención psicoeducativa. CIDE, Informe de investigación inédito.

- DÍAZ-AGUADO, M.J. (1995): "Educación Intercultural y desarrollo de la tolerancia". Revista de Educación, 307, pp. 163-183.

- DÍAZ-AGUADO, M.J. (1999): "Aprendizaje cooperativo y educación intercultural". Psicología educativa, 5,2; pp.115-140.

- DÍAZ-AGUADO, M.J. (1999a): "Igualdad y Diversidad. De la educación compensatoria a la educación intercultural". Psicología educativa, 5,2, pp. 115-140.

- DÍAZ-AGUADO, M.J. (1999b): Intervención educativa y desventaja sociocultural. Madrid. CIDE:

- DÍAZ-AGUADO, M.J. (2006): Educación intercultural y aprendizaje cooperativo. Madrid. Pirámide.

- DÍAZ-AGUADO, M.J. (dir.) (1996): Programas de educación para la toleancia y prevención de la violencia en los jóvenes. Cuatro volúmenes y dos vídeos. Madrid: Instituto de la Juventud, Ministerio de Trabajo y Asuntos Sociales.

- DÍAZ-AGUADO, M.J. y BARAJA, A. (1993): Interacción educativa y desventaja sociocultural. Un modelo de intervención para favorecer la adaptación escolar en contextos interétnicos. Madrid. CIDE.

- DÍAZ-AGUADO, M.J. y MARTínEZ ÁRIAS, R. (1991): "Programas para favorecer la integración escolar de alumnos ciegos". Madrid. ONCEInforme de investigación inédito DIAZ-AGUADO, M.J. (1992). Educación y desarrollo de la tolerancia. Volumen II. Cuatro volúmenes y un vídeo. Madrid. Ministerio de Educación y Ciencia.

- DÍAZ-AgUAdO, M.J. y MARTíNEZ ARIAS, R. (2001): Programas para favorecer la integración escolar de alumnos ciegos. Madrid. ONCE- Informe de investigación inédito.

- DÍAZ-AGUADO, M.J. y MEDRANO, C. (1996): Educación y razonamiento moral. Una aproximación constructivita para trabajar los contenidos transversales. Ediciones Mensajero. Bilbao.

- DISMAN, M. (1983): "Inmigrants and other grieving people: insights for counselling practices and policy issues". Canadian Ethnic Studies XV, 3. pp. 106-118. 
- DOISE, W.; MUGNY, G.; PERRET-CLERMONT, A.N. (1975): "Social interaction and the development of cognitive operations". European Journal of Social Psychology.3, pp.135-136.

- DOVIDIO, J.F. y GAERTNER, S.L. (1986): "The aversive formo f racism". En J.F. Dovidio y S.L Gaertner (Eds.). Prejudice, discrimination and racism. Nueva Cork: Academic Press. pp. 61-89.

- $\quad$ EGELAND,B., JACOBITZ, D. y SROUFE, A.(1988): "Breaking the cycle of abuse". Child Development, 59, pp. 1080-1088.

- EAGLY, A. y WODD, W. (1991): "Explaining sex differences in social behaviour: a meta-analytic perspective. Special Issue: Meta-analysis on personality and social psychology". Personality and Social Psychology Bulletin.17, pp. 306-315.

- EAGLY, A.(1996): "Differences between women and men: Their magnitude, practical important, and political meaning". American Psychologist, 51, pp. 158-159.

- EBBUT, D. y ELLIOT, J. (1985): Issues in teaching for understanding. SCDC, New York. Longman.

- ECHEVARRÍA, A.; GARAIGORDOBIL, M.T.; GONZÁLEZ, J.L. y VILLARREAL, M. (1995): Psicología Social del prejuicio y del racismo. Madrid. CEURA.

- $\quad$ EGLAND, B., JACOBITZ, D. y SROUFE, A. (1988). Breaking the cycle of abuse. Child Development, 59, 1080-1088.

- $\quad$ ELKONIN, 1985): Psicología del juego. Madrid. Visor.

- ELLIOT, J. (1993): El cambio educativo desde la investigación-acción. Madrid. Morata.

- ERICKSON, F. (1989): "Métodos cualitativos de investigación sobre la enseñanza". En WITTROCK, M. (dir.): La investigación de la enseñanza, vol II. Barcelona. Paidós. pp.195-302.

- ERICKSON, F. (1993): El discurso en el aula como improvisación: Las relaciones entre la estructura de la tarea académica y la estructura de la participación social en clase. En VELASCO, H.; GARCÍA, F.J. y DÍAZ, A.: Lecturas de antropología para educadores. Madrid. Trota. pp. 325-353. 
- $\quad$ ERICSSON, F. (1993): "El discurso en el aula como improvisación: Las relaciones entre la estructura de la tarea académica y la estructura de la participación social en clase". En VELASCO, H.; GARCÍA, F.J. y DÍAZ, A.: Lecturas de antropología para educadores. Madrid. Trota. pp.325-353.

- ESCUDERO, J.M. (1990): "Tendencias actuales en la investigación educativa: los desafíos de la investigación crítica". Qurriculum, nº 2, pp.325.

- ESCUDERO, J.M. (1990): "Tendencias actuales en la investigación educativa: Ios desafíos de la investigación crítica". Qurriculum, n² 2, pp.325.

- ESSED, P. (1991). Understanding Everyday Racism. Newbury Park, California: Sage. pg. 31.

- ESSOMBRA. M.A. (2008). La gestión de la diversidad cultural en la escuela. Barcelona. Graó.

- $\quad$ FAGAN, J.L y L.T. SINGER (1979): "The role of simple feature differences in infant's recognition of faces". Infant Behavior and Developmente, 2, pp. 39-45.

- FALERONI, C. (1999): "Condiciones y características de los pavimentos deportivos interiores", en Instalaciones Deportivas XXI, 100, pp. 134-140.

- FERRARESI, L. (1988): Identitá sociale, categorizaciones e pregiudizio. Tesis di Laurea, University of Bologna.

- FESTINGER, L. (1954): "A theory of social comparision processes". Human Relations, 7, 117-40.

- FERNÁNDEZ ENGUITA, M. (1999): "Alumnos gitanos en la escuela paya". En el Cap. 7: La irrupción en las aulas. Barcelona. Ariel.

- FERNÉNDEZ ENGUITA, F. (2000): "Escuela y etnicidad. El caso de los gitanos". Gitanos. Pensamiento y cultura. № 7/8, pp.140-200.

- FERNÁNDEZ ENGUITA, F. (2001): "La educación intercultural en la sociedad multicultural". Organización y Gestión Educativa. № 6. Noviembre/Diciembre; pp. 3-7.

- FERNÁNDEZ ENGUITA, M. GAETE, J.M. Y TERRÉN, E. (2008): "¿Fronteras en las aulas? Contacto transcultural y endogamia en las 
interacciones del alumnado". En Revista de Educación, 345, pp. 157-181. Madrid.

- FORRESTER, M. A. (1992): The development of young children's socialcognitive skills. Hove, UK. Hillsdale, New Jersey, USA. Erlbaum. 0.

- GARCÍA-BACETE, F.J.; LARA CARRIÓN, A.; MONJAS CASARES, M.I. (2005): "¿Por qué los niños no quieren jugar con otros niños? Un análisis exploratorio de los motivos de rechazo entre iguales". En: Fajardo, I. Vicente, F., Ventura, A. Ruiz, I y del Barrio, J.A. (2005). Aportaciones psicológicas ymundo actual. Dando respuestas. Badajoz: Psicoex. pp. 257269.

- GARCÍA, F.J., RUBIO, M., BOUACHA. O., (2008). "Población Inmigrante y escuela en España: un balance de investigación". Revista de Educación, 345, 23-57. Madrid.

- GARCÍA MONGE, A. (1997): Los recreos: el cuerpo desatado (juego y transmisión de valores). Comunicación en el III congreso Internacional de Filosofía de la Educación: Antropología y Educación. UNED. Madrid.

- GARCÍA MONGE, A. (2001): "Juego motor reglado y transmisión de valores culturales". En Ágora para la educación física y el deporte, nº 1, pp. 55-70.

- GARCÍA MONGE, A. (2004): Desarrollo curricular del juego motor reglado en la educación física escolar. Tesis Doctoral. Inédito.

- GARCÍA ZARZA, E. (2003): La inmigración en Castilla y León a comienzos del S.XXI. Análisis, problemática y perspectivas. Universidad de Salamanca.

- GERARD, H. (1983): "School desegregation. The social science role". American Psychologist. August. pp. 869-876.

- GEERTZ, C. (1975). The Interpretation of Cultures., New York: Basic Books. pg.12.

- GERARD, H.B. y MILLER, N. (1975): School Desegregation: A long-range study. New York. N. Y. Plenum Press.

- GLASER Y STRAUSS, (1967). The discovery of Grounded Theory. Chicago, Illinois. Aldine.

- $\quad$ GLOCK C. et al. (1975). Adolescent prejudice. New-York: Harper and Row. 
- GOETZ, P. y LECOMPTE, M.D.(1988): Etnografía y diseño cualitativo en investigación educativa. Madrid. Morata.

- GOODMAN, M.E. (1952): Race Awareness in Young Children. Nueva York: Collier Macmillan (Ed. de 1964).

- GORSUCH, R.L. (1988): "Psychology of religion". Annual Review of Psychology, 39, 201-221.

- GIL, F. y otro (1999): La escuela de la ciudadanía. Bilbao. Desclée de Brouver.

- GIL ARAUJO, S. (2005): "Cartografías migratorias: migraciones internacionales en el marco de las relaciones Norte-Sur". En ZÚÑIGA GARCÍA-FALCES, N.: La migración. Un camino entre el desarrollo y la cooperación. Madrid. CIP-FUHEM. pp.13-38.

- GUBA, E.G. (1983): "Criterios de credibilidad en la investigación naturalista". En GIMENO SACRISTÁN y PÉREZ GÓMEZ: La enseñanza: su teoría y su práctica. Akal, Madrid, pp.13-27.

- $\quad$ GUBA, E.G. y LINCOLN, Y.S. (1981): Effective Evaluation. San Francisco. Jossey-Bass Publishers.

- $\quad$ GRESHAM, F.M. y ELLIOT, S.N. (1990): Social skills rating system manual. Circle Pines, MN: American Guidance Service.

- HABERMAS, J. (1988): La lógica de las Ciencias sociales. Madrid. Tecnos.

- HABERMAS, J. (1999): Teoría de la acción comunicativa. 2 vol. Madrid: Taurus.

- HAIM GAZÏEL, Col. (2000): La calidad en los centros docentes del siglo XXI. Madrid. La Muralla, S.A.

- HAMMERSLEY, M. y ATKINSON, P. (1994): Etnografía. Métodos de investigación. $2^{a}$ edición revisada y ampliada. Barcelona. Paidós.

- HARGREAVES, D. (1986). Las relaciones interpersonales en la educación. Madrid. Narcea.

- HARGREAVES, D. (2003): Profesorado, cultura y posmodernidad. Madrid. Morata.

- $\quad$ HALLINAN,M. (Ed.)(1987): The social organization of schools. New York: Plenum Press. 
- $\quad$ HAMILTON, D. L.; DUGAN, P. H. y TROILER, T. K. (1985): "The formation of stereotypic beliefs: Further evidence for distinctiveness-based illusory correlations". Journal of Personality and Social Psychology, 48, pp. 5-17.

- $\quad$ HARTUP, W. W.(1983): "Per relations". En HETHERINGTON, E. M. (Ed.). Socialization, personality and social development (Handbook of child Psychology, Vol. IV. New York. Wiley.

- HARTUP, W. W. (1985): "Las amistades infantiles". En J. PALACIOS, A. MARCHESI y M. CARRETERO (comp.), Psicología Evolutiva II. Desarrollo Cognitivo y social del niño. Madrid. Alianza.

- HARTUP, W.W: (1996): "The company they keep: Frindships and their developmental significance". Child Development, 67, pp.1-13.

- HARRIS, P. (1989): Children and emotion. Ltd. Basil Blackwell. Trad. Española 1992. Madrid: Alianza.

- HIRSCHEFELD, L. (1988): "On acquiring social categories: cognitive development and anthropological wisdom". Man 23. pp. 611-638.

- HIRSCHEFELD, L. (1997): "The Conceptual Politics of Race: Lessons from our Children" Ethos 25 (1). pp. 63-92.

- $\quad$ INSTITUTO DE LA MUJER. (1990). Indicadores Sociales para la Mujer. Instituto de la Mujer. Madrid. 396/73

- JACKSON, M.F. et al. (2006). Clasrroom Contextual Effects of Race on Children's Peer Nominations. Child Development, 77(5), 1.325-1.337.

- JANSEN, V.G. y GALLAGER, J.J (1966): "The social choices of students in racially integrated classes for the culturally disadvantaged talented". En DÍAZ AGUADO, M.J. et cols. (1998). Educación y desarrollo de la tolerancia. Programas para favorecer la Interacción Educativa en contextos étnicamente heterogéneos. Vol. IV. Instrumentos de evaluación. Ministerio de Educación y Ciencia. Madrid.

- JORDÁN, J. (2001): La educación intercultural, una respuesta a tiempo. Barcelona. Ediciones de la Universitat Oberta de Cataluña.

- JIMÉNEZ, C. (1997): Pedagogía diferencial. Universidad Nacional de Educación a Distancia. Madrid. 
- JIMÉNEZ, C. (2003): Apuntes del curso Mediación Intercultural. EMSI.

- JOHNSTON, L. y JOHNSTON, M. (1982): "Effects of cooperative and individualistic instruction and handicapped and nonhandicapped students". Journal of Social Pychology, 118, pp. 257-268.

- JOHNSTON, L. y JOHNSTON, M. (1999): El aprendizaje cooperativo en el aula. Barcelona. Paidós. (Fecha de primera edición en inglés, 1994).

- JOHNSTON, D.W. (1972): Psicología Social de la educación. Buenos Aires. Kapelusz.

- JOHNSTON, D.W, y HEWSTONE, M. (1992). Cognitive models of stereotype change: subtyping and the perceived typically of disconforming groups members. Journal of Experimental Social Psychology, 28, pp. 360386.

- JOHNSTON, D.W., JOHNSON. R.T. y HOULUBEC, E.J. (2001). El aprendizaje cooperativo en el aula. Buenos Aires. Paidós.

- JORDÁN, J.A. (1996): Propuestas de educación intercultural para profesores. Barcelona. Ediciones. CEAC.

- JUSTICIA, F. (1986): "Proceso de socialización y educación". En J. MAYOR (Ed.). Sociología y psicología social de la educación. Madrid. Anaya.

- KAGAN. J (1986): "Teacher-student interactions: Effects of student race, sex, and grade level". Journal of Educational psychology, 7(1), pp. 14-21.

- $\quad$ KATZ, P. (1976). "The adquisition of racial attitudes in chilfren". P:A. Katz (Ed.), Towards the elimination of racism. New York: Pergamon Press.

- KELLY, J. A. (1982): Entrenamiento en habilidades sociales. DDB. Bilbao.

- KATZ, P. y ROSENBERG, Z.(1978): "Modification of children's Racial Attitudes". Developmental Psychology. 14(5), 447-461.

- KEMMIS, S. (1981): The Action Research Planner. Deakin University, Victoria.

- $\quad$ KERBO, HAROLD R. (2004): Estratificación Social y Desigualdad. Madrid. McGraw-Hill.

- $\quad$ KOHN, M (1977): Social Competente, symptoms and underachievement in childhood: A longitudinal perspective. Washington: Winston and Sons. 
- KOLHBERG, L. (1969): "Stage and sequence: The cognitive-developmental approach to socialization". En E. MACCOBY, The Development of Sex Differences. Stanford, California: Stanford University Press.

- KOLHBERG, L. (1992): Psicología del desarrollo moral. Bilbao: Editorial Desclée de Brower, S.A.

- $\quad$ KOLHBERG, L. POWER, F.C., HIGGINS, A. (1997): La educación moral. Barcelona. Ed.: Gedisa.

- KUROKAWA, M. (1971): "Mutual perceptions of racial images: White, black, and Japanesse-Americans". Journal of Social Issues. 27 (4). pp. 213-235.

- $\quad$ KUPERSTMIDT, J. (1983). Predicting delincuency and academia problems from childhood peer status. En D. Coie (Ed.) Strategies for identifying chikdren at social risk: Longitudinal corelates and consecuentes. Bienniel Meeting of the Society for Research in Chile Development, Detroit.

- $\quad$ LADD, G.W. (1990). Having friends, keeping friends, making friends, and being liked by peers in the classroom: predictors of children's early school adjustment. Child Development, 61, 1081-1100.

- LAMBERT, W.E. y O. KLINEBERG (1967): Children's Views of Foreign Peoples. Nueva York: Appleton Century Crofts.

- LANDE, J. (2007): "À propos de cours d'école". Revista eps 1 n 133, pg. 5.

- LANGLOIS, J.H.; L.A. ROGGMAN, R.J.; CASEY, J.M.; RITTER, L.A.; RIESER-DONNER y JENKIS, V.Y. (1987): "Infant preferentes for attractives faces: rudiments of a stereotype". Developmental Psychology, 23, 363-369.

- LAPIERRE, A. y ACOUTURIER, B. (1985). Simbología del movimiento. Barcelona. Editorial Científico Médica.

- $\quad$ LENSKY, G. (1984): Power and Privilege: A theory of Social Stratification. North Carolina University Press.

- LENSKY, G. (1999): Power and Privilege. New York. McGraw-Hill.

- $\quad$ LOMABRDI (1962): Factors affecting changes in attitudes toward Negroes among high school students. Unpublished doctoral dissertation, Fordham University. 
- LÓPEZ MELERO, M. (2004): Construyendo una escuela sin exclusiones: una forma de trabajar en el aula con proyectos de investigación. Archidona. Aljibe.

- LÓPEZ, A. (2007):14 ideas clave. El trabajo en equipo del profesorado. Barcelona. Grao.

- MANN, J.H. (1959): "The effect of interracial contact on sociometric choices and perceptions". Journal of Social Psychology. 50, 143-152.

- MARCHESI, A. (2003): Controversias en la educación española. Madrid. Alianza.

- MÁRQUEZ A.(2002): Estudio cualitativo realizado sobre la percepción de los estudiantes inmigrantes en la E.S.O. (a través de group focus).Inédito. Centro de Formación Padre Piquer, Obra social Caja Madrid.

- MARTíN, E. (2007): Competencia para aprender a aprender. Madrid. Alianza.

- $\quad$ MARTíN, E. y MARCHESI, A.(1998): Calidad de la enseñanza en tiempos de cambio. Madrid. Alianza.

- MARTíN, E.; COLL, C. (Coords.) (2003): Aprender contenidos, desarrollar capacidades: intenciones educativas y planificación de la enseñanza. Barcelona. Edebé.

- $\quad$ MARTÍNEZ ÁlVAREZ, L. y GARCÍA MONGE, A. (1997): "Educación Física y Género: una mirada al cuerpo en la escuela". En ALARIO, T y GARCÍA, C. (coord.): Persona, Género y Educación. Salamanca. Amarú. pp. 57-68.

- MARTínEZ BONAFÉ, J. (1990): "Estudio de casos en la investigación educativa". En MARTÍNEZ RODRÍGUEZ (ed.): Hacia un enfoque interpretativo de la enseñanza. Universidad de Granada, Granada, pp. 5768.

- Mc WHIRT, R.A.(1967): "The effects of desegregation on the prejudice, academic aspiration and self - concept of the tenth grade students". En DÍAZ AGUADO, M.J. et cols. (1998). Educación y desarrollo de la tolerancia. Programas para favorecer la Interacción Educativa en contextos étnicamente heterogéneos. Vol. I. Teoría. Ministerio de Educación y Ciencia. Madrid. 
- MCCONAHAY, J.B. (1986): "Modern Racism, ambivalence, and the Modern Racism Scale". En J.F. DOVIDIO Y S.L. GAERTNER (Eds.). Prejudice, discrimination and racism. Nueva Cork: Academic Press. pp. 91-125.

- Mc FALL, RM. (1982). "A review and reformulation of the concept of social skills". Behavioral Assessment, 4, pp.1-33.

- MCCONAHAY, J.B., HARDEE, B.B. y BATTS, V. (1981): "Has racism declined in America? It depends upon who is asking and what is asked". Journal of Conflict Resolution, 25, pp. 563-579.

- MEAUX, K. y EMSWILER, T. (1974): "Explanations of successful performance on sex-linked tasks: What is skill for the male is luck for the female". En ARONSON, E. (2005). El animal social. Psicología y Educación. Madrid. Alianza Editorial.

- MERIEU, P. (1998): Frankestein educador. Barcelona. Editorial Alertes.

- MERTON, R.K. (1957): Social theory and social structure. Glencoe. Free Press.

- MIÑAMBRES, A. y JOVÉ, G.: La atención a las necesidades educativas especiales: De la educación infantil a la Universidad. Lleida, Ediciones de la Universidad de Lleida.

- $\quad$ MONJAS CASARES, M. I. (1996): Programa de enseñanza de habilidades de interacción social (PEHIS) para niños y niñas en edad escolar. CEPE, Madrid.

- MONJAS CASRES, M.I. (2000): Programa de Enseñanza de Habilidades de Interacción Social (PEHIS). Para niños y adolescentes. Madrid: CEPE.

- MONJAS CASARES, M.I. (2007). Cómo promover la convivencia. Programa de asertividad y Habilidades Sociales (PAHS). CEPE, Madrid.

- MONTANDON, C. (1992): "La socialisation des emotion: un champ nouveau pour la sociologie de l'éducation". Revue Francaise de Pédagogie, n.101.

- MORALEDA, M. (1995). Comportamientos sociales hábiles en la infancia y adolescencia. Valencia. Promolibro.

- MORALES OROZCO, L. (2006): "La integración lingüística del alumnado inmigrante. Propuestas para el aprendizaje cooperativo". Cuadernos de Educación Intercultural. Madrid. La Catarata. 
- MORENO, J.L. (1965): Fundamentos de sociometría. Buenos Aires. Paidós.

- MICHELSON et al. (1987): Las habilidades sociales. Barcelona. Martínez Roca (original 1983).

- MYERS, D.G. (1995). Psicología Social. Madrid. McGraw-Hill.

- NAVARRO, JLN. (2005): El conocimiento de la lengua castellana en alumnado inmigrante escolarizado en $1^{\circ}$ de la ESO. Madrid. Ministerio de Educación y Ciencia.

- $\quad$ NAVAS, M.S. y J.F. RUEDA (1996): "Hacia una evaluación de las nuevas formas del prejuicio racial: las actitudes sutiles del racismo". Revista de psicología social, ISSN 0213-4748, Vol. 11, № 2, pp. 131-150.

- NAVAS, M., PUMARES, P. y otros. (2004). Estrategias de aculturación: La perspectiva de los inmigrantes y de los autóctonos en Almería. Almería: Junta de Andalucía.

- NEEWCOMB, A. F., BUKOWSKI, W. M. oooy PATTEE, L. (1993): "Children's peer relations: A meta-analytic review of popular, rejected, neglected, and average sociometric status". Psychological Bulletin, 113 (1). pp. 99-128.

- $\quad$ NOE, D. CABELLO, J., ZÚÑIGA, I. (2005): Brecha étnica e influencia de los pares en el rendimiento escolar: evidencia para Chile. Naciones Unidas. CEPAL.

- OLABUÉNAGA J.L., RUIZ E.J., y TORRADO V., (1999): Los inmigrantes irregulares en España. Bilbao. Universidad de Deusto.

- OVEJERO A. y RODRÍGUEZ, F.J. (Coords.) (2005): La convivencia sin violencia. Madrid. Eduforma.

- OVEJERO BERNAL, A. (1990): El aprendizaje cooperativo: Una alternativa a la enseñanza tradicional. Barcelona, PPU.

- OVEJERO BERNAL, A. (1981). El autoritarismo como variable de personalidad. Tesis Doctoral. Madrid. Editorial Complutense.

- OVEJERO BERNAL, A. (1997). "Las habilidades sociales y su entrenamiento en el ámbito escolar". En Habilidades sociales F. Gil y J.M. León (Eds.): Teoría, investigación e intervención". Madrid. Síntesis. 
- OVEJERO BERNAL, A. (1998): Las relaciones humanas. Psicología social teórica y aplicada. Madrid. Biblioteca Nueva. Psicología Universidad. Pg. 246.

- OVEJERO BERNAL, A. (1999): La nueva psicología social y la actual postmodernidad. Oviedo. Servicio de Publicaciones de la UNIOVI.

- OVEJERO BERNAL, A. (2004): Globalización, sociedad y escuela: cómo hacer frente a los principales problemas actuales desde la psicología social crítica. Secretariado de Publicaciones e Intercambio Editorial. Universidad de Valladolid.

- PADRÓN DEL 1 DE ENERO DEL 2007. Madrid.

- $\quad$ PAIS SEMANAL, 8 de Octubre de 1995.

- PAJARES, M. (1998): La inmigración en España: retos y propuestas. Barcelona. Icaria.

- PAJARES, M. (2000): "Políticas Sociales de Integración de los inmigrantes". Madrid. Foro para la Integración Social de los inmigrantes. pp. 111-130.

- PARKER, J., ASHER, S. (1987): "Peer relations and later personal adjustment: Are low accepted children at risk?". Psychlogical Bulletin, .102, pp. 357-389.

- PARLEBÁS, P. (2001): Juegos, deporte y sociedad. Léxico de praxiología motriz. Barcelona. Paidotribo.

- PELECHANO, V. (1979): Psicología educativa comunitaria. Valencia: Alfaplús.

- PELEGRÍN, A. (1996): Gesto, juego, cultura. Revista de Educación [monográfico de Educación Física Escolar], nº 311, pp.77-99.

- PÉREZ GÓMEZ, A. (1992): "Comprender la enseñanza en la escuela. Modelos metodológicos de investigación educativa". En GIMENO, J. y PÉREZ, A.: Comprender y transformar la enseñanza. Madrid. Morata. pp. 115-136.

- PÉREZ SERRANO, G. (1990): Investigación-acción. Aplicaciones al campo social y educativo. Madrid. Dykinson,

- PÉREZ SERRANO, G. (1994a): Investigación cualitativa. Retos e interrogantes: Métodos. Madrid. La Muralla. 
- PÉREZ SERRANO, G. (1994b): Investigación cualitativa. Retos e interrogantes: II Técnicas y análisis de datos. Madrid. La Muralla.

- PETTIGREW, T.F. y MEERTENS, R.W. (1992): "Le racisme voile: dimensions et mesure". En M. WIEVIORKA (Dir.). Racisme et modernité. París: La Découverte. pp.109-126.

- PETTIGREW, T.F. y MEERTENS, R.W. (1995): "Subtle and blatant prejudice in Western Europe". European Journal of Social Psychology, 25, pp. 57-75.

- PFEIFFER, John (1977): The Emergence of Society: A Prehistory of the Establishment. New York. McGraw-Hill.

- $\quad$ PHYLACTOU y THOREN (1990): "Acquiring social categories". Man (N.S.) 25. pp. 144-5.

- PIAGET, J. (1937): La construction su réel chez l' enfant. Neuchátel: Delachaux y Niestlé (hay edición en castellano (1989): La construcción de lo real en el niño. Barcelona: Crítica.

- $\quad$ PIANTA, R., EGELAND, B. y ERICKSON, M.F. (1989): The antecedents of maltreatment: Results of the Mother-Child Interaction Research Project.

- PINILLOS, J.L. (1982): "Los prejuicios y la sociedad contemporánea". Cuenta y Razón. 5, pp. 15-25.

- PLAN MARCO DE ATENCIÓN PARA LA ATENCIÓN A LA DIVERSIDAD, (2002). Junta de Castilla y León.

- $\quad$ PORRAS VALLEJO, R. (1998): Una escuela para la integración educativa. Sevilla. M.C.E.P.

- PUJOLÁS, P. (2004): Aprender juntos, alumnos diferentes. Barcelona. Octaedro.

- RAMÍREZ GOICOECHEA, E. (2007): Etnicidad, identidad y migraciones. Teorías, conceptos y experiencias. Madrid. Editorial universitaria Ramón Areces.

- REBOREDO, A. (1983): Jugar es un acto político. México. Nueva Imagen.

- $\quad$ RENSON, R. (1991): "El retorno de los deportes y juegos tradicionales". En Rev. Perspectivas de la Actividad Física y el Deporte, nº 8, pp. 2-4.

- REVISTA DEL PAÍS SEMANAL en el 2004. 
- $\quad$ RINCÓN, D. et. al. (1995): Técnicas de investigación en ciencias sociales. Madrid. Dykinson.

- RODRíGUEZ ROJO, M. (1997). Hacia una didáctica crítica. Barcelona. La Muralla.

- RODRIGO, M. J. (1999): Contexto y desarrollo social. Madrid. Síntesis Psicología.

- $\quad$ ROFF, M. y WIRT, D.(1984): "Childhood agresion and social adjustment as antecedents of delincuency". Journal of Abnormal and Chile Psychology. 12, pp.111-126.

- ROSENTHAL R., JACOBSON L. (1968): Pygmalion in the classroom. Teacher expectations and pupil's intellectual development. New York: Holt, Rinehart y Winston.

- ROSS, E.A. (1977): "The intiuitive psychologist and his shortcomings, distortion the attribution process", en L. BERKOWITZ (ed.): Advances in experimental social psychology, vol 10. Nueva York. Academic Press.

- $\quad$ RUBIN, Z. (1980): Children's friendships London: Open Books Publishing. Trad. Cast., Madrid. Ed. Morata.

- $\quad$ RUEDA, J.F., Y NAVAS, M. (1996). "Hacia una evaluación de las nuevas formas del prejuicio racial: las actitudes sutiles del racismo". En: Revista de Psicología Social, 11 (2), pp.131-149.

- RUIZ, J. L. (1999): Los inmigrantes irregulares en España. Bilbao. Universidad de Deusto.

- RIVAS, F. (1997): El proceso de enseñanza-aprendizaje en la situación educativa. Barcelona. Ariel.

- SABINO, C. (1996). El Proceso de Investigación. Buenos Aires. Ed. Lumen - Humanitas.

- SÁNCHEZ i PERIS, F., ROS, C. Y GARFELLA, P. (2004). La escolarización de los alumnos inmigrantes en la ciudad de Gandía. IV Congreso estatal del/a educador/a social. Santiago de Compostela, Galicia, 30 septiemnre - 2 octubre.

- SALAS, M.A. (1998): El profesor frente al trabajo cooperativo. Variables que determinan la elección. Tesis Doctoral. Universidad de Comillas. 
- SANTOS GUERRA, M.A. (1990): Hacer visible lo cotidiano. Teoría y práctica de la evaluación cualitativa de los Centros Escolares. Madrid. Akal.

- $\quad$ SANTOS GUERRA, M.A. (1994): "Evaluación de los cambios organizativos en la Reforma Española". Revista de Educación, n 35, pp.128-141.

- SANTOS GUERRA, M.A.. (1998): Hacer visible lo cotidiano. Teoría y práctica de la evaluación cualitativa de los centros escolares. $3^{a}$ edición. Madrid. Editorial Akal,

- SASSEN, S. (1999): Migranti, colini, refugiati. Dell imigrazione di massa alla fortezza Europa. Milán. Campi del sapere, Fratinelli.

- SCHOFIELD, J. (1978): "School desegregaton and intergroup relations". En: D. BAR-TAR y SAXE, L. (eds.) Social Psychology of education, Hemisphere Publishing Corporation.

- $\quad$ SCHWARZWAL, J. y COHEN, S.(1982): "Relationship between academia tracking and degree of interethnic acceptance". Journal of Educational Psychology. 74 (4), pp. 588-597.

- $\quad$ SEARS, D.O. y KINDER, D.R. (1971): "Racial tensions and voting in Los Angeles". En W.Z. HIRSCH (Ed.). Los Angeles: viability and prospects for metropolitan leadership. Nueva York: Praeger. pp.51-88.

- $\quad$ SHARAN, S. (1980): "Cooperative learning in teams: recent methods and effects un achievement, attitudes, and thinc relations". Rewiew of Educational Research, 50, pp. 241-272.

- SHARAN et. al. (1984): Cooperative learning in the classroom: Research in desegregated schools. Hillsdale, NJ: Erlbaum.

- $\quad$ SHERIF, M. (1953). The Psychology of social norms. New York. Harper.

- SHERIF, M. (1967). Group conflict and cooperation: Their social psychology. Londres, Routledge and Kegan Paul.

- SICILIA, A. (2004): Las retóricas de la investigación: dilemas narrativos en el proceso de redacción de una tesis doctoral. En SICILIA, A. y FERNÁNDEZBALBOA, J.M. (coords.): La otra cara de la investigación. Reflexiones desde la Educación Física. Wanceulen, Sevilla, pp.61-81.

- $\quad$ SIMENON, G. (2004): Las memorias de Maigret. Madrid. El País Colecciones, Clásicos del siglo XX.

- $\quad$ SLAVIN, R.E. (1983): Cooperative learning. New York :Longman. 
- SLAVIN, R.E. (1985): La enseñanza y el método cooperativo. México. Edamex.

- SLAVIN, R.E. (1986): "Cooperative learning and intergroup relations: contact theory in the classroom". En EPSTEIN Y KARWEITT (ed.) pp. 93114.

- SLAVIN , R. E. (1999): Aprendizaje cooperativo: Teoría, investigación y practica. Argentina: Aique Grupo Editor.

- SPENCE, J. (1987): "Masculinity, femininity, and gender-related traits: A conceptual analysis and critique of current research". En B. A. MAHER \& W. B. MAHER (Eds.): Progress in experimental research in personality, (V. 13, pp. 1-97). New York: Academic Press.

- STAIMBACK, S. y STAIMBACK, W. (2001). Aulas inclusivas. Un Nuevo modo de enfocar y vivir el currículo. Madrid. Narcea.

- $\quad$ STAINBACK, S. y JACKSON, H. (1999): "Hacia las aulas inclusivas". En S. STAINBACK y W. STAINBACK. Aulas inclusivas. Madrid: Narcea.

- STAKE, R.E. (1995): The art of Case Study Research. London. Sage Publications.

- $\quad$ STAKE, R.E. (1998): Investigación con estudio de casos. Madrid. Morata.

- STENGLE, E. (1971): Suicide and attempted suicide. Middlesex. Penguin.

- SUOMI, S. (1979). Peers, play and primary prevention in primates. En. KENT, M. y ROLF, J. (eds.): Primary prevention of psychopatholog. Vol 3. Social competence in children. Hannover: University Press of New England.

- TAJFEL, H. (1959): "The anchoring effects of value in a scale of judgements". British Journal of Psychology, 50, pp. 294-304.

- TAJFEL, H. (1979): Differentiation between the social Graus. Londres. Academic Press. (1972, 1976, 1981).

- TAJFEL, H. y TURNER, J. (1986): "The social identity theory of intergroup behaviour". En WORCHEL, S. y W.G. AUSTIN (eds.): Psychology of Intergroup Relations. Chicago: Nelson. pp. 7-24.

- tamayo, M. (1998). El Proceso de la Investigación Científica. $3^{a}$ ed. México Ed. Limusa S.A. 
- TAYLOR, C.P.(1967): Some change in self-concept in the first year of desegregated schooling. Unpublished doctoral disseration, Universoty of Delaware.

- $\quad$ TAYLOR, S.J. y BOGDAN, R. (1992): Introducción a los métodos cualitativos de investigación. Barcelona. Paidós.

- THOMPSON, S.K. (1975): "Genders labels and early sex-role development". Chile Developmente, 46, pp. 339-347.

- TEDESCHI, J.T., LINDSKOLD, S., ROSENFELD, P. (1985). Introduction to Social Psychology. West Publishing Company. St. Paul.

- TOREN, C. (1993): "Making History: the Signifiance of Childhood Cognition for a Comparative Antropology of Mind". Man 28. pp. 461-478.

- TORREGO, L. (2004): "Ser profesor, ¿un reto en el contexto de convergencia europea? Un recorrido por declaraciones y comunicados". En Revista Interuniversitaria de Formación del Profesorado.18 (3).

- $\quad$ TROYNA, B. y HATCHER, R. (1992): Racism in children's lives: A study of mainy white primary schools. London: Routledge.

- TURNER, J.C. (1978): "Social comparision, similarity and ingroup favouritism". En TAJFEL (ed.): Differentation psychology of intergroup relations, Londres: Academic Press.

- TURNER, J.C. (1980): "Fairness or discrimination in intergroup behaviour? A reply to Braithwaite. Doyle y Lighbown". European Journal of Social Psychology, 10, 131-147.

- VACA, M. (2001): "El ámbito corporal en la Educación Primaria. Una propuesta curricular, el curso 2001-2002". Rev. Ágora para la Educación Física y el Deporte, $n^{0} 1$, pp. 71-84.

- VACA, M. (2002): Relatos y reflexiones sobre el Tratamiento Pedagógico de lo corporal en la Educación Primaria. Palencia. Asociación Cultural Cuerpo, Educación y Motricidad.

- VÁSQUEZ (1995): "La socialización en la escuela y la integración de las minorías: Perspectivas etnográficas en el análisis de la educación de los años 90". Aprendizaje. Madrid. pg. 67.

- VÁSQUEZ, A. e INGLE, H. (1982): "Multicultural and Minority Education", en MITZEN, H. E. (Ed). O.C.1, pp. 267-1.268. 
- VÁSQUEZ, A. y MARTínEZ, I. (1996): La socialización en la escuela. Una perspectiva etnográfica. Barcelona. Paidós.

- VAUGHAN, G.M. (1964): "Ethnic awareness in relation to minority group membership". Journal of Genetic Psychology, 105, pp.119-130.

- VÁZQUEZ, R. y ANGULO. F. (Coord). (2003): Introducción a los estudios de casos. Los primeros contactos con la investigación etnográfica. Granada: Ediciones Aljibe.

- VELASCO, H. y DÍAZ DE RADA, A. (1997): La lógica de la investigación etnográfica. Un modelo de trabajo para etnógrafos de la escuela. Madrid. Editorial Trota. pg. 35.

- VELASCO, H. y DÍAZ DE RADA, A. (2004): La lógica de la investigación etnográfica: Un modelo de trabajo para etnógrafos de la escuela ( $4^{\mathrm{a}} \mathrm{Ed}$.). Madrid: Trotta. (PS/10/337; ED/39/VEL).

- VERDUGO ALONSO, M.A. (1997): PHS. Programa de habilidades sociales: programas conductuales alternativos. Salamanca. Amarú Ediciones.

- VIGOTSKY, L. (1986): Thought and language. Massachussets. MIT.

- WEBB, N.M. (1982): "Group composition, group interaction, and achievement in cooperative small groups". Journal of Educational Psychology, 74 (4), pp. 475-484.

- $\quad$ WEINSTEIN , R., MIDDLESTAD, S. (1979): "Student perceptions of teacher interactions with male high and low achievers". Journal of Educational Psychology, 49, pp. 223-236.

- WENKE, R. (1980): Patterns in Prehistory: Mankind's First Three Million Years. New York: Oxford University Press.

- $\quad$ WITHALL, J. (1949): "The development of a technique for the measurement of social-emotional climates in classrooms". Journal of Experimental Education, vol.17, pp.347-361.

- WOODS, P. (1987): La escuela por dentro. La etnografía en la investigación educativa. Madrid. Paidós. /M.E.C.

- $\quad$ WOODS, P. (1990): L’ Ethnographie de l' école. Paris. Armand Colin. 
- WORCHEL, S., ANDREOLI, V.A. y FOLGER, R. (1977): "Intergroup cooperation and intergroup attraction: the effect of previous interaction and outcome of combined effort". Journal of Experimental Social Psychology, 13. pp. 131-140.

- YEE, M.D. y BROWN, R.J. (1988): Children and Social Comparision, final Report to the ESCR, University of Kent.

- YUBERO, S., BODOQUE, A., laRRAÑAGA, E. (2006). "Aspectos psicosociales del proceso de socialización: La familia como escenario de desarrollo". Castilla la Mancha. Boletín informativo de trabajo social, 9,

- ZAPATA-BARRERO, R. (2000): "Inmigración e innovación política". Migraciones. № 8, pp. 7-58. 